\title{
Akademische Strenge und künstlerische Freiheit
}

Die Gemälde des 19. Jahrhunderts in der Kunstsammlung der Universität Göttingen

\author{
Christian Scholl und \\ Anne-Katrin Sors (Hg.)
}

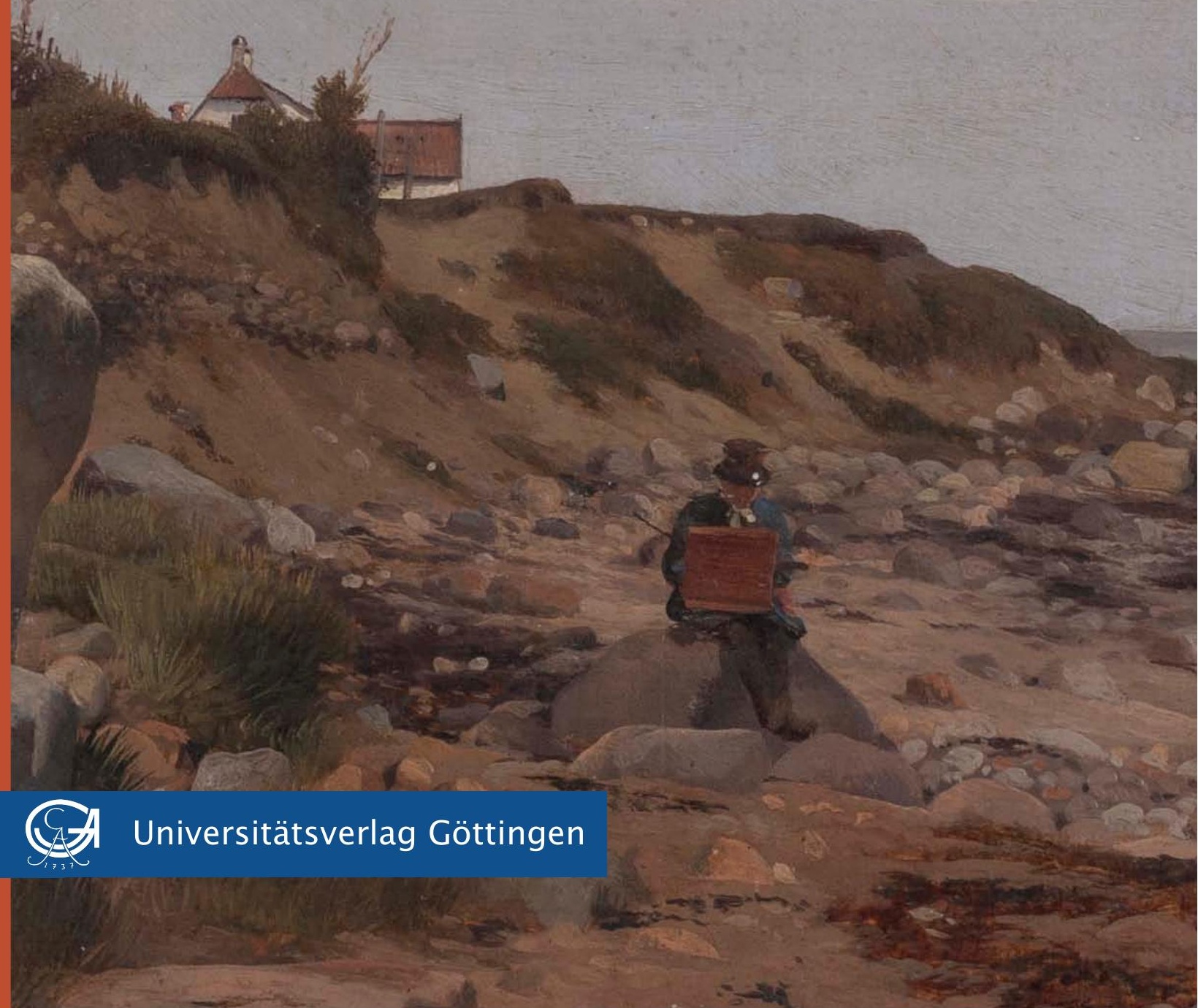



Christian Scholl und Anne-Katrin Sors (Hg.)

Akademische Strenge und künstlerische Freiheit

This work is licensed under the Creative Commons License 3.0 "by-sa", allowing you to download, distribute and print the document in a few copies for private or educational use, given that the document stays unchanged and the creator is mentioned.

\begin{tabular}{|c|}
\hline C) \\
SOMIERIGHIS RESERVED
\end{tabular} 
erschienen im Universitätsverlag Göttingen 2013 
Christian Scholl und

Anne-Katrin Sors (Hg.)

Akademische Strenge und
künstlerische Freiheit

Die Gemälde des 19. Jahrhunderts in der Kunstsammlung der

Universität Göttingen

Bestandskatalog

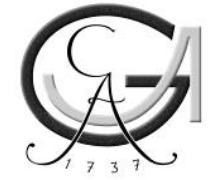

Universitätsverlag Göttingen 2013 


\section{Bibliographische Information der Deutschen Nationalbibliothek}

Die Deutsche Nationalbibliothek verzeichnet diese Publikation in der Deutschen Nationalbibliographie; detaillierte bibliographische Daten sind im Internet über $<$ http://dnb.ddb.de $>$ abrufbar.

Anschrift der Herausgeber

PD Dr. Christian Scholl

Dr. Anne-Katrin Sors

Georg-August-Universität Göttingen

Kunstgeschichtliches Seminar und

Kunstsammlung

Nikolausberger Weg 15

37073 Göttingen

Tel.: 0551 / 39-5093

Email: kunsts@gwdg.de

Dieses Buch ist auch als freie Onlineversion über die Homepage des Verlags sowie über den OPAC der Niedersächsischen Staats- und Universitätsbibliothek (http://www.sub.uni-goettingen.de) erreichbar und darf gelesen, heruntergeladen sowie als Privatkopie ausgedruckt werden. Es gelten die Lizenzbestimmungen der Onlineversion.

Satz und Layout: Christian Scholl

Umschlaggestaltung: Jutta Pabst, Franziska Lorenz

Titelabbildung: Louis Gurlitt: Maler in steinigen Sanddünen, 1833

Foto: Katharina Anna Haase

(C) 2013 Universitätsverlag Göttingen http:/ / univerlag.uni-goettingen.de ISBN: 978-3-86395-102-3 
Prof. Dr. Carsten Peter Warncke zum 65. Geburtstag 



\section{Inhalt}

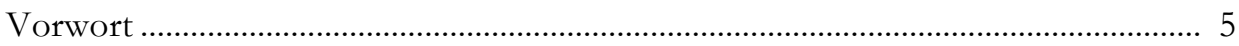

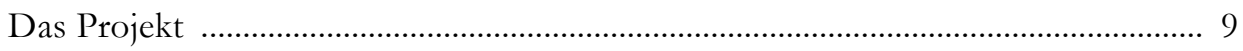

Aufsätze

Christian Scholl

Dialog der Gattungen: Zur kunsttheoretischen Verortung der Gemälde des

19. Jahrhunderts in der Göttinger Universitätskunstsammlung

Anne-Katrin Sors

Die Provenienzen der Göttinger Gemälde des 19. Jahrhunderts

Katalog der Gemälde des 19. Jahrhunderts in der Göttinger

Universitätskunstsammlung

Ifee Tack, Christian Scholl

„was malen S' den heuer für ein Malheur?":

Profanhistorie - Geschichtsmalerei - Mythologie ................................................... 53

Kat. Nr. 1: Friedrich Becker: Drei Damen beim Bade überrascht..................... 65

Kat. Nr. 2: Friedrich Spangenberg: Bernhard von Clairvaux predigt

den Kreuzzug 
Kat. Nr. 3: Friedrich Spangenberg: Geiserich führt die gefangene Eudoxia aus dem geplünderten Rom 77

Kat. Nr. 4: Friedrich August von Kaulbach: Die Erziehung des Bacchus 83

\section{Julia Diekmann}

„Und jeder hätte demnach seinen eigenen Gott.“ Die religiöse Malerei des 19. Jahrhunderts im Spannungsfeld zwischen Säkularisierung und religiöser Erneuerung

Kat. Nr. 5: Karl Franz Jacob Heinrich Schumann: Die heilige Familie mit den Engeln 97

Kat. Nr. 6: Johann Dominicus Fiorillo: Die heilige Familie ............................ 109

Kat. Nr. 7: Francesco Podesti: Taufe und Heilung des Paulus 117

Kat. Nr. 8+9: Heinrich Petri: Mater Dolorosa, Madonna..... 121

Kat. Nr. 10: Franz Xaver Laudage: Heilige Elisabeth von Thüringen 127

Kat. Nr. 11: Carl Oesterley: Segnender Christus 133

\section{Christina Eifler}

Alltäglichkeit im Aufschwung: Die Genremalerei des 19. Jahrhunderts 143

Kat. Nr. 12: Josef Danhauser: Der Maler im Dachstübchen 149

Kat. Nr. 13: Henry Ritter: Schiffbruch 155

Kat. Nr. 14: Unbekannt, deutsch oder niederländisch?: Schlittschuhläufer .. 159

Kat. Nr. 15: Unbekannt, deutsch: Dorflandschaft mit zechenden Bauern..... 163

Kat. Nr. 16: Eduard von Gebhardt: Bei der Kupplerin / Bauerninterieur..... 167

Kat. Nr. 17: Maximilian Wachsmuth: Junges Paar 173

\section{Phil Miller}

Emanzipation einer Gattung: Die deutsche Landschaftsmalerei im 19. Jahrhundert

Kat. Nr. 18: Ignatius Josephus van Regemorter: Felsenschlucht 187 
Kat. Nr. 19: Friedrich Philipp Reinhold: Der Hirte auf der Bergspitze bei Abendschein.

Kat. Nr. 20: Louis Gurlitt: Maler in steinigen Sanddünen

Kat. Nr. 21: Louis Gurlitt: Uferlandschaft 205

Kat. Nr. 22: Louis Gurlitt: Blick auf Salzburg 209

Kat. Nr. 23: Bernhard Fries: Kap Manerba am Gardasee 213

Kat. Nr. 24: Johann Friedrich Voltz: Enten am Starnberger See 219

Kat. Nr. 25: August Keßler: Strand bei Blankenberghe 223

Kat. Nr. 26: Karl Buchholz: Der Teich 225

Kat. Nr. 27: Otto Peters: Göttinger Vorstadthaus um 1880 233

Kat. Nr. 28: Karl Ludwig Adam Heinisch: Seeufer mit Angler im Schilf......

Verena Suchy

Die Tiermalerei im Gattungsdiskurs des 19. Jahrhunderts:

Eine Sondergattung etabliert sich

Kat. Nr. 29: Paul Meyerheim: Tauben auf dem Dach. 247 Jan Stieglitr.

Zwischen Publikumsinteresse und Kunstkritik: Stilllebenmalerei 251

Kat. Nr. 30: Art des (Fälschung nach?) Joris van Son: Blumenstillleben 255

Kat. Nr. 31: Joseph Correggio: Früchtestillleben. 259 Anne-Katrin Sors

Porträts/Kopfstudien 263

Kat. Nr. 32: Franz Xaver Winterhalter?: Bildnis einer Dame im Grünen ..... 279

Kat. Nr. 33: Unbekannt, deutsch: Aufblickender Mann mit Turban 284

Kat. Nr. 34-54: Weitere Porträts des 19. Jahrhunderts in der Göttinger Universitätskunstsammlung..... 289 


\section{Anhang}

Archivgut 297

Literatur 298

Konkordanz der Bestandskataloge und Inventare ........................................... 346

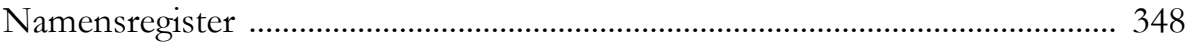

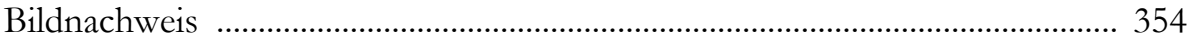




\section{Vorwort}

„Echte Kunst kennt keine getrennten Genres. Gattungsmalerei ist eine Art von Moos oder parasitischem Schwammwuchs auf dem großen Stamm der Kunst...Darum ist Fächeln keine Kunst und sollte in einer Akademie keinen Platz finden“. Es gehört zu den zahllosen Paradoxien des 19. Jahrhunderts, dass Künstler der Romantik wie Peter Cornelius, die hinter der Fahne eines hohen, ungeteilten Kunstbegriffs im Namen von Freiheit und Gefühl gegen den akademischen Kanon und seine Werthierarchien aufbegehrten, eine Generation später als Reformer selbst dafür sorgten, dass dieselben Kunstakademien mit ihren Ausbildungsformen, Klassen, Gattungen und Stilkategorien bis an die Schwelle der Moderne eine beherrschende Institution des Kunstbetriebs blieben, ja in ihrer praktischen Bedeutung als Ausbildungsstätten die Akademien des Absolutismus sogar noch übertrafen. Noch im späten 19. Jahrhundert, nach einer Phase der Ausdifferenzierung, Umwertung und Auflösung gehörten ihre akademische Zeichenpraxis und ihr Gattungskanon von Historie, Genre, Porträt, Landschaft und Stillleben noch immer zu den Kernbestandteilen der Ausbildung von Malern in Deutschland.

Antiakademisches Pathos ist ein Privileg von Akademikern. Die Polemik der klassischen Moderne gegen die etablierten Institutionen des Kunstbetriebs lässt heute leicht übersehen, dass fast alle großen Künstler des 19. Jahrhunderts in Akademien ausgebildet wurden und sich innerhalb ihrer Normen und Ausbildungsformen entwickelten, selbst dort, wo sie diese in Frage stellten. Die Kritik an erstarrten und verschulten Ausbildungsformen war verbreitet und populär, aber sie verdeckt, dass Neuerungen selten von Autodidakten oder Dilettanten ausgingen, sondern häufiger von denjenigen, die das System durchlaufen hatten und erfahren genug waren, seine Grenzen nicht nur zu fühlen, sondern auch produktiv zu erweitern. Denn an der Vorstellung des 18. Jahrhunderts, dass wahre Kunst grundsätzlich lehr- und lernbar sei, hat sich das 19. Jahrhundert mit seinen Brüchen und Widersprüchen zwar vielfältig abgearbeitet, es hat sie relativiert, umformuliert und 
anders begründet. Es hat sie aber, vom rhetorischen Pathos einzelner Äußerungen abgesehen, in der praktischen Ausbildung nicht grundsätzlich aufgegeben.

Das kunstgeschichtliche Seminar in Göttingen ist durch seine Entstehungsgeschichte mit den künstlerischen und kunsttheoretischen Strömungen des 19. Jahrhunderts eng verbunden. Johann Dominicus Fiorillo (1748-1821), sein erster Lehrstuhlinhaber, war der universitäre Lehrer von August Wilhelm Schlegel, Wilhelm Heinrich Wackenroder und Ludwig Tieck und blieb zeitlebens ein kritischer Zeitgenosse der Nazarener und ihrer neuevangelischen Kunst. Sein Nachfolger im Amt, der mit den Künstlergruppen in Rom, Berlin und Düsseldorf eng verbundene Carl Oesterley (1805-1891) praktizierte als Hofmaler des Welfenhauses deren ästhetische Kategorien noch, als anderswo längst neue Entwicklungen auf dem Weg waren. Es gehört daher zu den glücklichen Zufällen der Sammlungsgeschichte, dass die Lehrsammlung des Kunstgeschichtlichen Seminars noch heute über eine zwar kleine, thematisch aber sehr vielseitige Gemäldekollektion des 19. Jahrhunderts verfügt, die nicht nur die Geschichte des Göttinger Fachs und seiner Protagonisten widerspiegelt, sondern fast alle wichtigen Strömungen und Denkansätze der deutschen Malerei dieser Epoche: Ihre führenden Schulen in Wien, Düsseldorf, Berlin oder Weimar, ihre leitenden Gattungsdiskurse von der Neuformulierung der Historienmalerei in München und Düsseldorf bis zur Rehabilitierung von Genre und Landschaft, schließlich ihren kunstgeschichtlichen Reflexionshorizont von Klassizismus, Raffaelismus und niederländischem Genre bis zur Schule von Barbizon. Neben bekannteren Malern wie Friedrich Philipp Reinhold (17791840), Josef Danhauser (1805-1845), Louis Gurlitt (1812-1897), Paul Meyerheim (1842-1915) und Karl Buchholz (1849-1889) umfasst sie auch weniger bekannte Namen wie Heinrich Petri (1834-1872) oder Friedrich Spangenberg (1843-1874) Künstler, die nur in einem lokalen Umkreis tätig waren, aber durch Ausbildung und Kontakte mit den Größen ihrer Zeit, mit Friedrich Overbeck, Carl Theodor von Piloty, Peter Cornelius, Wilhelm Schadow oder Adolph Menzel oft eng verbunden waren. Eine solche Gemäldekollektion bietet daher ideale Möglichkeiten, um am lokal begrenzten Gegenstand nicht nur Archivstudien zu betreiben und die Karrieren der Maler, ihre Kontakte und Vorbilder zu untersuchen, sondern ihre Tätigkeit auch vor einem breiteren europäischen Horizont akademischer und kunsttheoretischer Diskurse zu reflektieren und damit als Auseinandersetzung mit den künstlerischen Wertvorstellungen ihrer Zeit zu begreifen.

Auswärtigen Besuchern ist die Kunstsammlung der Universität Göttingen heute vor allem durch ihre niederländischen Gemälde und die reichen Schätze an Druckgraphik bekannt, die zu den ältesten und sicherlich wichtigsten Beständen gehören. Umso mehr sind wir Herrn PD Dr. Christian Scholl als ausgewiesenem Romantikforscher und Frau Dr. Anne-Katrin Sors als Leiterin der Kunstsammlung dankbar, dass sie durch die hier präsentierten Forschungsergebnisse auch die unbekannteren Gebiete dieser Sammlung in den Blick gerückt und zum Gegenstand eines mustergültigen Lehrprojekts gemacht haben: Fortgeschrittene Studierende der Kunstgeschichte durften dabei mit finanzieller Unterstützung durch das Cam- 
pus QPLUS-Programm der Universität Göttingen, das neue, forschungsorientierte Lehrformen fördert, unter fachlicher Anleitung alle inhaltlichen und praktischen Aspekte einer Ausstellungsplanung selbstverantwortlich konzipieren und realisieren. Diese reichten von der materiellen Untersuchung der Artefakte, die vielfach erst im Depot zu entdecken waren, über Archivrecherchen, Reisen in andere Sammlungen und Gespräche mit auswärtigen Fachleuten bis zur Profilierung eines Ausstellungsthemas, der Gestaltung der Sammlung zu einem begehbaren „Wissensraum" und schließlich der öffentlichen Vermittlung. Dabei erwies sich die Frage nach dem akademischen Gattungsbegriff des 19. Jahrhunderts als äußerst fruchtbar: macht sie doch über die Geschichte der Einzelwerke hinaus deren gemeinsame Verankerung in einem zentralen Diskursfeld zwischen Klassizismus und Moderne deutlich und erfüllt damit ein wichtiges Ziel aller Fachdidaktik: ihre Fähigkeit, auch am begrenzten und nicht immer erstrangigen Gegenstand grundlegende und übergreifende Fragen sichtbar und verständlich zu machen.

Die Ausstellung „Akademische Strenge und künstlerische Freiheit“ wurde am 22. April $2011 \mathrm{im}$ Auditorium der Universität Göttingen eröffnet und fand eine breite Resonanz bei Studierenden wie bei Besuchern innerhalb und außerhalb der Universität. Der nun vorliegende Katalog präsentiert die umfangreichen Forschungsergebnisse dieses Projekts. Er ist zugleich ein wichtiger Baustein in den langfristigen Bestrebungen des Instituts, die 2010 durch Dr. Anne-Katrin Sors neu eingerichtete Kunstsammlung noch intensiver als bisher durch professionelle Arbeitsbedingungen zugänglich und sichtbar zu machen und als Instrument der universitären Ausbildung zu stärken. Weitere Ausstellungen über Eduard Bendemann (2012) und die druckgraphische Verbreitung von Antikenwissen (,abgekupfert“", 2013) setzen derzeit diese Initiative fort. Von 2014 an soll die geplante Neueinrichtung des Graphischen Kabinetts die Nutzbarkeit der Bestände für Studierende weiter verbessern.

Der vorliegende Band ist Prof. Dr. Carsten-Peter Warncke zur Vollendung seines 65. Lebensjahrs gewidmet, dem langjährigen Lehrstuhlinhaber und Direktor des Kunstgeschichtlichen Seminars in Göttingen. Seit 1996, nach Stationen in Wuppertal, Tübingen und Braunschweig, hat Carsten-Peter Warncke die Geschicke des Seminars und seiner Kunstsammlung gelenkt und seinen derzeitigen Ruf als Stätte von Forschung und Ausbildung maßgeblich begründet. In dieser Zeit hat er als weltweit anerkannter Fachmann für die frühneuzeitliche Emblematik und Sinnbildkunst nicht nur die Moderne mit gewichtigen Publikationen in Göttingen etabliert, sondern auch die Verankerung der musealen Praxis in Forschung und Lehre auf vielfältige Weise durch Projekte und Initiativen gefördert. Es ist nicht zuletzt sein Verdienst, dass die älteste Lehrsammlung der universitären Kunstgeschichte heute, nach ihrer Neueinrichtung in den Räumen des Auditoriums, als wertvolles und vielfach genutztes Instrument einer forschungs- wie praxisorientierten Ausbildung in eine gesicherte Zukunft blicken kann. Im Hinblick auf das Thema dieses Katalogs sei nicht verschwiegen, dass Carsten-Peter Warncke, in Fortsetzung seiner eigenen Studien zu Anselm Feuerbach und zur deutschen 
Romantik, nicht geringen Anteil daran hat, dass auch die Malerei des 19. Jahrhunderts heute als Forschungsfeld in Göttingen breit etabliert ist und diese fachgeschichtlich so wichtige Epoche in der eigenen Sammlung mehr und mehr aufgearbeitet wird. Denn es sind seine Schüler und Mitarbeiter, die durch die EmmyNoether-Forschungsgruppe zur Romantikrezeption (2004-2009) Impulse seiner Forschungen zum frühneuzeitlichen Bildverständnis aufgegriffen und für das 19. Jahrhundert fruchtbar gemacht haben.

Wenn heute aus dem Kreis dieser Schüler, Mitarbeiter und ihrer Studierenden ein solches Echo an den Geehrten zurückkehrt, ist dies als Ermunterung an zukünftige Studentengenerationen zu verstehen, ihren Gegenstand abseits der standardisierten Lehrformate am Original und mit frischer Neugier zu entdecken. Es ist zugleich der Dank an einen Forscher, Lehrer, Mentor und Kollegen, der das Seminar auf vielfältige Weise geprägt und bereichert hat und ihm in guter Erinnerung bleiben wird.

Manfred Luchterhandt 


\section{Das Projekt}

Der vorliegende, Prof. Dr. Carsten-Peter Warncke gewidmete Bestandskatalog stellt erstmals die Gemälde des 19. Jahrhunderts vor, welche in der Kunstsammlung der Georg-August-Universität Göttingen aufbewahrt werden. Er entstand aus dem von den Unterzeichnern betreuten studentischen Forschungsprojekt „Gattungstheorie und Gattungspraxis: Untersuchungen zum Bestand der Gemälde des 19. Jahrhunderts in der Göttinger Universitätskunstsammlung“, das im Wintersemester 2011/12 am Kunstgeschichtlichen Seminar der Universität Göttingen durchgeführt werden konnte. Zwei glückliche Umstände kamen dabei zusammen: das Bestehen einer Universitätskunstsammlung, welche den Studierenden ein objektnahes Forschen ermöglicht, sowie ein universitäres Programm, welches diese Forschung strukturell und finanziell fördert. Wir sind überaus dankbar, dass wir das Projekt im Rahmen des von der Göttinger Hochschuldidaktik initiierten Programms „Forschungsorientiertes Lehren und Lernen“ (FoLL, als Teil des Qualitätsprogramms Göttingen Campus QPLUS) durchführen konnten. Dieses Programm verfolgt die Aufgabe, Studierenden ein eigenständiges Forschen früh, praxisnah und in Gruppen zu ermöglichen und die Ergebnisse auf vielfältige Weise zu präsentieren. In Zeiten einer zunehmenden Verschulung des Studiums bietet es mithin ideale Möglichkeiten zum freien, vom Gegenstand her bestimmten Arbeiten. Obgleich das Programm vornehmlich für Bachelor-Studierende gedacht ist, war es uns wichtig, auch Studierende im Masterstudiengang am Projekt zu beteiligen, um auf diese Weise ein Voneinanderlernen zu ermöglichen, wie es in unserer eigenen Studienzeit selbstverständlich war. Am Ende hat jede und jeder Studierende mehr geleistet, als es sich in „Creditpoints“ ausdrücken ließe. Unser großer Dank gilt daher Julia Diekmann, Christina Eifler, Katharina Immoor, Janna Krützer, Phil Miller, Jan Stieglitz, Verena Suchy, Ifee Tack und Lisa Weiß, die als Studierende des Faches Kunstgeschichte dieses Projekt mit großem Engagement 
durchgeführt haben. Wie nachhaltig das Projekt gewirkt hat, zeigt sich nicht zuletzt daran, dass in dessen Folge mehrere Abschlussarbeiten entstanden sind. ${ }^{1}$

Desweiteren danken wir herzlich Vizepräsident Prof. Dr. Wolfgang Lücke, dem Projektleiter des Programms CampusQPLUS, sowie Susanne Wimmelmann von der Hochschuldidaktik der Georg-August-Universität Göttingen, die unser FoLL-Programm mit großem Enthusiasmus betreut hat.

Hervorzuheben ist die Selbständigkeit, mit der die Studierenden dieses Projekt durchgeführt haben. Sie waren es, die 2011 von sich aus mit der Idee an uns herangetreten waren, einen in sich geschlossenen Bestand an Werken der Universitätskunstsammlung wissenschaftlich zu bearbeiten. Die Wahl fiel dann bald auf das 19. Jahrhundert, da hier - bei einer verhältnismäßig übersichtlichen Werkgruppe, die aus einer an Quellenmaterial reichen Zeit stammt - am ehesten neue Ergebnisse zu erwarten waren. Zudem handelt es sich um einen Bestand, der jenseits des Sammlungsschwerpunkts, welcher bei der Göttinger Universitätskunstsammlung auf der Niederländischen Malerei liegt, Überraschungen versprach. Als übergeordnete Fragestellung bot sich die Gattungstheorie an. Auf diese Weise ermöglichte das Projekt zweierlei: eine unmittelbare Auseinandersetzung mit Kunstwerken als Objekten sowie die Entwicklung einer historischen Perspektive auf die ganz eigenen, überaus folgenreichen Kunstkonzepte und Umgangsweisen mit Bildern, die im 19. Jahrhundert entwickelt worden sind. In diesem Sinne trägt auch der vorliegende Katalog hoffentlich den Charakter eines forschungsorientierten Lehr- und Lernbuches.

Diesen Katalog zu erarbeiten, war von vornherein das Hauptziel des Projektes. Im Rahmen der Vorbereitungen entstand dann aber recht bald die Idee, den bis dahin nahezu unbekannten Bestand zusammen mit den neuen Forschungsergebnissen der Öffentlichkeit in einer Ausstellung zu präsentieren. Die Exposition mit dem Titel „Akademische Strenge und künstlerische Freiheit“ (auch für diesen Titel zeichnen die Studierenden verantwortlich) fand vom 22. April bis zum 9. September 2012 in der Gemäldegalerie der Universitätskunstsammlung statt. Die Vorbereitung mit ihren ebenso theoretisch-konzeptionellen wie handwerklichpraktischen Anforderungen legte bei den Studierenden noch einmal so manche Begabung offen, die im normalen Lehrbetrieb üblicherweise kaum Beachtung gefunden hätte. Für das außergewöhnliche Engagement danken wir Julia Diekmann, Christina Eifler, Phil Miller, Jan Stieglitz, Verena Suchy, Ifee Tack und Lisa Weiß, den Praktikanten Ines Barchewicz, Stephanie Götsch, Elisa Jubert, Annkristin Kaluza, Izabela Mihaljevic, Toni Schreiber, Katharina Timpe, Lisa Weiß sowie den

1 Abgeschlossene MA-Arbeit: Christina Eifler: „Wege einer neuen Ästhetik - Werke Friedrich Philipp Reinholds im Spiegel der Landschsftstheorie um 1800"; abgeschlossene BA-Arbeiten: Phil Miller: „Abneigung und Anziehung. Eine Untersuchung über die beeinflussende Wirkung von Karl Buchholz auf das Frühwerk Paul Baums“; Verena Suchy: „Tiermalerei zwischen Akademie und Avantgarde. Eine exemplarische Untersuchung am Frühwerk Paul Meyerheims"; Lisa Weiß: „Landschaftsmalerei im Spannungsfeld der Akademie - Louis Gurlitts Kopenhagener Jahre“. In Vorbereitung ist eine MA-Arbeit von Julia Diekmann zu Karl Franz Jacob Heinrich Schumann. 
studentischen Hilfskräften der Kunstsammlung Antje Habekus, Tobias Heine und Ifee Tack. Unser Dank gilt zudem Ingrid Rosenberg-Harbaum für die tatkräftige Unterstützung beim Ausstellungsaufbau. Mit (nicht nur restauratorischem) Rat und Tat stand uns Dipl.-Rest. Dr. Bettina Achsel zur Seite, der wir ebenfalls herzlich danken. Dankbar sind wir zudem auch dem Freundeskreis Kunstsammlung der Universität Göttingen e.V. für finanzielle Unterstützung. Und schließlich danken wir besonders herzlich Nadine Luneke für die stets zuverlässige Erledigung anfallender Verwaltungsakte sowie für außergewöhnliches Engagement bei der Vorbereitung von Preview und Ausstellungseröffnung.

Parallel zur Ausstellung erfolgte die Vorstellung der Forschungsergebnisse durch die Studierenden im Rahmen der Vortragsreihe „Kunstwerk des Monats“. Am 11. Mai 2012 fand zudem in der Gemäldegalerie ein interdisziplinäres Kolloquium zum Forschungsprojekt statt. Allen Wissenschaftlern, die unserer Einladung nach Göttingen gefolgt sind, sei hiermit herzlich gedankt: Prof. Dr. Thomas Noll (Bonn), Dr. Saskia Pütz (Hamburg), Prof. Dr. Anselm Schubert (Erfurt), Dr. Kerstin Schwedes (Braunschweig) und Prof. Dr. Michael Thimann (Passau).

Angesichts des engen Zeitrahmens und parallel laufender Projekte ${ }^{2}$ mussten Ausstellung und Bestandskatalog getrennt werden. So erfolgte die Erarbeitung und Endredaktion des Textes in einem zweiten Schritt, dessen Ergebnis nun in diesem Band vorgelegt werden kann. Als wissenschaftliche Erschließung einer bislang so gut wie unbeachtet gebliebenen Werkgruppe in der Göttinger Universitätskunstsammlung behält dieser gewiss auch unabhängig von der Ausstellung seine Bedeutung. Dabei versteht sich der Katalog als Anstoß für eine weitere Auseinandersetzung mit diesem durchaus bemerkenswerten Bestand: Es gibt immer noch einige Bilder, zu denen bislang kaum etwas bekannt ist. Einige Werke (z. B. Kat. Nr. 14, 30) sind erst kurz vor Redaktionsschluss in den Katalog aufgenommen worden.

Für die photographische Ausstattung des Katalogs danken wir Katharina Anna Haase, Stephan Eckardt und Christine Hübner. Eine besondere Freude ist es uns schließlich, dass wir nun bereits den zweiten Bestandskatalog in Zusammenarbeit mit dem Göttinger Universitätsverlag publizieren können. Hier gilt unser persönlicher Dank Jutta Pabst, die unsere Projekte stets zuverlässig und geduldig betreut hat.

Christian Scholl und Anne-Katrin Sors

2 Gleichzeitig erfolgte - ebenfalls im Rahmen eines studentischen Projektes - die Bearbeitung des Bestandes an Zeichnungen Eduard Bendemanns in der Göttinger Universitätskunstssammlung. Die Eröffnung der Ausstellung „Vor den Gemälden: Eduard Bendemann zeichnet“ fand am 28. Oktober 2012 statt (vgl. Ausst.-Kat. Göttingen 2012). 


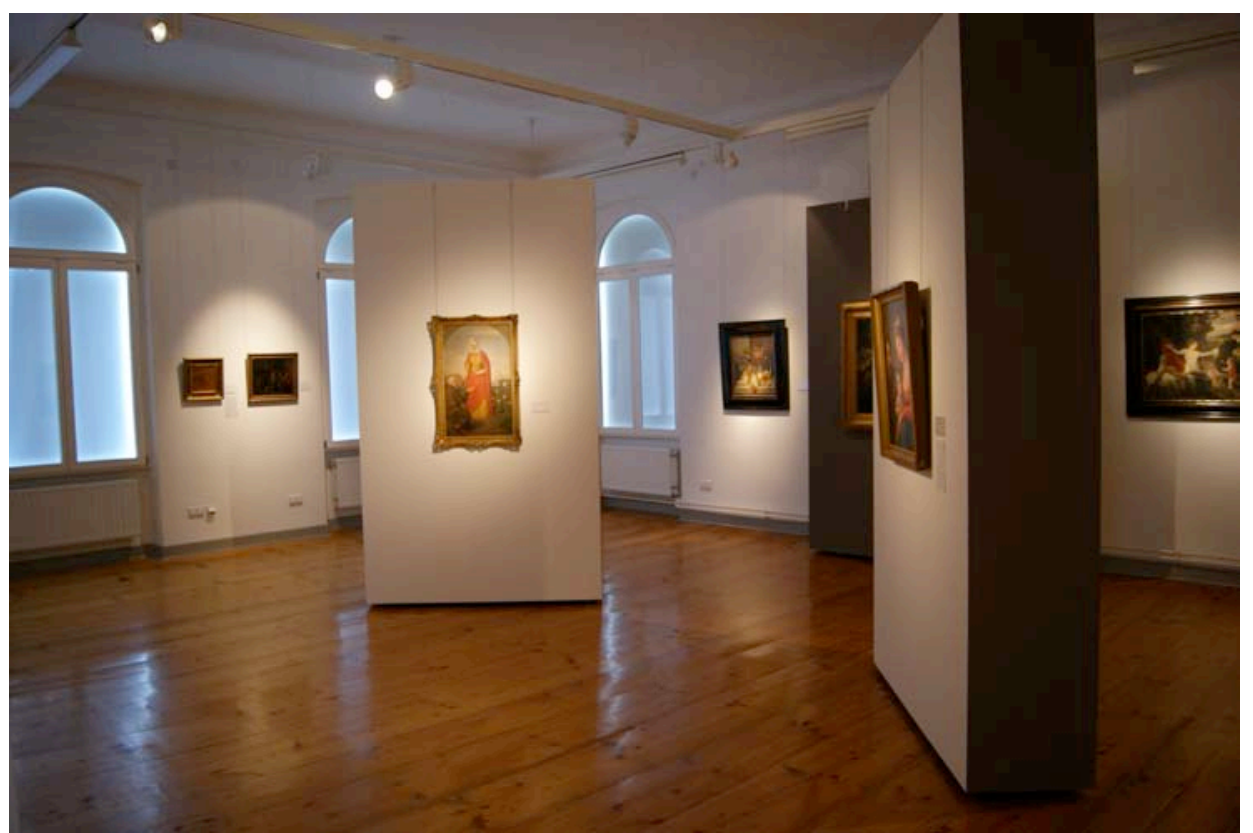

Blick in die Ausstellung „Akademische Strenge und künstlerische Freiheit“, Göttingen, Kunstsammlung der Universität, Gemäldegalerie im Auditorium, 22. April - 9. September 2012 
Aufsätze 



\title{
Dialog der Gattungen: \\ Zur kunsttheoretischen Verortung der Gemälde des 19. Jahrhunderts in der Göttinger Universitätskunstsammlung
}

\section{Christian Scholl}

\begin{abstract}
Malerei des 19. Jahrhunderts in Göttingen
Ruft man sich die Gemäldebestände der Göttinger Universitätskunstsammlung ins Gedächtnis, so wird man wohl zunächst an Bilder niederländischer und flämischer Künstler aus dem 17. Jahrhundert denken. Dass es in dieser Kollektion auch einen zwar zahlenmäßig kleinen, aber qualitativ durchaus beachtlichen und vor allem überaus facettenreichen Bestand an Gemälden des 19. Jahrhunderts gibt, gleicht dagegen einer Neuentdeckung. Dabei waren die Werke an sich keineswegs unbekannt - bezeichnenderweise ist ein Großteil derselben bereits im „Verzeichnis der Bilder anderer Schulen“ im Anhang des von Gerd Unverfehrt bearbeiteten Sammlungskatalogs Die niederländischen Gemälde von 1987 erfasst. ${ }^{1}$ Doch erst jetzt, da die systematische Aufarbeitung dieser Gruppe von Bildern begonnen hat, wird deutlich, dass sie sich tatsächlich zu einer eigenen, für Forschung und Lehre höchst aussagekräftigen Abteilung formieren lässt. Umso wichtiger ist es, dass der Bestand mit dem vorliegenden Katalog nun auf nachhaltige Weise wissenschaftlich er-
\end{abstract}

1 Unverfehrt 1987, S. 180-195. 
schlossen wird, nachdem er bereits 2012 mit der Ausstellung „Akademische Strenge und künstlerische Freiheit“ der Öffentlichkeit vorgestellt werden konnte.

Eine gezielte Auseinandersetzung mit Kunstwerken des 19. Jahrhunderts bedarf heute keiner besonderen Rechtfertigung mehr. Durch eine intensive Forschungsarbeit ist in den letzten Jahrzehnten die Vielschichtigkeit und Komplexität der Malerei dieser Zeit immer deutlicher zu Tage getreten. Diese umfasst nicht nur Bilder, welche der Gegenwart unmittelbare Zugänglichkeit zu suggerieren scheinen, sondern auch höchst Eigentümliches, Befremdliches und mitunter Verstörendes. Man begegnet einer Fülle eigenständiger Kunstkonzepte und Lösungsansätze, die sich einer teleologischen, auf die Kunst des 20. Jahrhunderts abzielenden Sichtweise weitgehend entziehen. Vieles davon ist von einer hohen Qualität, für die es freilich ein spezifisches Sensorium zu entwickeln gilt.

Betrachtet man vor dem Hintergrund dieser Vielfalt die Gemälde des 19. Jahrhunderts in der Göttinger Universitätskunstsammlung, so kann man Bemerkenswertes feststellen: Selbst wenn es sich um eine eher kleine Kollektion von 31 Wer$k_{k n}{ }^{2}$ handelt, erweist sich diese doch als erstaunlich repräsentativ für die Vielfalt dessen, was in jenem Centennium an Kunst entstanden ist. Da gibt es einerseits Bilder wie die Studie von Karl Buchholz (Kat. Nr. 26), die mit dem Kunstverständnis der Moderne besonders kompatibel zu sein scheinen. Daneben findet man andererseits aber auch nazarenisch geprägte Werke religiöser Malerei sowie Ölstudien für Monumentalbilder, die lange Zeit als „Historienschinken“ bezeichnet und nur wenig geschätzt wurden. Intime Landschaftsausschnitte stehen neben pointiert erzählten Genreszenen; Historien erscheinen sowohl in penibler Ausführung als auch mit malerischer Verve ausgeführt und ein brillant gemaltes Tierstück führt die hohe Malkultur des Realismus in der zweiten Jahrhunderthälfte vor Augen. Eine größere Vielfalt, aber auch ein höheres Potential für das objektbezogene Entwickeln und Erörtern kunsttheoretischer Dialoge und Korrespondenzen lässt sich in einem solchen eher eng gesteckten Rahmen kaum vorstellen.

Es mag paradox klingen: dass diese kleine Sammlung von Malerei des 19. Jahrhunderts so repräsentativ ausfällt, hängt vermutlich genau damit zusammen, dass sie sich zu weiten Teilen keiner systematischen Sammlungstätigkeit verdankt. Zwar gab es in der Vergangenheit - namentlich unter den Kuratoren Hans Wille und Konrad Renger - durchaus Ansätze zu einem gezielten Ausbau der Kollektion von Werken des 19. Jahrhunderts. ${ }^{3}$ Viele Bilder kamen jedoch durch Schenkungen in

2 In dieser Zahl sind die Porträts und Kopfstudien, die einer eigenen Bearbeitung bedürfen, nicht mit inbegriffen. Sie sind im Anhang dieses Katalogs aufgelistet, wobei zwei Werke auf exemplarische Weise ausführlicher besprochen werden (Kat. Nr. 32+33). Ausgeklammert bleiben auch die zahlreichen Ölstudien aus dem Nachlass von Carl Wilhelm Friedrich Oesterley, die ein eigenes Konvolut für sich bilden, das noch der wissenschaftlichen Aufarbeitung bedarf.

3 Beispielhaft für dieses Bestrebungen ist ein Brief von Dr. Hans Wille an Prof. Dr. G. Gruber vom 22.8.1969 (Göttingen, Kunstsammlung der Universität, Archiv, Bildakte GG 214 zu Unbekannt, deutsch: Bildnis des Benno Karl von Waechter; vgl. auch Kat. Nr. 48 in diesem Band): „Sehr geehrter Herr Professor, / sehr herzlich möchte ich mich bedanken für die schöne Miniatur, die Sie 
die Sammlung, und manche wurden offenbar gerade deshalb abgegeben, weil man sie für den eigenen Bildgebrauch für unzeitgemäß hielt. Die meisten gezielt angelegten Sammlungen von Kunst dieser Zeit haben demgegenüber ein spezifisches Profil. Gerade im Gefolge der Revision um 1900 bestand ein Ansporn für Sammler darin, gleichsam die „Rosinen“ aus einer an sich als problematisch angesehenen Periode herauszupicken. ${ }^{4}$ Die Göttinger Sammlung besitzt ebenfalls solche „Rosinen“: Die Ölstudien von Louis Gurlitt (Kat. Nr. 20-22) oder das Tierstück von Paul Meyerheim (Kat. Nr. 29), um nur eine Auswahl zu nennen, könnten jeder noch so erlesenen Sammlung zur Zierde gereichen. Die Kollektion enthält, um beim sprachlichen Bild zu bleiben, aber nicht nur „Rosinen“, sondern auch „Teig“: Das qualitative Gefälle ist mitunter durchaus beträchtlich. Gerade dies darf aber in einem solchen Fall als Chance bezeichnet werden, denn wie könnte man in der kunsthistorischen Lehre besser einen Sinn für Qualität vermitteln als anhand von Originalen unterschiedlicher Güte?

Entscheidend ist allerdings, dass sich die Qualität vieler Werke überhaupt erst dann erschließt, wenn man um die spezifischen Prämissen, Regeln und Bedingungen weiß, unter denen diese entstanden sind. Gerade weil eine kleine Zahl von Bildern des 19. Jahrhunderts nach wie vor unmittelbare Zugänglichkeit zu suggerieren scheint, ist eine differenzierte Sicht auf die Kunst dieser Zeit erforderlich, welche deren ganz eigenständige, sich heute nicht mehr ohne weiteres erschließende Funktionsweisen in den Blick nimmt und die Werke vor einer vorschnellen Enthistorisierung schützt.

\section{Gattungsdiskurse als historische Perspektive}

Tatsächlich war die Kunst des 19. Jahrhunderts in ein ausdifferenziertes, wenn auch keineswegs starres System eingebunden, das sowohl die Gestaltungsansätze der Künstler als auch die Erwartungshaltungen des Publikums in starkem Maße regulierte. Hier ist vor allem die Einteilung in Gattungen (Historienmalerei, Porträt, Sittengemälde, Tierstück, Landschaft, Stillleben, usw.) zu nennen, wobei die spezifischen Möglichkeiten und Grenzen der einzelnen Genres intensiv diskutiert wurden. Gerade für eine wissenschaftliche Annäherung an den Göttinger Bestand von Gemälden des 19. Jahrhunderts bietet sich die Gattungstheorie als Zugang an. Immerhin beruht der oben beschworene repräsentative Charakter dieser Kollekti-

uns geschenkt haben. Dieses Stück ist eine sehr willkommene Bereicherung unserer Abteilung des 19. Jahrhunderts, die, wie Sie ja wissen, zu unserem besonderen Aufbauprogramm zählt.“

4 Ein charakteristisches Beispiel bietet die Sammlungspolitik Alfred Lichtwarks als Direktor der Hamburger Kunsthalle, für die sich bereits dessen Nachfolger Gustav Pauli entschuldigt: „So kommen [in der Sammlung der Hamburger Kunsthalle] beispielsweise die Nazarener und die späteren Deutsch-Römer aus der zweiten Jahrhunderthälfte nicht hinlänglich zu Worte oder es wurden von ihnen, wie von Böcklin, Feuerbach, Marées, Bildnisse und Landschaften erworben, in denen sie sich der säkularen Entwicklungslinie des Impressionismus nähern, die also für ihre besonderen Absichten minder bezeichnend sind.“ Vgl. Pauli 1927, S. IV. 
on vor allem darauf, dass hier ein bemerkenswert breites Spektrum von Gattungen abgedeckt wird.

Für ein historisches Verständnis von Kunst ist die Gattungstheorie im mehrfacher Hinsicht von Bedeutung. Einerseits wurde hier verhandelt, mit welchen Mitteln Künstler bestimmte Themen und Motive umsetzen sollten. Dass beispielsweise ein Altarbildmaler wie Carl Wilhelm Friedrich Oesterley eine Christusfigur nicht mit derselben malerischen Verve und den breiten, pastos gesetzten Pinselstrichen malen durfte, mit denen Paul Meyerheim seine Tauben auf dem Dach (Kat. Nr. 29) ins Bild gesetzt hat, war durch die Gattungstheorie weitgehend festgelegt. 5 Man würde dem Segnenden Christus von Oesterley (Kat. Nr. 11) also gar nicht gerecht werden können, wenn man hier eine markantere künstlerische Handschrift erwartete. Andererseits ist die Gattungstheorie als Rahmen zur Erfassung des entsprechenden Göttinger Gemäldebestands gerade deshalb interessant, weil es sich eben nicht um ein statisches, ein für allemal fixiertes System handelte. Vielmehr wurde die Ordnung der Gattungen über das gesamte 19. Jahrhundert hinweg immer wieder neu verhandelt und schließlich sogar komplett aufgebrochen. An kaum einem Feld lässt sich die Dynamik kunsthistorischer Entwicklungen in dieser Zeit so gut verfolgen wie an den Auseinandersetzungen um Sinn und Stellenwert von Gattungsdifferenzierungen. Da die Göttinger Universitätskunstsammlung Werke aus nahezu allen Phasen dieses von grundlegenden Umbrüchen geprägten Centenniums umfasst, lässt sich auf diese Weise Grundlegendes zu deren Verortung und Bedeutung sagen.

Um einen Rahmen für die historische Verortung der Gemälde des 19. Jahrhunderts in der Göttinger Universitätskunstsammlung zu entwickeln, ist es dementsprechend sinnvoll, die gattungstheoretischen Auseinandersetzungen in dieser Zeit zumindest überblicksweise nachzuzeichnen. Ein besonderer Stellenwert kommt dabei dem in der Frühen Neuzeit entwickelten, lange Zeit überaus wirkmächtigen Konzept der Gattungshierarchie zu. In diesem fanden die ausdifferenzierten Gattungen eine Einbindung in ein Wertesystem, bei dem die Historienmalerei auf die oberster Stufe gestellt, anderen Gattungen wie der Genre- oder Landschaftsmalerei dagegen ein niederer Rang zugesprochen wurde. ${ }^{6}$

\section{Auflösung und Reetablierung der Gattungshierarchie um 1800}

Bereits im 18. Jahrhundert war das System der Gattungshierarchie, das im 17. Jahrhundert an der Academie Royale de peinture et de sculpture in Paris ${ }^{7}$ kunsttheoretisch systematisiert worden war, nicht mehr unbestritten. Ansätze, wie sie Werner Busch unter dem Begriff des „sentimentalischen Bildes“ beschrieben hat, implizieren

\footnotetext{
Vgl. hierzu Krüger 2007, S. 52-55.

Vgl. hierzu einführend Gaehtgens, Th. 1996, S. 16-39.

Vgl. Gaehtgens, Th. 1996, S. 31-34; Busch 1993, S. 19-24.
} 
zumindest tendenziell eine Auflösung der traditionellen Gattungshierarchie. ${ }^{8}$ So entwickelten Künstler wie Jean-Baptiste Greuze in Frankreich oder Daniel Chodowiecki und Gerhard von Kügelgen in Deutschland Bilder einer mittleren Höhenlage mit hohem Empathiepotential und weitgehend zurückgenommener konventioneller Ikonographie. ${ }^{9}$ Man kann solche Werke als Teil eines aufklärerischutopischen Projektes verstehen, unmittelbar wirksame Bilder zu schaffen, die auf kein Vorwissen mehr angewiesen seien und sich einer hierarchischen Gattungsordnung entziehen. Auch im weiteren 19. Jahrhundert entstanden Bilder, die zumindest teilweise mit diesem Ansatz in Verbindung gebracht werden können. In der Göttinger Universitätskunstsammlung kann man etwa auf Johann Dominicus Fiorillos Heilige Familie (Kat. Nr. 6) mit ihrer offenbar bewusst reduzierten christlichen Ikonographie verweisen. Unklar ist, ob noch ein Werk wie Friedrich Beckers Drei beim Bade überraschte Damen (Kat. Nr. 1) in einer solchen Tradition zu sehen ist oder ob hier einfach das Wissen um die Thematik verloren gegangen ist.

In eine ganz andere Richtung gingen die Romantiker bei ihren eigenen - allerdings keineswegs einheitlichen - Ansätzen, die Gattungshierarchie zu sprengen. Maler wie Philipp Otto Runge und Caspar David Friedrich durchbrachen die hierarchische Ordnung, indem sie niedere Gattungen mit einem zum Teil erheblichen Aufwand an ikonographisch konnotierten Elementen aufzuwerten suchten. ${ }^{10}$ Friedrich Schlegel als einer der wichtigsten Theoretiker der Romantik und Impulsgeber für die Nazarener wiederum insistierte in seinem Nachtrag italiänischer Gemälde von 1803 darauf,

„daß es keine Gattungen der Mahlerei gebe, als die eine, ganz vollständige Gemälde, die man
historisch zu nennen pflegt; schicklicher, aber gar nicht besonders, oder symbolische Ge-
mählde nennen würde. Was man sonst von andern als wirklich verschiednen und abgeson-
derten Gattungen zu sagen pflegt, ist nur eitler Wahn und leere Einbildung. Die Landschaft
ist der Hintergrund des vollständigen Gemäldes, und nur als solcher hat sie ihre volle Bedeu-
tung; der Vorgrund aber müßte sehr schlecht und trivial behandelt sein, falls er ausführlich
ist, wenn man ihn nicht ein Stilleben nennen könnte.“11

So zukunftsträchtig solche frühen Ansätze zu einem Bruch mit der traditionellen Gattungshierarchie aus moderner Sicht erscheinen mögen, so ist doch zunächst einmal zu beobachten, wie sich dieses akademische Konzept unter neuen, primär ästhetischen Vorzeichen um und nach 1800 wieder verfestigte. Tatsächlich kommt es in dieser Zeit zu einer bemerkenswerten Verbindung zwischen Autonomieästhetik und dem Festhalten an den spezifischen Grenzen der Gattungen und Kunstformen. „Eines der vorzüglichsten Kennzeichen des Verfalles der Kunst ist die Vermischung der verschiedenen Arten derselben“, schreibt Johann Wolfgang Goe-

8 Busch 1993.

9 Vgl. Busch 1985, S. 15-24; Busch 1993, u. a. S. 49-55, 238-242. Hier sind etwa Bilder von JeanBaptiste Greuze, Daniel Chodowiecki oder Gerhard von Kügelgen zu nennen.

10 Vgl. Scholl 2007, S. 195-269.

11 Schlegel 1959 [1803]b, S. 72. 
the in seiner Einleitung in die Zeitschrift Propyläen aus dem Jahr $1798 .{ }^{12}$ Dementsprechend gliedert Goethes „Weimarischer Kunstfreund“ Heinrich Meyer seinen Aufsatz Ueber die Gegenstände der bildenden Kunst, der im selben Band der Propyläen erschien, nach Gattungen. ${ }^{13}$ Und auch der im gleichen Weimarer Umfeld agierende Carl Ludwig Fernow geht von einer hierarchischen Einteilung der Bildenden Kunst aus, in deren Rahmen der Darstellung des Menschen der höchste Stellenwert zukomme. ${ }^{14}$ Die genannten Vertreter einer dezidierten Autonomieästhetik beharrten nicht zuletzt deshalb auf der hierarchisch differenzierten Gattungstrennung, weil diese einen Maßstab bot, die verschiedenen Künste und Genres nach kunstimmanenten Kriterien bewerten zu können. Das Festhalten an normativen Grenzziehungen hatte also gerade einen emanzipatorischen Charakter: Um der Freiheit der Kunst willen wurden hier die künstlerischen Freiheiten beschränkt.

Dies war einer der Gründe, weshalb auch die meisten Junghegelianer in der Zeit des Vormärz am Konzept der Gattungshierarchie festhielten. So wendet sich Friedrich Theodor Vischer ausdrücklich gegen Versuche, eine niedere Gattung wie die Landschaftsmalerei ikonographisch aufzuwerten, wie dies im Umkreis der Romantik etwa bei Caspar David Friedrich oder Carl Friedrich Lessing stattfand:

\begin{abstract}
„Man hört für eine solche Erhöhung der Landschaft in das Genre oder die Historie häufig noch ein andres Moment geltend machen. Die getrennten Zweige der Malerei in einer höhern Gattung zu vereinigen, Historie oder Genre und Landschaft zu verschmelzen, erklärt man für ebenso lobenswerth, als überhaupt jedes Streben, getrennte Glieder eines Ganzen organisch zu verbinden. Als ob nicht jedes Menschliche, und so auch jeder Zweig der Kunst gerade in seiner Trennung und Selbständigkeit groß würde! Je selbständiger jeder Zweig, je individueller, desto vollkommener stellt er in seiner besondern Art das allgemeine Wesen der ganzen Gattung dar." 15
\end{abstract}

Ähnlich wie Goethe bezeichnet Vischer eine Vereinigung der Gattungen, wie sie Friedrich Schlegel propagierte, als einen „Fehlgriff unreifer Kunstperioden“. ${ }^{16}$

Es ist wichtig, dass im Gefolge der autonomieästhetisch fundierten Neufassung der Gattungshierarchie keineswegs in jedem Fall gefordert wurde, nur noch hohe Gattungen wie die Historienmalerei zu pflegen. So konnte Heinrich Gustav Hotho in seiner Redaktion von Georg Wilhelm Friedrich Hegels Ästhetik einer „niederen“ Gattung wie der Genremalerei ihr eigenes Recht einfordern und sogar zu der Feststellung gelangen, dass deren eigentlicher Stoff „so gemein nicht“ sei, „als man gewöhnlich glaubt““.17 Entscheidend ist auch hier, dass die Künstler die Grenzen der Gattung nicht überschreiten sollten. So fordert Hotho, dass die Genremaler ihre Gattung als „,etwas Geringfügiges“ behandeln sollen. ${ }^{18}$ Man könne

12 Goethe 2006 [1798], S. 20.

13 Meyer 1798, Erstes Stück, S. 20-54, Zweites Stück, S. 45-81. Vgl. hierzu auch Scholl 2013.

14 Fernow 1806, S. 14 f.

15 Vischer 1842, S. 556.

16 Ebd.

17 Hegel 1986 [1835], Bd. 1, S. 222.

18 Ebd., S. 224. 
demnach in einer „,niederen“ Gattung nur dann Bedeutendes schaffen, wenn man deren Möglichkeiten nicht überfordere.

Während die Kunsttheoretiker und -kritiker einerseits vor solchen „Überforderungen" warnten, so rieten sie andererseits aber auch von gegenteiligen Tendenzen ab. Dementsprechend konnten sich innerhalb der Gattungsgrenzen Rangabstufungen herausbilden: Eine komponierte Landschaft galt beispielsweise lange Zeit mehr als eine einfache Vedute. ${ }^{19}$ In der Göttinger Sammlung kann man auf das Gemälde Hirte auf der Felsspitze im Abendschein von Friedrich Philipp Reinhold (Kat. Nr. 19) verweisen, bei dem sich ein deutliches Bestreben zeigt, mehr als einen der Realität abgeschauten Naturabschnitt zu zeigen und in einem unübersehbar komponierten Bild ein gedankliches Konzept umzusetzen. Es war eine graduelle Frage, wann man bei solchen Darstellungen eine Grenzverletzung wahrnahm. ${ }^{20}$

In diesem Zusammenhang ist auch die Unterscheidung zwischen Studien und ausgeführten Bildern zu beachten, welche fest im zeitgenössischen Kunstverständnis verankert war. In der Göttinger Kollektion befindet sich eine Reihe von zum Teil sehr reizvollen kleinformatigen Landschaftsstudien, die trotz ihrer hohen Qualität von den Künstlern selbst wohl nicht als vollendete Bilder angesehen worden sind. Hierzu gehören die drei Landschaften von Louis Gurlitt (Kat. Nr. 20-22) sowie das Gemälde Cap Manerba am Gardasee von Bernhard Fries (Kat. Nr. 23). Eventuell handelt es sich bei dem Bild Aufblickender Mann mit Turban eines bislang unbekannten Malers (Kat. Nr. 33) ebenfalls um eine Studie - in diesem Falle vielleicht für ein Historienbild.

Generell gab es über das gesamte 19. Jahrhundert hinweg eine ausgeprägte Kultur spezialisierter Gattungsmalerei, welche das Ausstellungswesen wie auch den Kunstmarkt bestimmte. Die von unbekannten Künstlern geschaffenen Gemälde Schlittschubläufer (Kat. Nr. 14) und Dorflandschaft mit zechenden Bauern (Kat. Nr. 15), das Blumenstillleben in der Art des Joris van Son (Kat. Nr. 30), Joseph Correggios Früchtestillleben (Kat. Nr. 31) und August Keßlers Strand bei Blankenberghe (Kat. Nr. 25) zeigen innerhalb des Göttinger Sammlungsbestandes beispielhaft, wie langfristig bestimmte Darstellungskonventionen, welche sich zum Teil bis ins 17. Jahrhundert zurückverfolgen lassen, innerhalb der jeweiligen Gattungen wirksam waren. Dass derartige Konventionen auf durchaus bewusst und mit qualitätvollen Resultaten weitergeführt werden konnten, belegt bereits das Gemälde Felsenschlucht des Ignatius Josephus van Regemorter (Kat. Nr. 18).

19 Vgl. hierzu etwa Fernow 1806, S. 11 f.: „Derselbe Unterschied, welcher in der Menschendarstellung zwischen treuer Nachbildung wirklicher und freier Darstellung idealischer Gegenstände statt findet, gilt auch in diesem Zweige der Kunst. Eine Landschaft, ein Seestük, ist entweder treu der Wirklichkeit nachgebildet, oder dichterisch erfunden. Im ersten Falle ist die Darstellung Prospekt, Aussicht auf eine wirklich vorhandene Gegend; im lezten ist sie Bild einer idealischen Naturscene der Land- oder Wasserwelt. Demzufolge theilt sich diese Kunst in Darstellung idealischer Naturscenen und Prospektmalerei.“

20 Solche Grenzverletzungen werden gerade in der zeitgenössischen Rezeption der Werke Caspar David Friedrichs immer wieder verzeichnet: vgl. hierzu Scholl 2001, S. 427-434. 


\section{Die Nazarener und ihre Kritiker}

Einen bedeutenden Gegenentwurf zu dieser ausdifferenzierten Kunstpraxis vertraten die Nazarener. Sie strebten nach einer Rekontextualisierung ihrer Kunst in heteronomen Funktionsverhältnissen und träumten davon, die Wände von Kirchen und Palästen mit Bildern zu bedecken, welche sich gerade nicht an eine kennerschaftliche Betrachtung wendeten, sondern an eine fromme, auf den Bildgegenstand ausgerichtete Verehrung. ${ }^{21}$ Dementsprechend fand in diesem Umkreis Friedrich Schlegels Forderung nach einer Vereinigung der Gattungen Gehör. Peter Cornelius, ein Hauptvertreter nazarenischer Kunst, der sich für die Erneuerung orts- und zweckgebundener Monumentalmalerei einsetzte und hierfür vor allem die Freskotechnik propagierte, sprach sich als Direktor der Münchner Kunstakademie gegen die Einrichtung eines eigenen Lehrstuhls für Genre- und Landschaftsmalerei aus: „Einen Lehrstuhl der Genre- und Landschaft-Malerei halte ich für überflüssig. Die wahre Kunst kennt kein abgesondertes Fach; sie umfaßt die ganze sichtbare Natur. Die Gattungs-Malerei ist eine Art von Moos oder Flechtengewächs am großen Stamme der Kunst." 22

Die Göttinger Universitätskunstsammlung besitzt zwar keine NazarenerFresken, aber immerhin zwei Werke, die unter nazarenischem Einfluss gezielt für Kirchenräume entstanden sind: Francesco Podestis Studien für zwei Wandbilder, die für die Neuausstattung der 1823 abgebrannten Basilika San Paolo fuori le Mura in Rom gemalt wurden (Kat. Nr. 7), sowie Carl Oesterleys Altargemälde Segnender Christus für die Kirche in Stemmen (Kat. Nr. 11).

Gerade Oesterleys Gemälde zeigt allerdings auch die charakteristischen Angriffsflächen für die im 19. Jahrhundert wachsende Kritik an der religiösen Malerei der Nazarener. Schon die „Weimarischen Kunstfreunde“ Johann Wolfgang Goethe und Heinrich Meyer polemisierten in ihrer 1817 publizierten Streitschrift Neudeutsche religios-patriotische Kunst gegen den romantischen Ansatz, Kunst auf eine religiöse Basis zu stellen und äußerten den Wunsch, dass „alle falsche Frömmeley aus Poesie, Prosa, und Leben bald möglichst verschwinden und kräftigen heitern Aussichten Raum geben“" möge. ${ }^{23}$ Johann Dominicus Fiorillos Heilige Familie (Kat.

21 Vgl. diesbezüglich den programmatischen Brief von Peter Cornelius an Joseph Görres vom 3. November 1814, zitiert nach: Görres 1874, S. 438 f.: „Dan würden sich in Kurzem Kräfte zeigen, die mann unserm bescheidenen Volke in dieser Kunst nicht zugetraut. Schulen werden endstehen im alten Geist, die ihre wahrhaft hohe Kunst mit würksamer Kraft in's Herz der Nation, in's volle Menschenleben ergössen, es schmückten und erhöhten, so daß von den Wänden der hohen Dome, der stillen Kapellen und einsamen Klöster, der Raths- und Kaufhäusern und Hallen herab, alte vaterländische befreundete Gestalten, in neuerstandener frischer Lebensfülle in holder Farbensprache auch dem Geschlechte sagten, daß der alte Glaube, die alte Liebe, und mit ihnen die alte Kraft der Väter wieder erwacht sey, und darum der Herr unser Gott wieder ausgesöhnt sey mit seinem Volk."

22 Peter Cornelius an Ludwig I. von Bayern, Anfang Dezember 1825. Zitiert nach: Förster 1874, Bd. 1, S. 368. Zur Erneuerung der Freskomalerei durch Cornelius vgl. u. a. Droste 1980, S. 14-19; Büttner 1980/1999, Bd. 1, S. 64-76.

23 Weimarische Kunstfreunde 1999 [1817], S. 129. 
Nr. 6) bietet ein bemerkenswertes, von der bisherigen Forschung bislang nicht wahrgenommenes Beispiel für einen offensichtlich gezielt konzipierten Gegenentwurf zur nazarenischen Malerei. Das Bild des heute vor allem als Kunsthistoriograph bekannten Gelehrten bildet eine gemalte Parallele zur verbal formulierten Nazarenerkritik in dessen Geschichte der zeichnenden Künste in Deutschland und den vereinigten Niederlanden. ${ }^{24}$ Hier beruft sich Fiorillo auch direkt auf den Aufsatz Neudeutsche religios-patriotische Kunst. ${ }^{25}$

Obgleich der Aufsatz der „Weimarischen Kunstfreunde“ nach seinem Erscheinen scharfe Kritik erfuhr, fanden die hier entwickelten Topoi der Nazarenerkritik in den folgenden Jahrzehnten doch eine rege Verbreitung. ${ }^{26}$ Dies gilt insbesondere für den Vorwurf der „Trockenheit“, „Trübsinnigkeit“ und „Lebensferne“. Goethe und Meyer warfen die Frage auf, ob die Nazarener nicht Gefahr laufen, „den schönen Styl der Formen gegen Magerkeit, klare, heitere Darstellungen gegen abstruse, trübsinnige Allegorien umzutauschen“. ${ }^{27}$ Dies wurde namentlich von den Junghegelianern in der Zeit des Vormärz übernommen. In seiner berühmten Rezension zu Friedrich Overbecks nazarenischem Programmbild Der Triumph der Religion in den Künsten greift Friedrich Theodor Vischer zu drastischen Formulierungen: „Es ist castrirter Rafael“. ${ }^{28}$ Auch in der zweiten Jahrhunderthälfte finden sich entsprechend scharfe Kritiken. Hier sei nur Carl Albert Regnet angeführt, der über die Nazarener schreibt: „Ihre Kunst erschien ihnen um so gottgefälliger, je weiter sie sich von der Natur entfernte und darum schufen sie sogar im Lamm Gottes eine eigene Race mit den charakteristischen Kennzeichen verhimmelter Blödheit." 29

Die Nazarener blieben von solchen Vorwürfen erstaunlich unbeeindruckt. Vielmehr haben sie eine Malerei kultiviert, welche diejenigen Elemente gerade positiv fasste, die von anderer Seite her kritisiert wurden. Dies gilt auch für die nazarenisch geprägte Düsseldorfer Schule Wilhelm von Schadows, von der Carl Oesterley maßgeblich geprägt wurde. ${ }^{30}$ Romeo Maurenbrecher lobt im Schornschen Kunstblatt von 1828 dementsprechend gerade die Harmonie und Ruhe in den Werken Schadows und seiner Schüler:

„Allenthalben zeigen sich Selbstbeherrschung, feste Haltung und Ruhe, Reflexion und Studium, Eigenschaften unserer Maler, die nothwendig an ihren Gemälden jene zusammenstrebende Harmonie und Einheit, jene übersichtliche und durchdachte, gefällige Klarheit, Ab-

24 Vgl. insbesondere Fiorillo 1820, S. 102. Siehe hierzu auch den entsprechenden Beitrag in diesem Katalog sowie Scholl 2013.

25 Vgl. Fiorillo 1820, S. 79.

26 Zur Rezeption des Aufsatzes Neu-deutsche religios-patriotische Kunst vgl. insbesondere Büttner 1983.

27 Weimarische Kunstfreunde 1999 [1817], S. 113.

28 Vischer 1841, S. 127. Vgl. hierzu: Frank 2002, S. 87-98; Scholl 2012a, S. 315-336.

29 Regnet 1873, S. 13.

30 Zum Düsseldorfer Einfluss bei Oesterley vgl. Senf 1957, S. 20-22. 
rundung und Leichtigkeit der Kompositionen hervorbringen mußten, welche die wahrhaft stehenden Vorzüge der Bilder aus Schadow’s Schule ausmachen.“31

Solche Qualitäten lassen sich auch in Oesterleys Segnendem Christus wiederfinden. Tatsächlich waren die Nazarener bei der Entwicklung eines spezifischen Modus für kirchliche Kunst überaus erfolgreich. Es gelang ihnen, andere Darstellungsweisen, wie sie in Göttingen etwa durch das eklektisch angelegte Gemälde Heilige Familie mit Engeln von Karl Franz Jacob Heinrich Schumann (Kat. Nr. 5) vertreten wird, weitgehend abzulösen. Wie sehr man von einem für lange Zeit bestehenden nazarenischen Monopol auf religiöse Malerei sprechen kann, belegt in dieser Sammlung auch Die heilige Elisabeth von Thüringen von Franz Xaver Laudage (Kat. Nr. 10). Auch Heinrich Petris Gemälde Mater Dolorosa (Kat. Nr. 8) steht in dieser Tradition, zeigt allerdings die intensivere Farbigkeit der Düsseldorfer Malerschule.

Erst sehr spät gelang die Lösung von diesem Monopol. Eine Schlüsselfunktion kam dabei Eduard von Gebhardt zu, von dem die Göttinger Sammlung zwar kein religiöses Gemälde besitzt, wohl aber eine bemerkenswerte Studie, welche einen der wichtigsten Orientierungspunkte für dessen Entwicklung einer antinazarenisch-naturalistischen religiösen Kunst offenlegt: die niederländische Genremalerei (Kat. Nr. 16). In dieser Phase stand das System der Gattungshierarchie erneut und diesmal nachhaltiger - in Frage.

Die Stellung nazarenischer Kunst in den zeitgenössischen Gattungsdiskursen ist ambivalent: Obwohl die Nazarener eigentlich die Gattungshierarchie auflösen wollten, fanden sie sich am Ende doch in dieser wieder. Ihre Bilder erwiesen sich anders als die Landschaften Runges und Friedrichs - als weitgehend kompatibel mit dem System, indem es sich überwiegend um Historienbilder handelte. Der eigentliche Streit um die nazarenische Malerei fand auf der verbindenden Höhenlage der Historie statt: Dabei ging es vor allem um den Vorrang zwischen profaner und religiöser Historienmalerei und um die Zulässigkeit allegorischer Konstruktionen. ${ }^{32}$ Dass Landschaft und Genremalerei als „niedere“ Gattungen anzusehen seien, war Konsens.

\section{Förderprogramme für die Historienmalerei}

Nun erfreuten sich gerade diese „niederen“ Gattungen beim Publikum großer Beliebtheit, was die idealistische Kunstkritik regelmäßig vor Probleme stellte. In den Ausstellungsrezensionen finden sich daher immer wieder Klagen über ein Überhandnehmen der Landschafts- und Genremalerei sowie über die Prioritäten der Besucher. ${ }^{33}$ Josef Danhausers doppelbödiges Gemälde Maler im Dachstübchen

31 Maurenbrecher 1828, S. 322.

32 Vgl. etwa Vischer 1842, S. 552.

33 Vgl. etwa Wähner 1833, S. 230: „Die Landschaft, besonders die Prospektmalerei, das Bildnis und des [sic!] Genre herrschen auch in München, wie überall, entschieden vor. Die Zahl der angeführten historischen Bilder ist geringfügig. Der Grund dieser eben nicht erfreulichen Erscheinung liegt 
(Kat. Nr. 12) bietet - neben vielen anderen Aspekten - auch ein Bild von der ärmlichen Situation vieler Historienmaler. Wie bedeutend die Gattungshierarchie für das 19. Jahrhundert war, zeigt sich nicht zuletzt an der lange Zeit bestehenden und sich eben nicht von selbst regelnden Spannung zwischen dem idealistisch fundierten Glauben an eine Superiorität der Historie und den völlig anders ausgerichteten Realitäten des Kunstmarktes. Sie hat zahlreiche Biographien gebrochen.

Um das Konzept der Gattungshierarchie überhaupt aufrecht zu erhalten, bedurfte die Historienmalerei einer besonderen Förderung, damit sie gegenüber den verkäuflichen Kleinformaten anderer Gattungen Bestand haben konnte. Eine wichtige Steuerungsfunktion übernahmen dabei die Kunstvereine. Arnold Ruge, Mitherausgeber der jungheglianisch geprägten Hallischen Jabrbücher, beklagte sich bitter über den Kunstverein in Halle, weil dieser nach wie vor Landschaften ankaufte und demgegenüber die Historienmalerei als eigentliche Manifestation des Geistes vernachlässigte. Dabei kommen die idealistischen Vorbehalte gegenüber den niederen Genres zum Ausdruck, die es - neben der Akzeptanz, dass jede Gattung ihr eigenes Recht habe - auch gab:

„Das Schwelgen in der stummen, eintönigen Natur und die reintechnischen Kleinigkeiten
sollten aufhören das Hauptinteresse unseres Kunstvereins zu sein, und ich will den Wunsch
nicht unterdrücken, daß wir den Magdeburgern und Halberstädtern nacheifern und irgend
ein historisches Bild [...] bestellen möchten. [...] Die Viehwirthschaft, die Kernerwagen, der
Baumschlag, die Fruchtstücke und gar die Architektur sind auf die Länge nichts als die Lan-
geweile und die permantenterklärte Geistlosigkeit, die nur gelten können als Zugabe zu dem
wahren Mittelpunkte der Kunst, den historischen Bildern, die aber durch Bestellung der
Kunstvereine zu excitiren sind.“ ${ }^{34}$

Tatsächlich widmeten sich andere Kunstvereine gezielt der Förderung großer Historienbilder. Hierzu gehörte etwa der 1829 gegründete „Kunstverein für die Rheinlande und Westphalen“, der die Förderung von Monumentalkunst in öffentlichen Räumen gezielt in sein Programm aufnahm. ${ }^{35}$ Im Jahre 1854 war - durch einen Zusammenschluss der deutschen Kunstvereine zu einem Aktienunternehmen - zudem die Verbindung für historische Kunst gegründet worden. ${ }^{36}$ Wie diese funktionierte, zeigt sich an den beiden Bildern von Friedrich Spangenberg in der Göttinger Sammlung (Kat. Nr. 2+3). Es handelt sich bei ihnen nämlich gewissermaßen um gemalte Exposés: um Ölstudien, die der Künstler bei der Verbindung für bistorische Kunst einreichte, damit diese bei positiver Begutachtung eine großformati-

zwar zum Theil, doch nicht so völlig, wie einige Künstler glauben in der Kälte des Publikums gegen höhere Darstellungen."

34 Ruge 1838, Sp. 1398.

35 Vgl. Liber 1834, S. 382: „Der Kunstverein für die Rheinlande und Westphalen hat von gleich vom Anfang seines Zusammentretens an die höhere Aufgabe der Kunst im Auge gehabt und gleich einen Theil seiner Mittel für öffentliche Zwecke bestimmt; zunächst für würdigen Schmuck der Kirchen, dann auch für Rathhäuser und Stadtmuseen. " Zu diesem Verein vgl. u. a. auch Droste 1980, S. 107 f.; Grossmann 1994, S. 102 f.; Mai 2010, S. 124.

36 Vgl. hierzu Schmidt, H.-W. 1985. 
ge Ausführung finanzierte. Im Falle des Gemäldes Geiserich führt die gefangene Eudoxia aus dem geplünderten Rom (Kat. Nr. 3) ist dies auch gelungen.

Kunstgeschichtlich stehen Spangenbergs Werke für eine erneuerte Historienmalerei, die sich vor allem mit dem Namen des in München wirkenden Malers Carl Theodor von Piloty verbindet. 1855 hatte Piloty mit seinem Gemälde Seni vor der Leiche $W$ allensteins Furore gemacht. ${ }^{37}$ Er vertrat einen gesteigerten, in der Historie bis dahin nicht üblichen Naturalismus, der durchaus erst einmal auf Widerstände stieß. ${ }^{38}$ Allgemein wurde diese Entwicklung zu einem gesteigerten Kolorismus jedoch begrüßt. Bereits 1850 liest man in einer Nachricht aus Wien im Deutschen Kunstblatt von 1850: „Besonders hervorzuheben ist die Veränderung in der Technik bei mehreren unserer Historienmaler, die vordem ganz der alten blut- und farblosen Technik der s. g. Nazarener zugethan waren, jetzt aber sichtbar bestreben, Farbe und Leben in ihre Gemälde zu bringen." 39

Man kann diese fortgesetzte Dynamik in der Göttinger Kunstsammlung nachvollziehen, wenn man etwa Friedrich Beckers Drei beim Bade überraschte Damen (Kat. Nr. 1) mit Friedrich August von Kaulbachs Die Erziehung des Bacchus (Kat. Nr. 4) vergleicht. Auch wenn es sich bei letzterem Gemälde erneut um eine Studie handelt und der sehr freie Pinselstrich daher nur bedingt in den Vergleich einbezogen werden kann, so zeigt doch allein die Kombination der Farben eine neue Qualität.

Der Zugewinn an maltechnischer Brillanz manifestiert sich nicht zuletzt an Paul Meyerheims Tierstück Tauben auf dem Dach (Kat. Nr. 29). Gerade hier zeigt sich allerdings auch, wie wichtig eine historische Perspektive auf die Malerei des 19. Jahrhunderts ist. Zum einen wird man der Malerei der ersten Jahrhunderthälfte nicht gerecht, wenn man sie an solchen Bildern misst. Was Meyerheim kultiviert, war von den Künstlern um 1800 bewusst vermieden worden, weil es diesen als geradezu unethisch erschien. ${ }^{40}$ Zum anderen war selbst zu Meyerheims Zeiten die

37 München, Neue Pinakothek. Zu diesem Gemälde und seiner Wirkung vgl. Härtl-Kasulke 1991, S. 137-146; Ausst.-Kat. München 2003, S. 163-170.

38 Vgl. etwa die Kritik bei Reber 1876: Die Darstellung des Beiwerks, der Geräthe auf dem Tische, der meisten Stoffe u. s. w. bekämpft das Interesse an dem eigentlichen Gegenstande siegreich, und es ist schwerlich zu glauben, dass ein Beschauer bei den fatalistischen Betrachtungen Seni’s länger verweilen wird, als bei der Bewunderung der meisterlichen Behandlung des mobiliaren und geräthlichen Beiwerks, welche einem Stilllebenmaler alle Ehre machen würden. [...] Wie die Tragödie auf dem Höhenpunkte der inhaltlichen Entwicklung einer lapidaren Sprache bedarf und in ihrer idealen Erhebung die volle Durchbildung der Realität nicht erträgt, so lässt auch in der bildenden Kunst die Naturwirklichkeit der Erscheinung des Einzelnen und Nebensächlichen nicht mehr an den Kern und Mittelpunkt des Ganzen glauben, weil dieser nicht mehr zur verhältnissmässigen Wahrheit und Bedeutung gesteigert werden kann.“

39 Anonym 1850, S. 215.

40 Vgl. etwa den Studiumsbericht von Franz Pforr, zitiert nach Lehr 1924, S. 36 f.: „Unsere Behandlungsart der Kunst wollte uns jetzt nicht mehr genügen, unsere Arbeiten gaben uns nicht den Genuß, den unser Innerstes von einem Werk forderte. Ich äußerte die Lust etwas zu malen, indem ich auf einen möglichen Grad von Ausführung und Bestimmtheit hinstreben möchte; [Friedrich] Overbeck munterte mich auf und ich malte einige Figuren bis an den halben Leib sichtbar. Wer einmal etwas gründliches gekostet hat, der kann nicht wieder an einem flüchtigen Sinnenblick Ge- 
Zulässigkeit einer so pastosen Malweise noch immer weitgehend auf die „niederen“ Gattungen beschränkt, bei denen es um die Visualisierung materieller Qualitäten und nicht - wie bei der Historie - um ideelle Gehalte ging. ${ }^{41}$

\title{
Auflösung der Gattungshierarchie
}

Allerdings gibt es in dieser Zeit verstärkt Ansätze, die traditionelle, nach 1800 unter ästhetischen Gesichtspunkten zunächst einmal wieder verfestigte Gattungshierarchie endgültig aufzulösen. Die Impulse gingen dabei von verschiedenen Entwicklungen aus. Bedeutsam war zum einen die Etablierung einer formalen Ästhetik in der zweiten Hälfte des 19. Jahrhunderts, welche den Rang von Kunstwerken völlig unabhängig von deren Sujet zu bestimmen suchte. Hier ist namentlich der in Wien wirkende Herbart-Schüler Robert Zimmermann ${ }^{42}$ zu nennen, der im ersten Teil seiner Aesthetik von 1858 eine wichtige, das Wertesystem der Gattungshierarchie letztlich auflösende Auffassung vertritt: „Formvollendung bei geringem Gehalt bleibt ästhetisch bedeutend, mag sie auch ethisch noch so geringfügig sein, während formelle Mangelhaftigkeit auch beim trefflichsten Gehalt aus ästhetischen Gesichtspunkt verwerflich erscheint." 43

Zum anderen erfolgte die Auflösung der Gattungshierarchie vor allem durch die Aufwertung von bis dahin als ,niederrangig“ geltenden Gattungen wie der Landschafts- und Genremalerei. War die Neigung des Publikums zu diesen Gattungen lange Zeit als prekär angesehen worden, so hält sie der anonyme Rezensent ${ }^{44}$ der Berliner Kunstausstellung von 1852 für vollkommen berechtigt:

\begin{abstract}
„Vor welche Bilder auf der Ausstellung treten die Schaulustigen? Vor den Genrebildern, wo sich der echt menschliche, unschuldige, reine Geist offenbart, kann man sie sich drängen, zu den Landschaften, worüber Gottes Heiligkeit und Größe ausgebreitet liegt, kann man sie wallfahrten sehen. Oder sind das etwa Entartete, Ungläubige? - Nein, es sind Hungrige und Dürstende; aber keine Macht der Erde wird sie vor Bildern verweilen lassen, zu denen keine Brücke des Verständnisses führt. Man kann sich einmal nicht an Darstellungen erwärmen, welche nicht zu dem Gefühle sprechen, welche den ohnmächtigen Versuch machen, in der traditionell-religiösen Weise das Göttliche an sich, das einmal unmalbar ist, zur Anschauung zu bringen, wobei sie sich dann jener helfenden allegorisirenden Weise in die Arme werfen." $" 45$
\end{abstract}

schmack finden; so ging es uns auch. Ein neues Licht zeigte sich uns, nach Bestimmtheit, die nur durch Ausführung erlangt werden kann, strebten wir von jetzt.“

41 Vgl. Krüger 2007, S. 29-32 und passim.

42 Vgl. hierzu u. a. Nachtsheim 1984, S. 67-73; Wiesing 1997, S. 16; Wiesing 2001, S. 283-296.

43 Zimmermann, R. 1858, S. 716.

44 Vermutlich handelt es sich um Friedrich Eggers. Dieser hat auch die Berliner Kunstausstellung von 1850 für das Deutsche Kunstblatt rezensiert und bereits hier für die eigene Bedeutung der Genremalerei plädiert (Eggers 1850, S. 178).

45 Anonym 1852, S. 365. 
Auch der Kunstkritiker Friedrich Pecht sieht „,nur eine Gattung unserer Kunstübung, die sich bis jetzt zur Allgemeingültigkeit durchgerungen und die Welt erobert hat, und das ist gerade die auf dem echt nationalsten Boden beruhende: unsere Genremalerei."46 In seinem Aufsatz Die deutsche Historienmalerei der Zukunft von 1884 bewertet Pecht die Genremalerei sogar höher als die Historienmalerei der Münchner Schule des Peter Cornelius, welche nur „Kunst aus zweiter Hand“ geliefert habe:

\footnotetext{
„Es wäre doch endlich an der Zeit, sich das einzugestehen, nicht minder, daß in dieser ganzen Periode erst die Sittenbildmalerei wieder neue Formen, wahrhaft Lebendiges und Dauerhaftes erzeugt hat, weil sie nach dem Beispiel der Niederländer wieder bei der Natur in die Schule ging und den Menschen mit all seiner Bedingtheit, damit aber auch in seiner unerschöpflich mannichfaltigen Erscheinung darstellte und so unsere Kunst von dem ewigen leblosen Nachbeten fremder Muster endlich wieder losriß.“47
}

Eine solche Aufwertung der Genremalerei korrespondiert mit den künstlerischen Erfolgen, die Maler wie Ludwig Knaus in dieser Zeit mit ihren Sittenbildern feierten. Schon 1858 hatte der Kunstkritiker und -historiker Anton Springer Knaus als verheißungsvolles Talent geschildert und den Wunsch geäußert, dass er „dauernd die deutsche Innigkeit mit solch ungewöhnlicher technischer Meisterschaft verbinde.“48 Damit sprach er die spezifischen Qualitäten an, welche das Ansehen der neueren Genremalerei in der deutschen Kunstkritik zunehmend bestimmten: Neben der Beherrschung des Kolorits war dies vor allem die mit „Innerlichkeit“ und „Gemütlichkeit“ konnotierte Akzentuierung des Erzählerischen. Maximilian Wachsmuths Gemälde Junges Paar (Kat. Nr. 17) in der Göttinger Sammlung zeigt, was damit gemeint ist - vor allem in seiner narrativen Anlage. Kompositorisch und maltechnisch bleibt Wachsmuth mit diesem Bild dann aber doch weit hinter der Raffinesse zurück, mit der damals gefeierte Genremaler wie Benjamin Vautier oder Franz von Defregger zu Werke gingen.

Wie Springers Bemerkung belegt, waren „Innerlichkeit“ und „Gemütlichkeit“ in dieser Zeit nicht zuletzt national konnotiert. ${ }^{49}$ In diesem Sinne lobt etwa auch Franz Reber die Münchner Genremaler,

„welche in echt deutscher Gemüthlichkeit auf die einfachen Thätigkeiten, Unterhaltungen und Empfindungen des naiven Volksthumes einzugehen wissen, ohne in die Carricatur und Persiflage der Niederländer, in die Mitleiderweckungssucht der Engländer oder in die landschaftliche Auffassung der Franzosen, denen das Landvolk wie Bäume oder Vieh nur als Theil der Stimmungslandschaft zu erscheinen pflegt, zu verfallen." ${ }^{50}$

\footnotetext{
46 Pecht 1877, S. 125 f.

47 Pecht 1884, S. 361.

48 Springer 1858, S. 168.

49 Vgl. hierzu auch Söntgen 2000a, S. 30-46; Söntgen 2000b, S. 395 f.

50 Reber 1876, S. 649.
} 
Wichtig ist dabei vor allem die Opposition zur französischen Malerei. Sie erklärt auch, warum idealistisch eingestellte Kunstkritiker und -historiographen zunehmend bereit waren, die Anteilnahme des Publikums für eine ursprünglich als „,niedrig“ angesehene Gattung wie die Genremalerei positiv zu bewerten. Inzwischen etablierte sich nämlich gerade von Frankreich her eine völlig neue Bildauffassung, bei der das Narrative ganz und gar zurückgedrängt wurde.

\section{„Landschaftliche Auffassung“}

Wenn Franz Reber gegen die „landschaftliche Auffassung“ französischer Maler opponiert, welche „das Landvolk wie Bäume oder Vieh nur als Theil der Stimmungslandschaft" behandeln, so hatte er vermutlich einen Künstler wie Gustave Courbet oder die Schule von Barbizon im Sinn. Mittlerweile hatte sich das Konzept des auf narrative Elemente weitgehend verzichtenden „Zustandsbild“ auch in Deutschland verbreitet - Wilhelm Leibl bietet hierfür ein prominentes Beispiel. ${ }^{51}$ Eine katalysatorische Wirkung kam dabei der Internationalen Kunstausstellung von 1869 in München zu, auf der unter anderem Werke von Courbet zu sehen waren. ${ }^{52}$

Gleichzeitig entwickelte sich eine avancierte, formalästhetische Kriterien befolgende Kunstkritik, welche das inhaltlich-narrative Element nicht nur für unerheblich, sondern zunehmend sogar für abträglich hielt. Der Kunstschriftsteller Conrad Fiedler konstatiert 1876, dass „das Interesse an der Kunst erst in dem Momente [beginnt], wo das an dem Gedankengehalte des Kunstwerkes erlischt. "53 In diesem Sinne wendete sich Adolph Bayersdorfer in seinem Aufsatz Neue Kunstbestrebungen in München von 1874 gegen die traditionellen Genremaler:

„Bald sind sie drollig, bald sinnig, bald rührend; immer aber machen diese Lieblinge des Publikums eine für die Malerei irrelevante, weil abstrakte, aus der Erscheinung nur gefolgerte Eigenschaft des Gegenstandes zum einzig beabsichtigten Inhalte ihrer Werke und verkennen die Natur der bildenden Kunst derart, daß sie nach dem der erzählenden Dichtkunst vorgestreckten Ziele streben. In Wirklichkeit sind ihre Bilder auch nichts weiter als textbedürftige Illustrationen, welche im wohlerzählten Zusammenhang ihres gegenständlichen Details von entzückten Kommerzienräten, bureaukratischen Kunstprotektoren, bildungsklugen Müttern, strebsamen Töchtern, tanzkundigen Leutnanten und einfältigen Rezensenten auf der Stelle begriffen und wie Kurszettel, Protokolle und Romane abgelesen werden können. “54

Bayersdorfers Kritik war zukunftsweisend für die Durchsetzung formalistischer Ansätze, in deren Zug die Genremalerei immer mehr an Ansehen verlor. Der Kunstkritiker und -historiker Cornelius Gurlitt, ein Sohn des Landschaftsmalers

\footnotetext{
51 Zu Leibl vgl. Söntgen 2000a; Söntgen 2000b, S. 391-400.

52 Vgl. u. a. Hansky 1994; Werche 2010, S. 89-104.

53 Fiedler 1971 [1876], S. 13.

54 Bayersdorfer 1902 [1874], S. 227.
} 
Louis Gurlitt, von dem die Göttinger Sammlung drei Studien bewahrt, konstatiert 1890 schließlich einen Rückgang des Genres:

„Die Maler haben es endlich satt bekommen, die Läppischkeiten der Welt zu malen, oder im besten Falle deren Niedlichkeiten. [...] Unsere Kunst ist ernster geworden: das ,Kind mit der Katze' und die ,zerbrochene Puppe' ziehen wohl noch bei einer großen Anzahl von Menschen, aber es sind nicht die, deren Bewunderung die Künstler anstreben." ${ }^{55}$

Nach 1850 waren es Genre- und Landschaftsmalerei gleichermaßen gewesen, die als „niedere“, vom Publikum jedoch hochgeschätzte Gattungen das System der Gattungshierarchie in Frage zu stellen halfen. Nachdem aber ab den späten 1870er Jahren das narrative Moment der Genremalerei in die Kritik geriet, blieb die Landschaftsmalerei als paradigmatische Kunst für die Erneuerung von Kunsttheorie und -kritik übrig. Nicht umsonst sprach Reber von „Landschaftliche[r] Auffassung“. Dabei vollzogen sich innerhalb der Landschaftsmalerei ganz ähnliche Prozesse, wie man sie beim Umbruch zwischen „Sittenbild“ und „Zustandsbild“ beobachten kann. Ein Idealisieren und Absetzen der komponierten Landschaft von der Vedute, wie es von Carl Ludwig Fernow gefordert und unter anderem von Friedrich Philipp Reinhold praktiziert worden war, geriet nun ebenfalls in Verruf. ${ }^{56}$ Als neues Leitbild diente die von der Schule von Barbizon musterhaft kultivierte „Stimmungslandschaft“ („paysage intime“). ${ }^{57}$ Ein solches Konzept von Landschaftsmalerei wurde auch in Deutschland zunehmend wirksam - man denke nur an die in München arbeitenden Maler Eduard Schleich d. Ä. und Adolf Heinrich Lier sowie an die Künstler die Weimarer Malerschule. ${ }^{58}$ Johann Friedrich Voltz' Enten am Starnberger See (Kat. Nr. 24) und natürlich Karl Buchholz' Gemälde Der Teich (Kat. Nr. 26) können in diesem Zusammenhang gesehen werden. Dabei ist letzteres Werk eines der Hauptvertreter der Weimarer Malerschule sicher immer noch als Studie anzusehen, welcher zumindest von der Intention des Künstlers her nicht der Status eines eigenständigen Gemäldes zukam. In den kommenden Jahrzehnten wurden solche Grenzziehungen allerdings mehr und mehr aufgelöst. Carl Heinischs kleinformatiges Bild Seeufer mit Angler im Schilf (Kat. Nr. 28) ist sicher als selbständiges Bild angelegt. Jahrzehnte zuvor hätte es nie als solches gelten können. Und die Art und Weise, wie die Studie von Buchholz in gerahmtem und gefirnisstem Zustand aus der Sammlung Eugen Dumont in die Göttinger Universitätskunstsammlung gelangt ist, spricht für ihre nachträgliche Aufwertung zu einem

55 Gurlitt, C. 1890 , S. 30.

56 Dies wurde von der konservativ-idealistischen Kunstkritik verständlicherweise mit großer Skepsis beobachtet. Vgl. etwa S. 1862, S. 15: „Es ist in der That schon jetzt dahin gekommen, daß die Meisten in ihr nur das Abbild bestimmter äußerlicher Erscheinungen sehen und nur nach der technischen Vollendung dieser Nachahmung fragen. Die historische Kunst ist dadurch fast unmöglich, das Genre bedeutungslos geworden, die Landschaft erscheint zwar als die begünstigte Gattung, aber nur unter der Bedingung, daß sie mehr und mehr zur Vedute werde.“

57 Vgl. hierzu u. a. Müllerschön/Maier 2010, S. 29-35.

58 Vgl. ebd. 
eigenständigen Gemälde. ${ }^{59}$ Dass so etwas möglich war, kann an sich schon als bemerkenswerter Beleg für die grundlegenden Umbrüche im Kunstverständnis des ausgehenden 19. Jahrhunderts angesehen werden.

\section{Revision}

In den letzten Jahren des 19. Jahrhunderts kam es zu einem Umbruch, der das gesamte Verständnis der Malerei dieses Centenniums grundlegend verändern sollte. Die neuen Auffassungen zur Funktions- und Wirkungsweise von Kunst, die in der zweiten Jahrhunderthälfte entwickelt worden waren, traten nun in eine Interaktion: die Entwicklung neuer, formalästhetischer Kriterien zur Bewertung von Kunstwerken, das Auseinanderbrechen der Gattungshierarchie sowie die Kritik am vermeintlichen Fehlen eines Gegenwartsbezugs und einer historistischen Fixierung auf vergangene Kunst. Deren Resultat war eine dramatische Abwertung eines Großteils derjenigen Künstler, die bis dahin - trotz aller frühzeitig einsetzenden Kritik - als Hauptvertreter der Malerei des 19. Jahrhunderts gegolten hatten. Die fundamentale Revision betraf weite Teile der nazarenischen Kunst ebenso wie die offizielle Historienmalerei etwa eines Peter Cornelius, Wilhelm von Kaulbach oder Carl Theodor von Piloty, denen mangelnde Eigenständigkeit zugeschrieben wurde. Auch das Verständnis für eine auf Narration angelegte Gattung wie die Genremalerei mit einstmals so berühmten Vertretern wie Ludwig Knaus oder Franz von Defregger ging weitgehend verloren. ${ }^{60}$

Der Kunstkritiker Julius Levin äußert sich über das Zeitalter des Peter Cornelius: „Wenn man Michelangelo’s Zeitalter Renaissance nennt, so ist dasjenige Cornelius' als Renaissance der Renaissance zu bezeichnen, und die Werke des ersten verhalten sich zu dem des letzteren, wie frische Früchte zu Conserven."61 Dabei war gerade Cornelius lange Zeit als bedeutendster Maler seiner Zeit angesehen worden. ${ }^{62}$ Der Kunsthistoriker Richard Muther überbietet Levins Vergleich der Malerei von Cornelius mit einer Konserve noch, indem er über den vormals so gefeierten Künstler schreibt: „Man glaubt durch’s Telephon die grosse Stimme des alten Florentiners [Michelangelo] zu hören, nur abgedämpft oder falsch pathetisch in Dingen, zu denen es gar keines Pathos bedurfte." 63

Generell deutete man in dieser Zeit die bis dahin tradierte Geschichte einer Erneuerung in eine Geschichte des Verfalls und des Niedergangs um. War man bislang davon ausgegangen, dass die Qualität der Kunst im Laufe des 17. und 18. Jahrhunderts stetig gesunken sei und erst kurz vor 1800 durch die Rückbesinnung

59 Vgl. Wille 1970, Kat. Nr. 3 (unpag.).

60 Vgl. hierzu Scholl 2012b, S. 475-519.

61 Levin, J. 1887, S. 56.

62 Zur Bewertung von Cornelius vgl. auch Scholl 2009, S. 327-353, sowie Scholl 2012b, S. 483-485, 494-496, u. a.

63 Muther 1893, Bd. 1, S. 216. 
auf Antike und Renaissance einen erneuten Aufschwung nahm, kehrte sich diese Einschätzung nunmehr in ihr Gegenteil. Auch vieles, was die Göttinger Sammlung aufbewahrt, war dadurch von einem massiven Wertverlust bedroht: Historienbilder wie die Werke von Spangenberg (Kat. Nr. 2+3) und Kaulbach (Kat. Nr. 4), religiöse Malerei mit historisierenden Tendenzen von Schumann (Kat. Nr. 5), Podesti (Kat. Nr. 7) oder Oesterley (Kat. Nr. 11) und auch narrative Genrebilder wie die von Danhauser (Kat. Nr. 12) und Wachsmuth (Kat. Nr. 17).

Die Abwertung von bislang Hochgeschätztem macht aber nur die eine Seite des Revisionsprozesses aus. Dessen konstruktivere Kehrseite bestand in der gezielten Suche nach bislang eher unbekannten Künstlern, die mit ihren Werken den veränderten Vorstellungen tatsächlich oder vermeintlich entsprachen. Als avancierter Vertreter der Revision propagierte Richard Muther beides:

\begin{abstract}
„Manche der Hochgepriesenen, die, von dem Erbe der Vergangenheit zehrend, anscheinend Bedeutendes leisteten, werden mit diesem Massstabe gemessen wenig Interesse erregen, da ihre Kunstsprache, auf dem Fundament ehemals entstandener kanonischer Werke beruhend, nicht ihre eigene, sondern eine erborgte war. In Andern dagegen, die abseits von der herrschenden Strömung den Muth hatten, lieber dürftig aber sie selbst zu sein, mit eigenen Augen beobachtend der Natur entgegenzutreten oder naiv sich dem Walten ihrer künstlerischen Phantasie zu überlassen, werden die eigentlichen Träger des modernen Geistes zu sehen sein. Und dann wird sich zeigen, dass auch die Kunst des 19. Jahrhunderts wie die jeder früheren Periode ihr eigenes Gewand hat, wenn sie auch bei officiellen Gelegenheiten gern die Prunktoiletten früherer Jahrhunderte aus dem Kleiderkasten hervorholte." ${ }^{\circ 64}$
\end{abstract}

Muther entwickelt hier eine Art imaginäres Künstlerprofil, das für die von ihm und anderen vertretene Revision als richtungweisend angesehen werden kann. Die Maler, nach denen er sucht, hätten ,abseits von der herrschenden Strömung“ gestanden und seien gleichsam bei sich selbst geblieben; sie seien „dürftig“ und „naiv" gewesen, hätten aber einen eigenen Blick auf die Natur entwickelt, an der sie sich vornehmlich orientierten. Gattungstheoretisch ausgedrückt bedeutet dies, dass sie alles vermieden haben sollten, was im Sinne der traditionellen Gattungshierarchie als eine den „Rang“ erhöhende Wirkung verstanden worden sein konnte. In der Tat ist es bemerkenswert, dass die Revision am Ende des 19. Jahrhunderts weniger eine Auflösung als vielmehr eine Umkehrung der Gattungshierarchie zur Folge hatte. Chancen hatten jetzt vor allem Werke vormals „niederer“ Gattungen.

In der folgenden Zeit wurde die gezielte Suche nach solchen Künstlern aufgenommen. Eine Schlüsselrolle übernahm dabei Alfred Lichtwark, der als Direktor der Hamburger Kunsthalle vergessene Maler aufspürte und in diesem Zusammenhang unter anderem Philipp Otto Runge für sich entdeckte, zu dem er ganz neue Interpretationsansätze entwickelte. ${ }^{65}$ Die vermutlich nachhaltigste Entdeckung

64 Ebd., S. 9.

65 Lichtwark 1893, S. VII: „Man hat kaum erst angefangen, die Kunstbewegung am Anfang unsers Jahrhunderts ernsthaft zu studieren, eine kritische Sichtung des Stoffes hat noch nicht stattgefunden. Aus der Kunstgeschichte sind Künstler verschwunden, die bei einer Darlegung der künstleri- 
machte jedoch ein norwegischer Kunsthistoriker: Andreas Aubert, der bei seinen Studien über Johan Christian Dahl auf Caspar David Friedrich stieß.66 Heute ist Friedrich der mit Abstand bekannteste deutsche Maler des 19. Jahrhunderts.

Seinen Kulminationspunkt fand der Revisionsprozess 1906 in der „Jahrhundertausstellung deutscher Kunst (1775-1875)“ in der Berliner Nationalgalerie.67 Hugo von Tschudi, der als Direktor der Nationalgalerie zu den Initiatoren dieser Ausstellung gehörte, charakterisiert in seiner Katalogeinführung deren Zielsetzung:

„Die Werke all jener Bescheidenen und Vergessenen, die Werke aus der aufrechten Jugend-
zeit jener, die später im Kampf um die Kunst und Gunst verdarben und jener Stärkeren, die
sich mühsam wieder auf sich selbst besannen, um die wenigen Großen, die erhobenen Haup-
tes ihrem Ziele zustrebten, zu sammeln, schien eine wichtige Aufgabe von nationaler Bedeu-
tung. Man durfte also hoffen, eine Vorstellung der gesunden Kräfte zu geben, die unter gün-
stigeren Bedingungen der deutschen Kunst wohl zu einer glänzenderen Wirkung verholfen
haben würden, deren stille und redliche Arbeit aber doch nicht ohne Anteil an dem Erfolg
der Auserwählten war.“ 68

Die „Jahrhundertausstellung“ hat die Sicht auf die Malerei des 19. Jahrhunderts nachhaltig verändert. Die hier vertretenen, auf die Kunst der Moderne abgestimmten Werturteile blieben lange Zeit gültig. Erst in den 1970er und 80er Jahren wurde auch wieder verstärkt diejenige Malerei in den Blick genommen, die um 1900 abgewertet worden war. Heute möchte man die Kenntnis um damals kanonisierte Werke von Künstlern wie Runge oder Friedrich keineswegs missen. Gleichzeitig werden aber auch die historische Bedingtheit dieser Revision sowie deren Grenzen deutlich, während die ganz eigenen Qualitäten der seinerzeit abgewerteten Kunst wieder in den Vordergrund treten.

Anhand des kleinen aber erstaunlich vielseitigen Bestandes an Malerei des 19. Jahrhunderts in der Göttinger Universitätskunstsammlung kann man beides: Hier ist es möglich, sowohl die Argumente für den Revisionsvorgang um 1900 anhand von Originalen zu diskutieren als auch den Blick für dasjenige weiten, dessen Rang damals in Zweifel gezogen wurde. So ist es ein ebenso großer Glücksumstand, in dieser Kollektion Werke von Gurlitt und Buchholz zu haben, welche die Qualität der Malerei jenseits der akademischen Gattungshierarchie veranschaulichen, als auch Werke von Oesterley und Spangenberg, welche die historischen Wertmaßstäbe dieser Zeit vor Augen führen - und die Historizität von Wertmaßstäben überhaupt.

schen Ideen an erster Stelle stehen müßten, ihre Werke liegen in Magazinen und auf Rumpelkammern." Vgl. hierzu auch Dibbern 1980, S. 46-48, Scholl 2012b, S. 571-575.

66 Aubert 1894, S. 83-97. Zur Wiederentdeckung Friedrichs vgl. u. a. Börsch-Supan/Jähnig 1973, S. 56-58; Schulz-Hoffmann 1974, S. 149-154; Wolbert 2001, S. 189-197; Scholl 2012b, S. 576-582.

67 Vgl. hierzu insbesondere Beneke 1999.

68 Ausst.-Kat. Berlin 1906a, S. XI. 



\title{
Die Provenienzen der Göttinger Gemälde des 19. Jahrhunderts
}

\author{
Anne-Katrin Sors
}

Provenienzforschung ist in den vergangenen Jahren zu einem immer wichtiger werdenden Feld der Kunstgeschichte geworden und ihre Bedeutung wird in $\mathrm{Zu}$ kunft weiterhin zunehmen. War die Provenienz seit jeher vorrangig für den Kunsthandel interessant, um bei herausragender und gut dokumentierter Herkunft und Überlieferung eine Wertsteigerung zu sichern, nimmt ihre Bedeutung vor allem für den Umgang mit NS-Raubkunst seit der Washingtoner Erklärung von 1998 zu. ${ }^{1}$ Institutionell findet diese Entwicklung der letzten zwanzig Jahre Ausdruck in der „Koordinierungsstelle Lost Art Magdeburg“, die 1994 gegründet wurde, ${ }^{2}$ sowie in der 2008 eingerichteten Arbeitsstelle für Provenienzrecherche/forschung beim Institut für Museumsforschung der Staatlichen Museen zu Berlin Stiftung Preußischer Kulturbesitz. ${ }^{3}$ Das Bundesamt für zentrale Dienste und offene Vermögensfragen betreibt ebenfalls eine Datenbank ${ }^{4}$ zum „Restbestand CCP“ (Central Collecting Point München). ${ }^{5}$

1 Vgl. http://www.lostart.de/Webs/DE/Koordinierungsstelle/WashingtonerPrinzipien.html (zuletzt 2.7. 2013).

2 http://www.lostart.de/Webs/DE/Koordinierungsstelle/Aufgaben.html (zuletzt 2.7.2013).

3 http://www.hv.spk-berlin.de/deutsch/projekte/ArbeitsstelleProvenienzforschung_1.php (zuletzt 2.7.2013).

4 http://www.badv.bund.de/003_menue_links/e0_ov/d0_provenienz/b0_dokumentationen /Liste.php (zuletzt 24.6.2013).

5 Hier findet man auch weiterführende Literatur: http://www.badv.bund.de/003_menue_ links/e0_ov/d0_provenienz/b1_aufsaetze/index.html (zuletzt 24.6.2013). 
Für Museen und Sammlungen sollte die Provenienzforschung und damit -sicherung - nicht nur in Zusammenhang mit NS-Raubkunst - selbstverständliche und alltägliche Routine der wissenschaftlichen Erfassung des Bestandes sein, besonders als Grundlage jeglicher weiterer Rezeptions- und Sammlungsgeschichte, so etwa der Erforschung adeliger und bürgerlicher Geschmackskulturen oder künstlerischer Vorlieben. Leider vermerken Inventarbücher häufig nur den unmittelbaren Vorbesitzer oder den Kunsthandel, aus dem sie erworben wurden, so dass eine weiter zurückreichende Provenienzforschung häufig sehr schwierig ist. ${ }^{6}$ Die wissenschaftliche Grundlagenarbeit kann dabei aufgrund der stetig wachsenden Belastung der Kustoden durch immer stärker geforderte Öffentlichkeitsarbeit und „Eventausstellungen“ kaum noch geleistet werden - für die Arbeit und Forschung am eigenen Bestand fehlt oft die Zeit. Bestandskataloge entstehen heute in der Regel als drittmittelfinanziertes Forschungsprojekt mit temporär beschäftigen Mitarbeitern, die eng mit den jeweiligen Kustoden zusammenarbeiten. Das immer größer werdende Interesse an diesem Themenfeld schlägt sich u.a. in der steigenden Anzahl von Tagungen zum Thema nieder. ${ }^{7}$ Erfreulicherweise findet die Provenienzforschung mittlerweile auch in der selten am originalen Einzelobjekt arbeitenden universitären Kunstgeschichte mehr Interesse, denn die Rekonstruktion von alten Sammlungen, deren Ordnung, ihr Zustandekommen usw. verheißt großen Erkenntnisgewinn als Grundlage jeder weitergehenden Form der Rezeptionsforschung. 8

Zur Provenienzforschung in der Kunstsammlung der Universität Göttingen liegen für die Anfänge geradezu ideale Bedingungen vor: Die Sammlung Uffenbach mit 10.000 Blatt Druckgraphik und 1000 Zeichnungen wurde vom ersten Kustos Johann Dominicus Fiorillo in Inventarbücher - acht Foliobände für die Druckgraphik sowie zwei für die Zeichnungen - aufgenommen. Die Sammlung des Johann Wilhelm Zschorn gab Fiorillo 1805 als gedruckten Katalog heraus. ${ }^{9}$ In beiden Fällen liegen sogar die Inventarbücher der Vorbesitzer Uffenbach und Zschorn vor, die mit den Sammlungen an die Universität kamen. So lässt sich die Provenienz hier zumindest bis ins 18. Jahrhundert zurückverfolgen. ${ }^{10} \mathrm{Im}$ Laufe des 19. Jahrhunderts war die Betreuung der Kunstsammlung hingegen nicht stetig gleichbleibend gewährleistet, so dass die Zugänge nicht immer in Inventarbüchern

6 Dr. Thomas Psota, Bern: „Objekte ohne Biographien - im Eingangsbuch des Museums steht nur der letzte Besitzer“, Vortrag auf der Tagung „Sammlungsgeschichte und Provenienzforschung. Erwerbungspolitik im 20. Jahrhundert", Museum Rietberg Zürich, 08.06.2013.

7 Beispielhaft sei hier genannt: Sammlungsgeschichte und Provenienzforschung. Erwerbungspolitik im 20. Jahrhundert, Museum Rietberg Zürich, 08.06.2013, Tagung im Rahmen der Sonderausstellung „Von Buddha bis Picasso - Der Sammler Eduard von der Heydt“ (20.4.-18.8.2013).

8 Als Beispiele seien genannt: Brakensiek 2003; Sickel 2006, S. 163-221; Ausst.-Kat. Antwerpen 2004, Duverger 1984 ff.

9 Fiorillo 1805.

10 Die Provenienz der Uffenbachschen Bestände lässt sich durch erhaltene Korrespondenz und andere Quellen teilweise noch weiter zurückverfolgen. Die Erforschung erfolgt momentan durch Dietrich Meyerhöfer, Göttingen, in seiner Dissertation zu Johann Friedrich von Uffenbach. 
notiert wurden. Erst Konrad Lange legte ab 1884 ein Inventarbuch an, in das er ab 1887 nach dem von Fiorillo geschriebenen und herausgegebenen Katalog von 1805 sämtliche Gemälde eintrug. ${ }^{11}$ Bereits 1884 hatte er mit der Erfassung der Gipsabgüsse begonnen,, 1886 folgten Möbel,,33 ein Verzeichnis der Originalkupferplatten, ${ }^{14}$ eine Aufstellung der seit 1927 neu erworbenen Graphik ${ }^{15}$ sowie ein Verzeichnis der seit 1927 neu erworbenen Aquarelle, Pastelle und Handzeichnungen. ${ }^{16}$ Für die Gemälde wird dieses Inventar bis heute weitergeführt, Zeichnungen und Druckgraphik finden seit 1950 Eingang in separate Inventarbücher. Die Zeichnungen und Druckgraphiken tragen seit 1927 Inventarnummern, die aus dem Eingangsjahr und der numerischen Reihenfolge in demselben bestehen (z.B. H 1950-1). Den Altbestand an Zeichnungen hat Konrad Renger, Kustos der Sammlung in 1970er Jahren, in ein eigenes Inventarbuch aufnehmen lassen, in das sowohl der Uffenbachsche Bestand als auch alle weiteren Zeichnungen, die nicht in den anderen beiden Inventaren (1927 und seit 1950) auftauchen, eingetragen wurden und seitdem numerische Inventarnummern (H 1- H 946) tragen. Der Altbestand der Druckgraphik trägt zum größten Teil noch keine Inventarnummer, doch läuft seit 2012 die stetige Neuinventarisierung und Digitalisierung des graphischen Bestandes, in deren Zuge auch für diesen ein Inventarnummernsystem eingeführt wird. Die Gemälde fanden bisher Identifizierung durch Katalognummern; erschienen neue Kataloge, so wurden die neuen Nummern in das Gemäldeinventar eingetragen, was mitunter verwirrend sein kann. Auf den Gemälden selbst fanden sich größtenteils keine (und wenn ganz verschiedene) Nummern, so dass 2010 in einem Seminar gemeinsam mit Studierenden der Restaurierungswissenschaften der Hochschule für angewandte Wissenschaft und Kunst Hildesheim ein einheitliches Inventarnummernsystem für die Gemälde eingeführt wurde - inklusive einer Methode, die Inventarnummer auf der Rückseite konservatorisch adäquat und gut leserlich anzubringen. ${ }^{17}$ So speisen sich die Informationen über die Herkunft der Werke aus verschiedenen Quellen. Im Idealfall finden sich alle Informationen in den sogenannten Bildakten, die zu jedem Gemälde und jeder Zeichnung im Archiv der Kunstsammlung existieren.

Im Rahmen des studentischen Forschungsprojektes „Gattungstheorie und Gattungspraxis - die Gemälde des 19. Jahrhunderts der Göttinger Universitätskunstsammlung" konnte der entsprechende Bestand grundlegend aufgearbeitet werden. Ausgenommen blieben die Porträts, die einen großen Teil der Gemälde des 19. Jahrhunderts ausmachen und den Rahmen des Projektes bei weitem ge-

11 Göttingen, Kunstsammlung der Universität, Inventar 1884 ff., S. 1-75 ff.

12 Ebd., S. 177 ff.

13 Ebd., S. 183 ff.

14 Ebd., S. 193 ff.

15 Ebd., S. 115 ff.

16 Ebd., S. 169 ff.

17 Informationen zu System und Methode dazu finden sich in der Akte „Inventarisierung“ im Archiv der Universitätskunstsammlung. 
sprengt hätten. Sie finden der Vollständigkeit halber Eingang in den vorliegenden Bestandskatalog (Kat. Nr. 32-54) und werden in der Einführung kurz besprochen. ${ }^{18}$ Die intensivere Erforschung dieses Bestandes muss einem weiteren Projekt vorbehalten bleiben, so dass auch auf ihre Provenienzen hier nicht näher eingegangen werden kann.

Im folgenden soll die Provenienz der Gemälde des 19. Jahrhunderts, ihre sammlerische Herkunft und ihr Weg in die Göttinger Universitätskunstsammlung nachgezeichnet werden, wobei von besonderem Interesse ist, in welchem Zusammenhang (und mit welchen anderen Werken und Werkgruppen) die Bilder in die Sammlung gekommen sind und aus welchen gesellschaftlichen Kontexten diese stammen. So werden zunächst Werke unbekannter Herkunft, danach Leihgaben, Ankäufe, Schenkungen und zum Schluss Nachlässe vorgestellt. In einigen Fällen sind die Werke Teile von Konvoluten, deren Zusammensetzung es erlaubt, Aufschlüsse über Sammlungsgeschichte sowie die Interessen und Neigungen der Vorbesitzer zu erlangen.

\section{Gemälde unbekannter Herkunft}

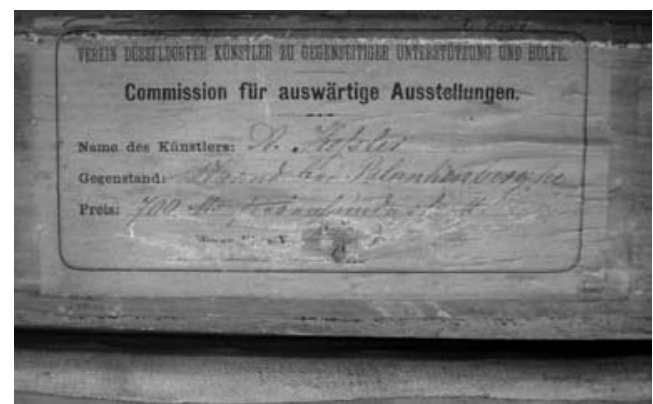

Abb. 1: August Keßler: Strand bei Blankenberghe (vgl. Kat. Nr. 25), Schild auf der Bildrückseite

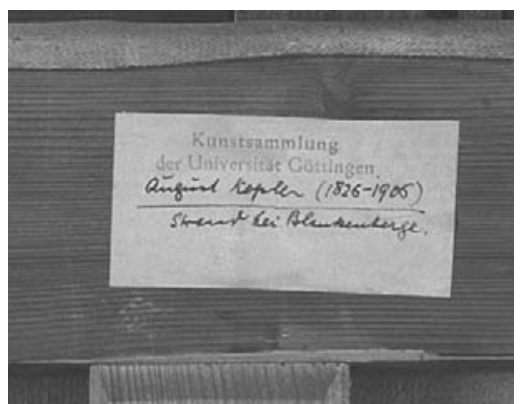

Abb. 2: August Keßler: Strand bei Blankenberghe (vgl. Kat. Nr. 25), Schild auf der Bildrückseite

Für drei der insgesamt 32 hier ausführlicher behandelten Gemälde des 19. Jahrhunderts in der Göttinger Universitätskunstsammlung muss weiterhin die Angabe „Herkunft unbekannt“ gelten. Das Gemälde Strand bei Blankenberghe (Kat. Nr. 25) ${ }^{19}$ von August Keßler (1826-1906) von 1882 ist sowohl signiert als auch datiert, jedoch finden sich (bisher) in keinem Inventar der Kunstsammlung noch in den

18 Ausnahmen bilden Kat. Nr. 32 und 33, die hier auf exemplarische Weise mit eigenen Katalogtexten bedacht sind. Dabei handelt es sich bei Kat. Nr. 33 vermutlich eher um eine Kopfstudie und nicht um ein Porträt.

19 Unverfehrt 1987, S. 185, Kat. Nr. A 36. 
Akten Eintragungen, die auf Schenkung, Ankauf oder Nachlass schließen lassen. Das Objekt selbst gibt nur in geringem Maße Auskunft über seine Herkunft: durch zwei auf der Rückseite aufgeklebte Zettel. Dem einen ist zu entnehmen, dass das Gemälde - Künstlername und Titel werden genannt - über den Verein Düsseldorfer Künstler zur gegenseitigen Unterstützung und Hülfe für 700 Thaler angeboten wurde $\left(\right.$ Abb. 1) ${ }^{20}$. Auf dem zweiten Zettel sind neben dem Stempel „Kunstsammlung der Universität Göttingen“ handschriftlich Künstler und Bildthema genannt: „August Keßler ( 1826-1905) / Strand bei Blankenberghe“ (Abb. 2). Die Handschrift lässt sich anhand von vielen handschriftlich existierenden Dokumenten in den Kunstsammlungsakten Wolfgang Stechow (1896-1974) zuweisen, der von 1923 an als Assistent, seit 1926 als Privatdozent und ab 1931 als Außerordentlicher Professor für Kunstgeschichte in Göttingen tätig war, bevor er 1936 in die USA emigrieren musste. Durch diesen Zettel lässt sich zumindest die Aussage treffen, dass sich das Gemälde bereits in den 1920er oder 1930er Jahren in der Sammlung befunden haben muss.

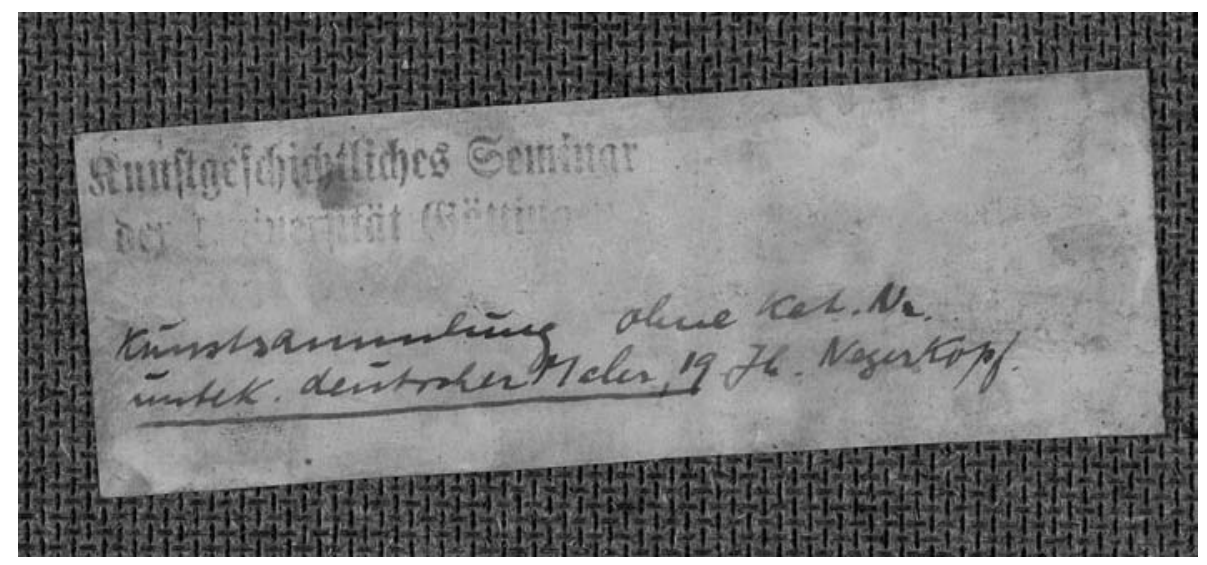

Abb. 3: Unbekannt, deutsch: Aufblickender Mann mit Turban (vgl. Kat. Nr. 33), Schild auf der Bildrückseite

Auch die Herkunft des Gemäldes Aufblickender Mann mit Turban (Kat. Nr. 33) ${ }^{21}$ von unbekannter Hand ist bisher weder durch Inventareinträge noch durch Akten nachweisbar. Hier befindet sich auf der Rückseite des Rahmens ein aufgeklebter Zettel mit einem alten Stempel des Kunstgeschichtlichen Seminars sowie einer handschriftlichen Notiz (Abb. 3): „Kunstsammlung ohne Kat. Nr., unbek. deutscher Maler, 19. Jh., Negerkopf." Auch diese Handschrift stammt von Wolfgang Stechow. Über den Grund, weshalb das Bild keinen Eingang in den von Stechow

20 Ein ganz ähnlicher Zettel findet sich auf der Rückseite des Gemäldes von Heinrich Petri (Kat. Nr. 8)

21 Unverfehrt 1987, S. 195, Kat. Nr. A 114. 
Anne-Katrin Sors

erstellten Katalog von 1926 fand, lässt sich nur spekulieren: Vielleicht kam es erst nach Fertigstellung des Kataloges in die Sammlung oder es wurde übersehen, vergessen oder aufgrund von minderer Qualität (was sich aus heutiger Sicht nicht nachvollziehen ließe) außen vor gelassen (vgl. den Fall des Gemäldes in der Art des Joris van Son, Kat. Nr. 30, aus der Sammlung Dumont, das keinen Eingang in den Katalog 1987 von Gerd Unverfehrt fand).

Das kleinformatige Gemälde Schlittschuhläufer (Kat. Nr. 14) ${ }^{22}$ ist ebenfalls unbekannter Herkunft. Auf der Rückseite des Rahmens findet sich handschriftlich „v. M.“, was möglicherweise auf einen Vorbesitzer zurückzuführen ist. Da das Gemälde in keinem Bestandskatalog der Sammlung 23 aufgeführt wird, ist davon auszugehen, dass es nach 1987 in die Sammlung kam.

\section{Leihgaben}

Sammlungen erfahren stets wichtige Ergänzung durch Leihgaben: Seit 1967 ist das Gemälde Drei beim Bade überraschte Damen (Kat. Nr. 1) ${ }^{24}$ von Friedrich Becker (1808?) als Leihgabe von Prof. Dr. Walter Paatz (1902-1978) ${ }^{25}$ und Dr. Elisabeth Paatz (1900-1991) in der Sammlung. Hans Wille zufolge, dem Kustos der Sammlung in den 1960er Jahren, stammt es aus der Hinterlassenschaft des Geheimrats Valentiner. ${ }^{26}$ Diese Provenienz ist in zweifacher Hinsicht interessant: Erstens waren die Eheleute Paatz beide Kunsthistoriker und zweitens ist Elisabeth Paatz, geb. Valentiner ${ }^{27}$ die Tochter des Geheimrats Justus Theodor Valentiner (1869-1952), ${ }^{28}$ der in seinen Jahren als Universitätskurator von 1921-1937 für viele Neuerwerbungen für die Universitätskunstsammlung verantwortlich zeichnet. ${ }^{29}$ Das Gemälde von Becker ist nicht das einzige Werk, das aus dem Nachlass Valentiner Eingang in die Kunstsammlung fand: ${ }^{30}$ seit 1968 ist das Gemälde Heilige Familie mit Johanneskna$b_{e n}{ }^{31}$ eines unbekannten Italieners in der Nachfolge Correggios als weitere Leihga-

22 Inv. Nr. GG 239.

23 Waldmann 1905; Stechow 1926; Wille 1970; Unverfehrt 1987.

24 Wille 1970, Kat. Nr. 113; Unverfehrt 1987, S. 195, Kat. Nr. A 111.

25 Seeliger 1998, S. 736; Riedl 1980, S. 115-117; Belting 1979, S. 116 f.

26 Wille 1970, Kat. Nr. 113; Unverfehrt 1987, S. 195, Kat. Nr. A 112.

27 Vgl. Paatz 1976.

28 Vgl. Seeliger 1998, S. 736; Anonym 1939; Hans Wille: Justus Theodor Valentiner, in: Wille 1970, o. S. (4 Seiten mit Aufzählung des Vermächtnisses); Paatz 1976, S. 33-41.

29 Die kleine aber feine Skulpturensammlung vor allem gotischer und barocker Bildwerke geht zum größten Teil auf sein Engagement zurück, ebenso zeichnet Valentiner aber auch für die Erwerbung der Mappe Kleine Welten von Wassily Kandindsky verantwortlich. Vgl. Hans Wille: Justus Theodor Valentiner, in: Wille 1970, o. S. (4 Seiten mit Aufzählung des Vermächtnisses).

30 Valentiners bedeutende bibliophile Lyriksammlung befindet sich geschlossen in der Göttinger Staats- und Universitätsbibliothek, dem Kunsthistorischen Institut der Universität Heidelberg wurde die Photosammlung überwiesen. Vgl. Hans Wille: Justus Theodor Valentiner, in: Wille 1970, o. S. (4 Seiten mit Aufzählung des Vermächtnisses).

31 Unverfehrt 1987, S. 197, Kat. Nr. A 125. 
be durch das Ehepaar Paatz in der Sammlung. Valentiner hatte dieses $1901 \mathrm{im}$ Berliner Kunsthandel aus dem Nachlass des Prinzen Georg von Preußen erworben. ${ }^{32}$ Aus dem Vermächtnis Valentiner kamen schließlich 1952, unmittelbar nach dessen Tod, durch das Vermächtnis seiner Witwe drei Skulpturen in die Sammlung. ${ }^{33} 1968$ folgten weitere Schenkungen ${ }^{34}$ und Leihgaben durch das Ehepaar Paatz.

Aus der Evangelisch-lutherischen Kirchengemeinde Stemmen bei Barsinghausen kam 1978 ein Gemälde als Dauerleihgabe in die Sammlung: Der Segnende Christus (Kat. Nr. 11) von Carl Wilhelm Friedrich Oesterley (1805-1891) aus dem Jahre 1881. ${ }^{35}$ Ein in den Akten erhaltenes Foto zeigt das Gemälde an seinem ursprünglichen Ort in der Kirche vor dem Orgelprospekt (Abb. 18). In den 1970er Jahren dürfte das Gemälde derart mit dem Zeitgeschmack kollidiert sein, dass die Kirchengemeinde sich dafür entschied, dieses Ensemble historischer Kirchenausstattung aufzulösen, wodurch die Göttinger Universitätskunstsammlung aber ein repräsentatives Stück dort sonst nicht dokumentierter Sakralkunst erlangen konnte: Die Aufgabe historischer Kontexte ist nicht selten Voraussetzung für museales Sammeln, das bewahrend wirkt, funktionale Kontexte jedoch in den seltensten Fällen darzustellen vermag. So ergänzt das Gemälde unsere Sammlung in hervorragender Weise als Beispiel für nazarenisch geprägte Altarbildkunst im südlichen Niedersachsen.

Seit 1966 befinden sich - wie in vielen Sammlungen in Deutschland - einige Leihgaben der Bundesrepublik Deutschland in der Universitätskunstsammlung. Diese Leihgaben aus Bundesbesitz gehen auf Adolf Hitlers Linzer Museumsplanungen zurück. ${ }^{36}$ Aus dem 19. Jahrhundert gehören folgende vier Gemälde zu diesem Komplex: ${ }^{37}$

1. Friedrich August von Kaulbach (1850-1920), Die Erįiebung des Bacchus, um 1875 (Kat. Nr. 4) 38

2. Josef Danhauser (1805-1845), Maler im Dachstübchen, 1831 (Kat. Nr. 12) $)^{39}$

32 Wille 1970, Kat. Nr. 112; Unverfehrt 1987, S. 197, Kat. Nr. A 125.

33 Wille 1970, Kat. Nr. 94, 95 und 97.

34 Ebd., Kat. Nr. 95, 98, 99, 100.

35 Unverfehrt 1987, S. 187, Kat. Nr. A 54.

36 Schwarz 2004.

37 Weitere Gemälde sind: Kopie nach Pieter Bruegel d.Ä.: Der bethlehemitische Kindermord; Christian van Couwenbergh: Junge Frau mit Frücbtekorb; vgl. Wille 1970, Kat. Nr. 102, 101, Unverfehrt 1987, S. 50 f., 58 f., Kat. Nr. 17, 22. Folgende Zeichnungen gehören ebenso zu dieser Leihgabe: Eugen Napoleon Neureuther: Entwurf für eine Wanddekoration; Johann Georg Dillis: Das Forum Romanum bei Mondschein; Carl Blechen: Italienische Gebirgslandschaft mit Agaven; vgl. Wille 1970, Kat. Nr. 118, 116, 115. Der einzige Kupferstich ist: Unbekannter Künster: Stanislaus ein Tugendhafter.

38 Wille 1970, Kat. Nr. 106; Unverfehrt 1987, S. 184, Kat. Nr. A 34.

39 Wille 1970, Kat. Nr. 105; Unverfehrt 1987, S. 181, Kat. Nr. A 12. Aus der jüngsten Korrespondenz vom 15.07.2011 des Bundesamtes für zentrale Dienste und offene Vermögensfragen geht für die Provenienz folgendes hervor: „Linz-Nr. 235; RS: ,K 549‘, 1831/32 Kunstverein Wien(?); 4.3.1884 b.Kunstaukt.Miethke,Wien erworb.,14.3.1917 Kunstaukt. Wawra, Wien, Einlief. U .Ersteig. ni. ermitt. (bei d.Auktion Smlg. Schäffer u.SlmgStrache verst.); 24.8.1938 Maie Gebauer- 
3. Henry Ritter (1816-1853), Schiffbruch, 1841 (Kat. Nr. 13) ${ }^{40}$

4. Johann Friedrich Voltz (1817-1886), Enten am Starnberger See, nach 1850 (Kat. Nr. 24).41

Die Provenienzforschung zu diesen Werken wird vom Bundesamt für zentrale Dienste und offene Vermögensfragen (BADV), Referat B 1 wahrgenommen. ${ }^{42}$

\section{Erwerbungen}

In früheren Jahren waren der Kunstsammlung durch einen eigenen kleinen Ankaufsetat Erwerbungen möglich. Auch der Universitätsbund förderte viele Ankäufe, wie z.B. 1969 den Erwerb des Gemäldes Bildnis einer Dame im Grünen (Kat. Nr. 32, hier unter Vorbehalt Franz Xaver Winterhalter zugeschrieben) ${ }^{43}$ aus Göttinger Privatbesitz der Familie von Treskow-Albert. ${ }^{44}$ Von der Klosterkammer Hannover erfuhr die Kunstsammlung großzügige Unterstützung, um 1968 das Gemälde Hirt auf der Bergspitze im Abendschein (Kat. Nr. 19) ${ }^{45}$ von Friedrich Philipp Reinhold (1779-1840) aus Göttinger Privatbesitz ${ }^{46}$ anzukaufen. Die MotorwagenHandelsgesellschaft E. und H. Apell, Göttingen, und das Universitätskuratorium stifteten der Kunstsammlung 1970 die zwischen 1838 und 1845 entstandene italienische Landschaft Cap Manerba am Gardasee (Kat. Nr. 23) ${ }^{47}$ von Bernhard Fries (1820-1879), die sich bis dahin in Göttinger Privatbesitz befunden hatte. Die Taufe und Heilung des Paulus (Kat. Nr. 7) ${ }^{48}$ von Francesco Podesti (1800-1895) wurde 1974 mit Sondermitteln des Kurators aus römischem Kunsthandel erworben. Die

Füllneg. Wien (?-vermut.); Gem.relat.früh i. „Linzer Smlg.“, wahsch. Somm. 38 (nied.Linz-Nr.), mögl. weis v. A. Hitler od. Reichskanzlei erworb. (Unterl. konnt. nicht ermitt. werd); Vermerk B1VV6200-1478/ v.20.11.2008“،

40 Wille 1970, Kat. Nr. 109; Unverfehrt 1987, S. 188, Kat. Nr. A 64; zur Provenienz vgl. www.badv.bund.de/003_menue_links/e0_ov/d0_provenienz/b0_dokumentationen/Kunstwerk. php?id_kunstwerk=6378\&modus=provenienz (zuletzt 14.07.2013).

41 Wille 1970, Kat.-Nr. 114; Unverfehrt 1987, S. 192, Kat. Nr. A 87. Aus der jüngsten Korrespondenz vom 15.07.2011 des Bundesamtes für zentrale Dienste und offene Vermögensfragen geht für die Provenienz folgendes hervor: „Seit ca. 1933 Firmenbestand d. Kunsthdlg. Helbing/München; von dort an Galerie a.d. Wagmüllerstr./Mün.; 16.2.42 von dort für RM 4.500,- an Schloß Posen (P 38) (Nachricht Dr. Hess v.21.5.51); Vor dem hier geschilderten Hintergrund bleibt die Provenienz ungeklärt, zumal alle Quellen ausgeschöpft sind. Anhaltspunkte für weitere Recherchen liegen derzeit nicht vor. B1-VV6200-1487/00 v. 26.01.2010“.

42 http://www.badv.bund.de/003_menue_links/e0_ov/d0_provenienz/index.html (zuletzt 24.6. 2013).

43 Unverfehrt 1987, S. 194, Kat. Nr. A 102.

44 Angekauft wurden gleich zwei Gemälde: das zweite ist eine Felslandschaft eines unbekannten Flamen, Anfang des 17. Jahrhunderts; vgl. Unverfehrt 1987, S. 167, Kat. Nr. 106.

45 Wille 1970, Kat. Nr. 18; Unverfehrt 1987, S. 188, Kat. Nr. A 62.

46 Der Vorbesitzer stiftete 1969 zudem die in einer Schatulle gefasste und verglaste Miniatur eines Münchner Miniaturisten: Bildnis Benno Karl von Waechter, um 1840 (Kat. Nr. 48), GG 214. Vgl. Wille 1970, Kat. Nr. 24; Unverfehrt 1987, S. 195, Kat. Nr. A 109.

47 Wille 1970, Kat. Nr. 6; Unverfehrt 1987, S. 182, Kat. Nr. A 20.

48 Unverfehrt 1987, S. 188, Kat. Nr. A 60; Huber 1979, S. 197-281. 
Kunsthistorikerin Judith Huber hatte die Gemälde bei den Antiqutätenhändlern Carlo und Marcello Sestieri entdeckt und den damaligen Göttinger Assistenten Herwarth Röttgen darauf aufmerksam gemacht, so dass dieser das Werk - nach Zuschreibung von Judith Huber an Podesti - für die Göttinger Kunstsammlung erwarb. ${ }^{49}$ Aus Göttinger Kunsthandel kaufte der damalige Kustos Konrad Renger 1977 drei Ölskizzen von Louis Gurlitt (1812-1897) mit Stiftungsmitteln der Universität für die damals stolze Summe von 7000,- DM: Uferlandschaft (Kat. Nr. 21) ${ }^{50}$ und Maler in steinigen Sanddünen (Kat. Nr. 20) ${ }^{51}$, beide von 1833 sowie Blick auf Salzburg (Kat. Nr. 22) ${ }^{52}$ von 1836. Alle drei Ölskizzen sind mit einem Nachlassstempel des Künstlers versehen und gehören zu den wertvollsten Werken des 19. Jahrhunderts in der Universitätskunstsammlung.

Den umfangreichsten Ankauf für die Kunstsammlung im 20. Jahrhundert ermöglichte die Stiftung Volkswagen, die 1966 Mittel zur Verfügung stellte, um große Teile der Sammlung Dumont zu erwerben. Dabei machen die sechs für diesen Katalog bearbeiteten Gemälde ${ }^{53}$ nur einen kleinen Teil dieser Stiftung aus:

1. Ignatius Josephus van Regemorter (1785-1873), Felsenschlucht, 1815 (Kat. Nr. 18)

2. Karl Buchholz (1849-1899), Der Teich, nach 1880 (Kat. Nr. 26)

3. Eduard von Gebhardt (1838-1925), Bei der Kupplerin, Mitte 19. Jh. (Kat. Nr. 16)

4. Unbekannt, Deutsch, Dorflandschaft mit zechenden Bauern, Mitte 19. Jh. (Kat. Nr. 15)

5. Carl Heinisch (1847-1932), Seeufer mit Angler im Schilf, Ende 19. Jh. (Kat. Nr. 28).

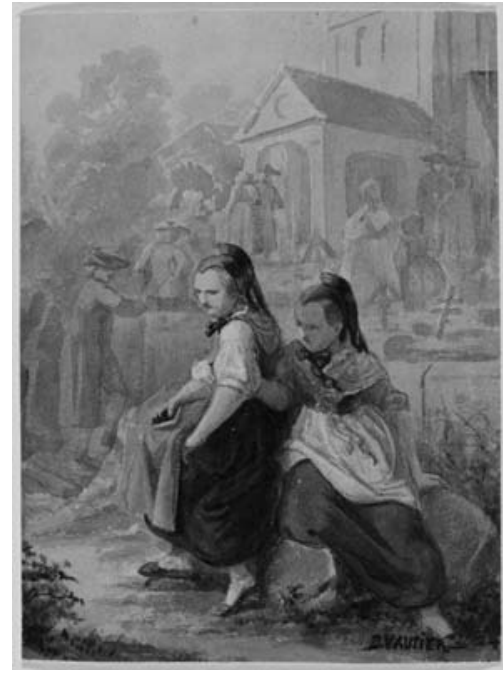

Abb. 4: Benjamin Vautier: Zwei Mädchen vor dem Kirchgang, Aquarell, 153 x 112 mm, Göttingen, Kunstsammlung der Universität, Inv. Nr. 1968/10

6. Art des (Fälschung nach?) Joris van Son, Blumenstillleben, 19. Jahrhundert (Kat. Nr. 30).

49 Huber 1979, S. 197-218; vgl. auch Girgensohn 1976, S. 340.

50 Unverfehrt 1987, S. 183, Kat. Nr. A 26.

51 Ebd., S. 183, Kat. Nr. A 28.

52 Ebd., S. 183, Kat. Nr. A 27.

53 Die Schenkung umfasste sieben Gemälde. Das einzige nicht aus dem 19. Jahrhundert stammende Gemälde ist Inv.-Nr. GG 127: Christian Wilhelm Dietrich (1712-1774): Beweinung Christi (Wille 1970, Kat., Nr. 4, Unverfehrt 1987, S. 181, Kat. Nr. A 14). 
Der Schauspieler Eugen Dumont (1877-1957) ${ }^{54}$ sammelte bereits während seiner Düsseldorfer Zeit ${ }^{55}$ und setzte dies in Göttingen fort, wo er 1957 verstarb. Seine Witwe räumte dem damaligen Kustos das Vorkaufsrecht ein. Desweiteren umfasste der Ankauf 39 Zeichnungen, 144 Druckgraphiken, die originale Kupferplatte einer Radierung des 18. Jahrhunderts, welche eine Landschaft mit Bauern und Wassermühle zeigt, sowie die englische Rokoko-Ausgabe von François Fénelons The Adventures of Telemachus mit originalem Einband und 25 Illustrationsradierungen. Unter den Zeichnungen finden sich allein achtzehn Werke von Caspar Scheuren, eine Felsenstudie von Carl Friedrich Lessing, ein Mädchenkopf von Franz von Lenbach, vier Zeichnungen von Andreas Achenbach sowie eine von Franz von Defregger. 1967 konnten von Irene Dumont 40 Holzschnitte des Petrarca-Meisters, 1968 das Aquarell Zwei Mädchen vor dem Kirchgang von Benjamin Vautier (Abb. 4) erworben werden. So erfuhr die Universitätskunstsammlung durch die Erwerbung der Sammlung Dumont vor allem Zuwachs auf dem Gebiet des 19. Jahrhunderts - allerdings nicht vorrangig durch die erworbenen Gemälde, sondern vor allem durch das Konvolut der Zeichnungen, die noch einer eigenen wissenschaftlichen Bearbeitung bedürfen.

\section{Gemälde aus Künstlernachlass}

Direkt aus dem Nachlass des Künstlers erwarb die Kunstsammlung 1822 das Gemälde Die Heilige Familie (Kat. Nr. 6) ${ }^{56}$ von 1820 für 50 Reichstaler Gold, den Rahmen für 7 Reichstaler Courant ${ }^{57}$. Der Künstler ist kein geringerer als der erste Sammlungskustos und Professor für Kunstgeschichte Johann Dominicus Fiorillo (1748-1821).

Ebenfalls aus Künstlernachlass schenkte der Vater Friedrich Spangenbergs (1843-1874) der Kunstsammlung 1886 die beiden Ölstudien Geiserich führt Eudoxia mit ihren Kinder aus Rom, sowie Bernhard von Clairvaux predigt den Kreuzzug, beide 1869 (Kat. Nr. 2+3): ${ }^{58}$ Sie wurden - laut Inventareintrag - „ohne weitere Angabe in die Aula gebracht und erst Erkundigung[en] beim Photographen Nölle ergaben, dass

\footnotetext{
54 http://www.filmportal.de/person/eugen-dumont (zuletzt 10.7.2012)

55 Interessant erscheint die Notiz bei der am 16. März 2011 beendeten ebay-Versteigerung eines angeblichen Gemäldes Jacob van Ruisdaels (die Versteigerung lässt sich im Internet leider nicht mehr aufrufen): „Noch eine wichtige Info: Mein Onkel, der Schauspieler Eugen Dumont (1877 bis 1957) war leidenschaftlicher Kunstsammler und hatte damals auf Grund seines Berufes die Möglichkeit, diverse Kunstgegenstände durch Beziehungen zu erwerben, zumal sein Bruder Deutscher Botschafter auch zeitweise in Holland und Frankreich war. Von wem er allerdings das Bild erworben hat, kann ich leider nicht sagen."

56 Göttingen, Kunstsammlung der Universität, Inventar 1884 ff., Nr. 192, S. 49; Waldmann 1905, Nr. 156; Stechow 1926, Kat. Nr. 55; Unverfehrt 1987, S. 182, Kat. Nr. A 18.

57 Für die Entschlüsselung der Währungszeichen danke ich Dietrich Meyerhöfer M.A., Göttingen.

58 Göttingen, Kunstsammlung der Universität, Inventar 1884 ff., S. 72; Waldmann 1905, Nr. 255 und 256; Stechow 1926, Kat. Nr. 167/168; Unverfehrt 1987, S. 190, Kat. Nr. A 73 u. A 74.
} 
Spangenberg sie testamentarisch vermacht habe. "59 Im Inventar von 1887 werden sie als „zwei Farbenskizzen zu historischen Gemälden“60 bezeichnet; Emil Waldmann bezeichnet Kat. Nr. 2 als „Farbenskizze zu einem historischen Gemälde der Kreuzfahrer“ und Kat. Nr. 3 als ebensolche ,,aus der römisch-germanischen Geschichte."61 Wolfgang Stechow schlüsselt die Themen 1926 schließlich konkret auf und legt damit die Grundlage für den heutigen Wissensstand. ${ }^{62}$

\section{Schenkungen}

Durch großzügiges Mäzenatentum bekam die Kunstsammlung immer wieder Schenkungen, auf die sie heute mehr denn je angewiesen ist, da Ankäufe aufgrund eines fehlenden Ankaufsetats kaum noch möglich sind.

1916 erhielt die Sammlung das großformatige Gemälde Die Heilige Familie mit den Engeln (Kat. Nr. 5) von Karl Franz Jacob Heinrich Schumann (1767-1827) als „Geschenk von Prof. Droysen 1916“ (Inventareintrag). In den 1870er Jahren soll es laut Inventar ${ }^{63}$ im Besitz des Arztes Privatdozent Dr. Wiese gewesen sein, aus dessen Nachlass es stammt. Leider fehlen bei beiden Einträgen die Vornamen und bei Prof. Droysen die Fachrichtung, so dass es vor allem bei letzterem schwierig war, die Person zu identifizieren. Hört man den Namen Droysen, denkt man sofort an den bedeutenden Historiker Johann Gustav Bernhard Droysen ${ }^{64}$, der allerdings von 1808 bis 1884 lebte und damit als Donator nicht in Frage kommt. Mit Göttingen in Verbindung steht sein Sohn aus erster Ehe, Gustav Droysen (18381908). Er war von 1869 bis 1872 daselbst außerordentlicher Professor für Geschichte ${ }^{65}$ und danach Professor in Halle (Saale). Da er bereits 1908 in Halle starb, scheidet auch er trotz seiner Göttinger Beziehung aus. Johann Gustav Bernhard Droysens Sohn aus zweiter Ehe, Hans Droysen (1851-1918), war Historiker und Gymnasialprofessor in Berlin. Er lebte zum Schenkungsdatum 1916 zwar noch, doch lässt sich keine Verbindung nach Göttingen aufzeigen, geschweige denn zu dem Privatdozenten und Arzt Wiese. ${ }^{66}$ Es bedurfte daher weiterer Recherchen. Im Corpus Academicum Gottingense (1737-1928)67 sowie im Catalogus Professorum Gottingen-

59 Göttingen, Kunstsammlung der Universität, Inventar der Universitätskunstsammlung 1884 ff., S. 72 .

60 Ebd., S. 72.

61 Waldmann 1905, Nr. 255+256.

62 Stechow 1926, S. 53 f., Nr. 167+168 (mit Verweis auf die ausgeführte Fassung von Kat. Nr. 3, heute Kiel, vgl. die Ausführungen von Jan Stieglitz in diesem Band, S. 77-81).

63 Göttingen, Kunstsammlung der Universität, Inventar der Universitätskunstsammlung 1884 ff., S. 89, Nr. 294.

64 Schieder, Th. 1959, S. 135-137.

65 Ebel 1962, Ph 3, Nr. 120.

66 An dieser Stelle gebührt mein herzlicher Dank Dr. Ulrich Hunger, Göttingen, der mich auf die richtige und damit zielführende Literatur aufmerksam machte.

67 Arnim/Selle 1930. 
sium (1734-1962)68 lässt sich ein weiterer Droysen nachweisen, von dem aus sich zudem eine Verbindung zu einem ebenfalls in den beiden Werken nachweisbaren Dr. Wiese ergibt: Dr. Felix Droysen (1852-1919) lehrte von 1884 bis 1919 an der Georgia Augusta Geburtshilfe und Gynäkologie ${ }^{69}$ und war seit 1895 Titularprofessor. Dr. Robert Wiese (1822-1886) war an der Göttinger Universität von 1847 bis 1886 als Mediziner tätig. So darf davon ausgegangen werden, dass es sich bei dem Inventareintrag um diese beiden in Göttingen tätigen Mediziner handelt. Im Inventar findet sich desweiteren ein in Bleistift geschriebener Zusatz, der lautet: „Mit Schreiben vom 27 IV 1921 der Theologischen Fakultät für das Waisenhaus bis auf weiteres leihweise überlassen." Wann das großformatige Gemälde in die Kunstsammlung zurückkam, ist momentan nicht nachvollziehbar. Bemerkenswert ist, dass es das einzige Bild Schumanns ist, das im Lexikonartikel über den Künstler in Ulrich Thiemes und Felix Beckers Standardwerk Allgemeines Lexikon der bildenden Künstler von der Antike bis zur Gegenwart eigens angeführt wird. ${ }^{70}$

1956 erhielt die Kunstsammlung das 1871 entstandene Gemälde Tauben auf dem Dach (Kat. Nr. 29) von Paul Meyerheim (1842-1915) als Schenkung von Dr. Walter Gerson (1899-1971). Gerson wurde in Berlin geboren und ging dort zur Schule. ${ }^{71}$ In Berlin, Münster und Bonn studierte er Medizin, beendete 1924 seine Dissertation Über Psychosen nach Morphiumentziehung und wurde zum Dr. med. promoviert. ${ }^{72}$ Seit 1939 als Arzt und Leiter des Göttinger Jugenderziehungsheims tätig, wurde er 1936 aus seiner Stellung entlassen, da er mütterlicherseits jüdischer Abstammung war. ${ }^{73}$ Danach war er als praktischer Arzt tätig, bis ihm auch dies verboten wurde und er als Buchhalter arbeitete. 1941 bekam er eine Landpraxis in Rietmarshausen zugewiesen, die besetzt werden musste, bis er 1944 als Lagerarzt in ein Arbeitslager in Holzminden kam. Nach dem Krieg erhielt er wieder seine Stelle als Direktor des Jugenderziehungsheims in Göttingen und hielt als Honorarprofessor an der Georgia Augusta bei der Sozialpädagogik Vorlesungen. Wie Gerson in den Besitz des Gemäldes kam und aus welchen Gründen er es der Kunstsammlung als Schenkung hinterließ, lässt sich bisher nicht feststellen.

Testamentarisch vermachte Frau Prof. Ilse Walter der Kunstsammlung vier Werke. ${ }^{74}$ Bei zweien handelt es sich um Gemälde des 19. Jahrhunderts: Junges Paar (Kat. Nr. 17) von Maximilian Wachsmuth sowie Früchtestillleben (Kat. Nr. 31) von

68 Ebel 1962.

69 Felix Droysen: Zur Aetiologie des Blasenkatarrh's, Med. Diss., Berlin 1883.

70 Thieme/Becker 1907-1950, Bd. 30, 1936, S. 341.

71 Alle Angaben zur Person in: Schäfer-Richter/Klein 1992, S. 74 f.

72 Horn 2003, S. 237.

73 Manthey/Tollmien 1999, S. 737: ,und ebenfalls bei dem als ,Halbjuden' geltenden Walter Gerson, dem Leiter des Göttinger Jugenderziehungsheims, sind Zweifel ob seiner Zugehörigkeit zur jüdischen Religionsgemeinschaft angebracht."

74 Göttingen, Kunstsammlung der Universität, Archivakten (Ordner Schenkungen sowie Bildakten GG 233 und GG 234). Die beiden anderen Werke sind erstens der Kupferstich von Albrecht Dürer Madonna auf der Mondsichel sowie zweitens ein Frauenporträt von Stumpf. 
Joseph Correggio (1810-1891). Beide Bilder gingen 2008 in den Besitz der Kunstsammlung über.

Das Gemälde Göttinger Vorstadthaus um 1880 (Kat. Nr. 27) von Otto Peters (1835-1920) kam als Schenkung von dessen Urgroßneffen Heinz Erler, Buchholz, in die Sammlung. Motiviert wurde die Schenkung zum einen durch die Existenz eines weiteren Gemäldes von Peters in der Kunstsammlung (Kat. Nr. 53) sowie zum anderen durch die Tatsache, dass Peters als Universitätszeichner in Göttingen tätig war.

Im Jahre 2010 kam das Gemälde Die heilige Elisabeth von Thüringen des Paderborner Kirchenmalers Johannes Franz Xaver Laudage (1821-1893) als Schenkung von Maria Pabst, Duderstadt, in die Sammlung. Diese Schenkung konnte nur durch die Vermittlung von Dietrich Meyerhöfer zustandekommen, der seit seiner Studienzeit mit der Kunstsammlung eng verbunden ist. Frau Pabst hatte das Gemälde 1987 von ihrer Tante Elisabeth geerbt, welche die Darstellung ihrer Namenspatronin 1924 oder 1925 von ihrem Duderstädter Arbeitgeber als Dank geschenkt bekommen hatte.

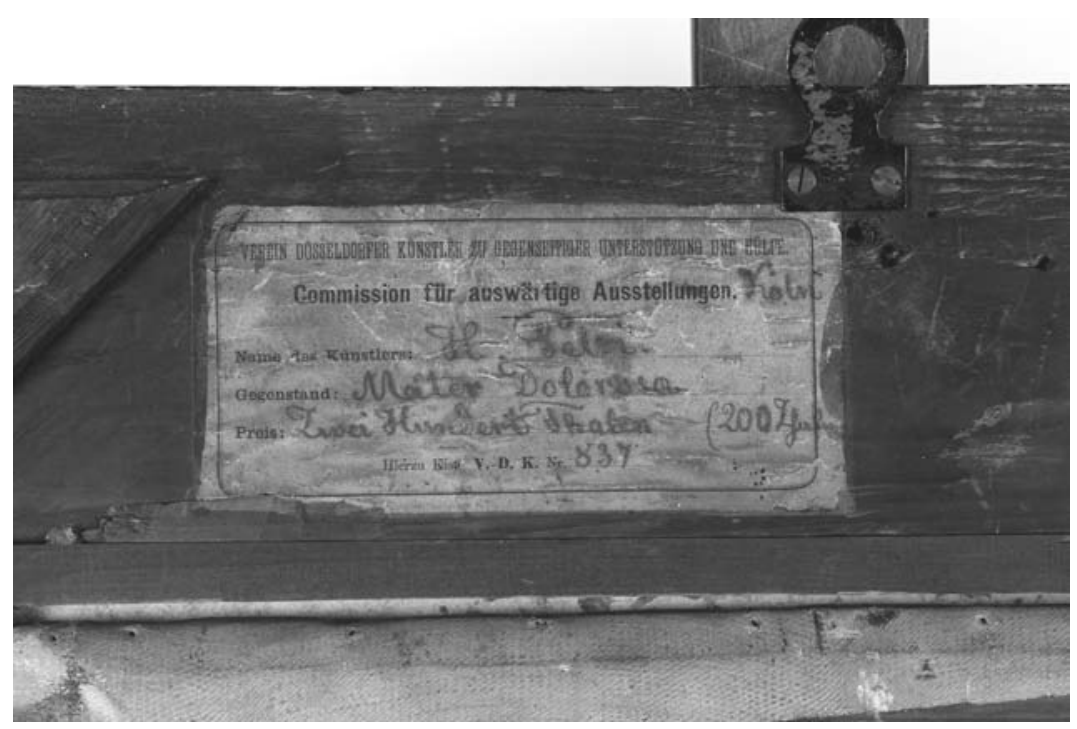

Abb. 5: Heinrich Petri: Mater dolorosa (vgl. Kat. Nr. 8), Schild auf der Bildrückseite

Die Ausstellung „Akademische Strenge und künstlerische Freiheit“, in deren Zusammenhang der vorliegender Katalog entstand, regte eine weitere Schenkung von Werken des 19. Jahrhunderts an: Dr. Sabine Engelhardt übergab der Sammlung im Sommer 2012 die beiden Gemälde Mater Dolorosa (Kat. Nr. 8) und Madonna (Kat. Nr. 9) sowie die Bleistiftzeichnung einer verschleierten, trauernden Maria (Abb. 16) 
des Malers Heinrich Petri. Die Gemälde fanden unmittelbar Eingang in die bereits laufende Ausstellung und wurden in den Bestandskatalog aufgenommen. Sie sind in der Sammlung eine hervorragende Ergänzung für den Bereich der religiösen Malerei der Düsseldorfer Malerschule der ersten Hälfte des 19. Jahrhunderts repräsentiert durch einen Spross der Stadt Göttingen. Auch wegen ihrer lückenlosen Provenienz sind sie wertvoll und interessant: sie befanden sich durchgehend in Familienbesitz und lassen sich von der letzten Besitzerin bis zur Familie des Künstlers selbst zurückverfolgen:

Heinrich Petris Schwester Marie Fobbe (1832-1903) hatte eine Tochter, Wilhelmine Fobbe, die ihren gesamten Besitz ihrer Pflegetochter Minna Dümer vererbte. Die Großeltern der letzten Besitzerin der Gemälde, Dr. Sabine Engelhardt, waren sowohl mit Wilhelmine Fobbe als auch mit deren Pflegetochter Minna eng befreundet. Nach deren Tod im Jahr 1981 gingen die beiden Gemälde (neben anderen Bildern, v. a. Landschaften) in den Besitz der Familie der Stifterin über. So sind die Kunstwerke bis auf Petris Schwester Marie zurückzuführen. Bis zu ihrer Überführung in die Universitätskunstsammlung wurden sie in der Familie der Stifterin aufbewahrt.

Ein Aufkleber auf der Rückseite der Mater Dolorosa (Kat. Nr. 8) trägt die Aufschrift: „Verein Düsseldorfer Künstler zur gegenseitigen Unterstützung und Hülfe / Commission für auswärtige Ausstellungen Köln“ (Abb. 5). Neben Namen des Künstlers „H. Petri“ und dem Bildthema „Mater Dolorosa“ wird der damalige Preis genannt: „Zweihundert Thaler (200 Thaler)“. Da das Gemälde in Familienbesitz verblieb, konnte es damals offensichtlich nicht verkauft werden. Außerdem gibt es die Aufschrift „Hierzu Kiste VDK Nr. 837“ - die Abkürzung „VDK“ dürfte sich auf den Verein Düsseldorfer Künstler beziehen.

An dieser Stelle darf nicht unerwähnt bleiben, dass sich bereits seit 1899 eine Schenkung aus der Familie Petri in der Kunstsammlung befindet, die Robert Vischer in der Universitätschronik verzeichnet: „Fräulein Anna Petri (dahier) ist die Schenkung einer Handzeichnung von W. von Schadow zu danken." 75 Anna Petri (1841-1903) war Tochter von Philipp Petri (1800-1868)76 und seiner zweiten Frau Wilhelmine, geb. Krüger (gest. 1853) und damit eine Halbschwester des Malers Heinrich Petri, dessen Mutter die erste Ehefrau des Philipp Petri - Emma, geb. Wedemeyer (1813-1834) - war. Bei der Schenkung wird es sich um die Krenztragung Christi (Inv. Nr. H 880) handeln, da dies die einzige bekannte Zeichnung Wilhelm von Schadows in der Sammlung war, bevor Christian Scholl das Studienblatt H 934 diesem Künstler zuschreiben konnte. ${ }^{77}$ Es ist also durchaus denkbar, dass Heinrich Petri die Zeichnung in seiner Düsseldorfer Zeit von Wilhelm von Schadow persönlich erhielt oder erwarb und sie seiner Halbschwester vermachte. Ist

\footnotetext{
75 Chronik der Georg-August-Universität 1898/99, S. 27.

76 Vgl. u. a. Brinkmann 2000, v. a. S. 14-23.

77 Vgl. Scholl 2012c.
} 
dies der Fall, wäre auch diese Zeichnung in ihrer Provenienz bis zum Künstler zurückzuverfolgen.

Die Provenienzen der Göttinger Kunstsammlung sind zum größten Teil gesichert durch die alten Bestände Uffenbach 1770 und Johann Wilhelm Zschorn 1796 und deren eigene Inventarbücher sowie durch diejenigen von Fiorillo. Die Kunstwerke des 19. Jahrhunderts, die hier im Zentrum des Interesses stehen, gehören natürlich alle nicht dazu. Deshalb war es umso interessanter, der Herkunft dieser Werke nachzuspüren - interessant für die Geschichte der Sammlung insgesamt, aber vor allem für die einzelnen Stücke und ihren repräsentativen Wert, denn die historische und kunsthistorische Verortung der Bilder zeigt nicht nur regionale Tendenzen, sondern, bedingt durch den großen Einzugsbereich der Göttinger Universität im 19. Jahrhundert, auch Beispiele räumlich entfernter Porträtkunst, die durch Studenten oder Hochschullehrer hierher fand. So können Historien- und Landschaftsmalerei, Genre und Stillleben sowie Bildnisse unterschiedlichster Qualität und künstlerisch unterschiedlichster Tradition in der Universitätssammlung verglichen werden.

An dieser Stelle ist der angemessene Ort, um einen herzlichen Dank allen denen auszusprechen, welche die Göttinger Universitätskunstsammlung durch Leihgaben, Nachlässe, Schenkungen und Stiftungen bereichert haben. Ohne ihre Großzügigkeit wäre diese wunderbare Sammlung nicht zustandegekommen - und demzufolge auch dieses Projekt nicht möglich gewesen. 

Katalog der Gemälde des 19. Jahrhunderts in der Göttinger Universitätskunstsammlung 



\title{
„was malen S' denn heuer für ein Malheur?“‘: Profanhistorie - Geschichtsmalerei - Mythologie
}

\author{
Ifee Tack und Christian Scholl
}

Der Begriff „Historie“ leitet sich vom lateinischen Wort „historia“ (italienisch: „istoria“) ab. Zu den Themen der Historienmalerei zählen historische Ereignisse wie beispielsweise Schlachten oder Friedensschlüsse, Geschichten aus der Literatur, aber auch Themen der Mythologie, der Bibel sowie Heiligengeschichten. Nach einer Einführung in die Entwicklung der Historienmalerei wird im folgenden vor allem von Profanhistorien sowie von Geschichtsmalerei als besonders wichtiger Spielart der Historienmalerei des 19. Jahrhunderts die Rede sein. Der religiösen Malerei, welche ebenfalls Historien einschließt, ist im Anschluss daran ein eigenes Kapitel gewidmet.

Historienmalerei in der Gattungshierarchie von der frühen Neuzeit bis zur Aufklärung

In der Kunst der Neuzeit entwickelte sich die Historienmalerei seit dem 14. Jahrhundert zunächst in Italien und, von dort ausgehend, auch im Norden. ${ }^{1} \mathrm{Da}$ Künstler und Kunsttheoretiker die Darstellung von Menschen in differenzierten Aktionen als besonders anspruchsvoll ansahen, erlangte die Historienmalerei das höchste Ansehen unter den Gattungen der Bildenden Kunst. Sie stand damit bis

1 Jahn/Lieb 2008, S. 366. 
weit ins 19. Jahrhundert hinein an der Spitze der Gattungshierarchie, gefolgt von Porträt, Genre, Landschaft und Stillleben.

Die Ausdifferenzierung der Gattungen war das Ergebnis eines längeren Prozesses, der sich vom 15. bis ins 17. Jahrhundert verfolgen lässt. Eine erste Einteilung und Bewertung der einzelnen künstlerischen Sujets fand in der Renaissance statt. Im Italien des 15. Jahrhunderts erarbeitete namentlich Leon Battista Alberti (1404-1472) mit seinem Traktat Della pittura (1436) hierfür wichtige kunsttheoretische Grundlagen. Für Alberti stellte das geschichtliche und literarische Wissen die Ausbildungsgrundlage eines Malers von Historien dar. ${ }^{2}$ In seinem Traktat unternimmt er den Versuch, die Bedeutung der „historia“ zu bestimmen. Sein entsprechender Begriff meint dabei noch nicht die Darstellung eines vergangenen Ereignisses, sondern vielmehr einen erzählerischen Zusammenhang in einem Bild. ${ }^{3}$

Im 16. Jahrhundert führte unter anderem Leonardo da Vinci die Kunsttheorie Albertis fort. Für Leonardo stellten Naturstudium und mathematische Kenntnisse die Grundlage der Malerausbildung dar. ${ }^{4}$ Neben dem technischen Können war auch seiner Ansicht nach die historische Bildung eines Malers entscheidend für die Umsetzung eines Bildprogramms. ${ }^{5}$ Die Einhaltung der „convenevolezza“, der Angemessenheit, wurde als ein grundlegendes Mittel angesehen, um das Bildgeschehen entsprechend darzustellen und die Betrachter emotional anzusprechen. ${ }^{6}$ Die Grundlage solcher kunsttheoretischen Forderungen bildete die antike Tradition der Rhetorik. ${ }^{7}$ Mit der Etablierung einer rhetorisch fundierten Kunsttheorie erfuhr die Malerei eine beträchtliche Rangerhöhung und wurde letztlich den freien Künsten („artes liberales“) gleichgesetzt. Damit einhergehend änderte sich auch die soziale Stellung von Malern, deren Tätigkeit zunehmend weniger als bloßes Handwerk angesehen wurde.

Ein entsprechender Wandel vollzog sich in der zweiten Hälfte des 17. Jahrhunderts in Frankreich. Die Debatte über Kunst wurde hier vor allem an der 1648 in Paris gegründeten Academie Royale de peinture et de sculpture weitergeführt. ${ }^{8}$ Dabei erfuhr noch einmal eine Bekräftigung, dass Künstler und Handwerker zwei unterschiedliche Professionen seien. Gleichzeitig nahm man die Historienmalerei als fester Bestandteil in die Akademieausbildung auf. Anhand von Referenzwerken - namentlich Bildern von Nicolas Poussin (1593-1665) - diskutierten die Künstler, die hauptsächlich selbst Historienmaler waren, an der Akademie in den sogenannten „Conférences“ über Zweck und Inhalt der Historienmalerei. Sie entwickelten Grundlagen und Regeln, auf denen die künstlerische Lehre aufbauen

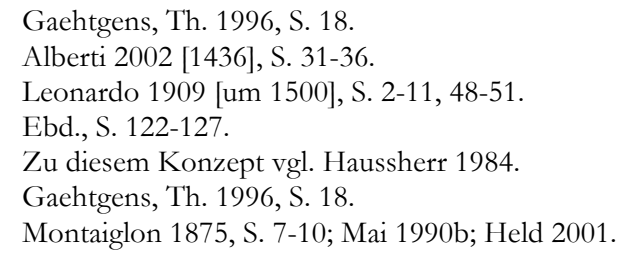


und die Malerei ausgeübt werden sollte. ${ }^{9}$ Dabei wurden ausschließlich Historiengemälde besprochen, da man die anderen Gattungen als minderwertig ansah. ${ }^{10}$ Hierin manifestiert sich die Gattungshierarchie, die bis weit in das 19. Jahrhundert wirksam blieb.

Ohne diese Hierarchie grundsätzlich in Frage zu stellen, entwickelte der Maler, Kunstschriftsteller und Sammler Roger de Piles (1635-1709) bereits gegen Ende des 17. Jahrhunderts Kriterien für eine Beurteilung von Bildern, welche von den Positionen der Akademie abwichen. ${ }^{11}$ Seiner Ansicht nach sollte man ein Gemälde nicht allein nach dem dargestellten Gegenstand bewerten, denn Malerei sei „,mehr als bloße Geschichtsschreibung"“.12 De Piles betonte, dass sowohl Landschaften als auch Stillleben der Schönheit fähig seien, und plädierte dafür, den Gesamteindruck eines Werkes zunächst einmal unabhängig vom Thema zu betrachten. Damit bereitete er einen Weg für die Betrachtung von Kunstwerken jenseits der Gattungshierarchie, der großen Einfluss auf das 18. Jahrhundert hatte. ${ }^{13}$

In der Zeit der Aufklärung wurden weitere Ansätze entwickelt, welche geeignet waren, das Konzept der Gattungshierarchie zu relativieren. Hier ist etwa Denis Diderot (1713-1784) mit seinem Eintreten für die Werke von Jean-Baptiste Greuze (1725-1805) zu nennen, welche letztlich auf eine Verwischung der Grenzen zwischen Historie und Genre hinausliefen. ${ }^{14}$ Hier wurde eine Art von Malerei entwickelt, die Werner Busch mit dem Typus des „sentimentalischen Bildes“ beschrieben hat, und die nicht mehr Bilder vorbildhafter, auf einer exponierten Höhenlage agierender Helden zeigt, sondern vielmehr handlungsarme Personendarstellungen, die auf möglichst unmittelbare, allgemein wirksame Empathie setzen. Dies konnte bürgerliche Protagonisten mit einschließen. ${ }^{15}$ In der Kunst der Düsseldorfer Malerschule fand die im späten 18. Jahrhundert ausgebildete Tradition des „sentimentalischen Bildes“ ab den 1830er Jahren eine eigenständige Fortsetzung, wobei die Stoffe jetzt vor allem aus der Literatur genommen wurden. ${ }^{16}$ Sie bildet möglicherweise auch einen Deutungskontext für das Gemälde Drei Damen beim Bade überrascht von Friedrich Becker in der Göttinger Universitätskunstsammlung (Kat. Nr. 1), das sich ansonsten einer Interpretation bislang weitgehend entzieht.

Die mit dem Typus des „sentimentalischen Bildes“ verbundene Option eines tendenziellen Aufgehens in Mischgattungen stellte nach 1800 allerdings nur eine

9 Montaiglon 1875, S. 31.

10 Ebd, S. 32.

11 Piles 1699, S. 28-32.

12 Gaethgens, Th. 1996, S. 36.

13 Ebd.

14 Vgl. den Kommentar von Robert Scherkl in Gaehtgens/Fleckner 1996, S. 251 f. sowie Busch 1993, S. 49 f. Zu den in diesem Zusammenhang ausgebildeten Mischgattungen zwischen Historie und Genre vgl. auch Muhr 2006; zur Fortsetzung derartiger Gattungsüberschreitungen siehe Kepetzis 2009.

15 Busch 1993.

16 Vgl. Körner 2011. 
von mehreren Entwicklungsmöglichkeiten der Historienmalerei dar. So ist bezeichnend, dass gerade die Kunst der Düsseldorfer Malerschule in der Zeit des Vormärz aufgrund ihres Lyrismus, ihrer Sentimentalität und der bewusst zurückgenommenen Aktion massiv angegriffen wurde. Die Kritiker, welche insbesondere aus dem Umfeld der Hegelianer kamen, vertraten ein entgegengesetztes Verständnis von Historienmalerei, das im 19. Jahrhundert mindestens ebenso wirkmächtig war und auf die Darstellung nicht nur bewegender, sondern auch bewegter Handlungen setzte. ${ }^{17}$

\section{Um 1800: Eine neue Auffassung von Geschichte}

Allgemein kann man in der Zeit um 1800 eine weitere Ausdifferenzierung der Historienmalerei in verschiedene, nicht selten miteinander konkurrierende Ansätze und Wege beobachten. Dabei ging diese Vervielfältigung mit einem fundamentalen Wandel der Gattung einher, in dessen Folge von der frühneuzeitlichen Historie letztlich nur noch der rahmensetzende Anspruch fortbestand, an der Spitze der Gattungshierarchie zu stehen. Um diesem Wandel gerecht zu werden, gibt es in der Forschung seit längerem den an sich durchaus plausiblen Vorschlag, einen bestimmten, für das 19. Jahrhundert besonders charakteristischen Bereich terminologisch von der Historienmalerei im traditionellen Sinne abzugrenzen und als „Geschichtsmalerei“ zu bezeichnen. ${ }^{18}$ Dieser Vorschlag wird hier nur deshalb nicht aufgegriffen, weil das 19. Jahrhundert selbst in der Regel am Begriff „Historienmalerei“ festhielt und sich damit bewusst in die Tradition der älteren Malerei stellte. ${ }^{19}$ Vom Wandel um 1800 muss hier gleichwohl die Rede sein, denn er ist auch für ein Verständnis der Historiengemälde in der Göttinger Universitätskunstsammlung von grundlegender Bedeutung.

Entscheidend ist, dass sich in der zweiten Hälfte des 18. Jahrhunderts eine neue Auffassung von Geschichte durchsetzte, welche die historische Eingebundenheit aller Ereignisse in eine dynamische, zusammenhängende Entwicklung betonte. ${ }^{20}$ Reinhart Kosellecks These, dass historische Ereignisse in diesem Zusammenhang ihren Charakter als universal einsetzbare Lehrbeispiele verloren und Geschichte nun nicht mehr als „Magistra vitae“21 fungierte, bedarf für den Bereich der Bildenden Künste sicher einer gewissen Relativierung. Aber auch da, wo die Darstellung eines historischen Ereignisses nach 1800 vorbildhafte

17 Vgl. u. a. Radziewski 1983, S. 150-154; Gethmann-Siefert 1984, S. 263-280; MonschauSchmittmann 1993, S. 137-142; Scholl 2012b, S. 113-118.

18 Vgl. Hierzu insbesondere Brieger 1930, S. 2-4; Büttner 2003, S. 26-65; Fastert 2000, S. 17-41; Kohle 2001, S. 123-126.

19 Zudem werden im folgenden Abschnitt auch zwei Gemälde (vermutlich) profanhistorischen Inhalts vorgestellt, die nicht unter die Rubrik Geschichtsmalerei fallen: Kat. Nr. 1 und Kat. Nr. 4.

20 Dieser Wandel manifiestiert sich nicht zuletzt in der begriffsgeschichtlichen Durchsetzung des Kollektivsingulars „Geschichte“ selbst - vgl. Koselleck 1989, S. 38-65.

21 Ebd. 
Exempel visualisierte, tat sie dies auf eine neue und andere Weise, als es etwa bei den Götter- und Heroendarstellungen der frühen Neuzeit der Fall gewesen war. Historische Ereignisse erschienen jetzt eingewoben in das „Netz“ der Geschichte, in das man auch die eigene Gegenwart eingebunden sah. Sie ließen sich nicht mehr ohne weiteres isolieren und übertragen, sondern mussten auf ihre Zusammenhänge hin befragt werden. Es ist für das neue historische Denken charakteristisch, dass diese Zusammenhänge bis in die eigene Gegenwart hinein verfolgt wurden. So ist das 19. Jahrhundert die Zeit, in der Kunstkritiken bevorzugt als Kunstgeschichten verfasst wurden, welche nicht selten von der Antike bis zur Gegenwart reichen. ${ }^{22}$ Dass die ,Theorie jeder Kunst in ihren Werken und in dem Gang ihrer Entwicklung liege“, war eine weit verbreitete Überzeugung. ${ }^{23}$ Geschichte avancierte somit zum allgegenwärtigen Erklärungsmittel und - indem sie als erforschbare Voraussetzung der eigenen, als historisch bedingt erfahrenen Zeit sowie als Movens für die Zukunft gesehen wurde - zu einem sowohl Identifikation vermittelnden als auch Abgrenzungen ermöglichenden Sinngefüge.

Der solchermaßen die eigene Position mit einbeziehende Blick auf Geschichte führte zur Konstruktion von Traditionslinien, aber auch zu Diskussionen, was historisch relevant bzw. irrelevant sei und in welchen Ereignissen sich das Wirken von Geschichte in besonderer Weise verdichte. Hier wiederum konnte eine Malerei ansetzen, die Momente verbildlichte, denen man eine erhöhte historische Relevanz zuschrieb. Nicht als Darstellung zeitloser Exempel, wohl aber als Veranschaulichung folgenreicher und bewegender historischer Umschlagpunkte, erhielten Historienbilder als Geschichtsbilder erneut einen belehrenden Charakter. Und weil Geschichte zunehmend als wichtigste Triebkraft menschlichen Lebens angesehen wurde, behielt die ihr gewidmete Kunst ihre Spitzenposition in der Gattungshierarchie.

\section{Nazarenische Historienmalerei}

Was an Historienmalerei in diesem - hier nur sehr verknappt charakterisierten und in sich alles andere als homogenen - Umfeld historischen Denkens entwickelt wurde, erweist sich als vielfältig und nicht selten auch als spannungsvoll. Dass dabei das Konzept einer als Exempel für die Gegenwart wirkenden Geschichte nicht gänzlich irrelevant wurde, zeigt sich insbesondere an der Kunst der Nazarener, jener zunächst so erfolg- und folgenreichen Bewegung innerhalb der Romantik, welche die Kunst auf der Basis der christlichen Religion nach dem Vorbild des Mittelalters und der Frührenaissance neu zu begründen suchte. ${ }^{24}$ Franz

\footnotetext{
Vgl. Scholl 2012b, S. 38 f.

Schorn 1824, S. 1.

24 Zu den Nazarenern vgl. einführend Ausst.-Kat. Frankfurt a. M. 1977; Ausst.-Kat. Rom 1981; Ausst.-Kat. Frankfurt a. M. 2005; Grewe 2009; Ausst.-Kat. Mainz 2012.
} 
Pforrs Gemälde Der Einそug Rudolfs von Habsburg in Basel 1273 von 1808-10, ${ }^{25}$ eine Inkunabel nazarenischer Profanhistorienmalerei, bietet bereits an sich (mit Bildern im Bild) bemerkenswerte typologische Verflechtungen alttestamentlich-biblischer und mittelalterlich-profanhistorischer Geschichten. Darüber hinaus sollte es wiederum als vorbildhafte Szene für die Gegenwart figurieren, indem es Rudolf von Habsburg als Rollenmuster für ein neues, christlich fundiertes Königtum empfahl, das Napoleon Widerstand zu leisten vermochte. ${ }^{26}$ Historia ist hier durchaus „Magistra vitae“. Dabei wurde von den Nazarenern jedoch - ganz im Sinne des neuen historischen Bewusstseins - das kulturelle Umfeld mitgedacht und eine generelle Erneuerung mittelalterlicher Frömmigkeit angestrebt.

Als modern erwiesen sich die Nazarener, indem sie nicht nur die Malerei selbst, sondern auch deren Entstehungsbedingungen sowie die Art und Weise ihrer Wahrnehmung zu verändern suchten. Das Denken in historischen Zusammenhängen sollte es ermöglichen, den Fortgang der (Kunst-)Geschichte zu beeinflussen. In einer Zeit, die von einem zunehmend autonom werdenden Kunstbetrieb geprägt war, arbeiteten die Nazarener an einer erneuten funktionalen Einbindung von Kunst als Vermittlerin religiöser und nationaler Gehalte. ${ }^{27}$ Sie suchten nach Mäzenen für Kunst an öffentlichen Orten und eigneten sich künstlerische Techniken an, die dieser ortsgebundenen Kunst entsprechen sollten. Besonders wichtig ist hierbei die von Peter Cornelius angestoßene Erneuerung der Freskomalerei. Nach den Initialprojekten in Rom - der Ausmalung eines Raumes in der Casa Bartholdy ${ }^{28}$ sowie des Casino Massimo ${ }^{29}$ - entstand in Deutschland eine ganze Reihe anspruchsvoller Ausmalungsprogramme. An mythologischen und profanhistorischen Zyklen sind hier etwa die Freskierung von Glyptothek, Pinakothek und Hofgartenarkaden in München, sowie die Ausmalung des Gartensaals von Schloss Heltorf und der Vorhalle des Alten Museums in Berlin (letztere nach Entwürfen Karl Friedrich Schinkels) zu nennen, die von Cornelius und seinen Schülern realisiert wurden. ${ }^{30}$

\section{Kontroversen}

Dabei war diese Freskomalerei - wie die Kunst der Nazarener generell - in ihrer Zeit alles andere als unumstritten. Kontrovers wurden neben der Themenwahl insbesondere zwei Aspekte diskutiert: die für die Nazarener so charakteristische

25 Frankfurt a. M., Städelsches Kunstinstitut und Städtische Galerie, Dauerleihgabe des Historischen Museums.

26 Vgl. Grewe 2009, S. 46-52.

27 Vgl. Scholl 2007, S. 100-106.

28 Vgl. Geismeier 1967, S. 45-53; Ziemke 1977b, S. 49 f.; Büttner 1980/1999, Bd. 1, S. 76-97.

29 Vgl. Ausst.-Kat. Rom 1981, S. 288-347.

30 Vgl. hierzu u. a. Büttner, 1979a, S. 53-55; Droste 1980; Büttner 1980/1999, Bd. 1, S. 125-223, Bd. 2, S. 3-43, 61-152; Wagner 1989, S. 41-64; Fastert 2000, S. 118-148; Trempler 2001, S. 21-28; Baumgärtel, B. 2011b, S. 122-135. 
Allegorisierung historischer Darstellungen sowie die generelle Eignung des Mediums Fresko für historisch bewegende Bilder. ${ }^{31}$ Für die Nazarener im Umkreis von Cornelius stand beides in engem Zusammenhang. Allerdings gab es schon bei den Fresken in den Münchner Hofgartenarkaden, einem der frühesten Projekte öffentlicher Freskomalerei überhaupt, abweichende Vorgehensweisen: Die mit der Ausmalung betrauten Schüler von Cornelius bemühten sich um historische Genauigkeit, wie sie von Cornelius selbst gerade nicht angestrebt wurde. ${ }^{32}$ Ebenso lassen sich gerade ab der Mitte des 19. Jahrhunderts immer mehr Versuche nachweisen, öffentliche Kunst mit anderen Maltechniken als der Freskomalerei zu realisieren. Hier sind etwa die von Julius Schnorr von Carolsfeld in enkaustischer Technik ausgestatteten Kaisersäle in der Münchner Residenz ${ }^{33}$ zu nennen, vor allem aber die Ausmalung des Treppenhauses im Neuen Museum in Berlin durch Cornelius' Schüler Wilhelm von Kaulbach. Dieser steigerte die Kompositionsmittel seines Lehrers mit einer durch die Technik der Stereochromie ermöglichten, an der venezianischen Kunst orientierten Farbigkeit, ohne auf allegorische Elemente zu verzichten. ${ }^{34}$ Sein im zweiten Weltkrieg zerstörter Zyklus mit den sechs Hauptbildern Turmbau zu Babel, Homer und die Griechen, Die Zerstörung Jerusalems, Die Hunnenschlacht, Kreusfabrer und Das Zeitalter der Reformation bedeutete einen Höhepunkt der Geschichtsmalerei mit ihrem Interesse an historischen Blütezeiten und Katastrophen. Von Kaulbach sind auch vielzitierte Aussprüche überliefert, die man geradezu als Credo der Geschichtsmalerei verstehen kann: „Geschichte müssen wir malen, Geschichte ist die Religion unserer Zeit, Geschichte allein ist zeitgemäß“.35

Während im Umkreis von Cornelius vor allem die öffentlichkeitswirksame, wandgebundene Freskomalerei gepflegt wurde, kultivierten die Vertreter der

31 Vgl. hierzu Scholl 2012b, S. 107-112, 203-211.

32 Vgl. Büttner 1990, S. 89.

33 Vgl. hierzu als rezeptionsgeschichtliches Zeugnis: Marggraff 1840, S. 225 f: „Man wird jetzt aufhören, unsern Malern den Vorwurf zu machen, daß sie bei der Oel- und Freskomalerei stehen blieben, von deren Vergänglichkeit und künstlerischen Unzulänglichkeit sie sich doch durch die tägliche Erfahrung überzeugen könnten. Man wird jetzt namentlich aufhören, diesen Vorwurf gegen die Meister der neudeutschen Malerschule zu wiederholen, welche, von dem königlichen Beschützer der Kunst dazu berufen, die Decken und Wände bedeutsamer Bauwerke mit geschichtlichen Darstellungen zu schmücken, aus Mangel an einer andern guten Technik, sich ausschließlich an die Freskomalerei hielten, wiewohl dieselbe nicht für alle Zwecke und Gegenstände architektonischer Malerei völlig ausreichte; während das große Publikum, durch das Ueberhandnehmen des Oelbilderwesens verwöhnt, nur ihre Mängel, nicht aber zugleich auch ihre unerreichbaren Vorzüge anerkennen wollte. Jener Vorwurf wird aber seine Wirkung jetzt um so mehr verfehlen, da wir gerade von einem der Mitbegründer der neudeutschen Malerschule, und in Folge seiner Verwendung, jene neue Malweise in Ausübung gebracht sehen, die fast alle Vorzüge der Fresko- und Oelmalerei in sich vereinigt, ohne die Beschränktheit der einen, hinsichtlich des Umfangs ihrer Farbenscala und in Betreff des Gebrauchs der Lasuren, noch an der nachdunkelnden Eigenschaft und Vergänglichkeit der andern theilzunehmen."

34 Vgl. hierzu u. a. Wagner 1989, S. 126-163; Menke-Schwinghammer 1994.

35 Zitiert nach Teichlein 1876, S. 264. 
Düsseldorfer Malerschule unter dem Direktorat Wilhelm von Schadows die Ölmalerei. Hier entwickelte sich jene moderne Form des sentimentalischen Bildes, von der - und von deren Kritik - bereits die Rede war. In Düsseldorf kam es in der Zeit des Vormärz aber auch zur Ausprägung einer bewegenden Historienmalerei, welche sich gerade solchen historischen Konflikten widmete, die für die Gegenwart ein hohes Dynamisierungspotential aufwiesen. Dabei ist insbesondere Karl Friedrich Lessing (1808-1880) mit seinen Bildern zum Wirken von Jan Hus und den Hussiten zu nennen, die vor dem Hintergrund der konfessionellen Auseinandersetzungen im preußisch regierten Rheinland großes Aufsehen erregten. ${ }^{36}$ Junghegelianische Kritiker wie Arnold Ruge und Friedrich Theodor Vischer erhofften sich von derartigen Darstellungen geradezu revolutionäre Impulse. ${ }^{37}$

Furore machte in dieser Zeit auch die Ausstellung der beiden sogenannten „Belgischen Bilder“, die 1842 bis 1845 in mehreren deutschen Städten zu sehen war. Louis Gallaits Abdankung Karls $V$. und Edouard de Bièfves Der Kompromiß des niederländischen Adels $1566^{38}$ zogen mit ihrer Detailgenauigkeit und ihrer intensiven Farbigkeit ein großes Publikum an und sorgten zugleich für Kontroversen in der zeitgenössischen Kunstkritik. ${ }^{39}$ Ein Befürworter wie Jacob Burckhardt sah hierin historisch denkend - einen unmittelbaren Beleg für den Zusammenhang zwischen Kunst und politischer Situation: Die Bilder schienen zu vermitteln, dass das politisch unabhängig gewordene Belgien eine kraftvolle und gegenwartsbezogene Historienmalerei schaffen könne. 40 Dagegen stießen die „Belgischen Bilder“ bei Befürwortern der Nazarenischen Kunst und auch der Cornelius-Schule auf scharfe Ablehnung. ${ }^{41} \mathrm{Um}$ welche Themen gestritten wurde, macht eine ironische Bemerkung von Ludwig Igelsheimer deutlich, der beschreibt, wie ein Münchner Cornelius-Schüler ein Thema wie die Abdankung Kaiser Karls V. gemalt hätte:

\begin{abstract}
„Man hätte in München bei dem vorliegenden Sujet es gewiß nicht unterlassen, große historische Anschauungen einzuweben, und hiezu die Allegorie in Dienst zu nehmen. Man hätte etwa die Tiara des Papstes und das Schwerdt des Kaisers irgendwo angebracht. Man hätte zwei Engel zu den Häupten des Kaisers postirt; den einen die Monstranz, den andern die Bibel tragend. Ein Geistreicherer hätte auch wohl zwei Fenster nach Osten und Westen so anzubringen gewußt, daß man die untergehende Sonne erblickt hätte.“42
\end{abstract}

\footnotetext{
36 Vgl. u. a. Jenderko-Sichelschmidt 1973, S. 28-119; Mai 1979, S. 27; Gagel 1979, S. 68 f.; Leuschner 1979, S. 90-92; Jenderko-Sichelschmidt 1979, S. 101 f.; Leuschner 1982, Bd. 1, S. 158-193; Grossmann 1994, S. 185-187; Sitt 2000a, S. 16 f.; Sitt 2000b; Scholl 2012b, S. 118-129.

37 Vgl. Scholl 2012b, S. 123 f.

38 Beide in Brüssel, Musées des Beaux-Arts.

39 Vgl. Dahm 1953, S. 57-60; Schoch 1979, S. 171-186; Busch/Beyrodt 1982, S. 184-207; Koschnick 1985, S. 121-135; Schoch 1997, S. 161-179; Gaehtgens/Fleckner 1996, S. 58-60; Fastert 2000, S. 312-319; Scholl 2012b, S. 154-162.

40 Burckhardt 1843, S. 15.

41 Förster 1842/43, 1843, S. 110-119.

42 Igelsheimer 1844, S. 29.
} 
Umgekehrt beschreibt der Münchner Cornelius-Apologet Rudolf Marggraff am Beispiel der Zerstörung Sodoms von Bonaventura Genelli die Bildauffassung derjenigen Künstler, welche die „Belgischen Bilder“ befürworteten:

„Unsere modernen, der materialistischen Richtung verfallenen Künstler würden diesen Gegenstand allerdings ähnlich wie B. Gozzoli fassen als eine effectreiche Feuersbrunst, aber ohne die sinnige Beigabe der Engel wie überhaupt ohne die naive, dichterische Unbefangenheit des alten Malers. Auf ihre Darstellung würden wir, wenn wir uns nicht irren, anwenden dürfen, was Lessing von dem durch Caylus aus der Ilias entlehnten Gemälde der Pest sagt: ,Der größte Reichthum dieses Gemäldes ist Armuth des Dichters!'“433

\section{Gemalte „Malheurs“}

Im Zuge solcher Entwicklungen verlor die nazarenische Historienmalerei zunehmend an Boden. In München, wo bis zu seinem Weggang nach Berlin im Jahr 1841 Peter Cornelius mit seiner idealistischen Freskomalerei tonangebend gewesen war, entstand mit Carl Theodor von Pilotys 1855 vollendetem Gemälde Seni vor der Leiche $W$ allensteins ein Schlüsselwerk der Geschichtsmalerei, das auf jegliche Allegorisierung verzichtete und seinen Gegenstand mit gesteigerter Theatralik, gleichzeitig aber auch mit geradezu stilllebenhafter Detailgenauigkeit und Farbenpracht umsetzte. ${ }^{44}$ Piloty ist hier auch deshalb von Bedeutung, weil die beiden Ölskizzen Kat. Nr. 2 und 3 von Friedrich Spangenberg in der Göttinger Universitätskunstsammlung in seiner unmittelbaren Nachfolge entstanden sind. Dabei galt das Hauptinteresse Pilotys nach wie vor geschichtlichen Umbruchssituationen, insofern sich diese in der Begegnung herausgehobener Protagonisten dramatisch und bildwürdig verdichteten. ${ }^{45}$ Hierauf bezieht sich eine Anekdote, der zufolge Piloty von Moritz von Schwind gefragt worden sein soll: „Herr Kollega, was malen S’ denn heuer für ein Malheur?“46

Generell umfasste die Historienmalerei auch in der zweiten Hälfte des 19. Jahrhunderts verschiedene und nicht selten gegensätzliche Konzepte. Welche Spannbreite dabei erreicht werden konnte, zeigen die beiden 1854 von der Verbindung für historische Kunst in Auftrag gegebenen Gemälde, die in ihrer Ausführung völlig unterschiedlich geraten sind: Moritz von Schwinds Kaiser Rudolfs Ritt zum Grabe ${ }^{47}$ steht in seiner ruhigen und abstrahierenden, einen exemplarischen Vorgang verbildlichenden Gestalt noch ganz in der Tradition nazarenischer Historienkunst, wohingegen sich Adolph Menzels Zusammenkunft Friedrichs II. mit

43 Marggraff 1839, S. 194.

44 München, Neue Pinakothek. Zu diesem Gemälde und zu seiner Wirkung vgl. Härtl-Kasulke 1991, S. 137-146; Ausst.-Kat. München 2003, S. 163-170.

45 Büttner 2003, S. 51.

46 Zitiert nach Gurlitt, C. 1899, S. 362.

47 Kiel, Kunsthalle. 
Kaiser Joseph II. zu Neißet8 als eine vom Bildverständnis her realistische Darstellung der Begegnung zweier Monarchen präsentiert. ${ }^{49}$

Während in diesen Jahrzehnten die Vorrangstellung der Historienmalerei vorerst weitgehend unangetastet blieb und eigene Programme zur Förderung dieser Gattung initiiert wurden, wuchs bis zum Ende des 19. Jahrhunderts die Kritik an den idealistischen Prämissen, welche die Gattungshierarchie bis dahin getragen hatten. Gleichzeitig ging das Interesse an einer Darstellung bewegender historischer Ereignisse zurück. Rückblickend äußert sich 1890 der Kunstkritiker Cornelius Gurlitt über die erregten Auseinandersetzungen des Vormärz und der Jahrhundertmitte:

\begin{abstract}
„Dann kamen die Historiker und Culturpolitiker mit Bildern aus der uns gleichgültigsten Geschichte: ,König Reccared der Westgothe wird gezwungen, aus der arianischen Kirche auszutreten', ,Fürst Sepiha verteidigt die Freiheit gegen König Johann Sobiesky im polnischen Reichstag'. Und wir erhitzten uns für den Arianismus gegen Rom und für das liberum veto gegen die Königsgewalt und fanden uns, sowie den Maler, der dies Gezänk in die Welt gesetzt hatte, sehr bedeutend, namentlich sehr modern. Die Kunst beginnt in das Leben der Nationen einzugreifen! hieß es damals. Weil Lessing Hußbilder malte, glaubte man eine protestantische Kunst zu haben. Man verwechselte auch hier den Inhalt mit dem Wesen des Bildes: Wenn ein Maler die religiösen Kämpfe der Derwische oder die Kalifen zu malen liebt, macht er damit noch keine mohamedanische Kunst!“50
\end{abstract}

Mit der Kunst der Moderne, zu deren frühen Befürwortern Gurlitt gehörte, verlor das traditionelle Gattungsdenken seine konzeptionelle Grundlage. Was die Historienmalerei bis dahin aufgewertet hatte, wurde nun nicht mehr als essenzielle Qualität von Kunst angesehen. Von diesem fundamentalen Wandel im Kunstverständnis profitierten vor allem niedere Gattungen wie die Landschaftsmalerei, die im späten 19. Jahrhundert eine enorme Aufwertung erfuhren. Hiervon wird im Kapitel über Landschaft im vorliegenden Band noch die Rede sein.

\title{
Mythologie im ausgehenden 19. Jahrhundert
}

Selbst wenn man sich dafür entscheidet, den Terminus „Geschichtsmalerei“ anzuwenden, so deckt er doch nicht alle Felder ab, die traditionell unter dem Oberbegriff Historienmalerei behandelt werden. Vielmehr bleibt er an eine bestimmte Auffassung von Geschichte gebunden, die sich in einer spezifischen Faszination für zugespitzte historische Umbruchssituationen manifestiert. Gerade im ausgehenden 19. Jahrhundert gibt es aber auch Bereiche der Historienmalerei,

48 Berlin, Nationalgalerie.

49 Zu diesem Auftrag und zur Rezeption der beiden Bilder vgl. Schmidt, H.-W. 1985, S. 41-61; Busch 1985, S. 317 f.; Busch 1990, S. 307-311; Busch 1991, S. 175-183; Gaehtgens/Fleckner 1996, S. 343-349; Büttner 2003, S. 47-50; Scholl 2012b, S. 310-313, 403 f.

50 Gurlitt, C. 1890 , S. 30. 
in denen ganz andere Themenfelder verbildlicht wurden. Hierzu gehört insbesondere die Darstellung von Themen aus dem Bereich der Mythologie, auf die hier eingegangen werden muss, weil sich mit Friedrich August von Kaulbachs Gemälde Die Erziehung des Bacchus (Kat. Nr. 4) ein entsprechendes Kunstwerk in der Göttinger Universitätskunstsammlung befindet.

Nach 1800 blieben Darstellungen aus der griechischen Mythologie für längere Zeit an den Stil und die Kompositionsweisen des Klassizismus gebunden. Erst in der zweiten Jahrhunderthälfte trat hier eine grundlegende Änderung ein. So orientierte sich etwa ein Künstler wie Anselm Feuerbach an der venezianischen Malerei, so dass in diesem Zuge auch frühneuzeitliche, durch den Klassizismus zwischenzeitlich verdrängte Umgangsweisen mit antiken Themen neu erschlossen wurden. ${ }^{51}$ Noch radikaler fiel die bildkünstlerische Neufassung antiker Motive bei Arnold Böcklin aus, der jenseits klassischer Formen mit neuen stilistischen und koloristischen Mitteln das Sinnliche und Dionysische der Antike betonte. ${ }^{52}$ Nach anfänglicher Skepsis des Publikums wurden seine Werke im späten 19. Jahrhundert immer beliebter. Kaulbachs Göttinger Ölskizze (Kat. Nr. 4) steht in ihrer Farbigkeit durchaus in gewisser Nähe zu Böcklin.

Böcklins mythologische Bilder wurden als Produkte einer überschäumenden Phantasie gesehen und als Ausdruck einer vitalen Künstlerpersönlichkeit gerechtfertigt. ${ }^{53}$ Auf diese Weise fanden sie - anders als die Geschichtsbilder der Jahrhundertmitte - auch bei einigen Vertretern der Moderne um 1900 noch Anerkennung und waren zunächst einmal nicht von der fundamentalen Abwertung betroffen, die etwa Maler wie Peter Cornelius, Wilhelm von Kaulbach oder Carl Theodor von Piloty in dieser Zeit traf. ${ }^{44}$ Erst Julius Meier-Graefe sollte in seiner Streitschrift Der Fall Böcklin von 1905 eine formalästhetisch begründete Generalkritik an Böcklin entwickeln, die allerdings in ihrer Zeit noch immer heftige Kontroversen auslöste. ${ }^{55}$ Damit aber ist man bereits im 20. Jahrhundert und bei einer Kunstauffassung angelangt, die dem 19. Jahrhundert zwar vieles verdankt, sich gleichzeitig aber auf radikale Weise von dessen Prämissen und Lösungsansätzen zu distanzieren suchte - Ansätze, auf deren Grundlage die

51 Zur Bedeutung der venezianischen Malerei für Feuerbach vgl. u. a. Ecker 1991, S. 40-44.

52 Vgl. hierzu Linnebach 1991. In gewisser Hinsicht handelt es sich um eine bildkünstlerische Parallele zu Friedrich Nietzsches berühmtem, 1872 publizierten Aufsatz Die Geburt der Tragödie aus dem Geiste der Musik.

53 Vgl. etwa Lichtwark 1883, S. 221: „Oft aber genügen dem Künstler sogar die abenteuerlichen Gebilde seiner Phantasie nicht mehr, ja, überhaupt kein Mittel seiner Kunst um Alles auszudrücken, was er empfindet. Dann ruft er durch Association eine andre Kunst stimmungserregend zu Hülfe. Der wiehernde Pan, die singenden Nymphen auf dem Gefilde der Seligen, der blasende Triton wie der klagende Hirtenknabe sollen in der Seele des Beschauers musikalische Fluthen erregen. Böcklin bedient sich dieses Auswegs zu oft, daß er lediglich als ein zufälliges Hereinspielen aufgefaßt werden dürfte.“

54 Vgl. Scholl 2012b, S. 483-519.

55 Meier-Graefe 1905, vgl. bereits Meier-Graefe 1904, Bd. 2, S. 452; vgl. hierzu u. a. Moffett 1973, S. 52-60; Honisch 1977, S. 14-23; Brummer 2000, S. 29-41; Jensen 1994, S. 257-263; Scholl 2012b, S. 541-559. 
Historienmalerei zwischen 1800 und 1880/90 noch einmal eine ganz eigenständige Bedeutung erlangt hatte. 
Kat. Nr. 1

Friedrich Becker (1808-unbekannt)

\section{Drei Damen beim Bade überrascht}

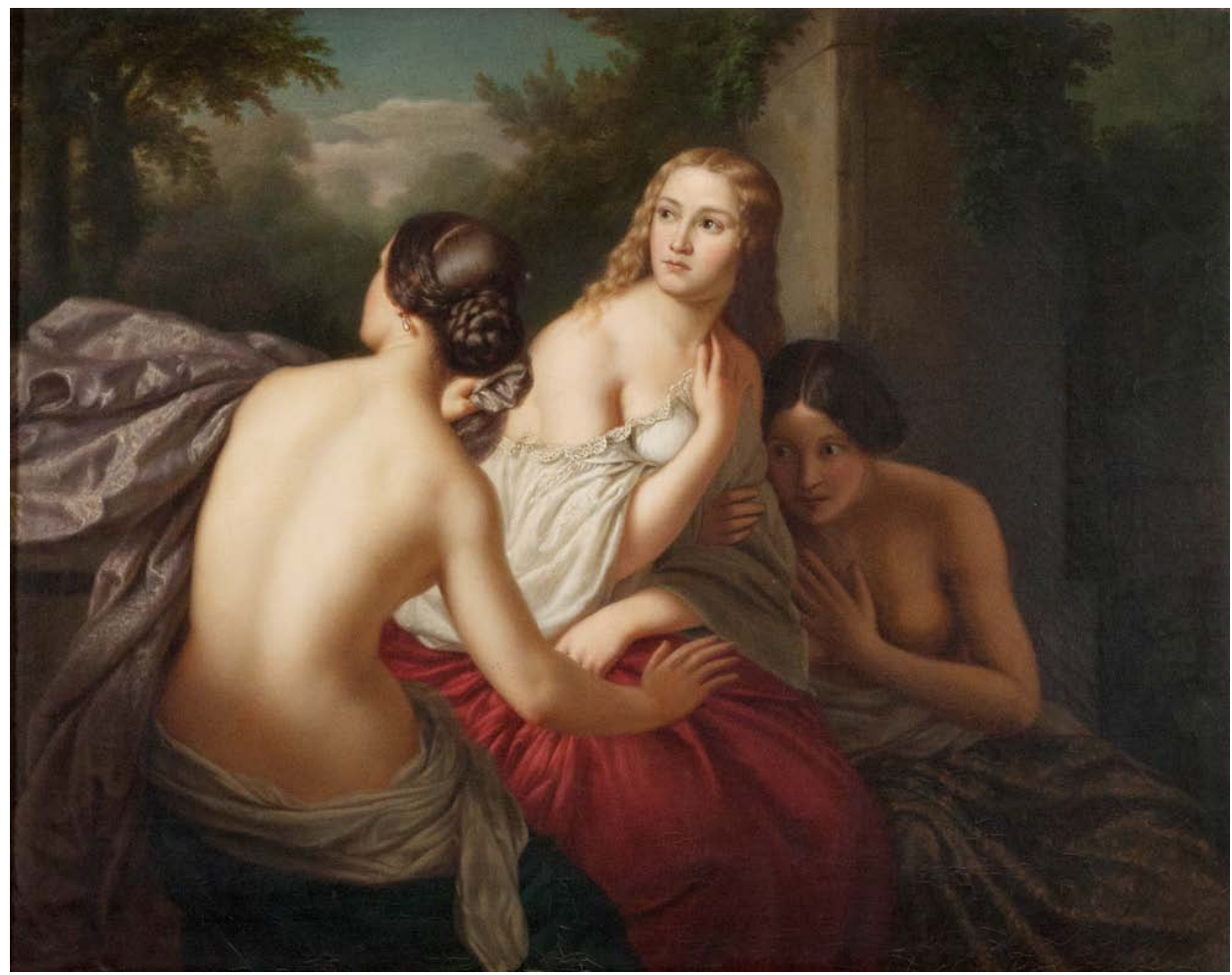

Öl auf Leinwand, 79 x $100 \mathrm{~cm}$, signiert, datiert und lokalisiert, Leihgabe Prof. Dr. Walter Paatz und Dr. Elisabeth Paatz, geb. Valentiner, Heidelberg

Das 1848 in Düsseldorf entstandene Gemälde Drei Damen beim Bade überrascht gehört zu den Werken der Düsseldorfer Akademie, nachdem diese 1826 einen Wechsel in der Leitung erfahren hatte. Wilhelm von Schadow hatte Peter von Cornelius als Direktor abgelöst und gab der Akademie eine neue Richtung. ${ }^{1}$ Unter anderem leitete Schadow eine Reform der Arbeitsweise ein - weg von Karton und

1 Gagel 1979, S. 69. 
Wandgemälde hin zur Ölmalerei mit Staffelei. ${ }^{2}$ Zusätzlich kam es zu einer Verschiebung der zu behandelnden Sujets. Cornelius hatte besonders die Umsetzung religiöser und historischer Themen in Freskotechnik gefördert. Unter Wilhelm von Schadow hingegen entstand der sentimentalische Stil, der für die Düsseldorfer Malerschule prägend werden sollte. ${ }^{3}$

Auch das Studium in der Natur erhielt durch ihn wieder einen maßgeblichen Stellenwert innerhalb der Akademie. ${ }^{4}$ So bildete die Landschaftsmalerei neben den meist literarisch fundierten Bildthemen aus Bibel, Historie und Weltliteratur eines der Haupttätigkeitsfelder der Akademieschüler. ${ }^{5}$ Die Mischung von Historie und Genre vor dem Hintergrund einer Landschaft wurde charakteristisch für die Düsseldorfer Akademie.

$\mathrm{Zu}$ den Absolventen dieser Akademie zählt unter anderem der Genre- und Historienmaler Friedrich Becker aus Paderborn. Er war von 1829 bis 1843 Schüler an der Düsseldorfer Akademie, hatte vor der Ausbildung aber als Graveur und Steinschneider gearbeitet. ${ }^{6}$ Becker war zudem Gründungsmitglied des Künstlervereins Malkasten, der sich im Zuge der Revolution von 1848 konstituierte und sich für den Künstleraustausch einsetzte. ${ }^{7}$ Beckers Cuvre umfasst Genrebilder sowie literarische, mythologische und biblische Historien. In den Jahren 1836, 1838, 1844 und 1848 stellte er Werke auf der Akademischen Kunstausstellung in Berlin aus. ${ }^{8}$ Todesjahr und -ort des Künstlers sind leider unbekannt.

1844 präsentierte Becker im Düsseldorfer Malkasten ein Werk mit dem Titel Mädchen vor dem Bade. ${ }^{9}$ Dem Titel nach scheint dieses Werk im Zusammenhang mit dem Göttinger Gemälde zu stehen. Da das Werk leider verschollen ist und sich keine Abbildung erhalten hat, bleibt die Frage, ob es sich möglicherweise um eine frühere Version unseres Bildes handelt, das Friedrich Becker später verändert hat, offen.

Im Zentrum des Göttinger Gemäldes sitzen drei junge Frauen in unterschiedlichen Posen. Der Hintergrund lässt auf eine bewaldete Szenerie schließen. Diese wird an der rechten Bildseite von einem bewachsenen Architekturelement - einer Art Pfeiler - begrenzt. Dahinter liegt, rechts im Dunkeln verborgen, ein wasserspeiender Löwenkopf.

Die linke der drei jungen Frauen wendet dem Betrachter den entblößten Rücken zu; um ihre Hüften schlingen sich zwei Stoffbahnen. Sowohl Oberkörper als auch das Gesicht sind nach links gewendet und geben den Blick auf ihr kunstvoll frisiertes Haar und einen Perlenohrring frei. Mit der linken Hand greift

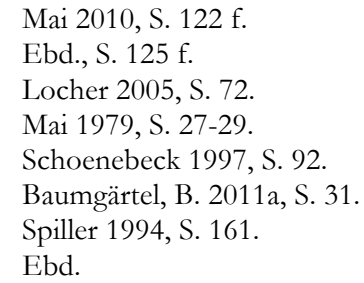


sie, womöglich um sich und die beiden anderen $\mathrm{zu}$ bedecken, nach einem schweren Stoff, der sich durch ihren plötzlichen Zug nach rechts stark aufbauscht und damit den größten Teil des Hintergrundes verdeckt. Mit ihrem rechten Arm schafft sie eine Verbindung zur mittleren Frau, welche leicht nach rechts zur dritten Frau gewandt ist, ihren Kopf jedoch ebenfalls zum Geschehen am linken Bildrand dreht. Ihr blondes Haar fällt in offenen Wellen hinter ihrem Rücken herab. Die erhobene rechte Hand hindert ein weißes, nur sehr locker ihren Oberkörper bedeckendes Gewand daran, hinabzugleiten, wohingegen ihre Linke das die Oberschenkel bedeckende rote Gewand rafft. Die überkreuzten Arme bilden dabei eine schützende Geste. An ihrem linken Arm hält sich die dritte Frau fest und duckt sich dabei in den Schatten. Die linke Hand hat sie an die nackte Brust erhoben. Das braune, zurückgebundene Haar lässt den Blick auf ihr erschrockenes Gesicht mit weit aufgerissenen Augen frei.

Durch die Gestik und Mimik der Damen erhält der Betrachter den Eindruck, dass diese durch ein unerwartetes Geschehen außerhalb des Bildes überrascht werden; wodurch oder von wem, bleibt jedoch ungewiss. Ihre leicht bekleideten Körper lassen auf ein Entkleiden bzw. ein Wiederankleiden schließen, womöglich im Kontext eines Bades im Freien - wie der später vergebene Titel Drei Damen beim Bade überrascht $t^{10}$ nahelegt.

Sowohl das Motiv des Überraschtwerdens beim Bade als auch jenes dreier unbekleideter Damen ist in der Malerei bekannt. Sucht man nach thematischen Vergleichswerken, so wird man sowohl im Bereich der Mythologie als auch der Bibel schnell fündig - unter anderem etwa beim Thema der drei Grazien oder der Bathseba beim Bade - zwei Motive, die im Laufe der Epochen immer wieder auf unterschiedliche Weise aufgegriffen worden sind - z.B. von Rubens, Van Dyck, Canova, Begas und Cézanne.

Und doch ergibt sich beim direkten Vergleich der Motive ein Problem: Die einzelnen Elemente passen nicht zueinander. In der antiken Mythologie beziehen sich die drei Grazien auf die griechischen Göttinnen der Anmut, die Chariten, welche besonders eng mit Aphrodite, der Göttin der Liebe verknüpft wurden. Ihr Wortstamm „charis“ geht auf das griechische Wort „chara“ zurück, welches im weitesten Sinne mit „Freude“ übersetzt werden kann. ${ }^{11}$ Doch warum sind die drei Frauen in Beckers Gemälde überrascht, während die Grazien eigentlich als drei heitere Geschöpfe dargestellt werden? Und warum sind sie im Gemälde bekleidet, wenn Grazien seit der römischen Antike meist nackt dargestellt werden? Eine mögliche Kombination aus mehreren Themen ist unwahrscheinlich, weil dabei die eindeutige Aussage für den Betrachter verloren gehen würde. Historien mussten

10 In der Leihgabevereinbarung von 1968 trägt das Gemälde zunächst den Titel Drei Jungfrauen und wird dem Genremaler Jakob Becker zugeordnet. Aufgrund der erst 2011 durch Dr. Justus Lange, Kassel (MHK) entdeckten Signatur „F Becker Ddorf 1848“ mittig links konnte es dem Historienmaler Friedrich Becker zugeschrieben werden. An dieser Stelle sei Herrn Lange ausdrücklich gedankt.

11 Vgl. Mertens 1994, S. 7-9. 
klar verständlich präsentiert werden, um die Interpretation und die Vorbildfunktion des Dargestellten eindeutig zu machen.

Bei genauerer Betrachtung der drei Damen entsteht der Eindruck, dass die mittlere durch ihre Stellung und Haltung von den beiden anderen abgehoben ist. Sie bildet eine Art Ruhepol und scheint zugleich das Zentrum des vorangegangenen Geschehens zu sein. Durch diese hierarchische Ordnung lassen sich die drei Frauenfiguren möglicherweise als eine Dame mit zwei Dienerinnen deuten. Sucht man nach einem historischen Stoff, der das Thema einer Badenden mit ihren zwei Dienerinnen - die zumal selbst reich gekleidet sind, wie der Perlenohrring der Linken zeigt - behandelt, wird man in der Bibel fündig. Im 2. Buch Samuel, Kapitel 11, wird die Geschichte von der schönen Bathseba und König David geschildert. ${ }^{12}$ Bathseba ist die Mutter des späteren Königs Salomon und die Frau Urijas des Hethiters, der dem Heer König Davids angehört. Während sich jener im Feldlager befindet, beobachtet David bei einem Spaziergang auf dem Dach seines Palastes in Jerusalem dessen Frau beim Bad. Aufgrund ihrer Schönheit lässt er sie zu sich holen. Dieser Augenblick, der in den Versen 1 bis 4 beschrieben wird, könnte im Bildmoment von Beckers Gemälde verarbeitet sein. Bei der Betrachtung verschiedener Bathsebadarstellungen wie der des Cornelisz van Haarlem $^{13}$ zeigen sich jedoch erneut Unstimmigkeiten. Es gibt zwar Momente, die übereinstimmen, wie die Betonung des Vordergrundes, die Einheit von drei Frauen und deren Anordnung, aber andere Dinge wiederum passen nicht. So stellt sich die Frage, warum Beckers Damen erschrocken sind. Dass David sie beobachtet, erfährt Bathseba laut biblischem Bericht erst nach ihrem Bad. Es fällt also schwer, die Bibelgeschichte auf das Gemälde Beckers zu übertragen.

Insgesamt bleibt die Thematik des Bildes offen. Ob möglicherweise gerade dies von Friedrich Becker intendiert war, bleibt vorerst eine ungelöste Frage, zumal man nur wenig über diesen Künstler weiß.

Ifee Tack

12 Für die Anregung danke ich herzlich Dr. Kerstin Schwedes.

13 Amsterdam, Rijksmuseum. 
Kat. Nr. 2

Friedrich Spangenberg (1843-1874)

\section{Bernhard von Clairvaux predigt den Kreuzzug}

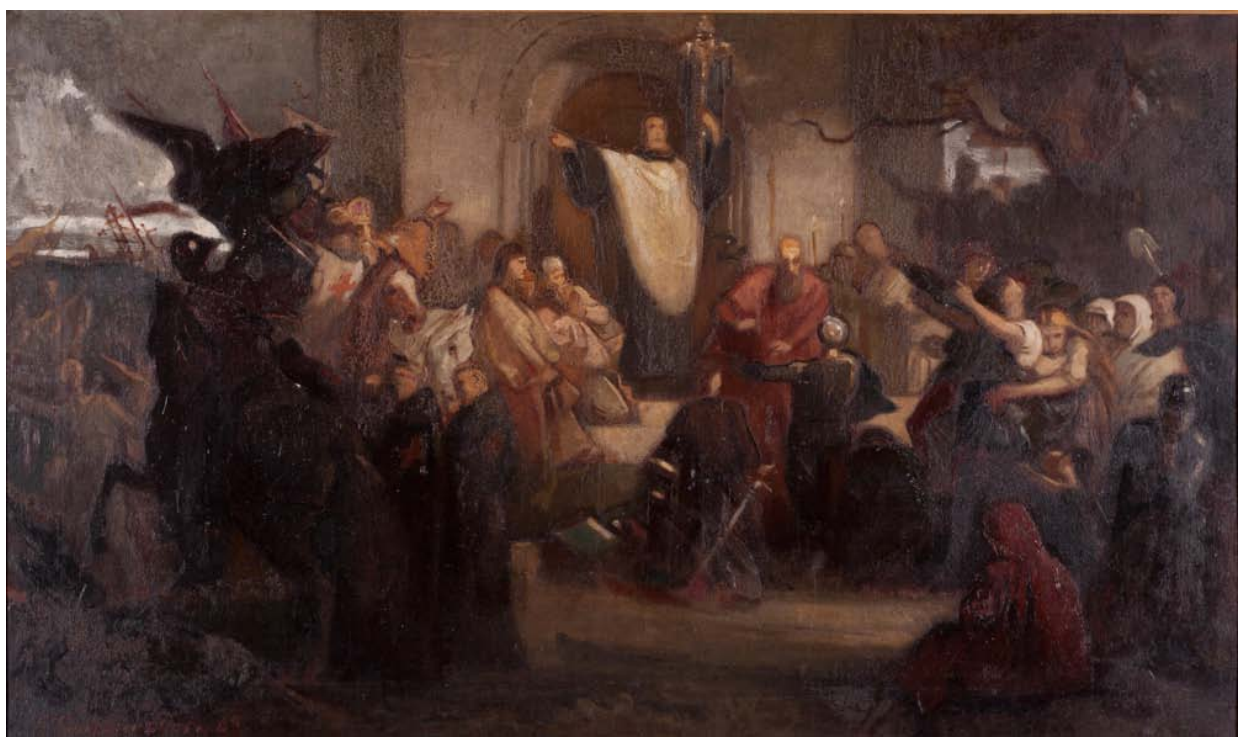

Öl auf Leinwand, 68 x 114 cm, signiert und datiert, Schenkung der Erben des Künstlers, Inv. Nr. GG 181

Das Gemälde Bernhard von Clairvaux predigt den Kren₹zug ist eine von insgesamt zwei Ölskizzen Friedrich Spangenbergs im Bestand der Göttinger Universitätskunstsammlung. ${ }^{1}$ Beide Skizzen des gebürtigen Göttingers sind nicht nur als Zwischenergebnisse eines auf vollendete Gemälde abzielenden Werkprozesses von Interesse. Vielmehr handelt es sich um bemerkenswerte Zeugnisse eines im 19. Jahrhundert neu entwickelten Systems der Kunstförderung, welches in Ergänzung individuellen Mäzenatentums und als Korrektiv zu den eigenen Regeln des Kunstmarkts darauf angelegt war, ausschließlich eine bestimmte Gattung der Malerei zu fördern:

1 Bereits 1867 wird ein „Entwurf zu einer Kreuzpredigt“ in den Akten der Weimarer Kunstschule genannt. Vgl. Weimar, Thüringisches Hauptstaatsarchiv [193], S. 7. Die Skizze wurde 1869 bei der Verbindung für historische Kunst eingereicht, wie aus den Versammlungsprotokollen der Verbindung hervorgeht. Vgl. Ausst.-Kat. Kopenhagen 1981, S. 235. 
Profanhistorie - Geschichtsmalerei - Mythologie

die Historienmalerei. Wie im folgenden gezeigt werden soll, entstanden Spangenbergs Ölskizzen für die Verbindung für historische Kunst, aus einem strategischen Zusammenschluss von Kunst- und Museumsvereinen sowie Privatpersonen. ${ }^{2}$

\section{Biographie und Werk}

Die einschlägigen Künsterlexika wissen nur wenig über den Maler zu berichten, der die Ölskizze Bernhard von Clairvaux predigt den Kreuzzug geschaffen hat. ${ }^{3}$ Friedrich Spangenberg jun. wurde am 3. Dezember 1843 in Göttingen als Sohn Johann Friedrich Spangenbergs geboren. ${ }^{4}$ Bei diesem erhielt er auch seine erste künstlerische Ausbildung. Sein Vater war Porzellanmaler, der zudem Bildnisse und Landschaften schuf. Die in Göttingen durchaus verbreitete Porzellanmalerei bildete die wirtschaftliche Basis der Familie, die es damit zu einem gewissen Wohlstand brachte. Spangenberg senior konnte sich durch seine Geschäfte immerhin zwei Häuser leisten: eines in der Weender Straße 56 und ein weiteres in der Kurzen Straße 5. Zudem beschäftigte er sich mit der Porträtphotographie. Sein Fotogeschäft wurde in seiner Nachfolge von den Brüdern Noelle weitergeführt. ${ }^{5}$ Friedrich Spangenberg jun. hatte einen Bruder, der als Kaufmann in den USA tätig war.

Bereits der Vater war nach seiner Ausbildung nach München gereist, um dort fünf Monate bei einem Porzellanmaler zu arbeiten, bevor er nach Göttingen zurückkehrte, um sich dann bei dem Künstler und Kunsthistoriker Carl Oesterley weiterzubilden. ${ }^{6}$ Friedrich Spangenberg jun. betrat somit kein völliges Neuland, als er sich am 25. Oktober 1859 im Alter von 16 Jahren an der Akademie der Bildenden Künste in München unter der Matrikel 1603 für die Antikenklasse einschrieb. ${ }^{7}$

München war für einen Maler in der Ausbildung, speziell für einen Maler, der die Historienmalerei studieren wollte, ein sinnvolles Ziel, lehrte hier doch seit 1856 neben dem ebenfalls hoch angesehenen Direktor Wilhelm von Kaulbach einer der bekanntesten deutschen Historienmaler des 19. Jahrhunderts, Carl Theodor von Piloty. Dieser hatte durch Werke wie Die Gründung der katholischen Liga durch Herzog Maximilian I. von Bayern (1854) und Seni vor der Leiche Wallensteins (1855) allgemeine Anerkennung und Bewunderung erlangt. ${ }^{8}$

2 Eine umfassende Untersuchung zu dieser Gesellschaft liefert Hans-Werner Schmidt. Vgl. Schmidt, H.-W. 1985.

3 Vgl. die Beiträge in Thieme/Becker 1907-1950, Bd. 31, 1937, S. 328; Singer 1920, S. 314; Boetticher 1891-1901, Bd. 2, S. 775; Noack 1974, S. 564.

4 Siehe Thieme/Becker 1907-1950, Bd. 31, 1937, S. 328.

5 Zu den Familienverhältnissen Spangenbergs vgl. Arndt 2002, S. 898-901; Brinkmann 2000, S. 2442; Deneke 2001, S. 65 f.

6 Brinkmann 2000, S. 25.

7 Der Eintrag enthält allerdings die Bemerkung, dass er die Matrikel erst am 11.01.1861 erhielt. Vgl. München, Akademie der bildenden Künste, Matrikelbuch II, Nr. 1603.

8 Vgl. Ausst.-Kat. München 2003, S. 77 f. 
Allerdings war Piloty in den Jahren um 1860 immer wieder auf Reisen in Italien, Frankreich und England, so dass es nicht verwundert, dass als Lehrer Spangenbergs noch weitere Münchner Historienmaler in Betracht zu ziehen sind. Darf man einem Artikel der Illustrirten Zeitung Glauben schenken, so war es vor allem Kaulbach, der den jungen Spangenberg unterrichtete. ${ }^{9} \mathrm{Zu}$ nennen sind aber auch Pilotys Schüler Georg Conräder, selbst nur fünf Jahre älter als Spangenberg, sowie der Historien- und Genremaler Arthur von Ramberg. Beide wurden von Graf Stanislaus von Kalckreuth als Lehrer an die erst 1860 in Weimar gegründete Kunstschule berufen, nachdem Piloty das Angebot, selbst Direktor dieser Einrichtung zu werden, ausgeschlagen hatte. ${ }^{10}$

Friedrich Spangenberg folgte den beiden Malern aus nicht genau bekannten Gründen 1861 nach Weimar. ${ }^{11}$ Möglicherweise sah er hier bessere Chancen, sein Auskommen als Künstler zu bestreiten als in München. Im Herbst 1861 wurde der letzte mögliche Lehrer Spangenbergs nach Weimar berufen: der Belgier Ferdinand Pauwels. Conräder verließ die Stadt bereits im Folgejahr wieder, um nach München zurückzukehren. Spangenberg blieb hingegen bis zum Jahr 1867 dort, bevor auch er nach München zurückkehrte. ${ }^{12}$ Hier erhielt er durch von Ramberg Anleitung bei der Ausführung des Gemäldes Geiserich führt die gefangene Eudoxia aus dem geplünderten Rom. ${ }^{13}$

Über Spangenbergs Ausbildungszeit in Weimar sind leider nur wenige Informationen erhalten. Gesichert ist, dass er hier sein Erstlingswerk Der Triumph der Union schuf. Das auf den Ausgang des Amerikanischen Bürgerkrieges bezogene Gemälde befindet sich heute in New York und zeigt eine schwebende Allegorie der Freiheit mit Schwert und Siegerkranz. Zu ihren Füßen sind die Sieger sowie die Besiegten mit ihren Generälen Grant und Lee zu sehen. Einige Akten des Hauptstaatsarchivs in Weimar belegen, dass das Werk 1867 bereits fertig gestellt war und am 11. April dieses Jahres erstmals ausgestellt wurde. In der Folge zeigte man das Gemälde noch in Berlin, Leipzig und Göttingen, bevor man es in die USA verschickte. Der Bestimmungsort des Werks war wohl das Kapitol in Washington. ${ }^{14}$ $\mathrm{Ob}$ es dort jemals angekommen ist, kann leider nicht nachgewiesen werden. Seit dem Jahr 1870 befand es sich allerdings sicher im Poppenhusen-Institut, einer gemeinnützigen Einrichtung in New York, die in demselben Jahr gegründet wurde. ${ }^{15}$ Über die Kontakte des Künstlers in die Vereinigten Staaten lassen sich ver-

9 Vgl. Anonym 1867, S. 372.

10 Ausst.-Kat. München 2003, S. 83.

11 Scheidig/Müller-Krumbach 1991, S. 239.

12 Vgl. Boetticher 1891-1901, Bd. 2, S. 775.

13 Vgl. Schmidt 1985, S. 151 Anm. 240.

14 Die Illustrirte Zeitung bespricht das Gemälde ausführlich in ihrer Ausgabe 1274 vom 30. November 1867: M. 1867, S. 372.

15 Vgl. unter http://poppenhuseninstitute.org/rental/ und https://www.facebook.com/notes/poppenhusen-institute/the-triumph-of-the-american-union-by-friedrich-spangenberg/ 155599 047801423 (zuletzt am 18.06.2013). Ausdrucke der Webseiten befinden sich im Archiv der Universitätskunstsammlung, Bildakte GG 180. 
schiedene Vermutungen anstellen. Sein Bruder war hier, wie bereits erwähnt, Kaufmann. Zudem lebten zwei seiner Tanten in den USA. ${ }^{16}$ Hinzu kommt, dass auch einer seiner Weimarer Lehrer, Ferdinand Pauwels, ein Gemälde in die USA verkaufte. Es handelte sich dabei um ein Thema, das ebenfalls mit dem Amerikanischen Bürgerkrieg zusammenhängt: eine Darstellung der Abschaffung der Sklaverei. ${ }^{17}$

Spangenbergs zweites, durch die Aktenlage nachweisbares Weimarer Werk ist eine Skizze mit dem Entwurf einer Kreuzpredigt, die am 20. August 1867 in Weimar ausgestellt wurde. ${ }^{18}$ Vermutlich handelt es sich dabei um einen Entwurf für die hier besprochene Ölskizze Bernhard von Clairvaux predigt den Kreuzzug im Besitz der Göttinger Universitätskunstsammlung bzw. sogar um diese Skizze selbst. Die beiden Göttinger Ölskizzen sind allerdings erst auf das Jahr 1869 datiert, was freilich auch mit deren Einsendung bei der Verbindung für historische Kunst zusammenhängen kann.

1873 erhielt Spangenberg, möglicherweise als Folge des in München ausgestellten Gemäldes Gefangennabme der Eudoxia (vgl. Kat. Nr. 3), ein Italienstipendium. Nachdem er zuvor Mitglied im Deutschen Künstlerverein zu Rom geworden war, starb der Künstler am 8. Juni 1874 beim Versuch, den Vesuv zu besteigen. Er liegt im italienischen Boscotrecase südlich des Vulkans begraben.

Friedrich Spangenbergs Euvre ist also aus verständlichen Gründen überschaubar. Neben den beiden Göttinger Skizzen und dem Werk in New York gibt es nur wenige Hinweise auf weitere Arbeiten. Laut Boetticher scheint noch ein Gemälde mit dem Titel Plündernde Vandalen in einer römischen Basilika existiert zu haben. ${ }^{19}$ Möglicherweise ist dies das Werk, welches ein Artikel der Südhannoverschen Zeitung vom 4./5. Dezember 1943 in Hannover verortet. ${ }^{20}$ Auch in Göttingen sollen sich aus dem Nachlass der Spangenbergs noch Skizzen und ein Selbstporträt des Malers in Privatbesitz befinden. ${ }^{21}$

\section{Thema und Darstellung}

Das Sujet der Ölskizze Bernhard von Clairvaux predigt den Krenzæug bezieht sich, wie einige Details nahelegen, auf eine ganz bestimmte und historisch besonders folgenreiche Predigt des 1174 heilig gesprochenen Bernhard von Clairvaux (1090-1153). Gezeigt wird dessen Weihnachtspredigt am 27. Dezember 1146 in Speyer. Hierhin war der Zisterzienserabt im Winter 1146 gezogen, um den staufischen König Konrad III., der dort das Weihnachtsfest verbrachte, für einen Kreuzzug ins Heilige Land zu begeistern. Nachdem es Bernhard zunächst nicht gelungen war, Konrad

16 Vgl. Deneke 2001, S. 66.

17 Vgl. Thieme/Becker 1907-1950, Bd. 26, 1932, S. 320. Außerdem ist von Pauwels ein Gemälde Verherrlichung der amerikanischen Union überliefert (vgl. Boetticher 1891-1901, Bd. 2, S. 229).

18 Vgl. Weimar, Thüringisches Hauptstaatsarchiv [193], S. 7.

19 Vgl. Boetticher 1891-1901, Bd. 2, S. 775.

20 Vgl. E. K. 1943.

21 Vgl. ebd. und E. K. 1942. 
davon zu überzeugen, das Kreuz zu nehmen, brachte die Predigt am 27. Dezember schließlich den gewünschten Erfolg. ${ }^{22}$

Der Betrachter von Spangenbergs querformatigem Bild erkennt zunächst eine auf der Mittelsenkrechten prominent in Szene gesetzte männliche Person, um die das Geschehen aufgebaut ist. Sie lässt sich als Bernhard von Clairvaux identifizieren, der erhöht auf einigen Stufen vor dem Rundbogenportal eines Gebäudes steht, welches sich trotz einiger Abweichungen als Westfassade des Speyerer Domes deuten lässt. Vom Portal gerahmt, steht Bernhard frontal zum Betrachter und weist mit seinem rechten, ausgestreckten Arm in Richtung des linken Bildrandes. Mit seiner Linken hält er ein kreuzförmiges Objekt. Er trägt eine weiße Glockenkasel über einer braunen Tunika und ist eindeutig als Geistlicher zu identifizieren. Seine zentrale Rolle für das Geschehen wird durch die Lichtsituation unterstrichen. Während der größte Teil des Gemäldes aus verschatteten Zonen besteht, ist der mittlere Bereich von einem Schlaglicht beleuchtet. So in Szene gesetzt, wird Bernhard durch sein in weißer Farbe angelegtes Obergewand zum hellsten Punkt der Skizze. Spangenberg stellt auf diese Weise sicher, dass sein Hauptprotagonist trotz der großen Zahl von Figuren im Bild gut zu erkennen ist. Um Bernhard herum zeigt sich dem Betrachter ein bewegtes Szenario. Eine Zäsur auf der Mittelsenkrechten unterhalb des Haupthelden teilt die Figuren in zwei Hauptgruppen. Die auf der rechten Seite dargestellten Personen repräsentieren die zum Kreuzzug aufgerufene Bevölkerung. Unterhalb und zur Rechten Bernhards befinden sich drei Personen, die in einer Dreieckskomposition angeordnet sind. Zwei Kniende und eine im Aufstehen begriffene Figur sind vor einem stehenden Mann in rotem Gewand dargestellt. Bei der linken Person ist deutlich ein Schwert zu erkennen. Beide Kniende legen offenbar soeben ihr Kreuzzugsgelübde ab.

Rechts neben der Dreiergruppe zeigt Spangenberg einige Figuren mit bewegten Gesten, die ihre Arme in Richtung Bernhards ausstrecken. Eine weitere Person mit langen blonden Haaren umarmt dabei eine der vor ihr stehenden und scheint diese zurückzuhalten. Im Bildhintergrund sind undeutlich weitere Menschen mit Kerzen zu erkennen. Rechts von ihnen zeigt die Leinwand dunkle Wolken bzw. Rauch. Im Vordergrund dieser Bildhälfte sind noch zwei sitzende Personen zu betrachten, davon trägt eine ein rotes Gewand, die andere stützt ihren behelmten Kopf.

Die linke Bildhälfte wird von verschiedenen Reitern dominiert. Der am prominentesten platzierte, allerdings auch fast völlig verschattete Mann reitet in Richtung des linken Bildrands. Neben ihm stehen zwei Mönche mit Tonsur in braunem Habit mit roten Kreuzen auf den Oberarmen. Im Hintergrund zeigt Spangenberg noch weitere Reiter. Sie werden vom Geschehen im Vordergrund größtenteils verdeckt, jedoch gleichzeitig durch die auf sie fallende Schlaglichtbeleuchtung her-

22 Herzlich danke ich an dieser Stelle Prof. Dr. Thomas Noll, der mich auf die Weihnachtspredigt in Speyer aufmerksam gemacht hat. Das Geschehen um das Weihnachtsfest wird unter Bezugnahme auf die mittelalterlichen Viten Bernhards zusammengefasst bei Dinzelbacher 1998, S. 293-296. 
Profanhistorie - Geschichtsmalerei - Mythologie

vorgehoben. Der erste, auf einem braunen Pferd sitzende, ist durch seinen weißen Überwurf mit rotem Kreuz eindeutig als Kreuzritter ausgewiesen. Er trägt mit der Rechten eine Fahne. Neben ihm, bekrönt und in goldgelber Kleidung, reitet auf einem weißen Pferd die zweite, wenn auch wenig betonte Hauptperson des Geschehens: König Konrad III. Seine Krone zeichnet ihn als Herrscher aus. Mit dem linken Arm weist er auf Bernhard, so wie dieser in Richtung des Königs deutet. Die Reiter und Bernhard werden dabei von einigen Betenden zu Füßen des Geistlichen getrennt.

Generell kann man feststellen, dass Friedrich Spangenberg mit seiner Darstellung die wesentlichen Punkte des historischen Geschehens der Überlieferung gemäß aufgreift. Gleichwohl decken sich nicht alle Bildelemente mit den historischen Berichten über die Weihnachtspredigt. In diesen ist zwar von großem Andrang in Speyer die Rede, welcher sich in der Vielfigurigkeit der Szene wiederfindet. Doch wird in der Vita Bernhards über die Predigt berichtet, sie hätte im Inneren des Speyerer Doms stattgefunden, womit die Ölskizze nicht übereinstimmt. ${ }^{23}$ Auch soll Konrad in Folge der Predigt unter Tränen dem Kreuzzug zugestimmt und daraufhin das Kreuz und die Heerfahne von Bernhard erhalten haben. ${ }^{24}$ Im Bild sind beide Gegenstände zu entdecken, allerdings an unterschiedlichen Orten. Mehrere Fahnen sind in der Nähe Konrads zu sehen. Eine von ihnen könnte durchaus die erwähnte Heerfahne sein. Ein Kreuz hält aber nur Bernhard in der Hand. Mit diesem meint Spangenberg wohl das in den Quellen genannte. Auch die Identifikation Konrads über die von ihm getragene Krone ist nicht ganz eindeutig. Die mit wenigen Pinselstrichen angedeutete Krone erinnert zwar entfernt an die Reichskrone des Heiligen Römischen Reiches. ${ }^{25}$ Allerdings ist das charakteristische Kreuz auf der vorderen Platte nicht zu erkennen. Als letzte Abweichung sei die Architektur im Hintergrund angeführt. Obgleich sie sicher die Westfassade des Speyerer Doms meint, ist sie mit dessen Bauausführung nicht genau zu vereinbaren. ${ }^{26}$ Es ist sehr wahrscheinlich, dass diese historischen Ungenauigkeiten dafür gesorgt haben, dass der Entwurf niemals ausgeführt wurde.

\section{Zur Funktion der Ölskizze}

Wie das ab 1887 geführte Gemäldeinventar der Kunstsammlung festhält, gelangte die Ölskizze Bernhard von Clairvaux predigt den Kreuzzug gemeinsam mit ihrem Pendant Geiserich führt die gefangene Eudoxia aus dem geplünderten Rom (vgl. Kat. Nr. 3) erst nach dem Tod von Spangenbergs Vater Johann Friedrich Spangenberg in den Besitz der Göttinger Universitätskunstsammlung. Dass dies auf eher kuriose Art und Weise geschah, belegt die folgende Notiz aus dem entsprechenden Inventar:

\footnotetext{
Vgl. Dinzelbacher 1998, S. 294-295.

Ebd. S. 295.

Vgl. z. B. Wolf 1995, S. 10, Abb. 1.

26 Zum Aufbau des Doms zu Speyer siehe Winterfeld 1993, S. 47-115.
} 
„Sie wurden ohne weitere Angabe in die Aula gebracht und erst Erkundigung[en] beim Photographen Nölle ergaben, dass Spangenberg sie testamentarisch vermacht habe. " 27

Der sorglose Umgang mit den Ölskizzen hat vermutlich mehrere Gründe: So war der früh verstorbene Spangenberg zu dieser Zeit nur noch wenigen bekannt und seine CEuvre somit von verhältnismäßig geringem Wert. Zudem sind Ölskizzen selbst nur die Vorstufen eines Gemäldes, das später auszuführen ist. Im Falle der Darstellung Bernhard von Clairvaux predigt den Kreuzzug ist solches allerdings nie geschehen.

An dieser Stelle ist ein kurzer Exkurs zu Begriff und Funktion der Ölskizze angebracht. Der Begriff an sich ist eigentlich eindeutig und meint eine mit Ölfarben angelegte Skizze. So wird der Terminus „Skizze“ etwa im Wörterbuch der Kunst als ein „erster flüchtiger Entwurf eines Bildes, eines Bildwerkes oder Bauwerks“ definiert. Sie soll „,einen Natureindruck festhalten oder Auge und Hand des Künstlers üben“.28 Diese Definition trifft allerdings auf die Skizzen Spangenbergs nur bedingt zu. Es handelt sich zwar, wie die grobe und schnell auf die Leinwand aufgetragene Pinselführung zeigt, um ein zügig angelegtes Werk, doch der Bildaufbau ist bereits sorgfältig durchdacht. Auch wird kein Natureindruck festgehalten und die Objekte sind auch keine Übungsstücke des Künstlers. Hieraus ergibt sich die Frage, ob der Begriff „Studie“ möglicherweise eher angebracht ist. Die Definition dieses Begriffs umfasst „das genaue Festhalten von Details für ein zu gestaltendes Kunstwerk“. Eine Studie sei ,auf möglichst exakte Wiedergabe oder Angabe [...] bedacht. “29 Auch dies wird der Skizze der Predigt Bernhards nicht gerecht.

Der am besten geeignete Terminus zur Definition der beiden Skizzen ist der aus dem Italienischen entlehnte Begriff des „Modello“. Er ist weniger über die künstlerisch-technischen Merkmale definiert, als über seine Funktion. Ein Modello bezeichnet ein Schaustück, das einem Auftraggeber vorgelegt wird, damit dieser seiner Ausführung als Gemälde zustimmt. Ölstudien und Ölskizzen zur Vorbereitung von Gemälden sind seit dem 16. Jahrhundert bekannt und spätestens seit dem 17. Jahrhundert keine Seltenheit mehr. ${ }^{30}$ Einige der bekanntesten Beispiele aus dieser Epoche sind die Ölskizzen von Peter Paul Rubens zur Vorbereitung des Medici-Zyklus in der Sammlung der Alten Pinakothek in München. ${ }^{31}$ Ihre Nutzungsmöglichkeiten blieben in der Folge bis in das 19. Jahrhundert weitgehend gleich. Als prominentes Beispiel des letztgenannten Jahrhunderts für die Nutzung von Ölskizzen zur Vorbereitung eines Werkes kann Spangenbergs Lehrer Carl Theodor von Piloty genannt werden. Er schuf für seine Werke vielfach Vorstudi-

27 Göttingen, Kunstsammlung der Universität, Inventar der Universitätskunstsammlung 1884 ff., S. 72.

28 Jahn/Lieb 2008, S. 777.

29 Ebd. S. 807.

30 Zum Begriff des „modello“ in Abgrenzung zu „bozetto“ und „ricordo“ vgl. u. a. von der Brüggen 2004, S. 17.

31 Vgl. an der Heiden 1984. 
Profanhistorie - Geschichtsmalerei - Mythologie

en, was am Beispiel mehrerer Ölskizzen für das Gemälde Thusnelda im Triumphzug des Germanicus sehr anschaulich zu beobachten ist. ${ }^{32}$

Wie oben bereits angesprochen wurde, ist der Funktionszusammenhang der Göttinger Skizzen von Spangenberg als Schaustücke gut belegt. Die beiden Werke wurden 1869 bei der Verbindung für historische Kunst33 eingereicht, einer im Jahr 1854 gegründeten Gesellschaft, die auf gezielte Weise Kunst mit historischen Sujets fördern wollte. ${ }^{34}$ Die Gründung dieser Gesellschaft kann als Symptom dafür gesehen werden, dass die Realität das Ideal der Gattungshierarchie bereits ein-, wenn nicht gar überholt hatte. Zwar galt die Historienmalerei wegen ihrer ideellen Themen und ihres die Betrachter belehrenden Charakters noch immer als bedeutendstes Teilgebiet der Malerei, doch spiegelte der Kunstmarkt dies nicht wieder. Offensichtlich hatten viele Künstler Probleme, sich mit Historiengemälden ihren Lebensunterhalt zu verdienen. Gleichzeitig beklagten idealistische Kunstkritiker zunehmend, dass die Historienmalerei gegenüber den vermeintlich „niederen“ Gattungen in eine Defensive geriet. ${ }^{35}$

Die Verbindung für historische Kunst sollte diesbezüglich gegensteuern und die Ausführung von Historienbildern gezielt fördern. Sie funktionierte so, dass jedes Mitglied einen Jahresbeitrag von mindestens 150 Mark oder einem Vielfachen davon zahlte. Dafür durfte es an den Jahreshauptversammlungen sowie an den Ausstellungen der Verbindung teilnehmen. Auf den Hauptversammlungen erfolgte dann eine Abstimmung über die anzukaufenden Bilder. Die erworbenen Werke wurden danach zunächst einigen Mitgliedern in Deutschland, Österreich-Ungarn und der Schweiz bis zu vier Wochen zur Ansicht und Ausstellung überlassen. War dies geschehen, wurden die Werke in der nächsten Hauptversammlung der Verbindung unter den Mitgliedern verlost. ${ }^{36}$

Der Modello zum Gemäldeprojekt Bernhard von Clairvaux predigt den Kreuzzug hatte bei der Verbindung für historische Kunst keinen Erfolg. Besser erging es Spangenberg mit seiner zweiten Ölskizze, Geiserich führt Eudoxia mit ihren Kindern aus dem geplünderten Rom (Kat. Nr. 3).

Jan Stieglitz

32 Vgl. Ausst.-Kat. München 2003, S. 326-335; zu beachten ist insbesondere Abb. 16.6 auf S. 329.

33 Vgl. Anm. 1.

34 Zur Gründungsgeschichte der Verbindung für bistorische Kunst vgl. neben Schmidt, H.-W. 1985, S. 13-40, auch Jordan/Klee 1904, S. 3-5.

35 Der Vorsitzende der Verbindung, Max Jordan, beschreibt dies in der anlässlich des 50. Gründungstages herausgegeben Denkschrift der Verbindung im Jahr 1904 mit folgenden Worten: „Seit Mitte des abgelaufenen Jahrhunderts trat auf unseren deutschen Kunstausstellungen immer mehr der Mangel an Gemälden hervor, welche höhere Ziele als die Befriedigung des populären Kunstbedürfnisses ins Auge fassten. Das Sittenbild und vor Allem die Landschaft nahmen überhand, während die Darstellung bedeutender Motive und großer Erscheinungen zurücktrat oder sich ausschließlich in der monumentalen Form der Wandbilder äußerte. Diese Beobachtung gab einem Kreise ernster Kunstfreunde den Antrieb, unsere Künstler zur Pflege höhere Gebiete der Malerei wieder anzuregen und ihnen Aussicht auf erfolgreiche Thätigkeit zu eröffnen." Vgl. Jordan/Klee 1904, S. 3.

36 Vgl. Jordan/Klee 1904, S. 9-13. 
Kat. Nr. 3

Friedrich Spangenberg (1843-1874)

\section{Geiserich führt die gefangene Eudoxia aus dem geplünderten Rom}

1869

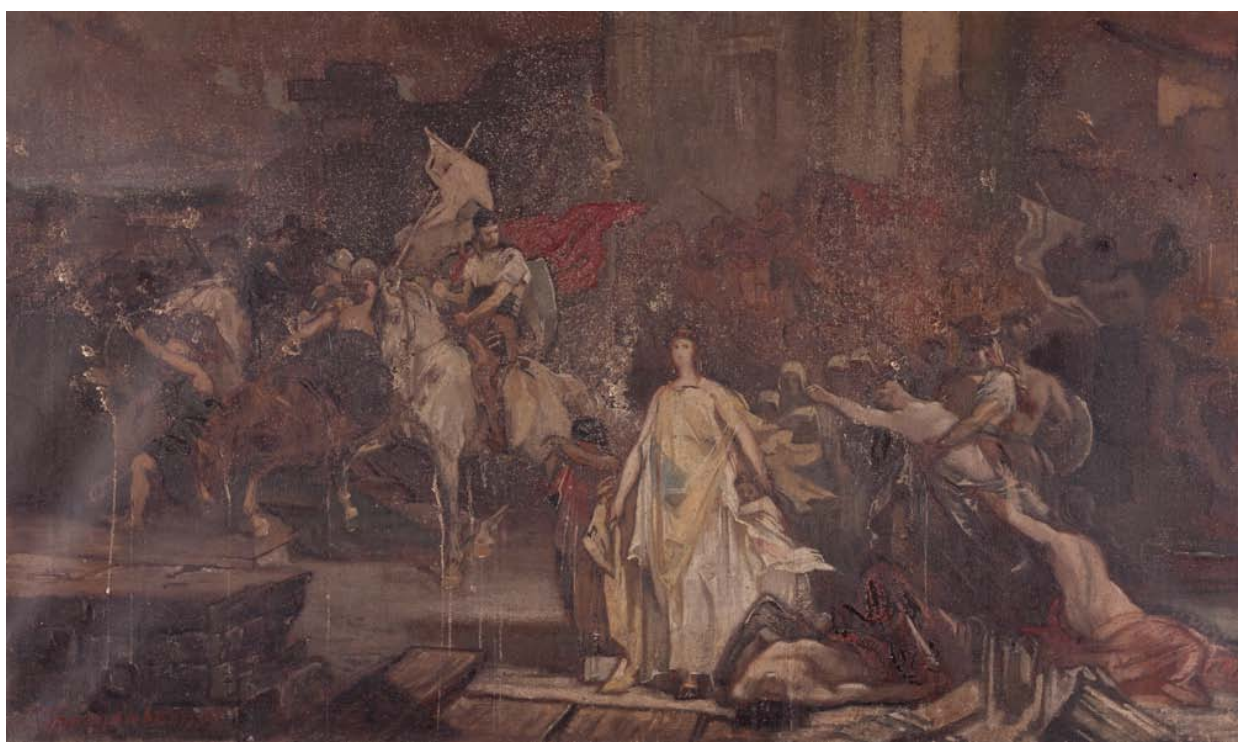

Öl auf Leinwand, 68 x 114 cm, signiert und datiert, Schenkung der Erben des Künstlers, Inv. Nr. GG 180

Im Jahr 1869 sendete Friedrich Spangenberg die beiden Ölskizzen Bernhard von Clairvaux predigt den Kreuzzug und Geiserich führt die gefangene Eudoxia aus dem geplünderten Rom bei der Verbindung für historische Kunst ein. Laut deren Versammlungsprotokollen wurde das zweite Bild zur Ausführung bestimmt. 1871 war es in München bereits weitgehend fertiggestellt. Es ist auf das Jahr 1872 datiert und gelangte 1873 per Losentscheid an die Kieler Kunsthalle (Abb. 6). ${ }^{1}$ Eine der Denkschrift zum fünfzigjährigen Gründungsjubiläum der Verbindung anhängende Liste der gekauften Werke führt das Werk Spangenbergs unter Punkt 19 auf und weist 4800 Mark als

$1 \quad$ Vgl. Ausst.-Kat. Kopenhagen 1981, S. 235. 
Preis aus. ${ }^{2}$ Im selben Jahr wurde das Werk, vor seiner Auslieferung nach Kiel, vom 14. bis zum 24. Juli noch einmal zehn Tage in München ausgestellt. ${ }^{3}$

Die Einnahme Roms durch den Vandalenkönig Geiserich gehört nicht gerade zu den häufig dargestellten Sujets der Historienmalerei. Gleichwohl dürfte das Thema einem breiten zeitgenössischen Publikum durch die Lektüre bedeutender Geschichtswerke wie The History of the decline and fall of the roman empire des Briten Edward Gibbon bekannt gewesen sein. Das überaus populäre und vielfach aufgelegte Geschichtswerk wurde bereits 1790-92 erstmals ins Deutsche übersetzt. ${ }^{4}$ Die Frau im Zentrum des Bildes ist demzufolge Licinia Eudoxia, die Witwe des Weströmischen Kaisers Valentinian III., die bereits kurz nach dessen Tod gezwungen war, seinen Nachfolger und möglichen Mörder Petronius Maximus zu heiraten. ${ }^{5}$ Daraufhin rief sie angeblich Geiserich, den Anführer des germanischen Stammes der Vandalen, welche nach längerem Umherziehen in Nordafrika sesshaft geworden waren, zu Hilfe. ${ }^{6}$ Dieser bemannte im Jahr 455 n. Chr. eine Flotte und fuhr nach Rom. Wie von Eudoxia gewünscht, besiegte er den Ursupator Petronius. Von nun an erwies er sich allerdings als wenig angenehme Person. Die Vandalen plünderten die Stadt Rom nach deren Aufgabe vierzehn Tage lang. Die Kaiserin selbst wurde unsanft von ihrem Besitz befreit und war gezwungen, mit ihren beiden Töchtern als Gefangene nach Karthago zu gehen. ${ }^{7}$

\section{Zur Darstellung}

Die Ölskizze zeigt im Vergleich zu ihrem bereits beschriebenen Pendant (Kat. Nr. 3) einige ähnliche Merkmale, aber auch deutliche Unterschiede. Wiederum steht eine Hauptperson im Bildzentrum: die in weiße Kleider gehüllte Eudoxia, die rechts und links ihre beiden Kinder mit sich führt. Sie ist im Gegensatz zu Bernhard weit im Vordergrund angeordnet. Vergleichbar ist dagegen die Hervorhebung der zentralen Figur durch ein Schlaglicht, dessen Quelle nicht im Bild auszumachen ist.

Vor Eudoxia liegt eine offensichtlich erschlagene Person am Boden. Sie trennt die erstgenannte Dreiergruppe von zwei unbekleideten weibliche Personen auf der rechten Bildhälfte, von denen eine am Boden liegt, während die andere, ihren Arm ausstreckend, von einem Mann mit behörntem Helm und blondem Zopf festgehalten wird. Bei dieser Raptus-Szene hat sich Spangenberg möglicherweise an der antiken Pasquino-Gruppe orientiert. ${ }^{8}$ Im Hintergrund sind weitere Personen sowie

\footnotetext{
Vgl. Jordan/Klee 1904, S. 26.

Vgl. Weimar, Thüringisches Hauptstaatsarchiv [193], S. 30.

Gibbon 1790-92, S. 166-177.

Castritius 2007, S. 105.

6 Wie die jüngere Forschung festhält, wurde dieser Hilferuf bereits von spätantiken Geschichtsschreibern als Gerücht gekennzeichnet: vgl. ebd.

7 Ebd., S. 105-108.

8 Zur Pasquino-Gruppe vgl. Haskell/Penny 1981, S. 291-296.
} 
die Architektur der Stadt Rom durch die starke Verschattung der Bildfläche und den verständlicherweise flüchtigen Farbauftrag der Skizze nur andeutungsweise zu sehen. Die Personen werden entweder aus der Stadt geführt oder plündern diese.

Links hinter Eudoxia erhebt sich der auf einem Pferd reitende Geiserich. Er blickt über seine linke Schulter zu der Frau und den Kinder herab. Hierdurch werden die beiden Hauptfiguren des Bildes, ähnlich wie Bernhard und der König auf der bereits behandelten Ölskizze Bernhard von Clairvaux predigt den Kreuzzug, miteinander in Beziehung gebracht. Wie die beiden Personengruppen auf der rechten Bildhälfte ist der Vandalenkönig gut ausgeleuchtet. Auf der linken Bildhälfte sind im Hintergrund noch weitere Reiter vor einem von Wolken verhangenen Himmel und einem Mauerteil dargestellt.

Neben der Präsentation und Beleuchtung der Hauptfiguren im Bildzentrum ist vor allem die Bewegungsrichtung von rechts nach links, entgegen der europäischen Leserichtung, mit der anderen Ölskizze vergleichbar. Auch die Lichtregie mit einer theatralischen Schlaglichtbeleuchtung auf dem Hauptgeschehen, die sich kontrastiv von einer zu großen Teilen verschatteten Bildfläche abhebt, erscheint als ein charakteristisches Element beider Bilder. Die bühnenartige Dramaturgie der Szene ist gerade auch für die Historienmalerei der Lehrer Spangenbergs typisch. ${ }^{9}$

Vergleicht man das ausgeführte Werk in Kiel mit der Göttinger Ölskizze, so sind deutliche Unterschiede festzustellen. Das vollendete Gemälde ist auf das Jahr 1872 datiert und in etwa dreimal so groß wie die Skizze. Insgesamt ist seine Ausführung detailreicher, der Farbauftrag gleichmäßig und ohne sichtbare Pinselfaktur. Dies ist besonders gut an der Gewandung der Eudoxia zu beobachten. Eine solche Art der Darstellung entsprach den zeitgenössischen Anforderungen an ein Historiengemälde - bei Werken ,niederer“ Bildgattungen war es eher gestattet, den Pinselstrich sichtbar zu lassen. ${ }^{10}$ Dies ist zum Beispiel auch im Vergleich mit dem Gemälde Tauben auf dem Dach von Paul Meyerheim (Kat. Nr. 29) zu beobachten.

Neben der für den Schritt von der Skizze zum ausgeführten Bild verständlichen Verfeinerung des Farbauftrags hat Spangenberg aber auch an der Komposition sowie an der Darstellung der Figuren Veränderungen vorgenommen, die hier in Kürze benannt sein sollen: Auf der Ölskizze wird die Szene im Vordergrund links unten durch eine bildparallel verlaufende, etwa kniehohe Mauer zum Betrachter hin optisch abgeriegelt. Diese ist in der ausgeführten Fassung entfallen. Stattdessen hat Spangenberg hier eine Rückenfigur eingefügt, die einen Mann, welcher die Augen geschlossen hat, nach links zieht, damit dieser nicht unter die Hufe von Geiserichs Pferd gerät. Möglicherweise ist mit dieser Person Petronius Maximus gemeint, der den Berichten zufolge gesteinigt und in den Tiber geworfen wurde. Darüber sind in der ausgeführten Fassung - anstelle einiger hier ursprünglich geplanter Reiter - zwei Fanfaren- und Hornbläser zu sehen. Hinter der Figur des

9 Auch hier ist Piloty das augenfälligste Beispiel, wie das Gemälde Thusnelda im Triumphzug des Germanicus, München, Neue Pinakothek, zeigt; vgl. Ausst.-Kat. München 2003, S. 318-349.

10 Vgl. Krüger 2007, S. 52-55. 
Geiserich ist ein neu konzipierter Reiter zu erkennen, welcher eine große gelbe Standarte präsentiert. Das Pferd des davor reitenden Vandalenfürsten ist beim Kieler Gemälde braun und nicht mehr, wie in der Göttinger Skizze, weiß. Auch weht der rote Umhang des Geiserich nicht nach hinten, sondern verdeckt einen großen Teil von dessen Körper. Im Verhältnis der Farbflächen stellt er nun ein Pendant zur gelben Standarte im Hintergrund dar. Zudem ist der Blick des Feldherren im Unterschied zur Skizze jetzt nicht mehr auf Eudoxia gerichtet, sondern nach rechts oben in die Ferne. Darüber hinaus hat Spangenberg die Größe von Geiserich auf seinem Pferd im Verhältnis zur Bildfläche stark verändert. Die Figur erscheint auf diese Weise wesentlich größer und wird damit auch prominenter ins Bild gesetzt. Die Dreiergruppe der Eudoxia mit ihren Kindern ist etwas nach rechts gedreht und steht auf einem steinernen Absatz parallel zur Bildfläche. Eudoxia hält mit ihrem rechten Arm ihr Gewand und trägt einen Schleier. Das kleinere ihrer Kinder schmiegt sich nicht mehr an ihr Gewand sondern hält in synchroner, wenngleich spiegelverkehrter Geste ihr eigenes Kleid. Diese Körperhaltung wird bei der hinter Eudoxia gehenden Frau gleich noch ein drittes Mal gezeigt. Die größere der beiden Töchter verdeckt ihr Gesicht nicht mehr, sondern wendet sich stattdessen demonstrativ vom Vandalenkönig ab. Sie zeigt einen trotzig-zornigen Gesichtsausdruck.

Friedrich Spangenberg hat beim ausgeführten Ölgemälde mit großer Konsequenz dafür gesorgt, dass zwischen Geiserich und Eudoxia keinerlei Handlung oder Beziehung mehr zu erkennen ist. Die Gefangene wendet sich kühl und mit gesenktem Blick ab, während Geiserich über sie hinweg schaut. In der Skizze war dies noch nicht vorgesehen: Dort sah zumindest der König auf die gefangene Römerin.

Die Veränderungen setzen sich auf der rechten Bildhälfte fort. Der Tote rechts im Vordergrund liegt beim Kieler Bild nicht mehr auf dem Boden, sondern wird, wie bei einer Pietà, mit Kopf und Schultern in den Schoß einer Frau gebettet, was die Drastik der Darstellung mildert. Die darüber angeordnete, in der Göttinger Skizze äußerst dramatisch gefasste, aus drei Personen bestehende Raptus-Gruppe wurde in der Endfassung ebenfalls beruhigt und zeigt nur noch zwei Personen. Das Grundmotiv ist allerdings gleich geblieben. Die männliche Person zieht die Frau zur rechten Seite hin. Sie ist aber nicht mehr eindeutig als Germanin zu identifizieren. Wahrscheinlich liegt dieser Veränderung ebenfalls eine Umdeutung der Gruppe zu Grunde. Der Mann scheint die Frau viel eher vom Zug der Gefangenen wegzuziehen, während sie auf der Skizze noch als Teil der Plünderung der Stadt aufzufassen ist. 


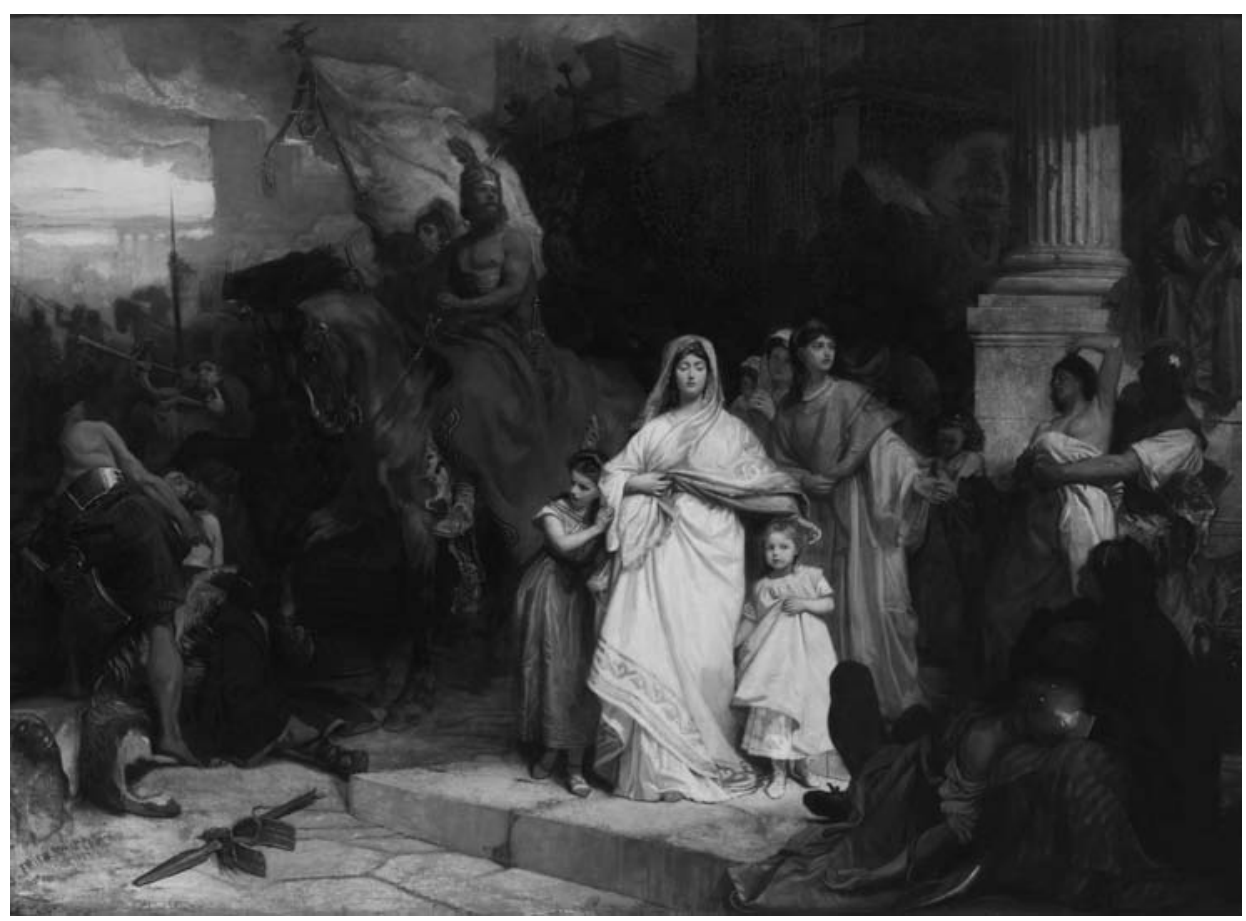

Abb. 6: Friedrich Spangenberg: Geiserich führt die gefangene Eudoxia aus dem geplünderten Rom, 1872, Öl auf Leinwand, 209 x 290 cm, Kiel, Kunsthalle

Die im ausgeführten Werk umgesetzten Veränderungen verleihen dem Werk somit bei grundsätzlich gleicher Anzahl und Positionierung der Figuren eine völlig neue Bildwirkung. Diese ist weniger auf eine drastische Bildwirkung, sondern vielmehr auf Mäßigung und ein distanziertes Verhältnis zwischen Römern und Germanen hin angelegt. Inwiefern dies etwa mit dem Deutsch-Französischen Krieg zusammenhängt, der während der Ausführung des Werks stattfand, kann nicht abschlieBend geklärt werden. Eine Gleichsetzung von Franzosen mit Römern sowie Germanen und Deutschen scheint unter den Zeitgenossen Spangenbergs durchaus verbreitet gewesen zu sein, so dass eine politische Lesart im Bereich des Möglichen liegt. ${ }^{11}$

Nicht unerwähnt soll schließlich die Verwandtschaft des Werkes mit Carl Theodor von Pilotys Gemälde Thusnelda im Triumphzug des Germanicus bleiben, das zeitgleich mit Spangenbergs Werk in München entstand. Sie betrifft vor allem die Art der Bilderzählung. Pilotys Bild wurde allerdings erst später, im Jahr 1873, in München fertig und daraufhin ausgestellt. Auch hier ist die Hauptperson eine Gefangene mit ihren Kindern. Thusnelda, die Frau des Arminius, war von ihrem Va-

11 Vgl. Ausst.-Kat. Kopenhagen 1981, S. 235. 
ter Segestes an den römischen Heerführer Germanicus übergeben worden. Sie nahm deshalb als Trophäe an dessen Triumphzug in Rom teil. Thusnelda ist gleich der Eudoxia im Bildzentrum positioniert und wird von einem Schlaglicht beleuchtet. Dadurch erhält der gesamte Aufbau ebenfalls den Charakter einer Bühne. Auch die Handlung dieses Gemäldes verläuft diagonal. Die künstlerische Idee hinter den Gemälden ist ähnlich, nur die Ausführung änderte sich. ${ }^{12}$

Jan Stieglitz

12 Vgl. Ausst.-Kat. München 2003, S. 326-335. 
Kat. Nr. 4

Friedrich August von Kaulbach (1850-1920)

\section{Die Erziehung des Bacchus}

1902 (?)

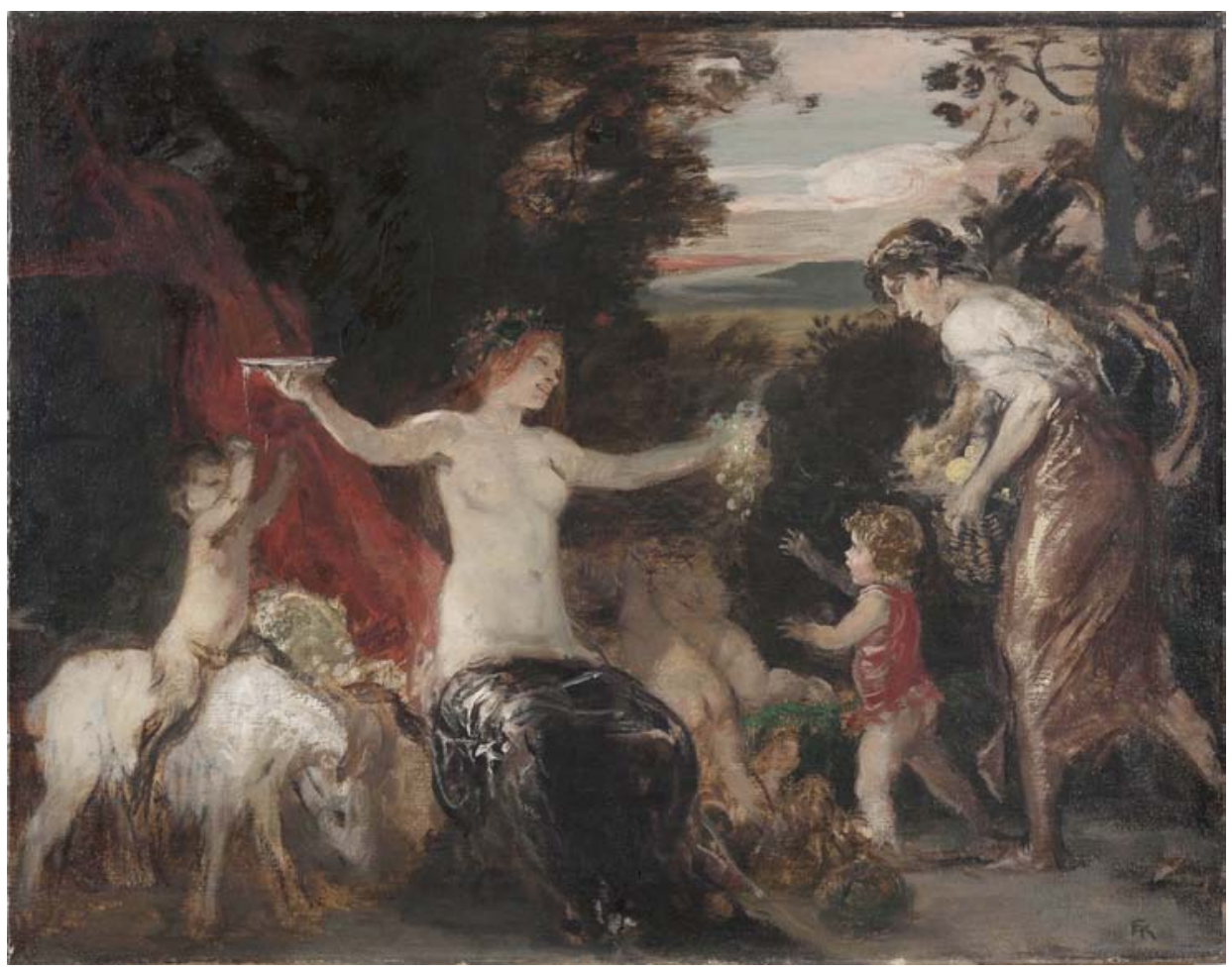

Öl auf Leinwand, 64 x 83 cm, signiert und datiert, Leihgabe der Bundesrepublik Deutschland (Objektnr. 19657)

Friedrich August von Kaulbach studierte bei seinem Vater, dem Porträtmaler Friedrich Kaulbach, sowie an der königlichen Kunstgewerbeschule Nürnberg bei dem für sein kräftiges Kolorit bekannten Maler August von Kreling und bei dem Landschafts- und Genremaler Karl Raupp. ${ }^{1}$ Ab 1871 in seiner Geburtsstadt München lebend und arbeitend, gehörte der Neffe des Historienmalers Wilhelm von

1 Vgl. Rosenberg 1910, S. 11-15; Zimmermanns 1980, S. 10. 
Kaulbach zu den sogenannten Münchener Malerfürsten und war einer der bestbezahltesten Porträtmaler. Im Umfeld von Künstlern wie Franz von Lenbach, Hans Makart und Gabriel von Max arbeitend, orientierte er sich an der farbintensiven Malerei von Künstlern wie Tizian, Giorgione, Veronese, Rubens und van Dyck, fand dabei aber durchaus eine eigene künstlerische Sprache. ${ }^{2}$ Eine prägende Rolle kommt den Parisreisen von 1878 und 1884 zu. ${ }^{3}$ Nachdem Kaulbach anfänglich Figuren in Kostümen des 16. und 17. Jahrthunderts malte, schuf er später neben Porträts (mit einem Schwerpunkt auf Damenbildnissen) auch idealisierte zeitgenössische Genrebilder. ${ }^{4}$ Kaulbach trat zudem als Karikaturist sowie als Schöpfer von populären Darstellungen wie dem „Schützenliesl“ in Erscheinung. 51885 wurde er persönlich geadelt und 1886 als Nachfolger Carl Theodor von Pilotys zum Direktor der Münchener Akademie berufen. ${ }^{6}$ Allerdings wurde ihm das Direktorenamt schnell zur Last, so dass er es 1891 wieder abgab. ${ }^{7}$

Charakteristisch für Kaulbachs Bilder ist ein lockerer Pinselstrich. Dabei bereitete der Künstler seine Bilder in akademischer Tradition nach wie vor mit zahlreichen - häufig bereits farbigen - Studien vor. ${ }^{8}$ Der komponierte Charakter seiner Bilder zeigt sich in der sorgfältigen Abstimmung von Figuren und Bildräumen. Hiervon zeugt auch das Gemälde in der Göttinger Universitätskunstsammlung, das auf das Jahr 1902 (evtl. auch 1908) datiert ist.9 Obgleich es im frühen 20. Jahrhundert entstand, repräsentiert es eine Kunstauffassung, die für das späte 19. Jahrhundert charakteristisch ist, so dass eine Behandlung in diesem Katalog gerechtfertigt erscheint. Das Bild zeigt dabei kein Porträt einer gesellschaftlich ranghohen Person, sondern vielmehr ein in Kaulbachs CEuvre eher seltenes Beispiel für die künstlerische Auseinandersetzung mit antiker Mythologie. ${ }^{10}$

\footnotetext{
Vgl. etwa Wolter 1912, S. 5; Zimmermanns 1980, S. 26.

Vgl. Zimmermanns 1980, S. $11 \mathrm{f}$.

Vgl. ebd., S. 25, 27.

5 Vgl. ebd., S. 34. Die Karikaturen entstanden insbesondere im Umfeld der Künstlergesellschaft "Allotria", deren Mitglied Kaulbach seit 1873 war; vgl. ebd., S. 10.

6 Vgl. ebd., S. 13.

7 Vgl. Pecht 1888, S. 373; Zimmermanns 1980, S. 14.

8 Zur Arbeitsweise von Kaulbach vgl. Zimmermanns 1980, S. 34 f.

9 Vgl. Zimmermanns 1980, S. 272, Kat. 652 (Abb. S. 170). Die Datierung befindet sich vor („19“) und - schwer lesbar - hinter der ligierten Signatur „FAK“ (,02“ - evtl. auch „,08“) rechts unten auf dem Bild. Eine frühe Farbabbildung des Gemäldes findet sich unter dem Titel Herbstfest bei Wolter 1912, zwischen S. 12 und S. 13. Auf einem Zettel der Galerie Almas-Dietrich auf der Rückseite des Bildes findet sich der Titel Die Freude. Zu den drei Titeln vgl. auch Zimmermanns 1980, S. 272.

10 Rosenberg 1910, S. 44, schreibt allerdings über Kaulbachs künstlerische Entwicklung ab dem Beginn der 1880er Jahre: „In den Genrebildern gab er fortan das altdeutsche Kostüm auf und belebte seine anmutigen Frühlings- und Sommerlandschaften fast nur noch mit Gestalten aus dem modernen Leben, nur gelegentlich auch mit Nymphen und anderen mythologischen Wesen, die in lauschiger Waldeinsamkeit ein träumendes Dasein führen." Letzteres passt recht genau auf das Göttinger Bild. Zimmermanns 1980, S. 272, führt drei weitere Bilder mit verwandter Thematik an, die sich allerdings auf die Darstellung von Einzelfiguren bzw. von zwei Figuren beschränken: Bacchantin (Kat. 653), Trauben (Kat. 656, vgl. Abb. 2) und Die kleine Bacchantin (Kat. 657).
} 
Die Erziehung des Dionysos- bzw. Bacchusknaben ist ein Thema, von dem in mehreren antiken Texten berichtet wird.11 Demzufolge wurde der von Zeus/Jupiter mit Semele gezeugte Gott als Kind von Hermes/Merkur nach Nysa gebracht, um ihn vor der Rache Heras/Junos zu schützen. In Nysa wurde er in einer Höhle von Nymphen aufgezogen. ${ }^{12}$ In der Bildenden Kunst ist dieser Stoff oftmals dargestellt worden. ${ }^{13}$

Kaulbachs Gemälde zeichnet sich durch eine pointierte Bilderzählung aus, die sich darauf konzentriert, wie der kleine Bacchus von einer Nymphe vor die Wahl zwischen Trauben und einer Schale mit Wein gestellt wird. Als Bühne für diese Art von „Nymphenpädagogik“ dient eine Landschaft, die das querformatige Bild auf spannungsvolle Weise strukturiert: Die linke Bildhälfte ist im Mittelgrund von dichten Bäumen oder Büschen hinterfangen, die sich im Gegenlicht zu einer weitgehend geschlossenen, grünschwarzen Fläche verbinden. Rechts daneben öffnet sich hingegen der Blick in die Ferne auf Berge und einen leicht geröteten Himmel. Ein Baum an der rechten Bildseite rahmt diesen Blick in klassischer Weise ein.

Kaulbach nutzt diesen Landschaftshintergrund, um seine Figuren auf effektvolle Weise davor in Szene zu setzen. Als Hauptfigur erscheint dabei - von der Mittelachse leicht nach rechts gerückt - eine nahezu frontal dargestellte, sitzende Nymphe mit nacktem Oberkörper, der sich durch sein helles, mit blaugrauen Farbeinschlägen versehenes Inkarnat leuchtend vom Hintergrund abhebt. Auf Kontrast setzt Kaulbach auch bei ihrem schwarzen Gewand, das die Beine bedeckt. Links neben und hinter der Frau verläuft eine rote, diagonal nach links ansteigende, schwer zu interpretierende Farbbahn, die sich nach hinten verliert. Sie ist über einem dunklen, hochrechteckigen Objekt am linken Bildrand (dem Eingang in die Höhle, in der Bacchus erzogen worden sein soll?) drapiert. Zwei als Rückenfiguren wiedergegebene, nackte Putti suhlen sich rechts im Schatten neben der Frau.

Die Nymphe hält die Arme seitlich ausgestreckt. In ihrer rechten Hand befindet sich eine Schale mit Wein, während sie in der linken Hand Weintrauben hält. Trauben und Wein gleichsam abwägend, wendet sie sich mit ihrem rothaarigen, blumenbekränzten Haupt dem Bacchusknaben zu, der als ein mit rotem Hemdchen bekleidetes Kleinkind im Profil dargestellt ist, das mit ausgestreckten Armen von rechts auf die Frau zuläuft. Es hat sich für die Trauben entschieden und ist im Begriff, nach diesen zu greifen. Unmittelbar rechts folgt Bacchus eine bekleidete

11 Vgl. u. a. den homerischen Hymnus XXVI auf Dionysos: „Ich will Dionysos preisen, den strahlenden Sohn der gerühmten / Semele und des Zeus, den brausenden, efeubekränzten, / Den die lockigen Nymphen vom fürstlichen Vater empfingen / Und an den eigenen Brüsten sodann in den Schluchten von Nysa / Sorgsam nährten. So wuchs er heran, [...].“ (zitiert in der deutschen Übersetzung von Karl Arno Pfeiff nach Gönna/Simon 2002, S. 65). Siehe auch Ovid, Metamorphosen III, 313-15: „Heimlich zog zunächst in der Wiege es [das Bacchuskind] auf seine Muhme / Ino, dann ward es den Nymphen des Nysa gegeben; in dessen / Grotte bargen es die und gaben Milch ihm zur Nahrung.“ (zitiert nach der Übersetzung von Erich Rösch: Ovid 1952, S. 103).

12 Vgl. u. a. Hederich 1996 [1770], Sp. 502.

13 Vgl. die Beispiele bei Reid 1993, Bd. 1, S. 360-362. 
Frau. Ihr Kopf ist bekränzt und sie trägt einen Früchtekorb, wodurch sie ikonographisch in die Nähe von Ceres-Darstellungen rückt. Ihre Schrittstellung (der rechte Fuß wird vom Bildrand angeschnitten, wodurch die Bewegung unterstützt wird) und ihr wehendes Gewand zeigen sie als heraneilende Person. Gleichzeitig beugt sie sich beim Laufen über den Bacchusknaben, wodurch Kaulbach zugleich ein kompositorisch souverän gesetzter Abschluss des Bildes gelingt. Zu dessen Hauptfiguren gehört noch ein Satyrknabe, der auf der linken Bildseite auf einem weißen Ziegenbock reitet und nach der über seinem Kopf schwebenden, bis zum Rand gefüllten Weinschale greift, aus welcher der Rebensaft bereits in seinen Mund trieft. Dies unterscheidet ihn von Bacchus, der sich vorerst mit ungegorenen Trauben begnügt.

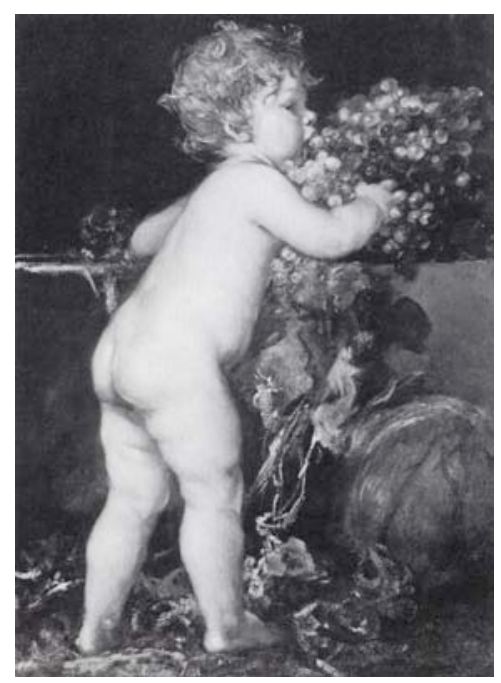

Abb. 7: Friedrich August von Kaulbach: Trauben, um 1903, Technik, Maße und Verbleib unbekannt
Insgesamt handelt es sich um ein scheinbar rasch entworfenes, gleichzeitig aber sehr gekonnt komponiertes Bild mit wohl durchdachtem, überaus effektvollen Aufbau. Hervorzuheben ist dabei nicht nur Kaulbachs Arbeit mit starken Hell-Dunkel-Kontrasten, sondern auch sein Umgang mit kalten und warmen Farben sowie mit den Komplementärfarben rot und grün.

Auffällig ist die lockere Pinselführung. Zwar ist diese charakteristisch für Kaulbachs Malerei. Gleichwohl erweist es sich aufgrund eines Vergleichs mit thematisch und formal ähnlich aufgebauten Werken wie dem Gemälde Trauben (Abb. 7) ${ }^{14}$ nicht als ausgeführtes Gemälde, sondern als Ölskizze. ${ }^{15}$ Dazu passt, dass sich das Bild bis zum Tod von Kaulbachs Frau in deren Privatbesitz befunden hat. Eventuell ist es als Studie für eine geplante Auftragsarbeit entstanden. $\mathrm{Ob}$ diese realisiert wurde, bleibt vorerst fraglich, weil sich bisher keine ähnliche Szenerie in seinem Gesamtwerk finden ließ.

14 Um 1903, Technik und Maße unbekannt, vgl. Zimmermanns, S. 272, Kat. 656.

15 Als solche wird es auch in der Bildunterschrift bei Wolter 1912, Abb. nach S. 12, bezeichnet. 


\section{Zur Provenienz}

Nach dem Tode des Künstlers befand sich das Gemälde zunächst weiter in Familienbesitz. Nach dem Ableben seiner Frau Frida wurde es jedoch nicht weiterhin von seinen Kindern verwaltet, sondern ging 1941 in den Besitz der Münchener Kunsthändlerin Maria Almas-Dietrich über. ${ }^{16}$ Diese führte ab 1918 die Kunstgalerie Almas in München und war zu jener Zeit die wichtigste Kunsthändlerin und lieferantin für Adolf Hitlers geplantes Führermuseum in Linz. Sie hatte mehrere Gemälde von Kaulbach in ihrem Besitz, die sie entweder an Hitler verkaufte oder aber versteigerte. Hierzu gehörte etwa das Gemälde Die Lautenschlägerin, das 1943 in München für die beachtliche Summe von 51.750 Reichsmark verkauft wurde. ${ }^{17}$

Das heute in Göttingen befindliche Bild verkaufte Almas-Dietrich ein Jahr nach dem Tode der Künstlergattin. Es ging in die Linzer Sammlung über und wurde daher, wie alle Gemälde dieses geplanten Projektes, mit einer speziellen Nummer versehen. Hitler, der vor allem Vertreter der Romantik sowie allgemein Münchner und Wiener Maler des 19. Jahrhunderts sammelte, hatte eigens für das Führermuseum den Kunsthistoriker Hans Posse als Leiter des sogenannten „Sonderauftrages Linz" betraut.18 Posse war von 1939 bis zu seinem Tode 1942 im Amt. Er hat das Gemälde von Almas-Dietrich vermutlich noch kurz vor seinem Tode um Weihnachten in der ,sechsten Lieferung“ erworben. ${ }^{19}$ Nach Kriegsende ging es in den Besitz der Bundesrepublik Deutschland über. Als Leihgabe wird es bis heute in der Göttinger Universitätskunstsammlung aufbewahrt.

Christian Scholl, Katharina Immoor

16 Vgl. die Bilddatenbank zum „Sonderauftrag Linz“ des Deutschen Historischen Museums (DHM) in Zusammenarbeit mit dem Bundesamt für zentrale Dienste und offene Vermögensfragen (BADV), Linz Nr. 2089: www.dhm.de/datenbank/linzdb/ (zuletzt aufgerufen 24.05.2013).

17 Vgl. Schwarz 2004, S. 166.

18 Vgl. ebd., S. 40.

19 Vgl. ebd., S. 56-58. 



\title{
„Und jeder hätte demnach seinen eigenen Gott. ${ }^{\text {(61 }}$ Die religiöse Malerei des 19. Jahrhunderts im Spannungsfeld zwischen Säkularisierung und religiöser Erneuerung
}

\author{
Julia Diekmann
}

Der Begriff Säkularisierung meint im ursprünglichen, kirchenrechtlichen Sinne den Übergang kirchlichen Eigentums in weltliche Hände. ${ }^{2}$ Darüber hinaus bezeichnet Säkularisierung aber auch einen sich seit der Frühen Neuzeit vollziehenden, übergreifenden geistesgeschichtlichen Vorgang in der europäischen Kultur. ${ }^{3}$ Dieser umfasst einen ganzen Komplex von Transformationsprozessen in Philosophie, Politik, Theologie, Rechtslehre und nicht zuletzt in der Bildenden Kunst. In diesem Zuge sind christliche „Zeit- Raum- Leid- und Erlösungsvorstellungen in die europäische und angelsächsische Kulturgeschichte "4 eingegangen und prägen diese bis heute auch in ihren säkularisierten Formen. ${ }^{5}$ Hierin zeigt sich die Ambivalenz des Säkularisationsbegriffs, der einerseits die Loslösung aus überkommenen (religiös-) kulturellen Vorstellungswelten, andererseits aber auch die kulturelle Gebundenheit und damit „bleibende Bezogenheit“ auf die christliche „Ursprungssphäre“ bedeutet. ${ }^{6}$ Auf diese Weise ist etwa ein Fortwirken religiöser Bildformeln in der profanen Malerei denkbar - das bekannteste Beispiel ist hier sicher Jacques-Louis

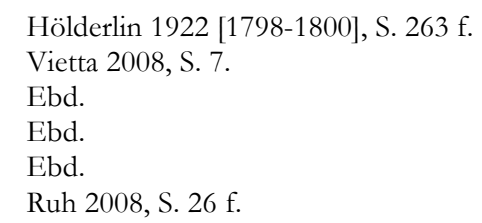


Davids Gemälde Der Tod des Marat von 1793 mit seiner Adaptation christlicher Pietà-Darstellungen. ${ }^{7}$ Säkularisation umfasst zudem die Möglichkeit, im Religiösen das allgemein Menschliche zu sehen - eine durch die Aufklärung verbreitete Option, die für das Verständnis von Johann Dominicus Fiorillos Gemälde Die heilige Familie (Kat. Nr. 6) in der Göttinger Universitätskunstsammlung von Bedeutung sein wird.

Obgleich der Begriff Säkularisation in seiner Ambivalenz an sich bereits komplexe und durchaus gegenläufige Entwicklungen beschreibt, reicht er doch nicht aus, um die vielschichtigen (kunst-)geschichtlichen Vorgänge im späten 18. und im 19. Jahrhundert adäquat zu beschreiben. Problematisch ist vor allem die mit diesem Terminus implizierte Teleologie: Entgegen der Annahme, Säkularisation als fortschreitenden und unumkehrbaren Prozess zu verstehen, sind Entwicklungen, die auf eine religiöse Erneuerung setzen, ernst zu nehmen. Dies betrifft gerade die Zeit um und nach 1800, in der sich zahlreiche Künstler „dem seit Beginn des Jahrhunderts kräftig anschwellenden Strom der religiösen Restauration“ anschlossen, „die politisch eine direkte Reaktion auf Aufklärung und Revolution war." "8 So wurde das 19. Jahrhundert in seinem Verlauf von zwei gegensätzlichen Strömungen geprägt: einer fortschreitenden Säkularisierung mit ausgeprägter Religionskritik einerseits und einer erneuerten Religiosität andererseits. ${ }^{9}$ In diesem Spannungsfeld stellte sich die Frage nach dem Verhältnis von Kunst und Religion neu: Welche Bedeutung hat die Religion für die Kunst und welche Bedeutung hat die Kunst für die Religion und für deren Vermittlung?10

\section{Nazarener}

Wenn von religiöser Kunst des 19. Jahrhundert in Deutschland die Rede ist, so gilt der erste Gedanke zumeist den Nazarenern. Dabei lässt sich nur schwer definieren, was nazarenische Kunst eigentlich ausmacht. ${ }^{11}$ Der Ursprung des Begriffes liegt vermutlich im Spott der Römer über die dort in einer religiös anmutenden Bruderschaft zusammenlebenden, altertümelnden, bleichen Deutschen mit langen Haaren (i nazareni) begründet. ${ }^{12}$ Der Lukasbund - wie sich die Kerngruppe der Nazarener selbst nannte - war 1809 in Wien gegründet worden. ${ }^{13}$ Dabei beinhaltete der dem Bund zugrunde liegende Bruderschaftsgedanke nicht nur religiöse Erneuerung, sondern auch ein Modell, welches später zum Topos eines modernen Kunstschaf-

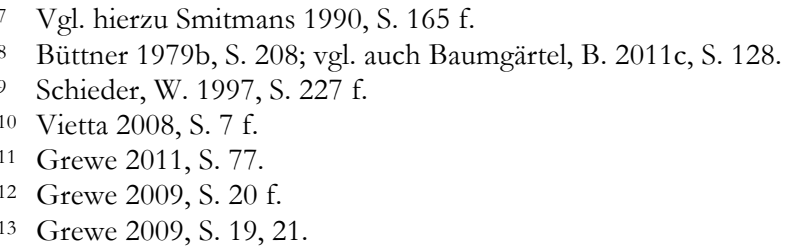

Vgl. hierzu Smitmans 1990, S. 165 f.

Büttner 1979b, S. 208; vgl. auch Baumgärtel, B. 2011c, S. 128.

Schieder, W. 1997, S. 227 f.

Vietta 2008, S. 7 f.

Grewe 2011, S. 77.

Grewe 2009, S. 20 f.

13 Grewe 2009, S. 19, 21. 
fens werden sollte: das „Künstlerkollektiv“.14 Vor allem aber rekurrierte er auf das Vorbild mittelalterlicher und frühneuzeitlicher Künstlerwerkstätten.

Bereits 1810 hatten die Gründungsmitglieder des Lukasbundes, angeführt von Friedrich Overbeck (1789-1869) und Franz Pforr (1788-1812), Wien in Richtung Rom verlassen. Begründet war dieser Entschluss in der Unzufriedenheit der Künstler mit den Verhältnissen an der Wiener Akademie. ${ }^{15}$ Schon 1820 löste sich der Lukasbunds wieder auf. ${ }^{16}$ Dennoch wirkten die Auffassungen der Nazarener in der deutschen Kunst noch lange nach, wie etwa Franz Xaver Laudages Gemälde Heilige Elisabeth von Thüringen von 1870 (Kat. Nr. 10) und Carl Oesterleys Altarbild Segnender Christus von 1881 (Kat. Nr. 11) in der Göttinger Universitätskunstsammlung belegen.

Eine vom Begriff „Nazarener“ suggerierte Stileinheit existierte dabei von Anfang an nicht. So vertraten vor allem Overbeck, Pforr und Peter von Cornelius (1783-1867) eine eher „radikal idealistische Richtung“, die „ArchaischPrimitivistisches“ mit einer gewissen Körperfeindlichkeit verband."17 Dagegen stand Wilhelm von Schadow (1788-1862) für eine ,naturalistischere und sinnlichere" Auffassung. ${ }^{18}$

\section{Raffael als Leitbild}

Charakteristisch für die nazarenischen Künstler ist ihre Abkehr vom Antikenideal Johann Joachim Winckelmanns (1717-1768). Als literarische Anregung können dabei insbesondere die von Wilhelm Heinrich Wackenroder (1773-1798) und mit Ludwig Tieck (1773-1853) verfassten Herzergießungen eines kunstliebenden Klosterbruders (1797) angesehen werden. Wackenroder stellt in einem Traumbild Raffael und Albrecht Dürer Hand in Hand als Leitbilder für eine Symbiose altitalienischer und altdeutscher Kunst dar. ${ }^{19}$ Diese Vorstellung wurde in Franz Pforrs Gemälde Sulamith und Maria (1811) ${ }^{20}$ sowie in Friedrich Overbecks Gemälde Italia und Germania $(1815-28)^{21}$ aufgegriffen. Ein weiterer wichtiger Impulsgeber der Nazarener aus dem Umfeld der literarischen Romantik war Friedrich Schlegel mit seinen Beiträgen in der Zeitschrift Europa. Im Aufsatz Vom Raphael aus dem Jahr 1803 empfiehlt auch er den zeitgenössischen Künstlern die Nachfolge dieses Künstlers. ${ }^{22}$

Die Raffael-Begeisterung wurde für die Nazarener in der Folgezeit geradezu identitätsstiftend. Von ihnen wurde der Künstler als Vertreter höchster Vollkom-

14 Grewe 2011, S. 79.

5 Grewe 2009, S. 19.

16 Ebd., S. 19, 21.

17 Grewe 2011, S. 79.

18 Ebd.

19 Wackenroder 1991 [1797], S. 95.

20 Schweinfurt, Museum Georg Schäfer. Vgl. Bushart/Eberle/Jensen 2002, S. 175-177.

21 München, Neue Pinakothek. Vgl. Ausst.-Kat. Düsseldorf 2011, Bd. 2, S. 94, 113.

22 Schlegel 1959 [1803]a, S. 48-60. 
menheit in der christlichen Kunst angesehen. ${ }^{23}$ Wenngleich es weitere nazarenische Leitbilder wie Dürer und die Maler des Mittelalters gab, die aufgrund ihrer vermeintlichen Einfachheit und „Naivität“ ebenfalls geschätzt wurden, so erfuhr der Urbinate doch eine besondere Verehrung und wurde regelrecht zum Künstlerheiligen stilisiert. ${ }^{24}$

Allerdings war die Raffaelbegeisterung alles andere als ein nazarenisches Alleinstellungsmerkmal. Vielmehr war sie um und nach 1800 generell verbreitet und wurde auch von den Gegnern der Nazarener kultiviert. Dies gilt für Goethe 25 ebenso wie für die junghegelianischen Kritiker in der Zeit des Vormärz. ${ }^{26}$ So ist auch festzuhalten, dass bereits Winckelmann Raffael als Leitstern vor Augen hatte, indem er ihn gleichsam als Bindeglied zwischen Antike und Renaissance ansah. ${ }^{27}$ Ein Beispiel für die Vorbildwirkung Raffaels in einem von den Nazarenern noch unbeeinflussten religiösen Gemälde bietet in der Göttinger Universitätskunstsammlung Karl Franz Jacob Heinrich Schumanns Heilige Familie aus dem Jahr 1819 (Kat. Nr. 5).

Wenngleich die Raffael-Verehrung bereits in den Viten des Giorgio Vasari vorgebildet ist, stellt die Apotheose des Künstlers im Kontext einer Verschmelzung von Kunst und Religion doch eine Besonderheit des 19. Jahrhunderts dar. Bis zu einem gewissen Gerade kommt hier das Konzept einer Kunstreligion zum Tragen. ${ }^{28}$ In der Vorstellungswelt der Nazarener war die Kunst der Religion allerdings klar untergeordnet. ${ }^{29}$ Für diese Gruppierung blieb Religion der Ursprung und die eigentliche Bestimmung von Kunst. Auch eine solche Haltung wurde auf Raffael projiziert, der nach Ansicht dieser Maler erst durch das Studium der Bibel zum „göttlichen Raffael“ geworden sei. ${ }^{30}$ So war für die Nazarener selbst das Studium

23 Vgl. Grewe 2012, S. 255-279.

24 Ebd. S. 255.

25 Vgl. Ausst.-Kat. Frankfurt a. M. 1994, S. 16 f.

26 Vgl. Scholl 2012b.

27 Schmälzle 2012, S. 101.

28 Die Idee der Kunstreligion basiert auf dem Gedanken, dass Kunst selbst die Rolle der Religion und somit der kulturellen Hegemonie übernimmt. Im Kern stellen bereits Wilhelm Heinrich Wackenroders und Ludwig Tiecks Herzensergießungen eine Manifestation der Idee einer Kunstreligion dar, denn der Klosterbruder vergleicht die Auseinandersetzung mit der Kunst mit einem Gebet (Wackenroder 1991 [1797], S. 106). Zum ersten Mal publiziert wurde der Begriff „Kunstreligion“ vermutlich in Friedrich Daniel Ernst Schleiermachers Schrift Über die Religion. Reden an die Gebildeten unter ibren Veräcbtern (Schleiermacher 2002 [1899], S. 120), vgl. auch Plaul 2011, S. 187-206. Gerade im Laufe des 19. Jahrhunderts wurde die Kunst zu einer Art Ersatzreligion.

29 Grewe 2012, S. 257-260. Gerade hier zeigt sich, wie problematisch eine Übertragung des Konzepts der „Kunstreligion“ auf die Nazarener ist. Cordula Grewe schlägt dementsprechend vor, den Künstler in der Vorstellungswelt der Nazarener eher als „Vermittlungsinstanz“ zu sehen, der als Schnittstelle zwischen göttlichem Schöpfungsakt und menschlichem Kunstschaffen agiert, vgl. ebd., S. 260-266.

30 Baumgärtel, B. 2011c, S. 128. 
der Bibel fundamentaler Bestandteil ihrer Arbeit. ${ }^{31}$ Auf der Suche nach einem traditionsreichen religiösen Fundament, bei dem die Kunstpflege fest institutionalisiert war, konvertierten viele der ursprünglich protestantischen Künstler im Umfeld der Nazarener zum Katholizismus.

\section{Alternativen}

Bedeutsam war der Anspruch der Nazarener auf Volksnähe sowie auf eine lebensnahe, dabei auch national und sogar lokal identifizierbare Kunst. Dieser Anspruch änderte allerdings nichts am idealisierenden Charakter der als Erbauungs- und Lehrstücke gedachten Bilder. ${ }^{32}$ Gerade in Düsseldorf schlug sich dies in einem akademisch-nazarenischen Christustypus nieder, welcher dem Betrachter zwar milde, aber auch Achtung gebietend gegenüber tritt. Zurückzuführen ist dieser Typus unter anderem auf den Christus der Disputà Raffaels. ${ }^{33}$ Ein aussagekräftiges Beispiel für diese Auffassung bietet etwa das Mittelbild von Wilhelm von Schadows Triptychon Purgatorium - Paradies - Hölle (1848-1852). ${ }^{34}$ Im Bestand der Göttinger Universitätskunstsammlung findet sich als Beleg dieser Auffassungsweise Carl Oesterleys spätnazarenisches Werk Segnender Christus (Kat. Nr. 11).

Um diesen Bildtypus abzulösen, wurden etwa ab der Mitte des 19. Jahrhunderts alternative Ansätze entwickelt. Ein Weg bestand in der völligen Abkehr von den Nazarenern und in der Kultivierung eines an niederländischen und altdeutschen Meistern orientierten Naturalismus. ${ }^{35}$ Als Hauptvertreter dieser Richtung kann hier Eduard von Gebhardt genannt werden, dessen Skizze Bei der Kupplerin (Kat. Nr. 16) sich im Bestand der Göttinger Universitätskunstsammlung befindet. Es handelt sich mithin nicht um eine religiöse Darstellung, sondern um eine Genreszene.

Während Christus bei Oesterley als milde triumphierender, zentral ins Bild gesetzter, von strahlendem Licht hinterfangener Mann mit ausgebreiteten Armen auftritt, zeigt Gebhardt in seinen religiösen Bildern einen in der Menschenmenge agierenden, menschlich-einfachen Christus. Im Vergleich zu Oesterleys überkonfessionell auftretendem Heiland sollte hier eine genuin lutherische Bildsprache entwickelt werden. ${ }^{36}$ Einen weiteren Aspekt von Gebhardts Überzeugungsrhetorik stellt die Verbindung von Elementen der frühen Neuzeit - der Zeit der Reforma-

31 Ebd., vgl. etwa Friedrich Overbecks Gemälde Selbstbildnis mit der Bibel, 1808/09, Lübeck, Museum für Kunst und Kulturgeschichte. Siehe hierzu Ausst.-Kat. Lübeck 1989, S. 108 f. sowie Scholl 2006, S. $81 \mathrm{f}$.

32 Baumgärtel, B. 2011c, S. 128.

33 Ebd.

34 Düsseldorf, Museum Kunstpalast, Dauerleihgabe des Oberlandesgerichts Düsseldorf. Vgl. Aust.Kat. Düsseldorf 2011, Bd. 2, S. 142-146.

35 Baumgärtel, B. 2011c, S. 128.

36 Vgl. Ausst.-Kat. Hamburg 1983, S. 504 f.; Levin, M. 2011, S. 241 f. Zu beachten ist, dass Oesterley auch Protestant war und Bilder für protestantische Kirchen schuf. 
tion - mit zeitgenössischen Elementen sowie die Einbindung vieler Szenen in eine topographisch bestimmbare mitteleuropäische Landschaft dar. ${ }^{37}$ Gebhardts religiöse Bilder, insbesondere seine Wandmalereien, sind demnach als visualisierte Predigten mit deutlichem Identifikationspotential für den einzelnen Gläubigen angelegt. 38

Auch innerhalb des Katholizismus entwickelten sich ab der Mitte des Jahrhunderts weitere Strömungen, die ein breites Spektrum umspannen. Ihre verschiedenen Auffassungen reichen von einer Abkehr von kirchlichen Dogmen bis hin zur nachdrücklichen Verfechtung eines an Rom orientierten Katholizismus ${ }^{39}$ sowie der Errichtung neuer, an Volksfrömmigkeit ausgerichteter Dogmen. ${ }^{40}$ So ist es keineswegs verwunderlich, dass die (spät-)nazarenische Kunst am Ende des Jahrhunderts nicht mehr die alleinige künstlerische Ausdruckmöglichkeit katholischer Glaubensinhalte repräsentierte. ${ }^{41}$

Gerade bei Aufträgen für Kirchenausstattungen bekamen die Spätnazarener zunehmend Konkurrenz von Vertretern archaisierender Strömungen, welche sich an frühchristlichen und byzantinischen Vorbildern orientierten. ${ }^{42}$ Dies lag an der relativen Individualität der Nazarener, welche sich den in historisierenden Stilen neu erbauten katholischen Kirchen nicht unmittelbar einfügen ließ und dem Streben nach stilistischer Einheitlichkeit der Ensembles entgegenstand. Ihr Stil stieß daher bei den an den Bauten beteiligten Historikern, insbesondere aber auch bei Theologen auf Ablehnung, denn diese waren an der Demonstration von Geschlossenheit der Institution Kirche auch nach außen interessiert. ${ }^{43}$

Nichtbiblische Heiligenbilder spielten Anfang des 19. Jahrhunderts zunächst keine große Rolle. Dies lag zum einen an den Nachwirkungen der Aufklärung, aber auch an einer ebenfalls distanzierten Haltung der katholischen Kirche gegenüber diesen Themen. ${ }^{44}$ Dies änderte sich mit der Intensivierung der Konfessionsstreitigkeiten in der Zeit des Vormärz sowie in der zweiten Hälfte des Jahrhunderts. So wurde beispielsweise 1841 der Verein zur Verbreitung religiöser Bilder gegründet, mit dem Ziel, das Niveau von Andachtsbildern zu steigern. ${ }^{45}$ In einen solchen Kontext ist wohl auch die Entstehung der Heiligen Elisabeth von Thüringen Franz Xaver Laudages (Kat. Nr. 10) einzuordnen, insbesondere, da nach derzeitigem Forschungsstand ein Bezug zum Erzbistum Paderborn anzunehmen ist.

37 Baumgärtel, B. 2011d, S. 158.

38 Bieber/Mai 1979, S. 174.

39 Ausgelöst durch die italienische Einheit und den Rückzug des Papstes in den Vatikan 1870. Vgl. Clark, C. 2003, S. 14-21.

40 Erhebung zum Dogma und Definition der unbefleckten Empfängnis am 08. Dezember 1854 durch Papst Pius IX., vgl. Clark, C. 2003, S. 18.

41 Smitmans 1980, S. 243.

42 Ebd.

43 Ebd.

44 Vgl. Ausst.-Kat. Düsseldorf 2011, Bd. 2, S. 118.

45 Ebd. 


\section{Religiöse Kunst in der Göttinger Universitätskunstsammlung}

Das Spektrum der in der Göttinger Kunstsammlung vertretenen religiösen Gemälde des 19. Jahrhunderts ist breit. Es beginnt mit Werken, die noch nicht von der nazarenischen Auffassung geprägt sind, sondern eine akademisch-klassizistische Bildauffassung zeigen, wie Franz Jakob Heinrich Schumanns Heilige Familie mit den Engeln (Kat. Nr. 5) bzw. trotz der Kenntnis nazarenischer Kunst bewusst an einer älteren, italienisch beeinflussten Auffassung des religiösen Bildes festhalten, wie Johann Dominicus Fiorillos Heilige Familie (Kat. Nr. 6). Fiorillos Gemälde ist eng mit seinem kunsttheoretischen Werk verbunden und bietet somit einen interessanten Bezugspunkt zu den zeitaktuellen kunsttheoretischen Auseinandersetzungen sowie ihren praktischen Umsetzungen.

Die Düsseldorfer Tradition nazarenischer Malerei ist vertreten durch die Madonnenbilder Heinrich Petris (Kat. Nr. 8+9) sowie durch Carl Oesterleys Gemälde Segnender Christus (Kat. Nr. 11). Nazarenisch beeinflusst ist auch Franz Xaver Laudages Heilige Elisabeth von Thüringen (Kat. Nr. 10). Weiterhin ist mit Francesco Podesti und seinen Skizzen Taufe und Heilung des Paulus (Kat. Nr. 7) ein Italiener vertreten, welcher vom Purismo beeinflusst war, dessen Ziele und Auffassungen jenen der Nazarener ähnelten. ${ }^{46}$ So erweist sich der Bestand der Universitätskunstsammlung Göttingen an religiöser Malerei des 19. Jahrhunderts trotz seiner Überschaubarkeit gleichsam als Spiegel der Ausdrucksformen des Centenniums für den religiösen Themenkreis.

46 Metken 1977, S. 327-331; Thimann 2005. 

Kat. Nr. 5

Karl Franz Jacob Heinrich Schumann (1767-1827)

\section{Die heilige Familie mit den Engeln}

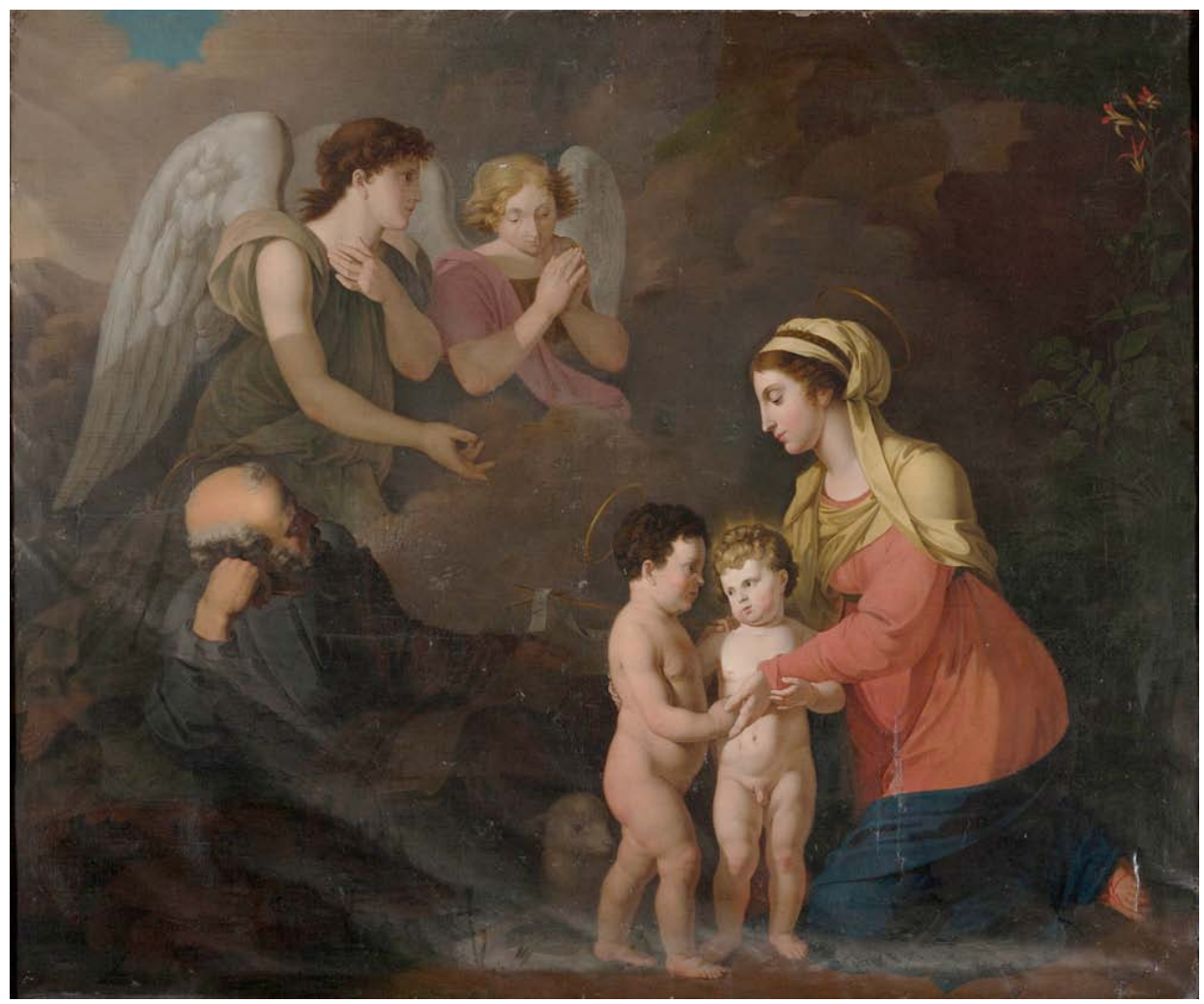

Öl auf Leinwand, 163 x 195 cm, signiert und datiert unten links, Schenkung von Prof. Dr. Felix Droysen, Göttingen, Inv. Nr. GG 178

Karl Franz Jacob Heinrich Schumanns Gemälde zeigt die Heilige Familie mit dem Johannesknaben, begleitet von zwei Engeln. Die szenische Darstellung dieser biblischen Figuren geht zurück auf das in den Meditationen des Pseudo-Bonaventura geschilderte Zusammentreffen des jungen Johannes mit der Heiligen Familie nach 
deren Rückkehr aus Ägypten. ${ }^{1}$ Darstellungen dieses Themas können sowohl Joseph als auch Elisabeth (die Mutter des Johannes) sowie Engel einschließen; oft werden aber auch nur die drei Hauptpersonen gezeigt. Ikonographisch implizieren diese Darstellungen zumeist einen Verweis auf die Passion.

Die von Schumann gemalten Figurentypen der Gottesmutter und der gelockten Knaben verweisen deutlich auf Raffael als Vorbild. In dessen Werk sind eine Reihe von Darstellungen dieses Themas zu finden, so z.B. Die Heilige Familie mit Johannes (Madonna del Passeggio) aus der Zeit um 1514 oder Die Heilige Familie mit beiliger Elisabeth und heiligem Johannes (Madonna oder Heilige Familie Franz I., Abb. 8) von 1517/18.2 Mit Raffael lassen sich auch die als Dreieck angelegte Komposition und das Kolorit der Gruppe um Maria in Verbindung bringen. Die Anordnung dieser Gruppe auf dem querrechteckigen Format, die unter einer gewissen Spannung stehende Kombination mit den Engeln, das Helldunkel, die Beleuchtung und die Farbigkeit des Hintergrundes verweisen dagegen auf einen anderen Künstler: auf Michelangelo Merisi da Caravaggio. Dass es sogar direkte Bezüge auf das Werk Caravaggios gibt, wird sich bei genauerer Betrachtung des Bildes bestätigen.

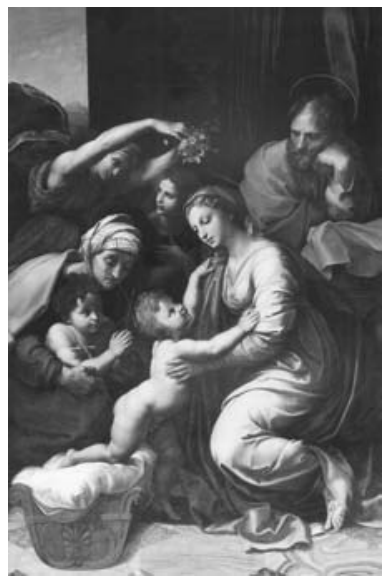

Abb. 8: Raffael: Die Heilige Familie Franz I., 1518, Öl auf Holz, übertragen auf Leinwand, $207 \times 140 \mathrm{~cm}$, Paris, Louvre

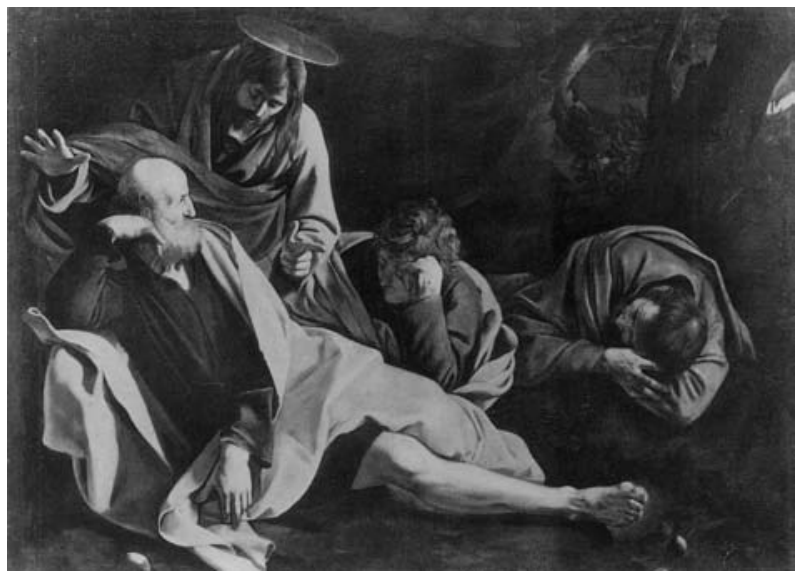

Abb. 9: Caravaggio: Christus am Ölberg, 1604-06, Öl auf Leinwand, 154 x $222 \mathrm{~cm}$, früher Berlin, Kaiser-FriedrichMuseum, verschollen

So zeigen Beleuchtung und Komposition auf eindrucksvolle Weise, dass nicht nur Raffael, sondern auch Caravaggio zu Beginn des 19. Jahrhunderts in der akademischen Kunst noch als nachahmenswert angesehen wurde, und dass Bildmotive 
beider Künstler sogar auf eklektische Weise miteinander verknüpft werden konnten.

Eher auf Raffael verweist dabei die das Gemälde beherrschende Gruppe Marias mit den beiden Kindern. Sie ist aus dem Zentrum des Bildes nach rechts verschoben, wobei Rücken und linkes Bein von Johannes dem Täufer gerade noch die Mittelachse schneiden. Maria, im Profil mit leicht gedrehtem Oberkörper wiedergegeben, kniet rechts neben den beiden Knaben. Ihr fürsorglicher Blick richtet sich auf beide Kinder. Ihre linke Hand hält die Rechte des Johannes und scheint sie in die rechte Hand Jesu legen zu wollen, der den Arm seiner Mutter mit der linken Hand berührt. Jesus fasst mit seinem rechten Arm um Johannes Rücken, während dieser ihm die linke Hand auf die Schulter legt. Dieses Motiv der Händeverknüpfung ist von Schumann mit großer Sorgfalt entwickelt worden und bildet den Fokus des Bildes.

Johannes ist ebenfalls im Profil dargestellt und mit seinem Attribut, dem Kreuzstab, gekennzeichnet, um den sich ein Schriftband legt. Auf diesem sind die Buchstaben „AGN“ und das Wort „DEI“ zu erkennen, was auf den traditionellen Schriftzug „ECCE AGNUS DEI“ (nach des Täufers Vorausdeutung auf Christus „Siehe, das ist Gottes Lamm, das der Welt Sünde trägt!“" Joh. 1, 29) schließen lässt. Der Jesusknabe selbst steht zwischen der Gottesmutter und Johannes, wird en face gezeigt und neigt den Kopf zu Johannes. Der frontal präsentierte Christus wird also gleichsam gerahmt von den Profilfiguren der Maria und des Johannes. Das Lamm als zusätzliches Attribut des Johannes liegt links hinter der Gruppe im verschatteten Bereich; von ihm sind lediglich Kopf und Hals erkennbar.

Oberhalb Marias, beinahe am rechten oberen Bildrand, sind rote Blüten zu sehen, die aus einer Pflanzengruppe herauswachsen. Diese hat ihren Ursprung im Bereich hinter der knienden Jungfrau. Es handelt sich vermutlich um die Blüten der Akeleipflanze, einem alten Fruchtbarkeits- und Mariensymbol. Ihre vogelähnlichen Blütenblätter brachten die volkstümlich auch Taubenblume genannte Akelei in Verbindung mit dem Heiligen Geist, der in der Regel als Taube dargestellt wird. Als Verweis auf Christus als dem kommenden Heil erscheint die Akelei auch auf Bildern, die Johannes den Täufer darstellen. ${ }^{3}$

Auf einer Rasenfläche gelagert ist auf der linken Bildhälfte Joseph erkennbar, der, den Kopf auf seinen rechten Arm gestützt, die Szenerie zu betrachten scheint, tatsächlich aber eher darüber hinwegschaut. ${ }^{4}$ Mit der linken Hand hält er eine ausgerollte Schriftrolle, die seinen Schoß bedeckt.

Caravaggio zeigt in seinem 1604-1606 entstandenen Gemälde Christus am Ölberg (Abb. 9) den Apostel Petrus in einer liegenden Haltung, die beinahe vollständig jener des Joseph in Schumanns Bild entspricht. ${ }^{5}$ Caravaggios Petrus ist lediglich höher aufgerichtet, er stützt seinen Kopf jedoch ebenso auf seiner Hand ab, wie

3 Seibert 2002, S. 18 f.

$4 \mathrm{Ob}$ dies gewollt ist, lässt sich angesichts des eklektischen Charakters der Bildkomposition nur schwer entscheiden.

5 Vgl. Ausst.-Kat. Berlin 2001a, S. 29. 
Schumanns Joseph. Hinter ihm sind bei Caravaggio der erzürnte Jesus sowie Johannes und Jakobus sichtbar. Schumanns Rückgriff hat dabei einen ganz konkreten Hintergrund: 1815 kaufte Friedrich Wilhelm III. von Preußen (1797-1840) in Paris die Sammlung Giustiniani, mit der auch Caravaggios Gemälde Christus am Ölberg nach Berlin gelangte. Ab dem 12. Mai 1816 wurde die Kollektion in den Räumen der Berliner Akademie der Künste gezeigt. ${ }^{6}$ Spätestens hier muss Schumann dem Bild begegnet sein. Seine Heilige Familie mit den Engeln von 1819 kann damit als eine direkte Reaktion auf diesen spektakulären Ankauf angesehen werden.

Hinter Joseph breitet sich in Schumanns Gemälde eine Wolken- und Felslandschaft aus, deren Details aufgrund des schlechten Zustandes des Bildes nur schwer $z u$ erkennen sind. In dieser Landschaft erscheinen oberhalb von Joseph zwei geflügelte Engel. Zwar entspricht die vornehme Zurückhaltung dieser Engel keineswegs dem expressiven Ausdruck von Jesus und Johannes bei Caravaggio. Gleichwohl hat deren Grunddisposition in Verbindung mit der Liegefigur durchaus vorbildhaft auf Schumann gewirkt. Dessen linker Engel weist mit einem Zeigegestus auf die Gruppe Marias und der beiden Knaben im Vordergrund des Bildes, blickt aber in Richtung der Akelei am rechten Bildrand. Der rechte Engel hat die Hände in anbetender Weise zusammengelegt und schaut auf die drei Hauptpersonen.

Maria, Joseph und der Johannesknabe sind jeweils mit einem Nimbus in Form eines Goldreifs gekennzeichnet; lediglich hinter dem Kopf des Christusknaben leuchtet ein kleiner Strahlenkranz. Insgesamt zeichnet sich das Bild durch eine divergente Lichtführung aus, die eine überzeitliche Situation charakterisiert. So sind die Figuren im Vordergrund von einer außerbildlichen Lichtquelle von links oben beleuchtet. Dabei erscheint das Inkarnat des Christusknaben wesentlich heller als jenes des Johannesknaben und auch Marias. Diese ganz in akademischer Tradition stehende Differenzierung bezieht sich auf die unterschiedlichen Alter, aber auch auf die Göttlichkeit Jesu und auf die legendarische Lebensweise des sonnengebräunten Johannes.

Der Körper Josephs verschwindet in seinem dunklen graublauen Gewand bereits im Dunkel, lediglich sein weitgehend haarloser Kopf und die Hand, auf die er diesen abstützt, sind beleuchtet. Auch der Großteil des Gesichts liegt im Schatten. Das Joseph umfangende Dunkel charakterisiert weite Teile des Bildes und hinterfängt die unteren Figuren vollständig. Lediglich Maria mit den beiden Knaben sowie die roten Blüten der Akelei, welche mit der Farbe von Marias Kleid korrespondieren, leuchten aus dem Dunkel heraus. Damit wird die Bedeutung dieser Bildelemente verdeutlicht.

Links oben im Bild reißen die Wolken hinter den beiden Engeln auf und es erscheint das Blau des Himmels. Aus dieser Richtung scheinen die Engel auch beleuchtet zu werden. Obwohl sie nicht in der himmlischen Sphäre schweben, sondern hinter Joseph auf dem Boden stehen, wird hier durch die Lichtführung eine 
Unterteilung in eine himmlische und eine irdische Sphäre vorgenommen. Wie insbesondere an den Haaren des rechten Engels erkennbar ist, weht in dieser himmlischen Sphäre offensichtlich ein Wind, von dem in der irdischen Sphäre kein Hauch spürbar ist. So, wie die Figurengruppe im rechten unteren Bild-Viertel mit den Symbolen des Kreuzes und des Lammes das Opfer Christi thematisiert, erscheint als Gegenpart im linken oberen Bildbereich die daraus folgende Erlösung im sich aufhellenden Himmel.

Kompositorisch fällt das Verhältnis der Personen zum praktisch nicht vorhandenen Bildraum auf. Die einzelnen Gruppen und Einzelfiguren (Maria mit den beiden Knaben, die beiden Engel sowie Joseph) wirken beinahe wie ausgeschnitten und in einen kaum definierten, dunklen Bildgrund montiert. Interaktion zwischen den Personen findet nur in der Gruppe Marias und der beiden Jungen statt. Mit Blick und Zeigegestus der Engel und der Kopfwendung des Joseph wird eine Verbindung der Bildteile versucht, die aber - nicht zuletzt aufgrund der Lichtsituation - nicht wirklich gelingt. Hier darf man sicher von kompositorischen Schwächen eines heute nahezu unbekannten Künstlers sprechen, der gleichwohl zu den interessanten Persönlichkeiten in einem immer noch zu wenig erforschten Feld der Berliner Kunstgeschichte gehört. Was weiß man über den Maler dieses in seinen Ausmaßen und in dem, was es auf eklektische Weise kompositorisch und koloristisch zusammenzwingt, durchaus anspruchsvollen Gemäldes?

\section{Der Künstler}

Karl Franz Jacob Heinrich Schumann, Sohn des Rechtsgelehrten und Kunstliebhabers Karl Schumann, erfuhr durch diesen bereits in seiner Kindheit Förderung auf künstlerischem Gebiet, indem er zum in Berlin wirkenden Hofbildhauer Giovanni Battista Selvino (1744-1789) in die Zeichenlehre gegeben wurde. Der selbst praktisch in Musik und Dichtkunst geübte Vater strebte für seinen Sohn offenbar frühzeitig eine Künstlerkarriere an. ${ }^{7}$ Dieser absolvierte seine Ausbildung bei dem Berliner Hofmaler Johann Christoph Frisch (1738-1815) und reiste 1795 auf Vermittlung der Berliner Akademie der Künste nach Rom, um seine Studien fortzusetzen. ${ }^{8}$ Nach einem Aufenthalt in Florenz kehrte er 1798 nach Berlin zurück, wo er 1802 eine Professur an der Akademie erhielt und in dieser Funktion der Zeichenklasse vorstand. ${ }^{9}$ Als sich 1814 der Berliner Künstlerverein konstituierte, gehörte Schumann zu dessen Gründungsmitgliedern. ${ }^{10} 1816$ wurde er zum Sekretär der Akademie ernannt.

\footnotetext{
Lacher 2005b, S. 66 f.

Ebd. S. 69 f.

Thieme/Becker 1907-1950, Bd. 30, 1936, S. 341.

10 Lacher 2005b, S. 71.
} 
Im Jahre 1810 zeigte Schumann eine Heilige Familie im Rahmen der Berliner Akademieausstellung. ${ }^{11} \mathrm{Da}$ das Göttinger Bild jedoch auf 1819 datiert ist, ${ }^{12}$ muss es sich um eine spätere Fassung dieses Themas handeln. Der Verbleib des 1810 ausgestellten Bildes ist nicht bekannt. Unklar ist auch, ob das Göttinger Gemälde für einen konkreten Zweck gemalt wurde. Laut Inventarbuch der Universitätskunstsammlung stammt die Heilige Familie mit den Engeln aus dem Nachlass des in den 1870er Jahren in Göttingen als Privatdozent tätigen Dr. Robert Wiese. Wie es danach in den Besitz Prof. Dr. Felix Droysens gelangte, der es schließlich der Universitätskunstsammlung vermachte, ist unklar. ${ }^{13}$

Ansonsten malte Schumann vorwiegend Szenen aus der brandenburgischen Geschichte, welche sich vor den Zerstörungen des zweiten Weltkriegs im königlichen Schloss und im Kronprinzenpalais in Berlin befanden. ${ }^{14}$ Ebenfalls im Jahr 1816 gab Friedrich Wilhelm III. bei einigen Akademiemitgliedern einen Zyklus von sechs Gemälden für die Potsdamer Garnisonkirche in Auftrag, zu dem Schumann ein Bild beisteuerte, dessen Verbleib derzeit ungeklärt ist. ${ }^{15}$ Dass das Bild in der Göttinger Universitätskunstsammlung für die Ausstattung der Potsdamer Garnisonkirche konzipiert wurde, kann allein aufgrund des Querformats ausgeschlossen werden. ${ }^{16}$ Dennoch wäre eine intendierte Bestimmung für eine Kirchenausstattung durchaus denkbar. Hierfür könnten u. a. die beträchtlichen Ausmaße des Bildes sowie die auf Untersicht angelegte Komposition sprechen.

Allerdings scheint Schumann auch bei religiösen Werken mitunter den Weg gewählt zu haben, ein Gemälde ohne spezifischen Auftrag für eine Ausstellung zu schaffen, das dann zum freien Verkauf stand. So stellte er 1816 ein Bild in der Berliner Akademie aus, welches anschließend vom König erworben und der Kirche in Paretz geschenkt wurde, wo es sich bis zum heutigen Zeitpunkt befindet. ${ }^{17}$ Es trägt den Titel Christus wird ₹u Grabe getragen (Abb. 10). ${ }^{18}$

11 Börsch-Supan 1971: 1810, S. 8, Nr. 27.

12 Unten links: „Schuman. p. 1819“; vgl. Stechow 1926, S. 52; Unverfehrt 1987, S. 190.

13 Göttingen, Kunstsammlung der Universität, Inventar 1884 ff., S. 89. Vgl. hierzu den Beitrag „Die Provenienzen der Göttinger Gemälde des 19. Jahrhunderts“ von Anne-Katrin Sors in diesem Band.

14 Thieme/Becker 1907-1950, Bd. 30, 1936, S. 341. Laut Lacher 2005b, S. 71 sollen sich noch zwei Historiengemälde im Besitz der Stiftung Preußischer Schlösser und Gärten befinden. Vgl. dazu auch Börsch-Supan 1980, S. 236-237.

15 Ich danke an dieser Stelle Prof. Dr. Anselm Schubert, Erfurt, für den Hinweis (am 11.05.2012) auf die „Acta betr. die von mehreren Künstlern für Garnison-Kirche zu Potsdam angefertigten Gemälde“ GStaA PK Berlin I. HA Rep. 89, Nr. 23450, fol. 6v, der zufolge Schumann für die Garnisonkirche Die Auferstehung Christi malte. Da der König Schumanns Skizzen „ganz verfehlt“ (ebd.) fand, wurde Peter Rittig (1789-1840) mit der Ausführung zu einem Ungläubigen Thomas beauftragt (vgl. ebd. und Bamberg 2006, S. 139).

16 Vgl. dazu die zeitgenössische Innenansicht mit einem Teil der ausgeführten Bilder sowie den Längsschnitt der Garnisonkirche bei Bamberg 2005, S. 36-37.

17 Schadow 1987 [1849], Bd. 2, S. 590 f.

18 Lacher 2005b, S. 71. 


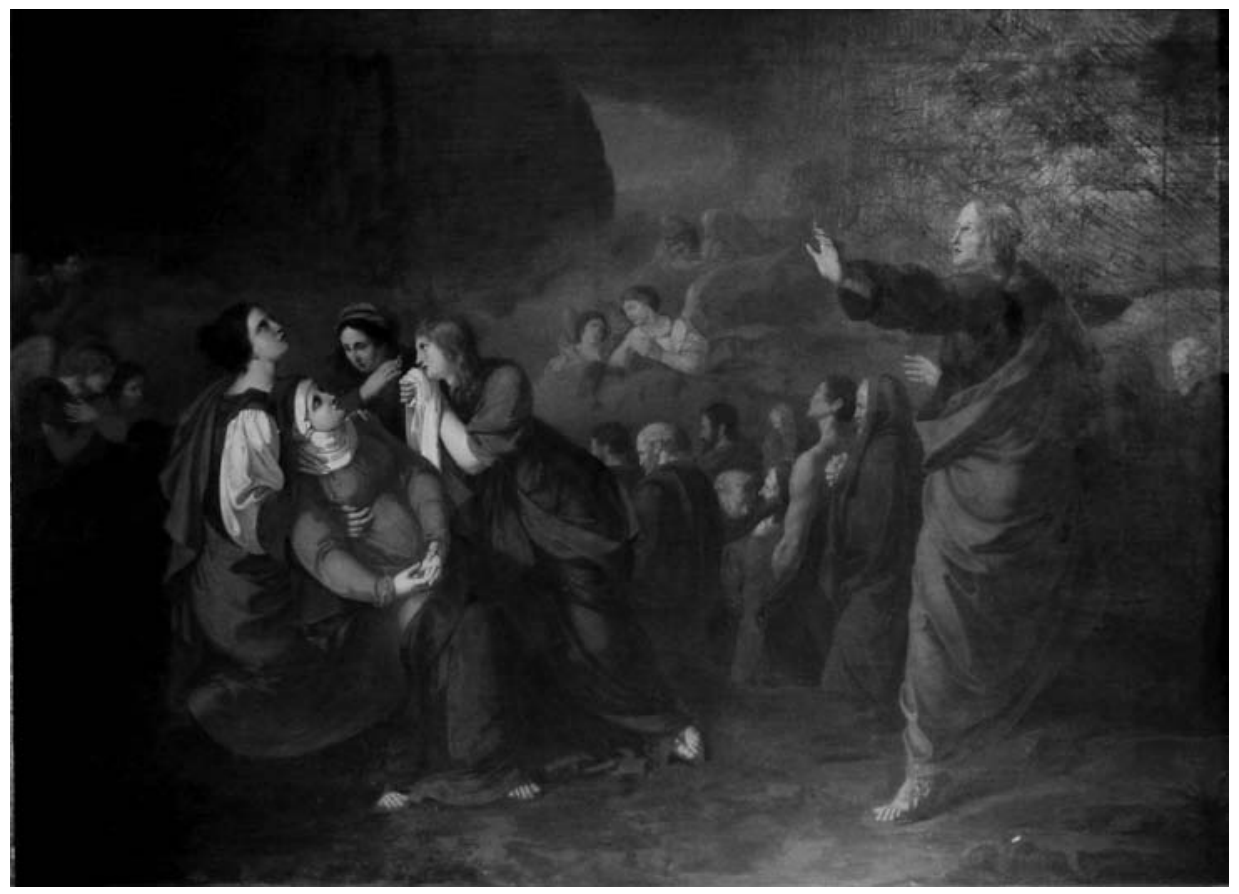

Abb. 10: Karl Franz Jacob Heinrich Schumann: Christus wird zu Grabe getragen, um 1816, Öl auf Leinwand, Paretz, evangelische Kirche

Zum jetzigen Zeitpunkt stellen das Gemälde in Paretz sowie dasjenige in der Göttinger Universitätskunstsammlung die einzigen bekannten Bilder religiösen Inhalts aus Schumanns CEuvre dar. Ein Vergleich der beiden Werke offenbart dabei bemerkenswerte Übereinstimmungen. Analogien ergeben sich vor allem bei der inkohärenten Lichtführung, bei der Hintergrundbehandlung sowie bei konkreten Figurentypen (z.B. bei den Engeln). Gleich dem Göttinger Bild erscheinen in Paretz die Personen wie ausgeschnitten und eklektisch vor einem weitgehend unbestimmt gelassenen Hintergrund zusammengefügt. Wie bei der Heiligen Familie findet auch zwischen den Personen des Paretzer Gemäldes kaum Interaktion statt. Gleichzeitig belegt die ungewöhnliche Komposition mit der im Hintergrund geradezu versteckten Hauptszene Schumanns Streben, sein Publikum mit ungewöhnlichen Kompositionen zu beeindrucken. ${ }^{19}$

Das Max-Planck-Gymnasium in Göttingen besitzt noch ein weiteres, erst kürzlich grundlegend restauriertes Bild des Künstlers, Ödipus und Antigone in Kolonos, das auf das Jahr 1808 datiert ist. Auf diesem Bild wurde erst anlässlich der Restaurie-

19 An dieser Stelle danke ich Harald Just, Diemarden, herzlich für die in Paretz gemachten Aufnahmen des Gemäldes. 
rung im Jahr 2009 die Signatur Schumanns entdeckt. ${ }^{20}$ So befinden sich gleich zwei großformatige Arbeiten dieses Malers in Göttingen. Obgleich man nach wie vor sehr wenig über ihn weiß, deutet sich damit doch ein durchaus vielschichtiges CEuvre an, das sich zwar weitgehend im Bereich der Historienmalerei bewegt, dabei aber sowohl religiöse Bilder als auch Profanhistorien und mythologische Darstellungen umfasst.

\section{Akademische Malerei im Banne Raffaels}

Schumanns Euvre steht für eine immer noch zu wenig erforschte akademische Kunst aus einer Umbruchszeit, in der die Nazarener gerade im Begriff waren, die führenden Kunsteinrichtungen in Deutschland zu übernehmen und umzuprägen. So orientiert sich der Künstler an dem um 1800 allgemein verehrten Raffael, zeigt sich dabei aber noch nicht beeinflusst von der spezifisch nazarenischen Perspektive auf die Malerei des Urbinaten. Er orientierte sich beispielsweise nicht - wie die Nazarener - an Raffaels lichten Hintergrundlandschaften. Schumanns Bildhintergrund ist vielmehr von Dunkelheit gekennzeichnet und weist geradezu caravaggeske Lichtführungen auf; die für Raffael typische, kräftige Farbigkeit beschränkt sich auf die Hauptgruppe. Hier zeigt sich - ebenso wie im gesamten Bildaufbau die Bindung Schumanns an die klassizistische Tradition der Berliner Akademie, die Ende des 18. Jahrhunderts vor allem durch die beiden Reformer Daniel Nikolaus Chodowiecki und Johann Gottfried Schadow begründet worden war. ${ }^{21}$

Die im Jahre 1696 von Kurfürst Friedrich III. ins Leben gerufene Akademie22 war im 18. Jahrhundert zunächst etwas vernachlässigt worden. ${ }^{23}$ Dies änderte sich ab 1786, und unter Friedrich Wilhelm III. wurde die Akademie schließlich neu belebt. ${ }^{24}$ Die Akademietätigkeit stand dabei unter der Prämisse der Lehr- und Erlernbarkeit von Kunst. ${ }^{25}$ Mit der Vergabe der Rom-Stipendien, zu deren NutznieBern auch Schumann gehörte, wurde seitens der Akademie das Ziel verfolgt, die jungen deutschen Künstler an den kanonisierten Vorbildern der Antike und der Renaissance zu schulen. Es wurde ein Formenkanon vermittelt, der sich wissenschaftlich-analytisch generierte und an der Natur sowie an der Antike orientiert war. ${ }^{26}$ Die Zeichnung - insbesondere nach Antiken oder kanonisch festgelegten

\footnotetext{
20 Restaurierungsbericht Dr. Bettina Achsel aus dem Jahr 2009. Der Bericht befindet sich auszugsweise in Kopie im Archiv der Universitätskunstsammlung Göttingen, Bildakte GG 178.

21 Mai 2010, S. 58.

22 Ebd. S. 53.

23 Vgl. ebd. S. 57 f.: Friedrich-Wilhelm I. kürzte den Etat der Akademie drastisch und Friedrich II. lehnte deutsche Künstler ab.

24 Ebd. S. 115-118.

25 Ebd. S. 29.

26 Ebd.
} 
Altmeistern - war das probate Ausbildungsmittel. ${ }^{27}$ Die Form und somit der Umriss sowie die Nachahmung waren in dieser Theorie die Leitlinien des akademischen Kunstverständnisses. So entwickelten sich gleichsam Muster, anhand derer die Werke dann zusammengesetzt wurden. ${ }^{28}$ Schumanns Gemälde Die Heilige Familie ist in seiner Inkohärenz exemplarisch für diese Kunstauffassung, zeigt aber auch noch den Stellenwert des Helldunkel, der von den Nazarenern erst einmal in Frage gestellt wurde.

\title{
Religiöse Kunst im unierten Berlin
}

Wenngleich über einen ursprünglichen Bestimmungsort nichts bekannt ist, erscheint ein Nachdenken lohnenswert, inwiefern das Göttinger Gemälde im Kontext der religionspolitischen Unternehmungen des regierenden Monarchen gedeutet werden kann. Im Vergleich zu seinen Vorgängern verfolgte Friedrich Wilhelm III. eine neue Religionspolitik. ${ }^{29}$ Selbst tief religiös, arbeitete er seit Ende 1815 an einer Reform der kirchlichen Liturgie, die, wie Anselm Schubert es zusammenfassend formuliert hat,

\begin{abstract}
„darauf hinauslief, dem nüchternen evangelischen Gottesdienst der Spätaufklärung eine gröBere Feierlichkeit, aber auch liturgische Einheitlichkeit in den Formen zu erreichen. Dieses Ziel hoffte der König durch einen Rückgang auf die liturgischen Formen der Alten Kirche zu erreichen, die nach damaliger Anschauung in den Liturgien der Reformationszeit erhalten geblieben seien. Auf lange Sicht sollte diese im Geiste eines vorkonfessionellen, allgemeinen Christentums erneuerte Liturgie nicht nur dem nach den Befreiungskriegen gewachsenen Bedürfnis nach intensiverem kirchlichen Leben Rechnung tragen, sondern auch die von den preußischen Königen seit langem geplante Union der protestantischen Konfessionen vorbereiten, ja letzten Endes sollte sie im Sinne der Restaurationspolitik der Heiligen Allianz für alle christlichen Konfessionen, auch für den katholischen und den (russisch-) orthodoxen Christen, verbindlich sein können." ${ }^{30}$
\end{abstract}

Die von Friedrich Wilhelm III. angestrebte Union der reformierten und der lutherischen Kirche wurde 1817 in Preußen tatsächlich vollzogen. ${ }^{31}$ Weitaus schwieriger gestaltete sich hingegen die Durchsetzung der vom König selbst verfassten, den Gottesdienst staatsweit vereinheitlichenden Agende, die bei ihrer Einführung im Jahr 1822 auf breite Ablehnung stieß und den Agendenstreit auslöste. ${ }^{32}$ Der König, dem es um die religiöse „Erziehung seiner Untertanen zu gottesfürchtigen, obrig-

27 Der hohe Stellenwert der Zeichnung findet sich auch in den Titeln der theoretischen Abhandlungen der Zeit, in denen die Malerei vielfach als zeichnende Kunst bezeichnet wird: Johann Dominicus Fiorillo: Gescbichte der zeichnenden Künste (Fiorillo 1820).

28 Mai 2010, S. 69 und 75.

29 Franz-Duhme/Röper-Vogt 1991, S. 32; Schubert 2008; Schubert 2010.

30 Schubert 2010, S. 117.

31 Schubert 2008, S. 178 f.; Franz-Duhme/Röper-Vogt 1991, S. 32-37.

32 Schubert 2008; Franz-Duhme/Röper-Vogt 1991, S. 34 f. 
keitstreuen und folgsamen Bürgern“"33 ging, setzte seine Liturgie zum Teil mit Polizeigewalt durch, denn viele Gemeinden wollten ihren Gottesdienst nicht nach diesem neu eingeführten, altertümelnden Ritus halten. ${ }^{34}$ Dabei reagierte die Reform durchaus auch auf die allgemein im Gefolge der Romantik erneuerte Religiosität, die gerade im Zusammenhang mit den Befreiungskriegen an Breitenwirkung gewonnen hatte, ${ }^{35}$ doch trat das kirchenpolitische Vereinheitlichungsstreben von Seiten des Königs zu dieser allgemeinen Religiosität in Widerspruch.

Kunstgeschichtlich waren Union und Agendenreform gleichwohl von großer Bedeutung, zumal künstlerische, kunsthandwerkliche, musikalische und allgemein ästhetische Elemente in den Plänen des Königs eine maßgebliche Rolle spielten. Für einen Historienmaler wie Schumann dürfte es von größter Wichtigkeit gewesen sein, dass Bilder in den Kirchenräumen des bis dahin reformierten brandenburgisch-preußischen Herrscherhauses jetzt überhaupt erst wieder erwünscht waren. ${ }^{36}$ Die Bildausstattung der Potsdamer Garnisonkirche und der Ankauf des Gemäldes Christus wird zu Grabe getragen für die Kirche in Paretz belegen, wie Schumann ganz konkret von diesen Entwicklungen profitieren konnte.

Inwieweit Schumann Bilder wie die heute in Göttingen befindliche Heilige Familie mit den Engeln dezidiert auf die Interessen des Königs hin konzipierte, lässt sich nur schwer rekonstruieren. Immerhin gibt es einige ganz allgemeine Vergleichsmomente mit einem - stilistisch und ikonographisch ansonsten deutlich abweichenden - Werk des Lieblingsmalers des König, Wilhelm Wach. Sein von der Stadt Berlin 1825 als Hochzeitsgeschenk für Prinzessin Luise von Preußen beauftragtes Gemälde Allegorie. Stiftung der cbristlichen Kirche (1826/27), ${ }^{37}$ welches das Wohlwollen des Königs fand, zeigt ebenfalls die im protestantischen Berlin erstaunliche Wahl eines Themas aus der Marienikonographie, das allerdings hier wie dort durch die Präsenz von Christus als Hauptfigur seine Berechtigung gewann. Bemerkenswert erscheint die Konzentration auf das Spiel der Hände, das auch in Wachs Bild zentrale Aussagen übernimmt. ${ }^{38}$ Schließlich bewirkt Schumanns ikonographisch zwar durchaus tradierte, nach 1800 aber keineswegs mehr selbstverständliche Entscheidung, Engel in die Darstellung der Heiligen Familie aufzunehmen, eine allegorische

33 Franz-Duhme/Röper-Vogt 1991, S. 32.

34 Ebd. S. 38.

35 Ebd. S. 56 f.

36 Üblicherweise sind reformierte Kirchen bildlos. Allerdings gibt es in Brandenburg-Preußen mit der reich ausgestatteten und bebilderten Kapelle von Schloss Charlottenburg eine prominente ältere Ausnahme (vgl. Ausst.-Kat. Berlin 2001b, Bd. 1, S. 23-25). Deren - für einen reformierten Kirchenbau ganz und gar untypisches - Bildprogramm hängt möglicherweise mit einem bereits für König Friedrich I. in Preußen nachweisbaren Streben zusammen, eine Union zwischen Lutheranern und Reformierten herbeizuführen. So führte Friedrich I. 1704 in der Schlosskapelle und im Berliner Dom die anglikanische Liturgie ein und heiratete 1708 die Lutheranerin Sophie Luise von Mecklenburg-Schwerin, die bei ihrer Konfession bleiben durfte; vgl. Luh 2001, S. 156, 162 164.

37 Vgl. hierzu Schubert 2010. Eine verkleinerte Replik Wachs gelangte über die Sammlung Wagener in die Berliner Nationalgalerie: vgl. Ausst.-Kat. Berlin 2011, Kat. Nr. 247, Reprintteil, S. 136 f.

38 Vgl. Schubert 2010, S. 121, 123. 
Überhöhung des Bildes, die auf einer - freilich sehr allgemeinen - Ebene mit Friedrich Wilhelms Streben nach einer feierlicheren, symbolisch aufgeladenen Gottesdienstform korrespondiert. Wie eine Darstellung desselben Themas aussehen kann, die auf Engel wie auf Heiligenscheine bewusst verzichtet und sich generell dem für die Zeit nach 1800 charakteristischen Streben nach erneuter Allegorisierung entzieht, zeigt die zweite Darstellung der Heilige Familie aus dem 19. Jahrhundert in der Göttinger Universitätskunstsammlung, die fast zeitgleich entstand (Kat. Nr. 6).

Julia Diekmann 

Kat. Nr. 6

Johann Dominicus Fiorillo (1748-1821)

\section{Die heilige Familie}

1820

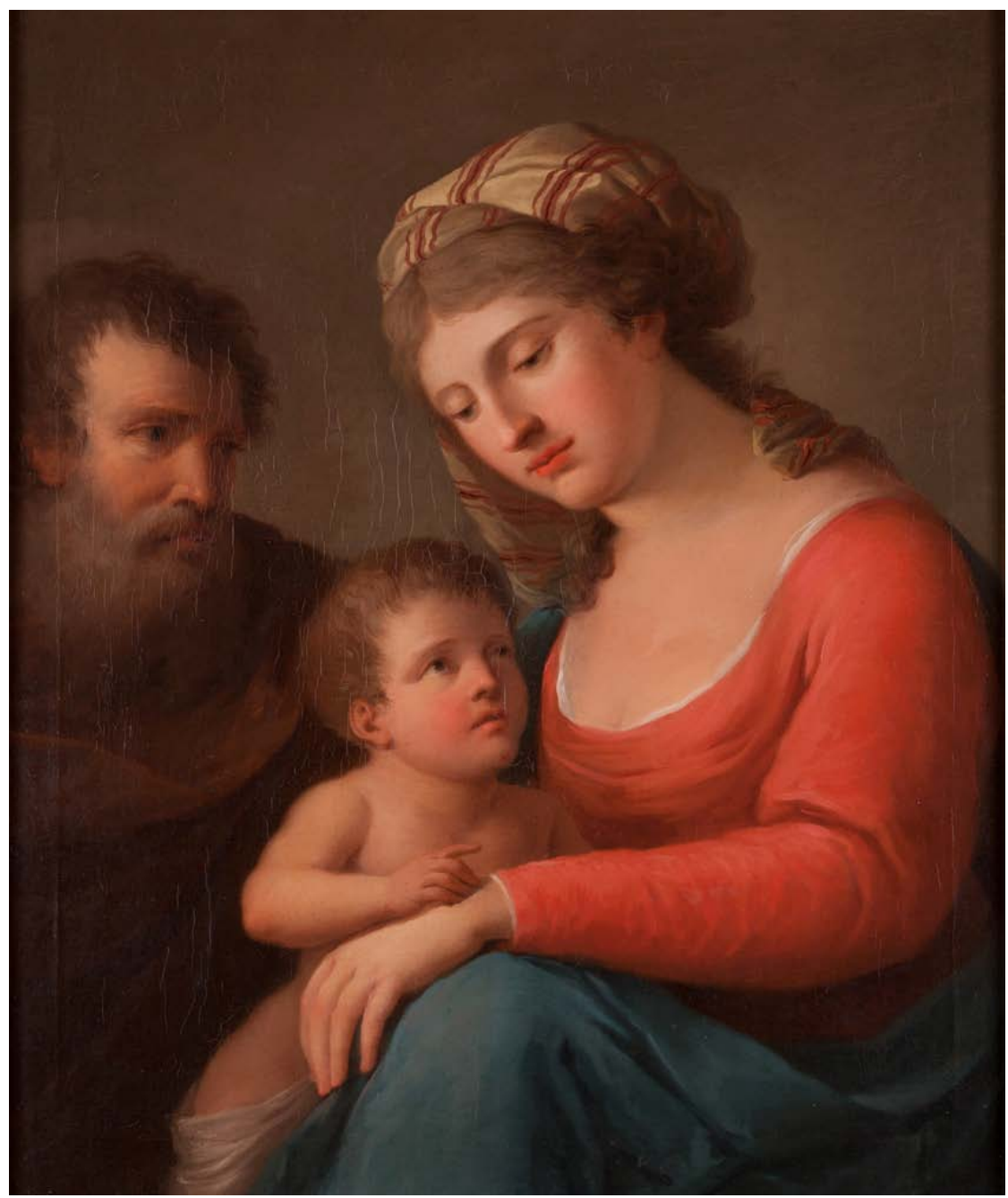

Öl auf Leinwand, 74 x 62,5 cm, rückseitig signiert und datiert, 1822 erworben von der Familie des Künstlers, Inv. Nr. GG 130 
Johann Dominicus Fiorillo ist heute weniger als Künstler denn als Kunsthistoriker bekannt. Er gilt als Mitbegründer der universitären Kunsthistoriographie in Deutschland. 1781 kam er an die Universität Göttingen, wo er zunächst als Zeichenlehrer tätig war. ${ }^{2}$ Sein Tätigkeitsfeld weitete sich schnell aus, so dass er bald auch Kunstgeschichte unterrichtete. In diesem Zusammenhang wurde Fiorillo 1784 zum Aufseher der Göttinger graphischen Sammlung ernannt. ${ }^{3} 1799$ erhielt er eine außerordentliche und 1813 die ordentliche Professur in Göttingen. ${ }^{4}$ Damit handelt es sich um einen der frühesten Fälle für die institutionelle Gründung des Faches Kunstgeschichte. ${ }^{5}$ Fiorillo nutzte die in seiner Obhut befindlichen Sammlungen umgehend auch für die Lehre und maß ihnen einen hohen didaktischen Nutzen bei. ${ }^{6} \mathrm{Zu}$ seinen Schülern gehörten unter anderem Wilhelm Heinrich Wackenroder, Ludwig Tieck und August Wilhelm Schlegel. Für die Frühromantiker ist Fiorillo damit einer der wichtigsten kunsthistorischen Vermittler geworden. Ein Schwerpunkt seines Lehrens lag dabei auf der Kunst der Renaissance. ${ }^{7}$

Mit dem Gemälde Die Heilige Familie in der Universitätskunstsammlung tritt Fiorillo als bildender Künstler in Erscheinung, als der er eigentlich an die Göttinger Universität berufen worden war. Das Bild zeigt die Heilige Familie nahsichtig vor einem bräunlichen Hintergrund ohne räumliche Ausdifferenzierung. Im Vordergrund sitzt die Gottesmutter, ihr brünettes Haar ist bedeckt von einem hellen, mit dunkelroten Streifen verzierten Tuch. Der linke Arm ruht auf ihrem angezogenen Knie. Ob sie mit dem rechten Arm ihren Sohn umfängt, ist nicht erkennbar. Dieser schmiegt sich an seine Mutter und blickt sie mit leicht geöffnetem Mund an. Den rechten Arm hat der Knabe angehoben, sein Zeigefinger deutet auf die Jungfrau. Diese wiederum schaut ihren Sohn nicht an, vielmehr geht ihr trauriger Blick ins Leere. Das helle Orangerot des Kleides der Gottesmutter wiederholt sich in

1 Middeldorf Kosegarten 1997, S. 8. Als Hauptwerke Fiorillos gelten Die Geschichte der zeichnenden Künste von ibrer Wiederauflebung bis auf die neuesten Zeiten in fünf Bänden (1798-1808) sowie Die Geschichte der zeichnenden Künste in Deutschland und den vereinigten Niederlanden in vier Bänden (1815-1820). Beide Werke sind eingegliedert in das Großprojekt Johann Gottfried Eichhorns: Geschichte der Künste und Wissenschaften seit der Wiederherstellung derselben bis an das Ende des achtzebnten Jabrbunderts, Göttingen, 1796-1799. Vgl. hierzu Schrapel 2004, S. 184-187 u. 208-213. Fiorillo entwickelt hier das in Frankreich und Italien entworfene System einer sich von der Künstlergeschichte zur Kunstgeschichte wandelnden Wissenschaft weiter und bettet es ein in die Göttinger Idee einer Universalgeschichte (vgl. Bickendorf 2007, S. 30-39), wobei er den zweiten Teil, Die Geschichte der zeichnenden Künste in Deutschland und den vereinigten Niederlanden, als Nationalgeschichte anlegt (vgl. ebd., S. 41).

2 Dilly 1979, S. 175.

3 Unverfehrt 1987, S. 9. Das Kernstück dieser Sammlung bildet bis heute der Nachlass des Frankfurter Patriziers Johann Friedrich Armand von Uffenbach (1687-1769). 1796 gelangte eine weitere Schenkung nach Göttingen: die Gemäldesammlung Johann Wilhelm Zschorns (1714-1795). Diese wurde ebenfalls der Obhut Fiorillos übergeben und stellt bis heute den Grundstock der Gemäldesammlung der Universität Göttingen dar (vgl. ebd.).

4 Dilly 1979, S. 176 f.; Beyrodt 1991, S. 314 f.; Stalla 2001, S. 41-43.

5 Dilly 1979, S. 178 f.

6 Fiorillo 1805, S. V-XIV.

7 Hölter 1993, S. 22-26. 
ihren Lippen ebenso wie in jenen des Kindes und dessen Wangen. Die Figur Josephs erscheint angeschnitten am linken Bildrand, lediglich sein Kopf und ein Teil seines Oberkörpers sind zu sehen. Der Blick des Mannes ist auf Mutter und Kind gerichtet. Durch sein dunkelbraunes Gewand, die Haare und den Bart scheint er gleichsam mit dem Hintergrund zu verschmelzen.

Fiorillos Heilige Familie tritt dem Betrachter zunächst gar nicht so heilig gegenüber. Es fehlen jegliche traditionelle Würdeformeln; so gibt es beispielsweise keine Nimben. Der oftmals segnende Gestus des Christusknaben ist reduziert auf eine einfache, zeigende Geste. Keinerlei Attribute kündigen die kommende Passion und das Heilsgeschehen an. Diese deuten sich lediglich im traurig-verlorenen Blick der Jungfrau an. Dennoch ist dem kunsthistorisch informierten Betrachter sofort klar, um welche Familie es sich hier handelt, denn einige der tradierten ikonographischen Merkmale der Darstellung dieses Themas sind eingehalten. So trägt die Gottesmutter typischerweise ein rotes Kleid (als Versinnbildlichung des Blutes und damit des Opfers Christi) ${ }^{8}$ und einen blauen Umhang (als Symbol des Himmels, der Reinheit, der Wahrheit und der Treue) ${ }^{9}$, Christus wird als unbekleideter Knabe (als Symbol der Unschuld) ${ }^{10}$ dargestellt, und Joseph nimmt lediglich eine beobachtende Position im Hintergrund ein. ${ }^{11}$

\section{Fiorillo als bildender Künstler}

Vor seiner Hinwendung zur Kunstwissenschaft im universitären Kontext hatte der in Hamburg geborene Sohn des in Deutschland tätigen neapolitanischen Musikers Ignazio Fiorillo eine künstlerische Ausbildung genossen. Ab 1759 erhielt er Zeichenunterricht an der Akademie Bayreuth. ${ }^{12}$ Mit 13 Jahren wurde er nach Rom geschickt, um seine Ausbildung bei Pompeo Girolamo Batoni und später bei Giuseppe Bottani fortzusetzen. ${ }^{13}$ Nach sechs Jahren besuchte Fiorillo 1765 die Accademia Clementina in Bologna, wo er insbesondere bei Vittorio Bigari und Ercole Lelli studierte. Im Jahr 1769 wurde der junge Maler schließlich Mitglied der Accademia Clementina, wo einige seiner Zeichnungen prämiert wurden. ${ }^{14} \mathrm{Nach}$ seiner Rückkehr 1769 hielt er sich zunächst am Braunschweiger Hof auf und wurde dort als Historienmaler geführt; allerdings ist kein Bild aus dieser Zeit von ihm bekannt. ${ }^{15}$

Seibert 2002, S. 112.

9 Ebd.

10 Ebd. S. 231.

11 Vgl. hierzu beispielsweise Die Heilige Familie mit Johannes (ca. 1514) von Correggio, Los Angeles County Museum of Art.

12 Schrapel 2004, S. 47-49.

13 Ebd. S. 50-53.

14 Ebd. S. 53-57.

15 Ebd. S. 58 f. 
Fiorillos Sujets waren hauptsächlich mythologischer Art. Wenige dieser Arbeiten sind zugänglich, einige befinden sich in Privatbesitz. Die Kunsthalle Bremen besitzt das Gemälde Achill entlässt die Briseis (1783). ${ }^{16}$ Im Stadtmuseum Göttingen ist ein Porträt Gottfried August Bürgers (ca. 1789) zu finden. ${ }^{17}$ Weitere Porträts von Fiorillos Hand wurden in Kupfer gestochen, so z.B. jenes der Dorothea Schlözer. ${ }^{18}$ Darüber hinaus schuf Fiorillo umfangreiche Illustrationszyklen zu literarischen Werken. ${ }^{19} 1787$ gestaltete er den Entwurf für das Denkmal des Herzogs Maximilian Leopold von Braunschweig-Wolfenbüttel. ${ }^{20}$

Interessant ist, dass der sehr arbeitsame Gelehrte sich künstlerisch offensichtlich nicht weiter entwickelte, sondern seinen Vorbildern verhaftet blieb. Eine Anlehnung insbesondere an Batonis mythologische Szenen ist etwa im Bremer Bild Achill entlässt die Briseis von 1783 erkennbar. Dies mag auch in Fiorillos Fokussierung auf die Kunstgeschichte begründet liegen.

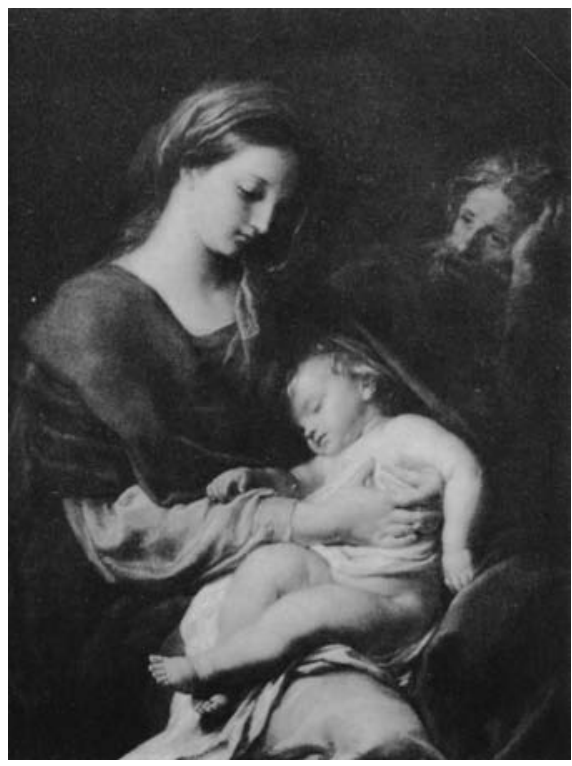

Abb. 11: Pompeo Girolamo Batoni: Heilige Familie, ca. 1741-42, Öl auf Leinwand, 95 x $72 \mathrm{~cm}$, Forli, Privatbesitz

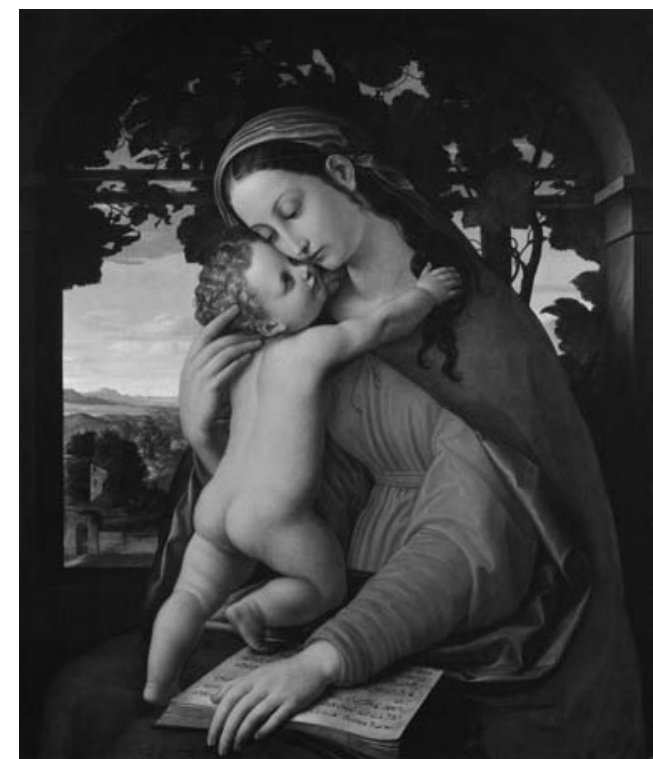

Abb. 12: Julius Schnorr von Carolsfeld: Maria mit dem Kinde, 1820, Öl auf Leinwand, 74 x $62 \mathrm{~cm}$, Köln, Wallraf-Richartz-Museum

16 Der Kunstverein in Bremen 1990, S. 34.

17 Arndt 1975, S. 133.

18 Hölter 2004, S. 234.

19 U. a. 16 Tafeln zu Gottfried August Bürger: Sämtliche Schriften, 1796-1802. Frontispize zum Göttinger Musenalmanach. Insgesamt 279 Vorlagen für die Vergil-Ausgabe Christian Gottlob Heynes (1787-1800) und weitere 28 für dessen Illias-Ausgabe (1802); vgl. hierzu Schrapel 2004, S. $72 \mathrm{f}$.

20 Schrapel 2004, S. 96-116. 
Dementsprechend tritt Fiorillos künstlerische Prägung auch im Göttinger Gemälde Die Heilige Familie deutlich zum Vorschein. Obwohl es sich um ein Spätwerk des Künstlers und Kunsthistoriographen handelt, ist die Anlehnung an seine römischen Lehrer Pompeo Girolamo Batoni (Abb. 11) und Giuseppe Bottani deutlich erkennbar. Diese manifestiert sich vor allem in der Figurenkomposition, dem Madonnentypus und dem Kolorit des Bildes. Eben jene Stilmerkmale der Kunst seiner Lehrer entsprechen dem römischen Darstellungsmodus der Heiligen Familie im 18. Jahrhundert. Insbesondere das Kompositionsschema und der Typus der Gottesmutter gehen aber auf noch ältere Vorbilder (z.B. Raffael) zurück, welche im italienischen Settecento eine gewisse „Weichzeichnung“ hinsichtlich Beleuchtung und Kolorit erfuhren. Man findet diesen Effekt im zurückgenommenen, gedämpften Kolorit des Mariengewandes sowie dem die Szene beleuchtenden Streulicht wieder. Die hinteren Partien verlieren sich im Dunkel, kein Element wird durch Schlaglicht besonders betont.

Die durch diese Lichtführung herausgehobene Person ist nicht Christus, sondern Maria, auf die das Licht zuerst trifft. Dies könnte auch auf eine Entstehung des Bildes im Kontext der Marienverehrung verweisen. Die Verehrung der Gottesmutter stellte für Fiorillo als italienischstämmigem Katholiken vermutlich einen ganz selbstverständlichen Bestandteil seines Glaubens dar. Da das Gemälde aus der Familie Fiorillos in den Besitz der Kunstsammlung der Universität Göttingen gelangte, ${ }^{21}$ ist ein privater Entstehungskontext denkbar. Es stellt derzeit das einzige bekannte Gemälde religiösen Inhalts in Fiorillos CEuvre dar.

\section{Das Gemälde im Kontext zeitgenössischer kunsttheoretischer Auseinandersetzungen}

Während Fiorillos herausragende wissenschaftsgeschichtliche Stellung mittlerweile unbestritten ist, hat sein künstlerisches Schaffen bis heute kaum Beachtung gefunden. Dabei lassen sich negative Wertungen bereits auf einen Aufsatz seines Schülers Karl Friedrich von Rumohr zurückführen, der ihm in dieser Kritik jegliche künstlerischen Fähigkeiten abspricht. ${ }^{22}$ Solche Urteile standen einer intensiveren Auseinandersetzung mit Fiorillos Gemälden bislang im Wege. Dabei lohnt sich eine solche durchaus, wie gerade das Beispiel der Heiligen Familie zu zeigen vermag. Dieses Gemälde ist nämlich nicht nur ansprechend und technisch solide gearbeitet. Es hat auch einen exemplarischen Charakter in Bezug auf Fiorillos theoretische Auseinandersetzung mit der zeitgenössischen deutschen Kunst.

Tatsächlich kann das Bild als Reaktion auf die Kunstauffassung der Nazarener gedeutet werden. ${ }^{23}$ Fiorillo stand dieser Bewegung junger, in Rom im Lukasbund

21 Göttingen, Kunstsammlung der Universität, Inventar 1884 ff., S. 49.

22 Rumohr 1821.

23 Vgl. zu dem folgenden auch die im Druck befindliche Publikation von Christian Scholl, auf den die Anregung zu dieser Interpretation zurückgeht (Scholl 2013). 
zusammenlebender und arbeitender deutscher Maler, welche die Konzepte der Romantik in die Realität umzusetzen suchten, überaus kritisch gegenüber. Zwar hatte er als Lehrer von Wilhelm Heinrich Wackenroder, Ludwig Tieck und August Wilhelm Schlegel selbst einen Anteil an der Entwicklung der romantischen Kunsttheorie. Auch stand er einem Werk wie den Herzensergießungen eines kunstliebenden Klosterbruders von Wackenroder und Tieck durchaus wohlwollend gegenüber. ${ }^{24}$ Den archaisierenden und allegorisierenden Vorgehensweisen der zumeist aus protestantischen Elternhäusern stammenden, dann aber nicht selten zum Katholizismus konvertierten Nazarenern in Rom stand er als katholisch aufgewachsener Künstler und Kunsthistoriograph jedoch überaus skeptisch gegenüber. So schreibt er im Kapitel „Blicke auf den gegenwärtigen Zustand der Mahlerey, besonders bey den Deutschen“ im vierten, 1820 erschienenen Band seiner Geschichte der zeichnenden Künste in Deutschland und den vereinigten Niederlanden:

\begin{abstract}
„Nun lässt sich aber in der That nicht einsehen, wie Protestanten (und ein großer Theil dieser Künstler sind Protestanten), die vermöge ihrer Glaubenslehren, eine Menge dieser Dinge verwerfen, ja, sie für Aberglauben und beynahe Idolatrie ansehen müssen; - die von den sieben Sakramenten des katholischen Glaubens nur zwey anerkennen; die die Beichte und letzte Oehlung wohl gar lächerlich finden; die die Gebote der katholischen Kirche nicht achten; aus dem Papst einen Antichrist gemacht haben und machen; - wie diese Protestanten tiefere Einsichten gehabt haben, und wie diese tieferen Einsichten nur der deutschen Nation eigenthümlich sein sollen?" 25
\end{abstract}

Gegen die seiner Ansicht nach allzu kopflastigen Anstrengungen der deutschen Nazarener setzt er den gleichsam ,natürlichen“ Katholizismus der Italiener. Diesen sei das „philosophische Nachgrübeln“26, welches dem deutschen Künstler nach seiner Ansicht zu Eigen ist, eher fremd. Aber „der Italiäner ist doch im katholischen Glauben geboren und erzogen; hat diese Dinge von Kindheit an vor Augen gehabt und hat von unzähligen Wundern dieser frommen Bilder gehört. “27 Fiorillo unterstellt also den katholischen Italienern ein innigeres und herzlicheres Verhältnis zum Glauben bzw. zu dessen Inhalten als den protestantisch erzogenen Deutschen.

Mit seiner Nazarenerkritik stand Fiorillo um 1820 keineswegs allein. Der wohl prominenteste Angriff war bereits 1817 aus Weimar gekommen. Von Goethe gestützt und von dessen „Kunstfreund“ Johann Heinrich Meyer verfasst, sollte der Aufsatz Neu-deutsche religios-patriotische Kunst in der Zeitschrift Über Kunst und Alterthum in den Rhein- und Mayngegenden ${ }^{28}$,als eine Bombe in den Kreis der Nazarenischen Künstler hinein plumpen“. ${ }^{29}$ Bemerkenswert ist nun, dass sich Fiorillo in

24 Fiorillo 1820, S. 83 f.

25 Ebd., S. 101.

26 Ebd., S. 102.

27 Ebd.

28 Weimarische Kunstfreunde 1999 [1817], S. 105-129.

29 Johann Wolfgang von Goethe an Carl Ludwig von Knebel, den 17. März 1817, zitiert nach Goethe 1985-1999, 2. Abt., Bd. 8, 1999, S. 86; vgl. auch Büttner 1994, S. 464 f. 
seinem Kapitel „Blicke auf den gegenwärtigen Zustand der Mahlerey, besonders bey den Deutschen“ auf genau diesen - damals höchst kontrovers diskutierten ${ }^{30}$ Aufsatz stützt und ihn als „herrliche Schrift“ bezeichnet. ${ }^{31}$ Er ergreift damit Partei für diejenigen Kritiker, welche den Nazarenern ihre als regressiv verstandene Orientierung an der Kunst des Mittelalters und der Frührenaissance, ihre zum Katholizismus neigende, ,unnatürliche“ Frömmigkeit und ihre Neigung zu allegorischen, nicht aus sich selbst heraus verständlichen Bildern vorwarfen.

Vor diesem Hintergrund ist es bemerkenswert, dass Johann Heinrich Meyer in seiner Schrift Ueber die Gegenstände der bildenden Kunst, die 1798 in der Zeitschrift Propyläen erschienen war, ein anderes Kunstmodell propagiert hatte, das ganz im aufklärerischen Sinne auf die Selbstevidenz und unmittelbare Verständlichkeit von Bildern gesetzt hatte. Dabei kam Madonnendarstellungen eine zentrale Rolle zu. Meyer behandelt sie bezeichnenderweise unter der Rubrik „Rein menschliche Darstellungen“:

„Unter rein menschliche Darstellungen sind vornehmlich zu zählen alle diejenigen sogenanten Madonnenbilder und heiligen Familien, deren Figuren, in Gestalt und Zügen, nicht über schöne Natur und Menschheit erhoben sind, wenn wir einige conventionelle Zeichen, z. B. den goldenen Schein um die Köpfe, und allenfalls episodische Nebenfiguren von Engeln, oder dem weissagenden kleinen Johannes dabey übersehen wollen, so können beynahe alle insgesammt unter diese Klasse gerechnet werden; denn die neuere Kunst erhob sich in wenigen von diesen Bildern bis zur höhern symbolischen Bedeutung, und was sind die übrigen anders als Mütter, welche ihre Kinder pflegen, tränken, ankleiden, zart und liebend in die Arme schließen?"32

Vor diesem Hintergrund gewinnt Fiorillos Darstellung der Heiligen Familie, die auf jedes allegorisierende Attribut verzichtet, und die genau in dem Jahr entstand, in dem sich der Künstler und Historiograph im vierten Band seiner Geschichte der zeichnenden Künste in Deutschland und den vereinigten Niederlanden kritisch mit den Nazarenern auseinandersetzt, eine eigene, geradezu programmatische Bedeutung. An sich stellt eine Darstellung der Heiligen Familie ohne Würdeformeln und Attribute keine neuartige Bilderfindung dar: Sie findet sich bereits in der italienischen Renaissance, so beispielsweise relativ früh bei Andrea Mantegna (1431-1506) ${ }^{33}$ oder im Tondo Doni Michelangelos (1475-1564). ${ }^{34}$ Im Kontext der künstlerischen Entwicklungen wird das Beharren Fiorillos in dieser Darstellungstradition zu einem bewussten und eigenständigen Akt, zumal man annehmen darf, dass er die Beiträge in den Propyläen kannte.

30 Vgl. insbesondere Büttner 1983.

31 Fiorillo 1820, S. 79: „Ich werde daher jetzt bey meinen Bemerkungen diese herrliche Schrift zum Grunde legen, und nur meine eigenen Untersuchungen, und einige erhaltenen Notizen mittheilen."

32 Meyer 1798, Erstes Stück, S. 23 f.

33 Dresden, Gemäldegalerie Alte Meister.

34 Florenz, Uffizien. 
Wie sehr sich das Bild von nazarenischen Darstellungen des Themas unterscheidet, zeigt ein Vergleich mit einem zeitgleich entstandenen Bild des Nazareners Julius Schnorr von Carolsfeld, Maria mit dem Kinde (Abb. 12). Schnorr betont Lokalfarben und Umrisslinien; gleichzeitig ist seine Farbpalette deutlich kühler als Fiorillos. Auch ohne die Verwendung von Nimben zeigt das Bild viele ikonographische Attribute: Maria ist durch das Buch mit hebräischer Schrift gekennzeichnet, die Passion Christi wird durch das Fensterkreuz und die Weinreben symbolisiert, was einem tradierten Darstellungsmodus entspricht. Die Verbundenheit mit mittelalterlichen Darstellungstraditionen bezeugt ebenfalls die Signatur in der Art eines Steinmetzen.

Was Fiorillos Heilige Familie dagegen bietet, hält sich vom akademischen Eklektizismus eines Karl Franz Jacob Heinrich Schumann ebenso fern wie von der historisierend bedeutungsgeladenen Malerei der Nazarener. Heinrich Meyers Kategorie der „,rein menschlichen Darstellung“ trifft diese Position recht genau. So liegt es nahe, das Bild als gemaltes Argument des gebürtigen Italieners, der seinen Zugang zu religiösen Themen auf einem „natürlichen Katholizismus“ begründet sah, gegen die kopflastige Malerei deutscher Konvertiten zu verstehen: als Programmbild, bei dem persönliche Glaubensvorstellungens auf bemerkenswerte Weise mit einem Bekenntnis zum aufgeklärten Kunstideal der Weimarischen Kunstfreude übereinkommen.

Julia Diekmann 
Kat. Nr. 7

Francesco Podesti (1800-1895)

\section{Taufe und Heilung des Paulus}

vor 1856

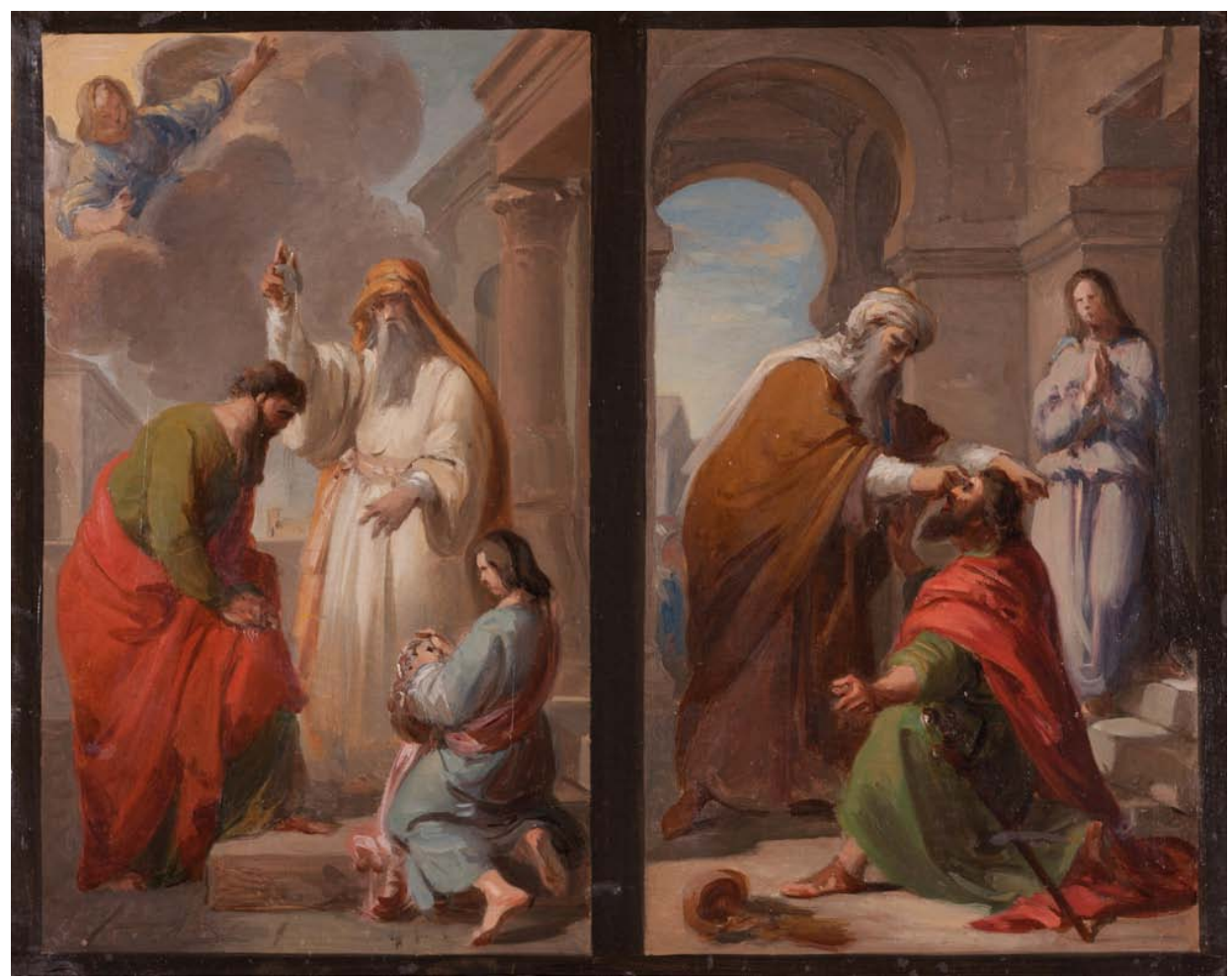

Öl auf Leinwand, 37,5 x $47 \mathrm{~cm}$, nicht signiert oder datiert, 1973 aus dem römischen Kunsthandel angekauft, Inv. Nr. GG 168

Der italienische Maler Francesco Podesti hat seine künstlerische Ausbildung an der Accademia di San Luca in Rom erhalten und blieb Zeit seines Lebens von den dort gelernten Idealen und Kunstkonzepten beeinflusst. Er machte sich insbesondere als Historien- und Porträtmaler einen Namen. ${ }^{1}$ Als Podestis Hauptwerk gilt die Ausmalung der Sala della Concezione im Vatikan.

1 Serra 1933, S. 173. 
Die beiden auf eine gemeinsame Leinwand gemalten Bozzetti in der Göttinger Universitätskunstsammlung zeigen rechts die Heilung des Paulus von seiner durch eine Christus-Erscheinung verursachten Blindheit durch Ananias von Damaskus und links dessen Taufe, wie es in der Apostelgeschichte erzählt wird. ${ }^{2}$ Ihr skizzenhafter Charakter kommt in der lockeren Pinselführung und in der wenig detaillierten Figurengestaltung zum Ausdruck. Die Bozzetti sind von einer an der Hochrenaissance orientierten Kunstauffassung geprägt, die sich in rhythmischer Gestik, einer dynamischen, gleichwohl gegenstandsgebundenen Lichtführung sowie einer hellen und klaren Farbigkeit manifestiert. Ihre Anordnung entspricht nicht der Chronologie, der zufolge die Heilung der Taufe vorausgeht.

Die im rechten Bozzetto gezeigte Heilung des Paulus spielt sich vor einer monumentalen, um die Ecke geführten Architektur ab, die sich links mit einem groBen Bogen zu einer städtisch geprägten Hintergrundlandschaft öffnet. Der erblindete Paulus kniet, in grüne und rote Gewänder gehüllt, rechts im Vordergrund. Ananias steht, mit einem braunen Übergewand bekleidet, leicht nach hinten versetzt links neben ihm, beugt sich über Paulus und legt seine Hände auf dessen Haupt und Augen, um ihn zu heilen. ${ }^{3}$ Rechts im Hintergrund steht auf einer Stufe erhöht mit gefalteten Händen eine jüngere Person, die sich als Begleiter des Paulus deuten lässt. ${ }^{4}$ Sie hatte vermutlich die Funktion, den erblindeten Mann zu führen und wird jetzt zum Zeugen des Heilungswunders.

Im linken Bozzetto taucht Paulus - erkennbar an derselben Kleidung - auf der linken Bildseite wieder auf. Sein Haupt ist geneigt und er steht im Profil leicht vornübergebeugt auf einer Stufe, auf der sich - nahezu frontal und leicht erhöht dargestellt - Ananias erhebt, der diesmal in ein priesterlich weißes Gewand gehüllt ist, das von einem ockerfarbenen Umhang hinterfangen wird. Ananias hat die rechte Hand erhoben und gießt aus einer kleinen Schale das Taufwasser über Paulus' Haupt. Die Szenerie spielt sich vor dem Hintergrund einer Tempelarchitektur ab. Über ihr erscheint in der linken oberen Bildecke ein Engel auf einer Wolke, von göttlich-goldenem Lichtglanz hinterfangen. Auch der junge Begleiter des Paulus ist wieder im Bild zu sehen: Er kniet in anbetender Haltung rechts im Vordergrund.

Die Bozzetti sind Entwürfe Podestis für die Ausmalung der Kirche San Paolo fuori le mura, die er in den Jahren 1856-60 zusammen mit einundzwanzig Künstlerkollegen aus der Accademia di San Luca vornahm. San Paolo ist eine der vier römischen Patriarchalkirchen und damit eine der wichtigsten, größten und ältesten Kirchen Roms. Ihre Ursprünge reichen bis in die konstantinische Zeit zurück, als

2 Vgl. Apg. 9, 10-19. Die Zuschreibung an Podesti erfolgte vor dem Erwerb der Bozzetti durch Judith Huber. Auf Grundlage dieser Zuschreibung wurden sie 1973 von Herwarth Röttgen von den römischen Antiquitätenhändlern Carlo und Marcello Sestieri für die Kunstsammlung der Universität Göttingen erworben; vgl. Huber 1979, S. 197, sowie den Beitrag „Die Provenienzen der Göttinger Gemälde des 19. Jahrhunderts" von Anne-Katrin Sors in diesem Band, S. 42 f.

3 Vgl. Apg. 9, 17.

4 Huber 1979, S. 198. 
über der Grabstätte des Apostels Paulus eine frühchristliche Basilika errichtet wurde. ${ }^{5}$ Die Gebeine des heiligen Paulus werden bis heute in San Paolo verehrt.

Der Baukörper der Kirche wurde im Laufe der Zeit immer wieder stark verändert, vergrößert und von den bedeutendsten Künstlern Italiens ausgestattet. So wurden die Hauptschiffwände von Pietro Cavallini gestaltet, während Arnolfo di Cambio für die Errichtung eines spätgotischen Ziboriums verantwortlich war. Auch Benozzo Gozzoli und Antoniazzo Romano verewigten sich lange vor Podesti in San Paolo. 6

Im Jahr 1823 wütete ein Großbrand in der Kirche, ihr Langhaus wurde mit all ihren Kunstschätzen fast vollständig zerstört. Der Wiederaufbau der Kirche, mit dem gleich nach dem Brand begonnen wurde, zählt zu den größten italienischen Bauprojekten des 19. Jahrhunderts. ${ }^{7}$

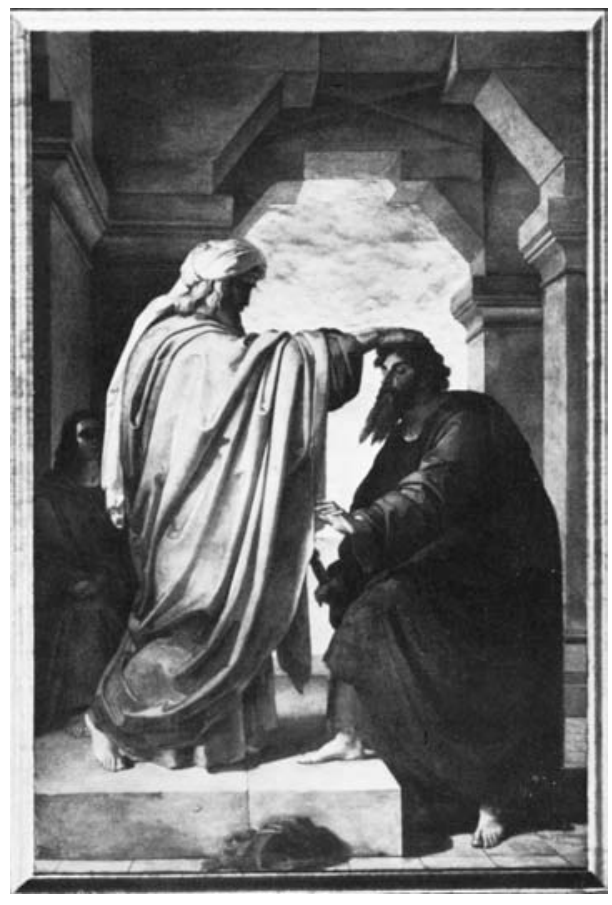

Abb. 13: Francesco Podesti: Heilung des Paulus, Rom, S. Paolo fuori le mura

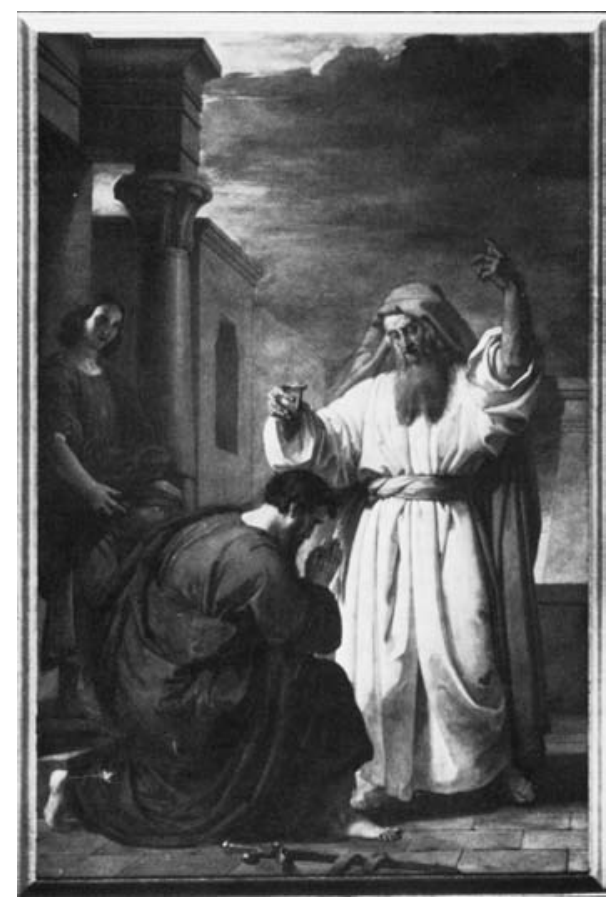

Abb. 14: Francesco Podesti: Taufe des Paulus, Rom, S. Paolo fuori le mura

In San Paolo malte Francesco Podesti lediglich die beiden Fresken mit der Taufe und der Heilung des Paulus, deren Entwürfe wir in den Göttinger Bozzetti vor Augen haben. Sie befinden sich als Teil eines übergreifenden Zyklus an prominen-

5 Vgl. Abbazia Benedettina di S. Paolo, 1994, S. 3.

6 Ebd., S. 6 f.

7 Grundlegend zu San Paolo im 19. Jahrhundert: Groblewski 2001. 
ter Stelle an einer Wand des Querhauses angebracht (Abb. 13+14). Hier sind sie in die richtige chronologische Reihenfolge gebracht, so dass sich die Heilung links von der Taufe befindet.

Aus der Anbringung der Fresken weit über Augenhöhe ergeben sich viele Eigenschaften der Göttinger Bozzetti: Um aus dem Kirchenschiff erkannt zu werden, mussten die Bilder entsprechend monumental ausgeführt werden. ${ }^{8}$ So lassen sich der klare, auf wenige Personen reduzierte Bildaufbau, die Staffelung, bei der die hinteren Personen deutlich erhöht sind, sowie die gelängten Oberkörper aus der Fern- und Untersicht erklären.

Die Fresken Podestis weichen von den Bozzetti nur geringfügig ab. Es fallen lediglich Änderungen in Details auf, mit denen der Maler vermutlich noch einmal auf die besondere räumliche Situation in San Paolo reagierte. So wird in den Fresken nicht nur der Engel über der Taufszene entfernt, sondern auch der Begleiter des Paulus wird stark in den Hintergrund gedrängt, so dass die ursprüngliche Dreifigurenkomposition zugunsten der Hauptprotagonisten Paulus und Ananias zugespitzt wird. Zudem weicht der tiefenräumliche Aufbau der Bozzetti einer eher die Fläche und den Vordergrund betonenden Bildanlage.

Tragen die Bozzetti in ihrer lockeren Malweise fast noch barocke Züge, so zeugen die ausgeführten Fresken in San Paolo von der puristischen Kunstauffassung Podestis. Als Purismo wird eine im Italien des 19. Jahrhunderts verbreitete Kunstströmung genannt, die in ihren Zielen und Ausdrucksformen den Konzepten der deutschen Nazarener nahestand. ${ }^{9}$ So weist Podestis Stil nicht nur viele historisierende Elemente auf, sondern sein CEuvre lässt auch immer wieder Bezüge zur italienischen Kunst der Frührenaissance und des 15. und 16. Jahrhunderts allgemein erkennen. ${ }^{10}$ Zudem bediente sich Podesti mit besonderer Vorliebe der Freskotechnik, die sowohl unter den Nazarenern als auch unter den Puristen eine Aufwertung erfuhr. Als weitere stilistische Vorbilder Podestis lassen sich zudem Raffael und Guido Reni ausmachen.

Podesti blieb Zeit seines Lebens in einer puristischen und klassizistischen Kunstauffassung verhaftet. Gegen Ende des 19. Jahrhunderts auch in Italien auftretenden impressionistischen Strömungen stand er ablehnend gegenüber. Nichtsdestotrotz gilt Podesti als einer der bedeutendsten akademischen Künstler Italiens im 19. Jahrhundert, insbesondere auf den Gebieten der Historien- und Porträtmalerei.

Verena Suchy

8 Huber 1979, S. 203.

9 Ebd., S. 208. Zum direkten Austausch zwischen den Vertretern des Purismo und den Nazarenern vgl. Thimann 2005.

10 Huber, S. 208. 
Kat. Nr. 8

Heinrich Petri (1834-1872)

\section{Mater dolorosa}

3. Viertel 19. Jahrhundert?

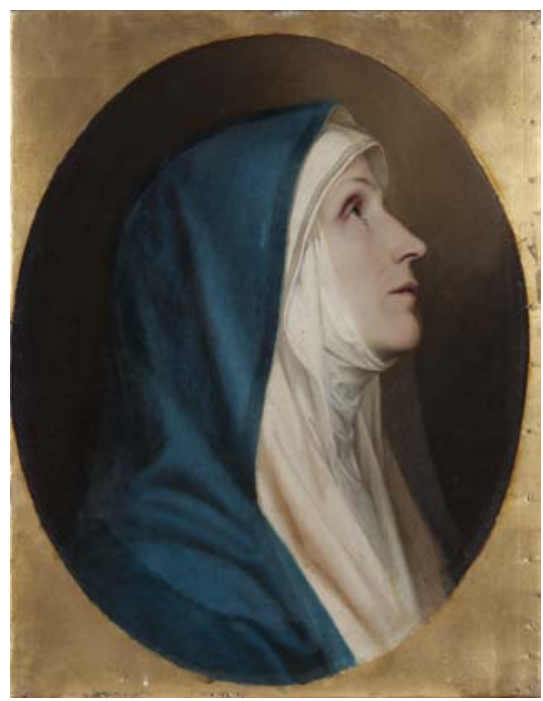

Leinwand, 48 × $37 \mathrm{~cm}$, im Oval, nicht signiert, 2012 von Dr. Sabine Engelhardt geschenkt, Inv. Nr. GG 280
Kat. Nr. 9

\section{Madonna}

3. Viertel 19. Jahrhundert?

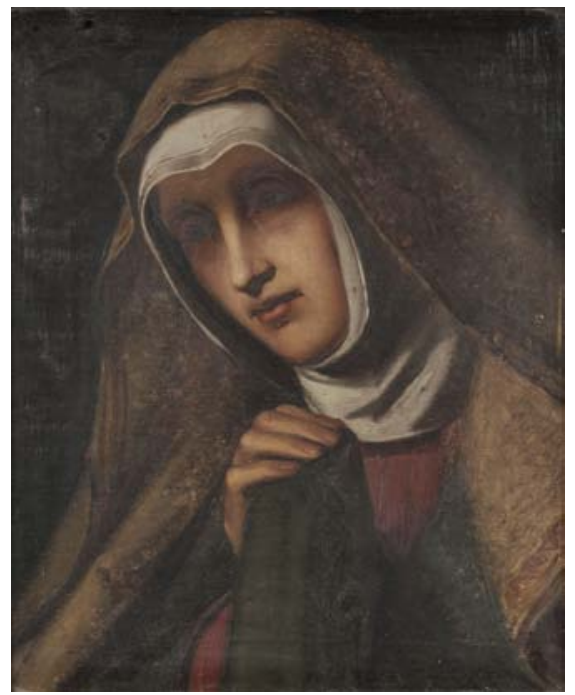

Leinwand, 46,5 × $38,5 \mathrm{~cm}$, nicht signiert, 2012 von Dr. Sabine Engelhardt geschenkt, Inv. Nr. GG 279

„Bei Petri lag das Ernste, um nicht zu sagen Hohe, vorbestimmt“" - diese Charakterisierung aus einem Nachruf Jakob Falkes auf den Historienmaler Heinrich Petri charakterisiert auch die hier vorgestellten Madonnenbilder treffend. Geboren als zweites Kind des Göttinger Porzellanmalers und Photographen Philipp Petri (1800-1868) ${ }^{2}$ erhielt Heinrich Petri schon in jungen Jahren eine künstlerische Ausbildung. Die Porzellanmanufaktur der Familie Petri hatte lange Zeit eine führende und stilbildende Rolle im Raum Göttingen inne. ${ }^{3}$ Die Arbeiten Philipp Petris zeichnen sich dabei, ähnlich wie die seines Sohnes Heinrich, durch einen feinen Stil und ein zartes Kolorit aus.

Falke 1873, S. 98.

Vgl. Thieme/Becker 1907-1950, Bd. 26, 1932, S. 496 f.

3 Brinkmann 2000, S. 18. 


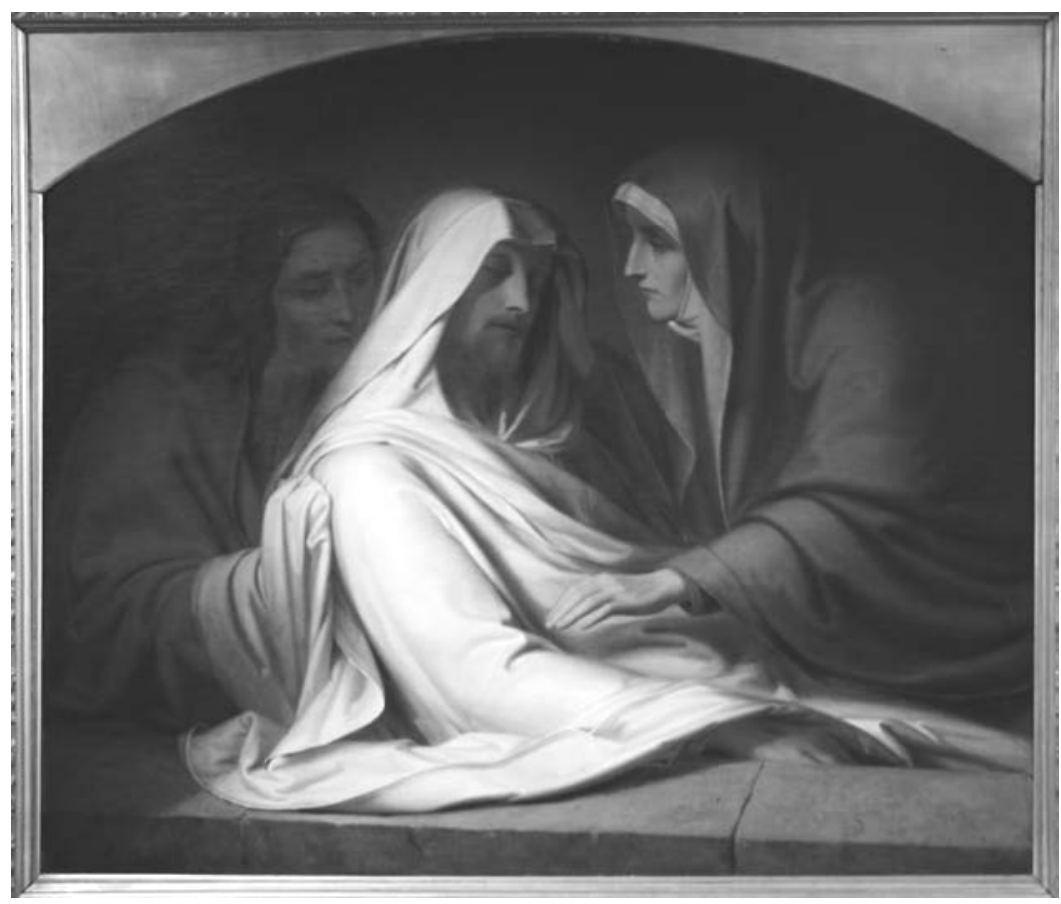

Abb. 15: Heinrich Petri: Beweinung Christi, Öl auf Leinwand, 103 x $125 \mathrm{~cm}$, Göttingen, Städtisches Museum

Die Familie war zudem eng mit der Stadt Göttingen und der dortigen Künstlergemeinschaft verbunden. So bestanden unter anderem Kontakte, mitunter aber auch Konkurrenzverhältnisse zu den Malern Spangenberg und Oesterley, von denen sich zum Teil ebenfalls Gemälde im Besitz der Göttinger Universitätskunstsammlung befinden. ${ }^{4}$

Heinrich Petri erhielt seine weitere künstlerische Ausbildung an der Düsseldorfer Kunstakademie, die er ab 1852 besuchte. ${ }^{5}$ Dort sollte insbesondere Ernst Deger (1809-1885) Petris engster Vertrauter und künstlerischer Leitstern werden. ${ }^{6}$ Unter Degers Einfluss wandte sich Petri der religiösen Historienmalerei nazarenischer Prägung zu. Im Nachruf von Jakob Falke wird seine Malerei allerdings mit der vermeintlichen „Blutleere“ der Bilder seiner Lehrers kontrastiert:

„Das Einfache, Aufrichtige, Wahre seines Wesens, sein Muth, das Wahre gradeaus zu bekennen, bewahrten ihn [Heinrich Petri, d. Verf.] völlig vor dem Einfluß jener äußerlichen, glat-

4 Ebd., S. 24; vgl. Kat. Nr. 11 (Oesterley). Bei Spangenberg handelt es sich um den Vater von Friedrich Spangenberg (vgl. Kat. Nr. 2+3), der in Göttingen Porzellanmaler war (vgl. Brinkmann 2000, S. 24-42).

5 Falke 1873, S. 97.

6 Ebd., S. 99. 
ten, süßlichen Art und falschen Empfindung, wie sie damals in Düsseldorf in der religiösen Malerei herrschten." 7

Das Bestreben, Petri von den Nazarenern abzusetzen, entspricht der verbreiteten Nazarenerkritik des ausgehenden 19. Jahrhunderts und sollte gerade im Kontext eines Nachrufes nicht überbewertet werden.

Seinen feinen, glatten und harmonisch durchgebildeten Stil perfektionierte Petri bei zwei Aufenthalten in Rom in den Jahren 1858 und 1868, bei denen er zudem enge Freundschaft mit dem wesentlich älteren, aber künstlerisch nahestehenden Johann Friedrich Overbeck (1789-1869) schloss. ${ }^{8}$ Mit den Nazarenern und insbesondere den Vertretern der Düsseldorfer Schadow-Schule teilte er neben seiner sehr feinen, zarten Malweise auch die Vorliebe für religiöse und historische Sujets. So nehmen Madonnendarstellungen im CEuvre des Katholiken Petri eine zentrale Stellung ein. ${ }^{9}$ Neben zahlreichen nicht szenischen Marienbildnissen kleinen

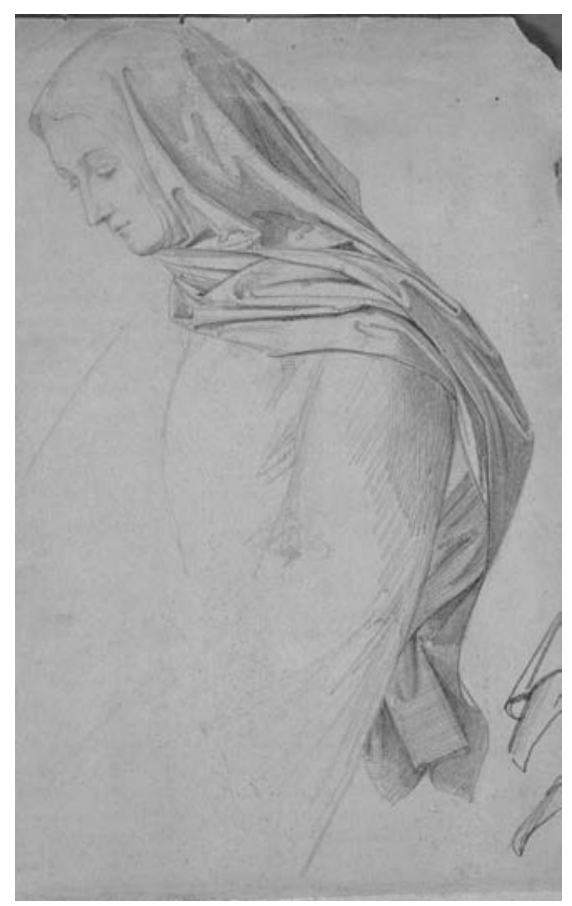

Abb. 16: Heinrich Petri: Mater dolorosa (Ausschnitt), Bleistiftzeichnung, $271 \mathrm{x}$ 131 mm, Göttingen, Kunstsammlung der Universität, Inv. Nr. 2012/1 und mittleren Formats fertigte er auch Altarbilder und Wandgemälde mit Themen der Marienverehrung an. ${ }^{10}$ Exemplarisch sei an dieser Stelle auf ein lebensgroßes Madonnenbild Petris in Wachsfarben für die Kirche zu Wellbergen in Westfalen verwiesen. ${ }^{11}$

Die beiden hier behandelten Madonnen sind sowohl stilistisch als auch thematisch typisch für Petris Malerei. Sie wurden der Göttinger Universitätskunstsammlung 2012 zusammen mit einer Handzeichnung Petris (Abb. 16) aus Privatbesitz übereignet. ${ }^{12}$ Ein Gemälde der Beweinung Christi von der Hand des Künstlers befindet sich im Göttinger Stadtmuseum (Abb. 15). Gerade im Vergleich der verschiedenen Marienfiguren wird deutlich, dass sich der Künstler immer wieder bestimmter Darstellungstypen bediente.

7 Ebd., S. 98.

8 Ebd., S. 100.

9 Vgl. ebd., S. 101.

10 Boetticher 1891-1901, Bd. 1, S. 247.

11 Ebd.

12 Vgl. hierzu auch den Beitrag „Die Provenienzen der Göttinger Gemälde des 19. Jahrhunderts“ von Anne-Katrin Sors in diesem Band, S. 47 f. 
Das Gemälde Mater dolorosa ${ }^{13}$ weist ein ovales Bildformat auf und zeigt Maria im Profil. Ihr Antlitz ist nahe an den Betrachter herangerückt, lediglich Kopf und Schultern sind sichtbar. Der Hintergrund ist nicht weiter ausdifferenziert und dunkel gehalten, weist jedoch einen aufgehellten Bereich rechts oben neben dem Gesicht der Madonna auf. Diese trägt einen leuchtend blauen Umhang über mehreren Lagen eines weißen Gewandes. Eine der Stoffbahnen, die um den Kopf der Madonna geschlungen sind, wird von einem grau abgesetzten Streifen gesäumt. Lediglich das Gesicht der Maria ist unbedeckt. Es ist vom Betrachter abgewandt. Mit traurigem und entrücktem Blick und leicht geöffnetem Mund schaut Maria nach rechts oben aus dem Bildraum hinaus. Eine einzelne Träne im Augenwinkel der Madonna bietet einen Anhaltspunkt, die Darstellung ikonographisch näher zu bestimmen. Maria ist hier als im Schmerz über den Tod ihres Sohnes versunkene Mutter, als Mater Dolorosa dargestellt.

Petri stellt das seelische Leid Marias auf durchaus dezente, erhabene und würdevolle Weise dar. Das gesamte Bild strahlt Ruhe, Harmonie und eine einfache, getragene Innerlichkeit aus. Petris kultivierte Feinmalerei sowie das zarte, zurückgenommene, aber dennoch klare und frische Kolorit unterstützen diesen Effekt. Diese ebenmäßige, sehr feine Malerei muss, wie zeitgenössische Quellen nahelegen, als typisch für Heinrich Petri angesehen werden:

\begin{abstract}
„Bei seinem ächt [sic] künstlerischen Streben erreichte er namentlich in seinen späteren Arbeiten eine sehr glückliche koloristische Wirkung, die durch Kraft und Tiefe ganz in Harmonie mit der ernsten, feierlichen Stimmung stand, die er anregen wollte." ${ }^{14}$
\end{abstract}

Das zweite Göttinger Madonnenbild Petris (Inv. GG 279) scheint hierbei zunächst stilistisch aus dem Rahmen zu fallen, da es sehr viel gröber gemalt ist, als die Mater Dolorosa. Es zeigt ein hochformatiges, ebenfalls nah an den Betrachter herangerücktes Bruststück der Jungfrau Maria vor einem dunklen, verunklärten Hintergrund. Kopf und Schultern sind von einem braunen Mantel umfangen. Marias Gesicht wird von einem weißen, ebenfalls grau gesäumten Schleier eingefasst. Ihr Gewand besteht aus rotem und grünem Stoff. Maria hält die Hände vor der Brust erhoben. Eine grüne Stoffbahn verhüllt ihre linke Hand, die Rechte ist locker auf die Linke aufgelegt. Marias Blick ist auch in diesem Bild abwesend aus dem Bildraum hinaus gerichtet. Sie schaut nach links unten und nimmt keinerlei Blickkontakt mit dem Betrachter auf. Ihr Gesicht ist leicht aus der en-face-Darstellung ins Profil gedreht. Ihre Augen werden von ihrem Schleier verschattet und der Mund ist leicht geöffnet.

Insbesondere der braune Mantel Mariens, ihr Gewand und der Hintergrund sind mit groben, deutlich sichtbaren Pinselstrichen gemalt, die in starkem Kontrast zu Petris üblicher Feinmalerei stehen. Die Farbe ist zudem sehr ungleichmäßig aufgetragen, so dass an einigen Stellen der Bildträger durchschimmert. Deutlich

13 Der Titel befindet sich auf einer Aufschrift auf der Rückseite des Gemäldes.

14 Falke 1873, S. 100. 
feiner gemalt ist hingegen das Gesicht der Madonna. Zwar sind auch hier noch vereinzelte Pinselspuren sichtbar, doch das Antlitz weist bereits den für Petri charakteristischen Ausdruck stiller, in sich gekehrter Erhabenheit auf. Es lässt sich daher mit einiger Wahrscheinlichkeit schlussfolgern, dass es sich bei diesem Madonnenbild um ein unvollendetes oder skizzenhaft angelegtes Werk handelt.

Interessant ist, dass es sich bei den beiden Göttinger Madonnenbildnissen nicht um szenische Darstellungen handelt. Die Madonnen stehen jeweils für sich und sind in keinen konkreten Handlungskontext eingebunden, sondern verkörpern überzeitliche Eigenschaften Mariens. Allenfalls ließe sich die Mater dolorosa als Teil einer Kreuzigungsszene denken. Von Petri ist bekannt, dass er mehrere solcher unszenischer Marienbildnisse für private Auftraggeber fertigte. ${ }^{15}$ Es ist also anzunehmen, dass die unszenischen und überzeitlichen Motive der Göttinger Madonnendarstellungen nicht auf einen vorbereitenden Charakter der Werke verweisen, sondern auf ikonographische Topoi der katholischen Marienverehrung zurückzuführen sind. In ihrer bildlichen Isolation übernehmen sie die Funktion von Andachtsbildern. Dass Petri solche Motive mit Vorliebe gemalt hat, dürfte einerseits in seiner eigenen Religiosität, andererseits in der Kunstauffassung der dem Katholizismus nahestehenden Nazarener begründet liegen.

Petris Göttinger Madonnendarstellungen sind von zarter Feinmalerei und einem harmonischen, dabei aber keineswegs blassen Kolorit geprägt und veranschaulichen exemplarisch die künstlerische Gediegenheit Heinrich Petris. Sie erwecken im Betrachter eine gleichsam sakrale Erhabenheit und nachdenkliche Innerlichkeit. In ihrer unpathetischen Ruhe und Harmonie vermitteln sie die stille und damit umso berührendere Trauer und Würde Mariens. Sie können damit nicht nur als charakteristisch für die religiöse Malerei Heinrich Petris angesehen werden, sondern verkörpern zudem die Ideale der nazarenischen religiösen Historie auf nahezu ideale Weise.

Verena Suchy

15 Vgl. Boetticher 1891-1901, Bd. 1, S. 247. 

Kat. Nr. 10

Franz Xaver Laudage (1821-1893)

\section{Heilige Elisabeth von Thüringen}

1870

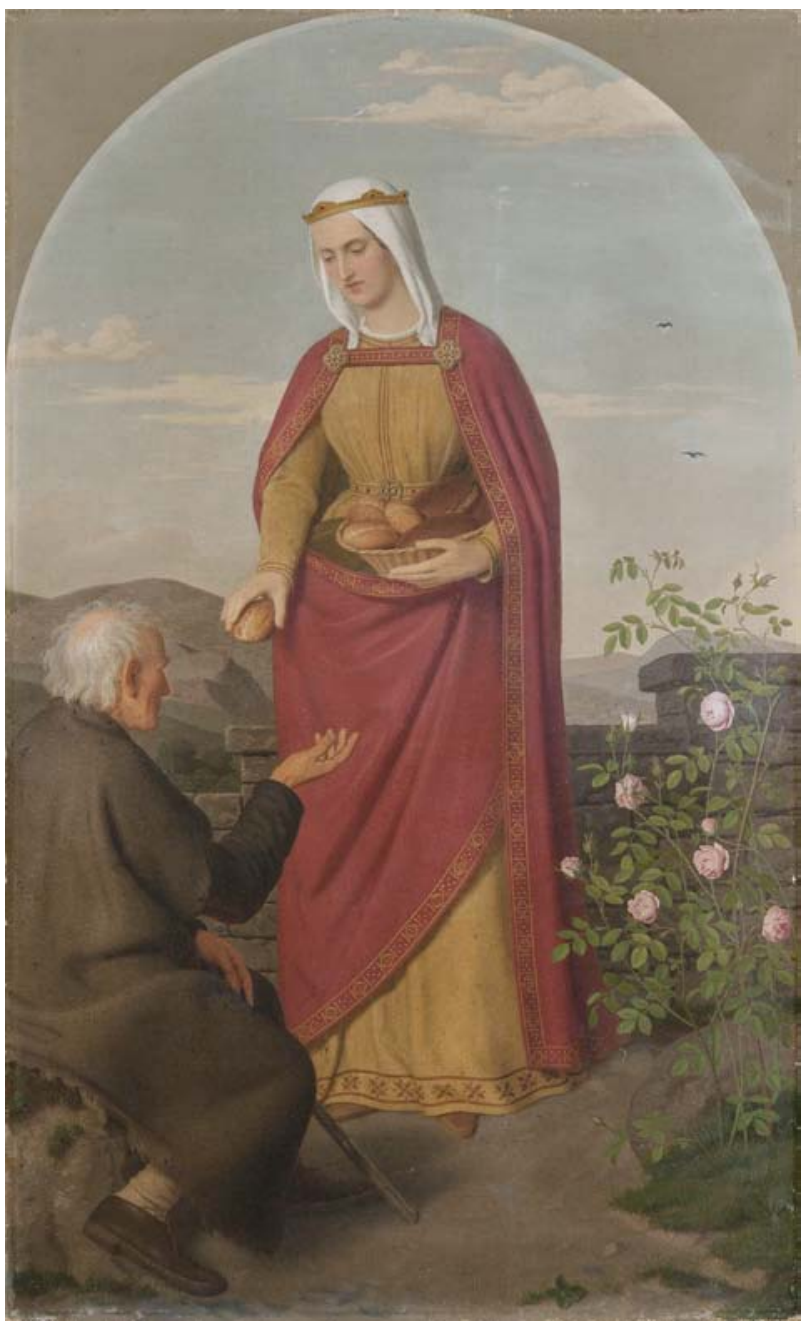

Öl auf Leinwand, $80,8 \times 48,8 \mathrm{~cm}$, signiert und datiert, Schenkung von Maria Pabst, 2010, Inv. Nr. GG 261 
Die Universitätskunstsammlung Göttingen besitzt eines der wenigen bekannten Gemälde des in Paderborn tätigen Malers Franz Xaver Laudage. Es zeigt die Heilige Elisabeth von Thüringen bei der Armenspeisung, dem, vor allem in der Druckgraphik, seit der Mitte des 19. Jahrhunderts vorherrschenden Motiv der Elisabethikonographie. ${ }^{1}$ Die Almosenspende in verschiedenen Formen ist gleichzeitig eine der ältesten ikonographischen Traditionen der mittelalterlichen Heiligen. Sie kommt in verschiedenen Formen vor, wobei neben der Brotspende vor allem die Tränkung von Durstigen und die Geldspende zu nennen sind. ${ }^{2}$ Zusätzlich zum gehaltenen Brotkorb ermöglichen sowohl die von der Frau getragene Krone als auch der rechts von ihr wachsende Rosenstrauch eine sichere Identifikation der Thematik. ${ }^{3}$

\section{Biographisches zu Laudage}

Der Schöpfer des Werkes - Johann Franz Xaver Laudage - ist den einschlägigen Künstlerlexika und Biographien nicht bekannt, weshalb eine kurze biographische Einführung und ein Abriss seines bisher bekannten CEuvres zweckmäßig erscheinen. Der Maler entstammte dem westfälischen Ort Büren südwestlich von Paderborn, in dem er 1821 getauft wurde. Vor seinem Tod am 11.03.1893 lebte er in der Stadt Paderborn, in deren Umkreis sich auch noch einige weitere Spuren seiner künstlerischen Tätigkeit finden. ${ }^{4}$ Es handelt sich dabei um fünf Darstellungen aus dem Leben Christi und dem der Maria, die sich in den Pfarrkirchen zu LangenstraBe und Westönnen befinden. ${ }^{5}$ Erstmals aktenkundig wird Laudage im Zusammenhang mit dem Auftrag für ein Gemälde für die Pfarrkirche in Langenstraße (heute Langenstraße-Heddinghausen). Die Verhandlungen für das Gemälde fanden im Jahr 1856 statt und zogen sich bis 1857 hin, wie einem Briefwechsel zwischen dem bischöflichen Generalvikariat und dem Kirchenvorstand der Pfarrkirche Langenstraße zu entnehmen ist. ${ }^{6}$ Während der Verhandlungen scheint Laudage offensicht-

1 Vgl. Overdick 2007, S. 543.

2 Zu den verschieden ikonographischen Traditionen der Darstellung Elisabeths von Thüringen vgl. neben dem Artikel von Hahn und Werner im Lexikon der christlichen Ikonographie (Hahn/Werner 1975) vor allem Ausst.-Kat. Marburg 1983; darin speziell zur Almosenspende S. 27-66.

3 Vgl. Hahn/Werner 1975.

4 Die Lebensdaten Laudages sind noch nicht wissenschaftlichen Standards genügend publiziert. Die einzige diesbezügliche Sekundärquelle ist ein im Internet veröffentlichter Artikel auf der Homepage der Gemeinde Westönnen. Hierin wurden die Lebensdaten des Malers von dem ehemaligen Werler Stadtarchivar Heinrich Josef Deisting ermittelt. Der Autor muss in diesem Fall der fachkundigen Arbeit des Stadtarchivars vertrauen. Vgl. http://www.westönnen.de/zzz_alt/home/ q2_2006/20060522_altarbilder2.htm. Ein Ausdruck der Website befindet sich in der Bildakte GG 261 der Universitätskunstsammlung Göttingen.

5 Vgl. zu den Gemälden in Langenstraße in den Akten der Inventarisation des Diözesanmuseums Paderborn Inv. Nr. 13544, 13545 und 13546. Zu den beiden Werken in Westönnen siehe Anm. 4.

6 Siehe: Paderborn, Diözesanarchiv, Sign. 466 Nr. 3., Aktennr. 6129 vom 15. Oktober 1857, unpag. 
lich noch in Büren gelebt zu haben, da im Schriftwechsel vom „Maler Laudage in Büren“ die Rede ist.7 Heute befinden sich in dieser Kirche drei Werke des Künstlers, eine Taufe Christi, eine Himmelfahrt Mariens sowie eine Beweinung Christi am Kreuz: ${ }^{8}$ Zudem existiert in den Akten des Generalvikariats ein Briefwechsel über ein Werk, das den Heiligen Antonius zum Thema hat, aus dem Jahre 1859.9 Der Verbleib des Gemäldes konnte allerdings nicht ermittelt werden. Interessant für den Lebenslauf des Malers ist jedoch, dass Laudage bei seiner Unterschrift den Ort mit Paderborn angab. Sehr wahrscheinlich war er also mittlerweile dorthin gezogen.

Die zwei verbleibenden Gemälde befinden sich, wie bereits erwähnt, in der Ortschaft Westönnen. Laudage malte für die Kirchgemeinde des Ortes eine Maria auf der Mondsichel stehend, sowie eine weitere Taufe Christi. Besonders auffällig ist bei beiden Gemälden die Darstellung vor goldenem Hintergrund und das verwendete, oben mit einem Spitzbogen schließende Format. Zudem ist zu bemerken, dass die Darstellung der Figuren bei der Taufe Christi in Westönnen mit der des Werkes in Langenstraße nahezu identisch ist. Bereits 1873 wurde zwischen dem Kirchenvorstand in Westönnen und dem Generalvikariat in Paderborn wegen der Bilder für die Seitenaltäre der Kirche verhandelt, zunächst schlug das Vikariat jedoch einen anderen Maler vor. ${ }^{10}$ Nachdem der Kirchenvorstand Westönnens aber mit Laudage in Kontakt getreten war, gestattete es die Ausführung durch den Maler, nachdem dieser einige Skizzen eingereicht hatte. ${ }^{11}$

\section{Laudages Göttinger Heilige Elisabeth}

Das Gemälde in der Göttinger Universitätskunstsammlung ist stilistisch und thematisch der nazarenischen Malerei zuzuordnen. Eigenschaften wie das lokalfarbene Kolorit und die geringe Tiefenräumlichkeit der Personendarstellung finden sich, wenn auch nicht immer in so ausgeprägter Form, bei vielen Werken nazarenischer Tradition. Auch der ruhige und geschlossene Umriss der Elisabeth sowie der lineare Faltenwurf ihrer Kleidung entsprechen dem. ${ }^{12}$ Die Vermählung Mariä ${ }^{13}$ und die Beweinung Christi ${ }^{14}$ von Friedrich Overbeck oder Sulamith und Maria ${ }^{15}$ von Franz Pforr sind als Werke der ersten Generation nazarenischer Künstler gut für einen

\footnotetext{
Ebd.

Vgl. Anm. 5.

9 Siehe: Paderborn, Diözesanarchiv, Sign. 466 Nr. 3, Aktennr. 7636 vom 13. Mai 1859, unpag.

10 Siehe: Paderborn, Diözesanarchiv, Sign. 801 Nr. 3, Aktennr. 13134 vom 20.12.1873 unpag.

11 Paderborn, Diözesanarchiv, Sign. 801 Nr. 4, Aktennr. 126 vom 7.1.1874 unpag.

12 Zum Begriff der Nazarener und den damit verbundenen stilistischen Eigentümlichkeiten vgl. Ziemke 1977a, S. 17.

13 Siehe Ausst.-Kat. Lübeck 1989, S. 146, Nr. 26.

14 Ebd., S. 156 Nr. 30.

15 Vgl. Ausst.-Kat. Frankfurt a. M. 1977, S. 47. Das Werk war nicht Teil der Ausstellung, ist aber trotzdem in Farbe abgebildet.
} 
Vergleich der unterschiedlichen stilistischen Ausprägungen dieser Kunstrichtung geeignet.

Über die allgemeine Thematik des Werkes sowie die ihm zugrunde liegende künstlerische Tradition hinaus können noch weitere Aussagen zu Thema und Darstellung getroffen werden. Das Format ähnelt den übrigen bekannten Werke Laudages: der Bildträger ist nicht rechteckig, sondern wird von einem Rundbogen abgeschlossen. ${ }^{16}$ Dies erinnert an Altarbilder. Seine im Vergleich dazu aber wesentlich geringere Größe lässt möglicherweise auf eine andere Funktion - etwa als privates Andachtsbild - schließen. ${ }^{17}$

Im Zentrum des Gemäldes, direkt auf der Mittelsenkrechten, ist Elisabeth dargestellt. Sie trägt einen roten Umhang über einem gelben Kleid und ist mit einer kleinen Krone bekrönt, unter welcher ein weißer Schleier ihr Haar bedeckt. Dabei steht die Heilige annähernd frontal zum Betrachter. Ihr Kopf ist leicht in Richtung des links vor ihr sitzenden alten Mannes geneigt, dem sie mit der rechten Hand ein Brötchen reicht. Dieses befand sich noch kurz zuvor in dem von ihrer linken Hand gehaltenen Korb mit weiteren Backwaren. Auffällig an ihrer Darstellung ist, dass ihre linke Hand, zusammen mit dem Korb und dem Umhang vor ihrer Taille, in einer geschwungenen Linie verlaufen.

Der vor Elisabeth sitzende, in einfache braune Kleidung gehüllte, alte Mann führt den Betrachter als Rückenfigur näher an das Geschehen heran. Er streckt seine rechte Hand nach dem Almosen aus und hält mit seiner linken Hand einen Stock vor seinem Schoß. Er hat graues, am Scheitel bereits schütteres Haar.

Elisabeth steht vor einer nach links in Absätzen absteigenden Mauer. Rechts neben ihr blüht ein Rosenstrauch, der auf das Rosenwunder verweist. Dabei handelt es sich um eine in der Vita der Heiligen beschriebene Legende, die in diesem Fall nicht das Hauptthema des Bildes darstellt. ${ }^{18}$ Der Strauch ist eher als auf die Person verweisendes Attribut $\mathrm{zu}$ verstehen. Der Bildhintergrund besteht zum größten Teil aus leicht bewölktem Himmel. Nur direkt über der Mauer ist eine Gebirgslandschaft mit niedrigen Bergen zu sehen, welche die hessischen oder thüringischen Mittelgebirge darstellen soll.

Laudages Darstellung der ungarischen Königstochter wurde anscheinend von verschiedenen literarischen und bildkünstlerischen Vorbildern beeinflusst. Allgemein wurde das Leben Elisabeths von zwei Autoren des 19. Jahrhunderts populär

16 Einen runden Abschluss hat Laudage auch bei den Gemälden in Langenstraße genutzt. Diese Werke sind mit einer Höhe von 190 bzw. $270 \mathrm{~cm}$ allerdings wesentlich größer als das Göttinger Gemälde.

17 Die Provenienz des Gemäldes widerspricht dieser These nicht. Die Stifterin erhielt das Werk laut mündlicher Aussage als Erbschaft von ihrer Tante, die es um das Jahr 1926 von ihrem Arbeitgeber erhalten hatte.

18 Zur Tradition des Rosenwunders vgl. Ausst.-Kat. Eisenach 2007, Bd. 1, S. 239-242. Die Legende des Rosenwunders wird zudem zusammengefasst bei Overdick 2007, S. 540. 
gemacht, Karl Wilhelm Justi ${ }^{19}$ und Charles de Montalembert ${ }^{20}$, von denen der letztgenannte den bedeutenderen Einfluss auf die nazarenischen Künstler hatte.

Bereits im Jahr der Erstausgabe der $\mathrm{Hi}_{\text {- }}$ stoire de Sainte Elisabeth hatte Montalembert Kontakt zu Friedrich Overbeck. Dieser fertigte zum Dank für ein Exemplar des Werkes eine Zeichnung für den Franzosen, die jener zunächst in ein eigenes Mappenwerk aufnahm. ${ }^{21}$ Michael Overdick vermutet, dass dieses Mappenwerk Vorbild für einen Stahlstich war, welcher 1846 vom erst vier Jahre zuvor geründeten Verein zur Verbreitung religiöser Bilder in Düsseldorf herausgegeben wurde (Abb. 17).22 Der Düsseldorfer Verein war eine der wichtigsten Institutionen zur Popularisierung religiöser Druckgraphik im 19. Jahrhundert, und es wäre somit nicht verwunderlich, wenn Laudage den Stich gekannt hätte. Die Elisabeth des Gemäldes zeigt einige Ähnlichkeit zur Darstellung im Stich. Die Heilige trägt in beiden Werken eine sehr flache Krone über einem hellen Schleier auf dem Kopf. Auch das schlichte Kleid und der darüber getragene Mantel finden sich wieder. Zudem ist die Neigung des Kopfs und das ebenmäßige Gesicht mit den niedergeschlagenen Augen beiden Darstellungen ebenso eigen, wie die Darstellung der Speisung des Bedürftigen mit dem rechten, fast senkrecht zu Boden gerichteten Arm. ${ }^{23}$

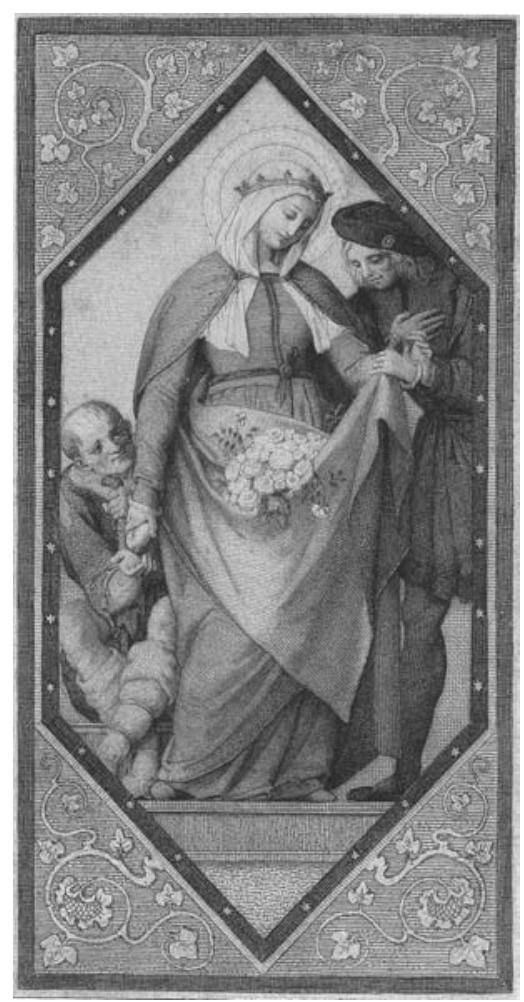

Abb. 17: Friedrich Ludy nach Friedrich Overbeck: S. Elisabeth, Stahlstich, 1846

19 Karl Wilhelm Justi: Elisabeth die Heilige, Landgräfin von Thüringen. Nach ihren Schicksalen und ihrem Charakter dargestellt, Zürich 1797 (Neu aufgelegt Marburg 1835).

20 Charles de Montalembert: Histoire de Sainte Elisabeth de Hongrie, Duchesse de Thuringe: (12071231), Paris 1836. Das Werk wurde bereits 1837 ins Deutsche übersetzt.

21 Ein Exemplar der Monuments de l'bistoire de Sainte Élisabeth von Montalembert konnte vom Verfasser leider nicht eingesehen werden.

22 Overdick 2007, S. 540 f.; zum Verein ₹u Verbreitung religiöser Bilder vgl. auch Metken 1977, S. 372.

23 Es bestehen natürlich auch bedeutende Unterschiede zwischen beiden Werken, die nicht verschwiegen werden sollen. Overbeck zeigt z. B. thematisch ein Rosenwunder, während die Elisabeth Laudages nur einen Armen speist. Der Arme ist dabei völlig unterschiedlich dargestellt. Overbecks Darstellung zeigt zudem drei Personen, zwischen denen aufgrund des Hochformats keinerlei Zwischenraum oder ausgearbeiteter Bildhintergrund besteht, während der Paderborner Maler seine Szene in eine Landschaft einbettet. 
Franz Xaver Laudages Elisabeth zeigt daneben noch Ähnlichkeiten zu einer weiteren Frauenfigur in Overbecks CEuvre. Die Maria der Vermäblung Mariä, heute im Muzeum Narodowe in Poznan (ehem. Posen), hält in ihrer linken Hand ein Buch. Diese Haltung, in Verbindung mit dem vor der Taille zusammengehalten Umhang, gleicht der später ausgeführten Elisabeth Laudages weitgehend. ${ }^{24}$ Allerdings ist festzuhalten, dass eine genaue Bestimmung, ob der Kirchenmaler diese Darstellung als Vorbild für seine Malerei nahm, nicht getroffen werden kann. Hierfür fehlen weiterführende biographische Kenntnisse oder Selbstzeugnisse des Malers. Gleiches gilt für ein weiteres Werk, das Ähnlichkeiten zur Elisabeth aufweist: Franz Ittenbachs 1864 gefertigte Klara von Assisi mit dem Hl. Hieronymus in der Pfarrkirche St. Remigius in Bonn. ${ }^{25}$

Das Gemälde Franz Xaver Laudages steht deutlich in der Tradition der religiösen Malerei nazarenischer Schule. Das Thema der Armenspeisung war seit dem Spätmittelalter bekannt und wurde bereits zuvor von Künstlern des 19. Jahrhunderts aufgegriffen. Als Beispiel können hier, neben den bereits erwähnten, noch Moritz von Schwinds Elisabethzyklus auf der Wartburg 26 oder das Rosenwunder der Brüder Riepenhausen ${ }^{27}$ genannt werden. Insgesamt ist die Darstellung der Heiligen Elisabeth im 19. Jahrhundert ein Phänomen, das sich über die Malerei hinausgehend nahezu in allen Kunstformen wiederfindet. 28

Jan Stieglitz

\footnotetext{
24 Ausst.-Kat. Lübeck 1989, S. 146, Kat. Nr. 26. Das Gemälde war Teil der bedeutenden Sammlung Raczynski in Berlin, vgl. Ausst.-Kat. München 1992, Kat. Nr. 4.

25 Vgl. Bertsch 2007, S. 532 Abb. 10.

26 Vgl. hierzu Schweizer 2007.

27 Bertsch 2007, S. 524 f.

28 Vgl. neben Ausst.-Kat. Eisenach 2007 und Ausst.-Kat. Marburg 1983 vor allem auch Elsner 1921.
} 
Kat. Nr. 11

Carl Oesterley (1805-1891)

\section{Segnender Christus}

1881

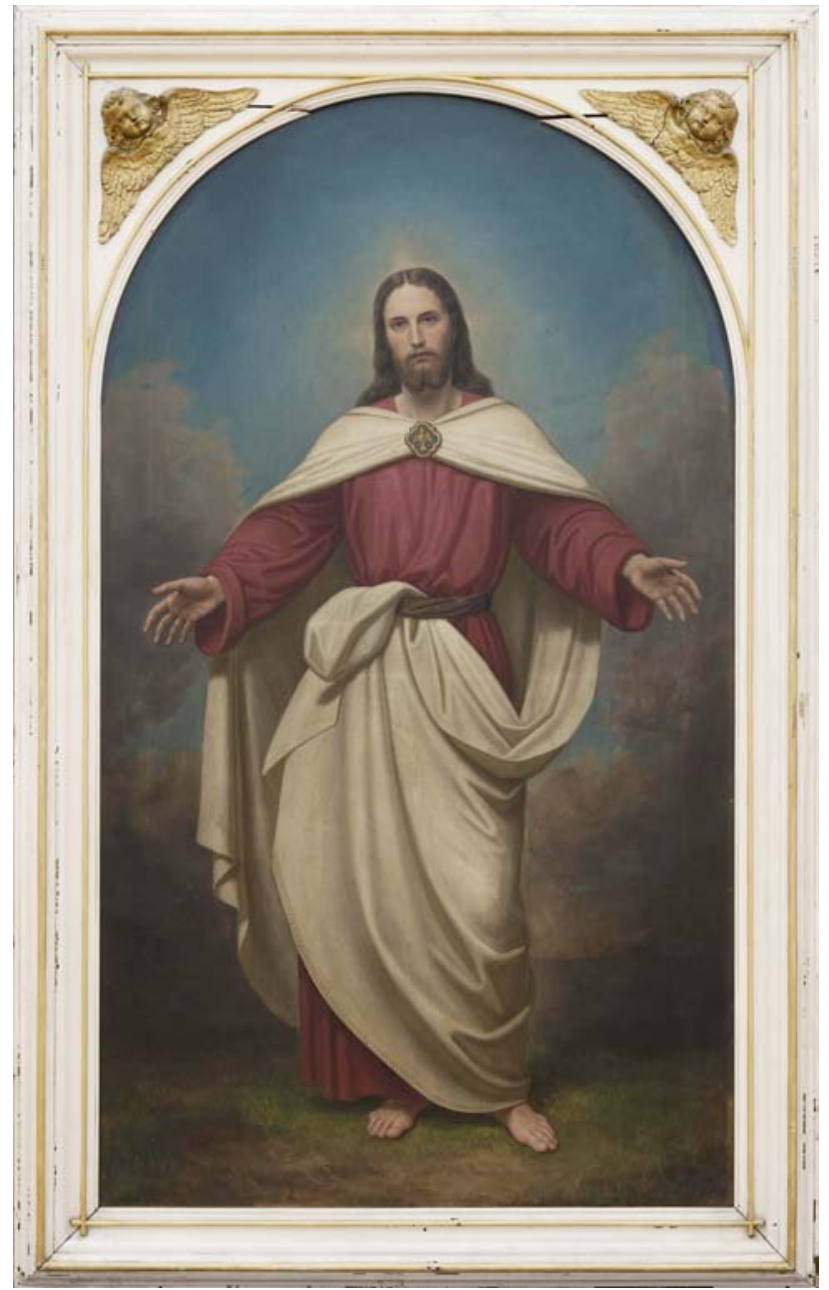

Öl auf Leinwand, 240 x 117 cm, monogrammiert, Leihgabe der Kirchengemeinde Stemmen 
Der Maler Carl Oesterley besitzt für die Kunstsammlung Göttingen einen besonderen Stellenwert. Nach Johann Dominicus Fiorillo (vgl. Kat. Nr. 6) war er ab 1829 Kustos der Universitätskunstsammlung sowie zwei Jahre später auch dessen Nachfolger als Professor der Kunstgeschichte. Dieses Altarbild fertigte er jedoch als Hannoverscher Hofmaler an, zu dem er 1845 ernannt wurde. In dieser Funktion stattete er viele Kirchen der Provinz Hannover mit Altarbildern aus, zu denen auch der Kanzelaltar der Kirche in Rosdorf bei Göttingen gehört. ${ }^{1}$ Gerade ab 1852 widmete sich Oesterley vermehrt der religiösen Malerei, da die Ankunft von Friedrich Kaulbach in Hannover, dem Vater von Friedrich August von Kaulbach (vgl. Kat. Nr. 4), eine große Konkurrenz für seine Porträtaufträge bedeutete. ${ }^{2}$

Das großformatige Altarbild mit der Gestalt Christi wurde der Universitätskunstsammlung 1978 von der Kirchengemeinde Stemmen als Dauerleihgabe übergeben, nachdem es 1960/61 bei einer Neugestaltung der Stemmener Kirche nicht mehr benötigt wurde. Die Kirche hatte das Altarbild 1881 als Schenkung des Landesökonomierats Friedrich von Kaufmann erhalten, welcher von 1874 bis 1895 Patron in Stemmen war. ${ }^{3}$ Kaufmann gab das Bild anscheinend persönlich bei Oesterley in Auftrag. So findet sich im Kassenbuch des Künstlers unter der Jahresangabe 1881 die Notiz: „Altarbild Stemmen, Landesök.rat Kaufmann, 1050 M.“4 Am 1. Advent desselben Jahres wurde das Altarbild feierlich eingeweiht. ${ }^{5}$

Eine Aufnahme aus der Zeit vor 1960 zeigt die Position des Altarbildes im Innenraum der Kirche vor dem Umbau (Abb. 18). Man blickt in den Chor am östlichen Ende der Kirche, der noch aus spätgotischer Zeit stammt. ${ }^{6}$ In den 5/8Schluss ist eine Empore eingesetzt, die sich auch an der Nordseite der Kirche entlangzieht. Das Altarbild ist vor die Emporenbrüstung gesetzt; darunter vermittelt ein Predellenfeld den Übergang zum Altartisch. Unmittelbar hinter dem Gemälde befindet sich auf der Empore die Orgel, die mit ihren Pfeifenfeldern das Bild flankiert. Auf diese Weise erscheint das Altarbild als Teil des Orgelprospekts.

Dass sich die Orgel über dem Altar befindet, ist im protestantischen Kirchenbau keine Seltenheit. Die Art und Weise, wie sie in Stemmen mit dem Altarbild verbunden war, scheint jedoch selten gewesen zu sein. Einen vergleichbaren Fall, bei dem ebenfalls ein Christusbild im Zentrum einer Orgel steht, bietet eine RöverOrgel aus dem Jahr 1896, die für die Kirche des Schröderstifts in Hamburg geschaffen wurde. ${ }^{7}$ Man kann hier geradezu von einer multimedialen Inszenierung sprechen.

1 Näheres zum Rosdorfer Kanzelalter siehe Leuschner 1981. Die Vorzeichnungen befinden sich in der Göttinger Universitätskunstsammlung.

2 Ebd., S. 27.

3 Seidel 1988, S. 148.

$4 \quad$ Als Anhang bei Senf 1957, S. 213.

Seidel 1988, S. 152.

Wolff 1899, S. 123

Siehe Rossner 2006, S. 55. Hier wird der Prospekt der Röver-Orgel als einzigartig bezeichnet. Die Röver-Orgel befindet sich heute im Orgelmuseum Valley in Oberbayern. 
Allerdings sind Orgel und Altarbild in Stemmen - anders als in Hamburg nicht gleichzeitig entstanden. Vielmehr wurde die Stemmener Orgel erst neun Jahre nach dem Altarbild eingesetzt. ${ }^{8}$ Wie das Altarbild vor diesem Einbau aufgestellt war, ist nicht bekannt.

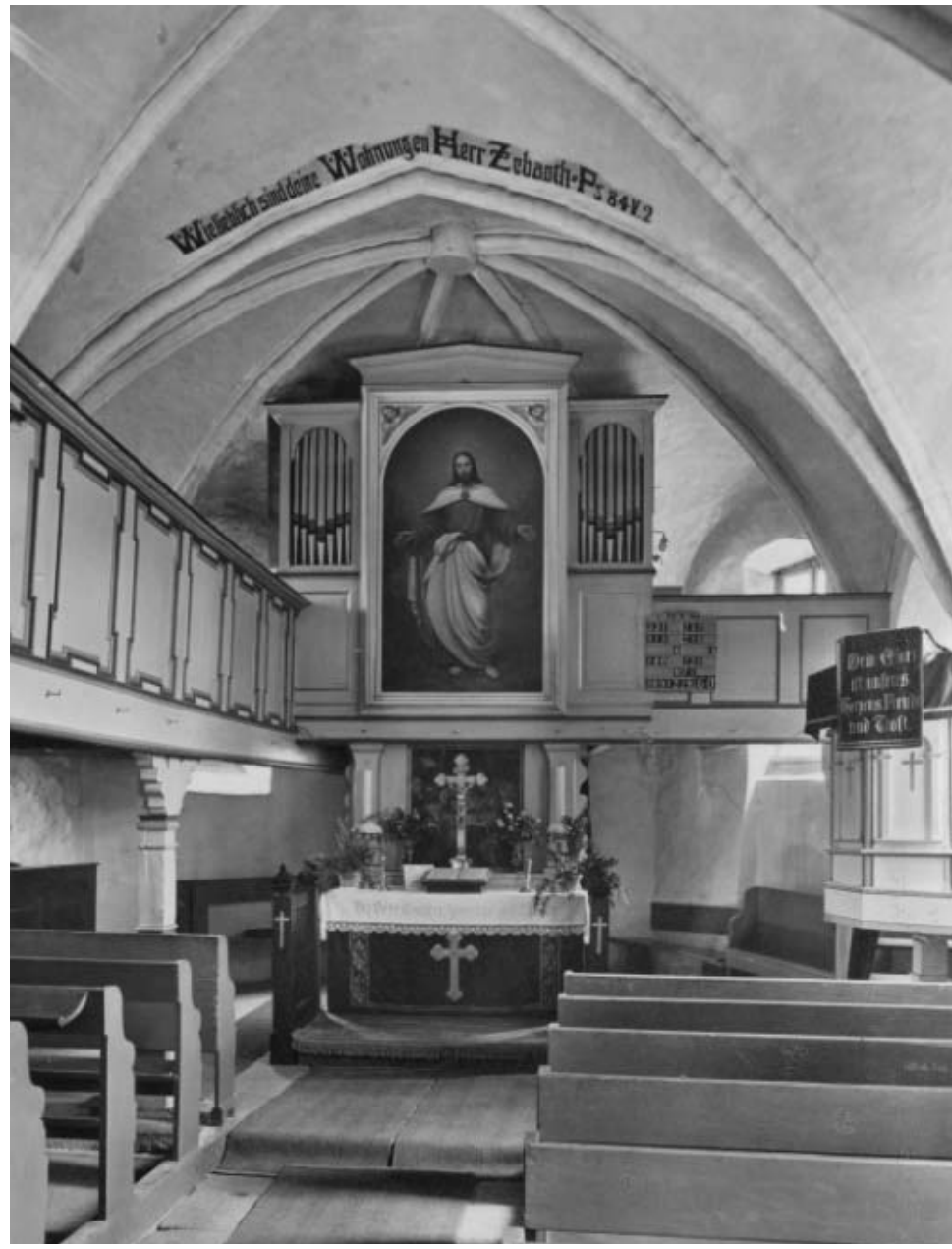

Abb. 18: Stemmen, Evangelische Kirche: Inneres nach Osten vor der Renovierung in den 1960er Jahren

8 Seidel 1988, S. 158. 


\section{Bildaufbau und Ikonographie}

Das hochformatige Altarbild zeigt einen frontal zum Betrachter stehenden, ganzfigurigen Christus in einer nicht näher definierten Umgebung. Der Hintergrund des Bildes wird durch einen hellblauen Wolkenhimmel gebildet, der in der Ferne mit dem darunterliegenden, grasbewachsenen Untergrund zu verschmelzen scheint. Hierdurch wird die Räumlichkeit verschleiert und die Christusfigur in eine zeitlose Ebene gerückt. Zum Bildrand hin wird der Hintergrund immer dunkler, beinahe schwarz. Nur um Christus herum ist der Raum erleuchtet und die Figur somit deutlich hervorgehoben. Hinter dem Kopf deutet sich als Lichterscheinung ein Kreuznimbus an.

Christus ist in einen weißen Umhang mit goldverziertem Saum gehüllt, der mittig vor der Brust von einer verzierten Spange zusammengehalten wird. Die Spange zeigt eine Taube mit Nimbus als Symbol des Heiligen Geistes. Unter dem Umhang trägt Christus ein langärmeliges, purpurfarbenes Untergewand, welches bis zu den unbekleideten Füßen reicht. Der Mantel wird durch die ausgebreiteten Arme weit geöffnet und fällt hinter den Körper der Figur. Unter ihrem rechten Arm wird der Stoff jedoch wieder nach vorn geführt und unter den Gürtel, der an der Taille um das Untergewand gebunden ist, gezogen. Darunter zeichnet sich Christus' linkes Knie ab, und auch sein linker Fuß ist wie in Schrittstellung nach außen gewendet. Das rechte Bein als Standbein ist hingegen durchgestreckt und trägt das Gewicht der Figur. Ein damit angedeuteter Kontrapost wird beim Oberkörper allerdings nicht weitergeführt: Dieser ist vielmehr frontal zum Betrachter gerichtet, wobei beide Arme im selben Winkel vom Körper abstehen. Die Hände sind mit den Innenflächen nach vorne gekehrt, doch zugleich leicht zum Boden gedreht. Dies könnte auf die Untersicht abgestimmt sein, die sich ursprünglich aus der erhöhten Anbringung des Bildes ergab. Die Gestik Christi war damit an den unter dem Bild stehenden Betrachter gerichtet.

Hände und Füße zeigen die Wundmale: Christus wird demnach als Auferstandener dargestellt, der den Gläubigen entgegentritt. Beachtet man seine Armhaltung, so spiegelt der bisher gebräuchliche Titel Segnender Christus den Bildinhalt nicht genau wieder. Eine segnende Pose, die sich durch einen Segensgestus mit einer erhobenen Hand und ausgestrecktem Zeige- und Mittelfinger auszeichnen würde, ist hier nämlich nicht zu erkennen. ${ }^{9}$ Die offen ausgebreiteten Arme mit zum Betrachter gerichteten Handflächen erwecken eher einen empfangenden oder Schutz gebenden Eindruck. In diesem Sinne findet sich in den Aufzeichnungen des damaligen Stemmener Pastors ein sehr treffender Titel: „[...] ein herrliches Altarbild ,der einladende Christus' (gemalt von Professor Oesterley in Hannover) $[\ldots]^{\prime “} .{ }^{10}$ Dabei bezieht sich die Einladung auf die Funktion als Altarbild: Der auferstandene Christus lädt die Gemeinde von Stemmen zum Abendmahl. Die eucharistische Aufladung dieser Gestalt wird durch die Wundmale unterstützt.

9 Poeschke 1972, Sp. 146.

10 Seidel 1988, S. 152. 


\section{Das Gemälde im Kontext von Oesterleys Werk und weiteren zeitgenössischen Christusdarstellungen}

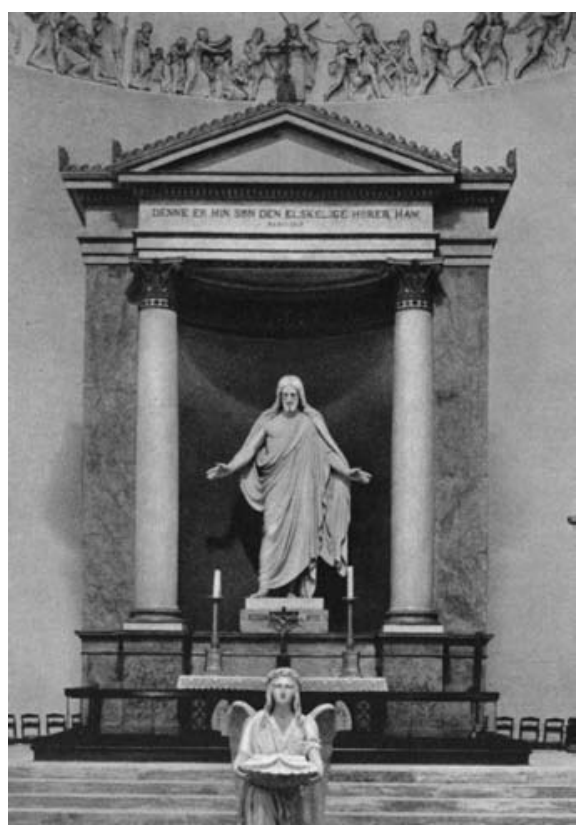

Abb. 19: Kopenhagen, Frauenkirche: Altar mit Christusstatue von Bertel Thorvaldsen (1821-39)

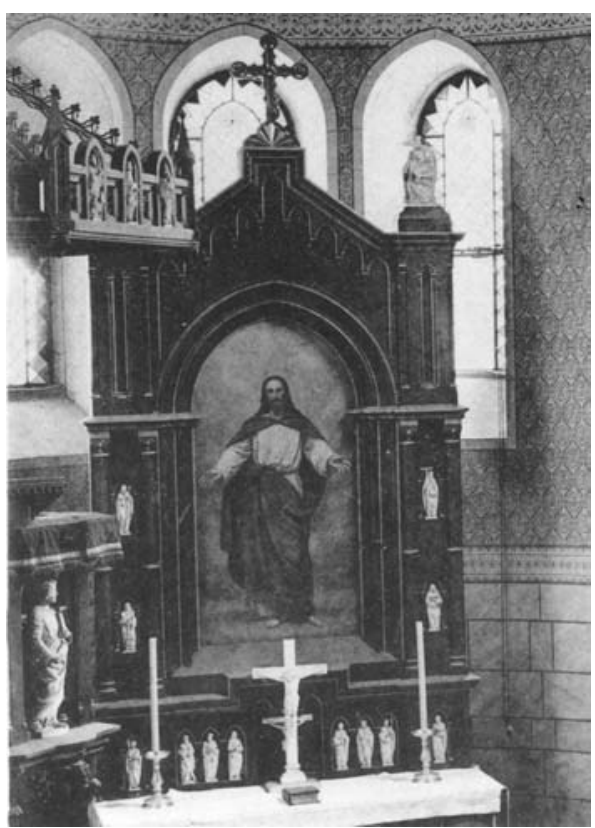

Abb. 20: Barsinghausen, Kirche: historische Aufnahme mit dem Altarbild von Carl Oesterley (1864)

In Oesterleys Werk lassen sich zwei weitere Altarbilder finden, die sehr ähnlich gestaltet sind. Das erste schuf der Maler 1852 für die Maria-Magdalenen-Kirche in Lauenburg an der Elbe,11 das zweite 1864 als Replik des Lauenburger Altarbildes für die Klosterkirche Barsinghausen (Abb. 20). ${ }^{12}$ Diese beiden Bilder unterscheiden sich nur in ihrer Größe und in der Form des Bogenabschlusses, der sich aus den Bildfeldern der jeweiligen Altäre ergab. ${ }^{13}$

Ein Blick auf diese Bilder macht deutlich, dass sie in enger Verbindung zu dem Stemmener Christus stehen müssen, denn die Christusfigur ist bei allen drei Gemälden bis auf die Farbigkeit des Gewandes und der Umhangbefestigung über der

11 Senf 1957, S. 160, Nr. 92; Kassenbucheintrag ebd., S. 205; Haupt/Weysser 1890 S. 94.

12 Senf 1957, S. 162, Nr. 119; Kassenbucheintrag ebd., S. 210; dazugehörige Gewandstudie ebd., S. 173, Nr. 100; Wolff 1899, S. 59.

13 Das Lauenburger Bild misst nach Senfs Angaben 151 x $102 \mathrm{~cm}$ und hat einen runden Abschluss. Das Bild aus Barsinghausen misst nach Senfs Angaben hingegen 240 x $117 \mathrm{~cm}$ und schließt mit einem Spitzbogen ab. 
Brust nahezu identisch. ${ }^{14}$ Der Hintergrund, welcher beim Stemmener Bild durch Gras und blauen Himmel gebildet wird, zeigt sich in Lauenburg und Barsinghausen als von orangem Licht erhelltes Wolkengebilde. ${ }^{15}$ Die Christusfigur wird hier somit noch deutlicher in eine übernatürliche Sphäre gerückt.

Da Stemmen nur etwa sieben Kilometer von Barsinghausen entfernt liegt, wäre nicht auszuschließen, dass der Stifter Kaufmann das Altarbild aus Barsinghausen bereits kannte und eine Replik bei Oesterley in Auftrag gab. Tatsächlich ähneln sich die Christusdarstellungen aus seiner Zeit als Hofmaler sehr. Im Nachlass des Künstlers befindet sich eine Studie eines Christuskopfes in Öl, die Renate Senf dem Himmelfahrtsfresko der Schlosskirche Hannover von 1838 zuordnete. ${ }^{16}$ Diese Kopfstudie passt auch auf die drei Darstellungen des einladenden Christus sowie zu weiteren Christusdarstellungen in Oesterleys Altarbildern. ${ }^{17}$ Da sich die Studie in Oesterleys Nachlass befindet, muss sie sich bis zu seinem Tod in seinem Besitz befunden haben. Eventuell hat er sie nach dem Himmelfahrtsfresko auch bei den folgenden Christusbildern verwendet.

Generell geht diese Darstellungsweise von Christus nicht auf Oesterley selbst zurück, sondern bezieht sich auf das wohl bekannteste und am weitesten verbreitete Christus-Bild des 19. Jahrhunderts: auf Bertel Thorvaldsens 1821-39 in Rom für die Kopenhagener Frauenkirche geschaffene Christusstatue (Abb. 19). Diese hat Oesterley höchstwahrscheinlich während seines Romaufenthaltes 1826-28 im Original zu sehen bekommen. ${ }^{18}$ Thorvaldsens Christus führt dieselbe Armbewegung aus, die bei Oesterleys einladendem Christus zu sehen ist, blickt dabei allerdings mit gesenktem Haupt herab. Auch er fungiert in Kopenhagen, unter einem Ziborium stehend, als Altarbild und betont mit seinen sichtbaren Wundmalen (Thorvaldsen zeigt zusätzlich die Seitenwunde) den Altarraum als Ort, an dem Christus für die Gemeinde im Abendmahl anwesend ist.

Der Sockel des Thorvaldsen-Christus trägt die Inschrift „Kommer til mig“ (dt. „Kommt zu mir“) und deutet damit auf die „Einladung der Mühseligen“ nach Matthäus 11, 28: „Kommet her zu mir alle, die ihr mühselig und beladen seid, so will ich euch erquicken!“ Diese Worte verbildlichte Thorvaldsen mit einer einzigen simplen Geste. Gegenüber August Kestner soll er dazu geäußert haben:

14 In Lauenburg ist das Untergewand Purpur und der Mantel Dunkelblau. Der Barsinghausener Christus trägt ein weißes Untergewand und einen purpurnen Mantel.

15 Farbphotographie des Barsinghausener Bildes von 2008 http://www.kirchenkreis-ronnenberg.de/ gemeinden/barsinghausen/barsinghausen_marien/klosterkirche/altar.html (16.01.2013).

16 Senf 1957, S. 167, Nr. 17; das Fresko wurde im Zweiten Weltkrieg zerstört.

17 Beispielsweise Rosdorf, Molzen und Bad Iburg.

18 August Kestner war zur Zeit von Oesterleys Romaufenthalt Hannoverscher Legationsrat in Rom. Da der Künstler Kestner in Rom aufsuchte, ist vielleicht über ihn ein Kontakt zu Thorvaldsen entstanden. Siehe Leuschner 1981, S. 193 und S. 211, Anm. 69; Arndt 2000, S.69; Senf 1957, S. 11. 
„[...] kann eine Bewegung einfacher sein $[\ldots]$ ? und zugleich drückt es seine Liebe, seine Umarmung der Menschen aus, so wie ich es mir gedacht habe, daß der Haupt-Charakter von Christus ist". 19

Als Anregung zu dieser so einfachen und gleichzeitig so wirkungsvollen Geste soll 'Thorvaldsen Peter von Cornelius' Gemälde Die fünf klugen und fünf törichten Jungfrau$e n^{20}$ gedient haben, welches sich zur Entstehungszeit der Statue im Besitz des Bildhauers befunden hat. ${ }^{21}$

\section{Oesterley als Nazarener}

Cornelius und die Malerei der Nazarener beeinflußten ihrerseits schon früh Oesterleys Schaffen. Deren Kunst lernte er während seines Romaufenthaltes 182628 kennen, als er sich eng mit Joseph Führich anfreundete, mit dem er gemeinsam italienische Kunstwerke studierte. ${ }^{22}$ Diese Zeit sollte Oesterleys künstlerische Laufbahn entscheidend lenken und ihn in die Richtung der religiösen Historie weisen. ${ }^{23}$

Ein weiterer bedeutender Einfluss auf sein Schaffen ging von der nazarenischen Richtung der Düsseldorfer Malerschule aus, der er unter anderem die Weiterbildung seiner Farbtechnik verdankte. Veranlasst durch die Kritik am Kolorit seines Gemäldes Moses zwischen Aaron und Hur, welches 1833 auf der 1. Kunstausstellung in Hannover gezeigt wurde, ${ }^{24}$ reiste Oesterley 1835 und nochmals 1844 an die Düsseldorfer Akademie, wo er dem Direktor Wilhelm von Schadow seine Zeichnungen vorlegte und daraufhin in dessen Atelier arbeiten durfte. ${ }^{25}$ Dort soll er sich den Düsseldorfer „Ton weichen Ernstes“ angeeignet haben, von dem, wie Senf betont, keines seiner Historienbilder ganz frei ist. ${ }^{26}$ Gerade in den erwähnten, ab 1852 entstandenen Altarbildern zeichnen sich die ,akademische[n] Vorstudien, zentralisierte Komposition und idealisierende Auffassung“ der Düsseldorfer Schule $\mathrm{ab} .{ }^{27}$

Dass sich Oesterley an älteren Vorbildern orientierte und von ihnen beeinflussen ließ, entspricht dem nazarenischen Kunstverständnis, dass sich bewusst in bestehende Traditionen einschreiben will. In der zweiten Hälfte des 19. Jahrhunderts geriet diese Position allerdings zunehmend in die Kritik. Hiervon zeugt eine Karikatur des Göttingers Eduard Ritmüller, die suggeriert, dass Oesterley Werke

19 Kestner 1850, S. 78; Gohr 1977, S. 343.

20 1813-16, Öl auf Leinwand, Düsseldorf, Museum Kunstpalast, Inv. Nr. 4011. Siehe Ausst.-Kat. Düsseldorf 2011, Bd. 2, S. 134, Abb. 94.

21 Einem 1981, S. 179; Gohr 1977, S. 345.

22 Senf 1957, S.12 f.

23 Leuschner 1981, S. 198; Arndt 2000, S. 71.

24 Senf 1957, S. 20.

25 Ebd. S. 20, Anm. 18; Leuschner 1981, S. 198.

26 Senf 1957, S. 118.

27 Bartilla 1998, S. 65. 
anderer Künstler sogar direkt kopierte und ihre Kompositionen nachahmte (Abb. 21). ${ }^{28}$

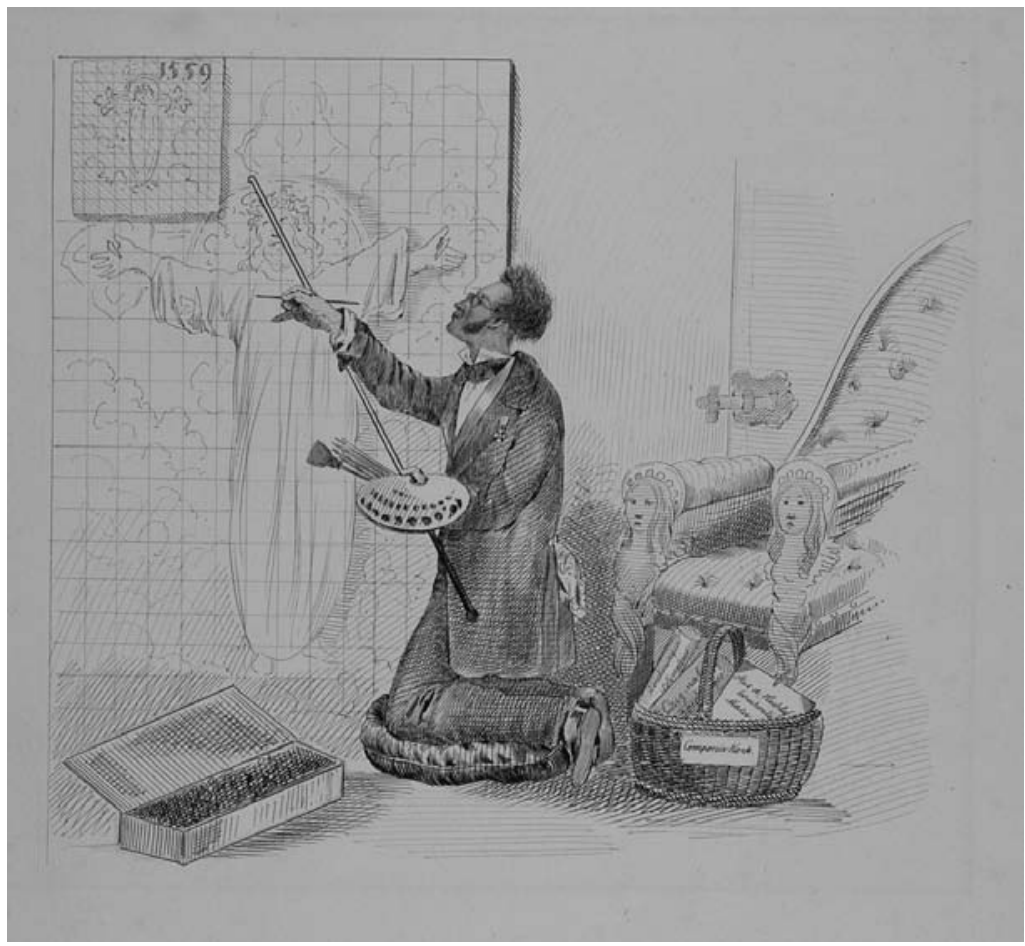

Abb. 21: Eduard Ritmüller: Carl Wilhelm Friedrich Oesterley, nach 1851, Federzeichnung, 433 x 336 mm, Göttingen, Kunstsammlung der Universität, Graphische Sammlung, Inv. Nr. H 1962/3

$\mathrm{Zu}$ sehen ist der Künstler, wie er, auf einem Kissen kniend, eine Graphik eines gekreuzigten Christus, welche die Jahreszahl 1559 trägt, mithilfe eines Rasters ins Großformat überträgt. Wichtigstes Detail ist dabei der „Componir-Korb“, der hinter Oesterley auf dem Boden liegt und mit Mappen und Rollen mit den Beschriftungen „Zeichnungen Cornelius“, „Aus d. Nachlass berühmter Maler“ und „Original Zeichnungen“ gefüllt ist. Hinzu kommt, dass dies hinter einer mit Riegel verschlossenen Tür geschieht, und der Künstler damit aus seiner Vorgehensweise ein Geheimnis macht. Ein tatsächliches Beispiel, das der Vorlage in der Karikatur oder einem von Oesterleys ausgeführten Werken entspricht, kann man jedoch nicht finden. Die Vorlage von 1559 muss aber auch kein konkretes Bild meinen, sondern könnte dafür stehen, dass Oesterley generell der alten Kunst verhaftet sei.

28 Arndt 1994, S. 98 f., Kat. 158. 
Da die Entstehungszeit der Karikatur in die Jahre nach 1851 fällt, wäre ein Zusammenhang mit dem 1851 fertig gestellten Rosdorfer Altar oder sogar dem 1852 gemalten Altarbild für Lauenburg möglich, denn in beiden Werken ist Christus die zentrale Figur. ${ }^{29}$ Vielleicht gab eines dieser Bilder Ritmüller den Anlass, Oesterleys Kunstrichtung durch seine Darstellung zu kritisieren. In diesem Zusammenhang kommt auch Oesterleys Beziehung zur nazarenischen Kunst zum Tragen. Zum einen ist diese durch die Vorlagen von Cornelius im „Componir-Korb“ vertreten, zum anderen spielt Oesterleys Haltung gegenüber dem Bild auf die religiös fundierte Kunstausübung der Nazarener an. Bei Ritmüller arbeitet der Künstler kniend vor dem Bild und schaut zur Christusdarstellung empor, als würde es diese im selben Zuge anbeten. Anstelle des frommen Künstlers sähe man hier einen „frömmelnden“ Künstler. 30

Unabhängig davon, ob Ritmüllers Karikatur Oesterley gerecht wird, ${ }^{31}$ manifestiert sich in ihr eine charakteristische zeitgenössische Rezeptionshaltung gegenüber Oesterleys „,nazarenischer“ Malweise, die genau diejenigen Einflüsse und Merkmale anspricht, die mit ihr in Verbindung gebracht werden: die Orientierung an alten sowie nazarenischen Vorbildern und natürlich die Religiosität des Künstlers.

Lisa Weiß

29 Die Datierung der Karikatur erfolgt anhand des Guelphen-Ordens, der sich an Oesterleys Brust befindet. Dieser wurde ihm 1851 verliehen, die Graphik muss also danach entstanden sein. Siehe Arndt 1994, S. 98 f., Kat. 158.

30 Arndt 2000, S. 67.

31 Karl Arndt erwähnt gleich im ersten Satz seines Katalogeintrags, dass die Beschreibung Oesterleys als kopierenden, unselbstständigen Maler „zu Unrecht“ geschehe. Siehe Arndt 1994, S. 98, Kat. 158. 



\title{
Alltäglichkeit im Aufschwung: Die Genremalerei des 19. Jahrhunderts
}

\author{
Christina Eifler
}

Der Begriff „Genre“ wurde im 18. Jahrhundert von der französischen Kunsttheorie geprägt. Er leitet sich vom lateinischen Wort „genus“ ab, welches „Geschlecht“, „Gattung““ oder „Art“ bezeichnet. ${ }^{1}$ In der Kunst und Kunsttheorie werden ihm Gemälde zugeordnet, auf denen narrativ gestaltete Darstellungen verschiedenster Situationen des privaten oder öffentlichen Alltags zu sehen sind. ${ }^{2}$ Bei dieser Gattung war es zumeist intendiert, Sitten, Bräuche oder Eigentümlichkeiten verschiedener Stände (Bauern, Bürger oder Adel) wiederzugeben. Nicht selten verband sich dies mit dem Anspruch, spezifische Wirkungen wie Erheiterung, Mahnung, Lehre oder Rührung durch Alltagsszenen zu vermitteln. Für solche Darstellungen wurde daher auch der Begriff „Sittenbild“ verwendet. Die Protagonisten der Genrebilder erscheinen dabei zumeist als namenlose Vertreter ihrer Personengruppe und sollen allgemein menschliches Verhalten repräsentieren. ${ }^{3}$ Aufgrund ihrer Themen hat die Genremalerei häufig einen populären Charakter, der sich nicht selten auch im Format der Bilder niederschlägt: Die meisten Genrebilder wurden - im Gegensatz zu Historiengemälden - in kleineren Formaten gefertigt und standen so einer breiteren Käuferschicht zur Verfügung.

In der traditionellen Gattungshierarchie nimmt die Genremalerei einen mittleren Rang ein. Einerseits grenzt sie sich von „niederen“ Gattungen wie der Land-

1 Immel 1967, S. 53; Ricke-Immel 1996, S. 9; Czymmek 2012, S. 9.

2 Peer 2007, S. 30.

3 Ricke-Immel 1996, S. 9. 
schaftsmalerei, den Tierstücken, dem Stillleben, aber auch dem Porträt ab, denn sie zeigt in der Regel eine Personenkonstellation, die in einer Handlung begriffen ist. Andererseits unterscheidet sie sich aber auch von der Historienmalerei, deren Ziel die Darstellung exemplarischer profaner oder religiöser Ereignisse von weltbewegender Relevanz ist, und die für ihr Personal in der Regel eine exponierte Höhenlage vorsieht. Gleichwohl sind Mischformen möglich - etwa, wenn der Landschaftsgrund gegenüber einer Genreszene dominiert, oder wenn ein Historienbild Personen „niederen“ Ranges zeigt.

\section{Die bleibende Vorbildwirkung niederländischer Genremalerei}

Eine erste, umfassende und bildreiche Kultur der Genremalerei entwickelte sich in der Niederländischen Malerei des 17. Jahrhunderts. Bereits hier befasste man sich mit der Wiedergabe bürgerlich häuslicher sowie bäuerlicher Szenen. ${ }^{4}$ Für die weitere Entwicklung dieser Gattung blieb die niederländische Genremalerei maßstabsetzend. Dies gilt gerade auch für das 19. Jahrhundert: Viele Künstler dieser Zeit adaptierten die von den Niederländern des 17. Jahrhunderts kultivierte Malweise sowie deren als realistisch angesehene Schilderung von Szenerien und übertrugen diese nicht selten auf gegenwärtige Situationen. Manche Maler des 19. Jahrhunderts schufen Kopien nach den alten Meistern, wozu sie in einigen Fällen sogar in das Ursprungsland der zu kopierenden Werke reisten, oder legten gar eigene Sammlungen an. ${ }^{5}$ Ein allegorischer Unterton, wie er für die Gemälde niederländischer Künstler charakteristisch war, ging allerdings im Laufe der Zeit aufgrund des sich wandelnden Kunstverständnisses weitgehend verloren. ${ }^{6}$

Wie weit die Vorbildwirkung niederländischer Genremalerei ins 19. Jahrhundert hinein reichte und die damit verbundene Bildauffassung gleichsam als Modus durchgehend verfügbar blieb, zeigen nicht zuletzt drei Beispiele in der Göttinger Universitätskunstsammlung: die Schlittschubläufer (Kat. Nr. 14) und die Dorflandschaft mit zechenden Bauern (Kat. Nr. 15), beide von unbekannten Malern geschaffen, sowie Bei der Kupplerin (Kat. Nr. 16) von Eduard von Gebhardt. Alle drei Werke beziehen sich in ihrer Anlage auf ältere niederländische Werke und wurden entweder vor Ort oder in Anlehnung an die alten Meister gefertigt. So weiß man über Eduard von Gebhardt, dass dieser Studienreisen in die Niederlande und nach Belgien unternahm, wobei er wahrscheinlich Skizzen nach den frühen Niederländern fertigte. ${ }^{7}$ Auch die Dorflandschaft des unbekannten Malers orientiert sich unübersehbar an der Niederländischen Malerei des 17. Jahrhunderts, so dass deren Entstehung im 19. Jahrhundert erst bei genauerer Betrachtung erkennbar wird. Neben dem damals

\footnotetext{
Peer 2007, S. 32.

Immel 1967, S. 59.

Ebd., S. 63.

Gries 1995, S.12.
} 
sehr beliebten Sujet der Wirtshausszenen werden hier auch formale Aspekte wie der tiefliegende Horizont übernommen.

\section{Neue Ansätze: Aufklärung und Sentimentalismus}

Während die niederländische Genremalerei des 17. Jahrhunderts als Vorbild präsent blieb und bildkünstlerisch in breiter Weise rezipiert wurde, vollzogen sich doch gleichzeitig grundlegende gattungsgeschichtliche Veränderungen. So bot etwa die Literatur der Aufklärung Anregungen für neue Themen und Szenerien. ${ }^{8}$ In Folge der Lehren Jean-Jacques Rousseaus rückte nicht zuletzt die Würde des ländlichen Lebens in den Vordergrund und wurde zum Thema der Genremalerei. ${ }^{9}$ Als Vertreter dieser Richtung in der Genremalerei seien Johann Daniel Bager, Georg Melchior Kraus, Johann Eleazar Zeissig gen. Schenau sowie Wilhelm von Kobell genannt. ${ }^{10}$

Ein bevorzugtes Sujet der Genremalerei des 19. Jahrhunderts bot das bäuerliche Leben. ${ }^{11}$ Zumeist ging es dabei jedoch nicht um die Darstellung ländlicher Armut oder des harten Lebens. Vielmehr reizte die Käufer von Genrebildern das Projizieren der eigenen bürgerlichen Wertvorstellungen auf den ländlichen Stand. ${ }^{12}$ Auf diese Weise sind viele Genrebilder aus einer sentimentalischen Perspektive heraus entstanden: Es wurden Sehnsüchte nach einem ruhigen ländlichen Leben im Einklang mit der Natur verarbeitet oder gemütlich idyllische Lebensweisen gemalt. Gerade mit dem Beginn der Industrialisierung figurierten solche Genrebilder als Gegenkonzepte zum unruhigen Leben in der Stadt. ${ }^{13}$ Selbiges gilt für Szenen, die in familiären Kreisen spielen und den häuslichen Frieden schildern sollten. Beides - das Ideal des harmonischen Familienlebens und die Verbundenheit mit der Natur - bot während des gesamten 19. Jahrhunderts beliebte Themen für die Genremalerei, die sich stärker als die idealistisch fundierte Historienmalerei an den Bedürfnissen des Kunstmarkts orientierte.

\section{Folklorismus}

Besonders beliebt war auch die folkloristische Darstellung regionaltypischer Szenen. So thematisierten Münchner Maler wie Johann Baptist Pflug oder Friedrich und Ludwig Voltz das Leben einheimischer Landbewohner wie der Oberbayern, der Schwaben und der Tiroler. Sie perfektionierten ihre Malweise und ihre poin-

8 Börsch-Supan 1988, S. 285-302.

9 Vgl. die Werke von Sigmund Freudenberger, Joseph Reinhart und Franz Nikolaus König, vgl. Börsch-Supan 1988, S. 287.

10 Ebd., S. 285-302.

11 Peer 2007, S. 34; Czymmek 2012, S. 16-18.

12 Börsch-Supan 1988, S. 285-302.

13 Peer 2007, S. 34 f. 
tierte Darstellungskunst im Laufe des 19. Jahrhunderts, so dass sich ihre Werke des ländlichen Genres oftmals leicht von denen anderer Schulen unterscheiden lassen. Als beispielhaft für diese Entwicklung ist der Piloty-Schüler Franz von Defregger zu nennen. In der Göttinger Universitätskunstsammlung folgt das Gemälde Junges Paar von Maximilian Wachsmuth (Kat. Nr. 17) dieser überaus populären Richtung innerhalb der Genremalerei und behandelt auf komödiantisch pointierte Weise das häusliche Familienleben eines Paares.

Aber auch der Reiz des Fremden wurde thematisiert. So ist für den Verlauf des 19. Jahrhunderts ein wachsendes Interesse an südlichen Ländern und Kulturen zu vermerken, in dessen Folge besonders das italienische und das orientalische Alltagsleben thematisiert wurden. ${ }^{14}$ Oftmals lagen diesen Werken idealisierende Vorstellungen einer unbeschwerten südländischen Atmosphäre zugrunde, wie sie beispielsweise bei Johann Erdmann Hummel oder Leopold Robert zu finden sind. Im Zuge des Kolonialismus breitete sich das folkloristische Genre auf immer fernere Länder aus.

\section{Genremalerei und Sozialkritik}

Doch nicht alle Genremaler des 19. Jahrhunderts zielten auf vordergründige und leicht zu vermittelnde Szenen, die den Wünschen des Publikums gerecht zu werden suchten. Im Gegenteil gibt es eine Vielzahl an Bildwerken, die mit der Intention gemalt wurden, Probleme und Missstände aufzudecken. Hier ist insbesondere die Düsseldorfer Malerschule zu nennen. In Düsseldorf entwickelte sich, beispielsweise vertreten durch Adolph Schrödter, ein humoristisches Genre, das etwa die Unvollkommenheit unbeliebter Zeitgenossen thematisierte. Es verwundert nicht, dass dies während des Vormärz in einer sozial- und politikkritischen Richtung gipfelte. ${ }^{15}$ Besonders Wilhelm Heine, Johann Peter Hasenclever und Carl Hübner griffen Themen aus den Auseinandersetzungen des Vormärz auf und schilderten die Willkür des Adels und des Militärs, die Ungerechtigkeit gegenüber Demokraten, den Eigennutz von Fabrikanten sowie die Notlage der kleinen Handwerker. ${ }^{16}$

\section{Aufstieg einer „,niederen“ Gattung}

Neben der Landschaft entwickelte sich das Genre zu einer der wichtigsten und populärsten Gattungen im 19. Jahrhundert, was vor allem mit der politischen Situation und mit der Möglichkeit zusammenhängt, ein breites Publikum anzuspre-

\footnotetext{
14 Ebd., S. 36; Czymmek 2012, S. 18.

15 Ricke-Immel 1996, S. 12 f.

16 Ebd., S. 12; Czymmek 2012, S. 18-21.
} 
chen. ${ }^{17}$ Als volksnahe Kunst mit der demokratischen Bewegung verbunden und gefördert durch das Bürgertum, fanden sich Genrebilder auf Schauen der neu initiierten Kunstvereine und auch bei akademischen Ausstellungen. ${ }^{18}$ Besonders ab den zwanziger Jahren des 19. Jahrhunderts stieg die Zahl der Gemälde und Hauptzentren ihrer Produktion bildeten sich heraus. ${ }^{19}$ Diese lagen in Berlin, Düsseldorf, München, Wien und Dresden.

Konsequenzen aus diesem Aufstieg, die das tradierte Modell der Gattungshierarchie in Frage stellten, wurden allerdings erst in der zweiten Hälfte des 19. Jahrhunderts gezogen. Für kurze Zeit übernahm die Genremalerei gemeinsam mit der Landschaftsmalerei eine Führungsrolle, bis sie mit ihrer anekdotischen Erzählkunst selbst in die Kritik geriet. ${ }^{20}$

Für die erste Jahrhunderthälfte blieb eine Spannung zwischen der Popularität niederer Gattungen und der idealistisch fundierten Annahme einer Superiorität der Historienmalerei prägend, wie sie etwa in der Göttinger Universitätskunstsammlung im Gemälde Maler im Dachstübchen (Kat. Nr. 12) thematisiert wird. Das Bild zeigt einen Historienmaler, der in ärmlichsten Verhältnissen lebt - vermutlich, weil er seine Bilder nicht verkaufen kann. Der gelernte Historienmaler des Bildes, Josef Danhauser, verbildlicht diese Situation mit einem Werk derjenigen Gattung, welche die Schilderung solcher Sujets zu leisten vermochte: der Genremalerei.

17 Peer 2007, S. 31.

18 Hütt 1955, S. 5.

19 Immel 1967, S. 22.

20 Vgl. Scholl 2012b, S. 442-453. 

Kat. Nr. 12

Josef Danhauser (1805-1845)

\section{Der Maler im Dachstübchen}

1831

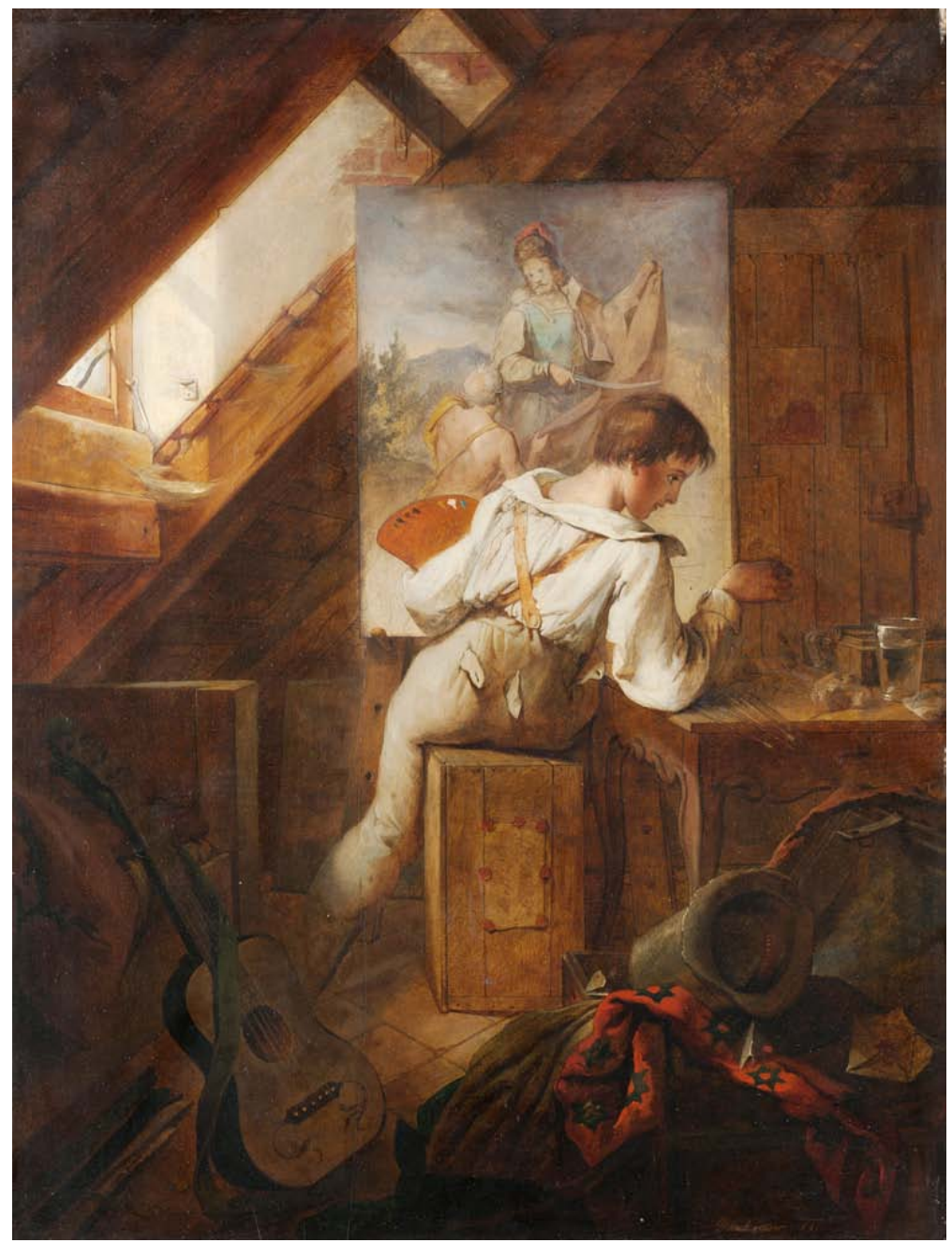

Öl auf Holz, 59 x $31 \mathrm{~cm}$, signiert und datiert, Leihgabe der Bundesrepublik Deutschland (Objektnr. 19329) 
Josef Danhauser wurde als ältester Sohn des wohlhabenden Bildhauers und Möbelfabrikanten Josef Ulrich Danhauser geboren. Zwischen 1820 und 1827 besuchte er die Akademie der Bildenden Künste in Wien. Dort wurde er von Johann Peter Krafft als Historienmaler ausgebildet. Im Jahr 1826 trat Danhauser erstmals öffentlich in Erscheinung, als er drei Gemälde zu Ladislaus Pyrkers Heldengedicht Rudolph vom Habsburg in Wien ausstellte. Im selben Jahr wurde er von Pyrker, dem damaligen Patriarchen von Venedig, nach Italien eingeladen. ${ }^{1}$ Der Tod des Vaters 1829 dämpfte zunächst Danhausers künstlerische Produktivität, da er sich gezwungen sah, die Leitung der väterlichen Möbelfabrik zu übernehmen. ${ }^{2}$ In dieser Zeit fertigte Danhauser vornehmlich kleine, genrehafte Bilder, zu denen auch Der Maler im Dachstübchen zählt. Von 1838 bis 1844 war er als Korrektor und von 1841 bis 1842 als Professor für Historienmalerei an der Akademie der Bildenden Künste in Wien tätig. Im Jahr 1845 starb er in Wien an Typhus.

Das Gemälde Der Maler im Dachstübchen zeigt eine Atelierszene. Es ist auffällig lasierend gemalt und macht einen beinahe unfertigen Eindruck: an verschiedenen Stellen ist die Unterzeichnung sichtbar. Das hochformatige Bild eröffnet den Blick in eine Dachkammer, die auf der linken Seite durch eine in die Tiefe führende Dachschräge sowie durch eine darunter eingezogene, bildparallel angelegte Holzwand definiert wird. Die Balken der Schräge verlaufen genau im Winkel von 45 Grad. Generell wird die Bildkomposition von orthogonal und diagonal angeordneten Bildgegenständen bestimmt, die auf spannungsvolle Weise miteinander verzahnt sind und dem Gemälde eine geradezu abstrakte Qualität geben.

Dach und Wand sind in warmen Brauntönen gehalten. Die Dachschräge wird durch eine vorn angeschnittene Gaube geöffnet, welche als imaginäre Lichtquelle des Bildes fungiert. Danhauser steigert deren Beleuchtungsfunktion, indem er ihre frontal angeordnete Seitenwand als mit hellem Putz bedeckt darstellt, auf dem sich das einfallende Licht des Fensters umso deutlicher abzeichnet. In der unteren Gaubenecke wirken Spinnweben als zusätzliche Lichtfänger. Nach oben hin bewirken Putzflecken, hinter denen sich Ziegelmauerwerk abzeichnet, eine Annäherung an die warme Farbigkeit der Balken und mildern damit zum Bildrand hin den Kontrast.

Im Zentrum des Bildes ist ein junger Maler, auf einer Holzkiste sitzend, als Rückenfigur vor seiner Staffelei dargestellt. In seiner Haltung nimmt er die Diagonale der Dachschräge auf: Sein linkes Bein ist zur Seite gestreckt und der Oberkörper wendet sich nach rechts. Der Kopf ist ins Profil gedreht und zur Seite geneigt. In der linken Hand hält der Künstler eine Palette, während er den Ellenbogen des rechten Arms auf einen Tisch stützt, der rechts neben ihm steht. Er sitzt genau im Licht der Gaube, das er mit seiner hellen Kleidung (er trägt eine graue Hose und ein weißes Hemd) reflektiert. Selbst seine über Kreuz geführten, braunen, die Far-

Grabner 2011, S. 14 f.

Ebd., S. 18. 
ben der Balken aufgreifenden Hosenträger scheinen auf die beiden Grundrichtungen des Bildes ausgerichtet zu sein.

Im Vordergrund wird links das Bett des Künstlers sichtbar, an das eine Gitarre gelehnt ist. Rechts türmt sich ein Berg von Kleidungsstücken auf, der nochmals als formales Echo auf die Diagonale der Dachschräge wirkt.

Hinter der Hauptfigur steht auf der Staffelei das Gemälde, mit dessen Ausführung der Maler offensichtlich gerade beschäftigt ist. Es wird frontal gezeigt und ist genau auf die orthogonalen Achsen des Gemäldes ausgerichtet, so dass es als Bild im Bild umso deutlicher hervortritt. Mit seiner linken oberen Ecke überschneidet es die Dachschräge und ragt in die Gaube hinein. Seine kühle Farbigkeit mit Blauund Türkistönen kontrastiert wirkungsvoll mit der braunfarbenen Umgebung.

Das Bild rahmt den Oberkörper des Künstlers ein, der auf diese Weise beinahe vollkommen mit dessen Ausführung absorbiert zu sein scheint. Allerdings - und hierin besteht die eigentliche Pointe des Gemäldes - durchbricht er mit seiner rechten Hand diese imaginäre Rahmung und wendet sich auch mit seinem Gesicht vom Bild ab, um sich dem Geschehen auf dem Tisch zuzuwenden. Hier werden bei genauerer Betrachtung einige Mäuse sichtbar, die der Künstler gerade mit seiner rechten, über das Bild im Hintergrund hinausragenden Hand mit Brotkrumen füttert.

Blickt man zurück auf das Bild, so wird der Zusammenhang deutlich: Der Künstler malt nämlich an einer biblischen Historie. Diese zeigt den Heiligen Martin, wie er seinen Mantel mit einem Säbel durchtrennt, um ihn mit einem Bettler zu teilen. Danhauser stellt hier eine bemerkenswert doppelbödige Szenerie vor Augen: Die religiös fundierte Handlung der bildimmanenten Heiligengeschichte, die vom Maler selbst ja überhaupt erst auf die Leinwand gebracht wurde, bewirkt - bei dafür erforderlicher Unterbrechung des Malaktes - eine Rückübertragung ins alltägliche Geschehen: Der in der Historie dargestellte Akt des Teilens wiederholt sich in der Teilung des Brotes mit den Mäusen. ${ }^{3}$

Dabei thematisiert Danhauser in dieser Szenerie auch die Lebensumstände junger Künstler im 19. Jahrhundert und reflektiert kritisch die Stellung der Historie in der Kunst. ${ }^{4}$ Die ärmlichen Umstände, in denen der junge Historienmaler lebt, zeugen davon, dass die Historie zwar formal als höchste Gattung galt, jedoch auf dem Kunstmarkt schlecht verkäuflich war, da sie den Ansprüchen privater Käufer nicht gerecht werden konnte.

\section{Zur Provenienz}

Die Provenienz des Gemäldes kann bis heute nicht lückenlos nachvollzogen werden. Es war Bestandteil des sogenannten „Sonderauftrags Linz“. Hierbei handelt es sich um einen Auftrag zur Beschaffung von Kunstwerken für das von Adolf

3 Zum Bildaufbau vgl. auch Schnell 1999, S. 285 u. 288 f.

4 Grabner 2011, S. 43. 
Hitler geplante Führermuseum in Linz, das nach dem Zweiten Weltkrieg gebaut werden sollte. Nach Ende des Krieges wurde die Sammlung von den Alliierten aufgelöst, so dass mit der Suche und Rückgabe der Werke an die ursprünglichen Besitzer begonnen werden konnte. 1949 wurde die Verantwortung für die Restitutionen von den USA an die Bundesrepublik Deutschland übergeben. Die ursprünglichen Eigentümer des Gemäldes konnten jedoch bisher noch nicht ermittelt werden.

\section{Zur gattungsgeschichtlichen Stellung}

Bei dem Maler im Dachstübchen handelt es sich nur um ein Beispiel von mehreren Atelierszenen, die Danhauser ausgeführt hat. Dieser setzte sich intensiv mit der Rolle des Künstlers in der Gesellschaft auseinander und kommentierte sie in seinen Genrebildern. So befasst sich beispielweise das Bildpaar Das Scholarenzimmer eines Malers (1829) und Komische Szene in einem Maleratelier (1829) auf humoristische und anekdotenhafte Weise mit den Konventionen des Kunstbetriebes im 19. Jahrhundert. ${ }^{5}$ Von besonderem Interesse ist in diesem Zusammenhang eine weitere Atelierszene Danhausers, die dem Göttinger Bild auffallend gleicht. In Das Atelier mit Mäusen II aus der Zeit nach 1831 (vgl. Abb. 22) ist ebenfalls ein junger Maler zu sehen, der, mit dem Rücken zum Betrachter vor einer Staffelei sitzend, Brot mit einigen Mäusen teilt. Indes, auf der Staffelei steht in diesem Fall kein Heiliger Martin, sondern der junge Maler arbeitet hier an dem Porträt eines Mannes. Dies ist insofern interessant, als bei einer solchen Komposition der doppelbödige, hintersinnige Bezug zwischen Bild und Bild im Bild wegfällt.

Danhausers Schaffen fällt in die Zeit des Biedermeier, jener Zeit also zwischen dem Wiener Kongress und der Revolution von 1848. Zunächst betätigte sich Danhauser vornehmlich als Historienmaler, bald jedoch sollte er sich vermehrt dem Genre zuwenden. Insbesondere spätere Genrebil-

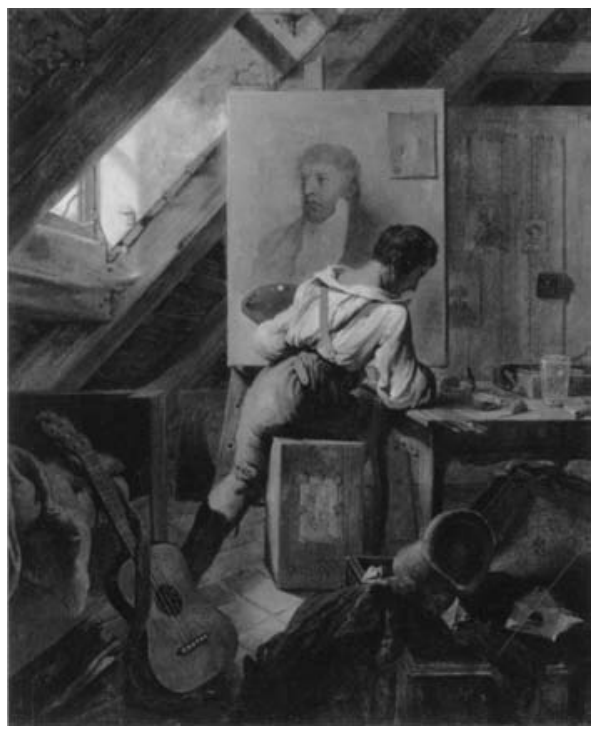

Abb. 22: Josef Danhauser: Das Atelier mit den Mäusen II, nach 1831, Öl auf Holz, 49,5 x $41 \mathrm{~cm}$, Privatbesitz

5 Vgl. Schnell 1999, S. 296; Grubner 2011, S. 38 f. 
zieherische Note, da er die Genremalerei aufgrund ihrer Nähe zum Publikum für die geeignete Gattung hielt, um moralische Inhalte $\mathrm{zu}$ vermitteln. ${ }^{6}$ Danhausers Kunstauffassung zeichnet sich also durch eine Hybridisierung der Gattungen aus. Seine Werke changieren zwischen Historie und Genre, was von zeitgenössischen Verfechtern der Gattungshierarchie in Rezensionen immer wieder kritisiert wurde. ${ }^{7}$

Danhauser stand der akademischen Tradition der Historienmalerei überaus kritisch gegenüber und versuchte, diese dahingehend zu modernisieren, dass er das historische Geschehen in unmittelbare zeitgenössische Bezüge einbettete. ${ }^{8}$ Dieses Stilmittel kommt auch in Der Maler im Dachstübchen zur Geltung. Dies lässt das Bild zu einem programmatischen Statement Danhausers zur Hierarchie der Gattungen und zur Rolle der Historie werden. Es offenbart sich dem Betrachter gleichsam als gemalte Kunsttheorie Danhausers.

Janna Krützer, Christian Scholl und Verena Suchy

6 Immel 1967, S. 205 und 207.

7 Grabner 2011, S. 19-21.

8 Ebd. 

Kat. Nr. 13

Henry Ritter (1816-1853)

\section{Schiffbruch}

1841

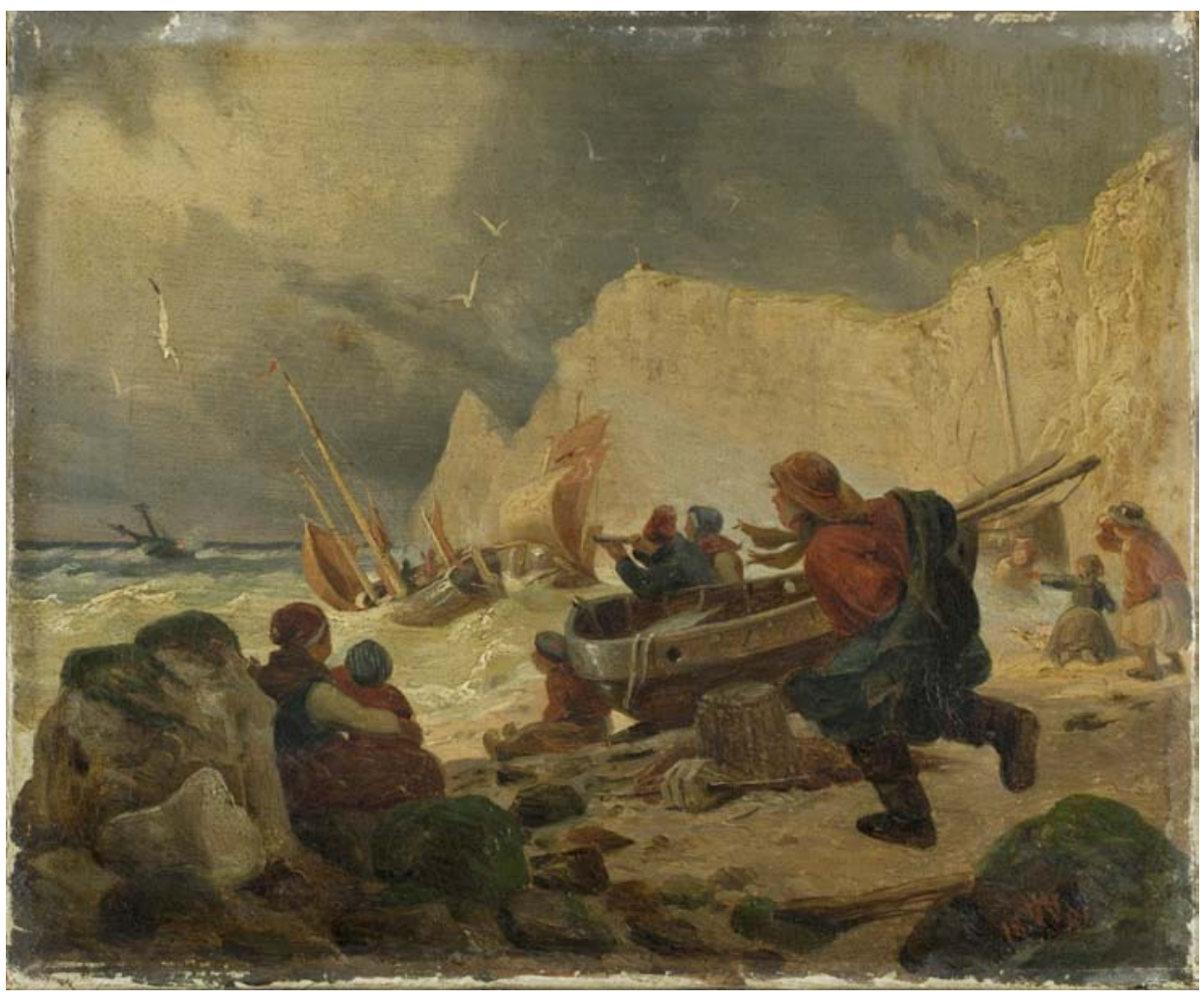

Öl auf Leinwand, 17,5 x $21 \mathrm{~cm}$, monogrammiert und datiert unten rechts, Leihgabe der Bundesrepublik Deutschland (Objektnr. 20951)

Während die Genremalerei in München zumindest in der ersten Jahrhunderthälfte keine institutionelle Verankerung an der Kunstakademie erfuhr, sondern auf die Förderung durch den Münchner Kunstverein ${ }^{1}$ angewiesen war, nahm diese Gattung an der Düsseldorfer Akademie seit dem Direktorat Wilhelm von

1 Vgl. u. a. Mittlmeier: 1977, S. 11 f. 
Schadows eine prominente Stellung ein und trug in erheblichem Maße zum Erfolg der Düsseldorfer Malerschule bei. ${ }^{2}$ Bilder wie Rudolf Jordans Heiratsantrag auf Helgoland (1834) ${ }^{3}$ oder Adolph Schroedters Don Quijote (1834) ${ }^{4}$ erfreuten sich großer Popularität. Daneben war Düsseldorf ein Zentrum sozialkritischer Genremalerei, wobei es zum Teil zu Verbindungen zwischen Genre- und Historienmalerei kam. ${ }^{5}$ Nach der Jahrhundertmitte war es gerade das Genre, in dem die Düsseldorfer Malerschule weiterhin erfolgreich blieb: zu nennen ist hier vor allem der zu Lebzeiten höchste internationale Anerkennung genießende Ludwig Knaus (1829-1910). ${ }^{6}$

Henry Ritter gehört zu den bedeutendsten Vertretern der Düsseldorfer Genremalerei in der ersten Hälfte des 19. Jahrhunderts. In Montreal als Sohn eines in britischen Diensten stehenden Offiziers aus Hannover und einer Engländerin geboren, verbrachte er seine Jugend in Hamburg, wo er erste künstlerische Anleitung erhielt. ${ }^{7} 1833$ wechselte er nach Düsseldorf, wo er zunächst einmal die Sonntagsschule des Malers Ernst Thelott besuchte. Ab 1836 studierte er an der Düsseldorfer Kunstakademie: Hier nahm er 1836/37 an der 2. Malklasse von Carl Ferdinand Sohn und 1838/39 an der 1. Malklasse des Direktors Wilhelm von Schadow teil, in dessen Meisterklasse er 1840-47 übernommen wurde. Er erhielt ein eigenes Atelier im Akademiegebäude. 1837/38 nahm Ritter zudem Privatunterricht bei Rudolf Jordan (1810-1887), mit dem ihn eine enge Freundschaft verband. Reisen führten ihn 1839 in die Normandie, 1840 nach Schottland und England sowie 1843 nach Westfriesland.

Das Cuvre Ritters steht thematisch, kompositorisch und maltechnisch in engster Verbindung mit der Genremalerei Rudolf Jordans. Ein Beispiel für diese Nähe bietet Ritters Gemälde Verlobung in der Normandie aus dem Jahr 1841, das unverkennbar an Rudolf Jordans Erfolgsbild Heiratsantrag auf Helgoland anknüpft. ${ }^{8}$

Charakteristisch sind Motive aus dem Fischer- und Seemannsleben. Zu Ritters bekannteren Werken gehören Der ertrunkene Fischersohn (1844) ${ }^{9}$ und Middys Predigt (1853). ${ }^{10}$

2 Zur spannungsvollen Stellung der Genremalerei an der Düsseldorfer Akademie vgl. neuerdings Mai 2012, S. 25-39.

3 Berlin, Nationalgalerie, vgl. Ausst. Kat. Düsseldorf 1979, S. 362, Kat. Nr. 127.

4 Berlin, Nationalgalerie, vgl. ebd., S. 481 f., Kat. Nr. 248.

5 Vgl. Ausst.-Kat. Düsseldorf 2011, Bd. 2, S. 294-323. Das bekannteste Beispiel für eine Gattungsvermischung ist Carl Wilhelm Hübners Gemälde Die schlesischen Weber von 1844 (vgl. ebd., S. 304 f., Kat. Nr. 255).

6 Vgl. u. a. Söntgen 2000a, S. 35-46; Scholl 2012b, S. 444-447.

7 Vgl. hierzu und zu dem folgenden: Weiß 1998, S. 144-146; Pickartz 2012, S. 166-169.

8 Abbildung bei Weiß 1998, S. 145, Abb. 171.

9 Düsseldorf, Museum Kunstpalast, vgl. Aust.-Kat. Düsseldorf 2011, Bd. 2, S. 396 f., Kat. Nr. 335.

10 Köln, Wallraf-Richartz-Museum, vgl. Ausst.-Kat. Düsseldorf 2011, Bd. 2, S. 422 f., Kat. Nr. 359. 


\section{Ritters Göttinger Gemälde Scbiffbruch}

Das kleine, querformatige Göttinger Gemälde fügt sich thematisch und gestalterisch nahtlos in das übrige Werk Henry Ritters ein. ${ }^{11}$ Es zeigt eine Küstenlandschaft: Den Vordergrund bildet, mit seiner Uferlinie nach rechts ansteigend, ein mit Steinen und größeren Felsbrocken besetzter Meeresstrand. Dahinter wird, in gezackten Formen von rechts nach links abfallend, eine Steilküste sichtbar, welche in ihrer Längserstreckung etwa zwei Drittel der rechten Bildseite einnimmt. Sie bildet mit dem Strand im Vordergrund eine Art Bucht. Links daneben öffnet sich der Blick auf die offene See, wobei die Horizontlinie unterhalb der Bildmitte liegt. Hier, im Hintergrund und noch recht weit vom rettenden Ufer entfernt, wird der Auslöser der lebhaften Szenen im Vordergrund gezeigt: ein Schiffbruch.

Das eigentliche Thema des Bildes sind die verschiedenen Reaktionen der Figuren, die sich im Vordergrund am Strand befinden, auf dieses Geschehen. Von rechts eilt ein im Dreiviertelprofil von hinten gezeigter Mann mit rotem Obergewand sowie brauner Mütze und Schal herbei. Er ist gerade im Begriff, sich einen blauen Mantel überzuziehen. Die Bogenform, die der bereits über die rechte Schulter gezogene Mantel beschreibt, übernimmt eine wichtige gestalterische Funktion, indem sie die Dynamik steigert und gleichzeitig die Komposition formal abrundet. Der laufende Mann überschneidet ein schräg am Ufer liegendes Boot. An die Seite des Bootes haben sich zwei stehende Figuren gelehnt, von denen eine das Geschehen auf dem Meer mit einem Fernrohr beobachtet. Davor sitzt, den Kopf gegen die Bootswand gelehnt, ein weiterer Mann.

Im Vordergrund links lehnt sich, als sitzende Rückenfigur dargestellt, eine Frau an einen großen, links das Bild abschließenden Felsbrocken. Sie hält ein Kleinkind auf dem Arm. Zum Mittelgrund hin wird rechts neben dem laufenden Mann eine Frau sichtbar, welche die Hand über die Augen hält, um besser zu sehen. Vor ihr steht ein Kind, das mit seinem linken Arm in Richtung Schiffbruch weist.

Unterhalb der Stelle, wo die Felsenküste im Mittelgrund nach links hin abbricht, werden offenbar Segelboote zur Rettung klar gemacht. Die leichten Gefährte sind bereits von den hohen Wellen des stürmischen Meeres erfasst und in eine Schieflage gebracht. Am Himmel fliegen Möwen umher.

Charakteristisch für Ritter ist die Grundanlage der Komposition mit der durch Figuren und Landschaft betonten, von links unten nach rechts oben aufsteigenden Diagonale sowie einem Fernblick auf der linken Seite. Vergleichbare Elemente findet man etwa in Ritters bereits angeführten Gemälden Verlobung in der Normandie (1841), Der ertrunkene Fischersohn (1844, hier ins Interieur übertragen) und Middys Predigt (1853).

Eine große Bedeutung kommt der Farbigkeit zu. Ritter malt einen dunklen, bewegten, graublauen Himmel, vor dem sich nicht nur die Möwen, sondern auch

11 Das Bild ist unten rechts monogrammiert "18 HR 41" (H und R ligiert). 
die Steilküste hell abzeichnen. Die Umkehrung der Lichtverhältnisse - helle Gegenstände vor dunklem Himmel - unterstützt die Dramatik der unwetterartigen Situation. Dabei werden die Wolken genutzt, um auf gestische Weise Bewegungen aufzugreifen, welche von den Figuren ausgehen.

Durch das helle Aufleuchten der Felsenküste gewinnt Ritter gleichzeitig einen Hintergrund, um seine Figuren kontrastreich und gut sichtbar in Szene zu setzen. Diese sind dementsprechend ihren dunklen Blau- und Rottönen gemalt. Gerade das Augenmerk auf der pointierten Personendarstellung lässt Ritters Werk als ein charakteristisches Genrebild der Düsseldorfer Malerschule aus der ersten Hälfte des 19. Jahrhunderts erscheinen.

Auffällig sind der lockere, zuweilen (gerade bei den Felsen) pastose Pinselauftrag und das kleine Format. Die oben angeführten Genrebilder von Henry Ritter erscheinen wesentlich feiner ausgeführt und sind in ihren Maßen auch größer (Verlobung in der Normandie: 29 x $39 \mathrm{~cm}$; Der ertrunkene Fischersohn: 71 x 84 cm; Middys Predigt: 47 x $42 \mathrm{~cm}$ ). Daher liegt es nahe, das Göttinger Bild als eine Ölstudie anzusehen, zumal Ritter für seine sorgfältige, den Gepflogenheiten der Düsseldorfer Malerschule entsprechende Vorbereitung der Bilder bekannt ist. ${ }^{12} \mathrm{Ob}$ der früh verstorbene Ritter dazu gekommen ist, eine detaillierter ausgeführte Fassung dieser Bildidee zu malen, ist zur Zeit nicht bekannt.

Christian Scholl

12 Vgl. Ausst.-Kat. Düsseldorf 2011, Bd. 2, S. 422. Zur Problematik der Ölstudien vgl. auch den Beitrag von Jan Stieglitz in diesem Band, S. 74-76. 
Kat. Nr. 14

Unbekannt, deutsch oder niederländisch?

\section{Schlittschuhläufer}

Mitte 19. Jahrhundert?

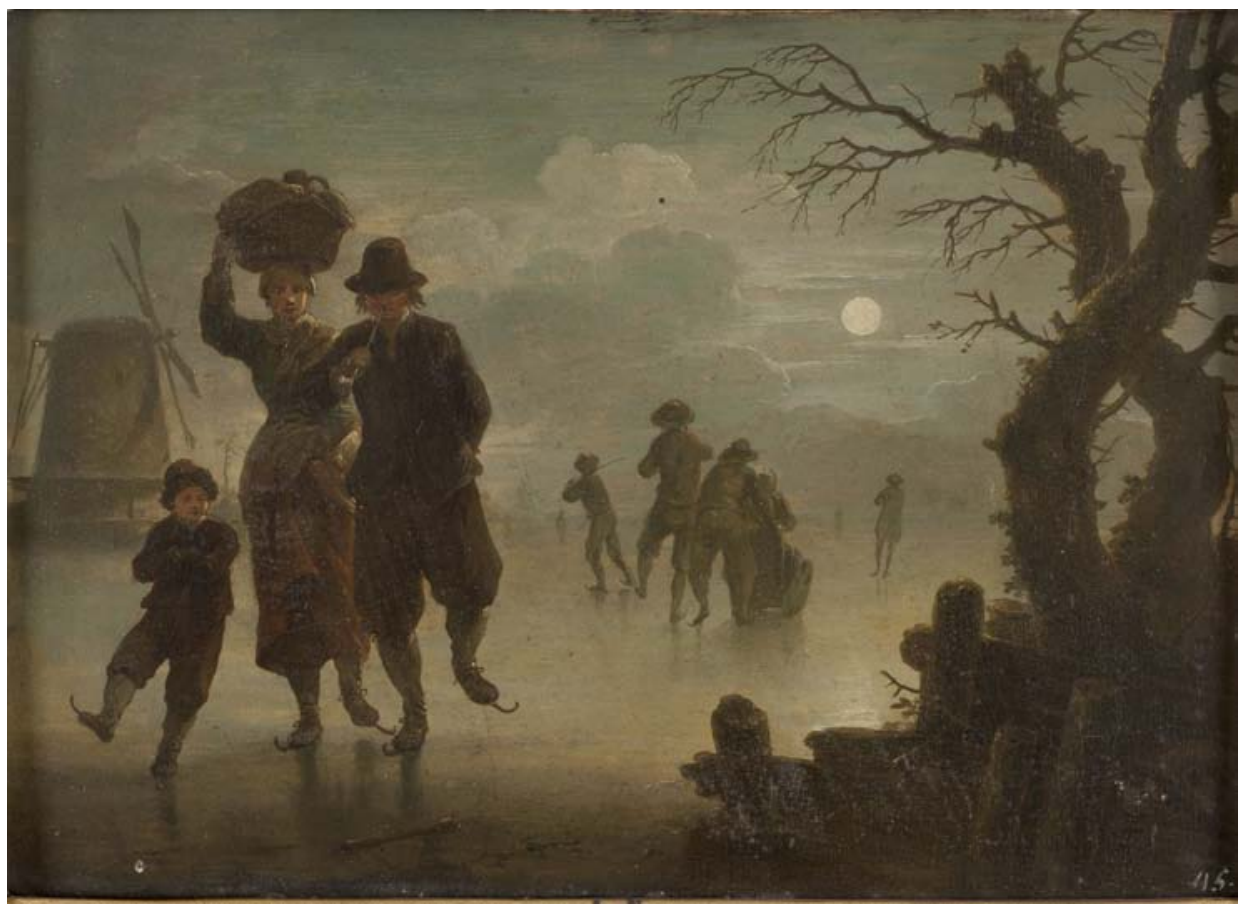

Öl auf Holz, 12,5 x 17,5 cm, monogrammiert (FV?), Herkunft unbekannt, Inv. Nr. GG 239

„Erstens also zugegeben, daß es einen Winter gibt - eigentlich sollt' es gar keinen geben! - so lob' ich mir doch die holländischen Winterlandschaften; da wird Schlittschuh gelaufen, die Schlote rauchen, da ist Leben und Bewegung [...]." Friedrich Christoph Förster hat diese Bemerkung Johann Wolfgang von Goethes überliefert, die sich kritisch gegen eine winterliche Friedhofslandschaft Carl Friedrich Lessings richtete. ${ }^{2}$ Das Gemälde eines bislang unbekannten Künstlers in der

Zitiert nach Biedermann/Herwig 1998, Bd. 3/2, S. 804.

2 Carl Friedrich Lessing: Klosterhof im Schnee, um 1829, Köln, Wallraf-Richartz-Museum. 
Göttinger Kunstsammlung hätte Goethes Kunstverständnis zumindest in Bezug auf die Wahl des Sujets vermutlich eher zugesagt. Das Bild erweist sich als eine deutliche Reminiszenz an die vom Dichter angesprochenen holländischen Winterlandschaften mit Schlittschuhläufern. Dabei verbindet es dieses Thema mit weiteren Motiven und Darstellungsweisen, für welche die Niederländische Malerei des 17. Jahrhundert berühmt geworden ist: mit einer Mondscheinlandschaft, wie man sie etwa von Aert van der Neer (1603-1677)3 her kennt, sowie dem geradezu topischen Motiv einer Windmühle.

Das kleine, querformatige Bild erhält sein imaginäres Licht vom Vollmond, der sich in der rechten Bildhälfte in einem nach unten hin zunehmend bewölkten Himmel befindet. Links im Hintergrund erhebt sich eine Windmühle, die sich mit den Flügeln dem Trabanten zuwendet. Davor und daneben erstreckt sich bis zum - unterhalb der Bildmittelachse gelegten - Horizont eine weite Eisfläche, die vom Mondlicht angestrahlt wird. Vor ihr heben sich im Gegenlicht mehrere Schlittschuh laufende Personen ab, welche den Horizont deutlich überschneiden: Die Betrachterperspektive entspricht demnach in etwa der einer sitzenden Figur.

Eine wichtige bildgestaltende Funktion übernimmt rechts im Vordergrund ein dunkles, in seinen Einzelheiten schwer zu identifizierendes Arrangement aus einer stegartigen Holzkonstruktion und zwei daraus erwachsenen, gegenläufig gewundenen und einander überschneidenden Baumstämmen, deren kahle Äste weit in die Szenerie hineinragen. Der Künstler hat hier ein traditionelles Repoussoirmotiv zusammengestellt, das Tiefenräumlichkeit schafft. Auf wirkungsvolle Weise rahmen die oberen Äste sowie die unteren Balken den Mond und schaffen damit einen spannungsreichen Kontrast: Die Lichtbahn des Himmelskörpers stößt unmittelbar gegen das Balkenwerk. Da, wo das Bild - abgesehen von der Vollmondscheibe selbst - am hellsten ist, befindet sich unmittelbar darunter auch dessen dunkelster Akzent.

Als formales Gegengewicht zu diesem Repoussoirarrangement ist auf der linken Bildhälfte im Vordergrund eine Gruppe von drei Personen angeordnet, die sich frontal auf den Betrachter zubewegen. Es handelt sich um ein Paar mit Kind: rechts ein Mann mit Hut, der seine linke Hand in die Tasche steckt und mit der rechten eine Pfeife hält. Dabei bietet er den rechten Arm zugleich der links daneben Schlittschuh laufenden Frau als Stütze an. Diese balanciert mit ihrer rechten Hand einen großen, mit Gegenständen gefüllten Korb auf ihrem Kopf. Das Paar ist also nicht zum Vergnügen auf dem Eis, sondern hat etwas zu erledigen. Links neben der Frau gleitet ein kleiner Junge mit routinierter Lässigkeit auf seinem linken Schlittschuh dahin - die Arme ineinander verschränkt und den rechten Fuß nach vorn gestreckt. Er trägt eine Mütze mit Pelzbesatz, welche die Windmühle im Hintergrund überschneidet.

3 Von Aert van der Neer befinden sich zwei Nachtlandschaften in der Göttinger Universitätskunstsammlung: Mondscheinlandschaft (Inv.-Nr. GG 057; Unverfehrt 1987, S. 104, Kat. Nr. 59) und Nachtlandschaft mit Feuersbrunst (Inv.-Nr. GG 058; ebd., S. 105, Kat. Nr. 60). 
In entgegengesetzer, in den Bildraum hineinführender Richtung sind weitere Schlittschuhläufer unterwegs, die im Bildmittelgrund um die Mittelachse herum gruppiert sind. Darunter befindet sich ein Mann, der eine Frau in einem Stuhlschlitten vor sich her schiebt. Derartige Gefährte kamen vor allem im späten 18. Jahrhundert in Gebrauch. ${ }^{4}$ Ihre Blütezeit hatten sie im 19. Jahrhundert ${ }^{5}$ - ein Hinweis für die Datierung des kleinen Göttinger Gemäldes, das im übrigen gerade aufgrund seiner topischen Zusammenfügung von Elementen der Niederländischen Malerei sowie wegen seiner pointierten Erzählweise als Werk des 19. Jahrhunderts erscheint. Dies wird auch durch eine mikroskopische Auflichtuntersuchung unterstützt. Diese zeigt, abgesehen vom Schwarz-Pigment, ausgesprochen fein gemahlene Pigmente, wie sie charakteristisch für die Mitte des 19. Jahrhunderts sind. Eine Entstehung des Bildes im 18. oder gar 17. Jahrhundert kann daher ausgeschlossen werden. ${ }^{6}$

Links neben der Stuhlschlittengruppe (räumlich davor) läuft ein Mann über das Eis, und noch weiter links (räumlich wiederum dahinter) ist ein Mann mit einer Angel erkennbar. Weitere Figuren befinden sich links und rechts dieser Gruppe, wobei diese farblich umso blasser gemalt sind, je weiter sie sich vom Vordergrund entfernen. Am Hintergrund ist unter anderem eine weitere Windmühle erkennbar. Der Künstler erweist sich als jemand, der die technisch durchaus anspruchsvolle Darstellung von Figuren im Mondschein gut beherrscht.

Insgesamt handelt es sich um ein Bild, das belegt, wie lange in bestimmten Feldern der Landschafts- und Genremalerei Bildmuster und Motive wirksam blieben, die im Zusammenhang mit der Niederländischen Malerei des 17. Jahrhunderts entwickelt worden waren. Dabei werden diese Motive im Göttinger Bild auf eine durchaus eigenständige, eher für das 19. als für das 17. Jahrhundert charakteristische Weise miteinander kombiniert. Bemerkenswert ist nicht zuletzt, dass die drei Hauptpersonen frontal auf den Betrachter zulaufen. Maltechnisch zeichnet sich das kleine Gemälde nicht zuletzt durch seine feine und stimmungsvolle Umsetzung einer Mondscheinlandschaft aus. So handelt es sich um ein Werk, über dessen Entstehungsumstände man gern mehr wüsste.

Christian Scholl

4 Vgl. Kammel 2008, S. 119-125; van Binnebeke 2008, S. 138 f.

5 Vgl. Kammel 2008, S. 121.

6 Für die überaus hilfreiche Untersuchung danke ich herzlich Diplom-Restauratorin Dr. Bettina Achsel, Göttingen. 

Kat. Nr. 15

Unbekannt, deutsch

\section{Dorflandschaft mit zechenden Bauern}

Mitte 19. Jahrhundert?

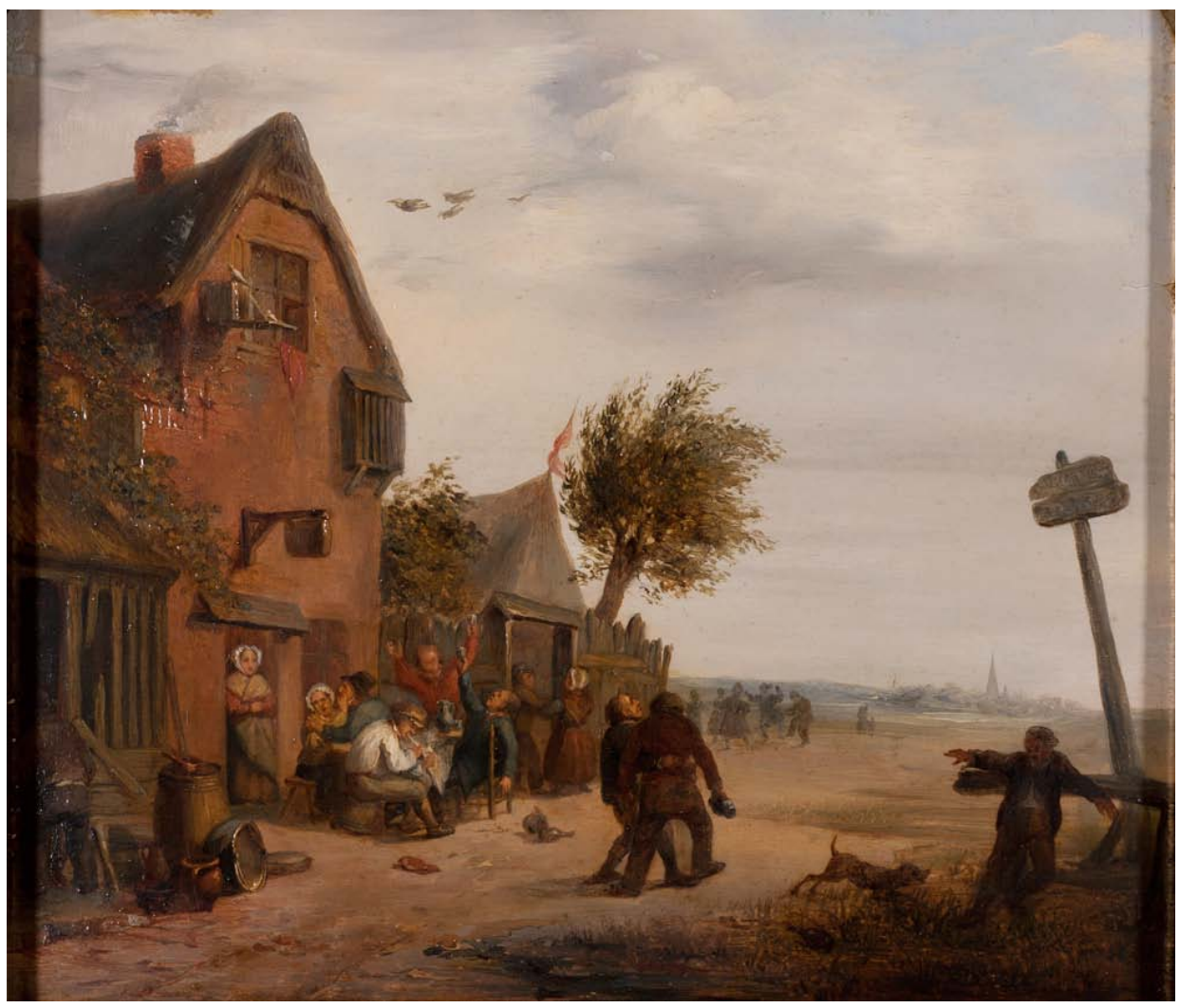

Öl auf Holz, 23,5 x 27,1 cm, 1966 aus der Sammlung Eugen Dumont mit Mitteln der Volkswagenstiftung angekauft, Inv. Nr. GG 216

Die Dorflandschaft mit zechenden Bauern stammt aus dem Besitz des Schauspielers Eugen Dumont (1877-1957), der in Düsseldorf und Göttingen gelebt und insbesondere Gemälde, Zeichnungen und Druckgraphik vom 16. bis zum frühen 20. 
Jahrhundert gesammelt hat. ${ }^{1}$ Das Bild wurde im Stil niederländischer Genremalerei des 16. und 17. Jahrhunderts gemalt, weist zugleich aber auch eigentümliche Abweichungen von diesem auf, die nahelegen, dass es erst im 19. Jahrhundert geschaffen wurde.

Das querformatige Bild, dessen niedrig gelegener Horizont auffällt, zeigt eine schräg nach rechts in den Hintergrund fluchtende Straße, an der auf der rechten Seite mehrere Gebäude stehen: Von links nach rechts erkennt man - vom linken Bildrand angeschnitten - eine eingeschossige traufständige Scheune, danach folgt ein größeres, zweigeschossiges, giebelständiges Haus und danach eine eingeschossige giebelständige Scheune, deren Fassade nach rechts hin von einem überlebensgroßen Bretterzaun fortgesetzt wird, hinter dem ein sich nach rechts neigender Baum herauswächst. Das zweigeschossige Haus wird durch ein über der Tür hängendes Schild sowie durch eine Versammlung von davor feiernden Menschen als Wirtshaus ausgewiesen. Hierzu passen auch diverse Einzelmotive wie Fässer oder Weinkaraffen.

Insgesamt bilden die Häuser, welche die linke Bildhälfte dominieren, die Kulisse für eine Vielzahl von davor gruppierten Personen und Gerätschaften. Die Hauptgruppe befindet sich sitzend und stehend vor dem Wirtshaus. Sie setzt sich aus einer aus der Tür heraustretenden Frau mit verschränkten Armen sowie einer Gruppe von Trinkenden zusammen. Durch eine Ansammlung von Behältnissen von dieser Hauptgruppe abgesondert, ist ganz links im Bild eine Figur auszumachen, die sich in die traufständige Scheune wendet. Rechts neben der Hauptgruppe öffnet sich die giebelständige Scheune mit einem großen Tor, durch das gerade ein Mann und eine Frau verschwinden wollen. Darunter befinden sich im Vordergrund auf der Mitte des Weges zwei Gestalten, die sich, Arm in Arm wankend, auf dem Weg zu einer Stadt begeben, deren Kirchturm im Hintergrund als Blickpunkt erscheint. Auf demselben Weg sind im Hintergrund weitere tanzende und feiernde Personen auszumachen.

Rechts im Vordergrund wird das Bild durch ein Schild mit einer (leider unleserlichen) Beschriftung und eine hölzerne Barriere nach vorn hin abgeschlossen. An die Barriere lehnt sich eine Figur, die von einem von links herbeilaufenden Hund überrascht wird. Der leicht bewölkte Himmel, der diese Szene überspannt, ist von einigen Vögeln bevölkert, die auf einen am Wirtshaus befindlichen Schlag zufliegen.

Insgesamt ist das Bild kompositorisch auf die Leserichtung von links nach rechts abgestimmt. So fällt der Blick des Betrachters zunächst auf die links befindliche große Häuserwand, die geradezu die Gesamthöhe des Bildes einnimmt. Den Personen in der Mitte und dem Weg folgend, wandert der Fokus sodann in die Weite der Landschaft, die sich durch einen rund zwei Drittel des Bildes einnehmenden Himmel auszeichnet, und endet auf der im Hintergrund befindlichen Stadt.

\footnotetext{
1 Kunstsammlung der Universität Göttingen, Archiv, Bildakte GG 216.
} 
Vergleichswerke für dieses Bild lassen sich, wie eingangs erwähnt, in der Niederländischen Malerei des 17. Jahrhunderts finden. Als ein bedeutendes Beispiel kann ein von Jan Victors (1620-1676) um die Mitte des 17. Jahrhunderts geschaffenes Werk mit dem Titel Rast vor der Schenke (Abb. 23) herangezogen werden, das sich in der Göttinger Kunstsammlung befindet. ${ }^{2}$ Es zeigt ebenfalls eine an einem Pfad befindliche Schenke, vor der sich verschiedene Personen finden lassen. Dabei zeichnet es sich besonders durch seine hohe technische Qualität aus. Der niedrige Horizont sowie die Kirchturmspitze sind Merkmale, die auch in dem Gemälde des deutschen Unbekannten vorgefunden werden können.

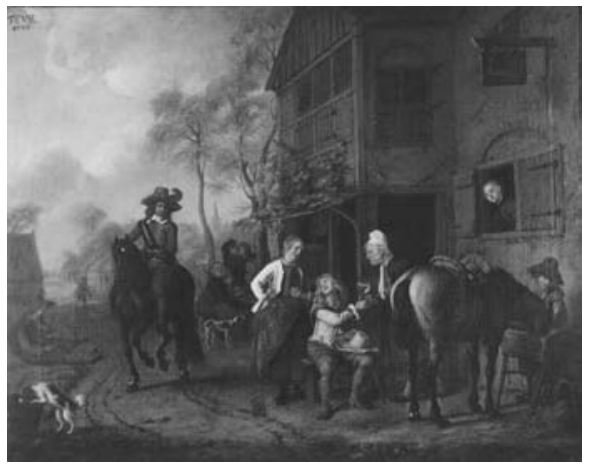

Abb. 23: Jan Victors: Rast vor der Schenke, Öl auf Leinwand, 79 x 99 cm, Göttingen, Kunstsammlung der Universität

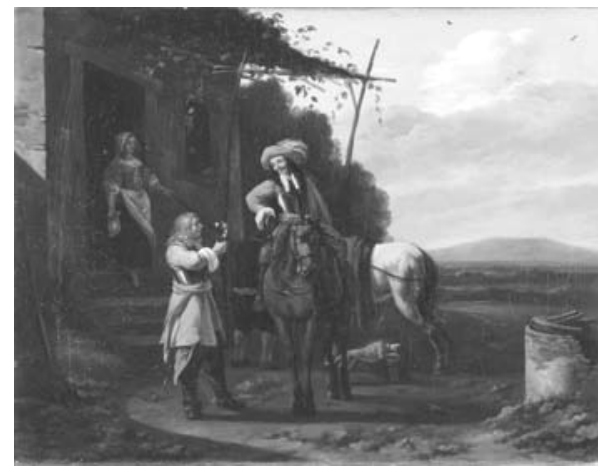

Abb. 24: Art des Karel Dujardin: Rast vor der Schenke, Öl auf Leinwand, 33 x $43 \mathrm{~cm}$, Göttingen, Kunstsammlung der Universität

Neben Victors Gemälde gibt es außerdem ein Werk in der Universitätskunstsammlung Göttingen, das als Kopie aus dem 18. Jahrhundert in der Art des Karel Dujardin (um 1622-1678) gehandelt und ebenfalls als Rast vor der Schenke bezeichnet wird (Abb. 24). ${ }^{3}$ Vergleichsmomente lassen sich einerseits im Thema finden, zum anderen aber auch im Bildaufbau und der Motivik. So tritt auch in diesem Gemälde eine Wirtin aus der Tür heraus, während sich zwei Offiziere vor der Schenke mit Wein erfrischen. Ein sich erleichternder Mann ist, wie bei dem Werk des Unbekannten, erst auf den zweiten Blick zu erkennen: er steht links hinter dem Reiter im Mittelgrund des Bildes. Ebenso wie im Gemälde Dorflandschaft mit zechenden Bauern befindet sich die Schenke dabei im linken Bildfeld, wobei der Blick des Betrachters ungestört in der rechten Bildhälfte durch die Landschaft wandern kann.

Beide Gemälde sind bühnenhaft aufgebaut und mit unterschiedlichstem Personal ausgestattet, was für Werke der Niederländischen Malerei, die sich häufig durch eine feine zeichnerische Qualität, differenzierte Tonalität und durch kompo-

2 Inv.-Nr. GG 090, vgl. Unverfehrt 1987, S. 148 f.

3 Inv.-Nr. GG 023, vgl. ebd., S. 62. 
sitorische Merkmale wie den niedrigen Horizont auszeichnen, charakteristisch ist. ${ }^{4}$ Nicht nur mit solchen Kompositionseigenschaften, sondern auch mit dem hier adaptierten Malgrund nähert sich die Dorflandschaft mit zechenden Bauern an Genrebilder des 17. Jahrhunderts an: Die Verwendung von Holz war im 19. Jahrhundert weitgehend unüblich geworden. ${ }^{5}$

Gleichwohl sprechen mehrere Merkmale des Werkes gegen eine Entstehung im 17. Jahrhundert. So erscheint der Farbauftrag an einigen Stellen zu pastos und die Farbigkeit nicht gedeckt genug. Auch wirkt die Kleidung der Protagonisten geradezu biedermeierlich, was besonders an dem Spitzenhäubchen der Wirtin deutlich wird. ${ }^{6}$

Im 19. Jahrhundert befand sich die Genremalerei im Aufschwung und Vorbilder der niederländischen Kunst wurden bei Künstlern und Betrachtern beliebter. Zudem war das Thema des Alkoholgenusses in der Mitte des 19. Jahrhunderts weit verbreitet. Besonders in Düsseldorf entwickelte sich das Trinkgenre, das die durch Weinseligkeit beförderte Geselligkeit aufzeigte. ${ }^{7}$ Das recht kleine Format und die relativ lockere Ausführung könnten daher dafür sprechen, dass die Dorflandschaft mit zechenden Bauern für den Verkauf auf einem breiten Markt mit geringeren finanziellen Möglichkeiten gedacht gewesen war oder als Studie eines Genremalers fungierte. ${ }^{8}$ Selbst eine bewusste Fälschung - worauf der Malgrund hinweisen könnte ist nicht ganz ausgeschlossen.

Christina Eifler

4 Becker 2007, S. 11-15; Schneider 2004, S. 15-25.

5 Für diesen während eines Kolloquiums am 11.05.2012 in Göttingen gegebenen Hinweis danke ich Herrn Prof. Dr. Thomas Noll, Bonn, herzlich.

6 Thiel 2004, S. 323.

7 Börsch-Supan 1988, S. 301.

8 Unverfehrt 1987, S. 148. 
Kat. Nr. 16

Eduard von Gebhardt (1838-1925)

\section{Bei der Kupplerin / Bauerninterieur}

2. Hälfte 19. Jahrhundert

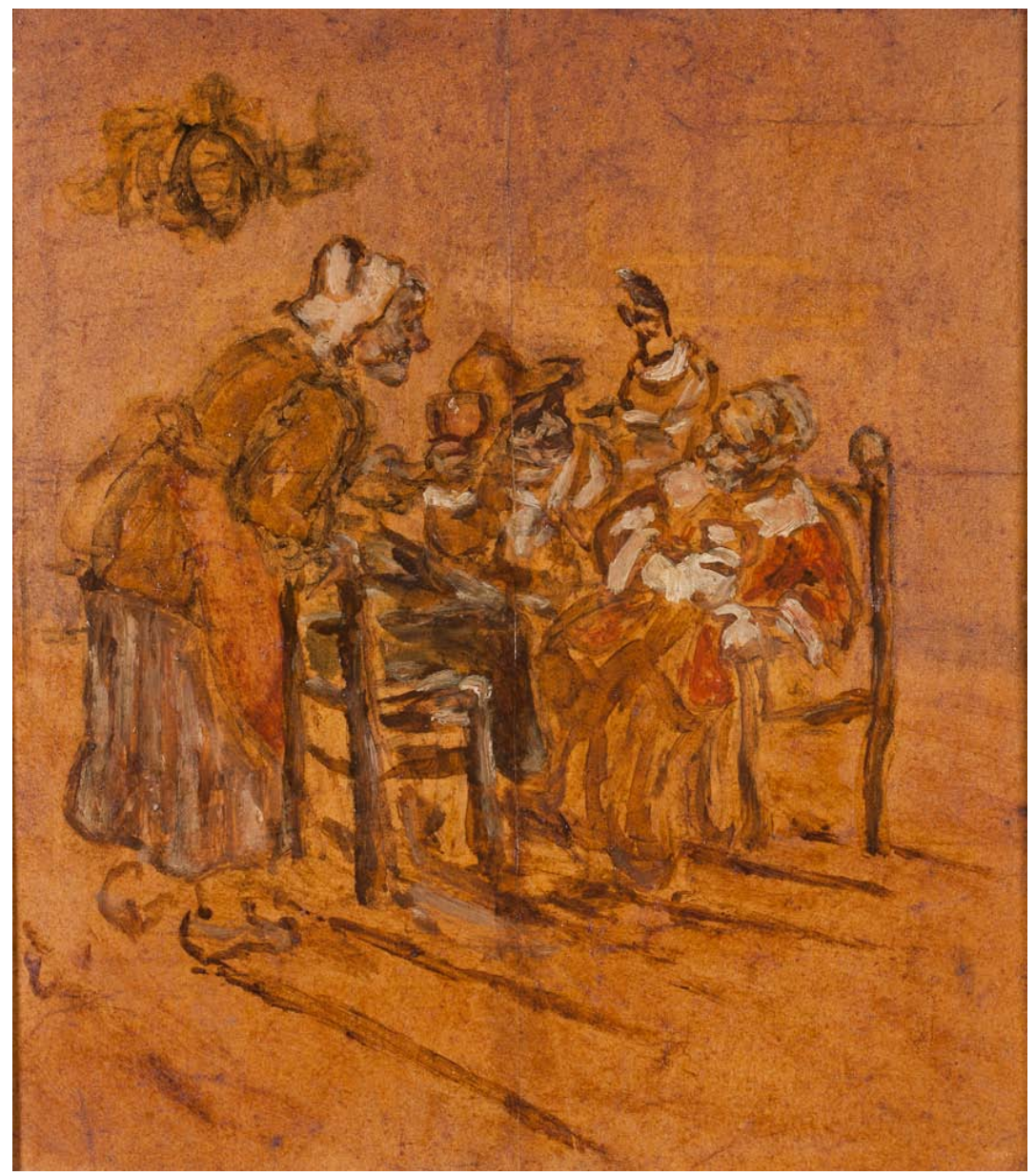

Öl auf Papier/Pappe, 25 x 22,2 cm, signiert unten links, 1966 aus der Sammlung Eugen Dumont mit Mitteln der Volkswagenstiftung angekauft, Inv. Nr. GG 134 


\section{Biographisches zu Eduard von Gebhardt}

Eduard von Gebhardt wurde in eine vom lutherischen Glauben geprägte Großfamilie hineingeboren. Sein Vater war Pastor in seinem estnischen Heimatort Sankt Johannis. Von 1855-1857 absolvierte er eine künstlerische Grundausbildung an der Akademie in Sankt Petersburg. Seine dortigen Lehrer gehörten zum einen dem sogenannten byzantinischen Stil ${ }^{1}$, und zum anderen der nazarenischen Strömung in Russland an, die von Friedrich Overbeck und seinem Umkreis beeinflusst war. ${ }^{2} \mathrm{Im}$ Jahr 1857 verließ Gebhardt Sankt Petersburg und ging nach Düsseldorf. Die dortige Akademie hatte unter Peter von Cornelius und Wilhelm von Schadow internationale Bedeutung erlangt, befand sich jedoch gerade in einer Phase der Neuordnung. ${ }^{3}$ Aus diesem Grund unternahm Gebhardt zunächst Studienreisen in die Niederlande und nach Belgien. Dort entdeckte er neben Rembrandt die frühen Niederländer wie Rogier van der Weiden und Jan van Eyck. Diese Einflüsse waren entscheidend für seine weitere Entwicklung, bei der den frühen niederländischen und den altdeutschen Meistern eine deutliche Vorbildwirkung zukam. ${ }^{4}$

Die zu dieser Zeit noch immer wirkmächtigen, idealistischen Auffassungen der Nazarener teilte Gebhardt nicht. ${ }^{5}$ Nach Aufenthalten in Wien, München und Tirol besuchte er die Karlsruher Akademie, an der Johann Wilhelm Schirmer (18021866) und Carl Friedrich Lessing (1808-1880) unterrichteten. Gebhardt studierte hier vor allem die Porträtmalerei, die einen nicht unerheblichen Teil seines späteren CEuvres ausmachen sollte. ${ }^{6}$ Dabei erlangte er die Fähigkeit, ausgeprägte Charakterstudien anzulegen. Ein Beleg hierfür befindet sich ebenfalls im Besitz der Universitätskunstsammlung. Es handelt sich um eine Studienzeichnung mit dem Titel Onkel Theodor (Abb. 25).

1860 kehrte Gebhardt nach Düsseldorf zurück und wurde dort Schüler von Wilhelm Sohn (1830-1899). Bei diesem vertiefte er seine Kenntnisse der Niederländer des 17. Jahrhunderts und vor allem Rembrandts. ${ }^{7} 1874$ wurde Eduard von Gebhardt als Professor an die Königliche Akademie Düsseldorf berufen. Er leitete dort Malklassen, bis er die Professur im Jahr 1912 niederlegte. ${ }^{8}$

Eduard von Gebhardt starb im Jahre 1925 in Düsseldorf. ${ }^{9}$ In den letzten Jahren seiner Lehrtätigkeit ergaben sich häufiger Diskrepanzen zwischen ihm und seinen Schülern, die mittlerweile andere künstlerische Auffassungen vertraten und beispielsweise durch den aus Frankreich kommenden Impressionismus beeinflusst

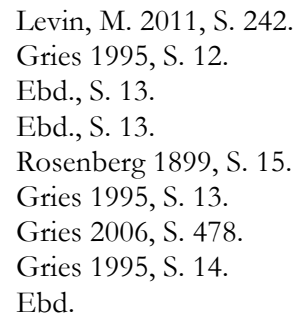


wurden. Diesen modernen Strömungen gegenüber verhielt sich Gebhardt ablehnend. ${ }^{10}$

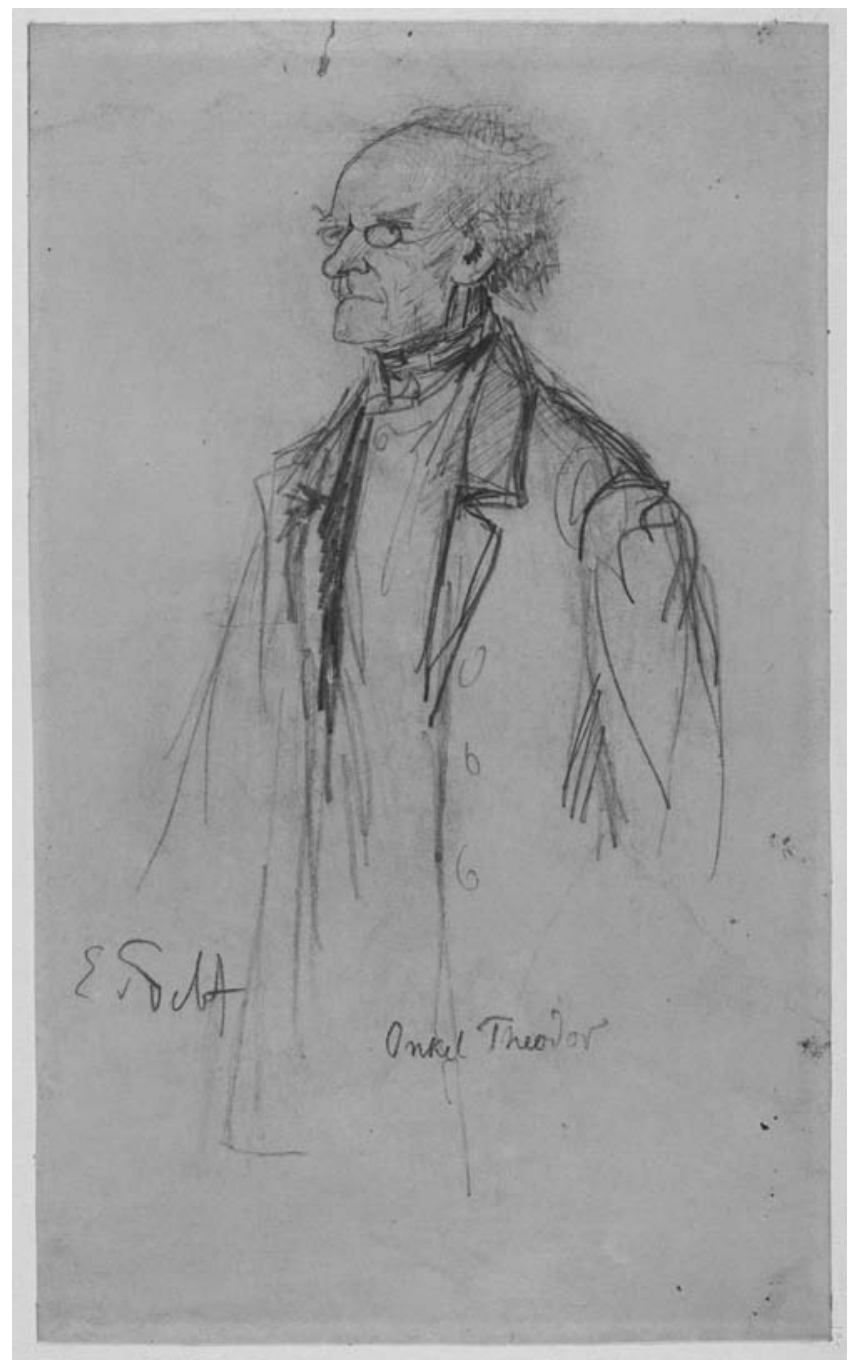

Abb. 25: Eduard von Gebhardt: Onkel Theodor, Bleistift, 261 x 157 mm, Göttingen, Kunstsammlung der Universität, Graphische Sammlung, Inv. Nr. H 1978/4

Die frühesten von Gebhardt ausgestellten Bilder (Einzug in Jerusalem, 1863, und Auferweckung von Jairi Tochter, 1864) riefen zunächst den Protest des Publikums hervor, denn dieses war an die nazarenische Auffassung insbesondere der religiösen

10 Gries 1995, S. 14, vgl. auch Thomson S, 59. 
Historienmalerei gewöhnt ${ }^{11}$. Diese symbolisch aufgeladene, antinaturalistische und idealistische Malerei hatte sich fest etabliert und den Zeitgeschmack geprägt. ${ }^{12}$ Wie grundlegend sich Gebhardts Auffassung davon unterschied, zeigt die Gegenüberstellung der Erweckung des Lazarus (1808) von Friedrich Overbeck (Abb. 26) mit der Gebhardt'schen Version desselben Themas von 1896 (Abb. 27). Später hatte Gebhardt jedoch zunehmend Erfolg. Als ,wahrer Erneuerer der religiösen Malerei Deutschlands auf evangelischer Grundlage" 13 erhielt er zahlreiche Aufträge. Seine Werke wurden als repräsentative Beispiele deutscher Kunst auf fünf Weltausstellungen gezeigt. ${ }^{14}$

1884 erhielt Eduard von Gebhardt den Auftrag, das Refektorium des Klosters Loccum mit einem umfangreichen Zyklus zu den sechs Bitten aus dem Vaterunser auszumalen. Kurz zuvor war er zum ersten Mal nach Italien gereist. Dort begeisterten ihn vor allem die Fresken Pinturicchios, Giottos und Filippino Lippis. ${ }^{15}$ Das zweite große Hauptwerk Eduard von Gebhardts stellte die Ausmalung der Friedenskirche in Düsseldorf (1899-1906) dar, die allerdings im zweiten Weltkrieg zerstört wurde. Die Gegenüberstellungen von Szenen aus dem Alten und Neuen Testament sollten - als Ergänzung zur gesprochenen Predigt - eine Predigt im Bild repräsentieren. ${ }^{16}$

Von Erik Thomsen stammt die erste monographische Betrachtung Gebhardts seit den 1930er Jahren (1991). Darin äußert er sich wie folgt:

„Eduard von Gebhardt ist sicherlich nicht der einzige Maler, der das biblische Geschehen, um es seinem Volk nahezubringen, aus dem Heiligen Land herauslöste und das Wirken Jesu auf Erden in einem anderen Land und in einer anderen Zeit hat geschehen lassen; für ihn war es das Land und die Zeit der deutschen Reformation. Auch Maler anderer Völker, Länder, ja Kontinente, haben Ähnliches getan, [...] keiner aber hat es wohl in so vielfältiger, auch monumentaler Weise getan und ausgeschöpft, wie Eduard von Gebhardt.“17

Eduard von Gebhardt ließ sich jedoch nicht auf eine Gattung festlegen, er malte kleinformatige wie monumentale, protestantisch geprägte, religiöse Historien ebenso wie Genreszenen, oft ebenfalls mit religiösem Charakter, Porträts und Landschaftsbilder. Für den Bereich der religiösen Malerei muss Gebhardt neben Fritz von Uhde (1848-1911) als einer der wichtigsten Erneuerer in Deutschland angesehen werden. ${ }^{18}$

\footnotetext{
11 Ebd., S. 15.

12 Vgl. hierzu die Einleitung zur religiösen Malerei in diesem Katalog, S. 90-93.

13 Nachruf in den Düsseldorfer Nachrichten vom 03.02.1925. Zitiert nach Gries 1995, S. 15.

14 Gries 1997, S. 390. (1873 Wien, 1878 Paris, 1900 Paris, 1904 St. Louis, 1910 Brüssel).

15 Bieber/Mai 1979, S. 173 f.

16 Ebd., S. 174.

17 Thomson 1991, S. 9.

18 Levin, M. 2011, S. 243.
} 


\section{Das Göttinger Bild}

Bei dem Bild in der Göttinger Universitätskunstsammlung handelt es sich um eine Ölskizze auf Papier. Zu sehen sind drei Personen, zwei sitzend und eine stehend. Der Bildraum wird lediglich durch ein paar Striche, die den Fußboden andeuten, sowie durch die schräg gestellten Stühle definiert. Auf dem hinteren der beiden nebeneinander stehenden Stühle sitzt eine männliche Figur mit Hut. Er hat die rechte Hand, in der er ein Glas hält, erhoben und streckt seine linke Hand in einem ausholenden Gesprächsgestus nach oben. Der Mann wendet sich der rechts neben ihm sitzenden Person zu: einer Frau, die in ihrer rechten Hand ebenfalls ein Glas hält. Sie beugt sich ein wenig von ihm weg und ergreift mit der linken Hand die Armlehne des Stuhls. Dennoch schaut sie den Mann an. Beiden gegenüber steht eine ältere Frau, die sich auf die Lehne des vor ihr stehenden Stuhles stützt und die beiden ebenfalls anblickt. Oben links im Bild ist ein nicht zu definierender Gegenstand erkennbar.

Die Skizze lässt sich mit keinem der bekannten Werke Eduard von Gebhardts in Verbindung bringen. Szenen dieser Art mit durchaus derbem Charakter, die das Leben in Wirtshäusern, Spielstuben oder Bordellen wiedergaben, waren ein äußerst beliebtes Thema der niederländischen und flämischen Genremalerei des 17. Jahrhunderts. Eine Reihe thematisch ganz ähnlicher Szenerien befindet sich auch in der Kunstsammlung der Universität Göttingen so z.B. Die Wachstube von Pieter Codde (1599-1678), das Bauerninterieur von Anthoni Victorijns (1620-1655/56) oder In der Schenke von Jan Joseph Horemans I. (1682-1759). ${ }^{19}$

Rezeptionsgeschichtlich wird der Genremalerei häufig ein realistischer Ansatz zugeschrieben. So wurde lange Zeit angenommen, dass die niederländische bzw. die Genremalerei im Allgemeinen die Wirklichkeit unmittelbar darstelle und gleichsam ein Spiegel der Sitten und Lebensformen einer Gesellschaft sei. Diese Einschätzung bedarf einer Relativierung, denn in der Regel handelt es sich um komponierte Szenen, welche in den Werkstätten der Maler für den prosperierenden niederländischen Kunstmarkt geschaffen wurden. ${ }^{20}$

Bei Gebhardts Begeisterung für die Niederländische Malerei und dem daraus resultierenden Naturalismus liegt es nahe, dass es sich bei der Göttinger Studie um eine solche Genreszene handelt, die zu Studienzwecken kopiert oder aber als Kompositionsübung in abgewandelter Form wieder gegeben wurde. Einem eindeutigen Vorbild lässt sich die Studie derzeit nicht zuordnen. In Gebhardts Nachlass findet sich jedoch eine Reihe weiterer Studien nach Alten Meistern. ${ }^{21}$ Auch Carola Bettina Gries geht 1995 in ihrer Dissertation von einer Skizze nach einem Alten Meister aus, wenngleich sie diese Einschätzung mit einem Fragezeichen versieht. 22

19 Unverfehrt 1987, S. 53, Kat. Nr. 19, S. 147, Kat. Nr. 92 und S. 81, Kat. Nr. 41.

20 Gaehtgens, B. 2002, S. 13.

21 Gries 1995, Werkverzeichnis, S. 357-361.

22 Ebd., Werkverzeichnis, S. 363. 


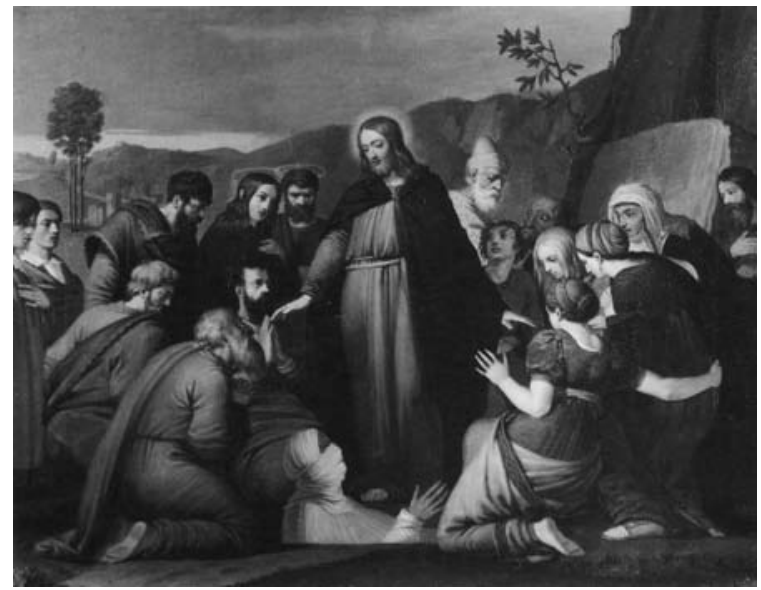

Abb. 26: Friedrich Overbeck: Die Auferweckung des Lazarus, 1808, Öl auf Leinwand, 41 x 53 cm, Lübeck, Museum für Kunst und Kulturgeschichte

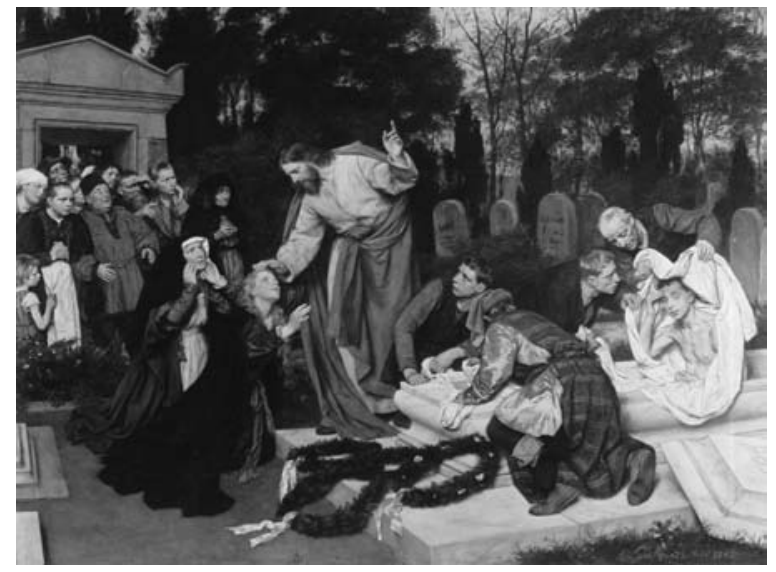

Abb. 27: Eduard von Gebhardt: Die Auferweckung des Lazarus, 1896, Öl auf Holz, 117 x 160 cm, Düsseldorf Museum Kunstpalast

Die lockere Pinselführung und der pastose Farbauftrag sind charakteristisch für die Skizzen Gebhardts. Hierin unterscheiden sich diese deutlich von Gebhardts ausgeführten Gemälden, die überaus detailliert in einer besonders feinen und glatten Malweise ausgeführt sind, welche sich an (alt)niederländischen Vorbildern orientiert. In der Skizze beschränkt sich der Maler auf wenige Farben im Spektrum Orange, Braun und Weiß. Trotz der skizzenhaften Darstellung sind die wesentlichen Aspekte des Geschehens auf pointierte Weise erfasst. 
Kat. Nr. 17

Maximilian Wachsmuth (1859-1912)

\section{Junges Paar}

Um 1900

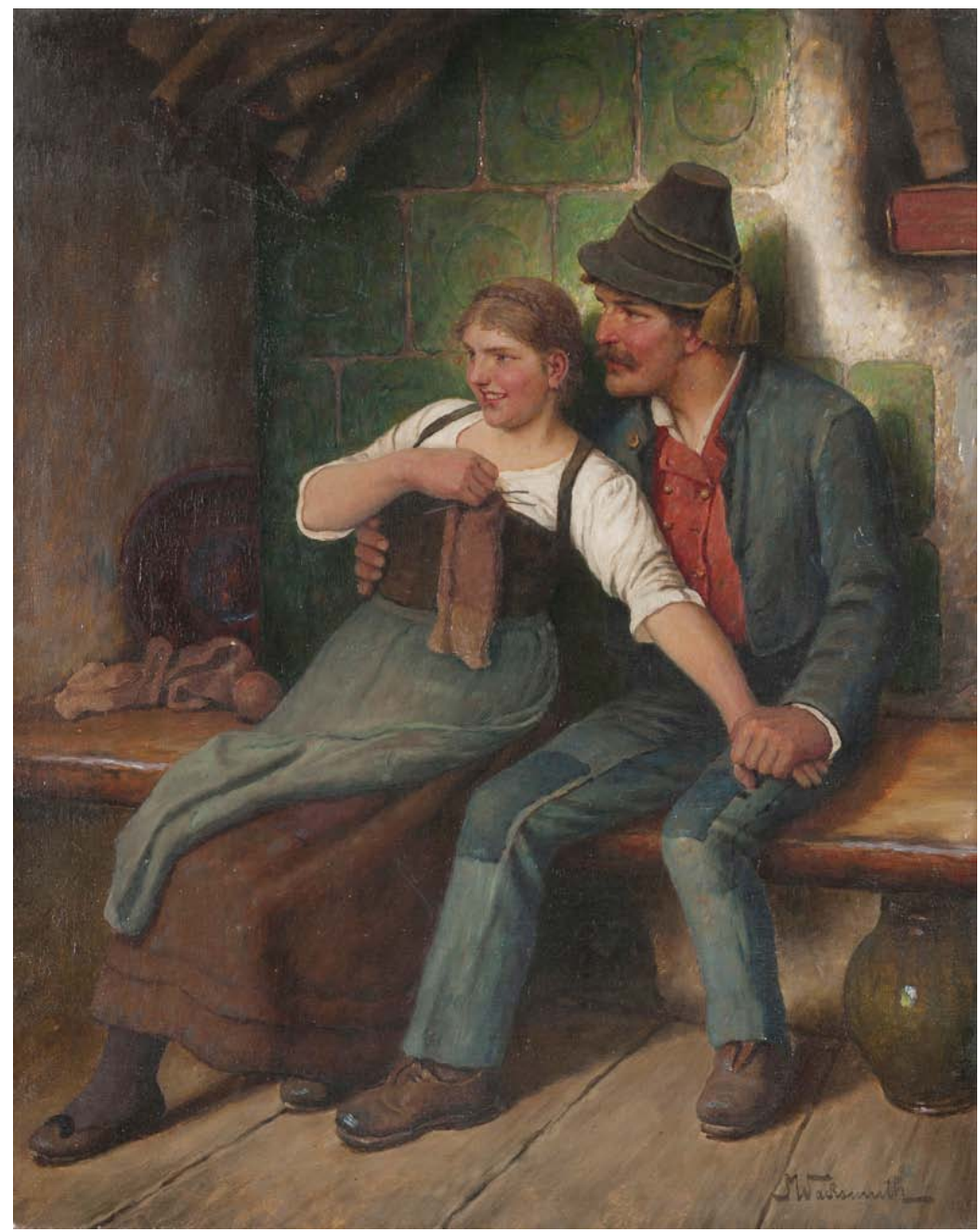

Öl auf Leinwand, 76 × 66 cm, signiert, 2008 aus dem Nachlass von Frau Prof. Ilse Walter, Göttingen erhalten, Inv. Nr. GG 234 
Maximilian Wachsmuth wurde am 14. Juli 1859 in Laßrönne geboren und trat am 26. Oktober 1883 in die Naturklasse der Akademie der Bildenden Künste in München ein, die zu dieser Zeit unter dem Direktorat von Carl Theodor von Piloty stand. ${ }^{1}$ Dieser legte bei der Lehre an der Akademie großen Wert auf ein solides technisches Können ${ }^{2}$ und so verwundert auch die dem Konzept des Realismus folgende Farbigkeit bei dem vorliegenden Werk von Wachsmuth nicht. Dass dieses Bild - gerade in der Proportionierung der Figuren - auch Schwächen aufweist, sei bereits an dieser Stelle nicht verschwiegen.

Als Sohn eines Beamten studierte Wachsmuth zwei Jahre in München, wobei Johann Caspar Herterich, Otto Seitz oder Nikolaus Gysis für diese Zeit als Lehrer in Frage kommen. In der bayerischen Residenzstadt wurde der Maler dann auch sesshaft und trat der dortigen Künstlergemeinschaft bei. ${ }^{3}$ Bei mehreren Ausstellungen im Glaspalast war er vertreten. So wurden von ihm 1904 Die Fuchsjagd, 1906 Ein warmes Plätzchen, 1908 Almenlieder und 1911 Beim Deandl ausgestellt. ${ }^{4}$

Der Betrachter des Gemäldes Junges Paar oder auch Tiroler Bauernpaar blickt auf einen in einer Bauernstube befindlichen, grün gekachelten Ofen, auf dessen Bank im Vordergrund eine weibliche und eine männliche Person Platz genommen haben. Beide schauen auf ein für den Betrachter nicht sichtbares Geschehen links außerhalb der Bildfläche. Der Mann ist mit einer blauen, mit Knieflecken versehenen Hose, einer blauen Jacke, einer roten Weste, einem weißen Hemd und einem Tirolerhut bekleidet, die Frau mit einem schwer wirkenden, bräunlichen, ärmellosen Kleid, unter dem eine weiße Bluse zum Vorschein kommt. Eine darüber gebundene Schürze ist über ihrem linken Bein hochgeworfen.

Der Mann sitzt vom Betrachter aus rechts auf der Ofenbank. Er hat sein linkes Bein stärker angewinkelt als das rechte - hier werden Proportionsprobleme offenbar, denn das rechte Bein erscheint wesentlich länger als das linke. Er zieht die Frau, die (von ihm aus gesehen) rechts neben ihm sitzt, dicht an sich heran, indem er sie mit seiner rechten Hand am Oberkörper umfasst. Die Frau wiederum hält Strickzeug in ihrer rechten, vor die Brust geführten Hand. Mit ihrem ausgestreckten linken Arm stemmt sie sich gegen den Mann, wobei ihre linke Hand auf dessen linken Oberschenkel gedrückt wird - eine Geste, die man als Ansatz einer Gegenwehr verstehen könnte, spräche nicht der lächelnde Gesichtsausdruck der Frau dagegen. Der Mann wiederum hält mit seiner linken Hand die auf seinem Schenkel gedrückte Linke der Frau mit festem Griff umfasst.

Neben diesen Hauptmotiven des Bildes lassen sich noch weitere Einzelelemente finden. So befindet sich unter der Bank im rechten Bildfeld ein großer grünlicher Krug. Auf der Bank im linken Bildfeld sind ein hochkant stehender Teller

\footnotetext{
München, Akademie der bildenden Künste, Matrikelbuch II, 1883.

Thieme/Becker 1907-1950, Bd. 27, 1933, S. 47.

Ebd., Bd. 35, 1942, S. 5.

Vgl. Ausst.-Kat. München 1904, S. 108; Ausst.-Kat. München 1906, S. 84; Ausst.-Kat. München 1908, S. 98; Ausst.-Kat. München 1911, S. 170 (die hier angeführten Kataloge sind als Digitalisate abrufbar unter www.bayerische-landesbibliothek-online.de/glaspalast).
} 
sowie ein Obststück oder Wollknäuel zu finden. Außerdem befindet sich dort ein Stoffstück, das aufgrund der Farbigkeit im Zusammenhang mit dem Handarbeitszeug der Frau gesehen werden kann und wohl einen schon fertig gestrickten Abschnitt eines Kleidungsstückes darstellt. Es könnte sich also um die Ärmel eines Pullovers oder um wärmende Stümpfe handeln. Auf dem Kamin liegt ebenfalls ein grünliches Tuch und in einer kleinen Nische rechts neben dem Kamin kann man Bücher erkennen.

Insgesamt wirkt das Bild aufgrund der vielen Schrägen, die sich in der Körperhaltung der beiden Protagonisten, den Holzdielen, dem Tuch am linken oberen Bildrand sowie der am Kamin angelehnten Bücher finden lassen, dynamisiert. Dabei wird der Blick des Betrachters auf die Hauptszene im Mittelpunkt des Bildes geführt. Gleichzeitig gibt es auch Elemente wie die Senkrechte des Kaminrandes links oder das die Bank stützende Gefäß, welche die Komposition beruhigen. Farblich arbeitet Wachsmuth bei der Kleidung und dem Hintergrund mit kühlen Farben, die jedoch ein stärkeres Heraustreten der wärmenden Farben in den Gesichtern hervorrufen.

Das Paar, um das es in diesem Gemälde geht, wirkt stark miteinander verbunden. Dies zeigt sich neben der gegenseitigen Adaptation der Fußstellungen vor allem am Um-, Er- und Übergreifen der Personen untereinander und an der Nähe ihrer Köpfe. Dass hier ganz bestimmte Rollenmuster und Geschlechterverhältnisse des 19. Jahrhunderts eine Ausarbeitung erfahren, wird beim Betrachten dieses Bildes schnell klar. So ist die Frau förmlich eingezwängt zwischen Mann, Ofen und Strickzeug. Ihr bleibt in dieser Konstellation wenig Handlungsspielraum.

Charakterisch für die Münchner Genremalerei dieser Zeit ist die überpointierte Vervielfältigung der Motive: In diesem Fall handelt es sich um das Thema Wärme, dass regelrecht durchdekliniert wird und im Ofen, im wärmenden Strickzeug, aber auch im wechselseitigen Temperieren der beiden Personen zur Anschauung kommt: So wärmt der Mann die Frau, indem er sie umfasst und ihre linke Hand mit seiner Linken festhält, „,nutzt“ sie aber gleichzeitig zur eigenen Erwärmung.

Dass dieser wechselseitige Umgang erotisch konnotiert ist, lässt sich dabei kaum übersehen. Hierauf verweist etwa der Griff auf den Oberschenkel des Mannes sowie die verrutsche Schürze der Frau. So dient das Genrebild seinen - sicher nicht im bäuerlichen Milieu zu suchenden Käufern - als ein durch den Stand der Dargestellten sanktionierter Einblick in die vermeintliche „Natürlichkeit“, Unbefangenheit und Derbheit der Landbevölkerung, welcher sowohl sentimentalische Sehnsucht als auch kulturelle Distinktion zulässt. Um Dezenz geht es dabei eher nicht.

Für derartige Darstellungen gab es im späten 19. Jahrhundert einen großen Markt. Gerade das alpenländische Genre, zu dem auch dieses Gemälde zählt, war besonders beliebt. Dargestellte Landleute in einfacher ländlicher Alltagstracht galten als Vermittler heiterer Ursprünglichkeit. ${ }^{5}$ Das Thema des Dirndls (d. h. der

5 Ebertshäuser 1979, S. 131. 
unverheirateten jungen Frau), welche(s) einem Jäger oder bayrischen Landmann gegenüber gestellt wird, findet sich häufig im Euvre Wachsmuths. In einem atmosphärisch gestalteten Interieur spielt der Künstler dabei mit verschiedenen Verhaltensmustern und Assoziationen, wobei er bestimmte Bildmotive, die auch beim Göttinger Bild auftauchen, gern wiederverwendet. Dies betrifft etwa die verrutschte Schürze, das Handarbeitszeug und den Tirolerhut. Wachsmuths Malweise bleibt dabei stets naturgetreu und detailliert.

In ihrer pointierten Bilderzählung, der „naturalistischen“ Detailerfassung und der differenzierten Farbigkeit lassen sich Wachsmuths Bilder mit Werken anderer Genremaler dieser Zeit vergleichen. Hier ist etwa Franz von Defregger zu nennen, der als bekanntester Vertreter des Bauerngenres gilt und ebenfalls an der Münchener Akademie unter Piloty studiert hat. Defreggers Werke zeichnen sich besonders durch ihre atmosphärische Gestaltung, ihren narrativen Charakter und ausgearbeitete Mimik aus. ${ }^{6}$ Bilder wie die Kraftprobe von 1898 oder Der Salon-Tiroler von 1882 (Abb. 28) belegen ein handwerkliches und bilderzählerisches Können,

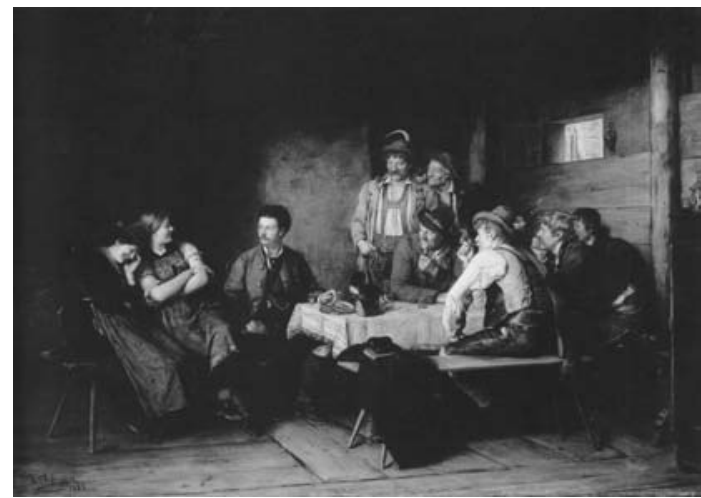

Abb. 28: Franz von Defregger: Der Salon-Tiroler, 1882, Öl auf Leinwand, 95 x $135 \mathrm{~cm}$, Berlin, $\mathrm{Na}-$ tionalgalerie das demjenigen Wachsmuths zweifellos überlegen ist. Gleichwohl ermöglicht Wachsmuths Bild in der Göttinger Universitätskunstsammlung bedeutende und informative Einblicke in eine der populärsten Gattungen des ausgehenden 19. Jahrhunderts.

Christina Eifler

6 Becker-Göthel 2002, S. 6-10. 


\title{
Emanzipation einer Gattung: Die deutsche Landschaftsmalerei im 19. Jahrhundert
}

\author{
Pbil Miller
}

Die Landschaftsmalerei erlebte um 1800 einen bedeutenden Aufschwung. Als selbstständige Gattung hatte sie sich bereits im 17. Jahrhundert in den Niederlanden etablieren können. ${ }^{1}$ Sie galt damals unter anderem als Mittel für „Kurzweil und Vergnügen“ für den Maler und diente dem Betrachter zur „Erheiterung des Gemüts".2 In der akademischen Gattungshierarchie war ihr Rang eher niedrig angesiedelt, da sie nur Unbewegtes darstelle. Nach André Félibien, 1669 Sekretär der Académie royale de peinture et de sculpture, galt demgegenüber die Historienmalerei als die höchste Gattung, da der Mensch das vollkommenste Werk der Schöpfung sei und seine Darstellung in Bewegung als anspruchsvollste künstlerische Aufgabe galt. ${ }^{3}$ Erst in der zweiten Hälfte des 18. Jahrhunderts wandelte sich die Stellung der Landschaftsmalerei grundlegend. Es handelt sich um einen Vorgang, der mit der generellen Aufwertung von Natur in dieser Zeit zusammenhängt.

1 Locher 2005, S. 28. Gerade die Holländische Malerei des 17. Jahrhunderts stellt als „,erste realistische Schule“ für das 19. Jahrhundert einen starken Bezugspunkt dar. Maler der Schule von Barbizon wie Jean-François Millet und Gustave Courbet griffen diese Anregungen auf. In Düsseldorf und Weimar sowie in München wurde der Einfluss dann ebenfalls groß, vgl. Locher 2005, S. 74. Gleichzeitig bestimmte sie in den Niederlanden selbst lange Zeit die Art und Weise, wie Landschaft gemalt wurde: vgl. etwa Ignatius Josephus van Regemorters Felsenschlucht (Kat. Nr. 18) in diesem Katalog.

2 Siehe Noll 2012, S. 28. Nach Äußerungen Leon Battista Albertis u.a., in: Busch 1997a, S. 64-73 und $79 \mathrm{f}$.

3 Vgl. Noll 2012, S. 28-30. 


\section{Aufwertung der Natur}

1750 legte Jean-Jacques Rousseau (1712-1778) der Akademie von Dijon seine Preisschrift ${ }^{4}$ vor, in der er konstatierte, dass sich der Mensch durch die Wissenschaft und Künste von der Natur entfernt habe. Im Kern forderte er „Retour à la nature“.${ }^{5}$ Dies war in erster Linie ein moralischer Appell und gegen die Dekadenz des Ancien régime gerichtet, konnte aber auch als Forderung einer neuen (moralisch fundierten) ästhetischen Wahrnehmung der Natur gelten. ${ }^{6}$

Rousseaus Gedanken fanden eine weite Verbreitung. So erschienen 1779 und 1780 zwei Serien des Berliner Radierers Daniel Chodowiecki (1726-1801), in denen „richtige“ und „falsche“ Verhaltensweisen des Lebens unter dem Titel Natürliche und affectierte Handlungen des Lebens dargestellt werden. ${ }^{7}$ Gezeigt werden unter anderem Paare in ihrer Reaktion auf die sie umgebende „Natur“, die in den Radierungen als Garten, aber auch allegorisch-personifiziert in Gestalt der Göttin Pomona erscheint. Die Paare stehen in gleichsam religiöser Andacht, mit innerer Anteilnahme vor der Natur. Im Falle der Pomona-Statue eröffnet sich eine weitere Deutungsebene: Indem die Göttin als Statue verbildlicht ist, bezieht sich die Andacht nicht nur auf die allegorisierte Natur, sondern auch auf deren künstlerische Darstellung. ${ }^{8}$

Bei Rousseaus zivilisationskritischem Ansatz geht es um eine zunehmende Entfernung des Menschen von der Natur. Generell wurde am Ende des 18. Jahrhunderts die „Vorstellung eines bereits stattgefundenen, gerade stattfindenden oder vermeintlich kurz bevorstehenden Verlustes der bisherigen naturräumlichen

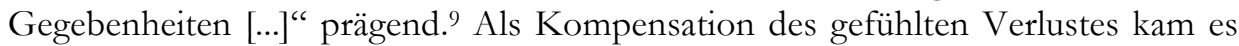
zu einer sentimentalischen Hinwendung zur Natur. ${ }^{10}$ In diesem Zusammenhang entwickelte sich eine gesteigerte Wertschätzung der wilden, „unklassischen“ Natur. Es entstand eine Reisebewegung mit dem Ziel, abgelegene Naturgebiete aufzusuchen. Ein besonders beliebtes Ziel stellten dabei die Schweizer Alpen dar. Einen literarischen Kulminationspunkt fand die Schweiz-Begeisterung - und das damit verbundene Ideal eines gleichsam ursprünglichen Lebens in der Natur - 1804 in Friedrich Schillers Schauspiel Wilhelm Tell. ${ }^{11}$

Als Folge solcher Entwicklungen erfuhr die Landschaftsmalerei im späten 18. Jahrhundert eine generelle Aufwertung. Die Konzepte, die dabei entwickelt wurden und die Konsequenzen, die bei der Gestaltung der Bilder gezogen wurden, waren vielfältig und nicht selten kontrovers. Dabei ging es nicht zuletzt um die

4 Rousseau 1997 [1750].

5 Locher 2005, S. 28. Den exakten Ausspruch findet man jedoch nicht bei Rousseau. Es handelt sich viel mehr um eine Quintessenz.

6 Ebd.

7 Vgl. Locher 2005, Abb. 12-13, S. 29.

8 Ebd., S. 28 f.

9 Noll/Stobbe/Scholl 2012b, S. 11.

10 Locher 2005, S. 12.

11 Ebd. 
unterschiedliche Bewertung von konkreter, ortsbezogener Landschaftsschilderung (Vedute) und erfundener, frei komponierter Landschaft. Diskutiert wurde auch, inwieweit Landschaft zum Träger bestimmter Konzepte werden und sich etwa mittels einer bedeutungsträchtigen Staffage aufladen lassen könne und solle. Solche Fragen wurden über das 19. Jahrhundert hinweg sehr unterschiedlich beantwortet, wobei die Lösungen vielschichtigen historischen Veränderungen und Umbrüchen unterlagen.

\section{Idealistische Landschaftsmalerei in Rom}

Für die idealistische Landschaftsmalerei um 1800 war eine Gruppe in Rom tätiger Künstler von großer Bedeutung, zu der u. a. Johann Christian Reinhart (17611847) und Joseph Anton Koch (1768-1839) gehörten. Diese Künstler sahen in der idealistischen Überformung der Natur eine Voraussetzung, um eine ideale Landschaftskunst zu entwickeln, deren Ziel darin bestand, Gedanken zu vermitteln. ${ }^{12}$ Dabei orientierten sie sich an den „heroischen Landschaften“ Nicolas Poussins und Claude Lorrains, bei denen die Bilder durch Staffagefiguren aus der Historienmalerei - oft mythologischen oder biblischen Themas - mit Bedeutung aufgeladen worden waren. Die idealisierte Landschaft nimmt hier die Rolle des „Handlungsraums des stets im kleinen Maßstab präsenten Menschen"13 ein, wobei die Szenerie in der Regel in idealer Zeit - meist der Antike - verortet ist. ${ }^{14}$ Handlung und Komposition der Landschaft transportieren so einen Gehalt bzw. eine Stimmung ähnlich der Historienmalerei. ${ }^{15}$

Die in Rom wirkenden Künstler erweiterten dieses Konzept allerdings, indem sie sich auch an konkreten Landschaftsansichten Roms und Neapels orientierten. Im Gegensatz zu Poussin und Lorrain bedienten sie sich der „,real existierenden Sehnsuchtslandschaften als Vorlage für ihre neuen Ideallandschaften ". 16 Dabei bestand ihr Anspruch darin, die ,ungeordnete Natur durch die Kunst der überformenden Komposition in eine harmonische Erscheinung [zu] überführ[en]."17 Konzeptionelle Grundlage für diese Vorgehensweise war dabei die Vorstellung einer Kultivierung der natürlichen Gegebenheiten durch die ordnende Kraft der Vernunft. Hubert Locher unterscheidet diese Art der ,idealistischen Landschaftsmalerei“ von der „,idealen“ Landschaft des 17 . Jahrhunderts. ${ }^{18}$

1803 entwickelte der Philosoph und Kunsttheoretiker Carl Ludwig Fernow (1763-1808) mit seiner Abhandlung Über die Landschaftsmalerei ein Theoriegerüst für diese Art von Landschaftsmalerei. Ihr Zweck sei die Erregung einer ästhetischen

12 Locher 2005, S. $30 \mathrm{f}$.

13 Ebd., S. 32.

14 Börsch-Supan 1988, S. 301.

15 Locher 2005, S. 30 f.

16 Ebd., S. 31

17 Ebd.

18 Ebd. 
Stimmung durch den „Totaleindruck“ der Komposition, wodurch „,mit dem Gefühle unserer wirklichen Beschränktheit zugleich eine Sehnsucht nach dem Idea$1 e^{\text {“19 }}$ erzeugt würde. Die Landschaft Italiens sei für diese Zwecke am geeignetsten, da sie dem Ideal am nächsten komme. ${ }^{20}$ Der Künstler solle die Landschaft daraufhin konzipieren, dass eine Stimmung erzeugt wird. Die menschlichen Figuren existieren als Allegorie des heroischen Bestehens des ideal gesinnten Menschen in der Natur. ${ }^{21}$ Dementsprechend sei eine Erhebung und Bildung des Menschen durch die Landschaft zu erzielen. Dadurch erreicht die Landschaftsmalerei gegenüber der Historienmalerei einen neuen Status, da sie in ihrer ästhetischen Wirkung ähnlichen Idealen zu entsprechen vermag. ${ }^{22}$ Die idealistische Landschaft war damit eine Option, um eine weitere Emanzipation dieser Gattung zu bewirken. Es ist daher auch nicht verwunderlich, dass dieses Konzept bis weit in die zweite Hälfte des Centenniums Bestand hatte. ${ }^{23}$

\section{Reisebilder}

Auch im weiteren Verlauf des 19. Jahrhunderts blieb Italien ein bedeutendes Reiseziel für Künstler aus Deutschland. Hier bestand neben dem Studium der Antike und der alten Meister die Möglichkeit, sich der Landschaftsmalerei zu widmen. ${ }^{24}$ Dabei gab es neben - aber auch in Verbindung mit - der idealistischen Landschaftsmalerei die Möglichkeit, sich den konkreten „malerischen Aussichten“ der italienischen Landschaft zu widmen. Johann Martin von Rohden (1778-1868), Carl Rottmann (1797-1850) und Adrian Ludwig Richter (1803-1884) können hier genannt werden. In der Göttinger Universitätskunstsammlung kann auf Bernhard Fries (Kat. Nr. 23) verwiesen werden, der sich in seiner Ausbildung unter anderem stark an Rottmann orientierte.

Eine Verbindung der klassischen Landschaftstradition mit einer tendenziell eher naturalistischen Auffassung, die namentlich in den vorbereitenden Studien und Skizzen zum Tragen kommt, pflegte in seinen frühen Jahren an der Kopenhagener Akademie auch Louis Gurlitt, der in der Göttinger Universitätskunstsammlung mit drei Ölstudien vertreten ist (Kat. Nr. 20-22). Sein Motiv ist in dieser Zeit allerdings nicht Italien, sondern die Landschaft Dänemarks, Norwegens und Schwedens.

\footnotetext{
19 Fernow 1806, S. II.

20 Locher 2005, S. 32.

21 Ebd., S. 33.

22 Ebd., S. 38.

23 Man kann hier etwa auf die Landschaften Friedrich Prellers verweisen: vgl. Scholl 2011.

24 Locher 2005, S. 39.
} 


\section{Romantik}

Generell kam der nordalpinen neben der italianisierenden Landschaft bei den deutschen Künstlern eine zunehmende Bedeutung zu. Ludwig Richter, der freilich selbst 1823-1826 in Italien war, sprach sich früh gegen die Darstellung fremdländischer Gegenden aus, da das heimische (deutsche) Publikum den Stimmungsgehalt seiner Ansicht nach nicht empfinden könne. ${ }^{25}$ Er wollte die „Deutsche Natur zu einem Ideal, zu edler Größe erheben."26 Schon zuvor war die heimische Landschaft von Malern der Romantik auf neue Weise in Bildern gefasst worden - etwa von Caspar David Friedrich (1774-1840).

Romantiker wie Friedrich lösten sich von der idealen, an Italien orientierten Landschaftsmalerei. Bei Friedrich wird die Natur nicht zur ,idyllischen Idealwelt stilisiert, sondern erscheint als pathetisch überformte irdische Realität." 27 In Atmosphäre und Detail wirkt die Landschaft realistisch, ist jedoch in Anordnung und Komposition in hohem Maße artifiziell. Gleichzeitig entwickelte Friedrich neue Strategien zur bildlichen Konstitution von Künstler- und Betrachtersubjekt und zur Bedeutungsaufladung. ${ }^{28}$ Die „Landschaft wird auf das erlebende Ich bezogen und damit subjektiv perspektiviert." 29 Einige dieser Strategien findet man bei Friedrich Philipp Reinholds Gemälde Der Hirte auf der Bergspitze bei Abendschein in der Göttinger Universitätskunstsammlung wieder (Kat. Nr. 19) - so etwa die dominante Anlage einer Rückenfigur. ${ }^{30}$

\section{Landschaftsmalerei an den Akademien}

Durch ihre niedere Stellung in der Hierarchie der Gattungen war die Landschaftsmalerei im Lehrbetrieb der Akademien zunächst nur partiell oder gar nicht vorhanden. Die monumentale Historienmalerei blieb für lange Zeit der Hauptzweck der Lehre. Die drei künstlerischen Zentren Deutschlands waren im 19. Jahrhundert München, Berlin und Düsseldorf. Der Kunstschriftsteller und Sammler Athanasius Graf Raczynski (1788-1874) stellte in seiner Geschichte der neueren deutschen Kunst die Schwerpunkte der drei Standorte auf pointierte (und sicher überspitzte) Weise heraus, indem er schrieb, dass Berlin mit Karl Friedrich Schinkel die Baukunst, München mit Peter von Cornelius die Freskomalerei und Düsseldorf mit Wilhelm von Schadow die Ölmalerei innehabe. ${ }^{31}$

\footnotetext{
Locher 2005, S. 39. Zu Richters Italienaufenthalt vgl. u. a. Neidhardt 1991, S. 16-20.

Richter 1895, S. 30, 19.11.1824; ebd., S. 40, 17.12.1824.

Locher 2005, S. 42.

Vgl. etwa Koerner 1998; Scholl 2007, u. a. S. 115-139, 166-177, 204-261, 298-328.

29 Noll/Stobbe/Scholl 2012b, S. 13.

30 Ebd.

31 Raczynski 1836, S. 42.
} 
An der Münchner Akademie war die Landschaftsmalerei nicht vertreten. Cornelius hatte diese Klasse aus Abneigung gegen die „Fächler“ abgeschafft. ${ }^{32}$ Dass für ihn die Historie die höchste und einzige Kunst war, wird deutlich, wenn man sich eine vielzitierte Briefpassage an König Ludwig I. von Bayern vom Dezember 1825 in Erinnerung ruft:

„Einen Lehrstuhl der Genre- und Landschaft-Malerei halte ich für überflüssig. Die wahre Kunst kennt kein abgesondertes Fach; sie umfaßt die ganze sichtbare Natur. Die GattungsMalerei ist eine Art von Moos oder Flechtengewächs am großen Stamme der Kunst. “33

Erst 1891 wurde in München eine eigenständige Landschaftsklasse wieder eingerichtet. ${ }^{34}$ Das gängige System sah vor, dass die Künstler durch das Studium alter Meister das nötige Handwerkszeug erlernen sollten. Die Landschaft war lediglich Handlungsraum der gehaltvollen Szene. Außerhalb der Akademie fanden sich im Münchner Umfeld aber Landschaftsmaler zusammen, die neue Strömungen aufnahmen und umsetzten. Zu ihnen gehörte etwa Adolf Lier (1826-1882). ${ }^{35}$ Aus dem Umfeld dieser florierenden Münchner Landschaftsmalerei, die in der zweiten Hälfte des 19. Jahrhunderts nicht zuletzt durch die Schule von Barbizon und (gegen Ende des Jahrhunderts) durch den französischen Impressionismus beeinflusst wurde, stammen die Maler Karl Adam Heinisch (Kat. Nr. 28) und Johann Friedrich Voltz (Kat. Nr. 24), die mit ihren Werken in der Göttinger Universitätskunstsammlung vertreten sind.

In Düsseldorf war die Akademie ab 1826 anders organisiert. Mit der Berufung Wilhelm von Schadows zum Direktor kam es zu einer Reform des Lehrbetriebs. Unter anderem wurde der Ablauf des Studiums geändert, so dass man von nun an nach einer Pflicht-Vorklasse in frei gewählte Meisterklassen wechseln konnte. ${ }^{36}$ Obwohl Schadow der idealen Malerei zugeneigt war, etablierte sich in Düsseldorf eine eigene naturalistische Richtung. ${ }^{37}$ Dies wurde ermöglicht durch die duldende Leitung Schadows, die Lehrern und Schülern Raum für individuelle Entwicklung gab. Hierin unterschied sich der Nachfolger von Peter von Cornelius, denn von dieser Förderung profitierte natürlich auch der Unterricht der niederen Gattungen: Genre, Stillleben und die Landschaftsmalerei. Letztere konnte sich so auch zu einem der stärksten Zweige der Düsseldorfer Schule entwickeln. ${ }^{38}$ Durch Schadow wurde die Düsseldorfer Schule, um Ekkehard Mai zu zitieren, „zum Inbegriff von Idealismus und Realismus, von Tradition und Modernität [...]“.39

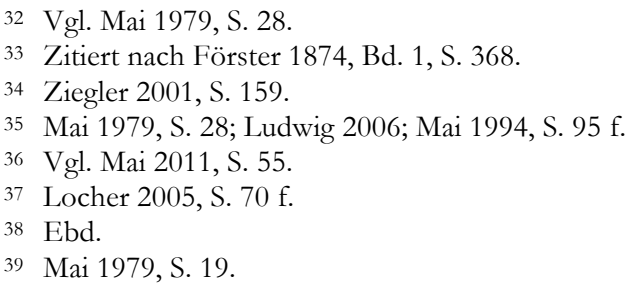


1830 wurde Johann Wilhelm Schirmer (1807-1863) mit der Düsseldorfer Landschaftsklasse betraut. Zunächst als Aushilfslehrer tätig, wurde er 1839 zum Professor ernannt. Basis seiner Landschaftsmalerei war das Studium vor Ort unter freiem Himmel in Zeichnung und Öl. In seiner künstlerischen Auffassung stimmte er mit Schadow durchaus überein. Schirmers ideale Landschaften stehen dabei in der Tradition von Joseph Anton Koch (1768-1839)..$^{40}$ Es handelt sich um komponierte Landschaften, die er durch Farb- und Lichteinsatz atmosphärisch auflud. August Keßler (Kat. Nr. 25) war Schüler von Schirmer, entwickelte jedoch in seinen Bildern eine eigene Farbigkeit. Auch der bereits erwähnte Bernhard Fries (Kat. Nr. 23) hat bei Schirmer studiert.

\section{Neue Anstöße: Realismus}

Gleichsam als eine „erste realistische Schule“ blieb die Niederländische Malerei des 17. Jahrhunderts neben den genannten Richtungen im gesamten 19. Jahrhundert als Vorbild wirksam. Nicht zuletzt durch die Nähe zu den Niederlanden wurden Werke Jacob van Ruisdaels, Jan van Goyens ${ }^{41}$ oder Meindert Hobbemas gerade in Düsseldorf verstärkt rezipiert. ${ }^{42}$ Aber nicht nur die Niederländer lieferten mit ihrem Einsatz von Licht und Atmosphäre neue Anstöße. In England entwickelte sich unter anderem bei John Constable und Richard Parkes Bonington eine Malerei, die mit ihrer Naturnähe und Lichtstimmung neue Wege beschritt. ${ }^{43}$ Besonders in Frankreich kam es zur Auseinandersetzung mit niederländischen und ab den 1820 er Jahren auch mit englischen Vorbildern. ${ }^{44}$ Namentlich die Schule von Barbizon sollte hierbei eine wichtige Rolle einnehmen. ${ }^{45}$

Diese Künstlerkolonie im Wald von Fontainebleau bildete sich aus einer ablehnenden Haltung gegenüber der Akademie heraus. Gründungsmitglied war der französische Landschaftsmaler Théodore Rousseau (1812-1867).46 In Barbizon entwickelte sich die Landschaftsauffassung des Paysage intime. Diese Art der Landschaftsmalerei konzentriert sich vor allem auf vertraute Gegenden. Meist vor Ort gemalt, handelte es sich dabei zunächst um Ölskizzen und Studien, die aber ab Mitte des Jahrhunderts langsam den Status autonomer Gemälde erlangten. ${ }^{47}$

\footnotetext{
40 Locher 2005, S. 72.

41 Von Jan van Goyen befindet sich das Gemälde Blick von der alten Maas auf Dordrecht in der Göttinger Universitätskunstsammlung: vgl. Unverfehrt 1987, S. 75, Kat. Nr. 35 (GG 033).

42 Mai 1979, S. 28; Häder 1999, S. 156. Ausführlich hierzu vgl. Ausst.-Kat. San Francisco 1962, S. 62.

43 Rödiger-Diruf 1998, S. 43.

44 Ebd.

45 Vgl. weiterführend Müllerschön/Maier 2010, S. 31.

46 Dabei handelt es sich nicht um eine Gründung im strengen Sinne. Es war eher eine heterogene Gruppierung, die später unter dem Namen „Schule von Barbizon“ zusammengefasst wurde. Müllerschön/Maier 2010, S. 29 f.; Rödiger-Diruf 1998, S. 44-46.

47 Müllerschön/Maier 2010, S. 30.
} 
Die Werke des Paysage intime brachen mit dem Konzept der idealen Landschaft. Gezeigt wurden keine erhabenen, weiten Landschaften, mit denen sich ein Bildungsanspruch verband. Vielmehr findet man Szenerien, die aus ihrer realen Anlage heraus eine Stimmung entwickeln sollten. Der Dichter Émile Zola beschrieb die neue Landschaftsauffassung wie folgt:

„Früher korrigierte man die Natur, um ihr Größe zu verleihen, [...]. Doch nun wurde bewiesen, daß die Landschaftsbilder, auf denen die ungeschminkte Natur zu sehen war, voller Gefühl, Kraft und Anmut waren, Eigenschaften, die den historischen Landschaftsbildern immer gefehlt hatten." 48

Wichtige Vertreter der Schule waren Jean-François Millet (1814-1875), Gustave Courbet (1819-1877) und Charles-François Daubigny (1817-1878). Der Einfluss der Schule war groß und sie entwickelte sich etwa Mitte des Jahrhunderts auch für deutsche Künstler zu einem wichtigen Anlaufpunkt. ${ }^{49}$ So war etwa der Berliner Tiermaler Paul Meyerheim (vgl. Kat. Nr. 29) in Barbizon und ließ sich dort anregen.

\section{Weimarer Malerschule}

Zu einem Zentrum ganz ähnlicher Ausprägung entwickelte sich in Deutschland die 1860 von Großherzog Carl Alexander von Sachsen-Weimar (1818-1901) gegründete Weimarer Kunstschule. ${ }^{50}$ Eigentlich mit dem Ziel gegründet, eine Ausbildung getreu der Gattungshierarchie zu bieten, entfaltete sich ein Schwerpunkt in der Landschafts- und Genremalerei. ${ }^{51}$ Über den Landschaftsmaler Theodor Hagen (1842-1919) und den Tiermaler Albert Brendel (1827-1895) hielt die Kunst Barbizons, aber auch der Niederländer des 17. Jahrhunderts und der Haager Schule, in Weimar Einzug. ${ }^{52}$ Unter diesen Voraussetzungen entwickelte sich das, was heute im Allgemeinen als „Weimarer Malerschule“ bekannt ist. ${ }^{53}$ Wichtige Vertreter sind dabei unter anderem Christian Rohlfs (1849-1938), Paul Baum (1859-1932) und ganz besonders der in diesem Katalog mit einem Werk vertretene Karl Buchholz (Kat. Nr. 26). Diese Künstler griffen das Konzept des Paysage intime auf und wendeten es auf das Weimarer Umland an, entwickelten aber gegenüber dem französischen Vorbild eine eigene Farbigkeit. ${ }^{4}$

48 Zola 1988 [1878], S. 199 f.

49 Bertuleit 2004, S. 14 f.

50 Ausführlich zur Gründungs- und Entwicklungsgeschichte der Weimarer Malerschule vgl. Scheidig 1971; Scheidig 1991; Ziegler 2001.

51 Ziegler 2001, S. 79 f.

52 Scheidig 1991, S. 85-90; Häder 1999, S. 155-156; Sillevis 2010, S. 61 f.

53 Zur Herleitung des Begriffs vgl. Ziegler 2001, S. 66-80.

54 Die Weimarer malen meist dunkler und ihre Bilder haben einen vermeintlich ,grauen Schleier“. Ziegler 2000, S. 25 f. 
Die Entwicklung der Weimarer Malerschule kann als exemplarisch für die Umbrüche in der Landschaftsmalerei der zweiten Hälfte des 19. Jahrhundert angesehen werden. Gegründet wurde sie vom Großherzog mit dem Ziel, Künstler in Weimar anzusiedeln. ${ }^{55} \mathrm{Ob}$ es sich dabei um eine kulturpolitische Agenda mit dem Zweck der Volksbildung handelte, ist nicht klar zu beantworten. ${ }^{56}$ Sicher ist jedoch, dass Carl Alexanders Kunstvorstellung an einem idealistischen Modell orientiert war, das gleichzeitig aber auch auf die identifikatorische Wirkung von Kunst setzte. ${ }^{57}$ Bei seinem Projekt, die Wartburg bei Eisenach auszugestalten, sollte „mit Erinnerungsmalen an die Landgrafenzeit, an Sängerkrieg und Luthers Aufenthalt auf der Wartburg“" erinnert werden.58 Das Vorhaben diente also der vertiefenden Bildung einer nationalen Identität mittels künstlerischer Spiegelung von Thüringischer Landschaft und Geschichte.

Dass sich gerade hier eine grundlegende Erneuerung vollzog, mit der die Weimarer Kunstschule in Deutschland eine Vorreiterrolle übernahm, hat zunächst einmal etwas mit dem geringen Etat der Kunstschule zu tun, der keinen Anreiz für etablierte Künstler wie Carl Theodor von Piloty bot. Die befristeten Professorenstellen ermöglichten es vor allem jungen Künstlern, sich hier zu positionieren. Durch das Ausbleiben älterer Künstler und durch die ständige Fluktuation im Lehrkörper konnten sich künstlerische Neuansätze ihren Weg bahnen. ${ }^{59}$

Die festen Grenzen, denen die Gattungen zu Beginn des Jahrhunderts noch streng unterworfen waren, begannen sich zunehmend aufzulösen. Im Kontext grundlegender Veränderungen wurden die alten Werte in Frage gestellt. Es waren die Künstler, die früh auf neue Problemstellungen reagierten. Nicht nur das zunehmende Aufbrechen der Gattungshierarchie ist hier zu nennen, auch im Kleinen, innerhalb einer Gattung, kann man Reflexionen und Neupositionierungen erkennen. So bietet gerade die besonders vielfältig in der Göttinger Universitätskunstsammlung vertretene Landschaftsmalerei Einblicke in grundlegende Veränderungen, aber auch in die vom späten 18. Jahrhundert bis in die Gegenwart reichende Persistenz von Natur als moralisch und ästhetisch aufgeladenem Sehnsuchtsraum.

5 Scheidig 1991, S. 12 f.

56 Ebd.

57 Deutlich wird dies am Projekt der Restaurierung der Wartburg. Hier malte Moritz von Schwind 1854/55 mehrere Wandgemälde, die Ausschnitte der Thüringischen Geschichte zeigen. Vgl. Scheidig 1991, S. 12 f.; ausführlich dazu Hoffmann 1980.

58 Scheidig 1991, S. 12; Ziegler 2001, S. 12 f.

59 Siehe Häder 1999, S. 153 f. und Wiechers 2007, S. 32 f. 

Kat. Nr. 18

Ignatius Josephus van Regemorter (1785-1873)

\section{Felsenschlucht}

1815

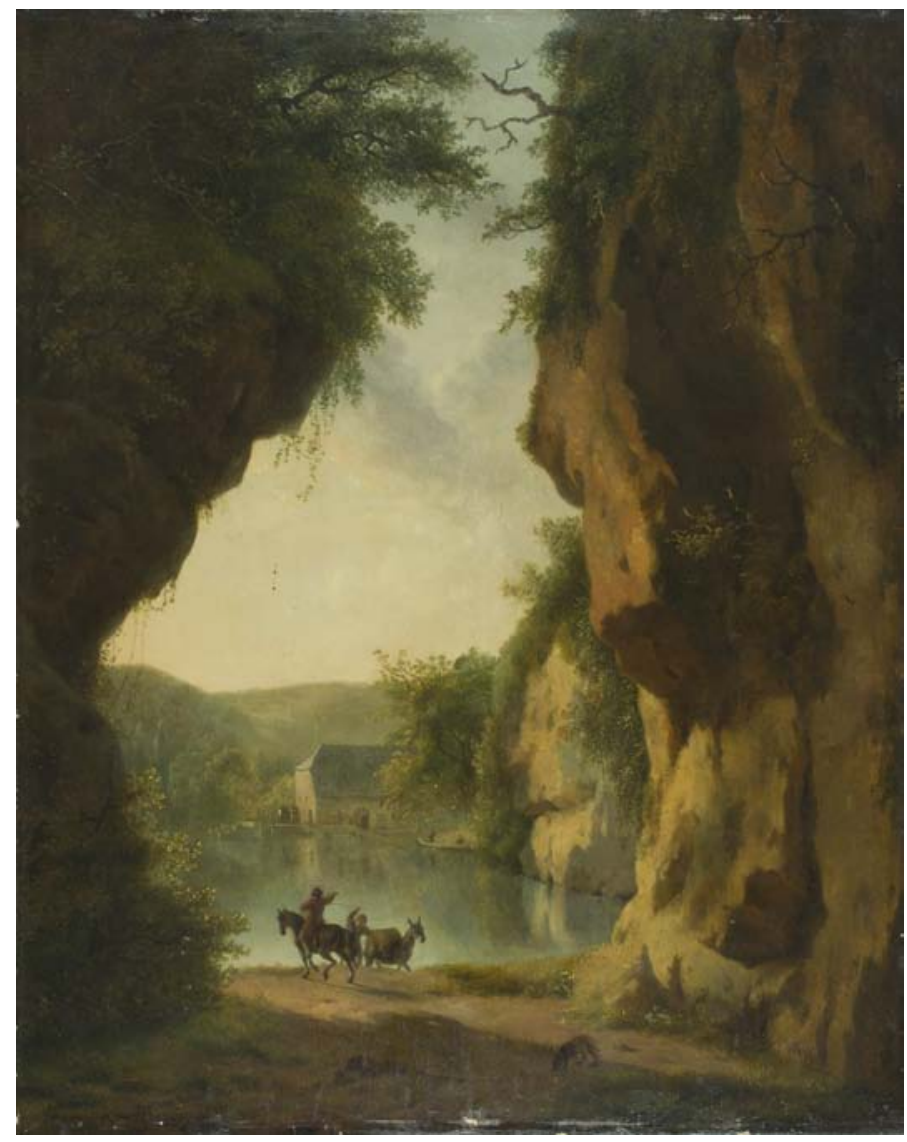

Öl auf Holz, 46,5 x $37 \mathrm{~cm}$, signiert und datiert unten links, 1966 aus der Sammlung Eugen Dumont mit Mitteln der Volkswagenstiftung angekauft, Inv. Nr. GG 068

Die Landschaftsmalerei des 19. Jahrhunderts umfasst eine große Vielfalt von Spielarten und Modi. In nicht wenigen Fällen wirkten dabei Darstellungstraditionen weiter, die in früheren Zeiten - etwa im 17. Jahrhundert - entwickelt worden wa- 
ren. Dies gilt beispielsweise für die sogenannte „historische Landschaft“ in der Nachfolge Claude Lorrains und Nicolas Poussins. ${ }^{1}$ Neben solchen - europaweit gepflegten - Darstellungsweisen gab es aber auch lokalspezifische Traditionen. Dies gilt namentlich für die Niederlande, in denen man immerhin auf ein sogenanntes „Goldenes Zeitalter“ mit einer ganz eigenen, reichen Kultur von Landschaftsmalerei zurückblicken konnte. ${ }^{2}$ Aus späterer Sicht erscheint das lange Nachwirken dieser Tradition hier vor allem als Fessel: Während sie für viele europäische Künstler des 19. Jahrhunderts eine wichtige Orientierung für die Überwindung künstlerischer Konventionen und die Entwicklung einer Malerei des „Realismus" bot (vgl. etwa Eduard von Gebhardt, Kat. Nr. 16), war sie in den Niederlanden selbst vermeintlich so konventionell geworden, dass sich viele Künstler erst einmal von ihr zu lösen suchten, um zu einer eigenen, „,zeitgemäßen“ Bildsprache zu finden. Ronald de Leeuw spricht in seinem Überblick über die niederländische Landschaftsmalerei des 18. und 19. Jahrhunderts dementsprechend vom „Schatten des 17. Jahrhunderts". 3

In diesem „Schatten“ scheint auch Ignatius Josephus van Regemorters Gemälde Felsenschlucht aus dem Jahr 1815 zu stehen. Der kompositorische Bezugspunkt dieses Bildes weist sogar in eine Phase vor dem eigentlichen „Goldenen Zeitalter" zurück: Wie bereits Gerd Unverfehrt feststellte, hat sich Regemorter offensichtlich am Gemälde Felsenschlucht des niederländischen Malers Joos de Momper (1564-1635) orientiert, das sich im Kunsthistorischen Museum in Wien befindet (Abb. 29). Dabei verband er diese kompositorische Erfindung mit weiteren Bildmitteln, welche eher für die niederländische Landschaftsmalerei des späteren 17. Jahrhunderts charakteristisch sind. ${ }^{4}$

\section{Der Künstler und sein Göttinger Bild}

Ignatius Josephus van Regemorter war Genre- und Landschaftsmaler, Kupferstecher und Lithograph. 51785 in Antwerpen geboren, studierte er bei seinem Vater, dem Interieur- und Genremaler Petrus Johannes van Regemorter (1755-1830), sowie bei Balthasar-Paul Ommegancks (1755-1826). 1809 bildete er sich in Paris weiter. 1829 wurde er Mitglied der Akademie in Amsterdam. Außerdem war er Mitbegründer des Antwerpener Verbond voor kunsten, letteren en wetenschappen.

Das Gemälde Felsenschlucht belegt Regemorters Bindung an die Tradition niederländischer Landschaftsmalerei. Die Komposition des hochformatigen Bildes wird von steilen Felshängen bestimmt, welche den Blick im Vordergrund zu beiden Seiten einrahmen. Sie reichen nicht nur über die obere Bildkante hinaus, son-

\footnotetext{
Vgl. Eschenburg 1998, S. 63-74.

Vgl. Ausst.-Kat. Amsterdam 2000.

Leeuw 1997, S. 12.

Unverfehrt 1987, S. 118. Zu dem Gemälde de Mompers vgl. Ertz 1986, S. 535, Kat. Nr. 237.

5 Vgl. hierzu und zu dem folgenden: Thieme/Becker 1907-1950, Bd. 28, 1934, S. 83.
} 
dern verengen sich auch nach oben, so dass sie annähernd die Form eines Hochovals bilden. In ihren oberen Partien weisen sie einen Bewuchs durch Büsche und Bäume auf, der auch an weiteren Stellen der felsigen Oberfläche auftaucht.

Der linke Felsen liegt gänzlich im Gegenlicht, nur das transparente Buschwerk an der Kante leuchtet grün auf. An der rechten Seite strahlt das von links oben kommende Abendlicht in die Felsschlucht hinein und taucht diese in warme Farben, die zwischen Rot- und Ockertönen changieren. Der Zusammenklang von Braun- und Grüntönen bestimmt auch den planen Erdboden des Vordergrunds zwischen den Felswänden, der sich - anders als bei de Momper - als begehbar erweist: Rechts erkennt man, eine diagonale Schattenkante überschneidend, einen Hund. An der Kante zum Mittelgrund sind ein Pferd mit Reiter sowie ein Lastesel mit Treiber zu sehen.

Diese Kante ist als Uferlinie eines Sees ausgebildet, welcher den Mittelgrund ausfüllt und an seiner rechten Seite von einer Fortsetzung der steilen, bewachsenen Felswand begrenzt wird. Unterhalb der Felswand ist in Ufernähe ein Boot mit zwei Insassen zu erkennen. Wirkungsvoll stellt Regemorter die warmen Farben der den Blick rahmenden Felsen im Vordergrund den kühleren, grünlich-blauen Farben der spiegelglatten Seeoberfläche im Mittelgrund und des sich darüber öffnenden Himmels gegenüber. Dabei bleibt dieser Kontrast subtil, denn gleichzeitig arbeitet der Künstler auch im Mittelgrund farblich mit „Restwärme“, die etwa der nach unten leicht errötete Himmel und der angestrahlte Felsen, aber auch der Giebel einer Wassermühle auf der gegenüberliegenden Uferseite des Sees ausstrahlen. Hinter dieser Mühle schlie-

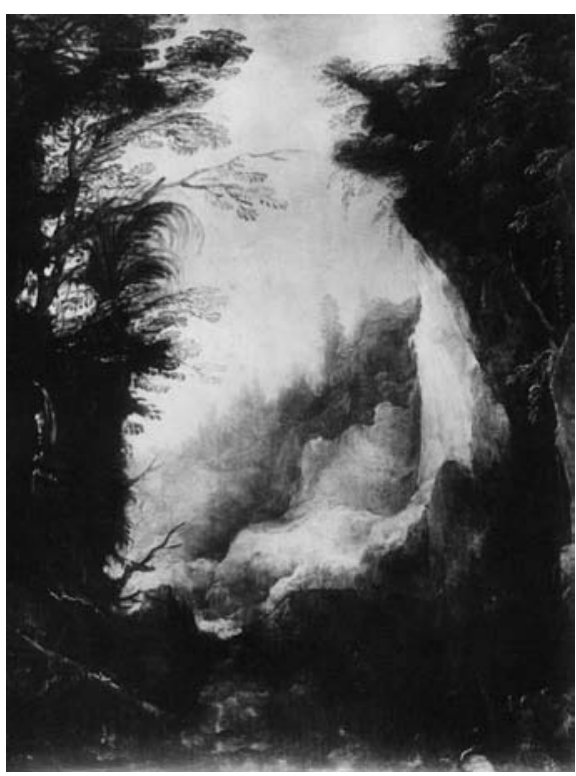

Abb. 29: Joos de Momper d. J.: Felsenschlucht, um 1630, 65,5 x 49,5 cm, Wien, Kunsthistorisches Museum Ben Hügel die Szenerie im Hintergrund $a b$.

Ganz in der Tradition der niederländischen Landschaftsmalerei kultiviert Regemorter in seinem Bild die atmosphärische Stimmung mit einer koloristisch fein und differenziert ausgeführten, gleichzeitig aber auch kräftigere Kontraste und Akzente (man beachte das aufleuchtende Rot an der rechten Felswand) nicht scheuenden Malweise. Direkte motivische Rückgriffe auf diese Tradition stellen die Mühle und die kleinen, als dunkle Kontraste eingesetzten Figuren dar, die bezeichnenderweise unmittelbar an die Uferkante gesetzt sind, so dass ihre Silhouetten 
betont werden. ${ }^{6}$ So steht das Bild unübersehbar in der Tradition der Niederländischen Malerei des 17. Jahrhunderts, ohne schematisch zu wirken.

\section{„Survival“ oder „Revival“?}

Angesichts solcher Qualitäten stellt sich die Frage, ob man diesem Bild gerecht wird, wenn man es lediglich als Beleg für ein langes, allmählich abklingendes Nachwirken des „Goldenen Zeitalters“ versteht. Handelt es sich lediglich um eine Art „Nachleben“, um ein „Survival“ der niederländischen Tradition, oder nicht doch vielmehr um ein künstlerisch durchaus eigenwertiges „Revival“?

Es gibt durchaus Indizien, die gegen ein mehr oder weniger passives Verharren Regemorters in einer auslaufenden Tradition sprechen und dessen Werk als eine reflektierte Auseinandersetzung mit der Kunst der Vergangenheit erscheinen lassen. So befindet sich im Rijksmuseum in Amsterdam ein bemerkenswertes Zeugnis für die Genrekunst dieses Malers: Das auf das Jahr 1828 datierte Gemälde zeigt Jan Steen, wie er seinen Sohn auf die Staße schickt, um Bilder für Bier und Wein zu handeln. ${ }^{7}$ Bildaufbau und Maltechnik reihen sich auch hier ganz in die Tradition der niederländischen Genremalerei des 17. Jahrhunderts ein, zu deren Hauptvertretern Jan Steen bekanntermaßen zählte. Das Thema aber entspricht dem 19. Jahrhundert mit seinem spezifischen, nicht selten nationalistisch aufgeladenen Interesse an Kunst und Künstlern. Regemorter hat ein Kunstwerk über die Kunst seines Landes in deren historischer „Blütezeit“ geschaffen, an die er zugleich als Maler selbst anzuknüpfen sucht. Sein Bezug zur Niederländischen Malerei des sogenannten „Goldenen Zeitalters“ erhält auf diese Weise einen geradezu historisierenden Charakter, den man auf der Ebene der Vergangenheitsaneignung durchaus mit dem Verhältnis der Nazarener zur Malerei Dürers und Raffaels vergleichen kann.

Betrachtet man Regemorters freien, auf so frühe Vorbilder wie Joos de Momper rekurrierenden Umgang mit Motiven und Kompositionsmiteln der älteren niederländischen Landschaftsmalerei, so gewinnt auch die Göttinger Felsenschlucht einen historisierenden Charakter. Dies wiederum stellt in der Gattung Landschaft durchaus eine Besonderheit dar. Dass es Regemorter gleichzeitig gelang, ein bei aller Reflexivität derart atmosphärisches und stimmiges Bild zu schaffen, belegt eindrucksvoll die künstlerische Qualität, welche in der Niederländischen Malerei des 19. Jahrhunderts auch dann möglich war, wenn man den „Schatten des 17. Jahrhunderts" bewusst suchte.

\section{Christian Scholl}

6 Vgl. etwa die ähnliche Silhouettenwirkung der Reisewagen und der Kühe auf Salomon van Ruisdaels Landschaft mit Reisewagen in der Göttinger Universitätskunstsammlung; vgl. Unverfehrt 1987, S. 126, Kat. Nr. 76.

7 Jan Steen stuurt zijn zoon de straat op om schilderijen te ruilen voor bier en wijn, Amsterdam, Rijksmuseum; vgl. Thiel/Bruyn Kops/Cleveringa/Kloek/Vels Heijn 1976, S. 465, Kat. Nr. A 1123. 
Kat. Nr. 19

Friedrich Philipp Reinhold (1779-1840)

\section{Der Hirte auf der Bergspitze bei Abendschein}

Vor 1816

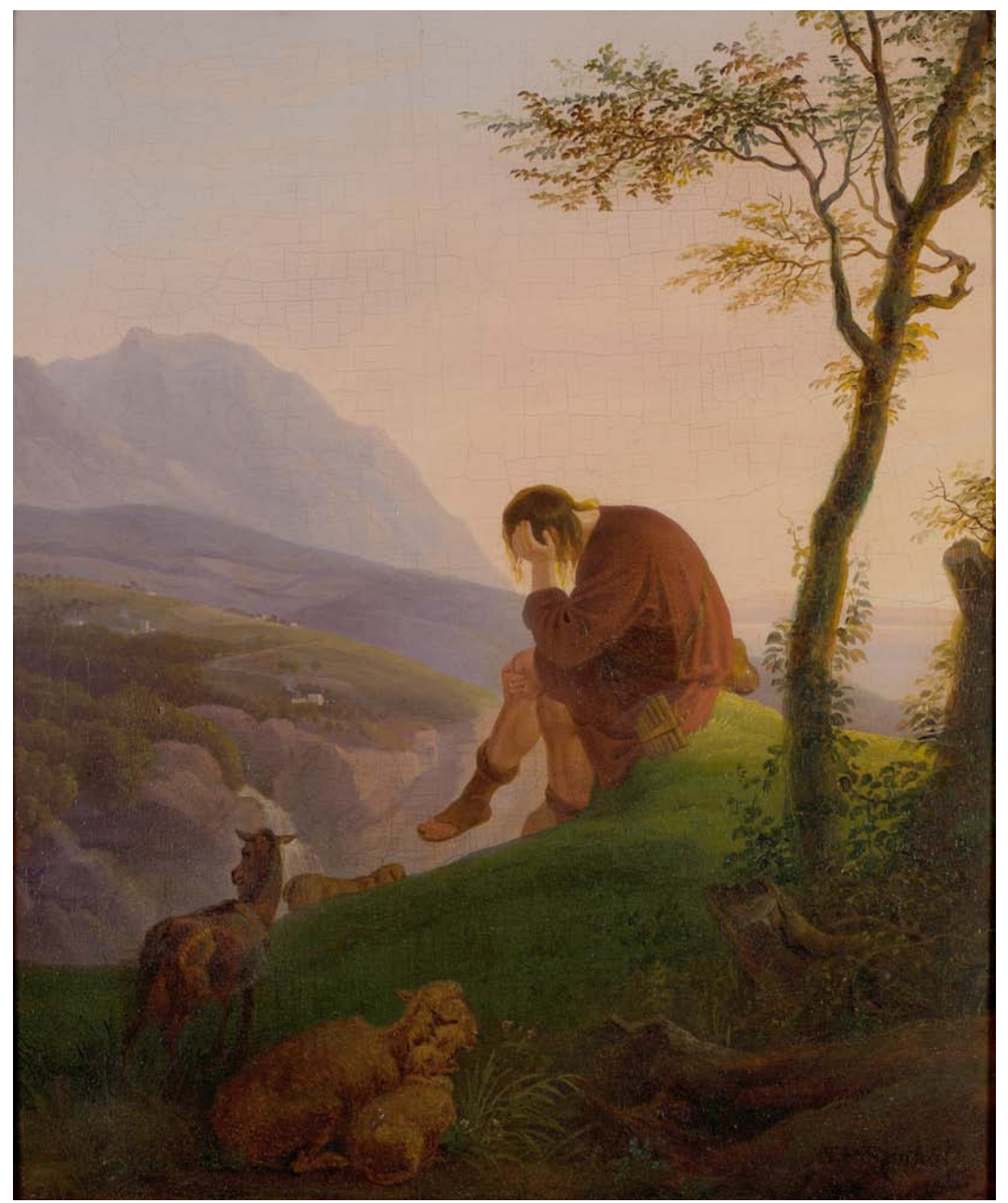

Öl auf Holz, 36,8 x 30,6 cm, signiert unten rechts, 1968 angekauft aus Göttinger Privatbesitz als Stiftung der Klosterkammer Hannover, Inv. Nr. GG 170 
Friedrich Philipp Reinhold wurde am 8. Januar 1779 als Sohn des Malers Johann Friedrich Leberecht Reinhold in Gera geboren. ${ }^{1}$ In der Zeit von 1797 bis 1804 besuchte er die Dresdner Akademie, wo er bei Johann Eleazar Zeissig gen. Schenau (1737-1806) in der Porträt- und Genremalerei ausgebildet wurde. Hier zählte er zu einem der Meisterschüler Schenaus. ${ }^{2}$ Zur selben Zeit wirkten auch Caspar David Friedrich und Philipp Otto Runge in Dresden, jedoch bleibt es eine Vermutung, ob Reinhold mit diesen heute bekanntesten Vertretern der deutschen Romantik in Verbindung stand. Zwischen 1805 und 1811 studierte Reinhold dann Historienmalerei an der kaiserlich-königlichen Akademie der Bildenden Künste in Wien. Hier entwickelte er freundschaftliche Beziehungen zum Kreis um Johann Friedrich Overbeck, dem Haupt des später gegründeten Lukasbundes, und freundete sich zusammen mit seinem Bruder Heinrich Reinhold mit Friedrich und Ferdinand Olivier an. ${ }^{3}$

Bevor Reinhold in Wien endgültig sesshaft wurde, arbeitete er zwischen 1811 und 1812 als Porträtist in Gera und Leipzig. Neben dem Anfertigen von Bildnissen zu Beginn seiner Malerkarriere verfolgte er die Historienmalerei, wandte sich jedoch ab 1815/16 entschieden der Landschaftsmalerei zu. Er unternahm mehrere Kunstreisen, darunter auch eine im August des Jahres 1818 zusammen mit seinem Bruder Heinrich sowie mit Ernst Welker, Johann Adam Klein und Johann Christoph Erhard nach Salzburg und Berchtesgaden. In den Jahren von 1816 bis 1839 fanden in Wien regelmäßig Ausstellungen der kaiserlich-königlichen Akademie der Bildenden Künste bei St. Anna statt, bei denen immer wieder Werke Reinholds zu sehen waren und auch verkauft wurden. ${ }^{4}$ Dies stellt einen der Gründe für die Schwierigkeiten dar, die sich heute bei der Beschäftigung mit Reinhold ergeben, denn seine Werke befinden sich oft in Privatbesitz oder sind gar verschollen. Am 22. April 1840 starb Friedrich Philipp Reinhold in Wien.

Auch das Gemälde in der Göttinger Kunstsammlung wurde nach seiner Präsentation auf der Wiener Akademieausstellung im Jahre 1816 zunächst an Caroline Pichler (1769-1843), eine österreichische Schriftstellerin, ${ }^{5}$ verkauft und gelangte erst rund 150 Jahre später aus Göttinger Privatbesitz in die Sammlung.

\section{Der Bildaufbau}

Der Vordergrund des Gemäldes Der Hirte auf einer Bergspitze bei Abendschein wird durch eine begrünte Anhöhe definiert, auf der eine männliche Person auf einem Stein sitzt. Diese Person schlägt die Beine übereinander und stützt den Kopf auf

1 Die folgenden Angaben bezüglich der Lebensdaten Reinholds stammen, wenn nicht anders vermerkt, aus: Oberhuber 1997, S. 201; Reinhold 1934, S. 130; Wurzbach, C. v. 1856-1923, Bd. 25, 1873, S. 218.

2 Wenzel 2008, s.v. Schenau.

3 Geismeier 1984, S. 210-213.

4 Vgl. Wurzbach, C. v. 1856-1923, Bd. 25, 1873, S. 218.

5 Kadrnoska 1983, S. 56 f. 
der linken Hand auf, wodurch eine in sich geschlossene Haltung im „Gestus Melancholicus"6 entsteht. Dass die Person den Blick ganz vom Betrachter abgewendet hat, um in ein hinter der Anhöhe befindliches Tal hinunter zu blicken, unterstreicht diese Wirkung. Die Kleidung - ein knielanges rotbraunes Gewand, an dessen Gürtel eine Panflöte und eine Trinkflasche gebunden sind, sowie Sandalen - muten antikisch an. Neben der Panflöte, die Attribut des griechischen Hirtengottes ist, ${ }^{7}$ weisen auch die vier Schafe auf der linken Bildhälfte die sitzende Person als Hirten aus. Diese Szenerie des Vordergrundes wird rechts von einem mit Efeu und Moos bewachsenen hohen Baum, dessen Äste den Hirten überfangen, gerahmt. In seiner Umgebung sind drei Baumstümpfe auszumachen, die von der noch lebendigen Natur langsam überdeckt werden und somit den Grund für neues Leben bilden.

Das Tal, das den Mittelgrund angeben würde, ist für den Betrachter nicht zu sehen. Stattdessen fällt der Blick links direkt auf eine dahinterliegende Gebirgslandschaft. Hier erhebt sich zunächst eine Steilwand mit Wasserfall, die vermuten lässt, dass sich in dem Tal ein See oder Fluss befinden muss. Auf ihrer begrünten Spitze sind Wege und Häuser auszumachen, aus deren Kaminen Rauch aufsteigt. Dahinter erhebt sich ein markant die Landschaft dominierender hoher Berg, bei dem es sich um den Traunstein bei Gmunden am Traunsee handeln könnte. Die Bildmotive entsprechen zwar einerseits der dortigen Topographie, sind aber nicht mit der südländischen Atmosphäre, die das Gemälde vorgibt, zu vereinen. Reinhold, der nie in Italien war und nur in der Umgebung von Wien arbeitete, schafft hiermit eine utopische Landschaft, die sich aus einer südländischen Küste und der Umgebung von Gmunden zusammensetzt.

Rechts im Bild erahnt man einen Sonnenunter oder -aufgang, der von dieser Stelle aus die Landschaft in ein diffuses Licht hüllt.

Eine gedachte Mittelsenkrechte bestimmt die Komposition des Bildes. Sie entsteht durch die Verlagerung der zentralen Figur, des Hirten, aus der Bildmitte in das rechte Bildfeld und wird vom Künstler genutzt, um einen spannungsvollen, auch inhaltlich motivierten Bildaufbau zu schaffen. Der Hirte wird nicht nur von seiner Herde, sondern auch von der Stadt im hinteren linken Bildfeld getrennt. Durch diese Verlagerung entsteht für den Betrachter links ein ungestörter Blick über die Anhöhe mit den Schafen hinweg hin zum begrünten Fels mit Wasserfall und Stadt herauf zur höchsten steinigen Erhebung des gesamten Bildes. Der unbegrünte Fels endet an der Mittelsenkrechten, was diese nochmals betont, und greift formal die Rückenkontur des Hirten auf. Zudem verdeckt er den Horizont, so dass die Landschaft als geschlossene Wand etwa zwei Drittel der Gesamthöhe des Bildes einnimmt.

Die rechte Bildhälfte dagegen wirkt durch die nach oben und nach rechts hin rahmenden Bäume, die als Senkrechten die Komposition stabilisieren, in sich ge-

6 Schuster 2005, S. 90-98.

7 Bernhard 1977, S. 230-240. 
schlossen. Allerdings bleibt hier die Sicht auf den Horizont, der auf halber Bildhöhe liegt, weitgehend frei. Der Blick des Betrachters fällt auf den sinnenden Hirten, dessen rechtes Bein in Kombination mit dem stützenden linken Arm ebenfalls durch Parallelität zur gedachten Mittelsenkrechten die formale Abgrenzung des Hirten zu Herde und Stadt verdeutlichen.

Der Betrachter wird nicht in das Bildgeschehen einbezogen, sondern erfährt als Außenstehender nur durch das Repoussoirmotiv von Hirt und Herde einen Bezug. Er scheint auf Augenhöhe mit dem Hirten zu sein, auf den sämtliche aufund absteigende Hügelprofile in Form von Schrägen weisen und ihn somit betonen. Dadurch, dass der Vordergrund dunkler gehalten ist als der Hintergrund, wird das Profil der vorderen Anhöhe betont und gibt die Leserichtung des Bildes an. Der Blick des Betrachters wandert also zunächst hinauf zum Hirten und folgt dann dessen Blick auf die gegenüberliegende Seite des Tales. Als hellster Punkt des Gemäldes erscheint wiederum der Sonnenuntergang, der dadurch ebenfalls den Blick des Betrachters anzieht.

Farblich arbeitet Reinhold stark mit Gegensätzen und stellt warme und kalte Farben sowie Komplementärfarben einander gegenüber, wie am Beispiel der roten Kleidung und des grünen Hügels oder an den warmen Farben des Sonnenuntergangs und den kühlen der Gebirgslandschaft zu sehen ist.

\section{Zwischen Klassizismus und Romantik}

Reinholds Gemälde steht nicht nur zeitlich, sondern auch thematisch in der Tradition der Landschaftsmalerei des 18. Jahrhunderts. Nach der Zeit der Aufklärung und der Französischen Revolution herrschte in Deutschland eine Zeit des Umbruchs, in der eine klassizistische Geistesbewegung entstand, welche die griechische Antike zu einem Ideal verklärte. ${ }^{8}$ Sogenannte arkadische oder ideale Landschaften mit mythologischer Staffage, die in der Tradition der klassischen Landschaftsmalerei Claude Lorrains und Nicolas Poussins standen, erfreuten sich groBer Beliebtheit. ${ }^{\text {? }}$

Im Gemälde Reinholds erblickt der Betrachter einen altertümlich gekleideten, sinnenden Hirten, der abseits des geselligen Lebens das Naturschauspiel eines Sonnenuntergangs erlebt. Der Hirte galt in der antiken Literatur als Bewohner idyllischer Landschaften und wurde auch in späterer Zeit zum Symbol für Natur und einfaches Leben. ${ }^{10}$ Zudem bettet Reinhold die Szenerie in eine südländisch anmutende Landschaft ein. Der Künstler verwendet also mehrere Motive der Antike und lässt mit seinem Bild sowohl das Ideal des Altertums als auch der Naturverbundenheit anklingen. Allerdings gibt es gleichzeitig einen augenfälligen Bruch mit den klassizistischen Bildkonventionen der arkadischen Landschaft: die Ver-

8 Börsch-Supan 1988, S. 301.

9 Vanhoeven 2000, S. 34 f.; Bernhard 1977, S. 130 f.

10 Bernhard 1977, S. 230-259. 
sperrung des Blickes in die Weite und der fehlende Mittelgrund. Zudem thematisiert Reinhold nicht die Tätigkeit eines antiken Hirten, sondern dessen Empfindsamkeit. Dadurch, dass der Betrachter den Hirten nur von hinten sieht, wird dieser $z u$ einer Identifikationsfigur. In ihr wird möglicherweise die Vergänglichkeit des eigenen Seins deutlich, wodurch die nachdenkliche Haltung des Hirten nachvollziehbar würde. Bildmotive wie die von neuem Leben überdeckten Baumstümpfe oder der Sonnenuntergang könnten auf das zyklische Sterben und Auferstehen der Natur verweisen. Der Wasserfall als Symbol für den ewigen Kreislauf und das immergrüne Efeu als Zeichen für ewiges Leben könnten diesen Verweis unterstreichen. ${ }^{11}$

Somit wendet Reinhold zwar Themen an, die aus dem Bereich der arkadischen Landschaften stammen. Gleichzeitig rückt er aber die Reflexion des Hirten in den Vordergrund und nähert sich damit an Darstellungen deutscher Romantiker am Anfang des 19. Jahrhunderts an. Der Sonnenuntergang und der Melancholiegestus bilden zwei von den Romantikern gern genutzte Motive. ${ }^{12}$

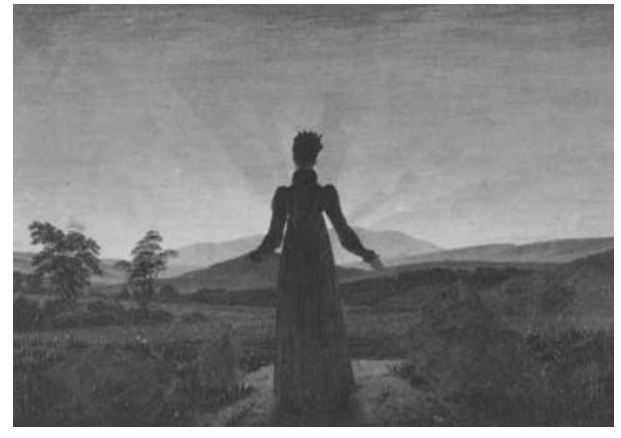

Abb. 30: Caspar David Friedrich: Frau vor auf- oder untergehender Sonne, um 1818, Öl auf Leinwand, 22 x 30 cm, Essen, Museum Folkwang

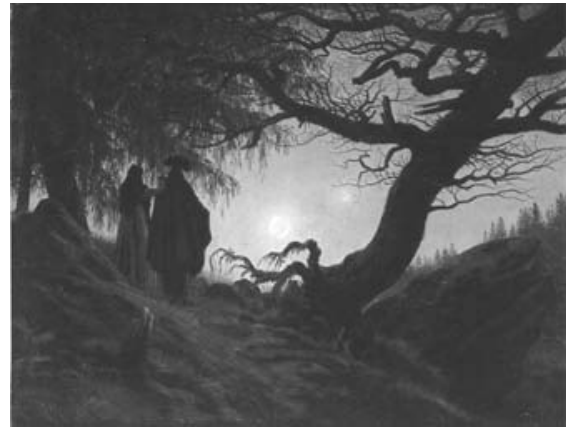

Abb. 31: Caspar David Friedrich: Mann und Frau den Mond betrachtend, um 1824, Öl auf Leinwand, 34 x 44 cm, Berlin, Nationalgalerie

Rückenfiguren, die dem Betrachter gleichsam einen Zugang ins Bild über eine imaginäre Identifikation vermitteln, sowie der verdeckte Mittelgrund sind typisch für die Bilderfindungen Caspar David Friedrichs. ${ }^{13}$ Ein besonders prominentes Beispiel ist der Wanderer über dem Nebelmeer. ${ }^{14}$ Wie bei seinen Gemälden Mann und Frau den Mond betrachtend (Abb. 31) oder Frau vor auf- oder untergehender Sonne (Abb. 30) versuchte Friedrich oftmals, seine persönliche ehrfurchtsvolle Sicht auf die als

11 Dierkesmann 2006, S. 113; 425.

12 Schuster 2005, S. 90-98; Scholl 2007, S. 135 f.

13 Börsch-Supan 1960, S. 7; Scholl 2007, S. 168 f.

14 Hamburg, Kunsthalle. 
Offenbarung Gottes verstandene Natur mithilfe des ergriffen-bewundernden Menschen zu veranschaulichen.

Anders jedoch als bei den meisten Bildern von Friedrich, die in vielen Fällen die Sehnsucht von Stadtmenschen beim Anblick der Natur thematisieren, ${ }^{15}$ ist die zentrale Figur bei Reinhold ein nachdenklicher Hirte. Dieser scheint mit der Natur durch die Adaption der Gipfelformation verwachsen zu sein und trägt Verantwortung für seine Herde. Bei Reinhold scheint eine andere Bildidee zugrunde zu liegen. Eine Hilfestellung bietet ein Gedicht, das die Käuferin des Bildes, Caroline Pichler, auf das Gemälde verfasst hat.

„Der Hirt auf der Bergspitze im Abendschein.

Nach einem Gemählde von Philipp Reinhold aus Sachsen, in der Kunstausstellung der k. k. Akademie.

Die Sonne sinkt,

Das Strombett blinkt,

Dort lieget die Stadt, dort woget das Leben.

$\mathrm{Zu}$ meiner Höh,

Zu der Alpen Schnee

Wird nimmer von dorther ein Bild sich heben!

Du sonniges Thal

Im Abendstrahl!

Einst sah ich so ruhig, so still zu dir nieder;

Da schwellte noch Muth

Mein jugendlich Blut,

Da tönten noch fröhlich des Hirten Lieder!

Jetzt sitz' ich allein

Auf schroffem Gestein,

Es schweifet mein trüber Blick auf die Flächen.

Vergangene Zeit

Vor dem Geist sich erneut,

Und es will vor Wehmut das Herz mir brechen.

Ach dort, ach dort,

An den glänzenden Ort,

Wo Mauern und Thürme sich stolz hin dehnen,

Dort zog sie hin,

Mit flatterndem Sinn,

Nicht achtend mein Flehn, nicht achtend mein Sehnen!

Ich wein' ihr nach,

Mein Schmerz ist wach,

Wenn das Frühroth steigt, wenn die Schatten thauen.

O ende die Noth

Barmherziger Gott,

Und nimm mich zu dir in die himmlischen Auen!

15 Allerdings gibt es von Friedrich auch Hirtendarstellungen - etwa die Landschaft mit dem Regenbogen, ehemals Weimar, Kunstsammlungen (vgl. Börsch-Supan/Jähnig 1973, S. 307 f., Kat. 182). 
Das Lied verklingt,

Die Dämmrung sinkt,

Zur Heerde steiget der Hirt hernieder,

Und stumm und blaß

Durch thauiges Gras

Führt er zur einsamen Hütte sie wieder." ${ }^{16}$

Das Gedicht von Caroline Pichler wurde 1816 auf der Wiener Akademieausstellung zusammen mit Reinholds Gemälde ausgestellt. ${ }^{17}$ Auch wenn nicht bekannt ist, ob Pichler es in Absprache mit Reinhold schuf, stellt es doch eine zeitgenössische Interpretation des Gemäldes aus dem direkten Umfeld des Künstlers dar. Man darf annehmen, dass der Künstler von der gemeinsamen Ausstellung von Text und Bild gewusst hat.

Als lyrisches Ich tritt der Hirt auf, der in sentimentalischer Perspektive auf eine Zeit zurückblickt, in der er ein fröhliches Leben führte. Die Gegenwart erscheint demgegenüber von Trauer und Wehmut erfüllt, und zwar, wie im weiteren Verlauf des Gedichts deutlich wird, aufgrund einer zerbrochenen Liebe. Demnach hat die Frau den Hirten verlassen. Allein zurück geblieben, bittet dieser Gott, ihn zu sich in die „himmlischen Auen“ zu holen. Diese Konstellation ist gerade im Vergleich zu Caspar David Friedrichs Rückenfiguren bemerkenswert, denn hier sehnt sich nicht der Städter nach der Natur. Vielmehr wird der mit der Natur eigentlich im Einklang lebende Hirt sentimentalisch, weil seine Geliebte in die Stadt gezogen ist. So steht Reinholds Bild tatsächlich sowohl motivisch als auch kompositorisch zwischen Klassizismus und Romantik. In der Göttinger Universitätskunstsammlung repräsentiert es eine Kunstauffassung, bei der Landschaft durch Komposition und Staffage zum Träger bestimmter Konzepte aufgewertet wird.

Christina Eifler

16 Pichler 1822, S. 299 f.

17 Wille 1972, S. 41. 

Kat. Nr. 20

Louis Gurlitt (1812-1897)

\section{Maler in steinigen Sanddünen}

1833

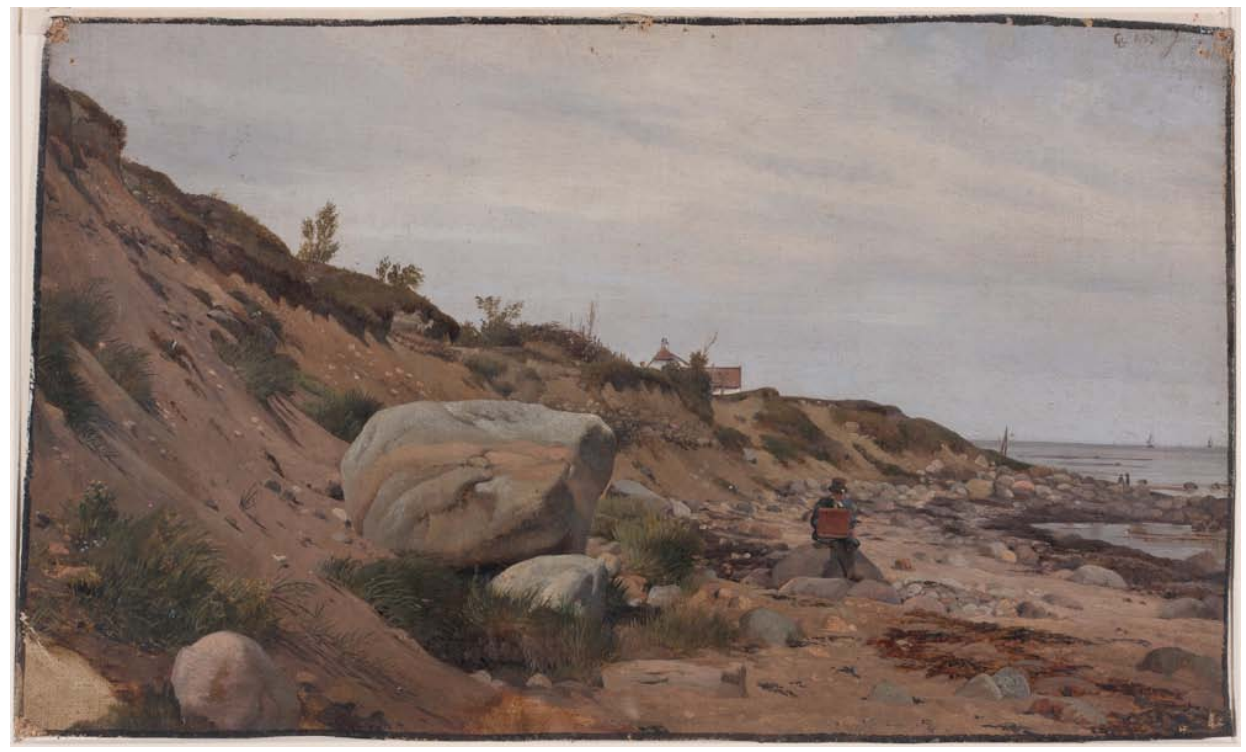

Öl auf Leinwand, 30 x 22 cm, monogrammiert oben rechts, 1977 mit Mitteln der Volkswagenstiftung im Kunsthandel erworben, Inv. Nr. GG 141

Unter den drei Göttinger Ölstudien des Altonaer Landschaftsmalers Louis Gurlitt sticht die Darstellung Maler in steinigen Sanddünen besonders hervor. In detailreicher Malweise gibt Gurlitt eine von Felsen übersäte Küste in einem schmalen Querformat wieder. Von links verläuft eine steile Düne abwärts und breitet sich als flacher Strand dem Meer entgegen aus. Vor dem hellen, blauen Himmel zeichnet sich die Silhouette dieser Formation kontrastreich ab, so dass die fallende Diagonale besonders akzentuiert wird. Diese trennt nicht nur den von feingliedrigen Details durchsetzten Strand vom zurückgenommenen Himmel, sondern betont zudem die Tiefenwirkung der Studie. So lenkt sie den Blick von links, dem höchsten Punkt der Düne, hinab nach rechts, wo der Strand in das Meer übergeht. Der Bildausschnitt konzentriert sich vor allem auf die Strandpartie, daher wird nur ein kleiner 
Ausblick auf das Meer gewährt. ${ }^{1}$ Unter den vielen kleineren Steinen, die auf der Küste verstreut liegen, dominiert ein riesiger Felsen, welcher, von der senkrechten Bildmittelachse nach links gerückt, am Fuße des sandigen Hanges nahe des Vordergrundes liegt. Seine wahre Größe offenbart sich dem Betrachter erst, wenn er ihn mit der kleinen Person rechts daneben vergleicht, welche dem Bildtitel zufolge einen Maler zeigt. Durch ihn werden die Größenverhältnisse des gesamten Bildes definiert: Der Hang wirkt im Vergleich viel höher als zuerst angenommen, und das Haus, das hinter ihm hervorschaut, viel weiter entfernt. Entdeckt man die zwei winzigen, im Hintergrund spazierenden Menschen im äußersten rechten Bildviertel, so tritt im Vergleich zum Maler auch die tiefenräumliche Erstreckung deutlicher zutage.

Die erwähnte feine Malweise gibt Gurlitt tendenziell auf, je weiter sich die Landschaft in der Ferne verliert. Auf die dem Betrachter entgegenstrebende Düne am linken Bildrand setzt er noch einzelne scharf gezeichnete Grashalme, welche ebenso klare Schatten werfen, während er die Steine in der rechten Bildhälfte bereits summarischer modelliert. Sie büßen zwar nichts an Plastizität ein, doch fällt auf, dass Gurlitt mit zunehmender Entfernung zum Betrachter eine flächigere Technik anwendet. Einen optischen oder atmosphärischen Effekt wollte er damit aber wahrscheinlich nicht erzielen, denn die im Hintergrund auf der Horizontlinie erkennbaren Schiffe sind als am weitesten entfernte Gegenstände wieder mit scharfen Konturen dargestellt.

Das Bild lässt aufgrund dieser Schärfe eine ruhige Arbeitsweise vermuten, bei welcher der Maler darauf bedacht war, jedes Detail der Natur festzuhalten und so genau wie möglich auf seine Leinwand zu übertragen. Da ein Künstler bei einer Ölskizze eher versucht, mit schnellen Pinselstrichen seine Idee, einen Eindruck oder Ausschnitt festzuhalten, ${ }^{2}$ trifft auf die detaillierte Malweise des Bildes Maler in steinigen Sanddünen eher die Bezeichnung Ölstudie zu. Offen bleibt dabei allerdings die Frage, wie viel der Künstler tatsächlich unter freiem Himmel ausgearbeitet hat und was er erst im Nachhinein hinzufügte - vielleicht etwa die kleineren Details, wie die Boote im Hintergrund oder das spazierende Paar, die die räumliche Entfernung veranschaulichen.

\section{Zu den Entstehungsumständen der Ölstudie}

Die Datierung in der oberen linken Ecke weist das Bild in das Jahr 1833. Nach Gurlitts Biographie, welche sein Sohn Ludwig 1912 aus Aufzeichnungen, Briefen sowie Erzählungen zusammenstellte, ist der Künstler in diesem Jahr von seiner

1 Bei Gurlitts anderer Studie aus demselben Jahr (Kat. Nr. 21) ist diese Verteilung genau andersherum. Dort liegt der Hauptanteil bei dem Meer, währen der Strand kaum ausgearbeitet ist.

2 Ausführlich zur Ölskizze siehe Busch 1983 und Busch 1997b. 
ersten, erfolglosen Norwegenreise nach Kopenhagen zurückgekehrt. ${ }^{3}$ Hier begann er gerade erst sein künstlerisches Studium an der Königlich Dänischen Akademie. ${ }^{4}$ Einer der wichtigsten Professoren in Kopenhagen war Christoffer Wilhelm Eckersberg (1783-1853), in dessen Unterricht die kleinformatigen Ölstudien bei den Kopenhagener Studenten Einzug fanden. ${ }^{5}$ Eckersberg hatte unter anderem in Paris in der Werkstatt Jacques-Louis Davids gelernt und vertrat eine Kunst, deren Wert ,weitgehend in der getreuen Wiedergabe der Natur liege“.6 Daher rief er seine Schüler zum selbstständigen Studieren der Natur auf. Gerade weil eine solche Vorgehensweise nicht im akademischen Lehrplan inbegriffen war, erwies sich diese Praxis vor allem für die angehenden Landschaftsmaler als besonders lehrreich. Dem Rat des Professors folgend begab sich Gurlitt also in den Semesterferien im Mai 1833 auf seine zweite Studienreise, die ihn unter anderem in die Gegend von Hellebæk und Helsingør im Norden Seelands führte. ${ }^{7}$ Ludwig Gurlitt beschreibt eine Zeichnung aus jener Zeit, die auch Louis’ Reisegefährten abbildet:

„Wir haben darunter ein Blatt, eine Bleistiftzeichnung aus dem Juli, von Hellebek mit dem Blick auf das Schloß von Helsingör, auf dem sich seine beiden Begleiter gezeichnet finden. Unter dem Malschirm sitzend Carl und weiter vorne im Grase faulenzend offenbar der Schauspieler Schneider." 8

Mit ihm reisten demnach sein Studienfreund Adolf Carl $^{9}$, ein aus Kassel stammender Maler, der zusammen mit Gurlitt bei Siegfried Bendixen (1786-1864) in der Lehre gewesen war, sowie ein Schauspieler namens J. L. Schneider, welcher sich

3 Lichtwark 1924, S. 224 f. Der Misserfolg rührte nach Lichtwarks Aussage daher, dass Gurlitt überall nach Jacob van Ruisdaels Motiven gesucht habe. Er „fand sie aber nirgends und malte schließlich aus halber Verzweiflung heraus was er vor sich sah“. Bei Schulte-Wülwer 1997, S. 28 findet sich der Zusatz, dass dies lediglich „Bäume und Felsen“ gewesen seien.

4 Die Akademie wurde 1754 nach Pariser Vorbild gegründet und entwickelte sich zur bedeutendsten Ausbildungsstätte für skandinavische Künstler. Im nur schwach bewohnten Norwegen gab es bis 1818 keine Anlaufstelle für Künstler, zudem stand das Land bis 1814 unter dänischer Herrschaft. Daher kamen norwegische Künstler vor allem nach Kopenhagen, aber auch nach Deutschland wie beispielsweise Johann Christian Dahl, der in Kopenhagen und Dresden studierte. Schweden etablierte in Stockholm ab 1773 eine Akademie ähnlich der Kopenhagener. Aufgrund der Abgelegenheit der Stadt entwickelte sie aber keine internationale Bedeutung. Siehe Klose/Martius 1975, S. $19-25$.

5 Monrad 2000, S. 3.

6 Ebd., S. 4. Dabei ist zu erwähnen, dass Eckersberg zugleich ein ideales Bestreben beim Darstellen der Natur verfolgte. So malte er ein Schiff nicht so, ,wie er es in Wirklichkeit gesehen hatte, sondern so, wie er es gesehen hätte, wenn er es unter optimalen Bedingungen hätte betrachten können“. Der Unterschied zwischen exakter Wiedergabe der Natur und der Idealisierung derselben spiegelt sich daher im Vergleich zwischen Ölstudie und vollendeten Werk wider; vgl. SchulteWülwer 1997, S. 49 f. Abb. 39 und Abb. 40.

7 Die Studienreise und einige Arbeiten davon werden vor allem bei Gurlitt, Ludwig 1912, S. 56-61 beschrieben.

8 Gurlitt, Ludwig 1912, S. 59 f.

9 Biographische Angaben über Carl siehe Ausst.-Kat. Hamburg 1996, S. 107. 
den Künstlern spontan angeschlossen hatte. ${ }^{10}$ Neben der Landschaft von Hellebæk hat Gurlitt in der von seinem Sohn beschriebenen Zeichnung den Maler Carl, der sich im selben Moment wohl ebenfalls damit beschäftigte, die Umgebung zeichnerisch oder malerisch festzuhalten, in seine Skizze mit aufgenommen. Es liegt daher der Schluss nahe, dass auch Gurlitts Maler in steinigen Sanddünen den Studienfreund Adolf Carl zeigt. Diesmal wäre er zwar nicht unter dem Malschirm, doch erneut beim Anfertigen einer Studie zu sehen.

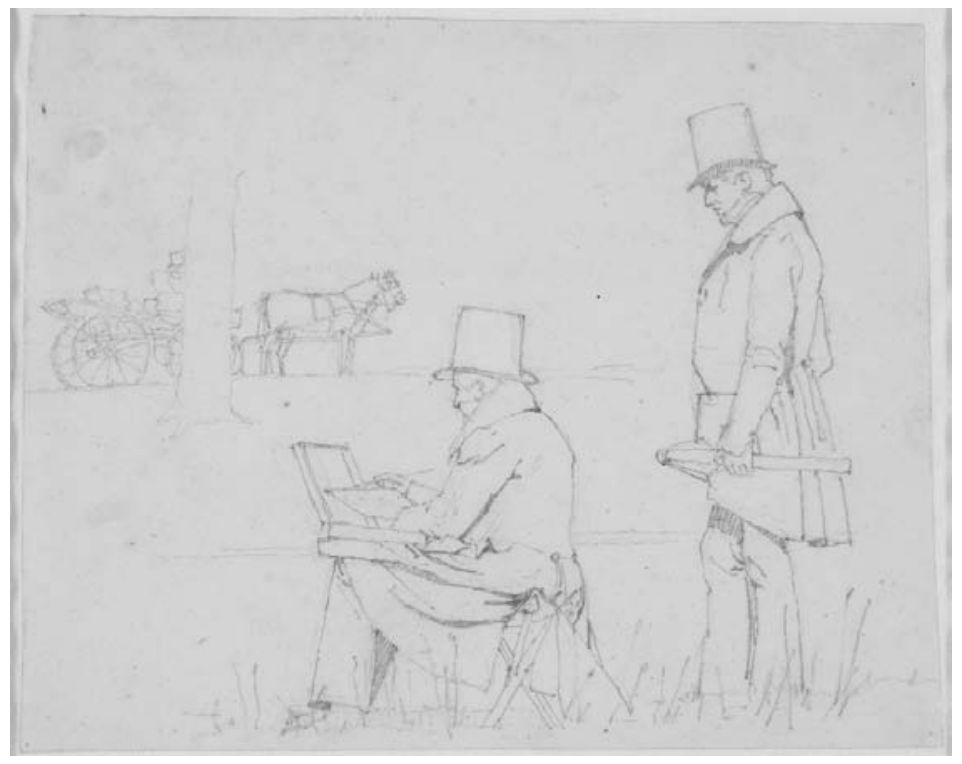

Abb. 32: Christen Købke: Eckersberg og Marstrand på studieudflugt, 1832, The Royal Collection of Graphic Art, Kopenhagen

Seine Darstellung in Öl bietet dem Betrachter zudem einen Einblick in das Erstellen von Ölstudien zu jener Zeit. Denn auf seinem Schoß hält er einen kofferartigen Gegenstand, hinter dessen aufgeklapptem Deckel ein dünnes, längliches Utensil hervorragt. Hierbei handelt es sich zweifellos um Malkasten und Malstock. Die früheste Beschreibung eines solchen Malkastens und seiner Benutzung sowie die Ursprünge der Ölstudien lassen sich bereits im 17. Jahrhundert finden. ${ }^{11}$ Der aufgeklappte Deckel ersetzt dabei die Staffelei, indem er ein Stück Leinwand oder einen anderen Malgrund im Inneren aufnimmt. Darunter liegen verschieden große

10 Gurlitt, Ludwig 1912, S. 59.

11 Die Beschreibung des Malkastens ist in einem Notizbuch von Richard Symonds enthalten, einem englischen Reisenden, welcher zwischen 1650 und 1652 in Rom im Atelier von Giovanni Angelo Canini studierte. Ihr kann man auch die genaue Unterteilung im Inneren des Kastens und die jeweiligen Funktionen entnehmen: vgl. Conisbee 1979, S. 414 f. Für den Hinweis auf diesen ergiebigen Aufsatz danke ich herzlich Prof. Dr. Thomas Noll. 
Fächer, so zum Beispiel ein schmales, längliches, in dem Bleistifte und wohl auch Pinsel Platz fanden, sowie mehrere kleine rechteckige für Pigmente und Öl. Mit der passenden rechteckigen Palette konnten diese Partitionen zugleich auf praktische Weise abgedeckt werden. ${ }^{12}$ Dass ein solcher Malkasten auch von den Kopenhagener Professoren benutzt wurde, belegt eine Zeichnung von Gurlitts Studienkollegen Christen Købke (Abb. 32). Dieser skizzierte Eckersberg auf einem Studienausflug, wie er, auf einem Klapphocker sitzend, in seinem Malkoffer hantiert.

Ludwig Gurlitt erwähnt auch andere Bleistiftzeichnungen von dieser Reise, die mit der Göttinger Studie in Beziehung stehen könnten, da der Künstler hier den mit Felsblöcken besäten Meeresstrand betone. ${ }^{13}$ Relevanter für die Provenienz der Studie ist aber seine Aussage über ,eine Reihe kleiner farbiger Studien, die mit unendlicher Sorgfalt staunenswerte Sicherheit des Blickes und gleiche Sicherheit der Hand verbinden. "14 Unter eben diesen Studien könnte sich auch der Maler in steinigen Sanddünen befunden haben, denn die rückseitige Bezeichnung nennt Ludwig Gurlitt. Das Bild hat sich vermutlich noch in dessen Besitz befunden, als er die Biographie verfasste. Anders als bei den anderen Göttinger Studien, befindet sich auf dieser Studie - wahrscheinlich aus Platzgründen - kein Nachlassstempel.15 Denkbar wäre, dass die Studie bis zu Louis Gurlitts Tod in dessen Besitz war und dann in Familienbesitz überging, oder dass er die Studie seinem Sohn noch zu Lebzeiten vermachte. Da solche kleinformatigen Studien nicht nur dem Ausbau der Fähigkeiten, sondern auch der Übertragung in großformatige Gemälde dienten, blieben sie meist im Besitz der Künstler, die aus ihnen über Jahre hinweg ihre Motive schöpften. So konnte Gurlitt zwei Jahre nach seiner letzten Norwegenreise das Münchener Publikum noch mit norwegischen Landschaften versorgen, welche dort zu jener Zeit sehr gut aufgenommen wurden. ${ }^{16}$

\section{Entscheidung für Kopenhagen}

Bevor Gurlitt 1832 seine Heimat Altona in Richtung Kopenhagen verließ, hatte er seit Mitte der 1820er bei verschiedenen Künstlern - darunter auch dem Dänen Jes Bundsen - Zeichenunterricht erhalten. Ab 1828 absolvierte er eine vierjährige Lehre zum Dekorationsmaler bei Siegfried Bendixen in Hamburg. Während der Hamburger Lehrjahre kopierte er vor allem niederländische Gemälde aus einer Sammlung, welche der Meister Bendixen verwaltete. ${ }^{17}$ Dort kam er zudem in Kontakt mit Christian Morgenstern, einem ehemaligen Bendixen-Schüler. Dieser hatte im Anschluss an seine Hamburger Ausbildung Norwegen bereist und mehrere

12 Conisbee 1979, Abb. 25.

13 Gurlitt, Ludwig 1912, S. 60.

14 Ebd.

15 Vgl. Kat. Nr. 21, Stempel mit der Aufschrift „Nachlass Louis Gurlitt“ in der unteren linken Ecke; Kat. 20, Nachlassstempel in der unteren rechten Ecke.

16 Schulte-Wülwer 1997, S. 46 f.

17 Wiese 1997, S. 16; Gurlitt, Louis 1940, S. 20. 
Jahre an der Kopenhagener Akademie studiert. ${ }^{18}$ Nach seiner Rückkehr kam er den Meister besuchen und wurde den neuen Schülern zum Vorbild. Beeindruckt vom Werdegang des Vorgängers, der zu jener Zeit schon als „einer der ersten deutschen Landschaftsmaler" 19 galt, zog es nun auch die jüngeren Künstler in den Norden. So reiste Gurlitt fünf Jahre nach Morgenstern nach Kopenhagen, um sich genau wie dieser nur kurz einzuschreiben, ein Zimmer zu mieten und sogleich weiter nach Norwegen aufzubrechen. Neben den Bildern Morgensterns zählten auch die Landschaften des norwegischen Malers Johan Christian Dahl (1788-1857) zu den Werken, die Gurlitt besonders begeisterten. ${ }^{20}$ Dahl hatte ebenfalls in Kopenhagen studiert, ging aber später nach Dresden, wo er sich eng mit Caspar David Friedrich befreundete und 1824 Professor an der Akademie wurde. Seine spektakulären Landschaftsgemälde wurden 1826 auf der ersten Ausstellung des Hamburger Kunstvereins ausgestellt, wo Gurlitt sie sicherlich gesehen hat. ${ }^{21}$

Neben der romantischen Anziehungskraft der unberührten Landschaft, welche die jungen Künstler in den Norden lockte, war es die schlechte Auftragslage in Hamburg und Altona, welche ein Fortgehen begünstigte. Dieser Umstand war zudem durch das Fehlen einer Akademie sowie eines Kunstmuseums erschwert und folglich ein weiteres Argument für den Schritt nach Kopenhagen. ${ }^{22}$ Unter anderem durch das Fehlen einer Akademie sowie eines Kunstmuseums bedingt scheinen diese Umstände ein weiteres treibendes Argument für den Schritt nach Kopenhagen zu sein. Hinzu tritt, dass Schleswig und Holstein seit 1773 und noch bis zum Deutsch-Dänischen-Krieg 1864 zum Herrschaftsgebiet des dänischen Königshauses gehörten. Somit war Kopenhagen auch die Hauptstadt beider Herzogtümer und es bestand ein politisch begründetes Zusammengehörigkeitsgefühl. ${ }^{23}$ Aus diesem Grund war ein Studium an der Kopenhagener Akademie die naheliegendste Entscheidung angehender Schleswig-Holsteiner Künstler.

Lisa Weiß

18 Gurlitt, Ludwig 1912, S. 48 f.

19 Ebd., S. 48.

20 Auch für Morgensterns Reise waren Dahls Bilder ausschlaggebend gewesen. Als einer der ersten bereiste er dessen Heimat Norwegen. Zu weiterführenden Informationen über Morgenstern vgl. Mauß 1969.

21 Die Ausstellung kam durch Bendixens Anregung zustande, wurde aber ein Misserfolg. Erst die Folgeausstellung im Jahr 1827 konnte das Publikum begeistern. Siehe Wiese 1997, S. 12.

22 Ebd., S. 11 f.

23 Monrad 2000, S. 4. 
Kat. Nr. 21

Louis Gurlitt (1812-1897)

\section{Uferlandschaft}

1833

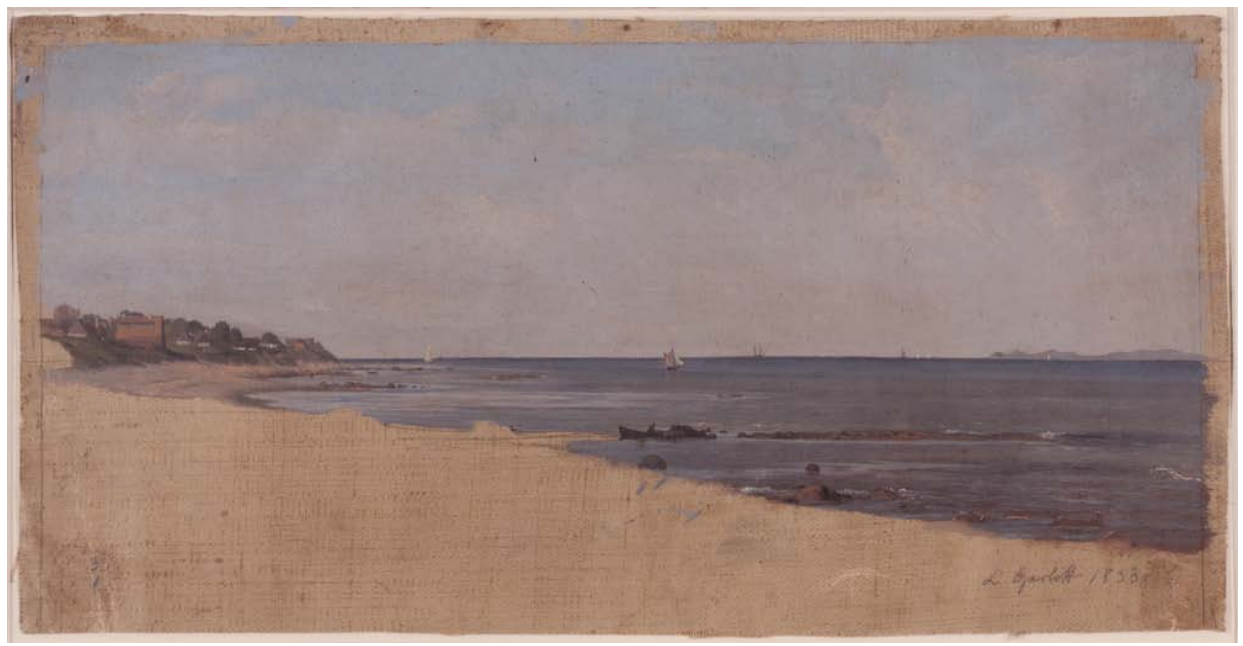

Öl auf Leinwand, 34 x 17 cm, signiert unten rechts, 1977 mit Mitteln der Volkswagenstiftung im Kunsthandel erworben, Inv. Nr. GG 138

Louis Gurlitts zweite Ölstudie aus dem Jahre 1833 entstand wie Maler in steinigen Sanddünen auf der Studienreise, die den Künstler in die Gegend um Helsingør und Hellebæk sowie an die schwedische Felsenküste von Kullen führte. Bei der Akademieausstellung auf Schloss Charlottenborg am 1. April 1834 stellte Gurlitt unter anderem Bilder mit den Titeln Ansicht von Kullen und Strandansicht zwischen Helsingor und Hellebak aus. ${ }^{1}$ Ein drittes Bild Gurlitts auf der Ausstellung zeigte einen Strand bei den Hammermollen, einem Ort, der ebenfalls bei Hellebæk liegt. So scheinen die auf jener Reise gesammelten Motive bereits kurz darauf zur Anwendung gekommen zu sein.

1 Reitzel 1883, S. 205; ersteres Bild wurde wahrscheinlich von Dahls großformatigem Gemälde Schiffbruch an der Küste Norwegens angeregt, welches 1833 in Kopenhagen ausgestellt wurde: vgl. Schulte-Wülwer 1997, S. 30, sowie ebd. Abb. 26, S. 32. 
Während die Ansicht von Kullen vom Kopenhagener Kunstverein erworben und verlost wurde, kaufte Kronprinz Christian, der spätere König Christian VIII. von Dänemark, die Strandansicht zwischen Helsingor und Hellebak. ${ }^{2}$ Das Gemälde wurde 1882 aus königlichem Besitz versteigert und ist seither unauffindbar. ${ }^{3}$ Dem Titel nach scheint es sich um ein Motiv zu handeln, welches dem der Göttinger Studie entsprechen könnte. Es wäre also möglich, dass Gurlitt diese Studie in dem ausgeführten Werk verarbeitet hat.

Die Studie zeigt in einem schmalen Querformat einen Ausblick auf das Meer, deren Küstenlinie jedoch nicht vollständig ausgearbeitet wurde. Nahe am Horizont lässt sich ein ansteigendes Gelände, wohl eine Düne, erkennen. Diese Düne bildet an ihrem höchsten Punkt einen Hügel, so dass die dahinterliegenden Häuser nur mit ihren Dächern hervorragen. Die Ansammlung dieser Dächer lässt eine Küstenstadt vermuten. Der Rest der Küste verläuft von der Mitte des linken Bildrandes in einer leicht abfallenden Schräge bis in die untere rechte Bildecke. Obwohl der Strand nicht gemalt wurde, täuscht die Struktur und Farbigkeit der hier freiliegenden Leinwand bei flüchtigem Blick die Materialität von Sand vor. Die Dreiecksform, die von diesem Bereich gebildet wird, wiederholt sich im darüber liegenden Meer. Angehäufte Steine und helle Reflexionen durchziehen das Wasser in waagerechten Linien und verstärken damit die Ruhe des Meeres.

Der knapp unterhalb der waagerechten Mittelachse des Bildes angelegte Horizont betont die Tiefenräumlichkeit der Landschaft und zieht den Blick des Betrachters in die Ferne. Hier beleben einzelne Schiffe, die sich nahe an der Horizontlinie befinden, die beruhigte See. Am rechten Bildrand lässt sich die Silhouette einer fernen Küste erahnen. Da die Horizontlinie bis in die Bildmitte heruntergezogen ist, nimmt der hellblaue Himmel die gesamte obere Bildhälfte ein. Dieser ist mit Wolken behangen, die sich nur schwach abzeichnen.

Warum ein großes Stück der Studie unbemalt blieb, kann man nicht mit Sicherheit beantworten. Man könnte darin eine Enthüllung der Vorgehensweise des Künstlers sehen, der sein Bild von oben nach unten abarbeitet. ${ }^{4}$ Wichtiger ist aber noch die Frage, ob der Künstler nun das Bild aus irgendeinem Grund nicht fertigstellen konnte - es also tatsächlich unvollendet ist - oder ob er es absichtlich in diesem Stadium gelassen hat. ${ }^{5}$ Stellt man die Uferlandschaft dem Maler in steinigen Sanddünen (Kat. Nr. 20) gegenüber, fällt auf, dass hier die Verteilung von Meer und

2 Zum Kronprinzen pflegte Gurlitt in der folgenden Zeit eine freundschaftliche Beziehung. So war es auch Christian VIII., der Gurlitt 1847 zum Ritter des Dannebrog-Ordens ernannte; vgl. Gurlitt, Ludwig 1912, S. 221-23 und Schulte-Wülwer, S. 85 f.

3 Bei einer Auktion 1882 wurde das Bild an den Maler H. Rasmussen für 101 Kronen verkauft; vgl. Reitzel 1883, S. 205.

4 Vgl. Schulte-Wülwer 1997, S. 53. Das dort angeführte Beispiel (Abb. 50) ist allerdings auf großformatigem Zeichenpapier angelegt und mit Bleistift vorgezeichnet.

5 Vgl. Rudloff 1977, S. 98. Martina Rudloff erwähnt das absichtliche Auslassen der Vordergrundpartie auch bei einer Gruppe von Ölstudien Friedrich Nerlys. Bei diesen Blättern ist der Vordergrund dennoch mit Bleistiftstrichen angedeutet, was bei Gurlitts Uferlandschaft nicht der Falls ist. Vgl. hierzu auch Wegner 2010. 
Strand genau umgekehrt ist. Beim diesem Bild liegt der Fokus auf dem felsigen Strand sowie auf dem dort arbeitenden Künstler. Die Uferlandschaft rückt hingegen vor allem das Meer in den Vordergrund. Möglicherweise liegt hierin eine besondere Akzentsetzung duch den Künstler. Werner Busch hat darauf aufmerksam gemacht, dass die Auseinandersetzung mit dem Vordergrund bei im Freien angefertigten Studien für die Künstler oftmals ein besonderes Problem darstellte. Dies liege vor allem daran, dass die Maler sich unmittelbar in der Landschaft befanden, der Vordergrund also auf sie zulief. ${ }^{6}$

Im Falle Gurlitts sollten farbige Ölstudien zu Gemälden in späterer Zeit seltener werden. Ähnliches beobachtet Martina Rudloff bei Friedrich von Nerly: „Mit zunehmender Routine verliert die Ölskizze als Mittel zur Aneignung von Kenntnissen ihre Bedeutung. " ${ }^{\text {"7 }}$ Sie wird bei Gurlitt von Zeichnungen abgelöst, da er vor Ort nicht mehr die nötige Ruhe für Freilichtstudien findet:

„Ich möchte gar zu gerne noch etwas malen [...], denn zu einer ausführlichen Studie fehlte mir die Zeit und die Ruhe. $\mathrm{Da}$ ich mich aber schon seit längerer Zeit daran gewöhnt habe, nach Zeichnungen zu malen, so hoffe ich, soll es meinen Bildern keinen Abbruch tun."8

Die Gegenüberstellung von Zeichnung und auf dieser Grundlage ausgeführtem Gemälde zeigt, wie der Künstler den Vordergrund aus anderen Einzelstudien zusammengesetzt hat. Bei Gurlitts Blick auf die Akropolis von Osten ${ }^{9}$ ist im Vordergrund ein steiniger von Agaven bewachsener Hügel zu sehen, während die Akropolis selbst in die Hintergrundebene gerückt ist. Auf der dazugehörigen Zeichnung findet man diesen Hügel nicht, stattdessen blickt man über Baumkronen hinweg auf Athens Akropolis.

Die Angewohnheit, detaillierte Ölstudien anzufertigen, scheint sich demnach auf Gurlitts Kopenhagener Zeit und die Jahre unmittelbar danach zu beschränken. Seine italienischen Ölskizzen von 1838 weisen im Vergleich schon eine weniger feine Malweise auf. ${ }^{10}$

Lisa Weiß

6 Busch 1983, S. 126-128. Busch zeigt auch, dass der Vordergrund eines ausgeführten Gemäldes auf eine andere Weise komponiert wird, denn der Künstler setzt diesen aus mehreren Einzelstudien zusammen. Vgl. Busch 1983, S. 126; Busch 1997b, S. 60; Wegner 2010.

7 Rudloff 1977, S. 101.

8 Gurlitt, Ludwig 1912, S. 312, Brief vom 21.10.1855 aus Olevano. Rudloff behauptet in einer Fußnote, Gurlitt habe im gleichen Brief geschrieben, er male seine Studien abends zu Hause, also nicht im Freien. Dazu führt sie Gurlitt, Ludwig 1912, S. 303/4 an, ein entsprechender Beleg lässt sich dort aber nicht finden; vgl. Rudloff 1977, S. 106, Anm. 38.

9 Siehe Schulte-Wülwer 1997, S. 105, Abb. 98.

10 Siehe ebd., S. 54, Abb. 50/51. 

Kat. Nr. 22

Louis Gurlitt (1812-1897)

\section{Blick auf Salzburg}

1836

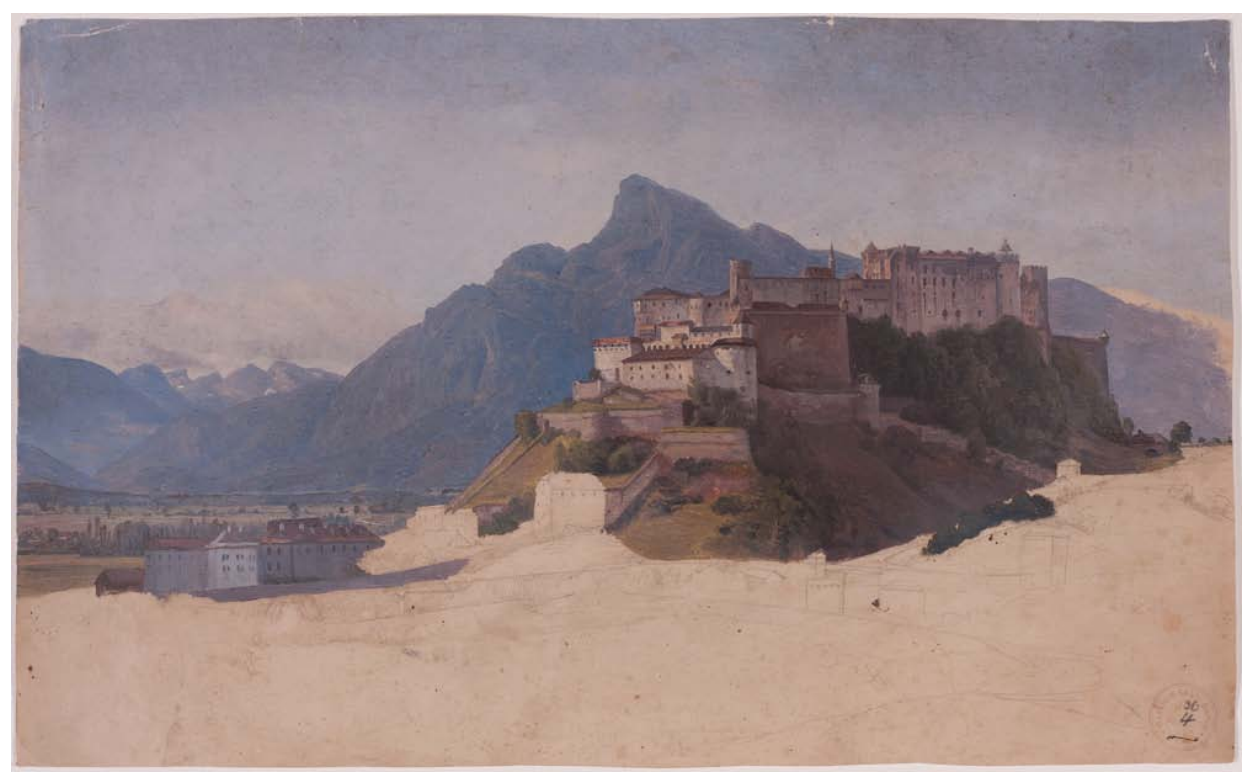

Öl auf Papier, 42 x 26 cm, 1977 mit Mitteln der Volkswagenstiftung im Kunsthandel erworben, Inv. Nr. H 1977/108 (alt: Inv. Nr. GG 139)

Als Gurlitt nach wiederholten Versuchen in Kopenhagen weder die ersehnte Goldmedaille noch ein alternatives Stipendium für eine Italienreise erlangen konnte, verließ er 1836 schließlich die Akademie in Richtung München. ${ }^{1}$ Dort angekommen, fand er schließlich Zugang zu dem bereits seit 1830 bestehenden Kreis von dänischen, schleswig-holsteinischen sowie Hamburger Künstlern, der sich um Christian Morgenstern gebildet hatte. ${ }^{2}$ Zwei Monate nach seinem Umzug begab sich Gurlitt zusammen mit Johann Mohr und Johann Heinrich Martens auf eine Studienreise, die ihn über den Chiemsee nach Berchtesgaden und Umgebung führ-

1 Schulte-Wülwer 1997, S. 38-43. Ein weiterer Grund für die Abkehr von Kopenhagen war zudem eine unangenehme Erfahrung mit einem anonymen Kritiker, der vor allem seine Ölstudien verriss. Vgl. ebd., S. $41 \mathrm{f}$.

2 Ebd., S. 45; Gurlitt, Ludwig 1912, S. 88. 
te. ${ }^{3}$ Von hier aus schreibt er bereits: „, [... Salzburg soll noch schöner sein. “4 Dorthin brach er am 3. September auf - Mitte September war er schon wieder in München. In jenem Zeitraum, der ersten Septemberhälfte 1836, muss also die farbige Studie Blick auf Salzburg entstanden sein.

Wie bei den anderen Göttinger Studien handelt es sich um ein kleines Querformat, allerdings auf Papier anstelle von Leinwand. Es zeigt eine auf einer begrünten Erhebung liegende Burg - die Festung Hohensalzburg -, die von einem massiven Gebirge hinterfangen wird. Dieses verläuft auf der linken Bildseite bis weit in den Hintergrund und erzeugt so eine große Tiefenwirkung im Bild. Die dunkle Farbe des Gebirges steht der sonnenbeschienenen Burg kontrastiv gegenüber und betont diese somit. Das untere Drittel des Blattes ist indes nicht bemalt. Hier liegt eine Vorzeichnung in Bleistift frei, welche die Landschaft des Vordergrundes und die darin liegenden Gebäude nur konturenhaft, teilweise mit schraffierten Ausfüllungen andeutet. Genauso hält Gurlitt zwei Jahre später italienische Landschaften auf großformatigem Papier fest. ${ }^{5}$ Ulrich Schulte-Wülwer schreibt über eine dieser Zeichnungen:

„Auf dem Zeichenpapier ist die weiträumige Landschaft mit flüchtigen Bleistiftstrichen erfaßt. Anschließend hat er damit begonnen, das Blatt von oben nach unten mit Ölfarbe auszumalen. Überall dort, wo der Pinsel aufgesetzt hat, ist die Studie vollendet.“"6

Die bildkünstlerische Erschließung des Salzburger Landes wurde zu Beginn des 19. Jahrhunderts insbesondere von Ferdinand Olivier geleistet. Olivier, der seit 1811 in Wien lebte, besuchte Salzburg zum ersten Mal 1815 auf der Durchreise, als er mit seinem Malerfreund Philipp Veit nach München zog. Veit musste Salzburg nach drei Tagen ohne seinen Freund verlassen, da Olivier, fasziniert von der Schönheit der Umgebung, spontan mehrere Wochen blieb. ${ }^{7}$ Von da an widmete sich Olivier in seinen Arbeiten intensiv dem Salzburger Land und begeisterte nach seiner Rückkehr nach Wien auch seinen Bekanntenkreis. So brach er im Juli 1817 zusammen mit seinem Bruder Friedrich Olivier, Karl Frommel und Johann Christoph Rist ein zweites Mal dorthin auf. Auch Julius Schnorr von Carolsfeld stieß kurze Zeit später zu ihnen. ${ }^{8}$

Auf diese zweite Reise hin entstand ab 1818 eine Folge von Lithographien unter dem Titel Sieben Gegenden aus Salz̧burg und Berchtesgaden geordnet nach sieben Tagen der Woche, verbunden durch zwey allegorische Blätter, welche 1823 von Olivier veröffentlicht wurde. ${ }^{9}$ Indem Olivier die Landschaften mit den sieben Wochentagen und Andeutungen auf verschiedene Tageszeiten und menschliche Lebensalter versieht, lädt er

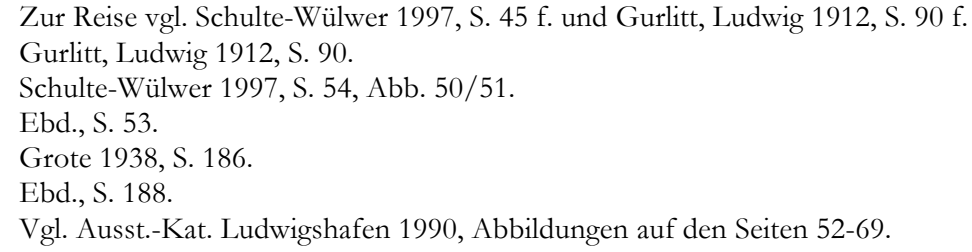


sie romantisch und allegorisch auf - nicht zuletzt durch die Allegorien selber, die das Werk umschließen. ${ }^{10}$ Damit bricht er mit den vedutenhaften Salzburger Ansichten seines Lehrers Friedrich Wilhelm Schlotterbeck, die 1808 ebenfalls als Folge herauskamen. ${ }^{11}$

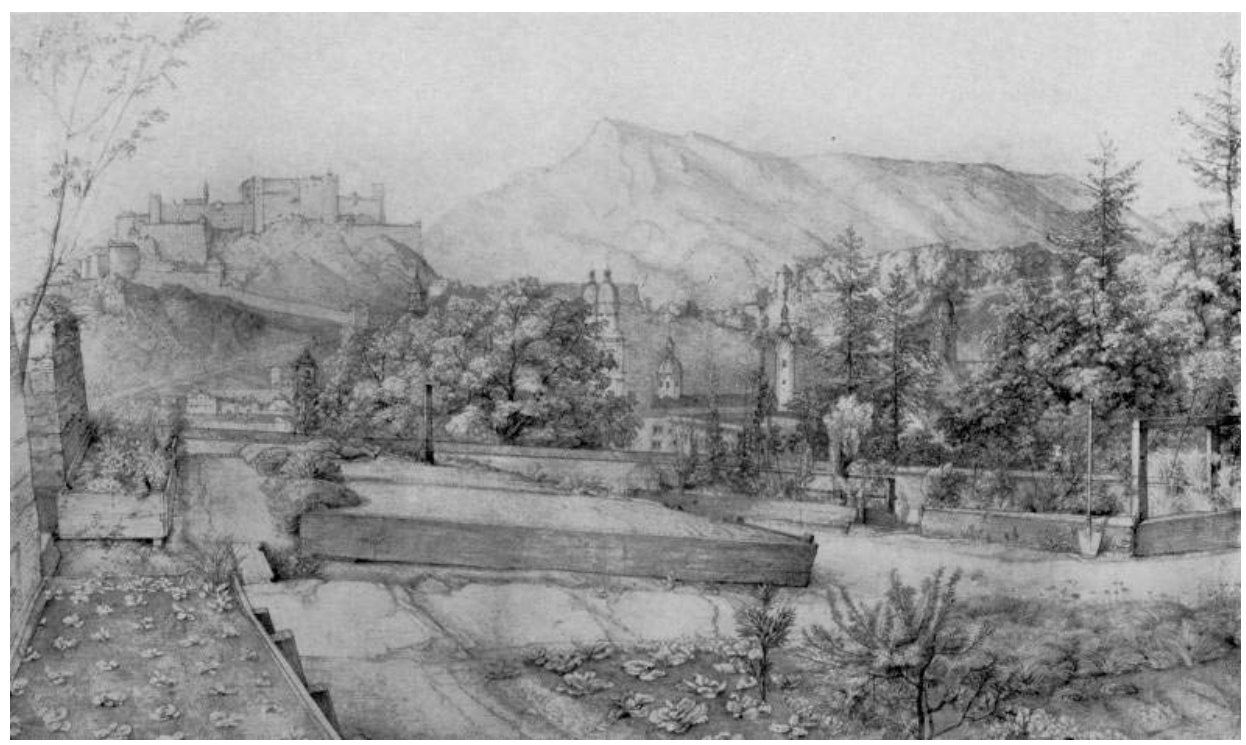

Abb. 33: Ferdinand Olivier: Blick vom Kapuzinergarten auf die Festung und Untersberg, 1818, Bleistift, weiß gehöht auf Papier, 322 x 542 mm, Dessau, Anhaltische Gemäldegalerie

F. Schnorr von Carolsfeld charakterisiert die Folge 1884 in der Allgemeinen deutschen Biographie als ,wenig bekannt geworden[es], aber von Kennern hochgeschätzte[s] eigenartige[s] Werk. "12 Tatsächlich scheint sie relativ weit verbreitet worden zu sein, denn auch Oliviers Bekannte in Rom bekamen Exemplare vom Künstler zugesendet und sogar in Amerika fanden sie Absatz. ${ }^{13}$

Eine von jener Folge unabhängige Salzburger Zeichnung Oliviers von 1818 präsentiert einen Blick vom Klostergarten der Kapuzinermönche auf die Festung Hohensalzburg im Süden (Abb. 33). Der Winkel, in dem man auf die Burg schaut, ähnelt dem auf Gurlitts Blatt sehr. Im Vergleich zu Olivier scheint Gurlitt aber etwas weiter östlich gestanden zu haben, denn der Untersberg liegt bei Olivier rechts von der Festung, während derselbe Berg in Gurlitts Studie links von ihr

10 Vgl. u. a. Grote 1932, S. 2; Grewe 2009, S. 253-276. Während die anderen Wochentage von vielen Figuren belebt werden, zeigt beispielsweise das Sonnabend-Blatt als letztes der Woche nur einen Friedhof, der von einer untergehenden Sonne flach angestrahlt wird; vgl. Grote 1938, S. 222-226.

11 Grote, 1938, S. 18 und S. 216.

12 Schnorr von Carolsfeld 1887, S. 310.

13 Grote 1938, S. 227. 
auftaucht. Ein weiterer Unterschied, der deutlich macht, von wo aus Gurlitt die Hohensalzburg malerisch festgehalten haben muss, liegt in der Höhe des Betrachterstandpunktes. Der Kapuzinergarten befindet sich am westlichsten Fuße des Kapuzinerberges, der in Richtung Osten ansteigt. Am höchsten Punkt des Berges liegt das Franziskischlössl, welches seit dem 19. Jh. als Ausflugsgasthaus genutzt wurde und in etwa nordöstlich der Hohensalzburg liegt. ${ }^{14}$ Von hier aus könnte Gurlitt die Aussicht genossen haben, welche er im Blick auf Salzburg festhielt.

Lisa Weiß

14 Dehio Salzburg 1986, S. 626. 
Kat. Nr. 23

Bernhard Fries (1820-1879)

\section{Kap Manerba am Gardasee}

Nach 1850

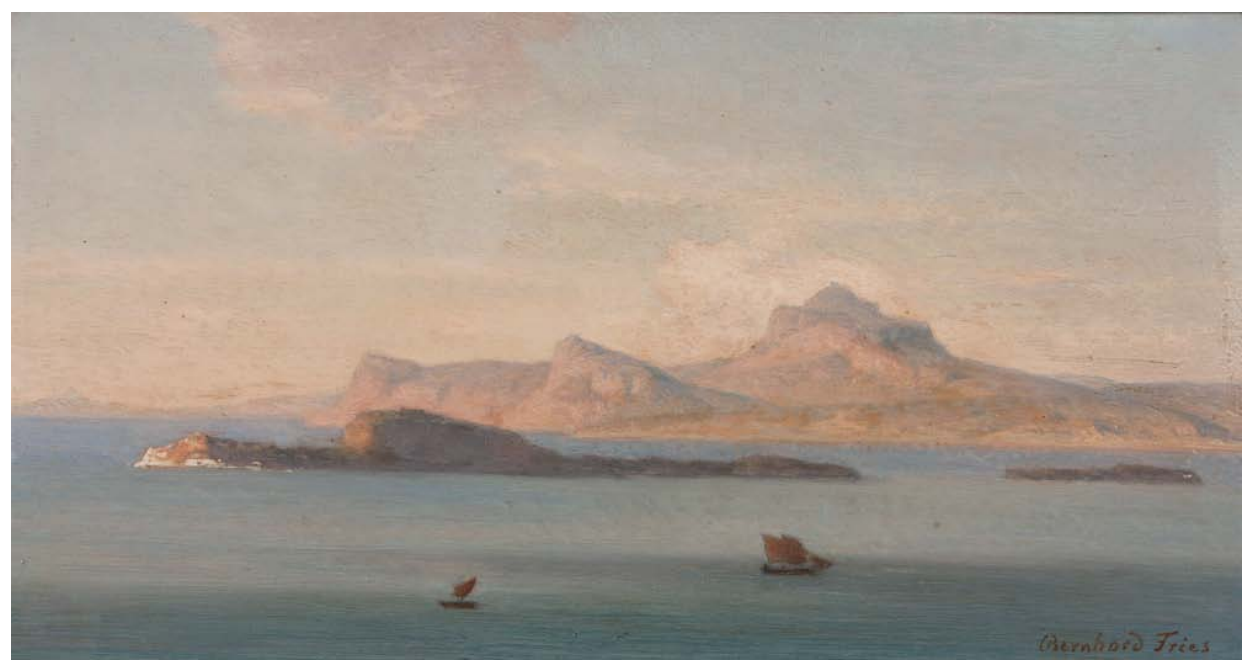

Öl auf Leinwand auf Holz, 12 x 23,5 cm, vorder- und rückseitig signiert, 1971 aus Privatbesitz mit Mitteln der Motorwagen-Handelsgesellschaft E. u. H. Apell und der GeorgAugust-Universität erworben, Inv. Nr. GG 132

Die Ölstudie zeigt Cap Manerba am Westufer des Gardasees. In hellen Farben hält Bernhard Fries hier eine bergige Küstenlandschaft mit zwei Inseln und zwei Segelschiffen bei sonnigem Wetter fest. Signiert ist die Studie am unteren, rechten Rand sowie auf der Rückseite des Bildes.

Das schmale Querformat wird zu großen Teilen von Wasser und Himmel ausgefüllt. Etwas mehr als das untere Drittel der Bildhöhe nimmt dabei die Wasserfläche ein; auf den restlichen zwei Dritteln erstrecken sich Küste und Himmel. Die niedrig liegende Horizontlinie sowie die Möglichkeit, über die Inseln hinweg auf das dahinterliegende Meer zu blicken, lassen auf einen erhöhten Betrachterstandpunkt schließen.

Entlang des Horizonts zieht sich das Ufer des Gardasees mit der Rocca di Manerba und dem Cap Manerba im Zentrum. Bei den vorgelagerten Inseln handelt es sich wahrscheinlich um die Isola di San Biagio, auch Isola di Conigli genannt. Da ihre Erscheinung den Gezeiten unterworfen ist, ändert sich ihre Größe regelmäßig. 
Im Vergleich mit heutigen Photographien weicht ihre Aussehen jedoch ab. Eine genaue Verortung kann daher nicht mit Sicherheit vorgenommen werden.

Anhand der leichten Aufhellung am linken Inselufer wird deutlich, dass die Sonne von der hinteren linken Seite aus strahlen muss und dabei sehr tief steht. So taucht sie Cap Manerba in helles Licht, während die kleineren Inseln vom Betrachterpunkt aus verschattet erscheinen. Vom Sonnenlicht illuminiert, hinterfängt das Ufer die dunklen Inseln. Auf der linken Seite geht das Ufer beinahe im blauen Dunst auf. Am unteren Bildrand entlang erstreckt sich eine dunkle Wasserfläche, die wahrscheinlich durch den Schatten einer Wolke hervorgerufen wird und das Bild nach vorn hin optisch abschließt.

Die Landschaft im Hintergrund ist hügelig und türmt sich in der rechten Bildhälfte zu einem Berg auf. Man erkennt das gestalterische Ordnen des Künstlers an der Ausrichtung der Berge anhand einer nach rechts aufsteigenden Linie, beginnend mit der unteren Insel hin zur hohen Bergspitze. Durch starke Verblauung der hinteren Berge, aber auch durch ihre Größenrelation, die in der Staffelung deutlich wird, deutet sich ein Tiefenzug an. Dieses Kompositionsmittel klassischer Landschaftsmalerei entfaltet in Fries' vollendeten Werken eine große Wirkung. Hier findet es sich zumindest ansatzweise.

Die zwei Segler auf dem Wasser scheinen lediglich Staffage zu sein. Sie fahren nach rechts und sind dabei jeweils gleich weit von der vertikalen Mittelachse entfernt. Ein Segler ist somit auf der linken, der andere auf der rechten Bildhälfte angeordnet. Traut man der Verortung nach Cap Manerba, so befindet sich weiter rechts ein Hafen als mögliches Ziel der Schiffe.

Vergleicht man dieses Werk mit ausgeführten Gemälden von Bernhard Fries, so ist unverkennbar, dass es sich bei Cap Manerba am Gardasee um eine Studie handelt. Bereits das kleine Format markiert einen gravierenden Unterschied zu den sonst erheblich größeren Gemälden dieses Künstlers (vgl. Abb. 34). ${ }^{1}$ Aber auch die lockere Ausführung lässt auf eine Studie schließen. Hier porträtierte der Künstler auf zügige Weise einen Landschaftseindruck. Denkbar ist, dass das Bild im Freien entstand. In seinen vollendeten Arbeiten zeigt Fries sonst eine sehr viel feinere Behandlung der Flora. ${ }^{2}$

Studien wie diese dienten Fries in traditioneller Weise als Vorlage, um in einem komponierten Bild später vergleichbare Natureffekte zu erzielen, oder einfach zur Übung. Niemals wäre in dieser Zeit eine solche Studie als autonomes Kunstwerk angesehen worden. Für diesen Rang musste die Landschaft erst im Atelier auskomponiert werden. Man kann Fries also noch in das Umfeld der traditionellen,

1 So hat beispielsweise das Gemälde Das Tal des Oreto bei Palermo von Fries die Maße 98 x 131,5 cm. Es ist also - vom gedrungenen Format und den daraus resultierenden Unterschieden im Seitenverhältnis abgesehen - beinahe neun Mal so groß wie die Göttinger Studie. Ebenfalls sieht man hier eine komplexere, auf Mannigfaltigkeit und formale Geschlossenheit hin angelegte Komposition sowie Staffagefiguren. An diesen Elementen erkennt man deutlich die Verhaftung von Fries in der akademischen Landschaftsmalerei.

2 Pérard 1930, S. 33. 
akademischen Malerei einordnen. Zu seinen Lebzeiten intensivierten sich allerdings die Spannungen zwischen klassisch-heroischer und stimmungsvollatmosphärischer Landschaft. Im CEuvre von Fries findet beides seinen Niederschlag. Seine spezifische künstlerische Prägung wird deutlicher, wenn man sich mit seiner Biographie auseinandersetzt.

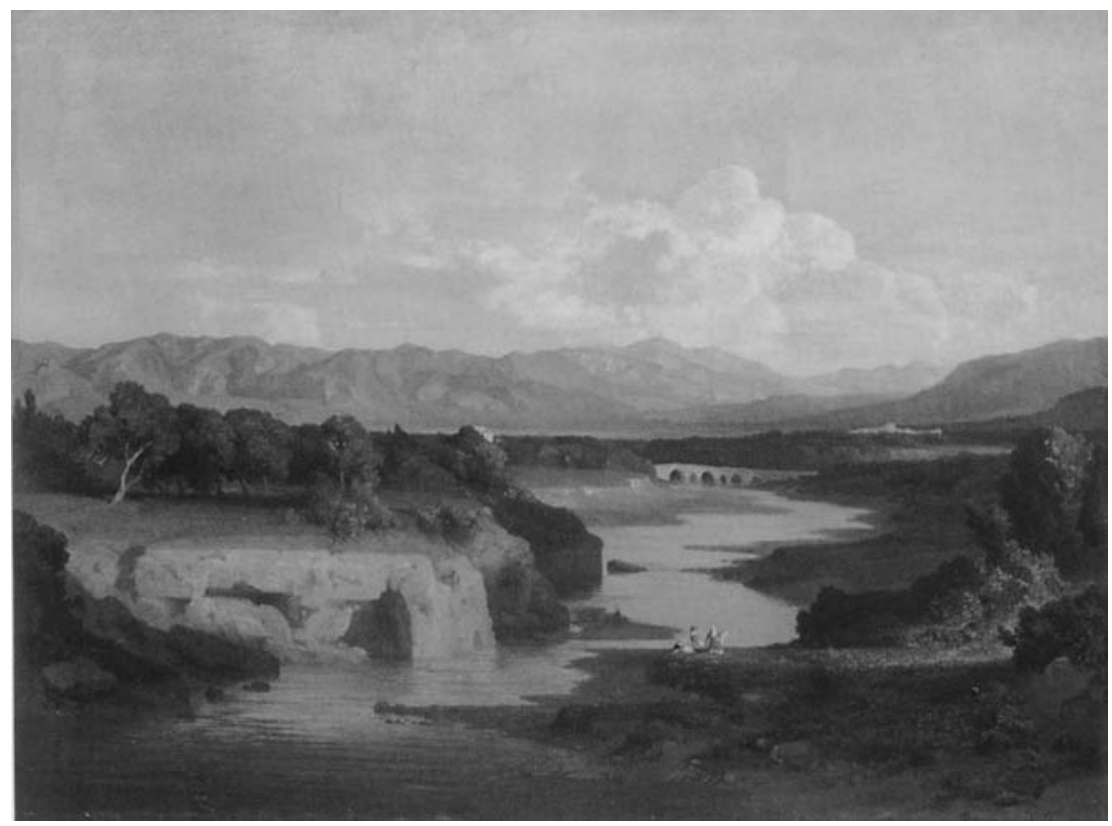

Abb. 34: Bernhard Fries: Das Tal des Oreto bei Palermo, um 1860, Öl auf Leinwand, 98 x 131,5 cm, München, Sammlung Schack

\section{Biographisches zu Bernhard Fries}

In Heidelberg am 16. Mai 1820 geboren, wuchs Bernhard Fries in einem Elternhaus auf, das vor allem durch die kulturellen Interessen des Vaters ein ,gesellschaftlicher Treffpunkt war und den wichtigen zeitgenössische Geistesströmungen und einem vielfältigen künstlerischen Umfeld offenstand." ${ }^{3}$ Dies sollte Fries' künstlerischen Werdegang beeinflussen. Der Vater, Christian Adam Fries, hatte es als Fabrikant und Bankier zu einigem Wohlstand gebracht und besaß eine große Kunstsammlung. Dort hatte Bernhard genügend Gelegenheiten, an Originalen sein Auge zu schulen.

Die Sammlung bestand zum großen Teil aus Landschaften von Niederländern des 17. Jahrhunderts sowie klassischen Landschaften Poussins und Claude Lor-

3 Rahman 1999, S. 33. 
rains. ${ }^{4}$ Sie erlangte ihren Ruhm unter anderem durch einen Besuch Goethes $1814 .{ }^{5}$ Generell war sie ein Anziehungspunkt für viele Künstler, die auf diese Weise in das Haus der Familie Fries kamen: so zum Beispiel der Schottische Maler Georg August Wallis, von dem sich vierzehn Werke in der väterlichen Sammlung befanden, sowie der aus der Heidelberger Umgebung stammende Maler Carl Rottmann. ${ }^{6}$ Wallis war vor allem durch seine koloristische Behandlung der Natur und die Darstellung von Witterungs- und Beleuchtungsphänomenen wichtig für die Heidelberger Künstler. ${ }^{7}$ Er verband eine ,,reale Naturwiedergabe mit einer überhöhten Darstellung in einem klassischen Bildaufbau und der Tendenz zur heroischen Ideallandschaft sowie eine romantische, Symbolkraft geladene Motivgestaltung und Stimmungshaftigkeit bei bewußter Übersteigerung der farblichen Wirklichkeit."8 Damit übte er großen Einfluss auf Rottmann und auch auf Bernhards Bruder Ernst Fries aus, ${ }^{9}$ wobei gerade ersterer der Behandlung von Licht- und Wettererscheinungen in seinem Werk besondere Aufmerksamkeit widmete. Alle drei genannten Künstler beeinflussten wiederum das Schaffen von Bernhard Fries.

Als Bernhard Fries seine Ausbildung begann, hatte es sein Bruder Ernst Fries bereits zu Ruhm als Landschaftsmaler gebracht. 1831 wurde dieser vom Badischen Großherzog zum Hofmaler ernannt. ${ }^{10}$ Nachdem er 1827 aus Italien nach Heidelberg zurückgekehrt war ${ }^{11}$, gab er dem jüngeren Bruder erste Unterweisungen in der Ölmalerei. ${ }^{12}$ Ernst Fries vertrat eine Naturmalerei, die sich in diesen Jahren an einer „sachlichen Erforschung der realen Umgebung, d. h. vor allem der genauen optischen Registrierung und der feinsten malerischen Umsetzung von Farb- und vor allem Licht-Phänomenen“ versuchte. ${ }^{13}$ Die romantische Prägung früherer Jahre legte Ernst damit beiseite, während gleichzeitig der Einfluss von Wallis seine Wirkung zu entfalten schien.

1833 traf Bernhard auf einen weiteren frühen Einflussgeber: William Turner. ${ }^{14}$ Durch ihn scheint sich bei Fries eine Aufhellung seiner Farbpalette ereignet zu haben. Auch das Festhalten vorüberziehender Lichterscheinungen und Luftstimmungen, die er bereits von Wallis kannte, die aber bei Turner expliziter zu Tage treten, kann auf diese Begegnung zurückgeführt werden. ${ }^{15}$ Beides sind Eigenarten, die man auch auf der Göttinger Studie zu beobachten kann.

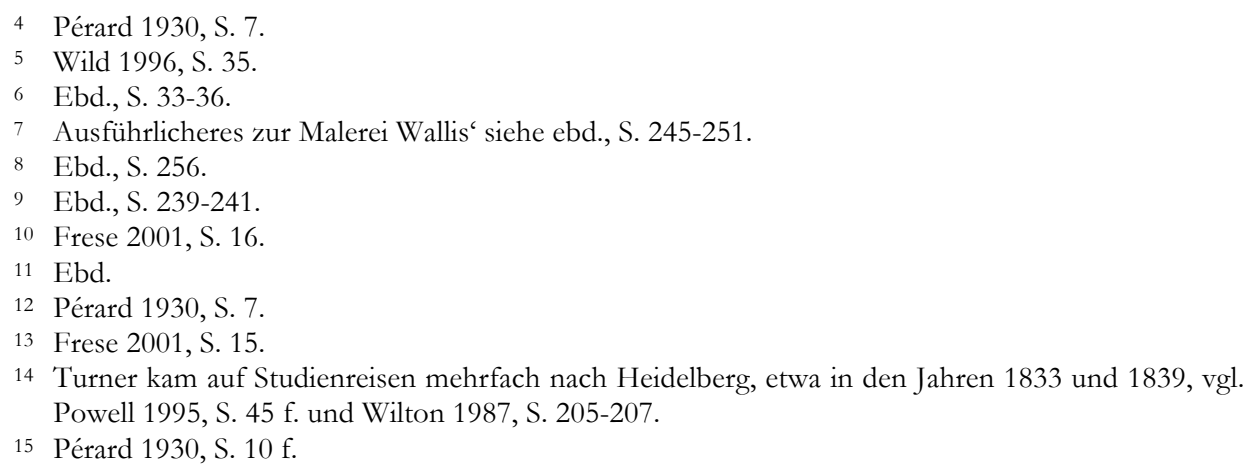


In Karlsruhe studierte Fries 1835 ein knappes Jahr bei dem Cornelius-Schüler Johann Carl Heinrich Koopmann das Figurenzeichnen, wechselte aber bereits im November desselben Jahres an die Kunstakademie in München. Seine akademische Ausbildung nahm Fries dort anscheinend nicht sehr ernst, denn er weilte nur unregelmäßig in der Bayrischen Hauptstadt und reiste immer wieder zurück nach Heidelberg. ${ }^{16}$

Drei Jahre später begab sich Bernhard Fries das erste Mal nach Italien. Die typische Reiseroute führte ihn durch Trient, Verona, Venedig, Padua, Mantua, Modena, Bologna und Florenz, bevor er Mitte September 1838 Rom erreichte. Auf dieser Reise wird er auch das erste Mal den Gardasee besucht haben.

Mit einigen Unterbrechungen hielt sich Fries bis 1845 in Rom auf. ${ }^{17}$ Aus einem Brief seines Vaters vom 26. Dezember 1838 geht hervor, dass er sich zu der Zeit zwar als Landschaftsmaler sah, seiner Meinung nach aber mehr „Geschick und Sinn“ für die Historie hatte. ${ }^{18}$ Seine endgültige Entscheidung für die Landschaftsmalerei scheint im Jahr 1839 gefallen zu sein, denn in diesem Jahr betonte der nazarenische Historienmaler Franz Nadorp Fries' große Fähigkeiten als Landschaftsmaler. ${ }^{19}$

Im Jahr darauf arbeitete er mit Johann Wilhelm Schirmer in den Sabiner Bergen und in der Campagna, wo jener ihn das Malen nach der Natur lehrte. ${ }^{20}$ Naturerscheinungen und Phänomene wurden von ihnen vor Ort in Skizzen und Studien festgehalten, um unter anderem anschließend in Gemälden Anwendung zu finden. 1842 schloss Fries sich in freier Form der Düsseldorfer Kunstakademie an, wo Schirmer seit 1839 als Professor der Landschaftsmalerei lehrte. ${ }^{21}$ Hier näherte sich seine Malerei einer „stimmungsvollen Landschaft“ an, welche letztlich eine Variante der Kunstauffassung seines Jugendeinflusses Wallis' darstellte. ${ }^{22}$

Sicherlich durch Anregung Schirmers reiste der 26-jährige Fries 1845 nach Paris, wo er den Malern der Schule von Barbizon begegnete. ${ }^{23}$ Deren Landschaftsauffassung brach mit der zu dieser Zeit immer noch verbreiteten Auffassung von Ideallandschaft. Sie malten nicht monumentale Landschaften Italiens, sondern die nahe Umgebung des kleinen Dorfes Barbizon. Die hier entstandenen Landschaftsgemälde gehören zum Typus des Paysage intime. Die Natur wird ohne Ausschmückungen meist als Ausschnitt gezeigt. Anders als in der klassischen Landschaftsmalerei mit ihren heroischen, idealen Landschaften und oft mythologischen Staffagefiguren zeigen sie stille, intime Ausschnitte der Natur. Es wird kein ideeller Inhalt transportiert, auch soll nicht die Urgewalt und die Exotik der Natur zur

16 Ebd., S. $11 \mathrm{f}$.

17 Ebd., S. 13 f.

18 Ebd., S. 14 f.

19 Ebd., S. 17.

20 Ebd., S. 17 f.

21 Bahns 1997, S. 376.

22 Pérard 1930, S. 20.

23 Ebd., S. 21 f. 
Schau gestellt werden. Motive des Paysage intime waren die heimatliche Landschaft und ihre Bewohner. ${ }^{24}$

Die Schule von Barbizon hat in der zweiten Hälfte des 19. Jahrhunderts groBen Einfluss auf die Malerei. Gerade in Deutschland breitet sich die neue Art der (Landschafts)Auffassung aus. ${ }^{25}$ Fries nahm zumindest teilweise naturalistischere Tendenzen in sein Schaffen auf, der reinen Freilichtmalerei stand er jedoch ablehnend gegenüber. ${ }^{26}$

Fries verließ Rom im Jahr 1846 endgültig und zog nach München, wo er an einigen von Kritikern sehr positiv besprochenen Ausstellungen teilnahm. ${ }^{27}$ Wegen vermeintlicher „Demokratischer Umtriebe“ musste er München im Revolutionsjahr 1848 aber wieder verlassen. Er begab sich in die Schweiz, wo er zusammen mit dem Maler Alexandre Calame am Genfer See arbeitete. ${ }^{28}$ Nachdem er nach München zurückkehren durfte, begann er um 1860 einen Italienzyklus, den er plante, an König Maximilian II. von Bayern zu verkaufen. ${ }^{29}$ Mit diesem Zyklus lehnte er sich an Carl Rottmann an, der zwischen 1838 und 1850 einen berühmt gewordenen Freskenzyklus griechischer Landschaften für die Münchener Hofgartenarkaden schuf. ${ }^{30}$ Dessen heroische Landschaftsauffassung findet sich bei Fries allerdings nicht.

Durch den Bankrott des Bruders kam es 1860 zum Verlust des gesamten Vermögens der Familie Fries, so dass Bernhard zum Verkauf mehrer Bilder des Zyklus' gezwungen war. ${ }^{31}$ Viele Gemälde sind bis heute nicht aufzufinden.

Die Werke der späten Jahre zeigen einen wachsenden Zwiespalt in seinem Schaffen. Auf der einen Seite finden sich große, zum Verkauf gemalte Landschaften im Stile Rottmanns, auf der anderen Seite stehen kleine Stimmungsbilder, die Fries in Öl oder als Aquarell malte. Diese Studien widmen sich vor allem der Lichtund Lufterfassung. ${ }^{32}$ Sehr wahrscheinlich ist die Göttinger Studie eines jener späten Werke, konzentriert Fries sich in diesen Jahren doch, wie eingangs beschrieben, stark auf die Ausleuchtung und Atmosphäre der Landschaft. Hinzu tritt die Begeisterung für das Bildmotiv des Gardasees, die in eben dieser Zeit seines Lebens vorherrschte. ${ }^{33}$

Phil Miller

24 Siehe den Artikel „Paysage intime“, in: Lexikon der Kunst 1987-1994, Bd. 5, 1993, S. 486 f.

25 Vergleiche in diesem Katalog die Bilder von Paul Meyerheim (Kat. Nr. 29), Johann Friedrich Voltz (Kat. Nr. 24), Karl Adam Heinisch, (Kat. Nr. 28) und Karl Buchholz (Kat. Nr. 26).

26 Bahns 1997, S. 376.

27 Pérard 1930, S. 86.

28 Ebd., S. 22 f.

29 Ebd., S. 33 f.

30 Umfassend hierzu vgl. Ausst.-Kat. München 2007.

31 Pérard 1930, S. 33.

32 Ebd., S. 52 f.

33 Ebd., S. 32. 
Kat. Nr. 24

Johann Friedrich Voltz (1817-1886)

\section{Enten am Starnberger See}

Nach 1850

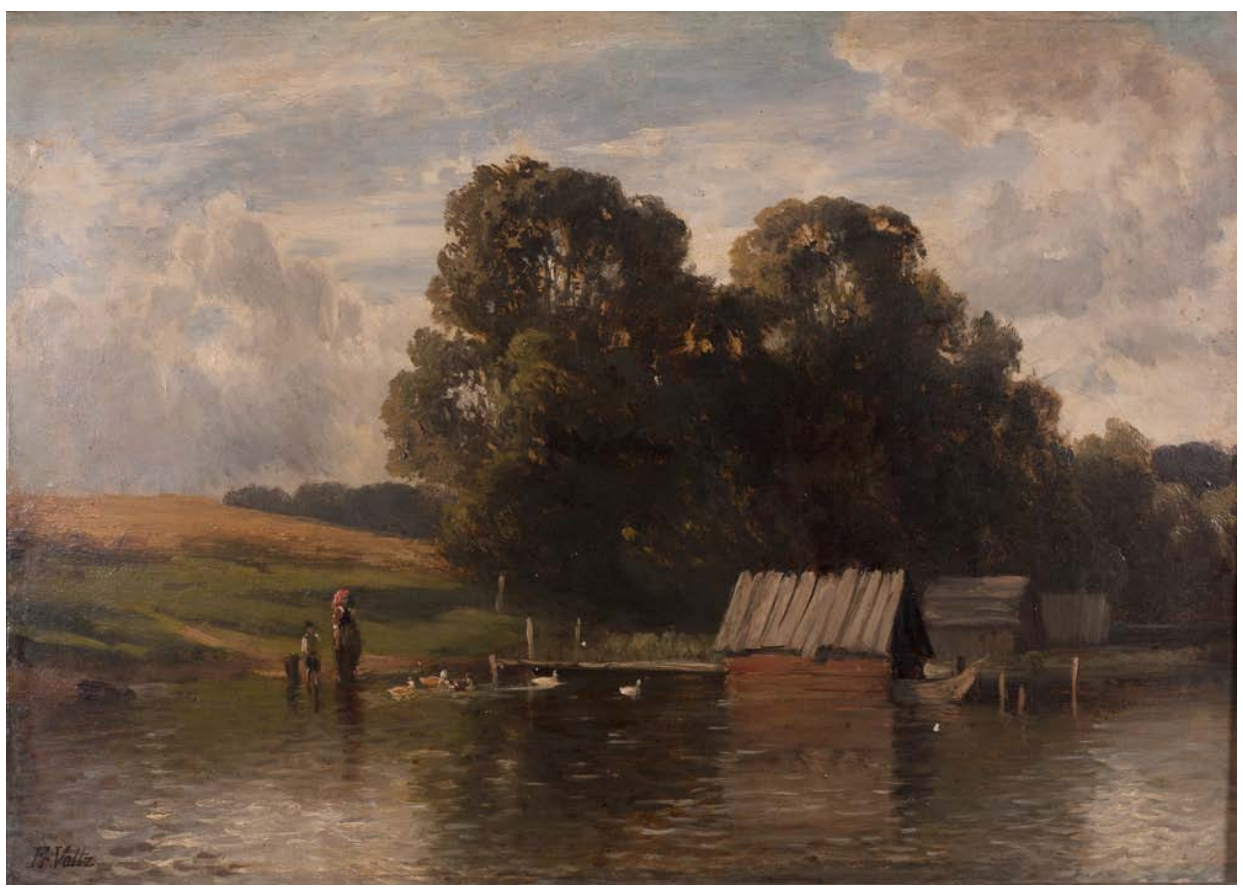

Öl auf Pappe, 27,5 x 39,5 cm, Leihgabe der Bundesrepublik Deutschland (Objektnr. 23785)

Johann Friedrich Voltz ist vor allem als Tiermaler in der Nachfolge des Malers und Lithographen Max Joseph Wagenbauer (1775-1829) bekannt. Angeregt durch die Schule von Barbizon, verband Voltz diese Münchner Maltradition mit der neu aufgekommenen Freilichtmalerei. ${ }^{1}$ Seine Gemälde sind geprägt von der Licht- und Farbauffassung der Freilichtmaler.

Zunächst studierte Johann Friedrich Voltz Malerei bei seinem Vater Johann Michael Voltz, einem angesehenen Illustrator und Historienmaler, bevor er 1833/34 seine Ausbildung an der Münchner Akademie fortsetzte. In erster Linie

1 Ebertshäuser 1979, S. 130. 
war er jedoch Autodidakt. ${ }^{2}$ Angeregt durch seine vielen Studienreisen ins bayrische Hochgebirge konzentrierte er sich auf die Darstellungen des Alpenlebens. ${ }^{3}$ Durch den Einfluss des Pferdemalers Albrecht Adam (1786-1862) begann sich Voltz schon in seiner Frühzeit neben Almdarstellungen für die Darstellung von Pferden $\mathrm{zu}$ interessieren. Dieses Interesse weitete sich im Laufe seines Lebens auf die Darstellung von Schafen, Ziegen und Rindern sowie auf exotische Tiere wie Kamele und Affen aus. ${ }^{4}$ In den 1840er Jahren begründete Voltz zudem das Rassenporträt der Kühe, welches bis dahin nur auf Pferde beschränkt war; zu seinen Lieblingsmotiven zählte das Ampermoosrind. ${ }^{5}$

Auf seinen Reisen, die ihn in den Jahren zwischen 1843 und 1855 nach Oberitalien, Belgien, Holland, Frankreich und England führten, hielt auch die Landschaftsmalerei Einzug in sein künstlerisches Schaffen. ${ }^{6}$ Seit Mitte der $1850 \mathrm{er}$ Jahre bestand sein Werk fast ausnahmslos aus Landschaften mit Tierstaffagen, vornehmlich von den Ufern des Starnberger Sees und seiner Umgebung. ${ }^{7}$ Dem Tier galt nach wie vor ein Hauptaugenmerk der Bilder, doch findet sich dieses nun nicht mehr wie in Gute Nachbarn (1850, Landesmuseum Hannover) im Innern eines Stalles, sondern meist als Gruppe eingebettet in die Landschaft und in das ruhige Landleben.

\section{Das Göttinger Gemälde}

Im Kontrast zu Gemälden wie Rinder im Waldbach (1854/56, Privatbesitz) und Kühe an der Tränke vor Erntelandschaft (1872/74, Privatbesitz) steht das Gemälde Enten am Starnberger See, indem hier nicht nur die Landschaft in den Vordergrund rückt, sondern auch Enten namensgebend für das Gemälde sind. Daher lässt sich das sehr gut erhaltene Göttinger Gemälde aufgrund seiner Motivik in die Zeit nach 1850 einordnen.

Das kleinformatige Bild zeigt einen Landschaftsausschnitt an einem See. Die untere Hälfte des Bildes wird vom Wasser des Sees und einem schmalen Streifen Ufer eingenommen, wohingegen der obere Teil durch den stark bewölkten Himmel gefüllt ist. So wird eine Art Gegenstück zum See geschaffen, wobei das Ufer eine Art Grenze der beiden Zonen bildet. Diese wird aufgebrochen durch die hohen Baumgruppen auf der rechten Bildseite, die bis in die Himmelzone hinein ragen. Von der Mitte aus reihen sich Stege mit Bootshäusern entlang der Baumreihen. Vor dem vordersten Haus liegt ein Boot im Wasser. Die linke Bildhälfte ist hingegen frei von Bäumen, wodurch sich ein Ausblick auf die Wiese

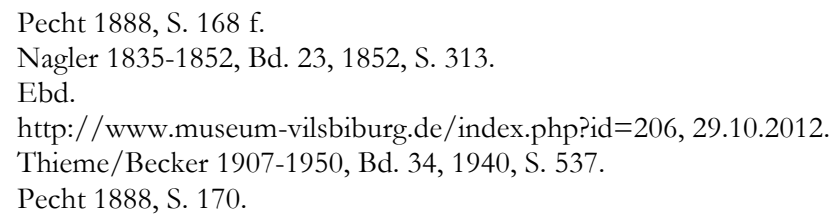


und die Felder mit begrenzender Baumreihe dahinter öffnet. Nahe des Ufers schwimmen Enten im Wasser, hinter denen ein kleiner Junge und ein Mädchen mit rotem Kopftuch stehen und auf den See hinaus zu schauen scheinen. Das Kopftuch des Mädchens bildet einen farblichen Akzent im Gemälde, in dem sonst nur Grün-, Braun- und Blautöne neben Weiß dominieren. Der sichtbare Pinselstrich lässt die einzelnen Farben ineinander verschmelzen, wohingegen die kleinen waagerechten Striche der Wellen des Sees die Spiegelungen der Landschaft im See leicht verzerrt wirken lassen. Im Kontrast zu diesem freieren Farbumgang stehen die fein ausgearbeiteten Details und die einzelnen Lichtreflexe wie das Kopftuch oder die kleinen Enten. Dieser Duktus lässt sich bei Voltz auch bei anderen Werken wie Hirt mit Kühen vor einem Dorf (1850, Museum der Bildenden Künste Leipzig) finden.

Das Gemälde Enten am Starnberger See strahlt durch seine Komposition Ruhe aus. Die Figuren und die einzelnen Elemente wirken unbewegt, ohne leblos zu erscheinen. Der Betrachter bleibt durch den See eindeutig vom Bildgeschehen ausgegrenzt. Die gedämpfte Farbpalette Voltz' passt sich diesem harmonischen Aufbau des Bildes an und unterstützt den Ausdruck der friedlichen Atmosphäre im Gemälde.

In der Art seiner Landschaftsauffassung sowie seines Kolorits steht Voltz u. a. Carl Spitzweg und Eduard Schleich d. Ä., nahe, die er auch persönlich kannte und mit denen er nicht zuletzt Gemeinschaftsarbeiten anfertigte. ${ }^{8}$ Besonders mit Schleich verband ihn eine enge Freundschaft. Die beiden Maler hatten 1871 zusammen Italien bereist, und einige von Voltz' Werken sollen in Zusammenarbeit mit seinem Freund entstanden sein. ${ }^{9}$ Auch soll Voltz an Schleichs Gemälden mitgeholfen haben, besonders bei der von Schleich so ungeliebten Staffage in den Bildern, so beispielsweise im Gemälde Waldlandschaft mit Rinderherde (1850, Privatbesitz). ${ }^{10}$

Die überwiegend bukolische Themenwahl seiner Bilder erfreute sich größter Beliebtheit beim Publikum und garantierte Voltz nicht nur die Anerkennung seiner Künstlerkollegen. 1863 wurde er zum Ehrenmitglied der Münchner Akademie, 1869 zum Mitglied der Akademie in Berlin sowie 1870 zum Mitglied der Akademie in Wien ernannt. ${ }^{11}$ Darüber hinaus wurde ihm durch König Ludwig II. von Bayern der Professorentitel verliehen. ${ }^{12}$

Ifee Tack

\footnotetext{
Ebertshäuser 1979, S. 274.

Rott 2003, S. 353.

http://www.museum-vilsbiburg.de/index.php?id=206, 29.10.2012.

Thieme/Becker 1907-1950, Bd. 34, 1940, S. 537.

12 Holland 1896, S. 280.
} 

Kat. Nr. 25

August Keßler (1826-1906)

\section{Strand bei Blankenberghe}

1882

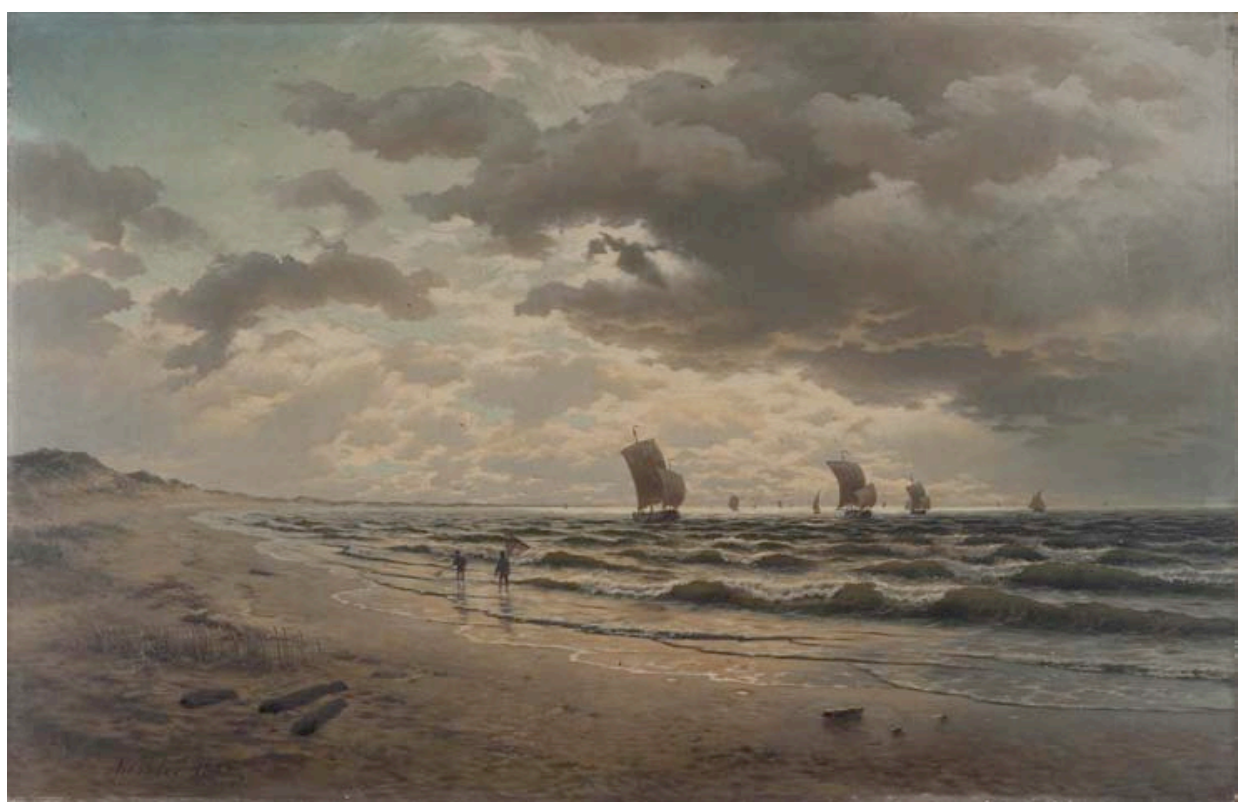

Öl auf Leinwand, 62 x 94 cm, signiert und datiert, Herkunft unbekannt, Inv. Nr. GG 147

August Keßlers Landschaftsgemälde präsentiert einen Blick auf einen Strandabschnitt im flämischen Blankenberghe, einem Ort an der Nordseeküste unweit der Stadt Brügge. Es ist ein querformatiges Ölgemälde mit einem tief liegenden Horizont und einer kaum wahrzunehmenden Abtönung zwischen den Blautönen des Himmels und der Meerespartie. Überlegt komponiert, zeigt die Szenerie einen Sandstrand, der, vom linken Bildrand kommend, sich in die rechte Bildhälfte zieht, und einen bewölkten Himmel, dessen schwere Wolken sich als gestalterisches Gegengewicht zum Strand von der rechten Bildhälfte ausgehend in die linke ausdehnen. Im Hintergrund ist eine Reihe von Segelschiffen erkennbar.

August Keßler war ein Maler, der sich in seinem Euvre ausschließlich der Landschaft widmete. Geboren 1826 im damaligen ostpreußischen Tilsit (heute Sowestsk im russischen Oblast Kaliningrad) und gestorben 1906 in Düsseldorf, 
war er bereits im Alter von 18 Jahren Schüler an der renommierten Düsseldorfer Akademie und lernte dort bis 1851 überwiegend bei Johann Wilhelm Schirmer, ${ }^{1}$ einem der erfolgreichsten Landschaftsmaler Deutschlands. Während Schirmer mit seinen Landschaften durch eine intensive Farbigkeit und Tonwirkung Stimmungsbilder zu erzeugen vermochte, zeigen Keßlers Exterieurs zumeist farblich eher gedämpfte Landschaften. Die Klarheit eines Schirmerschen Kolorits ist bei ihm verschleiert und die Szenerie wirkt wie in Nebel und Dunst gehüllt. Besonders typisch für sein Gesamtwerk sind deutsche Waldlandschaften. Seelandschaften, zu denen auch das Gemälde der Göttinger Universitätskunstsammlung gehört, malte Keßler nur gelegentlich. ${ }^{2}$

Vergleichsbilder zum Göttinger Gemälde finden sich im Euvre seines Lehrers Schirmer, der während eines Studienaufenthaltes in der Normandie einige kleinformatige Seestücke malte. ${ }^{3}$ Trotz seiner Kontakte zur sich in Frankreich entwickelnden Pleinairmalerei blieb Schirmer ein Vertreter einer klassisch-idealen Landschaftskunst, was sich auch auf seinen Schüler Keßler übertragen hat. Denn Keßler komponierte seine Landschaften, und obwohl er Freiluftstudien betrieben hat, ging er den letzten Schritt in Richtung der Stimmungsmalerei des Impressionismus nicht, sondern blieb bei der akademischen Landschaftsmalerei.

Katharina Immoor

\footnotetext{
1 Vgl. Lichtenberg 1998a, S. 227.

2 Vgl. ebd., S. 228.

3 Vgl. Lichtenberg 1998b, S. 204.
} 
Kat. Nr. 26

Karl Buchholz (1849-1889)

\section{Der Teich}

Nach 1880

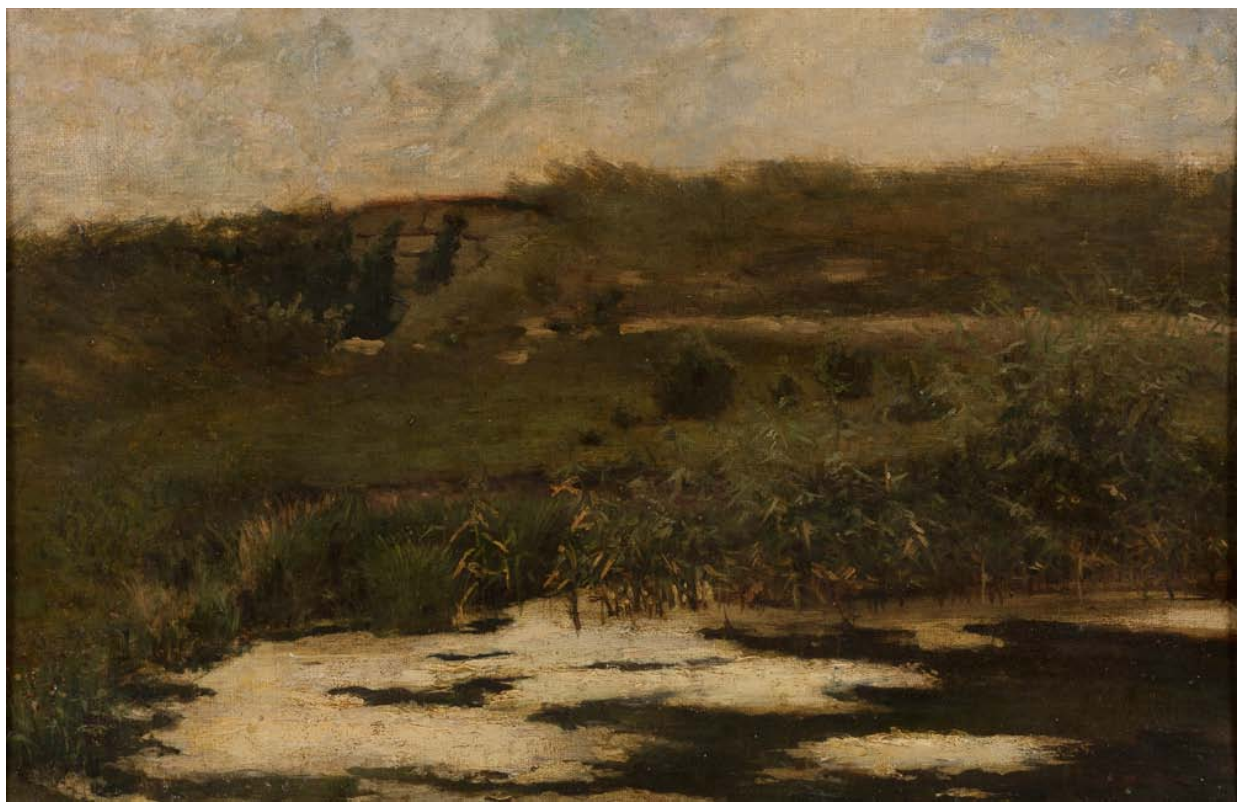

Öl auf Leinwand auf Pappe, 25,4 x 38,3 cm, rückseitig signiert und bezeugt, 1966 aus der Sammlung Eugen Dumont mit Mitteln der Volkswagenstiftung angekauft, Inv. Nr. GG 121

Mit dem Gemälde Der Teich hat man ein Werk vor sich, das eine besondere Stellung im CEuvre Karl Buchholz' einnimmt. Noch im Jahr 2000 nahm Eckart Kißling an, dass sich Buchholz in seiner Landschaftsmalerei auf flache Landschaftsausschnitte, Waldstücke wie dem berühmten Webicht bei Weimar, oder vereinzelt auf ein Fließgewässer beschränkt habe. Ein stehendes Gewässer wie einen Teich schloss er dabei aus Buchholz' Euvre aus. ${ }^{1}$ Diese Aussage lässt sich schon allein durch die Existenz des Göttinger Gemäldes widerlegen.

1 Kißling 2000a, S. 18 f. 


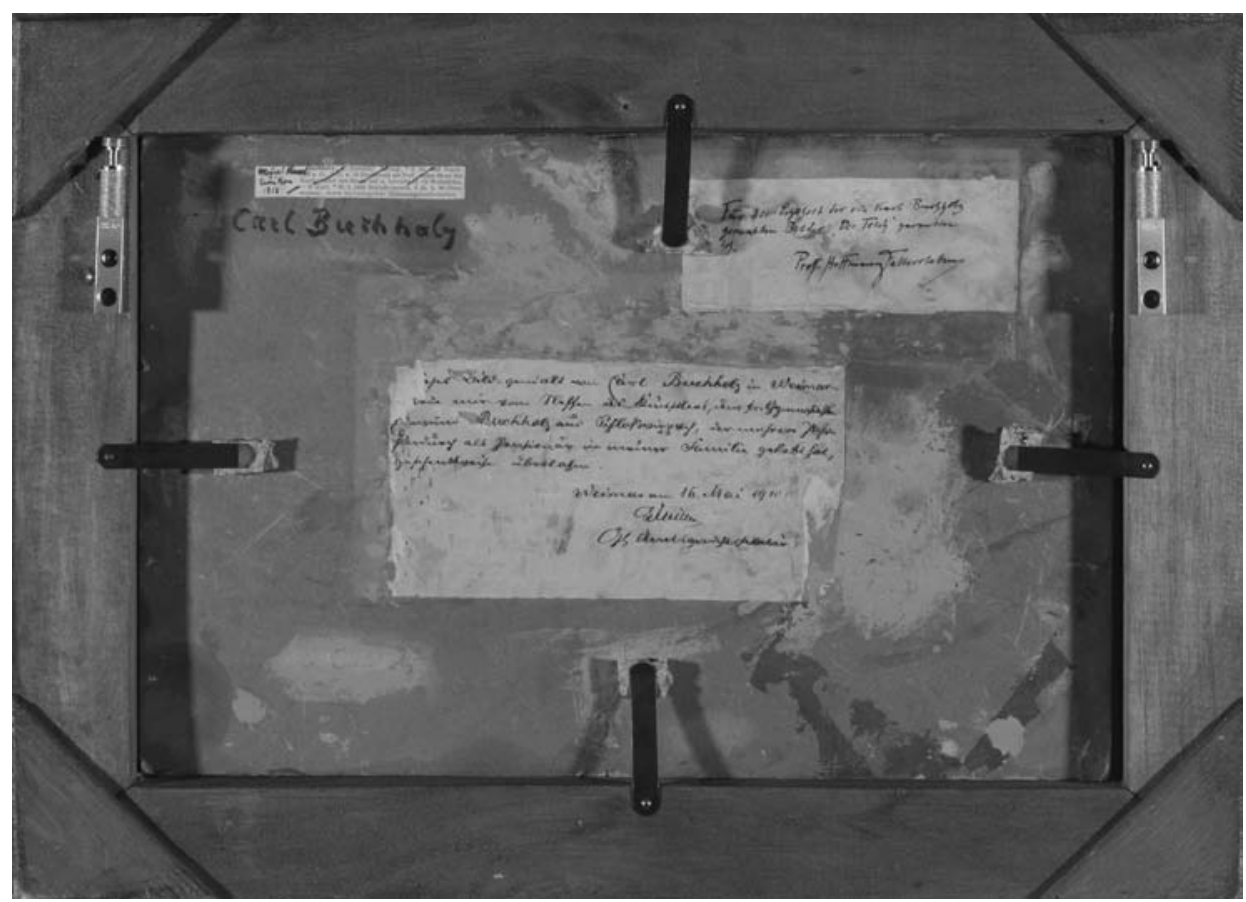

Abb. 35: Karl Buchholz: Der Teich, Rückseite mit Beglaubigungen

\section{Die Bildrückseite als Quelle}

Dass das Gemälde Der Teich tatsächlich von Buchholz gemalt wurde, wird durch mehrere Indizien untermauert. Rückseitig befindet sich die Signatur des Künstlers zusammen mit zwei handschriftlichen Echtheitsbeglaubigungen (Abb. 35). Die erste, oben rechts angebrachte Beglaubigung stammt von Prof. Franz HoffmannFallersleben, einem Kunsthistoriker und Maler, der zusammen mit Buchholz an der Weimarer Kunstschule studiert hatte und wohl zu den wenigen Personen gehörte, die dem Künstler nahe standen. ${ }^{2}$ Hier findet sich auch die Erwähnung des Titels Der Teich. Die zweite, in der Mitte angebrachte Beglaubigung stammt vom Großherzoglichen Amtsgerichtssekretär Müller und ist auf den 15. Mai 1910 datiert. Müller beglaubigt, das Werk von Edmund Buchholz, dem Neffen des Künstlers - wohl als Bezahlung - erhalten zu haben, da dieser längere Zeit bei ihm als Pensionär gelebt hatte.

2 So schildert er seine Erinnerungen an Karl Buchholz in einem Artikel, der in Der Türmer erschien; vgl.: Hoffmann-Fallersleben (1908/09). Neu abgedruckt in: Ausst.-Kat. Lübeck 2000, S.150-153. 
Diese Testate finden sich ein weiteres Mal an einem Werk des Künstlers, nämlich an der Ölstudie Landschaft in Oberfranken (Abb. 36, 37) im Besitz des Weimarer Schlossmuseums. ${ }^{3}$ In Urhebern, Schrift, Wortlaut und Papier gleichen sie den Göttinger Beglaubigungen fast vollständig. Beide Werke sind bislang die einzigen bekannten Stücke mit solchen Testaten auf ihrer Rückseite. Dabei ist bemerkenswert, dass beide Bilder Motive zeigen, die untypisch für das Euvre des Malers sind.

Nach dem Freitod von Karl Buchholz am 23. Juni 1889 wurden Gemälde und Studien, die sich zu diesem Zeitpunkt in seinem Atelier befanden, veräußert. Nicht signierte Stücke wurden mit Testaten von Personen aus Buchholz' näherem Umfeld versehen. ${ }^{4}$ Es ist also wahrscheinlich, dass beide Werke aus diesem Kontext stammen und es noch weitere Bilder mit ähnlichen Testaten gibt.

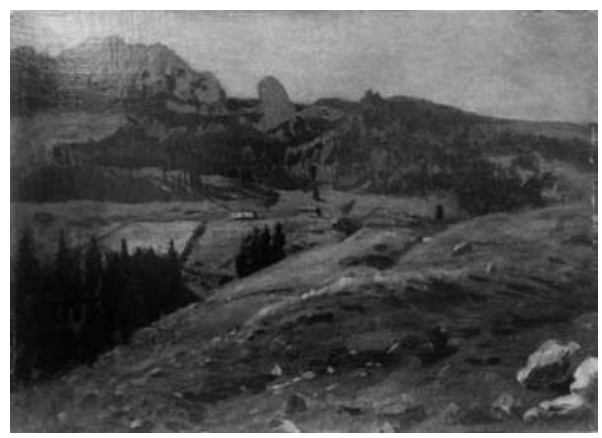

Abb. 36: Karl Buchholz: Landschaft in Oberfranken, Öl auf Pappe, 34,5 x 47,3 $\mathrm{cm}$, Weimar, Schlossmuseum

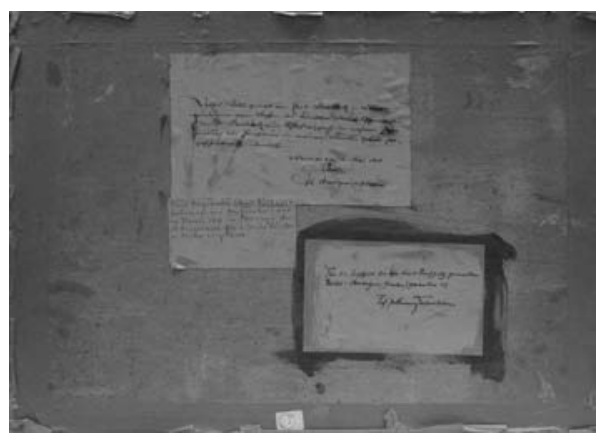

Abb. 37: Karl Buchholz: Landschaft in Oberfranken (wie Abb. 36), Rückseite

\section{Zum Bildaufbau}

Der Teich ist ein querformatiges Ölgemälde und zeigt ein stehendes Gewässer vor einem Landschaftshintergrund. Es ist anzunehmen, dass es sich hierbei um eine Ölstudie handelt. Vergleicht man die Ausführung mit fertiggestellten Gemälden von Buchholz, so zeigt sich der skizzenhafte Charakter in der vermehrt flächigen Ausführung und dem Verzicht auf eine detaillierte Ausarbeitung.

Die Studie ist in mehreren, weitgehend bildparallelen, tendenziell leicht von links nach rechts ansteigenden Schichten aufgebaut. Im Vordergrund befindet sich, von der Bildunterkante angeschnitten, der Teich, der an der linken Seite von einer

3 Karl Buchholz: Landschaft in Oberfranken, Öl auf Pappe, 34,5 x 47,3 cm, Schlossmuseum, Weimar, (Inv.-Nr.: Ge-2011/5).

4 Kißling 2000b, S. 115. 
in die Bildtiefe führenden Grasfläche begrenzt wird. Diese leicht ansteigende Fläche schirmt das Gewässer auch nach hinten hin ab. Sie ist mit mehreren Büschen besetzt und bildet den Mittelgrund des Bildes, der von einer hellbraunen, wohl einen Weg bezeichnenden Linie bildparallel abgeschlossen wird. Im Hintergrund wird ein Wall sichtbar, der sich links öffnet und den Blick auf Nadelbäume sowie auf eine hellbraune Fläche freigibt. Die obere Wallgrenze verläuft weitgehend parallel mit der leicht ansteigenden Begrenzung des Teiches im Vordergrund. Eine dunkle Farbpalette aus Braun- und Grüntönen verbindet Wasser, Wiese und Wall. Überfangen wird die Landschaft durch einen grau verhangenden Himmel, der vereinzelt ein leichtes Hellblau durchscheinen lässt.

Auf der Wasseroberfläche bildet sich nach links zunehmend eine weiße Fläche, die nicht genau bestimmt werden kann. Auf Grund der nahezu geschlossenen Wolkendecke erscheint die Möglichkeit einer Wolkenreflexion auf dem Wasser als unwahrscheinlich. Wahrscheinlicher ist, dass es sich um eine Algen- oder Schaumbildung handelt, die aber im unklaren bleibt. Sicher ist nur, dass diese Fläche als kompositorisches Mittel eingesetzt ist, indem sie einer dunkleren Schilffläche rechts, die am Teichufer steht, ein helles Pendant gibt.

An eben diesem Schilfwuchs lässt sich Buchholz' besonderes Talent für einen graphischen Pinselstrich erkennen. ${ }^{5}$ Mit feinen Linien und einem nur leicht aufgehelltem Grün-Ton setzt er die filigranen Halme an das Ufer. Daran sprießt ein Blattwerk, zwischen dem er mit kleinen Pinselstrichen in hellen Braun-Tönen Blüten setzt. Das Schilf gewinnt nach rechts an Höhe und Dichte. Der untere Bereich in der Nähe des Ufers ist dabei sehr dunkel, was auf einen dichten Wuchs schließen lässt. Nach oben hellt er sich merklich auf, so dass die am höchsten reichenden Pflanzen kaum noch klar zu erkennen sind. Indem die Schilfpflanzen des Vordergrunds beinahe alle Schichten des Bildes überschneiden, verklammert Buchholz den Bildraum und führt ihn auf die Bildfläche zurück.

Die detailreiche Ausführung nimmt zum Hintergrund hin ab, so dass sich trotz der spärlichen Angaben eine perspektivische Tiefenwirkung einstellt. Bereits der Mittelgrund wird flächiger behandelt. Hier lässt sich der Verlauf des Pinselduktus gut nachvollziehen - an einigen Stellen scheint aufgrund des dünnen Farbauftrags sogar die Leinwand durch.

Auf der sich im Mittelgrund erstreckenden Wiese, die nach hinten durch den Wall begrenzt wird, modelliert Buchholz mit grünen Nuancen mehrere Büsche plastisch heraus. Sie führen damit im Mittelgrund die dunkle Höhenerstreckung des Schilfs am Teich weiter.

In ihrer Farbigkeit und Malweise unterscheidet sich die Wiese kaum vom Wall. Buchholz setzt aber eine kompositorisch überaus wichtige, helle, horizontale Linie ein, die beide Flächen definiert und die Wiese rahmt. Dabei verwendet er die Farbe

5 Die geradezu graphische Darstellung von kahlen Bäumen, deren Äste sich fein verzweigen, ist für Buchholz charakteristisch und nimmt in seinem späteren Werk zu; vgl. Wendermann 2011, S. 17. 
der Uferlinie, während beim grauen Himmel die Fläche des Wassers wieder aufgenommen wird, so dass eine innerbildliche Rahmung entsteht.

Obwohl es sich um eine Ölstudie handelt, zeigt das Göttinger Bild die charakteristische Arbeitsweise von Karl Buchholz sehr deutlich. Zunächst legte dieser seine Bilder farblich an. Diese Farbschicht wurde dann mit Bimsstein abgeschliffen, um als Grundlage für seine graphische Feinmalerei zu dienen. Der bildimmanente Aufbau ist zudem typisch für die Weimarer Pleinairisten. Der zunächst als willkürlich gewählt erscheinende Bildausschnitt erweist sich bei genauerer Analyse durchaus als komponiert und bewirkt durch die Rahmung eine „,innere Festigkeit und Geschlossenheit“ des Bildes. ${ }^{6}$

Nach links löst sich die helle Linie, die man als Weg deuten kann, schrittweise auf. Nur punktuell erscheinen noch helle Farbflecken, die sich diesem zuordnen lassen - der kräftigste davon unter der Öffnung des Walls. Dieser helle Akzent wird unmittelbar unter dem dunkelsten Punkt des Bildes, dem Fuß einer Tanne, als Kontrastpunkt gesetzt.

In der Öffnung des Walls stehen mehrere nach rechts geneigte Tannen, von denen zwei klar zu erkennen sind, die restlichen aber zu einer dunklen Fläche verschmelzen. Mit ihrer Neigung führen sie den unterbrochenen Wall fort und verbinden ihn mit seinem rechten Teil. Zwischen den Tannen ragt eine graubraune Fläche hervor. Die feinen, dunklen Linien unterteilen diesen Bereich und erzeugen einen bearbeiteten Eindruck. Worum es sich hierbei genau handelt, bleibt unklar. Es könnte sich um den Steinbruch in Ehringsdorf handeln, den auch schon Christian Rohlfs abbildete. ${ }^{7}$ Da Buchholz nicht selten in der Gegend um Ehringsdorf malte, erscheint dies naheliegend. ${ }^{8}$

\section{Buchholz und die Weimarer Malerschule}

Karl Buchholz ist einer der wichtigsten Vertreter der Weimarer Malerschule. Gerade in der Phase zwischen 1870 und 1880 gehörte er zu denjenigen, die mit ihren Landschaftsdarstellungen den Stil der Schule maßgeblich prägten. ${ }^{9}$

In Schloßvippach bei Weimar geboren, kannte sich Buchholz in der Umgebung gut aus und konnte so auf ein reiches Motivreservoir zurückgreifen. Im Unterschied zu anderen Malern verließ er seine Heimatstadt sehr selten. Studienreisen nach Paris oder Barbizon, wie sie andere Künstler der Weimarer

6 Ziegler 2001, S. 85; weiteres zu Buchholz' Maltechnik siehe ebd., S. 84 f.

7 Rohlfs machte den Steinbruch ganze vier Mal zum Thema seiner Malerei. Zum Vergleich siehe: Steinbruch, in: Ausst.-Kat. Münster 1989, S. 74, Kat. 6, oder Verfallener Steinbruch, in: ebd., S. 75, Kat. 8.

8 Zu nennen wäre hier beispielsweise der motivische Gebrauch der Ehringsdorfer Kirche in seinen Werken Frübling auf dem Dorfe, in: Ausst.-Kat. Lübeck 2000, S. 57, Kat. 1 und Landschaft bei Ehringsdorf, in: ebd., S. 80, Kat. 13 aber auch in Kirchgang in Ehringsdorf, in: Scheidig 1971, S. 127, Abb. 55.

9 Ziegler 2001, S. 66 f. 
Malerschule zu unternehmen pflegten, machte er nie. Seine Besuche anderer Städte innerhalb Deutschlands waren ebenfalls rar. ${ }^{10}$ So wurde er beinahe zwangsläufig zu einem Spezialisten für die Landschaft von Weimar. Demnach verwundert es auch nicht, dass die Motive in seinem CEuvre hauptsächlich aus der nahen Umgebung Weimars stammen.

Eine Besonderheit der Weimarer Kunstschule war das große Gewicht, das man auf die Landschaftsmalerei legte. Anderenorts bildete diese kein eigenständiges Fach im akademischen Betrieb. In München beispielsweise bekamen die Schüler im Zusammenhang mit der Historienmalerei lediglich das Nötigste beigebracht, um eine geeignete Umgebung für ihre Handlung schaffen zu können. Eine eigenständige Landschaftsklasse wurde dort erst 1891 wieder eingerichtet. ${ }^{11}$ Einen Vorteil (und eine Neuerung) des Weimarer Lehrbetriebs stellte des weiteren die Option dar, als Schüler seinen Lehrer selbst wählen zu dürfen. Ein ungewollter Stil wurde somit niemanden aufgedrängt. ${ }^{12}$

Der Unterricht von Alexander Michelis, der von 1863 bis 1868 die Landschaftsklasse übernommen hatte, basierte auf der Freilichtmalerei. ${ }^{13}$ An der Düsseldorfer Akademie war diese schon seit Schirmer ein Bestandteil der Ausbildung, aber erst in Weimar wurde die Freilichtmalerei elementar für die Bildung des eigenen Stils der Schüler. ${ }^{14}$

Buchholz kam 1867 an die Malerschule und war nur kurz Schüler bei Michelis, da dieser bereits 1868 verstarb. Theodor Hagen, ab 1871 Professor für Landschaft in Weimar, sollte der wichtigere Lehrer für ihn werden. Er unterstützte ihn auch finanziell durch Freistellung oder Freiatelier. Hagens größte Leistung als Lehrer bestand jedoch darin, seinen Schülern Freiräume für die eigene Entwicklung zu geben. Er erkannte ihren eigenen Stil und förderte ihre Ausbildung, indem er seine, der Düsseldorfer Schule treu bleibende, Kunstauffassung nicht als Lehrdogma proklamierte. Stattdessen riet er seinen Schülern zu einer verstärkten Auseinandersetzung mit der Weimarer Umgebung. ${ }^{15}$ Zudem brachte Hagen von seiner Studienreise nach Paris und Barbizon im Jahre 1867 wichtige Impulse mit, welche die pleinairistische Ausrichtung der Weimarer Künstler bestätigten und festigten. ${ }^{16}$

Ein bedeutender Einfluss ging aber auch von Albert Brendel, von Haus aus Tiermaler, aus, der zwischen 1875 und 1895 Professor in Weimar war. Er hatte zuvor mehrere Jahre in Paris und Barbizon gelebt und kaufte 1879 für Weimar Reproduktionen nach Gemälden von Camille Corot. Weiterhin waren mehrere Druckgraphiken von Malern aus Barbizon und sogar Photographien der

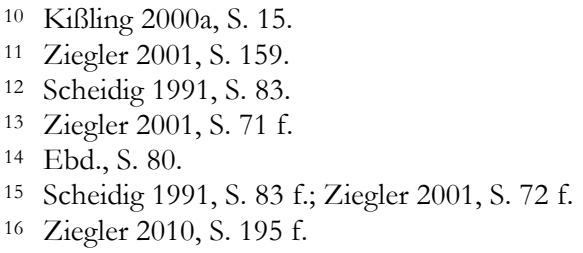


französischen Landschaft in seinem Besitz. ${ }^{17}$ Brendel kann demzufolge als einer der wichtigsten Vermittler zwischen Weimar und der barbizonistischen Kunstauffassung bezeichnet werden. ${ }^{18}$

In Werken von Buchholz wie Herbstwald bei Sonnenuntergang ${ }^{19}$ oder Im Webicht ${ }^{20}$ manifestiert sich eine Weimarer Variante des französischen Paysage intime. ${ }^{21}$ Buchholz fand diese intime Landschaft in der Umgebung Weimars.

Neben den französischen Künstlern gehörte zudem die niederländische Haager Schule, welche die französische Strömung mit niederländischen Traditionen verband, zu den wichtigen einflussgebenden Richtungen für Buchholz' Kunst. $^{22}$ In Weimar standen dem Künstler zudem die bereits erwähnten Photographien und Graphiken von Werken der Barbizonisten zu Studienzwecken zur Verfügung. Spätestens ab 1881 waren die Künstler von Barbizon mit Radierungen und Reproduktionen in der Permanenten Kunstausstellung in Weimar präsent. ${ }^{23}$ Und wenngleich er nicht viel reiste, war Buchholz auf der II. Internationalen Kunstausstellung im Münchener Glaspalast 1879 und zeichnete nach Originalen von Constant Troyon und Charles-François Daubigny. ${ }^{24}$

Es bestehen also viele Anknüpfungspunkte zur Schule von Barbizon. Gleichwohl ist eine explizite Anlehnung in der Forschung umstritten, so dass aus einer gewissen Verlegenheit heraus schon früh von einer „Gefühlsparallele“ gesprochen wurde. Nach diesem Erklärungsversuch sollen sich der Stil der Weimarer Malerschule und der Schule von Barbizon voneinander unabhängig entwickelt haben ${ }^{25}$ - eine These, die sicher auch vor dem Hintergrund des antifranzösischen Nationalismus um 1900 gesehen werden muss. Einig ist man sich in der Forschung aber in der Annahme, dass sich die Weimarer Künstler in ihrer Malerei durch die Franzosen und deren Erfolg zumindest bestätigt gesehen haben müssen. ${ }^{26}$

Viele Weimarer Künstler wie Theodor Hagen oder Christian Rohlfs wurden spätestens ab den 1890er Jahren durch den sich etablierenden Impressionismus beeinflusst. ${ }^{27}$ Wie offen Buchholz gegenüber modernen Strömungen war, hätte anhand einer Impressionismusrezeption deutlich werden können. Leider hat der Künstler 1889, unmittelbar vor deren Einsetzen in Weimar, den Freitod gewählt.

Phil Miller

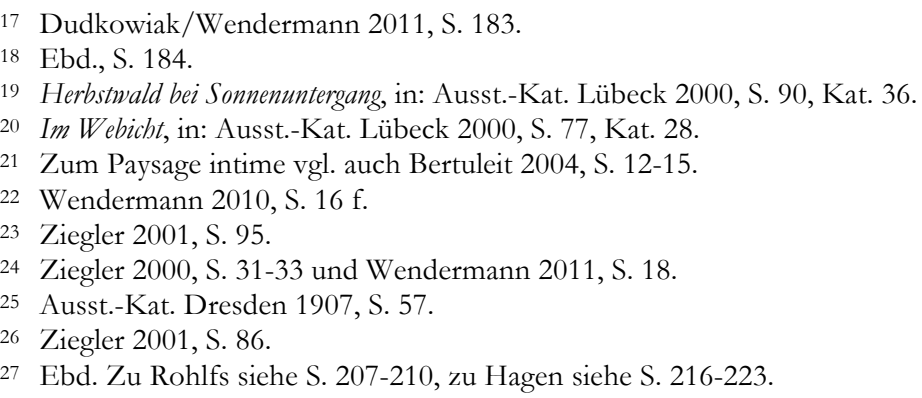

Dudkowiak/Wendermann 2011, S. 183.

Ebd., S. 184.

Herbstwald bei Sonnenuntergang, in: Ausst.-Kat. Lübeck 2000, S. 90, Kat. 36.

Im Webicht, in: Ausst.-Kat. Lübeck 2000, S. 77, Kat. 28.

Zum Paysage intime vgl. auch Bertuleit 2004, S. 12-15.

Wendermann 2010, S. $16 \mathrm{f}$.

Ziegler 2001, S. 95.

Ziegler 2000, S. 31-33 und Wendermann 2011, S. 18.

Ausst.-Kat. Dresden 1907, S. 57.

Ziegler 2001, S. 86.

27 Ebd. Zu Rohlfs siehe S. 207-210, zu Hagen siehe S. 216-223. 

Kat. Nr. 27

Otto Peters (1835-1920)

\section{Göttinger Vorstadthaus um 1880}

Um 1900

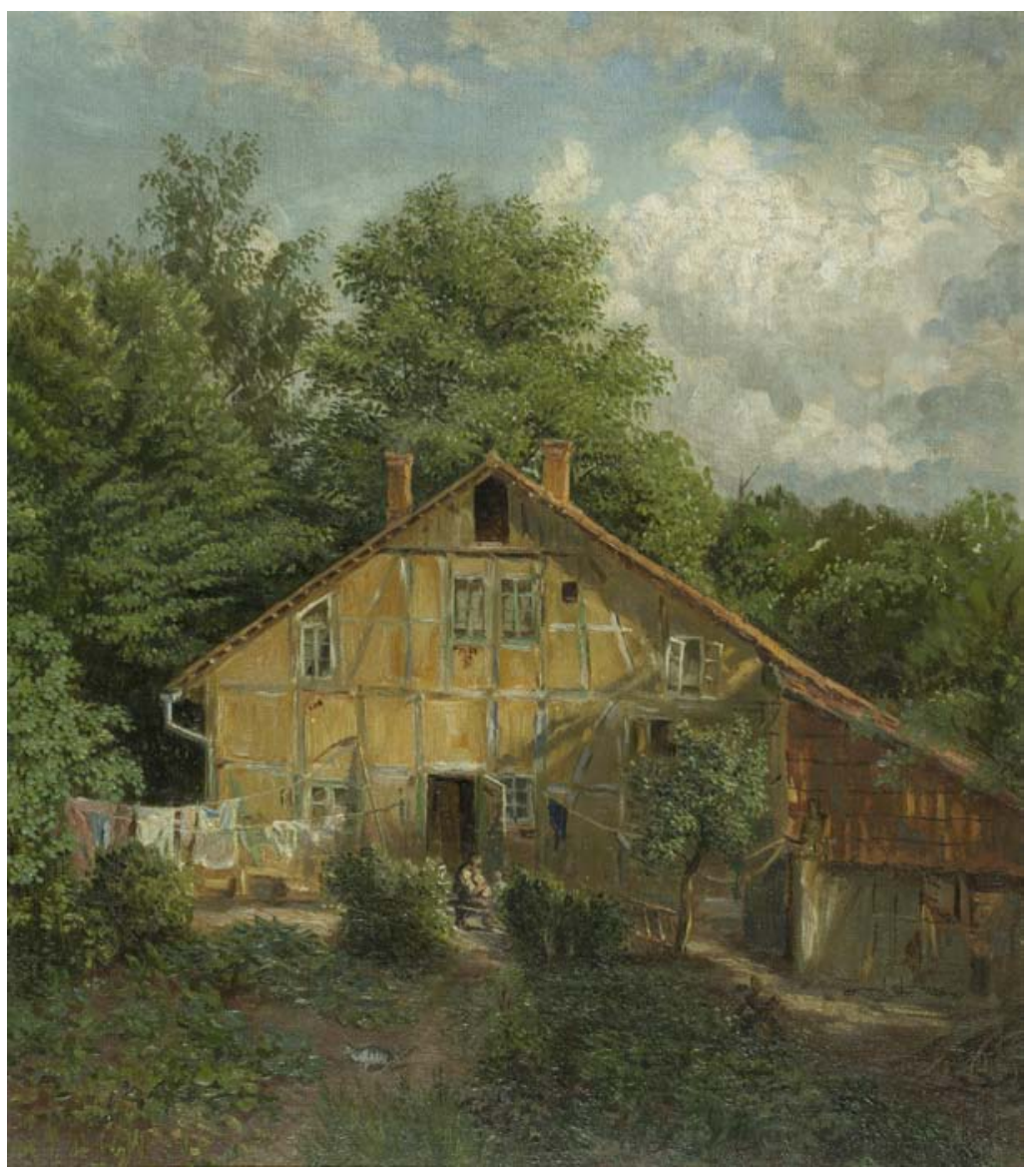

Öl auf Malpappe, 38 x 43,5 cm, 2010 von Heinz Erler geschenkt, Inv. Nr. GG 275

Zu den wichtigen Aufgaben der Landschaftsmalerei gehört das (zumindest dem Anspruch nach) wirklichkeitsgetreue Abbilden existierender Szenerien. Hier ist insbesondere die bedeutende Untergattung der Vedute zu nennen, für die sich ab 
der Frühen Neuzeit durch den aufkommenden Bildungstourismus ein eigener Markt entwickelte. ${ }^{1}$ Andere Bilder existierender Szenerien hatten eher einen privaten Charakter - so auch das Göttinger Bild von Otto Peters, das sich keiner berühmten Ansicht widmet, sondern dem intimen Blick auf ein benachbartes Wohnhaus. Gattungsgeschichtlich wurde der Rang solcher Ansichten innerhalb der Landschaftsmalerei zunächst eher niedrig angesetzt, weil hier die künstlerische Invention vermeintlich kaum zum Tragen kam. ${ }^{2}$ Im späten 19. Jahrhundert erfuhren sie allerdings - getragen von Kunstkonzepten aus dem Umfeld des „Realismus“ - eine zunehmende Wertschätzung. ${ }^{3}$

Das hochformatige Gemälde von Otto Peters zeigt den Blick von einer erhöhten Position auf den Giebel eines schlichten Fachwerkhauses, vor dem sich ein verwilderter Garten mit Büschen und Kräutern befindet. Bäume hinterfangen die Silhouette des Hauses, so dass sich insgesamt der Eindruck einer ländlichen Szenerie ergibt. Das Haus ist annähernd bildparallel angeordnet. Sein Dach, das in der eher flachen Form an Schweizerhäuser erinnert, bedeckt ein Erd- sowie ein Dachgeschoss, über dem sich eine Luke in einen niedrigen Boden öffnet. Auf der rechten Seite ist das Dach weiter hinuntergezogen. Hier ist eine Art Schuppen vor das Haus gesetzt, der vom linken Bildrand angeschnitten wird. Bunt bestückte Wäscheleinen sind zu beiden Seiten zwischen Haus und den davor angeordneten Bäumen gespannt. Vor der geöffneten Tür sitzt, von zwei Büschen eingefasst, eine Frau mit zwei Kindern auf einer Bank. Im Vordergrund sieht man auf einer Wegkreuzung eine grau getigerte Katze.

Das Bild wird von den warmen Ockertönen der offensichtlich mit Lehm verputzten Gefache sowie vom Rot der Dachziegel und der zwei Schornsteine des Hauses bestimmt, die sich vom Grün der Bäume und Büsche absetzen. Hinter den Bäumen wird ein blauer Himmel mit weißer und grauer Bewölkung sichtbar. Das Licht kommt von rechts oben und beleuchtet den Giebel, auf dem der Schuppen und die Bäume Schatten werfen. Eine größere weiße Wolkenfläche im rechten oberen Bildviertel bildet ein Gegengewicht zu den angestrahlten Giebelpartien. Der krautige Vordergrund ist hingegen verschattet.

\section{Der Künstler}

Otto Peters stammt aus einer vor allem in Schleswig-Holstein wirkenden Künstlerfamilie, deren Erwartungshorizont sich nicht zuletzt in der Namensgebung ihres Nachwuchses offenbart: der ältere Bruder hieß Raphael Peters und ein Onkel Hermann Titian Peters. ${ }^{4}$ Otto Peters studierte ab 1851 bei Theodor Hildebrandt an der Düsseldorfer Kunstakademie; später wechselte er

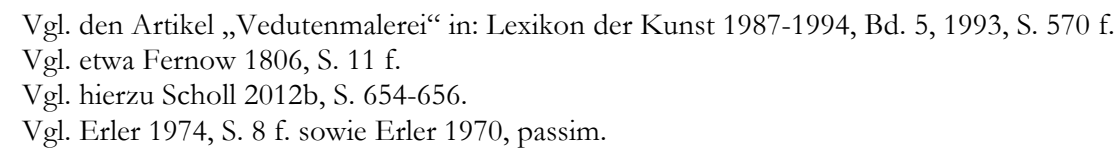


nach München, wo er nach eigenen Angaben bei Carl Theodor von Piloty lernte. Schließlich studierte er auch noch in Dresden. ${ }^{5}$ Nachdem er zeitweise als Zeichner an der Göttinger Anatomie gearbeitet hat, wurde er 1859 Zeichenlehrer an der Bergschule in Clausthal-Zellerfeld. ${ }^{6} 1864$ erhielt er auf Empfehlung des bedeutenden Göttinger Anatomen Jakob Henle (1809-1885) eine Stellung als Universitätszeichenlehrer an der Georgia Augusta in Göttingen. ${ }^{7}$ Henle, von dem die Göttinger Universitätskunstsammlung ein Porträt des ansonsten unbekannten Malers A. Schmidt besitzt (Kat. Nr. 47) und von dem unlängst eine Porträtzeichnung von Eduard Bendemann in Privatbesitz ${ }^{8}$ aufgetaucht ist, dürfte den Künstler von dessen Tätigkeit als Anatomiezeichner gekannt haben.

Peters gab an der Universität Göttingen Mal- und Zeichenunterricht und schuf Anschauungsmaterial für die medizinische Fakultät, für die naturwissenschaftlichen Disziplinen und für die Archäologie. Seine Stellung an der Universität, die er 50 Jahre lang innehatte, wird als schwierig und entbehrunsgreich beschrieben. ${ }^{9}$ Daneben arbeitete er als freischaffender Maler. Neben der hier besprochenen Landschaft bewahrt die Universitätskunstsammlung von seiner Hand als Leihgabe des Museumsvereins für das Fürstentum Lüneburg noch ein Porträt aus dem Jahre 1859, das Ernst Ehlers als Student zeigt (Kat. Nr. 53).

\section{Ein Bild aus dem alten Göttingen}

Glücklicherweise sind durch zahlreiche neuere Beschriftungen sowie ein Begleitschreiben des Schenkers umfassende Kenntnisse über das Göttinger Landschaftsgemälde von Peters überliefert. ${ }^{10}$ Tatsächlich beruht der besondere Wert dieses Bildes nicht zuletzt darauf, dass es eine konkrete Situation in Göttingen aus dem späten 19. Jahrhundert wiedergibt, für die es in dieser Form sonst wohl kaum noch Zeugnisse geben dürfte.

Peters wohnte in Göttingen im Düstere-Eichen-Weg 18. Das Göttinger Vorstadthaus um 1880 erweist sich als Blick aus seinem Atelier auf die Rückseite des Hauses Rohnsweg 5, welches die Familie Feußel bewohnte, die das Gebäude

\footnotetext{
Vgl. hierzu ebd., S. 9.

Vgl. ebd., S. 10.

Vgl. ebd. Peters wird von Henle als „ein mit den Bewegungen der modernen Kunst vertrauter Künstler von hohem Rang und vortrefflicher Lehrer" bezeichnet (zitiert nach ebd.). Henle leitete seit 1852 das Institut für Anatomie an der Universität Göttingen (vgl. Pagel 1905, S. 190 f.).

8 Georg-August-Universität Göttingen, Presseinformation Nr. 28/2013 - 20.02.1013: Zeichnung von Eduard Bendemann in Göttinger Privatbesitz entdeckt: www.uni-goettingen.de/ 3240.html?cid=4403 (zuletzt 10.07.2013).

9 Vgl. Erler 1970, S. 25-27; Erler 1974, S. 10.

10 Vgl. den Brief von Heinz Erler, dem Urgroßneffen des Malers, vom 7. Juli 2000 im Archiv der Universitätskunstsammlung, Bildakte GG 275. Siehe auch Erler 1970, S. 28; Ausst.-Kat. Lüneburg 1974, S. 23, Kat. Nr. 59.
} 
offenbar in den 1820er Jahren von der Familie Pauer erworben hatte: ${ }^{11}$ „von seinem Atelierfenster im ersten Stock sah er [Peters, C. S.] oft auf das familiäre Leben und Treiben im Hof und Garten der Familie Feußel mit den sechs Kindern."12 Hieraus erklärt sich die besondere Perspektive auf das Haus und dessen zum Teil mit abgebildete Bewohner.

Der Rohnsweg führt durch das Göttinger Ostviertel hinauf auf den Hainberg zum „Rohns“, einem klassizistischen, 1828-1830 errichteten Gebäude, das der Göttinger Bauunternehmer Christian Friedrich Andreas Rohns (1787-1853) als Ausflugslokal errichtet hatte und das sich lange Zeit großer Beliebtheit erfreute. ${ }^{13}$ Heute wird das Ostviertel - eine der gehobenen Gegenden der Stadt - durch seine gediegenen Villen bestimmt. Das Gemälde von Peters zeigt, dass sich hier noch in der zweiten Hälfte des 19. Jahrhunderts weitaus bescheidenere, geradezu ländlich anmutende Bauten befanden. So vermittelt es Einblicke in eine Vorstadtidylle, die in dieser Weise nicht mehr existiert.

Christian Scholl

11 Vgl. die Notiz auf der Bildrückseite: „um 1900 gemalt Mieter: Maurer Feußel m. 6 Kindern. / jährlich 60,- Mark Miete / In den 20er Jahren / kaufte Familie Feußel / das Haus von Familie Pauer sehr billig. Später umgebaut".

12 Heinz Erler an die Kunstsammlung der Universität Göttingen, den 7. Juli 2010.

13 Vgl. Freigang 2002, S. 797 f. Heute enthält das Gebäude Gästewohnungen der Universität Göttingen. 
Kat. Nr. 28

Karl Ludwig Adam Heinisch (1847-1923)

\section{Seeufer mit Angler im Schilf}

Spätes 19. Jahrhundert?

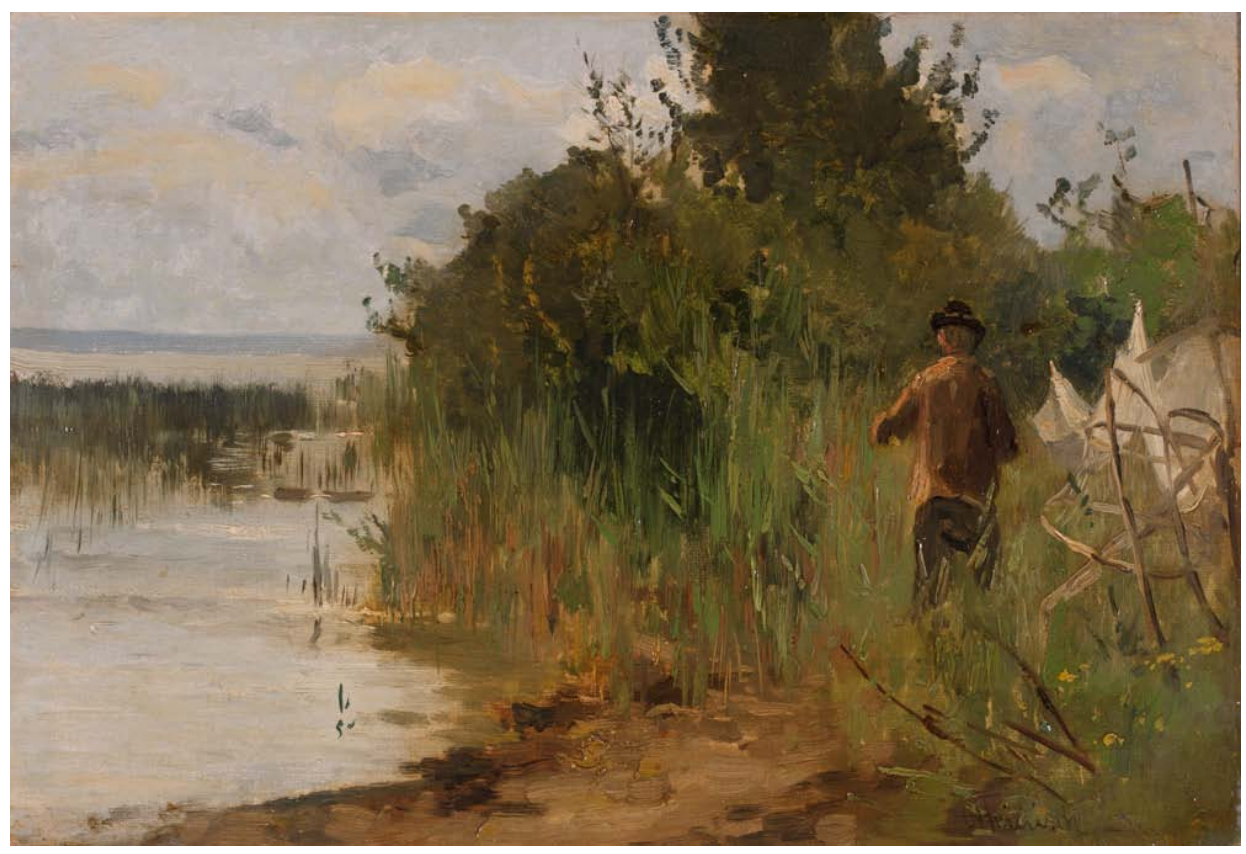

Öl auf Leinwand, 22,3 x 32,4 cm, signiert unten rechts, 1966 aus der Sammlung Eugen Dumont mit Mitteln der Volkswagenstiftung angekauft, Inv. Nr. GG 143

Der Maler und Radierer Karl Ludwig Adam Heinisch wurde am 23. März 1847 im schlesischen Neustadt (heute Prudnik) geboren und lebte ab 1870 in München. ${ }^{1}$ In diesem Jahr trat der 23-jährige am 4. Mai in die Münchner Akademie ein und

1 In der Literatur finden sich widersprüchliche Angaben über Heinischs Geburtstag und über das Jahr, ab dem er in München lebte. Der Maler wurde entweder am 23. März (Thieme/Becker 19071950, Bd. 16, 1923, S. 296) oder am 28. März (Ludwig 1982, S. 136) geboren. Bei Thieme/Becker wird jedoch explizit gesagt, dass er am 23. und nicht am 28. März geboren wurde. Die Angabe, ab wann Heinisch in München lebte, schwankt zwischen 1870 und 1871. Laut den BürgerrechtsAkten lebte er ab 1871 in München (Wichmann 1996, S. 259). Er war aber bereits seit 1870 in der Akademie eingeschrieben (vgl. Anm. 2). 
studierte dort unter der Matrikelnummer 2573.2 Mit seinen hellen Freilichtlandschaften war er zwischen 1879 und 1913 mit Motiven aus Oberbayern und vom Bodensee auf den Münchner Jahresausstellungen vertreten. ${ }^{3}$ Vom Publikum wurde er positiv aufgenommen, seine Gemälde konnte er daher gut verkaufen. ${ }^{4}$ Da Heinisch viele Gemälde mit ähnlichen Sujets schuf, ist eine Datierung des Göttinger Werkes nur schwer zu leisten.

\section{Heinischs Göttinger Landschaft}

Mit lockerem Pinselduktus hat Heinisch diese querformatige Uferlandschaft mit Angler gemalt. Die linke Seite wird von Wasser und einigen darin wachsenden Pflanzen eingenommen. Durch einen dunkleren, horizontalen Streifen erahnt man dort ein entferntes Ufer. Der erhöhte Horizont lässt den grau-blauen Himmel auf einer Höhe von zwei Dritteln des Bildes beginnen, auf welchem sich einzelne Wolken befinden. Der Blick in den Hintergrund ist nur im linken Bilddrittel möglich, die restliche Fläche des Gemäldes wird von der Flora des Ufers beherrscht und nach hinten begrenzt. Sie schließt sich zu einer grün-bräunlichen Fläche zusammen, welche - auch durch die Dominanz vertikal gesetzter Pinselstriche - einer illusionistischen Tiefenräumlichkeit entgegenwirkt und das Bild optisch auf die Fläche zurückbindet.

Die geschwungene Uferlinie verläuft auf der linken Bildhälfte weitgehend vertikal in den Hintergrund. Entlang einer horizontalen Achse setzt Heinisch links Uferpflanzen auf das Wasser, die als kompakte Fläche erscheinen. Diese trennen den Hintergrund von dem vorderen Bereich. Auf diese Weise wird mit dem begrenzten Vordergrundraum eine kleine Bühne geschaffen. Diese besteht aus erdigem Boden, der nach rechts hin in Gras- und Schilfwuchs übergeht. Dahinter türmt sich dichtes Gebüsch auf, dessen höchste Auswüchse den oberen Bildrand überschneiden. Mitten im Schilf steht im Vordergrund, den Rücken zum Betrachter gewendet, ein Mann, der eine braune Jacke und einen dunklen Hut trägt. Aus seiner Haltung lässt sich auf eine Tätigkeit schließen, von der jedoch nichts zu erkennen ist. Der Titel des Gemäldes verrät, dass es sich um eine Beschäftigung handeln muss, die mit Angeln in Verbindung steht. Vielleicht bereitet er seine Anglerausrüstung vor - eine Angel ist nämlich nirgends auszumachen. Am rechten Bildrand befindet sich ein durch die flüchtige Malweise schwer zu deutendes Objekt. Die weiße Fläche dort türmt sich spitz auf und fällt in langen Wölbungen in sich zusammen. Es ist wahrscheinlich, dass es sich dabei um ein zum Trocknen oder Flicken aufgespanntes Fischernetz handelt.

Der Pinselduktus des Malers ist in diesem Gemälde deutlich zu erkennen. Das erdige Ufer am unteren Bildrand wird in verschiedenen Brauntönen mit einem

2 München, Akademie der bildenden Künste, Matrikelbuch II, Nr. 2573.

3 Thieme/Becker 1907-1950, Bd. 16, 1923, S. 296.

4 Wichmann 1996, S. 259. 
breiteren Pinsel durch kurze, waagerechte Striche modelliert. Der Eindruck, dass das Ufer matschig erscheint, wird nicht zuletzt durch den pastosen Farbauftrag verstärkt. Gegen die breiten, horizontal verlaufenden Pinselzüge erheben sich kontrastiv die feinen, vertikalen Striche des darüber befindlichen Schilfs. Der dichtere Wuchs dahinter erlangt seine Plastizität durch helle Akzente, die mit kleinen Tupfern in verschiedenen Grüntönen auf die dunkle Masse gesetzt sind. Es handelt sich hierbei nicht um eine klar umgrenzte Ansammlung von Büschen und Bäumen, sondern um eine tonige Fläche. Erst die Akzente erzeugen den Eindruck von Körperlichkeit und Durchdringung.

Auch die Figur des Mannes entsteht aus Farbflächen heraus. Nicht klare Konturlinien definieren seinen Körper, dieser bildet sich vielmehr aus dem Kontrast zu den umliegenden Farben. Die hellen Braunnuancen links an dessen Kleidung zeigen an, dass ihn die Sonne von dieser Richtung her anstrahlt. Da die größere Fläche des Rückens dunkler ist, muss sie aus der linken Tiefe des Bildes strahlen.

Die Malweise verweist auf die Landschaftsmalerei der Münchner Schule, die Heinisch durch sein Studium an der dortigen Akademie kennen gelernt hat. Er malte in den Sommermonaten oft in Polling und Seeshaupt - beides Orte in der Nähe von München. ${ }^{5}$ Seeshaupt liegt dabei an der südwestlichen Spitze des Starnberger Sees, einem beliebten Motiv für Maler. ${ }^{6}$ Es ist nicht undenkbar, dass auch dieses Gemälde dort entstanden sein könnte, jedoch gibt es hierfür keine spezifischeren Anhaltspunkte.

In Polling und Seeshaupt arbeitete Heinisch zusammen mit anderen Künstlern. Diese waren Vertreter aus dem Umkreis der Münchner bzw. der Diez-Schule. In Polling hatte sich ab 1875 eine lose, vornehmlich Amerikanische Künstlergruppe um den Maler Frank Duveneck gebildet. ${ }^{7}$ Dieser studierte ab 1870, demselben Jahr, in welchem Heinisch sich immatrikulierte, in München bei dem Historienmaler Wilhelm von Diez. Es ist nicht bekannt, ob auch Heinisch Diez als Lehrer hatte. Angesichts seines herausragenden Rufes als der fortschrittlichste Lehrer der Akademie ist dies aber sehr wahrscheinlich. ${ }^{8}$ Eine Bekanntschaft zwischen Heinisch und dem Amerikaner Duveneck wäre ebenfalls denkbar.

Besonders die leichte Pinselführung, der skizzenhafte Duktus und die locker gemalten Kompositionen des Meisters Diez waren es, die auf seine Schüler übergingen. ${ }^{9}$ Aus seiner Schule gingen viele Maler der späteren Secession und des Impressionismus wie Max Slevogt hervor. ${ }^{10}$ Aber nicht nur Diez kann als Einfluss

5 Wichmann 1996, S. 259.

6 Vgl. den Beitrag zu Friedrich Voltz im vorliegenden Band (Kat. Nr. 24).

Siehe Ludwig 2006.

8 Ebd., S. 23.

9 Siehe Wilhelm von Diez: Rast, Öl auf Holz, 23,5 x 33,7 cm, 1899, Privatbesitz, in: Ludwig 1981, S. 230 und Wilhelm von Diez: Münchner Künstlerfest, Öl auf Leinwand, 55,5 x 87,2 cm, um 1870, Privatbesitz, in: Wichmann 1996, Abb. 498, S. 230.

10 Ebd., S. 230. 
geltend gemacht werden. Auch Wilhelm Leibl scheint mit seiner Pinselführung und der Betonung des Duktus auf die Maler aus diesem Umkreis gewirkt zu haben. ${ }^{11} \mathrm{Er}$ favorisierte eine „Alla-prima-Malerei“, bei der Nass auf Nass gemalt wurde, um den Buntwert der Farben zu erhalten, aber auch die malerische Handschrift heraustreten zu lassen. ${ }^{12}$ Diese Technik stammt aus der Öl-, Tempera- und Aquarellskizze, die meist in kurzer Zeit gefertigt und von den Impressionisten in besonderer Weise kultiviert wurde. ${ }^{13}$ Leibls Malerei war an der Erzeugung von „Tonflächen“ orientiert. Die Darstellung von Konturen solle sich auflösen, da klare Grenzlinien in der Wahrnehmung der Realität nicht vorkämen. ${ }^{14}$

Durch die erste Internationale Kunstausstellung in München 1869 kamen deutsche Künstler zudem in direktem Kontakt mit dem Französischen Realismus der Schule von Barbizon. Gerade die Werke von Gustave Courbet erregten die Aufmerksamkeit der Maler. Besonders Leibl war von dem Franzosen beeindruckt und es entwickelte sich eine Freundschaft zwischen den Malern. ${ }^{15}$

Karl Heinischs Gemälde Seeufer mit Angler im Schilf bündelt diese Einflüsse und bietet auf diese Weise ein reizvolles Beispiel für die Landschaftsmalerei seiner Zeit, die sich von den in der ersten Jahrhunderthälfte verbreiteten Idealen weit entfernt hat.

Phil Miller

11 Ebd.

12 Ruhmer 1984, S. 58.

13 Ebd., S. 58 f.

14 Ebd., S. 60. Siehe Wilhelm Leibl: Bauernhausgarten in Aibling, Öl auf Holz, 33, 2 x 25 cm, um 1897, Schweinfurt, Sammlung Dr. Georg Schäfer, in: Wichmann 1996, Abb. 511, S. 236.

15 Ebd., S. 263. 


\title{
Die Tiermalerei im Gattungsdiskurs des 19. Jahrhunderts: Eine Sondergattung etabliert sich
}

\author{
Verena Suchy
}

Die bildnerische Darstellung von Tieren ist so alt wie die Kunst selbst. ${ }^{1}$ Tiermotive finden sich in allen kunstgeschichtlichen Epochen, Stilrichtungen und auch Gattungen. Sie haben - zumeist als Staffage, Ornament oder allegorische Bedeutungsträger - ihren Platz in antiken Mosaiken genauso wie in frühneuzeitlichen Schlachtengemälden. Fabeldichtungen von Aesop bis Goethes Reineke Fuchs lassen das Tier seit Jahrhunderten zum Spiegelbild menschlichen Verhaltens werden; der frühmittelalterliche Physiologus interpretiert und deutet Tiermotive im Hinblick auf das christliche Heilsgeschehen und war lange Zeit entscheidend für die menschliche Wahrnehmung von Tieren. ${ }^{2}$ Mit zunehmender Bedeutung und Ausprägung der Naturwissenschaften, insbesondere auch mit der allgemeinen Anerkennung von Darwins Evolutionstheorie ${ }^{3}$ änderte sich ab dem 19. Jahrhundert der menschliche Blick auf das Tier grundlegend. 4

1 Man denke in diesem Zusammenhang an Höhlenmalereien mit Tiermotiven aus dem Paläolithikum.

2 Vgl. List 1993, S. 7 f.

3 Als malerische Verbildlichungen der Evolutionstheorie von Darwin können beispielsweise die Affenbilder Gabriel von Max' gesehen werden. Vgl. hierzu Ausst.-Kat. München 2010, S. 295-329.

4 Diese veränderte Einstellung zum Tier kommt auch in der Einrichtung zoologischer Gärten als bürgerlichen Bildungs- und Vergnügungsstätten zum Ausdruck. Diese waren zudem beliebte Studienorte für Tiermaler. 
Das 19. Jahrhundert präsentiert sich dabei als ein Saeculum verschiedenster Kunstströmungen und -auffassungen, die wiederum ein überaus breites Spektrum an Tierdarstellungen hervorbrachten. Klassizismus und Romantik, Biedermeier und Realismus, Impressionismus und Symbolismus - in allen diesen Strömungen wurden ganz eigene Interpretationen des Tiermotivs entwickelt. ${ }^{5}$

Das ausgehende 19. Jahrhundert war schließlich auch die Zeit, in der die Tiermalerei als eigenständige Gattung eine akademische Institutionalisierung erfuhr. Die Tierdarstellung emanzipierte sich von ihrer bis dahin vorherrschenden Funktion als Allegorie oder schmückendem Beiwerk und wurde in den Rang einer aus sich selbst heraus bildwürdigen Gattung erhoben. ${ }^{6}$ Die Wurzeln dieses Prozesses liegen dabei in Frankreich und England. ${ }^{7}$ Dort legten Eugène Delacroix ${ }^{6}$ Raubtierund Théodore Géricaults Pferdedarstellungen ${ }^{8}$ sowie die Tierhistorien Edwin Landseers die Grundsteine für die Etablierung der Tiermalerei auch an den deutschen Akademien.

In Deutschland wurden zwar bereits zu Beginn des 19. Jahrhunderts Versuche unternommen, die Tiermalerei in den Akademien zu verankern. Diese blieben aber zumeist fruchtlos. So war zwar 1808 bei der Gründung der Münchner Akademie die Einrichtung einer Klasse für Tier- und Landschaftsmalerei vorgesehen, dieses Vorhaben wurde aber, zumindest im Bezug auf die Tiermalerei, nicht realisiert.9 Endgültig in den Lehrbetrieb integriert wurde die Tiermalerei in München 1891, in der Düsseldorfer Akademie sogar erst 1898. ${ }^{10}$

Die akademische Institutionalisierung der Tiermalerei erfolgte also in weiten Teilen Deutschlands erst sehr spät. Auf dem außerakademischen Kunstmarkt dagegen stand die Tiermalerei bereits zur Jahrhundertmitte hoch im Kurs. Sie war, wie Claudia List festgestellt hat, bei Kritikern und Käufern gleichermaßen beliebt:

\footnotetext{
„Es bieten sich also einige Anhaltspunkte, die vermuten lassen, daß ihre eigentliche Entwicklung [die der Tiermalerei, V. S.] letztlich sich außerhalb der akademischen Pforten vollzog. Denn als sie schließlich im letzten Viertel des 19. Jahrhunderts Aufnahme findet, geschieht das zu einem Zeitpunkt, als die Akademie, die als veraltete und unmoderne Institution und als ein Instrument von Ideologie und Tradition unter heftigen Beschuß steht, im ,Verfall' begriffen ist. Im Grunde also erfolgte eine überfällig gewordene Aufwertung, die vor allem der Kunstmarkt, aber auch das Ausstellungswesen längst vollzogen hatten." ${ }^{11}$
}

List konstatiert dabei das Auftreten zweier divergierender Ausprägungen der Tierdarstellung im Deutschland des 19. Jahrhunderts:

5 List 1993, S. 197.

6 Dies bedeutet selbstverständlich nicht, dass es nicht schon in früheren Jahrhunderten eigenständige Tierbilder gegeben habe. Als herausragender Vertreter der Tiermalerei im 17. Jahrhundert ist beispielsweise der Pfälzer Johann Heinrich Roos zu nennen; vgl. Jedding 1998.

7 Artinger 1995, S. 17.

8 List 1993, S. $189 \mathrm{f}$.

9 Artinger 1995, S. 18 f.

10 Ebd.

11 Ebd., S. 19. 
„auf der einen Seite die Hirtenstücke holländischer Manier, anekdotische Dorflandschaften, Weidelandschaften und Schäfermotive, die hauptsächlich in der süddeutschen Malerei bis hin zu Heinrich von Zügel dominieren, auf der anderen Seite die malerisch aufgefaßten individuellen Tierstudien, zum Beispiel bei Menzel und Liebermann." ${ }^{2}$

Zu den wichtigsten Vertretern der süddeutschen Tiermalerei gehört der in München wirkende Friedrich Volz, dessen Hauptwerke zumeist Rinder in idyllischer Alpenlandschaft und in harmonischer Koexistenz mit dem Menschen zeigen. Er ist in diesem Katalog durch die Landschaft Enten am Starnberger See (Kat. Nr. 24) vertreten. Ein sprechendes Beispiel für die Tiermalerei des Realismus steht in diesem Katalog dagegen mit dem Bild Tauben auf dem Dach des Berliner Malers Paul Meyerheim (Kat. Nr. 29) vor Augen.

Im klassischen Kanon der Gattungen nahm die Tiermalerei lange Zeit eine untergeordnete beziehungsweise nicht genau definierte Zwischenstellung ein. Sie bewegte sich gewissermaßen in einer theoretischen Grauzone zwischen dem Stillleben, der Landschaft und bisweilen auch dem (Tier-)Porträt. Die Tiermalerei rangiert dabei als in der Regel nicht idealistisch oder narrativ aufgeladene Gattung am unteren Ende der Gattungshierarchie. So schreibt etwa Max Schasler in seinem Aufsatz Bemerkungen über Thiermalerei und Thierplastik von 1875:

„In der Reihe der Kunstdarstellungen von der Historienmalerei herab stehen das Stillleben und die Thiermalerei rücksichtlich der Motive auf den untersten Stufen [...].“13

Damit wurde die Tiermalerei sogar noch hinter der Landschaftsmalerei eingeordnet, da sie als bloße „Übergangsgattung von der ,Figuren- zur Landschaftsmalerei““ angesehen wurde. ${ }^{14}$ Lediglich das Stillleben nahm eine noch geringere Position ein, da es im Unterschied zur Darstellung lebender Tiere nahezu ausschließlich die unbelebte Natur wiedergab und somit noch weniger geeignet war, einen narrativen Inhalt zu transportieren.

Eine solche Hierarchisierung darf aber nicht mit einer normativen Ablehnung niedriger Gattungen verwechselt werden. Ein gut gemaltes Stillleben wurde in der zeitgenössischen Kunstkritik durchaus positiver rezipiert als eine schlecht gemalte Historie. ${ }^{15}$ Die hierarchisierende Ordnung der Gattungen diente also vordringlich dazu, eine Übereinstimmung von Form und Inhalt in der Bildenden Kunst im Sinne einer Dekorumslehre von den angemessenen bildnerischen Gestaltungsmitteln für jede Gattung zu gewährleisten.

So stimmt Kai Artingers Aussage, Tiermaler hätten ihren Bildern notwendigerweise einen narrativen, anthropomorphisierenden Gedanken implementieren müssen, um von der Kunstkritik als vollwertige Künstler anerkannt zu werden, nur

12 List 1993, S. 192.

13 Schasler 1875, S. 46.

14 Artinger 1995, S. 33.

15 Zimmermann, M. 1999, S. 21. 
bedingt. ${ }^{16}$ Zwar wurden nicht-narrative Tierstücke als bloße Porträts angesehen und standen somit in der Gattungshierarchie sehr weit unten, jedoch wurde auch solchen Darstellungen, sofern sie gut gemalt waren, keineswegs der Kunstcharakter abgesprochen. ${ }^{17}$

Tatsächlich gab es, worauf Artinger selbst hinweist, auch innerhalb der Gattung der Tiermalerei selbst zahlreiche weitere Differenzierungen und hierarchische Abstufungen:

\footnotetext{
„Das 19. Jahrhundert ist auf dem Feld der Gattungsmalerei eine Epoche ausufernder Spezialisierung, die heute nur noch mit einem ungläubigen Staunen zur Kenntnis genommen werden kann. Nirgendwo aber trieb diese Spezialisierung üppigere Blüten als in der Tiermalerei. “18
}

In seinem Aufsatz Bemerkungen über Thiermalerei und Thierplastik unterteilt Max Schasler die Tiermalerei in vier thematische Stufen. Auf der untersten Stufe ist das Tierporträt, d. h. die ,getreue Naturnachahmung im Detail“19 anzusiedeln, bei der es darum geht, ein einzelnes Tier oder eine Tiergruppe in ihrer spezifischen äußeren Gestalt zu erfassen. Die zweite Stufe beinhaltet „alles das, was der Thierphysiognomie ein seelisches Gepräge verleiht." 20 Dies meint vor allem eine Darstellung, in der das Tier in Bewegung gezeigt wird, wodurch dessen spezifische Charaktereigenschaften und Temperament verdeutlicht werden. Das Tier wird hier demnach zum Ausdrucksträger. In der dritten Stufe, dem Tiergenre, wird das Tier zum Träger einer Handlung. Es wird als Individuum dargestellt und in einen narrativen Kontext eingebunden. ${ }^{21}$ Diese inhaltliche Aufladung des Tiermotivs findet in der vierten Stufe, der Tiersymbolik oder Allegorie, ihren Höhepunkt. ${ }^{22}$ Das Tier ist in dieser Form über die rein physiognomische Naturdarstellung enthoben und wird gleichsam Bedeutungsträger.

Je nach Grad der inhaltlichen Ausdifferenzierung hält Schasler für jede Stufe der Tiermalerei verschiedene formale Gestaltungsmittel für angemessen. So fordert er für die niedrigste Stufe des Tierporträts explizit kleine Formate, während für die höheren Stufen auch größere Formate gewählt werden dürfen. ${ }^{23}$ Des weiteren sei nur bei den unteren Stufen eine malerisch-farbige Behandlung des Sujets angemessen. Gemäß des akademischen Postulats vom Primat der Linie, also des „dessin“, über die Farbe, solle die höchste Form der Tiersymbolik nicht als farbintensives Gemälde dargestellt werden:

\footnotetext{
16 Artinger 1995, S. 31.

17 Ebd.

18 Ebd., S. 11.

19 Schasler 1975, S. 47.

20 Ebd., S. 53.

21 Ebd., S. 54.

22 Ebd., S. 63.

23 Ebd., S. 47.
} 
„Unsere Behauptung gründet sich auf den von uns schon öfter ausgesprochenen ästhetischen Grundsatz, daß die Malerei, als die unter allen Darstellungsarten konkreteste, naturlebendigste und direkteste Reproduction der Naturwirklichkeit, auch nur solche Motive behandeln dürfe, welche eine direkte Lebenswahrheit haben. Das Symbol, welches als solches nur eine indirekte, abstrakte Bedeutung hat, kann auch nur durch eine von der direkten Wirklichkeit abstrahierende Technik, also entweder durch die Skulptur [...] oder durch die Zeichnung [...] oder ähnliche Manieren, wozu auch Grau in Grau u. s. w. gehört, dargestellt werden, ohne einen Widerspruch zwischen Inhalt und Form der Darstellung hervorzurufen.“ 24

In der zweiten Hälfte des 19. Jahrhunderts wurde diese theoretische Ausdifferenzierung, deren Hintergrund nach wie vor die Gattungshierarchie darstellte, durch Bewegungen wie den Realismus und den frühen Impressionismus angefochten. Zu dem Zeitpunkt also, als sich die Sondergattung der Tiermalerei ihren festen Platz in der Gattungshierarchie und ihre Anerkennung im akademischen Kunstbetrieb gesichert hatte, waren die Rahmenbedingungen bereits wieder in Frage gestellt.

24 Ebd., S. 63. 

Kat. Nr. 29

Paul Meyerheim (1842-1915)

\section{Tauben auf dem Dach}

1871

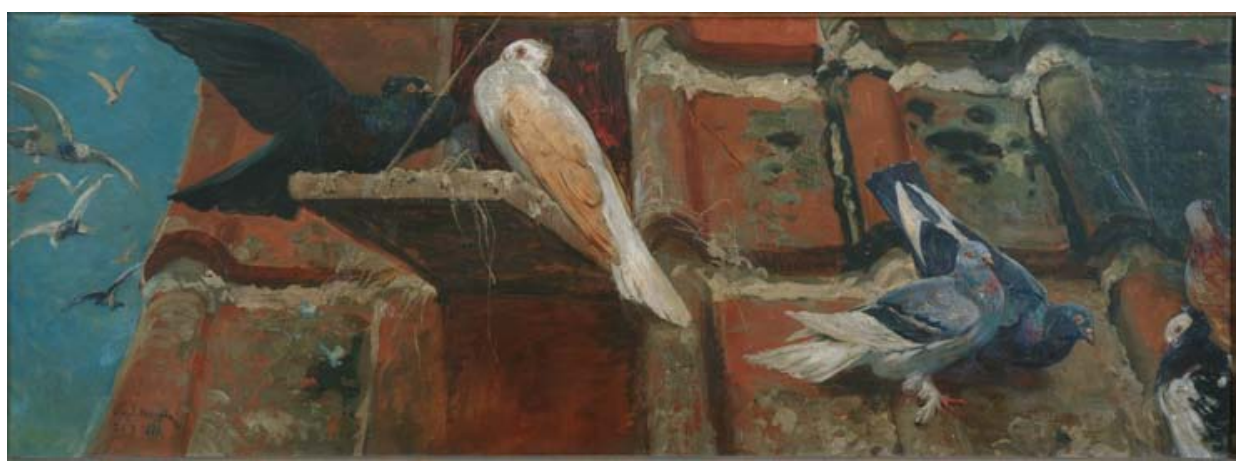

Öl auf Leinwand, 55 x $143 \mathrm{~cm}$, signiert und datiert unten links, Schenkung durch Dr. Walter Gerson 1956, Inv. Nr. GG 162

Paul Friedrich Meyerheim entstammt einer ursprünglich aus Danzig kommenden Künstlerfamilie. ${ }^{1}$ Seine erste künstlerische Ausbildung erhielt er durch seinen Vater Eduard Meyerheim, der sich insbesondere als Genremaler einen Namen gemacht hatte. ${ }^{2}$ Die Familie Meyerheim war zudem eng mit Adolph Menzel befreundet, der zum wichtigsten Lehrer, Vorbild und väterlichen Freund Paul Meyerheims avancieren sollte. Von 1859 bis 1862 war Meyerheim Schüler der Berliner Akademie. ${ }^{3}$ Im Anschluss an sein Studium bereiste er das europäische Ausland, insbesondere Holland, Belgien und Frankreich. In Paris wurde sein Bild Menagerie im Jahr 1866 mit einer goldenen Medaille des Salon prämiert. Zudem waren seine Werke auf der Pariser Weltausstellung von 1867 vertreten. Er hielt sich einige Zeit im Wald von Fontainebleau auf, um dort bei den Meistern von Barbizon seine Kenntnisse in der Freilichtmalerei zu perfektionieren. Die Maler von Barbizon und die französischen Realisten um Gustave Courbet zählen neben Menzel zu den wichtigsten Impulsgebern für das Schaffen Paul Meyerheims. 1869 wurde seine Ernennung zum Mitglied der königlichen Akademie der Künste bekannt gegeben. ${ }^{4}$ Zudem hatte Mey-

Thieme/Becker 1907-1950, Bd. 24, 1930, S. 498.

Lammel 1995, S. 41.

Ebd., S. 112.

4 Daege/Gruppe 1869, S. 240. 
erheim ab 1883 einen Lehrstuhl für Tiermalerei an der Königlichen Akademischen Hochschule für die Bildenden Künste in Berlin inne. ${ }^{5}$ Paul Meyerheim hat sich vor allem als Tiermaler einen Namen gemacht; seine zumeist narrativen, genrehaften Tierstücke waren bei dem Berliner Bürgertum äußerst beliebt. Wie in dem Bild Tauben auf dem Dach auf exemplarische Weise zu sehen ist, bleibt Meyerheim in seinen Tierdarstellungen stets dem Naturvorbild verhaftet. ${ }^{6}$

Den Hauptanteil in Paul Meyerheims Euvre nehmen zwar Tierstücke ein, er war allerdings auch Genre- und Landschaftsmaler sowie Porträtist. Neben Ölgemälden und Aquarellen fertigte er auch Lithographien und Buchillustrationen an. Als weiteres Haupttätigkeitsfeld Meyerheims, das vor allem in seinem Frühwerk eine wichtige Rolle spielte, ist die dekorative Wandmalerei zu nennen. ${ }^{7}$ Er schuf neben Arbeiten für private Räumlichkeiten auch bedeutende Wandzyklen in öffentlichen und halböffentlichen Räumen. Als herausragende Beispiele sind hier ein siebenteiliger Zyklus über den Herstellungsprozess einer Lokomotive für eine Loggia im Garten der Industriellenfamilie Borsig - eine der frühesten monumentalen Industriedarstellungen überhaupt - sowie die Ausmalung des Vestibüls im zweiten Obergeschoss der Berliner Nationalgalerie zu nennen. ${ }^{8}$

\section{Meyerheims Göttinger Bild}

Das Göttinger Bild Tauben auf dem Dach zeigt ausschnitthaft ein Ziegeldach, auf dem sich sechs verschiedenfarbige Tauben niedergelassen haben. Am linken Bildrand ist ein Stück Himmel zu sehen, in dem sich weitere sechs Tauben im Anflug auf das Dach befinden. Das Gemälde zeichnet sich durch eine ausgefeilte kompositionelle Betonung der fallenden Diagonalen, durch eine leuchtende Farbigkeit sowie durch eine außergewöhnlich pastose Malweise aus. Dieses starke Farbrelief ist in diesem Fall allerdings kein Hinweis auf einen skizzenhaften Charakter des Bildes mehr. Vielmehr ist es ein Ausdruck Meyerheims realistischer Kunstauffassung, die auf Impulse von Menzel, Courbet und den Malern von Barbizon zurückzuführen ist. Akademische Glattmalerei und Idealisierung lehnte Meyerheim ab. ${ }^{9}$

Das extreme Querformat, der ungewöhnlich nah an den Betrachter herangerückte Bildausschnitt sowie die auf Untersicht gearbeitete Perspektive des Gemäldes Tauben auf dem Dach legen eine Verwendung des Bildes als Wanddekoration nahe. Es ist anzunehmen, dass das Bild einem privaten Kontext entstammt und in dieser Funktion als Supraporte über einer Tür, einem Fenster oder Ähnlichem angebracht war.

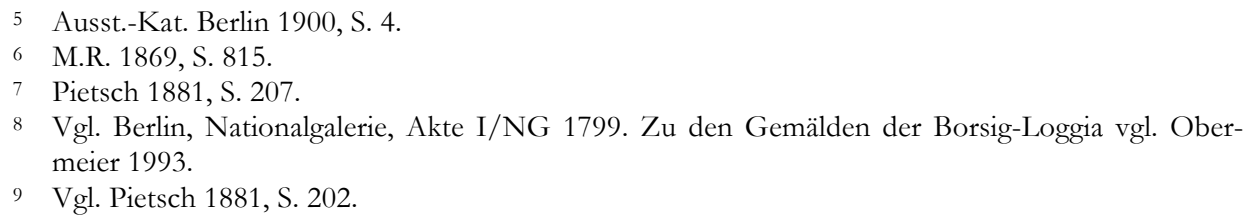


Das Gemälde Tauben auf dem Dach ist demnach in mannigfaltige kunsthistorische und -theoretische Diskurse der letzten Hälfte des 19. Jahrhunderts eingebunden. Es ist Zeugnis einer wachsenden Ablehnung idealisierender akademischer Kunstauffassungen und einer damit verbundenen Hinwendung zum Realismus.

Paul Meyerheims Beitrag zu diesen Diskursen bestand in einer Überwindung überwiegend klassizistischer Traditionen der Berliner Akademie zu Gunsten einer von Menzel und Courbet inspirierten naturalistischen Malerei. Er gilt neben Adolph Menzel als eine der führenden Künstlerpersönlichkeiten des sogenannten Berliner Realismus. ${ }^{10}$

Verena Suchy

10 Vgl. u. a. Neidhardt 2003, S. 168. 



\title{
Zwischen Publikumsinteresse und Kunstkritik: Stilllebenmalerei
}

\author{
Jan Stieglitz
}

Als Gattung, der in der Hierarchie ein „,niederer“ Rang zugesprochen wurde, ergab sich für die Stilllebenmalerei ${ }^{1}$ im 19. Jahrhundert eine paradoxe Situation: Einerseits erfuhr sie eine hohe Wertschätzung auf dem Kunstmarkt und andererseits wurde sie von der Kunstkritik lange Zeit eher gering geachtet, da sie ihre Sujets aus dem Bereich der unbelebten Welt bezog. So lange diese Situation wirksam war, stand die Gattung weitgehend im Bann einer jahrhundertealten Darstellungstradition. Erst als diese aufgelöst wurde, konnte die Stilllebenmalerei eine bewusste Neufassung durch die nach künstlerischer Autonomie strebende Avantgarde erfahren. Eine solche Neufassung fand allerdings erst im letzten Drittel des 19. Jahrhunderts statt. Gerade für die Kontextualisierung der in der Göttinger Universitätskunstsammlung aufbewahrten, keineswegs avantgardistischen Stillleben ist es erforderlich, die gattungsimmanenten Voraussetzungen und die sich hieraus ergebenden, lange Zeit prägenden Traditionen zumindest im Überblick zu thematisieren.

Als frühestes bekanntes eigenständiges Werk, welches unbelebte Gegenstände zeigt, gilt ein Trompe-l'oeil von Jacopo de' Barbari aus dem Jahr 1504. Es zeigt die Illusion dreier an der Wand befestigter Objekte: einen Rüstungshandschuh mit-

1 Eine Begriffsgeschichte des Wortes Stillleben ist an anderer Stelle bereits ausführlich geschrieben worden und soll in diesem Katalog nicht noch einmal abgefasst werden. Siehe z. B. König/Schön 1996, S. 17-36. 
samt Armbrustbolzen und totem Federvieh. ${ }^{2}$ Zwar hatte es zuvor bereits stilllebenähnliche Motive gegeben, diese existierten aber immer im Kontext eines anderen Werktypus, wie z. B. eines Altares oder einer bemalten Architektur. ${ }^{3}$

Zur Blüte gelangte die Malerei unbelebter Objekte erstmals im 17. Jahrhundert. Sowohl in Italien als auch in den Niederlanden schufen in dieser Zeit einige der bedeutendsten Künstler hervorragende Stillleben. Dazu zählen Caravaggio mit seinem vielzitierten Früchtekorb sowie die Maler Willem Kalf und Pieter Claesz für die nördlichen und Frans Snyders für die südlichen Niederlande. Besonders in den Niederlanden widmeten sich viele Künstler dem Malen von Stillleben, die sich bereits großer Beliebtheit am Kunstmarkt erfreuten. Sie schufen dabei Werke in einem präzisen, feinmalerischen Stil, der die Natur möglichst genau nachzuahmen suchte. ${ }^{4}$ Sie wurden in den folgenden Jahrhunderten nachgeahmt und bisweilen auch gefälscht, so wie es im Fall des Blumenstilllebens in der Art des Joris van Son (Kat. Nr. 30) naheliegt, das sich in der Göttinger Universitätskunstsammlung befindet und mit großer Wahrscheinlichkeit im 19. Jahrhundert entstand.

Gleichwohl - und im Kontrast zu ihrer großen Beliebtheit - nahmen Stillleben im Gefüge der Gattungshierarchie - und somit auch in den Augen vieler Kritiker von Anfang an den untersten Rang innerhalb der Malerei ein. Hierfür waren vor allem zwei Grundannahmen verantwortlich: Zum einen galten unbeseelte Objekte, also Pflanzen, tote Tiere und Gegenstände, als weniger darstellungswürdig als beseelte. Dies ist der Kerngedanke der Gattungshierarchie, wie er erstmals 1669 von André Félibien verschriftlicht wurde ${ }^{5}$ und zur Abstufung vom Historiengemälde bis zum Stillleben führte. Zum anderen nahm man an, dass für das bloße Abmalen eines „toten“ Objektes keine schöpferische Eigenleistung nötig sei, also keine Inventio stattfinde. ${ }^{6}$

Die idealistische Kunsttheorie und -kritik des 19. Jahrhunderts hielt an solchen Bewertungsmaßstäben weitgehend fest. Ein Beispiel hierfür bietet der Kunstkritiker Wolfgang Müller von Königswinter, der in seinem Werk über die Düsseldorfer Maler schreibt: „ein warmes lebendiges Menschenantlitz, frisch auf die Leinwand geworfen, ist mir lieber, als hundert todte Schnepfen und Hasen, wenn sie auch noch so meisterlich gemalt sind“.7 Müller von Königswinter argumentiert dabei ganz in der akademischen Tradition der Gattungshierarchie, wenn er sagt: „es ist ein großer Irrthum, wenn man meint, die Mittel bedingten das Kunstwerk, nein, das thut nur der Inhalt. "8 Im selben Zusammenhang muss er allerdings den Erfolg

2 Vgl. König/Schön 1996, S. 17. Zur Frage, inwieweit der Begriff „Stillleben“ für dieses Werk angebracht ist, vgl. ebd. S. 50.

3 Vgl. ebd. S. 46-49.

4 Vgl. u. a. Ebert-Schifferer 1998, S. 93-172.

5 Nachzulesen im Vorwort von Félibien zu den Conferences de l'Academie Royale de Peinture et de Sculpture veröffentlicht zu Paris im Jahr 1669.

6 Zu beiden Vorwürfen vgl. König/Schön, S. 55.

7 Müller von Königswinter 1854, S. 372.

8 Ebd. 
der Düsseldorfer Stilllebenmaler konstatieren, welcher dem mangelnden Anspruch ihrer Bilder vermeintlich widerspreche: „Ihre Bilder gehen nichts desto weniger ab, wie warme Semmel, denn es gibt noch Menschen genug, denen Darstellungen aus dem Stilleben lieber sind, als die Stanzen Raphael's."

\section{Neue Wege in der Stilllebenmalerei}

Diese abwertende Einstellung zur Stillebenmalerei wurde erst um die Mitte des 19. Jahrhunderts kritisch hinterfragt. Gleichzeitig brach man mit den über die Jahrhunderte hinweg tradierten Darstellungskonventionen. Die Weiterentwicklung der Stilllebenmalerei begann in Frankreich. Hier verzichteten Maler erstmals darauf, den feinmalerischen und auf detailgetreue Darstellung spezialisierten Stil der Niederländer fortzuführen, um sich stattdessen an der Maltechnik der französischen Landschaftsmalerei zu orientieren. Als relativ frühe und gleichzeitig prominente Beispiele für die neue Malweise sind die Stillleben Gustave Courbets zu nennen. ${ }^{10}$ Gleichzeitig änderten sich auch die Bildthemen und zuvor als nicht bildwürdig erachtete Objekte wurden auf die Leinwand gebracht. Sybille Ebert-Schifferer beschreibt dies als ,ästhetische Wende zur Aufwertung des Häßlichen und AbstoBenden als Inbegriff des Romantisch-Sublimen und des Erhabenen“. ${ }^{11}$ Spätestens Édouard Manets berühmtes Spargelbündel (um 1880) macht deutlich, dass für die französischen Avantgardekünstler der Bildinhalt seine Vorrangstellung gegenüber dem individuellen künstlerischen Ausdruck, den ein Künstler in seinem Werk festhält, verlor.

Der deutschsprachige Kunstraum kam erst in der zweiten Hälfte des 19. Jahrhunderts von Frankreich aus mit den neuen Ansichten in Kontakt und schon bald wurden auch hier Stillleben mit neuem künstlerischen Anspruch geschaffen. Betrachtet man die - dreißig Jahre nach Müller von Königswinters Text verfassten Schriften Wilhelm Trübners zur Kunsttheorie, so wird der in Zwischenzeit - zumindest innerhalb der Künstlerschaft - vollzogene Meinungswandel besonders deutlich. Trübner schreibt 1898: „Ob es inhaltlich interessant oder nicht, davon die Beurteilung eines Bildes abhängig zu machen, wird jederzeit zu falschen Resultaten führen, da es vielen großen Künstlern gelungen ist, interessante wie uninteressante Gegenstände reinkünstlerisch darzustellen."12 Trübners Aussage macht klar, dass gerade anhand der Diskussionen über den Wert der Stilllebenmalerei besonders präzise die Auflösung der von der akademischen Malerei getragenen Gattungshierarchie untersucht werden kann.

Kunsthistorisch wird Werken von Trübner oder Manet heute aus gutem Grund ein größeres Gewicht beigemessen als Stillleben nach „konventionellem“

9 Ebd., S. 373.

10 Vgl. Ebert-Schifferer 1998, S. 287-290.

11 Vgl. ebd., S. 287.

12 Trübner 1898, S. 19. 
Vorbild, zu denen auch das in Göttingen befindliche Werk von Joseph Correggio (Kat. Nr. 31) gehört. Gleichwohl dominierten Bilder letzterer Art lange Zeit den deutschsprachigen Kunstmarkt und wurden auch weiterhin in großer Zahl geschaffen, während sich die neuen Konzepte nur langsam durchsetzten und von steter Kritik begleitet waren. Die Göttinger Universitätskunstsammlung erweist sich auch hier als exemplarisch, indem sie keine Avantgardestücke zeigt, sondern Stillleben, wie sie in vielen Häusern dieser Zeit hingen. 
Kat. Nr. 30

Art des (Fälschung nach?) Joris van Son

\section{Blumenstillleben}

19. Jahrhundert

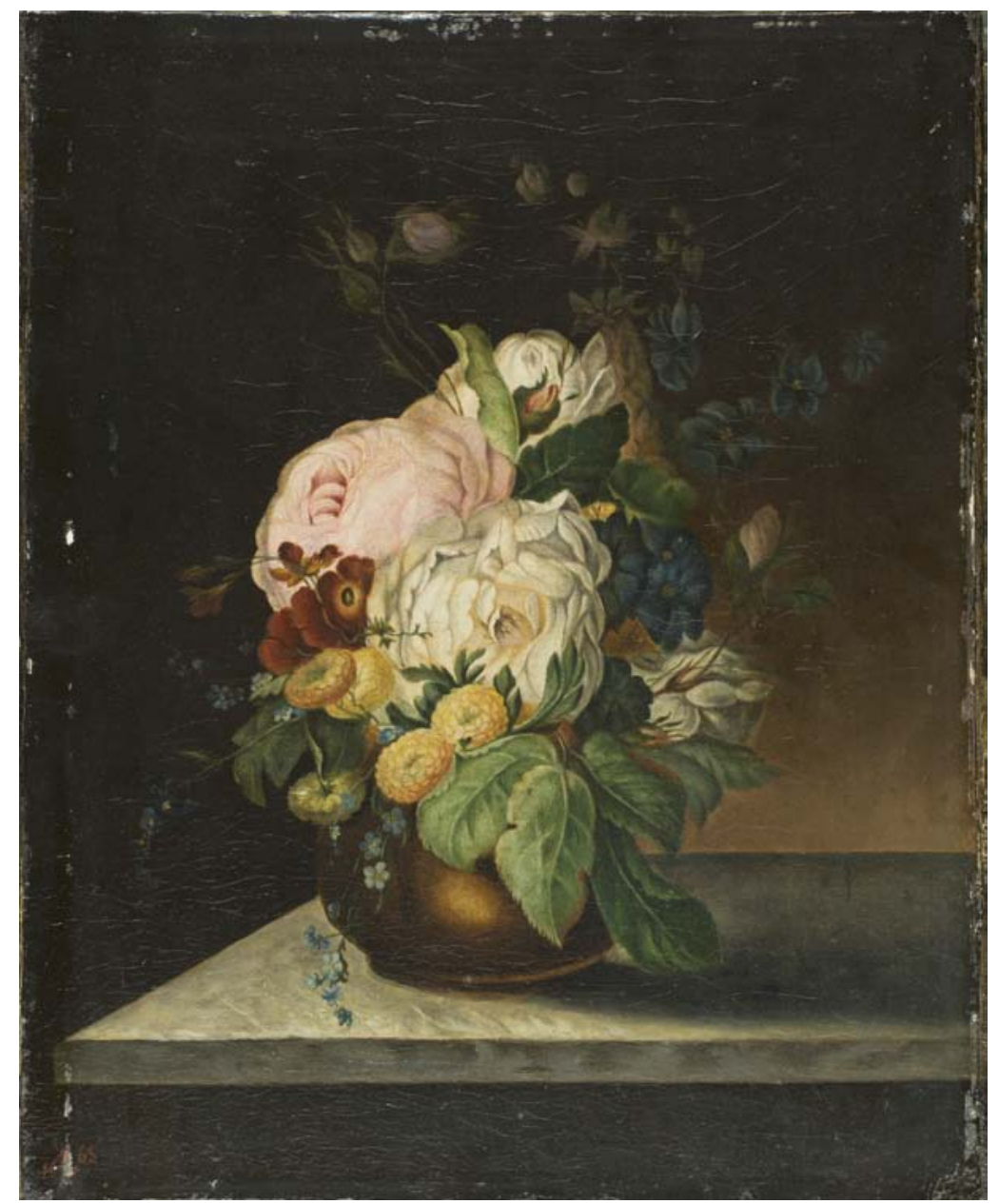

Öl auf Leinwand, 33,8 x 27,5 cm, signiert (?), 1966 aus der Sammlung Eugen Dumont mit Mitteln der Volkswagenstiftung angekauft, Inv. Nr. GG 273 
In der Stilllebenmalerei waren Werke der Niederländischen und Flämischen Malerei des 17. Jahrhunderts lange Zeit maßstabsetzend. Die in diesem Umfeld entwickelten Bildstrategien, Blumen, Früchte und andere Gegenstände - gern vor dunklem Hintergrund - kunstvoll zu arrangieren und in ihrer Sinnlichkeit, aber auch Vergänglichkeit zu präsentieren, prägten über Jahrhunderte hinweg die Darstellungskonventionen dieser Gattung. Da es sich um ein besonders populäres Genre handelte, ist aus dem 19. Jahrhundert eine kaum übersehbare Fülle von Bildern überkommen, die in dieser Tradition stehen. Darunter befinden sich Werke, bei denen sich die Künstler in mehr oder weniger freier Weise mit diesen Konventionen auseinandergesetzt haben, aber auch Kopien nach älteren Werken. Darüber hinaus ist mit gezielten Fälschungen zu rechnen.

Das hier zur Diskussion stehende Blumenstillleben gelangte 1966 über die Sammlung des Schauspielers Eugen Dumont in die Göttinger Universitätskunstsammlung. Eine moderne Beschriftung auf der Rückseite der doublierten Leinwand weist es als Werk des Joris van Son (1623-1667) aus - eine Zuschreibung, die von den Kunsthistorikern, welche die Göttinger Sammlung betreuten, offenbar frühzeitig in Frage gestellt wurde. Möglicherweise liegt hierin der Grund, weshalb das Bild keinen Eingang in den Göttinger Katalog der niederländischen Gemälde von Gerd Unverfehrt fand, obwohl dessen umfangreicher Anhang auch „Gemälde anderer Schulen“ behandelt und Raum für die Diskussion zweifelhafter Zuordnungen geboten hätte. ${ }^{1}$ Eine Notiz in der Bildakte von der Hand Unverfehrts bezeichnet das Werk als „Biedermeier-Kopie“.2 Unabhängig von der Kenntnis dieser Notiz haben Fachleute das Bild bei Anschauung des Originals unlängst erneut in das 19. Jahrhundert datiert, so dass sich diese Einordnung festigt. ${ }^{3}$ Gerade dadurch erscheint das Werk als ein besonders interessanter und aussagekräftiger Fall für den Umgang mit älteren Bildtraditionen, der eine eingehendere Betrachtung lohnt.

Das Göttinger Gemälde zeigt, auf der Mittelachse des hochformatigen Bildes angeordnet, einen Blumenstrauß in einer bauchigen Kupfervase, die auf einer hellen, marmornen Tischplatte steht. Die aufsichtig dargestellte Platte, deren Vorderkante sichtbar ist, wurde vom Maler bildparallel angeordnet. Sie fluchtet nahe der linken Bildkante perspektivisch in den Hintergrund. Auch ihr rückwärtiges Ende ist klar erkennbar.

Das Licht fällt von links oben auf Blumenstrauß und Tischplatte, deren Beleuchtung die Kupfervase reflektiert. Der die Bildgegenstände umgebende Raum ist überwiegend dunkel gehalten; nur rechts neben dem Strauß, wo die Vase einen dunklen Schatten auf die Platte wirft, ist er bräunlich aufgehellt, so dass sich hier

\footnotetext{
Unverfehrt 1987, S. 179-197.

2 Kunstsammlung der Universität Göttingen, Archiv, Bildakte GG 273: „Joris van Son / Kat. Neuerwerbungen / Bildakte / Zur Lit. Lübecker Katalog [gemeint ist wohl Kallen 1984, wo von S. 104 bis S. 109 mehrere Bilder von van Son besprochen werden, C. S.] / Biedermeier-Kopie ([Prof. Dr. Karl] Arndt/[Dr. Gerd] Unv[erfehrt].“

3 Prof. Dr. Michael Thimann, Prof. Dr. Ivan Gaskell und Prof. Dr. Martin van Gelderen am 24.06.2013.
} 
der Kontrast umkehrt: Hebt sich ansonsten der fast weiße, leicht geäderte Marmortisch vom dunklen Hintergrund ab, so steht hier der Tisch in seiner Verschattung dunkel gegen den aufgehellten Grund.

Die Blumen als Hauptmotiv sind bemerkenswerterweise farblich auf den Lichteinfall ausgerichtet. Deren Zentrum bilden eine weiße, frontal auf der Mittelachse angeordnete Rose sowie links daneben bzw. dahinter eine weitere, ins Dreiviertelprofil gedrehte, dem Licht entgegengereckte rosafarbene Gallicarose. ${ }^{4}$ Davor sieht man dunkle und hellere orangefarbene Blüten (letztere gefüllt), die sich botanisch nicht eindeutig zuordnen lassen. Auf diese Weise wird die linke Seite des Straußes weitgehend von hellen Blüten in weiß, rosa und orange bestimmt. Auf der rechten, dem Licht angewendeten Seite konzentrieren sich hingegen dunklere Blüten: Hier sind vor allem blaue Blumen unspezifischer Ausformung ${ }^{5}$ zu sehen. Um diesen kontrastiven Grundaufbau aufzulockern, sind auch hier im Hintergrund sowie oberhalb helle Rosen und Rosenknospen angeordnet. Dabei umspielen die kleineren Blüten und Knospen das kompakte Zentrum des Straußes. Nach unten hin wölben sich Rosenblätter über das Kupfergefäß und unten links reicht ein Zweig mit blauen Vergißmeinnicht bis auf die Tischplatte hinab, der auf diese Weise einen Gegenakzent zu den blauen Blumen im rechten oberen Bildviertel setzt.

So sorgsam und zugleich spannungsvoll das Bild komponiert ist, so deutlich fällt es doch in seiner malerischen Ausführung hinter dem zurück, was an Stillleben von Joris van Son bekannt ist. Dieser war einer der bedeutendsten flämischen Früchte- und Blumenmaler des 17. Jahrhunderts. In der Forschung wird er im Umfeld von Jan Davidsz. de Heem (1606-1683) verortet und mitunter als dessen Schüler angesehen. ${ }^{6}$ Von van Son ist bekannt, dass er 1643/44 Meister der Lukasgilde in Antwerpen und 1647 Mitglied der Sodaliteit de bejaerde jongmans wurde. 1656 hat er geheiratet. Die meisten seiner datierten Bilder stammen aus der Zeit zwischen 1653 und 1666.

Im Vergleich zu beglaubigten Werken van Sons fällt beim Göttinger Blumenstillleben etwa die mangelnde Ausdifferenzierung und Tiefenräumlichkeit der Blumendarstellungen, aber auch die in ihrer sensualistischen Präsenz nur bedingt überzeugende Malweise der Kupfervase sowie die eher flaue Ausführung der Blätter auf. Gleichwohl handelt es sich um ein Bild, das seine Qualitäten hat.

4 Für fachkundigen Rat bei der Bestimmung der Blumen (bzw. bei der Bestätigung, dass sich einige der Blumen nicht bestimmen lassen, sondern offenbar der Phantasie des Künstlers entstammen) danke ich dem Kustos des Alten Botanischen Gartens der Universität Göttingen, Dr. Michael Schwerdtfeger, herzlich.

5 Die Blütenform erinnert laut Dr Michael Schwerdtfeger (siehe Anm. 4) an Anagallis, die allerdings jeweils fünf Blütenblätter aufweist.

6 Vgl. hierzu und zu dem folgenden: Wurzbach, A. 1906-1911, Bd. 2, 1910, S. 639; Thieme/Becker 1907-1950, Bd. 31, 1937, S. 273; Kallen 1984, S. 104-109; Bernt 1980, Bd. 3, S. 20; EbertSchifferer 1998, S. 154. 
In der linken unteren Ecke befindet sich, vom Rahmen teilweise verdeckt, eine mit roter Farbe ausgeführte Datierung „1665“ mit eingeschlossenem, ligierten Monogramm ,JS“, die offensichtlich die Grundlage für eine Zuschreibung an Joris van Son darstellte. ${ }^{7}$ Aus stilkritischen Gründen kann eine solche Zuschreibung allerdings mittlerweile ausgeschlossen werden. Geht man von einer Datierung des Bildes ins 19. Jahrhundert aus, so übernehmen Datierung und Signatur eine Funktion, welche das Werk als Fälschung erscheinen lassen. Inwieweit dies vom ausführenden Künstler beabsichtigt war oder ob die Bezeichnung erst nachträglich auf das Bild gesetzt wurde, lässt sich zum gegenwärtigen Zeitpunkt nicht sagen.

Wichtige Aufschlüsse bietet die Herkunft aus der Sammlung Eugen Dumonts. Zum einen enthält diese - insofern man an der hier vertretenen Datierung des Blumenstilllebens festhält - bis auf ein Werk von Christian Wilhelm Dietrich8 ausschließlich Gemälde des 19. Jahrhunderts. Zum anderen befinden sich darunter mehrere Bilder, die in auffallendem Bezug zur niederländischen bzw. flämischen Kunst stehen. Darunter ist Eduard von Gebhardts Ölskizze Bei der Kupplerin (Kat. Nr. 16), das exemplarisch für die eigenständige Auseinandersetzung dieses bedeutenden Künstlers mit der niederländischen Genremalerei steht. Aus der Sammlung Dumont stammt aber auch das Gemälde Dorflandschaft mit zechenden

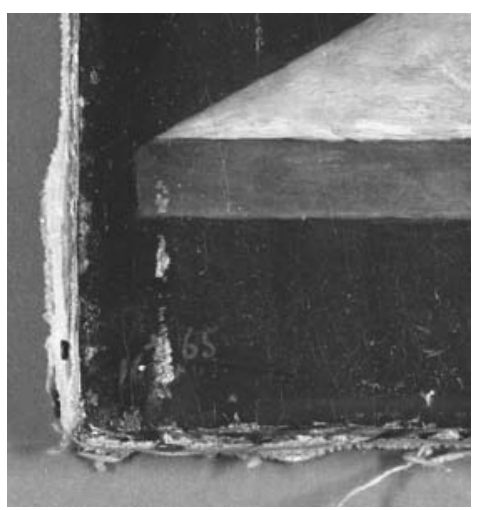

Abb. 38: Art des (Fälschung nach?) Joris van Son: Blumenstillleben, (gefälschte?) Signatur in der linken unteren Bildecke Bauern eines unbekannten Malers (Kat. Nr. 15). Dabei handelt es sich um eine Arbeit, die niederländischen Werken des 17. Jahrhunderts in Bildkomposition und Farbigkeit sehr nahe steht und sich erst bei genauerer Betrachtung als Bild des 19. Jahrhunderts erweist. Aufgrund ihres Bildträgers (Holz) erscheint es auch in diesem Fall überlegenswert, ob eine bewusste Fälschung vorliegt. ${ }^{9}$ Das Blumenstillleben in der Art des Joris van Son gewinnt auf diese Weise einen Kontext. Wenn es sich tatsächlich um eine Fälschung des 19. Jahrhunderts handeln sollte, so wäre mit diesem Gemälde eine interessante - und nach wie vor hochaktuelle - Facette des Kunstmarkts in der Göttinger Universitätskunstsammlung vertreten.

Christian Scholl

\footnotetext{
7 Die Künstlerlexika Wurzbach, A. 1906-1911, Bd. 2, 1910, S. 639, und Bernt 1980, Bd. 3, S. 20, überliefern bezeichnenderweise eine ganz andere Signatur für Joris van Son, bei welcher der Nachname ausgeschrieben ist.

8 Beweinung Christi (Wille 1970, Kat., Nr. 4, Unverfehrt 1987, S. 181, Kat. Nr. A 14).

9 Vgl. den entsprechenden Katalogtext von Christina Eifler im vorliegenden Band, S. 166.
} 
Kat. Nr. 31

Joseph Correggio (1810-1891)

\section{Früchtestillleben}

1865

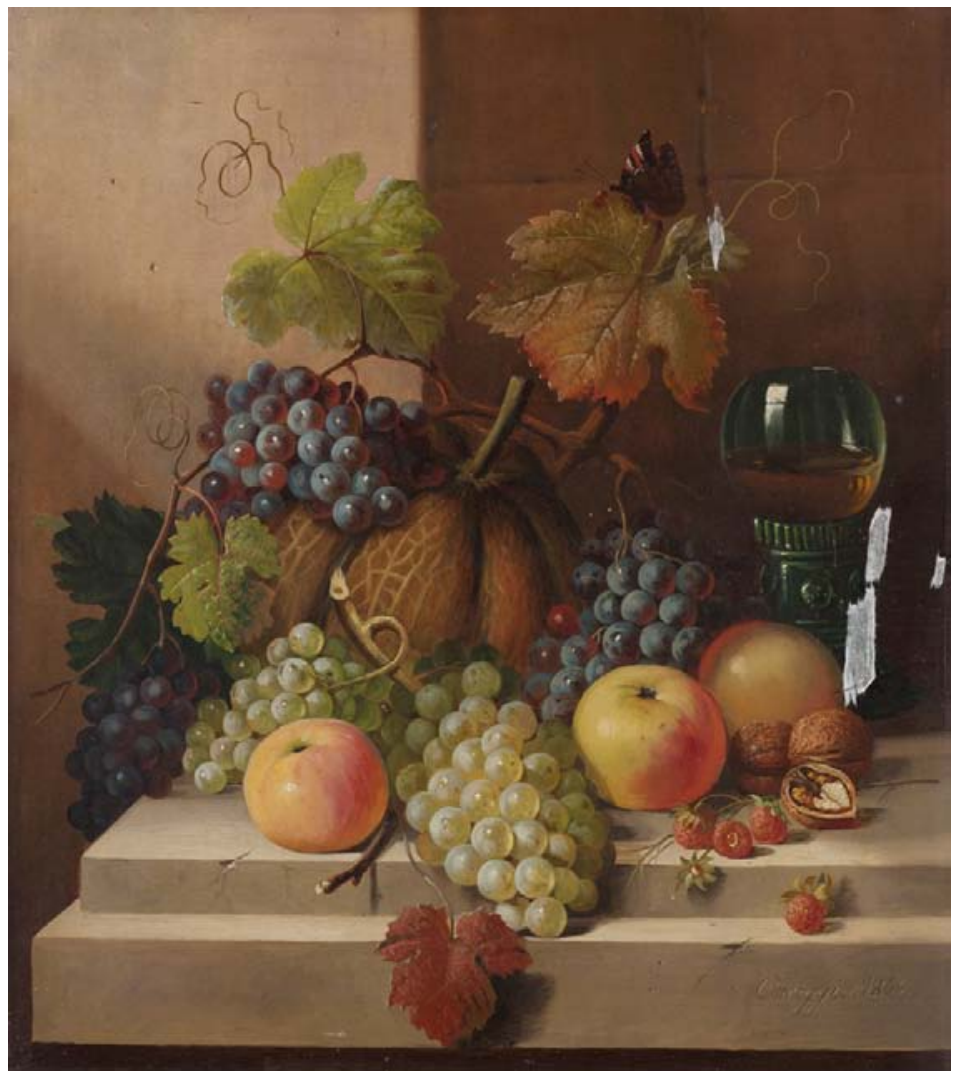

Öl auf Leinwand, 80,8 x 48,8 cm, signiert und datiert, 2008 aus dem Nachlass von Frau Prof. Ilse Walter, Göttingen erhalten, Inv. Nr. GG 233

Joseph Correggio, geboren in Wolfratshausen südlich von München, entstammte einer aus Italien ausgewanderten Familie, die am Schloss Nymphenburg angestellt war. Der Überlieferung nach lernte Correggio das Malen bei Johann Georg Hiltensperger an der Akademie der Bildenden Künste in München, welchem er auch 
bei der Ausmalung der Münchner Residenz geholfen haben soll. ${ }^{1}$ Leider lässt sich die Argumentation, die zur Annahme einer Schülerschaft Correggios bei Hiltensperger führt, nicht nachvollziehen. Hiltensperger, geboren 1806 und nur vier Jahre älter als Correggio, war zunächst ab 1846 als Hilfslehrer und schließlich zwischen 1851 und 1878 als ordentlicher Lehrer an der Akademie der Bildenden Künste angestellt. ${ }^{2}$ Weder für den Zeitraum seiner Anstellung noch für einen früheren Zeitraum findet sich ein Matrikeleintrag zum Namen Joseph Correggio in den Matrikelbüchern der Akademie. Einzig Correggios ältester Sohn Ludwig trat im Jahr 1862 eine Ausbildung in München an. ${ }^{3}$ Entweder hat sich Correggio also nicht ordentlich immatrikuliert, oder es liegt ein Irrtum vor. ${ }^{4}$ Correggio, der neben seiner Malerei auch an der Münchner Oper sang, schuf neben einigen Kopien flämischer Maler vor allem Jagd- und Früchtestillleben, von denen heute einige im Kunsthandel ausfindig zu machen sind. ${ }^{5}$

Viele dieser Stillleben zeigen große Ähnlichkeit mit dem Werk in Göttingen. Die ausgewogen angeordneten, auf das Bildzentrum ausgerichteten Objekte liegen dabei oft auf einer im Vordergrund dargestellten, bildparallel angeordneten Bank oder einem Tisch aus Stein, welche entweder die Bildfläche vollständig durchziehen oder noch vor dem Bildrand mit einer Ecke in den Hintergrund fluchten. ${ }^{6}$ In Göttingen liegt bezüglich der Unterlage der zweite Fall vor. Die Früchte - Äpfel, rote und grüne Trauben, Erdbeeren, Walnüsse und ein Kürbis - liegen auf einer Steinplatte, die von rechts in die Bildfläche ragt und kurz vor dem linken Bildende nach hinten umbricht. Auch das Detail der abgestuften Steinplatte als Untergrund existiert in weiteren Werken Correggios. ${ }^{7}$ Worauf die Platte ruht oder woran sie befestigt ist, bleibt für den Betrachter ebenso wenig nachvollziehbar wie der Raum, in dem sich die Früchte befinden. Im Hintergrund ist die Kante einer steinernen Mauer zu erkennen, die das Bild in einen beleuchteten Teil links und einen verschatteten Teil rechts unterteilt. Ein weiterer diagonal abfallender Schattenverlauf auf der linken Seite der Wand deutet auf ein Fenster als Lichtquelle hin.

1 Zum Lebenslauf Correggios vgl. Partsch 1999, S. 315; Thieme/Becker 1907-1950, Bd. 7, 1912, S. 466; Boetticher 1891-1901, Bd. 1, S. 201 und Prochazka 1981, S. 191 f.

2 Zum Lehrer Hiltensperger vgl. die Homepage zur Matrikel der AdBK: http://matrikel.adbk.de/ 07lehrer/lehrer/hiltensperger-johann-georg/ (zuletzt am 8.7.2013).

3 Vgl. den Eintrag zu Ludwig Correggio in München, Akademie der bildenden Künste, Matrikelbuch II, Martrikelnummer 1803.

4 Es könnte entweder eine Verwechslung mit seinem Sohn bzw. dem 1870 in Frankfurt a. M. geborenen Joseph Correggio vorliegen. Möglicherweise schloss man auch ohne eine Überprüfung der Matrikelbücher von seiner Mitarbeit an der Ausmalung der Münchner Residenz auf eine Schülerschaft an der Akademie.

5 Bereits nach kurzer Suche auf den Websites http://artsalesindex.artinfo.com/asi/search/ artistsAtoZ.ai (Suchbegriff „Joseph Correggio") und https://www.artnet.de/Künstler/ josephcorreggio/auktionsresultate (zuletzt am 8.7.2013) findet man eine ganze Reihe in jüngster Zeit gehandelter Werke des Künstlers, vor allem Stillleben, aber auch Porträts.

6 Vgl. neben den Abbildungen auf den eben genannten Websites v. a. Prochazka 1981, S. 191-192.

7 Siehe die beiden Abbildungen auf: http://artsalesindex.artinfo.com/asi/lots/3851373, sowie das Gemälde unter http://artsalesindex.artinfo.com/asi/lots/4214928 (zuletzt am 8.7.2013). 
Zumeist ordnet Correggio die Früchte dicht gedrängt um ein Objekt im Bildzentrum an, das vielfach rund ist - beispielsweise um einen Kürbis oder eine Melone. ${ }^{8}$ Im vorliegen Fall wird ein gelblich-brauner Kürbis von Weinreben umrankt, die sich zusammen mit einigen Blättern noch an den Zweigen der Weinstöcke befinden. Die runde Frucht ist dabei leicht nach rechts geneigt, wobei ihr Stiel in etwa auf der Mittelsenkrechten liegt. Er wird von insgesamt fünf Reben umgeben: drei roten und zwei grünen. Die dunkelroten Reben befinden sich dabei weiter im Hintergrund, wobei eine auf dem Kürbis aufliegt, während die zweite rechts neben ihm positioniert ist und die dritte zum größten Teil links von der Platte herabhängt. Die grünen Weinreben, von denen die rechte nach vorn hin von der oberen Tischkante herabfällt, sind vom selben Zweig und liegen vor dem Kürbis. Zwischen ihnen befindet sich der erste der gelbroten Äpfel; die beiden weiteren sind unterhalb der rechten roten Weinrebe positioniert. Äpfel und Weinreben rahmen den Kürbis somit zu mehr als drei Vierteln ein.

Auf der rechten Seite wird die Ansammlung von Objekten von einem zur Hälfte mit Wein gefüllten Römer begrenzt, in dem sich ein Fenster spiegelt. Es fehlt allerdings ein Fensterkreuz in der Spiegelung, das im Sinne einer christlichen Symbolik gedeutet werden könnte. Insgesamt scheint in diesem Falle kein religiöser oder auch moralischer Deutungshorizont vorzuliegen, wie er in der älteren Stilllebenmalerei eine gewisse Tradition hatte. Unterhalb des Glases werden noch einige Erdbeeren und zwei unversehrte sowie eine halbierte Walnuss gezeigt.

Auffällig ist die prominente Platzierung des Weinlaubes im Bild. Zwei große Blätter befinden sich oberhalb der Früchte, eines am unteren Bildrand vor der Platte und zwei weitere am linken Bildrand. Bei mehreren Blättern hat sich bereits eine Verfärbung ins Dunkelrote bzw. Rötlich-Braune eingestellt - ein deutlicher Hinweis darauf, dass Correggio ein Stillleben schaffen wollte, dass sich jahreszeitlich mit dem Hochsommer oder Herbst in Verbindung bringen lässt. Dem entspricht auch die Auswahl der Früchte, die allesamt in diesen Jahreszeiten zur Reife gelangen.

Joseph Correggio hat in sein Gemälde auch ein lebendiges Wesen integriert. Auf dem rechten der beiden oberen Weinblätter sitzt ein Schmetterling mit einer markanten Färbung. Seine Flügel sind auf der äußeren Seite von unten nach oben zweifach rot-weiß-schwarz gestreift. Er ähnelt dem in Deutschland zu findenden Admiral, scheint aber eher der Phantasie des Künstlers entsprungen zu sein. ${ }^{9}$

Kompositorisch erinnert das Werk vor allem an Arbeiten der bekanntesten Stilllebenmaler der Düsseldorfer Malerschule, Johann Wilhelm Preyer und Jacob Lehnen. Düsseldorf war in der ersten Hälfte des 19. Jahrhunderts neben Berlin und Wien das bedeutendste Zentrum der Stillebenmalerei im deutschsprachigen

Ebd.

9 Vgl. Settele/Feldmann/Reinhardt 1999, S. 273 und S. 337. 
Raum. ${ }^{10}$ Preyer und Lehnen schufen eine ganze Reihe von Früchte- und Jagdstillleben in naher Ansicht auf Tischen aus Stein oder Marmor. ${ }^{11}$

Joseph Correggios Stillleben kann als ein exemplarisches Werk derjenigen Gattung der Malerei angesehen werden, die bis zum letzten Drittel des 19. Jahrhunderts die niedrigste Stufe der Gattungshierarchie besetzte, aber auf dem Kunstmarkt sehr gefragt war. ${ }^{12}$

Jan Stieglitz

10 Ebert-Schifferer 1998, S. 281-287.

11 Wandschneider 2003, S. 106, Kat. Nr. 20; S. 110, Kat. Nr. 18; S. 111, Kat. Nr. 21 und S. 116, Kat. Nr. 23.

12 Gisela Baumgärtel bespricht dies hinsichtlich der großen Beliebtheit von Stillleben der Düsseldorfer Malerschule; vgl. Baumgärtel, G. 2003, S. 32-34. 


\section{Porträts und Kopfstudien}

\section{Anne-Katrin Sors}

Das Porträt, verstanden als bildliche Darstellung eines Individuums, geht bis auf die Antike zurück. ${ }^{1}$ Funktional diente es ebenso in Ahnenkult, memorialen Formen der Repräsentation wie in der Herrscherehrung und politischen Propaganda. Von dem breiten künstlerischen und medialen Spektrum antiken Bildnisgebrauchs blieben uns bis auf wenige gemalte Mumienporträts aus dem Wüstensand vornehmlich skulpturale Werke erhalten. In welch hohem Maß dabei künstlerische Stilisierung und Idealsierungsbestrebungen stärker als ein Ähnlichkeitsprinzip die formale Erscheinung bestimmten, beschäftigt seit langem die archäologische Forschung.

Auch in den verschiedenen Phasen mittelalterlicher Kunst findet die Darstellung von Personen weite Verbreitung. Der Grad der Ähnlichkeit spielt hier jedoch keinerlei Rolle; ausschließlich die Absicht, einen bestimmten Menschen darzustellen ist wichtig. Bildnisse, die im modernen Sinn individualisierte Ähnlichkeit anstreben, treten erst seit dem 14. Jahrhundert auf. Konvention, Tradition und Funktion bedingten in religiösen und profanen Kontexten vor allem typisierte und stilisierte Darstellungen von hoher Zeichenhaftigkeit.

Erst mit dem in der altniederländischen Malerei des 15. Jahrhunderts aufkommenden Paradigma der bildlichen Naturnachahmung wird wiedererkennbare Ähnlichkeit zwischen Darstellung und Dargestelltem zum Ziel von Künstlern und

1 Literatur zum Porträt im Überblick (Auswahl): Rave 1948; Schneider 1992; Preimesberger/Baader/Suthor 1999; Beyer 2002; Kemperdick 2006; Hirschfelder 2010a; Hirschfelder 2010b; Ausst.-Kat. München 2011. 
Auftraggebern: Das frühneuzeitliche, vornehmlich gemalte Porträt mit der Forderung nach größtmöglicher Ähnlichkeit mit dem oder den Dargestellten hat seine Anfänge in den Niederlanden der 1420er Jahre. Für die Anfänge im zweiten Viertel des 15. Jahrhunderts ist Jan van Eyck die wichtigste Künstlerpersönlichkeit, einflussreich auf die nachfolgende, nicht nur niederländische Bildniskunst sein Zeitgenosse Rogier van der Weyden (1399-1472). ${ }^{2}$

Bereits kurz nach 1500 hatten sich die grundlegenden Typen und Charakteristika der Porträtkunst herausgebildet. Im 16. und 17. Jahrhundert lässt sich die Auftraggeberschaft in Adel, Klerus und wohlhabendes städtisches Bürgertum aufteilen. Unterschiedliche Bildnisformen werden durch divergierende Ansprüche, Möglichkeiten und Formen der Bildnisverwendung bestimmt. Standesporträts zeigen die Dargestellten mit Attributen ihres Standes, Herrscherporträts dienen der Repräsentation, können die Dargestellten symbolisch vertreten, sogar das tatsächliche oder angestrebte Aussehen der Herrscher weit entfernten Untertanen nahe bringen, entweder in der teuren Variante des kopierten Gemäldes oder - meist und in großer Zahl genutzt - in der vervielfältigten graphischen Darstellung. Sogenannte Privatporträts, die familiärer Erinnerung oder auch Kommunikation dienen (etwa bei versendeten Verlobungs- oder Hochzeitsbildern) treten in unterschiedlichen Formaten und Bildtypen auf. Mythologische Rollenporträts gestatten Einzelpersonen und Paaren, in die konventionsbrechend leichtbekleideten Rollen von Mars, Venus oder Diana zu schlüpfen. Orientalische Kostümierungen oder literarisch motivierte Stilisierungen, genannt seien nur die literarische Mode ländlich pastoraler Idylle und Liebesgeschichten und dementsprechende Bildnisinszenierungen, können seit dem späten 17. Jahrhundert in Malerwerkstätten ebenso bestellt werden, wie standeszugeordnete Repräsentationsbilder öffentlichen Charakters. Zwischen kleinem transportablem und wandgroßem Format entsteht eine Vielzahl funktional bestimmter und eigene Traditionen bildender Porträttypen. Nur hingewiesen sei auf Gruppenporträts, die korporative Repräsentation und Dokumentation des zugehörigen Individuums verbinden, oder auf Scheinporträts, die genrehafte moralische Typen und Belehrungen in Form nur scheinbarer Bildnisse verbildlichen.

Formal ist die Spannweite groß: Ganzkörperporträts, Kniestücke, Halbfigurenporträts, Bruststücke bilden sich als Typen ebenso heraus wie Einzel-, Doppelund Gruppenporträts, wie beispielsweise Familienporträts. Im Laufe des 17. Jahrhunderts dominiert der niederländische Kunstmarkt die Produktion, der ganz Europa beliefert und differenziertere Typen wie die Untergattung des Tronie entwickelt, welches sich als Kostüm- oder Charakterstudie zuerst als „Diener“ der Historienmalerei, dann als eigenständiger, auf dem Kunstmarkt sehr beliebter Typus etabliert. ${ }^{3}$

\footnotetext{
Kemperdick 2006, S. 22 f.

Zur Tronie und der Definitionsproblematik vgl. Hirschfelder 2008; Gottwald 2011.
} 


\section{Das Porträt ab dem 18. Jahrhundert}

Das 18. Jahrhundert bringt - nicht zuletzt auf Grundlage neuer kunsttheoretischer und philosophischer Konzepte - wichtige Neuerungen hervor. ${ }^{4}$ In der ersten Hälfte des Jahrhunderts findet eine Rückbesinnung auf die Antike (u. a. angeregt durch Johann Joachim Winckelmann) und verbreitet durch die Akademien statt, die in der Porträtkunst zu eigenen Idealisierungsstrategien führt. In der zweiten Hälfte des 18. Jahrhunderts lenken Gelehrte wie Johann Caspar Lavater (1741-1801)5 und Johann Georg Sulzer (1720-1779) ${ }^{6}$ die Konzentration auf die Darstellung der bestimmten Physiognomie und Charakteristik eines Menschen, der unterstellt wird, unmittelbarer Ausdruck der jeweiligen Persönlichkeit zu sein. Grundlegend waren vor allem die Schriften Sulzers, etwa sein Artikel über das Porträt in der Allgemeinen Theorie der Schönen Künste:

„Nichts ist also gewisser, als dieses, daß wir aus der Gestalt der Menschen, vorzüglich aus ihrer Gesichtsbildung etwas von dem erkennen, was in ihrer Seele vorgeht; wir sehen die Seele in dem Körper. Aus diesem Grunde können wir sagen, der Körper sey das Bild der Seele, oder die Seele selbst, sichtbar gemacht."

Gesellschaftliche Gruppen, geburts- oder berufsständig konstituiert, wie Gelehrte, Professoren, Dichter, Rats-, Bruderschafts-, Gilden- und Zunftmitglieder werden als Gruppe oder Einzelperson weiterhin dargestellt, doch treten zeichenhafte Inszenierung und attributive Kenntlichmachung in den Hintergrund: Die Physiognomie, die individuelle Erscheinung des einzelnen rückt in den Fokus, kostümliche Differenzierungen lösen sich im Zuge von Verbürgerlichungstendenzen und ständeübergreifenden Moden zunehmend auf. Auch die Zahl der Dargestellten wächst. Verschiedene Faktoren bedingen eine vermehrte Nachfrage und ein verbilligtes Angebot. Weitere Teile des Bürgertums lassen sich nun porträtieren. Techniken wie farbige Zeichnungen, die weit schneller und billiger zu produzieren sind als Ölgemälde, eine ausgeweitete institutionelle Künstlerausbildung und Zeichenunterricht als Teil höherer Bildung adeliger und bürgerlicher Kreise führen zu einer Ausweitung der Bildnisherstellung, die auf den erhöhten Bildnisbedarf reagiert. Gesellschaftliche Verschiebungen spielen ebenso hinein: Auch Frauen finden Zugang zu Akademien oder lernen in der gehobenen Ausbildung Grundzüge der Malerei, es entstehen viele Laienporträts. Beides hat Auswirkungen auf Technik und Materialien: Pastellkreide auf Pergament, aber auch auf Papier, der Malerei zugerechnet, doch ungleich schneller und preiswerter in der Anwendung, findet vornehmlich im Porträtgenre Verwendung.

4 Literatur zum Porträt im 18. und 19. Jahrhundert in Auswahl: Kanz 1993; Kanz 1998; Thimann 2006; Ausst.-Kat. Wien 2007; Ausst.-Kat. Halberstadt 2010; Ausst,-Kat. Schweinfurt 2010.

5 1775-1778 erscheinen die Physiognomischen Fragmente zur Beförderung der Menschenkenntnis und Menschenliebe in vier Bänden.

61771 und 1774 erscheint die Allgemeine Theorie der schönen Künste in vier Bänden.

7 Sulzer 1792-1799, Bd. 3, S. 719. 
Die Tendenz zu kleinformatigen Porträts, die zur Erinnerung, als Freundschaftsgeschenk usw. in Auftrag gegeben werden, gelangt aus adeligem Brauchtum in bürgerliche Kreise. Hinzu kommt eine Popularisierung des Individuellen, eine Art Kult der Person, die in den verschiedenen Phasen und Strömungen des 19. Jahrhunderts immer wieder aufscheint und Bildnisbedarf motiviert. Bildnisse von Professoren, die von Studenten in Auftrag gegeben werden, Porträts und Abgüsse gerade Verstorbener, Bildnisse von Privatpersonen in verschiedenen Lebensphasen oder literarisch motivierte Selbststilisierungen sind Ausdruck solcher Tendenzen.

\section{Bildnisse des 19. Jahrhunderts in der Göttinger Universitäts- kunstsammlung}

Die Bildnisse des 19. Jahrhunderts, welche die Göttinger Universitätskunstsammlung aufbewahrt, vermitteln ein durchaus repräsentatives Bild von dieser breiten, gesellschaftsübergreifenden und doch ausdifferenzierten Kultur des Porträts. Darunter befinden sich großformatige Ölgemälde, die zum Teil von namhaften Spezialisten ihres Faches geschaffen wurden: so etwa das auf das Jahr 1804 datierte Bildnis eines unbekannten Herrn von Friedrich Georg Weitsch (1758-1828) (Kat. Nr. 37). ${ }^{8}$ Das von seinen Ausmaßen her größte Porträt der Universitätskunstsammlung ist unten links signiert mit „FGWeitsch“ und auf das Jahr 1804 datiert. Der Unbekannte ist fast lebensgroß im Halbporträt dargestellt, wendet sich mit Körper und Kopf nach rechts, so dass sein Blick nach unten links aus dem Bild herausgeht. Er trägt eine blaue Jacke über einer schwarzen, darunter ein weißes Hemd. Im dunklen Hintergrund erkennt man rechts einen Tisch mit einem Buch, auf das sich der Dargestellte mit seiner Linken abstützt. Seine rechte Hand hält ein beschriftetes Stück Papier, dessen Aufschrift bisher nur teilweise entziffert wurde. So scheint die oberste Zeile rechts einen Ortsnamen mit dem Anfangsbuchstaben M zu nennen, darunter liest man wohl das Datum „19. Nov. [18]02“.9 Dunkler Hintergrund und dunkle Jacke über weißem Hemd lenken die Konzentration ganz auf den Kopf, also auf Gesicht und Mimik des Unbekannten. Das Porträt führt eindrücklich die Umsetzung der Forderung vor Augen, dass ein Porträt nicht nur ähnlich sein solle, sondern die Seele und Empfindungen des Porträtierten sichtbar zu machen habe.

8 Unpubliziert, nicht im Werkverzeichnis von Lacher 2005a. Die Herkunft ist momentan unbekannt. Das Porträt ist weder im Katalog Unverfehrt 1987 noch im Bildniskatalog von Arndt 1994 zu finden. Reimar Lacher holte zwischen 2001 und 2003 Informationen über die beiden Zeichnungen (H 1964/2 und H 1967/6) und das Landschaftsgemälde (Inv. Nr. GG 196) von Friedrich Georg Weitsch in der Universitätskunstsammlung ein. Da ihm dieses Porträt nicht genannt wurde, ist momentan davon auszugehen, dass es sich zu der Zeit noch nicht in der Sammlung befand. Nachzuweisen ist es in der Sammlung erstmals am 2. Januar 2008, da ein digitales Foto des Gemäldes auf diesen Tag datiert (für Foto und Information danke ich Tobias Heine, Göttingen).

9 Für Begutachtung und Meinungsäußerung danke ich PD Dr. Arwed Arnulf, Frank Jasper Noll M.A., Lisa Marie Roemer M.A., PD Dr. Christian Scholl, Prof. Dr. Michael Thimann und Prof. Dr. Carsten-Peter Warncke. 
Hinzu kommt die Anlage des Bildnisses: In dunklem Innenraum scheint der Dargestellte formlos an den Tisch gelehnt, abgestützt auf das Buch als Gelehrsamkeitsattribut. Die Seitenwendung scheint den Dargestellten aus einer Gesprächssituation herausgelöst zu zeigen, sein Blick gilt wohl einem uns nicht sichtbaren Gesprächspartner. Dieser casuale Gestus erfährt Dramatisierung durch die Lichtführung: Nur Gesicht und Hemdbrust erhalten Beleuchtung.

Das Porträt des Biologen und Afrikaforschers Georg Heinrich Roentgen (1787-1811) (Kat. Nr. 36) ist unbekannter Herkunft, jedoch durch Kataloge seit der Zeit um 1900 in der Sammlung nachzuweisen. ${ }^{10}$ Waldmann gibt in seinem Katalog 1905 als Künstler M. Max Fellfoot an, der jedoch nicht weiter nachzuweisen ist, ${ }^{11}$ der Dargestellte bleibt unerkannt. Aus der erhaltenen Korrespondenz in der Bildakte geht hervor, dass der Dargestellte auf Grund der rückseitigen Aufschrift „Roentgen africanus“12 als Georg Heinrich Roentgen, Sohn des berühmten Möbeltischlers David Roentgen (1743-1807), identifiziert werden konnte. Er kam 1807 zum Studium der Naturwissenschaften nach Göttingen, besuchte Johann Friedrich Blumenbachs Vorlesungen und eröffnete diesem beim ersten Treffen „dass er nun schon seit mehreren Jahren für Afrika lebe, und nun herkomme, sich bey uns vollends zu einer Reise ins Innere dieses so wichtigen und so wenig bekannten Erdteiles vorzubereiten." 13 In den vier Semestern in Göttingen lernte er Arabisch, unternahm ausgedehnte Fußmärsche, ließ sich beschneiden und zur körperlichen Vorbereitung aß er täglich ,auf abessinische Art in dünne Scheiben geschnittenes, rohes Rindfleisch“.14 1809 ging Roentgen mit Empfehlung Blumenbachs nach London, jedoch waren die Gesandtschaften der Association bereits unterwegs nach Nordafrika und Sir Joseph Banks wollte keine zweite schicken. So konnte er erst 1811 nach Mogadore in Marokko reisen, wo er jedoch auf seinem Weg nach Timbuktu von einem Reisegefährten ermordet wurde. ${ }^{15}$ Das Porträt zeigt Roentgen im Halbporträt mit nach links gewendetem Kopf und Blick, der in die Ferne gerichtet ist. Er trägt das Haar kurz mit langen Koteletten, einen ausladenden weißen Kragen und eine schwarze Jacke. In seiner rechten Hand hält er eine gerollte Afrikakarte, auf der „teneo te Africam“ steht, ein Zitat, das er 1808 in einem Brief an Blumenbach verwendet: „[...] Ihnen zu melden, daß ich gestern durch die Beschneidung meine körperliche Ausbildung für Afrika vollendet habe.

10 Unverfehrt 1987, S. 181, Kat. Nr. A 16; Waldmann 1905, S. 64, Kat. Nr. 162. Für die Recherche und das Zusammenstellen der Unterlagen in der Bildakte GG 129 sei an dieser Stelle Nicole Zornhagen, Göttingen, herzlich gedankt.

11 Eine maschinenschriftliche Notiz in der Gemäldeakte GG 129 gibt ihn als unbekannten englischen Maler von der Wende des 18. zum 19. Jahrhundert an.

121932 schreibt H. Dörries, London, eine Postkarte mit der Information, dass „Roentgen africanus“ weiterhin ein großer Unbekannter bleiben müsse. Die Durchsicht des gesamten Nachlasses von Sir Joseph Banks, vor allem die vollständige Foreign Correspondence sei nicht erfolgreich gewesem. Blumenbach werde ständig erwähnt, nicht aber Roentgen; vgl. Bildakte GG 129.

13 Vgl. Plischke 1937, S. 42-47. Das Zitat ebd., S. 14.

14 Zitiert nach ebd., S. 43.

15 Plischke 1937, S. 45 f. 
Noch fehlt der Koran und ich bin ein vollkommner Muhammedaner u. rufe mit Caesar: teneo te Africam." 16

Bei dem Porträt eines jungen Mannes von Ernst Otto (1807-1847) (Kat. Nr. 45) handelt es sich aller Wahrscheinlichkeit nach um ein Selbstbildnis des Künstlers, entstanden nach 1825.17 Das Gemälde befindet sich als Leihgabe der Bundesrepublik Deutschland seit 1966 in der Kunstsammlung. ${ }^{18}$ Der Künstler wird 1807 in Dresden geboren, stirbt jung 1847 ebenda, war Schüler von Moritz Retzsch und in Dresden und Meissen als Bildnis- und Genremaler sowie als Lithograph tätig. ${ }^{19}$ Der junge Mann, dargestellt in Brustporträt mit dunkler Jacke, weißem Hemd und schwarzer Binde, dreht dem Betrachter den Kopf zu und schaut direkt und herausfordernd aus dem Bild. Der verwegene Blick wird durch die genialisch bewegte, blonde Haartracht betont. Seine rechte Hand hat er unter die Jacke geschoben, sie liegt auf seinem Herzen. Sollte dies ein Selbstporträt sein, ist festzuhalten, dass sich der Künstler nicht mit seinen berufsspezifischen Attributen wir Pinsel, Palette u.a. zeigt, sondern dass die Konzentration der Darstellung allein auf Gesicht und Mimik liegt.

Das Bildnis des Freiherrn Georg Heinrich von Langsdorff (1774-1852) (Kat. Nr. 44), ${ }^{20}$ deutsch-russischer Arzt, Naturforscher und Forschungsreisender, ${ }^{21}$ malte vermutlich ein unbekannter deutscher Künstler. Die Vermutung, dass es von einem russi-

16 Zitiert nach ebd., S. 95.

17 Unverfehrt 1987, S. 187, Kat. Nr. A 55; Wille 1970, Kat. Nr. 108.

18 Karteikarte Bundesamt für zentrale Dienste und offene Vermögensfragen (BADV) zu Objektnr. 21078: „Die Ermittlungen der Treuhandverwaltung von Kulturgut beim Auswärtigen Amt (TVK) zur Provenienz des Gemäldes ergaben, dass das Bild unter verschiedenen Titeln (BArch, B 323/610: Herrenportrait, BArch, B323/654: Portrait of a young gentleman; Karteikarte BADV: Selbstbildnis), von einem Künstler Ernst Otto gemalt wurde. Das Bild sei signiert ,Otto'. Es sei mit den folgenden Markierungen versehen: ,590/502‘, ,K 39‘ und ,M 21/c' (BArch, B 323/654). Über die Herkunft des Bildes ist fast gar nichts bekannt. Einzig eine zeitliche Eingrenzung liegt vor: ,vor dem Krieg erworben'. Die erneuten Recherchen ergaben folgendes: Die Markierungen stimmen mit den o. g. überein: Darunter ist die Inventar-Nummer für das Museum in Linz 590/502 sowie die Inventarnummer für den Aufbewahrungsort Kremsmünster K 39. Die weiteren Markierungen sind nicht identifiziert. Die Nummer 2622, die sich in doppelter Ausführung auf der Rückseite befindet, ist bekannt als die München-Nr. Der Dresdner Maler und Graphiker Ernst Otto (18071847) wurde für seine Porträts bekannt. Ob das Bild den Maler selbst darstellt, konnte nicht belegt werden. Nachgewiesen sind Bildnisse der Kinder des Künstlers, Rudolf und Marie (Ausst.-Kat. Berlin 1906b, S. 412, Nr. 1281). Der für diese genannte Besitzer war sehr wahrscheinlich der Sohn ,Rudolf Otto, Berlin‘. Grundsätzlich entstehen Porträts zumeist für Personen, die dem bzw. der Dargestellten nahestehen. Es ist sehr gut möglich, dass das Selbstporträt, gesetzt den Fall, es handele sich bei dem Dargestellten um eines, in der Familie oder dieser nahestehenden Personen verblieb. Über das Kunstwerk und seine Provenienz ergeben sich keine weiteren Hinweise. Ein Werkverzeichnis über den Künstler liegt nicht vor. Weder der Künstler noch das Werk sind in den einschlägigen Datenbanken nachzuweisen (Galerie Heinemann online, RKD, NEPIP, Lootedart.com, Sage Recovery). Vor dem hier geschilderten Hintergrund bleibt die Provenienz derzeit ungeklärt."

19 Thieme/Becker 1907-1950, Bd. 26, 1932, S. 91.

20 Unverfehrt 1987, S. 194, Kat. Nr. A 106.

21 Alle Angaben zur Biographie bei Ratzel 1883a, S. 689 f. 
schen Künstler stamme, rührt vermutlich von der Tatsache her, dass Langsdorff lange in russischem Staatsdienst stand.22 Die Identifizierung des Dargestellten erfolgte laut Bildakte über einen auf der Rückseite aufgeklebten Zettel mit der Aufschrift: „G. H. v. Langsdorff, Russr. General-Consul in Brasilien“ (Zettel heute nicht mehr vorhanden). Das in Öl auf Leinwand ausgeführte Brustbildnis trägt weder Datierung noch Signatur. Der Dargestellte ist vor grauem Hintergrund leicht nach rechts gedreht, er wendet Kopf und Blick jedoch dem Betrachter zu, über der weißen, hochgebundenen Halsbinde trägt er einen blauen Rock. Langsdorf stammte aus dem Elsaß, studierte in Göttingen Medizin, wurde 1797 promoviert, widmete sich anschließend weiterhin naturwissenschaftlichen Studien. Mit Prinz Christian von Waldeck, General der portugiesischen Armee, reiste er nach Lissabon und durch Portugal, wurde nach des Prinzen Tod Arzt in der Armee. 1803 kehrte er kurz nach Göttingen zurück, nahm dann an der Krusenstern'schen Expedition ${ }^{23}$ ab Kopenhagen teil, trennte sich 1805 von dieser, um Russisch-Amerika und Californien zu bereisen. 1808 trat er in russischen Staatsdienst ein und ging nach Brasilien. 1822 reiste er mit dem Astronomen Ruszow und dem Maler Rugendas durch Brasilien. Zurück in Deutschland, ließ er sich 1831 bis zum Ende seines Lebens in Freiburg im Breisgau nieder.

So unterschiedlich die genannten Porträts sind, so verbindet sie doch die Konzentration auf das Physiognomische. Die Bildhintergründe bleiben weitgehend monochrom. Lediglich bei Max M. Fellfoots Bildnis des Afrikaforschers Georg Heinrich Roentgen (Kat. Nr. 36) und bei dem Bildnis eines Herrn von Friedrich Georg Weitsch (Kat. Nr. 37) kommen Bücher oder eine Schriftrolle als Ausweis von Gelehrsamkeit hinzu. Insofern bieten sie charakteristische Beispiele für die bürgerliche Porträtmalerei in der ersten Hälfte des 19. Jahrhunderts. Ganz anders ist das Ganzkörperporträt Bildnis einer Dame im Grünen (Kat. Nr. 32) angelegt, das eine unbekannte Frau mit Blumenattributen auf einer Bank in einer parkähnlichen Landschaft zeigt. Es steht in einer namentlich von der englischen Malerei des 18. Jahrhunderts (u. a. Thomas Gainsborough) ${ }^{24}$ angeregten Tradition, die vor allem im Adel verbreitet war. Man findet entsprechende Werke im späten 18. Jahrhundert etwa bei Angelika Kauffmann (1741-1807) ${ }^{25}$ oder Johann Friedrich August Tischbein (1750-1812). ${ }^{26}$ Die Provenienz des Göttinger Gemäldes legt ebenfalls eine adlige Herkunft der Porträtierten nahe. ${ }^{27}$ Allerdings sollte man aufgrund der gesell-

22 Stechow 1926, S. 15 f., Nr. 47.

23 Vgl. Ratzel 1883b, S. 270-274.

24 Vgl. Gockel 1999, S. 131 f., 141-151.

25 Vgl. etwa Angelika Kauffmann: Bildnis Anne Loudoun, Lady Henderson of Fordell, 1771, Schwarzenberg, Angelika Kauffmann Museum (Ausst.-Kat. Bregenz/Schwarzenberg 2007, S. 114 f.).

26 Vgl. etwa Johann Friedrich August Tischbein: Gräfin Theresia von Fries, 1801, Hamburg, Kunsthalle (Ausst.-Kat. Kassel 2005, S. 190, Kat. Nr. 61).

27 Vgl. den Beitrag von Verena Suchy in diesem Band, S. 281 f. Das Bildnis einer Dame im Grünen gehört zu den Werken, die im Rahmen des studentischen Forschungsprojekts „Gattungstheorie und Gattungspraxis“ eingehender behandelt wurden. Dementsprechend erhält es im Folgenden einen eigenen Katalogbeitrag. 
schaftlichen Dynamik gerade in der Zeit um 1800 mit festen Zuweisungen bestimmter Porträttypen an soziale Schichten vorsichtig sein. ${ }^{28}$

Die Bildnismalerei der Mitte des 19. Jahrhunderts ist in der Kunstsammlung durch drei Herren- (Kat. Nr. 47, 51, 53) sowie zwei Damenporträts (Kat. Nr. 50, 52) vertreten:

Der Anatom Friedrich Gustav Jakob Henle (1809-1885) wurde 1840 von dem bisher nicht identifizierten Maler A. Schmidt porträtiert, der das Gemälde links mittig in roter Schrift datierte und signierte (Kat. Nr. 47). Aus der rückseitigen Inschrift auf dem Keilrahmen lässt sich die Information entnehmen, dass das Werk 1877 von dem bisherigen Besitzer G. A. Böhnisch übergeben wurde - jedoch vermutlich an einen weiteren Vorbesitzer und nicht an die Universitätskunstsammlung. Da es sich weder im Katalog von Gerd Unverfehrt von 1987 noch in dem von Karl Arndt von 1994 findet, ist davon auszugehen, dass es erst nach 1994 in die Universitätskunstsammlung kam.

Das Porträt eines unbekannten Herrn mit Brille eines unbekannten deutschen Künstlers (Kat. Nr. 51) ist auf das Jahr 1852 datiert in der ungewöhnlichen Technik Öl auf Zinn gemalt. Das Monogramm ließ sich bisher nicht auflösen. ${ }^{29}$ Der vor dunklem Hintergrund Dargestellte im Halbfigurenporträt blickt den Betrachter frontal an, ist mit schwarzer Jacke und dunkler Weste über weißem Hemd mit schwarzer Binde gekleidet, das Haar ist modisch bis über das halbe Ohr frisiert.

Otto Peters (1835-1920) ${ }^{30}$ malte Ernst Heinrich Ehlers 1859 als Student (Kat. Nr. 53). ${ }^{31}$ Der Dargestellte war ein Mitschüler von Otto Peters auf dem Johanneum in Lüneburg und studierte von 1857 bis 1861 Zoologie und Medizin in Göttingen. In Erlangen wurde er 1869 zum ordentlichen Professor für Zoologie, vergleichende Anatomie und Veterinärmedizin ernannt, bevor er 1874 nach Göttingen berufen wurde. ${ }^{32}$ Den Kopf leicht nach links gebeugt und gedreht schaut Ehlers den Betrachter nicht an, er trägt sein dunkles Haar im Seitenscheitel sowie Schnur- und Kinnbart. Das Schulterporträt vor dunklem Hintergrund führt uns den Studenten in dunkler Jacke über weißem Hemd mit schwarzer Binde vor.

Jedes der drei Herrenporträts ist typisch für die Mitte des 19. Jahrhunderts: die Gelehrten lassen sich ohne jegliches Attribut in zeitgenössischer Kleidung und Haartracht darstellen, die Konzentration liegt lediglich auf Gesicht, Blick und Mimik - eine private Verwendung darf für alle drei angenommen werden.

28 Vgl. etwa das (in seiner Zuordnung allerdings nicht sichere) Familienbildnis des gewiss nicht adligen, hier aber für sich offenbar dieselbe Bildnistradition aufgreifenden Künstlers Johann Friedrich August Tischbein (um 1795-1800), Kassel, Staatliche Museen, Neue Galerie (Ausst.-Kat. Kassel 2005, S. 180, Kat. Nr. 56).

29 Unverfehrt 1987, S. 195, Kat. Nr. A 108. Zur Herkunft: In der Bildakte GG 213 findet sich die handschriftliche Notiz - vermutlich von Konrad Renger: „In der Kunstslg bei Amtsantritt 1975 vorgefunden."

30 Ehlers 1970, S. 23. Vgl. auch Kat. Nr. 27.

31 Unverfehrt 1987, S. 187, Kat. Nr. A 58.

32 Ausst.-Kat. Lüneburg 1974, S. 25. 


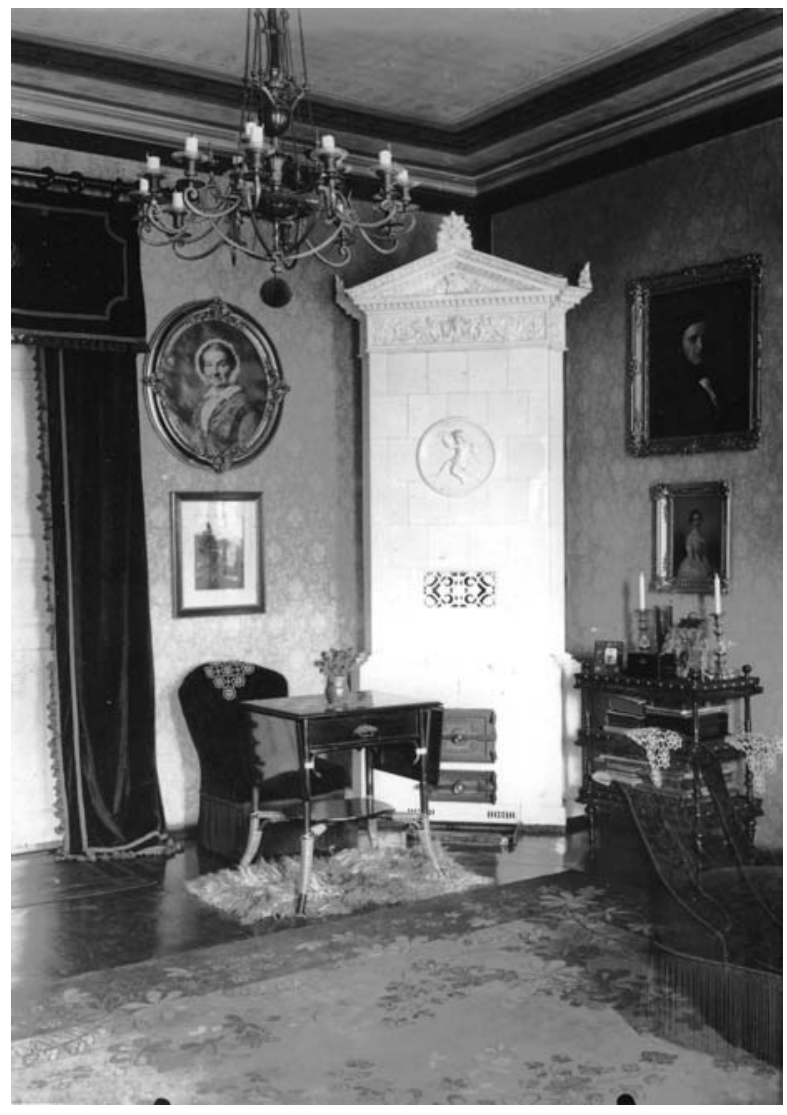

Abb. 39: Das Porträt von Christiane Künzel als Teil einer Wohnzimmerausstattung

Das hochovale Porträt der Christiane Künzel (Kat. Nr. 52), 331855 von Heinrich Lichtenberger gemalt, ist monogrammiert und datiert. ${ }^{34}$ Es stammt aus dem Nachlass des Archäologen Prof. Dr. Kurt Ferdinand Müller (1880-1972) ${ }^{35}$ und kam

33 Die Mutter des Schenkers war eine geborene Anna Künzel. Die Dargestellte wird eine Verwandte mütterlicherseits sein.

34 Unverfehrt 1987, S. 185, Kat. Nr. A 43.

35 Döhl 1997, S. 449 f.: Die Eltern von Kurt Müller waren der praktische Arzt Albert Wilhelm Müller und Anna, geb. Künzel. Er wurde in Dresden geboren, besuchte das Kreuzgymnasium (1891-99), anschließend studierte er Altphilologie, Alte Geschichte, Kunstgeschichte und klassische Archäologie in München und Leipzig, wo er 1905 bei Franz Studniczka mit der Dissertation Der Leichenwagen Alexanders des Grossen promovierte. Durch ein Stipendium des Deutschen Archäologischen Instituts konnte er 1905 bis 1907 Italien, Griechenland, Kleinasien und Ägypten bereisen. Von 1909 bis 1912 war er in Athen als Assistent tätig, nahm an Grabungen teil und kam 1912 nach Göttingen. Nach der Habilitation 1913 erhielt er 1919 den Professorentitel, 1937 entließ man ihn als Assistenten, erteilte ihm jedoch einen Lehrauftrag für Vor- und Früh- 
1973 in die Sammlung. In der Bildakte ist eine Photographie (Abb. 39) erhalten, auf dem man das Porträt im nicht mehr erhaltenen prunkvollen Rahmen in einem Wohnzimmer hängend sieht - der private Zweck des Bildes, die Erinnerung an eine Verwandte, ist somit dokumentiert. Das Bildnis zeigt die Dame als ältere Frau in zeittypischer Kleidung mit blauem Kleid, weißem Spitzenkragen und -häubchen.

Das nur auf den ersten Blick brav erscheinende Porträt ${ }^{36}$ einer Frau (Kat. Nr. 50), 1851 in Öl auf Leinwand gemalt von Ferdinand Tellgmann (1811-1897),37 entpuppt sich bei näherer Betrachtung als hochinteressantes Beispiel für die Umschwung von Porträtmalerei zu Porträtphotographie um die Mitte des 19. Jahrhunderts. Ferdinand Tellgmann, dessen künstlerisches Talent sich bereits zur Schulzeit zeigte, begann 1827 eine Ausbildung an der Kurfürstlichen Kunstakademie in Kassel und spezialisierte sich auf Porträtmalerei. Seit 1838 war er zunächst in seiner Heimat Eschwege/Wanfried sowie in Mühlhausen als Porträtmaler tätig, bevor er ab 1843 mit dem Kasseler Photopionier Moses J. Landauer zusammenarbeitete. Tellgmann nutzte zuerst die Technik der Daguerreotypie, später die der vervielfältigbaren Photographie. Das neue Medium wurde immer beliebter, so dass die Firma mehrere Filialen eröffnete. ${ }^{38}$ So ist also die Ablösung der Porträtmalerei durch die Photographie in der Mitte des 19. Jahrhunderts personell durch das von Ferdinand Tellgmann gemalte Bildnis in der Universitätskunstsammlung vertreten. Die Dargestellte ist vermutlich seine Ehefrau Cäcilie, geb. Bregazzi39, die der Künstler 1851 - acht Jahre nach seinen Anfängen in der Photographie - in Öl festhält.

\section{Pastelle}

Die Technik der Pastellmalerei auf Papier bzw. auf Pergament erfreute sich bereits im 18. Jahrhundert großer Beliebtheit. ${ }^{40} \mathrm{Im}$ 19. Jahrhundert war diese Technik vor allem für die Gattung des Porträts verbreitet und wurde auch von Laien genutzt.

Das Bildnis einer (bisher) unbekannten Dame eines unbekannten Künstlers unbekannter Herkunft (Kat. Nr. 49) dürfte ein Beispiel für diese Laienporträtmalerei sein. Die Dame ist im Halbporträt dargestellt, stützt sich mit ihrem rechten

griechisch. Von 1939 bis zu seiner Pensionierung 1946 durfte er den Lehrstuhl für Klassische Archäologie vertreten.

36 Unverfehrt 1987, S. 190, Kat. Nr. A 75.

37 Auf der Rückseite findet sich ein Etikett, dem zu entnehmen ist, daß das Porträt am 26.2.1962 als Schenkung an die Universitätskunstsammlung kam (Renger notiert in der Bildakte hierzu: „In Rosemanns Schrift Etikett: ...."). Rückseitig ist das Gemälde datiert und signiert: „Tellgmann pinx 11 15/5 51“.

38 Vgl. zu Ferdinand Tellgmann: Wiegand 1994 sowie Faulstich 2002, S. 177-179.

39 Vgl. das Foto der Gattin auf dem Plakat zum Firmenjubiläum, abgebildet in Faulstich 2002, S. 178.

40 In der Universitätskunstsammlung befindet sich ein prominentes Beispiel, das den Stifter der Gemäldesammlung von 1796 zeigt: Johann Wilhelm Zschorn, in Pastell auf Pergament gemalt von Friedrich Basilius von Ramdohr. Inv.-Nr. GG 169; Unverfehrt 1987, S. 188, Kat. Nr. A 61. 
Unterarm auf ein nicht sichtbares Möbel und ist dem Betrachter frontal zugewandt. Das braune Kleid ist mit schwarzen Stickereien verziert und schwarzer Spitze besetzt, darunter trägt die Dame ein weißes Gewand aus weißer Spitze, das aus dem Ärmel hervorlugt. Der weiße Kragen ist mit einer dunklen Schleife sowie einer Brosche verziert. Auf der Rückseite befindet sich eine bisher nicht lesbare Inschrift, die jedoch teilweise durch die Untersuchung mit UV-Licht zumindest zu einer Identifikation der Dargestellen geführt hat. ${ }^{41} \mathrm{Zu}$ lesen ist auf blauem hinterklebtem Papier in blauer, bereits sehr verblichener Schrift in sieben Zeilen: „Frau Universitätsrath Ulrich [Ulrich schwer zu lesen, A.K.S.] / geb. Junge ihre Mutter war eine S[...]der G[...] Augsburg [?] / geb. H[...] / [...] / [...] / [...] / [...]“. Im Neuen Nekrolog der Deutschen konnte Nicole Zornhagen, Göttingen, unter 1084 einen „Ulrich, Universitätsrath zu Göttingen“"42 feststellen, der im zweiten Teil näher beschrieben wird als „D.30 zu Göttingen der königl. großbrittab. Hannov. Universitätsrath Christ. Friedr. Wilhelm Ulrich - im 46. Lebensj.“,43 so dass man auf die Lebensdaten 1784/85-1830 kommt. Der Ehemann der Dargestellten ist vermutlich der Stiefsohn des Senators zu Göttingen Justus Christoph Grünewald (1764-1835), der 1801 die verwitwete Postverwalterin Ulrich, geb. Borhek, mit 7 Kindern heiratete. ${ }^{44}$

Die drei Pastellbildnisse von Lorenz Friedrich von Crell (1744-1816) (Kat. Nr. 39), ${ }^{45}$ David Julius Pott (1760-1838) (Kat. Nr. 41) ${ }^{46}$ und seiner Frau Auguste Johanna, geb. von Crell ( $†$ 11. Juli 1816) (Kat. Nr. 40) ${ }^{47}$ sind zusammen zu betrachten. Abgesehen von ihrer gemeinsamen Herkunft aus dem Knapp-Archiv in München $^{48}$ weisen sie dieselbe Größe von 58 x $45 \mathrm{~cm}$ auf. Das lässt darauf schließen, dass sie zusammen und für denselben Zweck erstellt wurden und wirft gleichzeitig die Frage auf, ob sie Teil einer größeren Serie waren. Lorenz Friedrich von Crell war Mediziner, Bergrat und Chemiker. Seine Tochter Auguste Johanna war verheiratet mit David Julius Pott, der von 1786-1787 Privatdozent, seit 1810 Professor für evangelisch-lutherische Theologie, Bibelwissenschaftler und Hochschullehrer in Göttingen war. ${ }^{49}$

Das Bildnis in Pastellmalerei auf Papier des Christoph Angebroth (Kat. Nr. 38) von einem unbekannten Künstler ist auf die Mitte des 19. Jahrhunderts zu datie-

41 Durchgeführt und analysiert von Nicole Zornhagen im Projektseminar „Inventarisierung“, Sommersemester 2011. Zum folgenden vgl. die von Nicole Zornhagen zusammengetragenen Dokumente in der Bildakte GG $217 \mathrm{im}$ Archiv der Kunstsammlung. An dieser Stelle sei Nicole Zornhagen gedankt für die gründliche Recherche.

42 Schmidt, F. A. 1824-1854, 8, 1830, Erster Theil, Ilmenau 1832.

43 Schmidt, F. A. 1824-1854, 8, 1830, Zweiter Theil, S. 968, Nr. 1084.

44 Eugen von dem Knesebeck: 272 Justus Christoph Grünewald, in: Schmidt, F. A. 1824-1854, 13, 1835, Zweiter Theil, Weimar 1837, S. 934-938.

45 Unverfehrt 1987, S. 194, Kat. Nr. A 103. Vgl. Oppenheim 1876, S. 587 f.

46 Unverfehrt 1987, S. 194, Kat. Nr. A 105. Arndt 1994, S. 101, Kat. Nr. 167.

47 Unverfehrt 1987, S. 194, Kat. Nr. A 104.

48 Ebenso wie die beiden Miniaturen des Ehepaares Pott (Kat. Nr. 42+43).

49 Siegfried 1888, S. 485 f.; Wesseling 1994, Sp. 867 f. 
ren. Es kam 1962 als Schenkung von Frau E. Stahler in die Sammlung. ${ }^{50}$ Einer Aufschrift auf der Rückseite verdanken wir die Identifizierung des Dargestellten: „Christoph Angebroth. Vater von Johanna Auguste Leinweber in Mühlhausen/Thür.“. Das Bildnis reiht sich vom Darstellungstypus her in die Reihe der Bildnisse von Langsdorff (Kat. Nr. 44), Herr mit Brille (Kat. Nr. 51) und Ernst Ehlers als Student von Otto Peters (Kat. Nr. 53) ein, denn es ist ein attributloses Bildnis im Brustporträt aus der Mitte des 19. Jahrhunderts. Nur die Technik in Pastell unterscheidet es von den andern dreien. Angebroth schaut den Betrachter frontal an, sein Oberkörper ist nach links gewendet. Er ist vor hellem Grund dargestellt und trägt zeittypisch unter seiner dunkelblauen Jacke ein weißes Hemd mit weißer Binde.

Das jüngste Pastellporträt ist das Damenbildnis von 1887, gemalt von Helene von Frauendorfer-Mühlthaler (1853-1933), die es signiert und datiert hat (Kat. Nr. 54). Es kam 1970 als Stiftung aus Göttinger Privatbesitz in die Universitätskunstsammlung. ${ }^{51}$ Die Malerin war nach Ulrich Thiemes und Felix Beckers Allgemeinem Lexikon der bildenden Künstler von der Antike bis zur Gegenwart Schülerin von Eduard Grützner, seit 1878 im Münchner Kunstverein und auf den Münchner Jahresausstellungen im Glaspalast vertreten. ${ }^{52}$ Manchmal nahm sie mit ihren Bildern auch an den Berliner Akademieausstellungen und den Düsseldorfer Deutschnationalen Ausstellungen von 1902 und 1907 teil. Sie schuf vor allem Damen- und Kinderporträts, Genrebilder und Blumenstücke in Pastell und Öl. In der Kunstchronik berichtet Adolf Rosenberg 1889 über eine Ausstellung in der Berliner Filiale der Düsseldorfer Kunsthandlung von Eduard Schulte:

„Endlich hat sich eine Münchener Künstlerin, Helene Mühlthaler, eine Schülerin von E. Grützner, die sich aber mehr nach Lenbach und F. A. Kaulbach, vielleicht auch etwas minder empfehlenswerten Mustern wie Piglhein und Koppay gebildet hat, durch etwa zwanzig Bildnisse, Studienköpfe und Genrebilder als eine hervorragende Pastellzeichnerin vorgestellt, welche nicht bloß den flaumigen, flockigen, flüchtig-visionären Ton der Pastellportraits des vorigen Jahrhunderts glücklich zu treffen sondern auch starke, realistische und koloristische Zeichnungen zu erzielen weiß, welche der moderne Geschmack verlangt, die aber streng genommen in Widerspruch zu den Mitteln dieser am Farbenstaub, nicht auf pastose Effekte gründenden Technik stehen. “53

\section{Miniaturen}

Ein Spezialfall der Porträtgattung sind Miniaturen, die bereits im 16. Jahrhundert aufkamen, sich aber vor allem im 18. und 19. Jahrhundert größter Beliebtheit erfreuten. Besonders interessant sind die verschiedenen Techniken und Malgründe, die in der Miniaturmalerei Verwendung fanden. So nutzte man als Malgrund, des-

\footnotetext{
50 Unverfehrt 1987, S. 195, Kat. Nr. A 110.

51 Unverfehrt 1987, S. 195, Kat. Nr. A 107; Wille 1970, Nr. 5; vgl. auch Frauendorfer 1975, S. 448.

52 Thieme/Becker 1907-1950, Bd. 12, 1916, S. 399.

53 Rosenberg 1889, Sp. 423 f.
} 
sen Beschaffenheit eine möglichst feine, sehr glatte Oberfläche zu sein hatte, nicht nur Gewebe und Holz, sondern ebenso Stein, Papier, Pergament, Porzellan, Emaille und vor allem hauchdünnes Elfenbein. ${ }^{54}$ Die große Herausforderung der Malerei in Gouache und Aquarell sowie in Öl bestand darin, akkurateste und möglichst detaillierte Präzision und Feinteiligkeit auf kleinstem Grund, häufig in Punkt- und Strichmanier zu erzielen. ${ }^{55}$ Elfenbeinblätter finden etwa seit 1700 nicht nur wegen ihrer glatten Oberfläche sehr häufig Verwendung, sondern vor allem auch wegen der - in der optischen Wirkung menschlicher Haut sehr nahe kommenden - wächsernen Transparenz ihrer Materialität. So konnte man Inkarnate stets durchscheinend malen und nicht deckend. Sowohl zur Stabilisierung als auch zur farbig durchscheinenden Wirkung wurden die Elfenbeinblättchen häufig mit Silberfolie oder farbigen (rosafarbenen) Papieren hinterklebt.

In der Göttinger Universitätskunstsammlung existieren sechs Miniaturen des 19. Jahrhunderts: ${ }^{56}$

Das uns bereits aus den Pastellporträts bekannte Ehepaar David Julius und Auguste Pott ist in der Kunstsammlung ebenfalls durch Bildnisminiaturen vertreten (Kat. Nr. 42+43). Jedoch gehören die Miniaturen nicht wie die Pastelle zusammen, sondern unterscheiden sich wesentlich voneinander: Das Bildnis des David Julius Pott (1760-1838) ${ }^{57}$ ist als hochformatiges Rechteck in Öl auf Elfenbein ausgeführt (Kat. Nr. 43). Vor dunklem Hintergrund blickt der Dargestellte den Betrachter direkt an. Die Schulter leicht nach rechts gedreht, tritt er uns in dunklem Rock und hochkragiger weißer Halsbinde entgegen. Die nur halb so groBe, hochovalförmige Miniatur der Ehefrau Auguste Johanna Pott (Kat. Nr. 42) ist ebenfalls in Öl auf Elfenbein gemalt, die Dargestellte zeigt sich vor hellem Hintergrund in leicht aus der Achse gedrehter, aber dem Betrachter zugewandter Haltung. Sie trägt ein weißes Kleid (oder Bluse) mit ausladendem Rüschkragen.

Die Bildnisminiatur des Johann Peter Waldeck, gemalt von „Dr. j. Ernst“ (Kat. Nr. 35), ist in Strichmanier in Gouache auf Bein ausgeführt. ${ }^{58}$ Der Dargestellte zeigt sich im Hochoval im Seitenprofil vor dunkelgrauem Grund. Waldeck war seit 1780 Privatdozent, dann außerordentlicher sowie ordentlicher Professor der Rechtswissenschaft in Göttingen.59

54 Zu Techniken und Materialien vgl. Kat. Celle 2000, S. 17-25; Ausst.-Kat. Braunschweig 2010.

55 Ausst.-Kat. Celle 2000, S. 22-25.

56 Eine weitere Miniatur in der Sammlung ist: Bildnis eines jungen Mannes, unbekannt holländisch, 2. Hälfte des 17. Jahrhunderts, Inv. Nr. GG 110, Unverfehrt 1987, S. 175, Kat. Nr. 114. Silhouetten werden in diesem Katalog nicht berücksichtigt.

57 Auf der Rückseite befindet sich ein alter Zettel mit Aufschrift: „Dr. Pott / Professor der Theologie / Consistorialrath in Göttingen / Abt von Braunschweig“".

58 Rückseitig zweifache Nennung des Malers sowie des Dargestellten: „Hofrath Waldeck. gemalt von Dr. Ernst“ und „Waldeck Hofrath gemalt vom Dr.j. Ernst 1800 in Göttingen“.

59 Arndt 1994, S. 123, Nr. 229a. 
Das Miniaturbildnis des Benno Karl von Waechter (1813-1879) ${ }^{60}$ (Kat. Nr. 48) fällt in zweierlei Hinsicht auf: Erstens ist die Qualität der Gouachemalerei auf Elfenbein von überraschend hoher feinmalererischer Qualität, vor allem im Bereich des Bartes und der Haare, aber auch der Kleidung. ${ }^{61}$ Zweitens ist sie nicht in einen üblichen Rahmen eingepaßt, sondern liegt in einem mit grünlichem Samt ausgeschlagenem Lederfutteral, dessen Innenseite mit grüner Seide bezogen ist. Das als Scharnier dienende Lederband ist durchgerissen und die Verschlusshaken fehlen. Eine Inschrift auf der Rückseite gibt folgende Auskunft: „Bierbrauer und Landwirt in Kaiserslautern, gemalt vor 1842“.

Einen Spezialfall unter den Miniaturen stellt vermutlich die des Johann Domincus Fiorillo (1748-1821) dar (Kat. Nr. 34), ${ }^{62}$ erstens weil es sich aller Wahrscheinlichkeit nach um ein Selbstbildnis des Künstlers handelt, zweitens weil auf der Rückseite geflochtene Haare (vermutlich des Dargestellten) unter Glas eingearbeitet sind (Abb. 40). Auf diese Weise erhält die Miniatur geradezu den Charakter einer profanen Reliquie und wirft damit ein bemerkenswertes Schlaglicht auf das Verhältnis von Porträtkultur und Persönlichkeitskult um 1800. Das Bildnis wurde der Kunstsammlung laut Inventarbuch vom Rektor und Senat am 7. November 1931 überwiesen. Es stammte ursprünglich aus dem Besitz der Frau Emilie Schreiter, einer Nachkommin Fiorillos. Desweiteren im Vermerk des Inventarbuches notiert: „Doch nicht die Vorlage des Stiches von [...] (1789)“.63

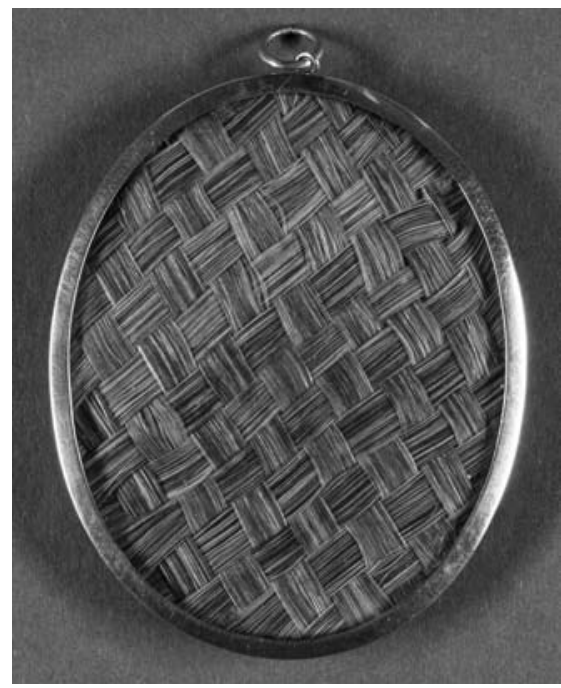

Abb. 40: Unbekannt, deutsch (evtl. Selbstporträt): Bildnisminiatur des Johann Dominicus Fiorillo (vgl. Kat. Nr. 34), Rückseite mit geflochtenen Haaren (vermutlich des Dargestellten)

Von herausragender Qualität ist ohne Zweifel die querovale Miniatur von Eduard Gärtner (1801-1877), den Pfarrer Kuntze und seine Braut als Doppelbild-

60 Verzeichniß des Lehrer-Personals und der sämmtlichen Studirenden an der Königl. LudwigMaximilians-Universität in München: Im Studienjahre 1835/36; Forst- und Baueleven: Benno Carl von Waechter, S. 24.

61 Unverfehrt 1987, S. 195, Kat. Nr. A 109.

62 Unverfehrt 1987, S. 195, Kat. Nr. A 107. Zur Person vgl. den Artikel von Julia Diekmann zu Fiorillos Gemälde Heilige Familie (Kat. Nr. 6) in diesem Band.

63 Diese Bemerkung bezieht sich wohl auf den Stich von Heinrich Schwenterley von 1789 nach einem Selbstbildnis Fiorillos, vgl. Schrapel 2004, S. 753, Abb. 21. 
nis zeigend (Kat. Nr. 46). ${ }^{64}$ Es ist in Öl auf Bein ausgeführt, unten rechts signiert und auf 1829 datiert (Abb. 41). ${ }^{65}$

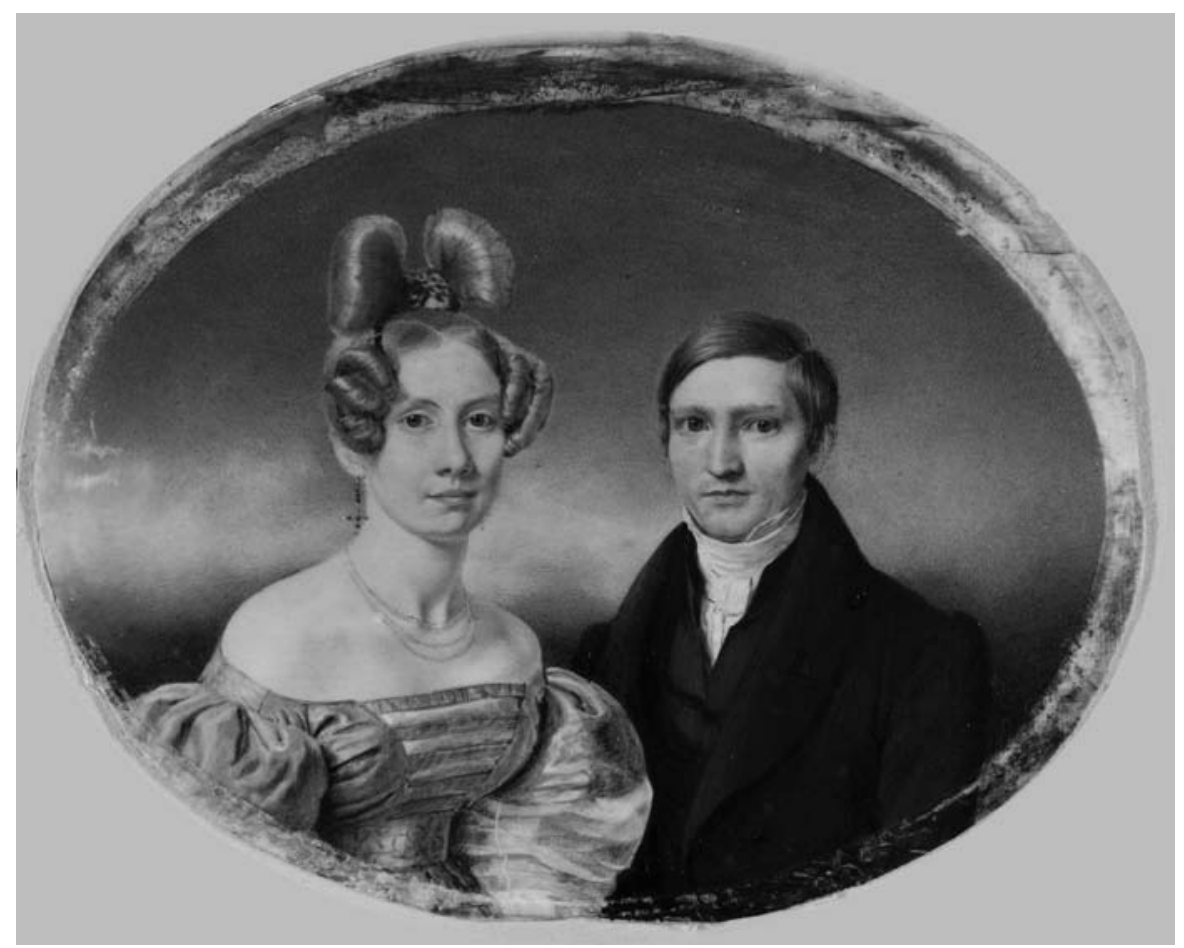

Abb. 41: Eduard Gaertner: Miniaturbildnis Pfarrer Kuntze und seine Braut, 1829, Öl auf Elfenbein, 12 × $16 \mathrm{~cm}$ (Kat. Nr. 46)

Kuntze gehörte zu den engsten Freunden Gaertners, den er seit seiner Jugend kannte und mit dem er 1825 gemeinsam nach Paris reiste. 1835 porträtiert er ihn in einem weiteren Bildnis im Talar, lithographiert es und fügt die Inschrift hinzu: „Eduard Kuntze, Prediger am großen Friedrichs-Waisenhaus in Berlin“.66 Kuntze war spätestens seit 1830 Pfarrer, denn er tauft am 7. März 1830 Gaertners ersten Sohn Reinhold sowie später acht weitere von insgesamt 12 Kindern. Im Göttinger Brustporträt ist das Paar in zeittypischer Kleidung - er in hochkragigem, dunklem Rock mit weißer Halsbinde, sie in schulterfreiem Seidenkleid - dargestellt, beide schauen den Betrachter an, sind sich einander nur leicht zugeneigt. In der heraus-

64 Ausst.-Kat. Berlin 2001, S. 402, Kat. Nr. 216.

65 Die Miniatur erwarb Prof. Dr. Karl Arndt in den 1960er Jahren im Berliner Kunsthandel, aus dessen Besitz sie in die Göttinger Universitätskunstsammlung überging.

66 Kuntze war 1834 ebenfalls Prediger an der Berliner Parochialkirche; vgl. Wirth 1979, S. 32 und S. 228, Kat. Nr. 10. 
ragenden feinmalerischen Qualität macht sich Gaertners Ausbildung als Porzellanmaler bei der Königlichen Porzellan-Manufaktur Berlin bemerkbar. ${ }^{67}$

\section{Kopfstudien}

Neben der umfangreichen Porträtproduktion des 19. Jahrhundert, für die sich in der Göttinger Universitätskunstsammlung zahlreiche Beispiele finden, fand auch das Anfertigen von Kopfstudien eine Weiterführung. Eine eigene Kultur des Tronie ist in diesem Jahrhundert nicht festzustellen. Gerade für die Konzeption und Ausführung von Historienbildern wurden aber nach wie vor gemalte Studien nach Köpfen angefertigt, bei denen die Porträtfunktion nicht mehr primär war. Gerade die Düsseldorfer Malerschule ist für derartige Ölstudien bekannt. ${ }^{68}$ Solche Arbeiten sind zum Teil formal nur schwer von von echten Porträts zu unterscheiden.

Im folgenden wird mit dem Gemälde Aufblickender Mann mit Turban (Kat. Nr. 33) ein Werk vorgestellt, bei dem eine Entstehung als Kopfstudie zumindest diskutierenswert erscheint. ${ }^{69}$ Damit wäre auch diese wichtige Bildgattung in der Göttinger Universitätskunstsammlung vertreten, die sich auf diese Weise ein weiteres Mal als kleine, aber erstaunlich repräsentative Kollektion von Werken des 19. Jahrhunderts erwiese.

67 Vgl. Siebeneicker 2001.

68 Solche Kopfstudien, die in der Regel auf keinen Rahmen aufgezogen waren, zeigt etwa Johann Peter Hasenclevers berühmte Atelierszene von 1836 links im Hintergrund an der Wand hängend (vgl. Ausst.-Kat. Düsseldorf 2011, Bd. 2, S. 55, Kat. Nr. 31). Ein konkretes Beispiel bietet Eduard Bendemann: Studie eines weiblichen Kopfes zu Gefangene Juden in Babylon, 1832, Öl auf Leinwand, $32 \mathrm{x}$ $23 \mathrm{~cm}$, Wuppertal, Stiftung Sammlung Vollmer; vgl. hierzu Ausst.-Kat. Lübeck 2009, S. 112 f., Kat. Nr. 12; Ausst. Kat. Düsseldorf 2011, Bd. 2, S. 165, Kat. Nr. 126. Auf einer Durchzeichnung des Bildes befindet sich die Beschriftung „Der Kopf des Weibes mit dem Kinde ist nach einem in Rom gemachten Studium, nach der schönem Francesca Primavera [...]. “ (zitiert nach Ausst.-Kat. Lübeck 2009, S. 112). So ist diese Studie - wie viele andere dieser Zeit - in ihrem Abbildcharakter letztlich doch auch Porträt.

69 Vgl. den einführenden Text von Verena Suchy in diesem Band, S. 284-287. Auch dieses Bild gehört zu den Werken, die im Rahmen des studentischen Forschungsprojekts „Gattungstheorie und Gattungspraxis“ eingehender behandelt und dementsprechend mit einem eigenen Katalogbeitrag bedacht wurden. 
Kat. Nr. 32

Franz Xaver Winterhalter? (1805-1873)

\section{Bildnis einer Dame im Grünen}

Um 1830

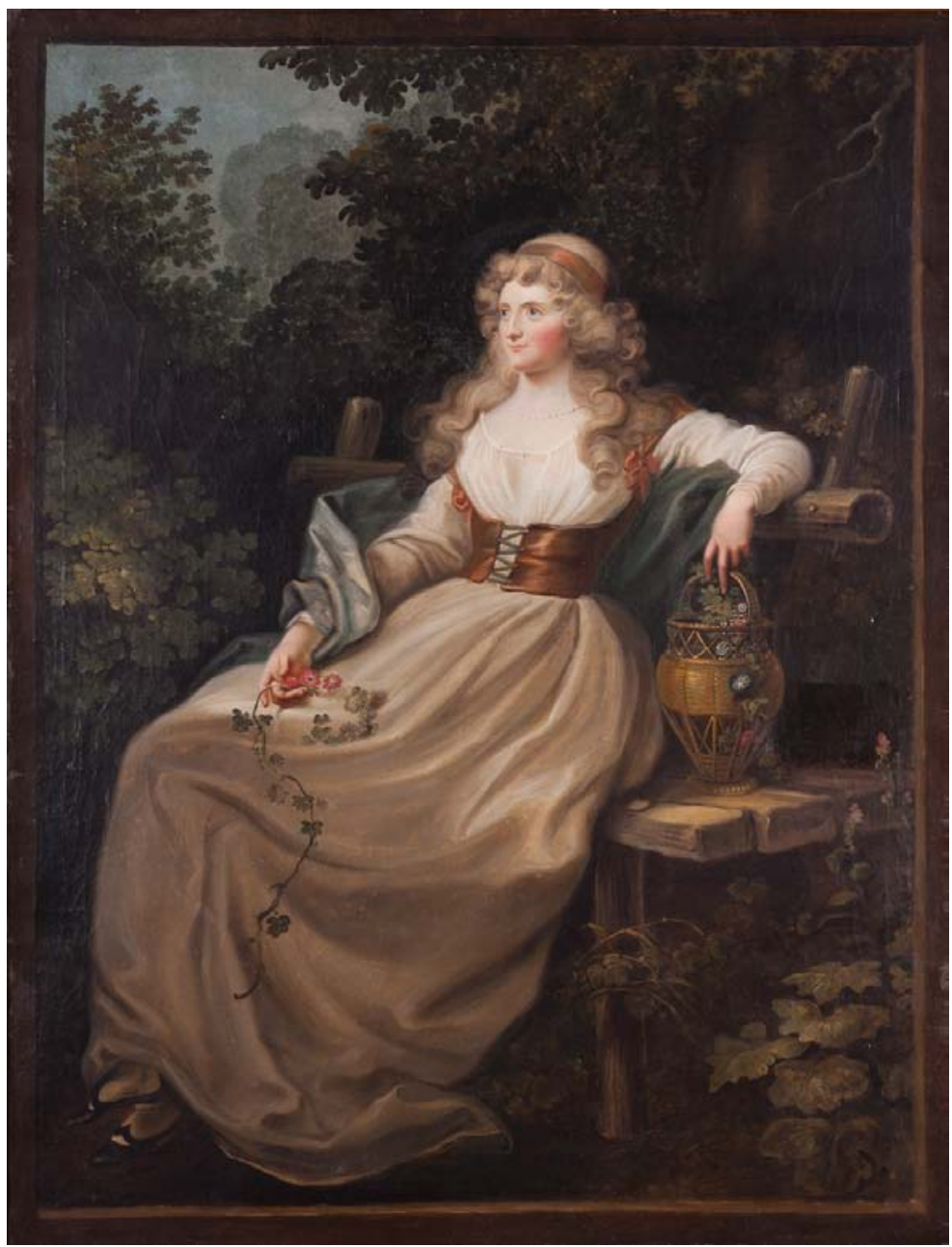

Öl auf Leinwand, 85 x 65 cm, nicht signiert und datiert, 1969 mit Unterstützung des Universitätsbundes erworben, Inv. Nr. GG 207 
Das Göttinger Bildnis einer Dame im Grünen zeigt die ganzfigurige Abbildung einer jungen Frau, die mit übereinandergeschlagenen Beinen auf einer hölzernen Parkbank sitzt. Ihr Körper ist leicht vom Betrachter abgewendet und auch ihr Blick schweift am Betrachter vorbei in die Ferne. Ihr jugendliches Gesicht ist leicht gerötet. Über ihre Schultern fallen lange, blond gelockte Haare. Das Kleid der Frau ist aus zartem, weißem und leicht durchscheinendem Stoff gefertigt, tief dekolletiert und wird in der Taille durch ein braunes Korsett zusammengerafft. Sie trägt kaum Schmuck und flache, schwarze Schuhe. Ihre rechte Hand hält eine Blumenranke locker auf ihrem Schoß, während die linke auf die Lehne der Bank aufgestützt ist und leicht den Henkel eines Blumenkorbes berührt.

Die Szene ist in eine Parklandschaft eingebunden, die sich lediglich in der linken oberen Bildecke in die Tiefe öffnet. Die junge Frau selbst ist von dichten, grünen Bäumen hinterfangen, was der gesamten Szenerie eine abgeschlossene, private und intime Atmosphäre verleiht. Dieser Eindruck wird durch die lockere Kleidung der Frau sowie ihren abwesenden Blick unterstützt.

Das Bildnis ist von einer zwischen Klassizismus und Biedermeier changierenden Kunstauffassung geprägt, die entfernt an die Werke eines Thomas Gainsborough oder George Romney erinnert. ${ }^{1}$ Anhand dieser stilistischen Kriterien lässt es sich in die Zeit etwa zwischen 1810 und 1830 einordnen.

In der Familie der Vorbesitzerin des Bildes ist eine Notiz überliefert, dass das Porträt aus der Hand Franz Xaver Winterhalters stammt. Das Bild selbst ist jedoch weder signiert noch datiert und es bestehen berechtigte Zweifel an der Urheberschaft Winterhalters.

Der künstlerische Werdegang des Malers und Lithographen Franz Xaver Winterhalter ist überaus bemerkenswert. Aus bescheidenen Verhältnissen in der badischen Provinz stammend gelang ihm der Aufstieg zu einem der gefragtesten Porträtmaler Europas. ${ }^{2}$ Winterhalter wurde zunächst im Atelier von Karl Schuler zum Kupferstecher ausgebildet. 1823 zog er nach München und arbeitete dort als Lithograph. Zwei Jahre später gelang es ihm, begünstigt durch ein Stipendium des Großherzogs Ludwig von Baden, an der Münchner Akademie zu studieren. Parallel zu seinem Studium arbeitete Winterhalter in dieser Zeit im Atelier von Josef von Stieler. In dieser Zeit begann Winterhalter auch, Kontakte zum europäischen Hochadel zu knüpfen, der später zu seiner wichtigsten Auftraggeberschicht avancieren sollte. So zog Winterhalter um 1830 nach Karlsruhe, um Zeichenlehrer der badischen Großherzogin Sophie zu werden. ${ }^{3}$

In den Jahren 1832-34 folgte die für Künstler dieser Zeit nahezu obligatorische Italienreise, in deren Anschluss Winterhalter zum badischen Hofmaler ernannt wurde. Bereits im selben Jahr erfolgte Winterhalters Umzug nach Paris, wo er bald Zugang zu den höchsten Kreisen des internationalen Hochadels erhielt und seinen

1 Für wichtige Hinweise anlässlich einer Arbeitstagung am 11.5.2012 danke ich Prof. Dr. Thomas Noll, Bonn, und Dr. Saskia Pütz, Hamburg.

2 Panter 1996, S. 14.

3 Ebd., S. 15-18. 
Ruf als Porträtmaler weiter festigte. 1854 wurde er zum Hofmaler des französischen Kaisers Napoleon III. ernannt. Es folgten verschiedene Reisen zu europäischen Fürsten- und Königshäusern, so unter anderem nach Belgien, Großbritannien, Italien und Österreich. Zu seinen bekanntesten Auftraggebern zählten neben Napoleon III. und seiner Frau, Kaiserin Eugénie, auch Queen Victoria von England, Königin Sophie der Niederlande und die Zarin Alexandra Feodorowna. Winterhalters wohl bekanntestes Werk ist ein Porträt der Kaiserin Elisabeth, genannt „Sissi“ von Österreich-Ungarn aus dem Jahr 1865.4

Winterhalters Malweise zeichnet sich in seiner Hauptschaffensphase vor allem durch einen hohen Grad an Idealisierung der dargestellten Personen aus. Insbesondere in seinen Damenporträts bedient er sich einer weichen, feinen Pinselführung, sein Kolorit ist zumeist zart und hell, die Kontraste sanft abgestuft. Seine Porträts strahlen Harmonie, Leichtigkeit und eine rokokoartige Anmut aus.

Sowohl die teilweise recht grobe Pinselführung als auch merkliche anatomische Ungenauigkeiten - insbesondere im Bereich der Füße der jungen Frau - sprechen gegen eine Zuschreibung des Werkes an Winterhalter. Zudem ist das Bildnis in keinem der gängigen Werkverzeichnisse des Künstlers aufgeführt. Es muss allerdings in Betracht gezogen werden dass das Bild um 1830 entstanden ist, gegebenenfalls also dem Frühwerk Winterhalters noch vor dessen Italienreise zugeordnet werden könnte.

In der Zeit vor 1832 weist der Stil Franz Xaver Winterhalters durchaus Merkmale auf, die denen des Göttinger Bildnisses sehr ähnlich sind. Als illustrierendes Beispiel sei an dieser Stelle auf ein gesichertes Porträt Winterhalters der Großherzogin Sophie Guillemette (um 1831; Cleveland Museum of Art) verwiesen. ${ }^{5}$ Das Bildnis der Großherzogin von Baden ist, wie auch das der Dame im Grünen, von einer biedermeierlichen Porträtauffassung geprägt. Es ist ebenfalls in eine Landschaft eingefasst, die einen relativ geschlossenen, intimen Rahmen bildet und sich lediglich in einem kleinen Ausschnitt in die Ferne öffnet. Auch hier ist die Körperhaltung der Dargestellten leicht in sich gedreht. Die grazile Handhaltung findet sich in diesem Porträt genauso wieder wie der in die Ferne gerichtete, abwesende Blick und das leicht gerötete Gesicht. Zudem fallen signifikante Gemeinsamkeiten im Kolorit und in der malerischen Behandlung vor allem des Faltenwurfs der Kleider der beiden Frauen ins Auge. So weisen auch in dem Porträt der Großherzogin Sophie Kleidung und Gestaltung der Füße noch nicht die für den späten Winterhalter typische lockere und zarte Malweise auf. ${ }^{6}$

Ein weiteres Indiz, das eine Zuschreibung des Göttinger Bildes zum Werk Winterhalters stützt, bietet die Provenienz des Bildes. Dieses befand sich über mehrere Generationen im Besitz einer großen deutschen Adelsfamilie. Das Bildnis entstammt also einer für Winterhalter typischen Auftraggeberschicht und es ist

\footnotetext{
4 Mayer 1998, S. 123-125.

5 http://www.clevelandart.org/collections/collection 20\%online.aspx?pid=(91ADCD8F-992A45A5- 8599-70835467DF5E)\&coid=5906633\&clabel=highlights (zuletzt 24.04.2012).

6 Eismann 2007, S. 20.
} 
wahrscheinlich, dass es sich bei der Dargestellten um ein Mitglied des deutschen Adels handelt, auch wenn nicht bekannt ist, wer die Dame im Grünen ist.

Gleichwohl überwiegen die Anhaltspunkte, die eine Zuschreibung Winterhalters unwahrscheinlich erscheinen lassen. Zwar weist das Bild formale Ähnlichkeiten $\mathrm{zu}$ dem Bildnis der Großherzogin Sophie Guillemette auf, jedoch muss bei eingehender Betrachtung zugestanden werden, dass dieses doch feiner ausgeführt und qualitativ hochwertiger ist als das Göttinger Bildnis. Zudem spricht die teils noch dem Klassizismus verpflichtete Porträtauffassung des Göttinger Bildes klar gegen eine Urheberschaft Winterhalters, dessen Frühwerk dem Biedermeier verpflichtet ist. ${ }^{7}$ Auch das Adelsgeschlecht, aus dem das Bildnis angekauft wurde, ist eher im ostdeutschen, bzw. osteuropäischen Raum beheimatet, so dass eine Verbindung zu dem in seiner Jugend in Baden und Bayern lebenden Winterhalter nicht nachgewiesen werden kann.

Verena Suchy

7 Für diesen Hinweis danke ich Prof. Dr. Thomas Noll. 
Kat. Nr. 33

\section{Unbekannt, deutsch}

\section{Aufblickender Mann mit Turban}

Ende 19. Jahrhundert

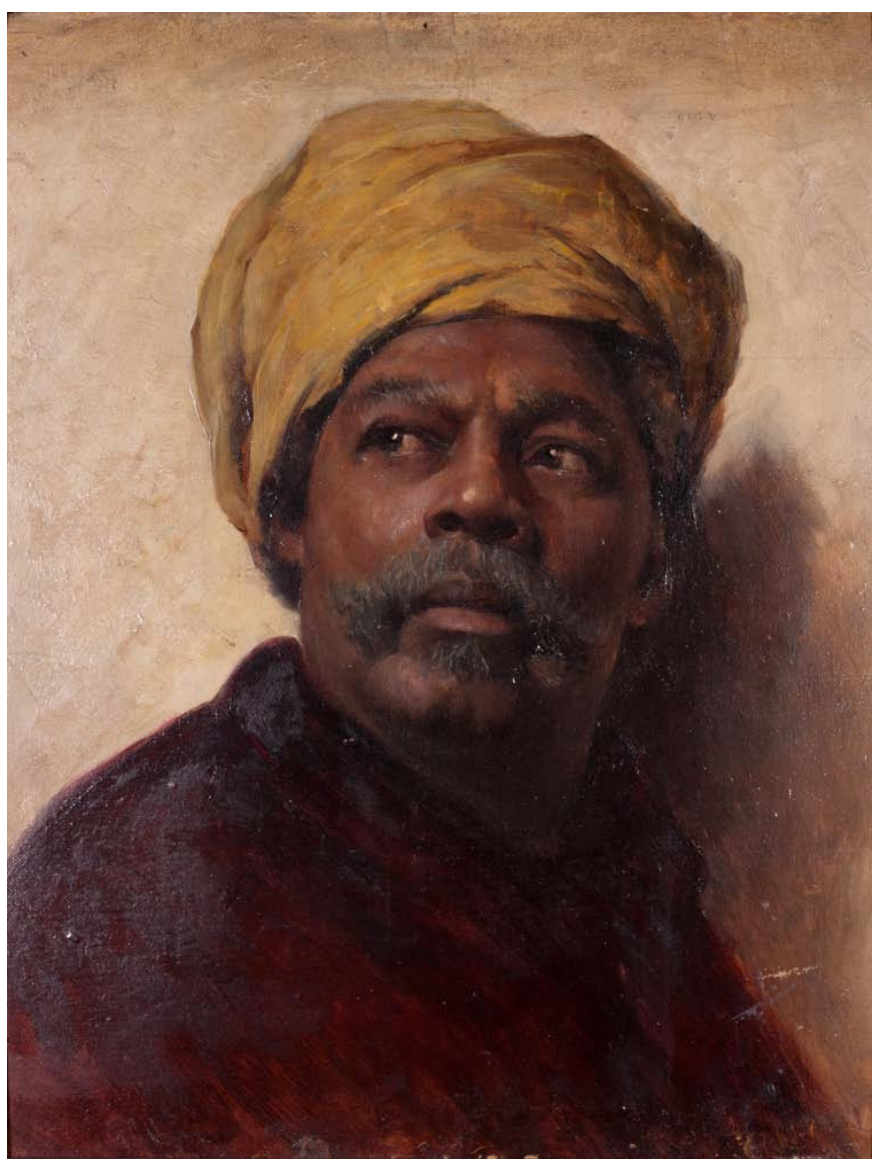

Öl auf Pappe, 47,5 x 36,5 cm, signiert unten rechts, Herkunft unbekannt, Inv. Nr. GG 218

Das hier gezeigte Bild stellt Kopf und Schulterpartie eines Mannes mittleren Alters mit dunkler Hautfarbe, braunen Augen und einem Oberlippenbart vor einem sand- 
farbenen Hintergrund dar. Um seinen Kopf ist ein ockerfarbener Turban geschlungen. Bekleidet ist er mit einem rotbraunen, nur mit lockeren Pinselstrichen angedeuteten Hemd mit Kragen. Kleidung und Teint des Mannes deuten darauf hin, dass er einem orientalischen Kontext entstammt.

Gerade das Gesicht des Mannes wirkt auf den Betrachter überaus individuell und wenig typisiert. Es herrscht ein porträtähnlicher Eindruck vor. Diese erste Einschätzung wird jedoch bei der weiteren Betrachtung verunklärt. So ist der Oberkörper des Dargestellten leicht zur Seite geneigt, der Kopf ist zum Betrachter gedreht, so dass sich das Gesicht des Mannes en face präsentiert. Der Dargestellte nimmt jedoch keinerlei Blickkontakt zum Betrachter auf, sondern blickt nach links oben aus dem Bildraum hinaus in die Ferne. Die jegliche Bezugnahme zum Betrachter vermeidende Haltung ist für ein Porträt eher untypisch. Das Bildnis irritiert den Betrachter also dadurch, dass es sich zunächst einer direkten Gattungszuordnung entzieht. Es entsteht der Eindruck, dass das Bild zwischen porträthafter Individualität und idealisierender Typisierung changiert. ${ }^{1}$

Farblich ist das Bild ausschließlich in monochromen Braun- und Ockertönen gehalten, was eine ausgesprochen harmonische und ruhige Farbwirkung erzielt. Malweise und Pinselführung sind virtuos. Das Gesicht des Mannes ist dabei mit weitaus größerem Detailreichtum und feinerem Duktus ausgearbeitet als der Rest des Bildes. Es findet also eine innerbildliche Differenzierung im Grad der malerischen Ausgestaltung statt. Hintergrund und Kleidung des Mannes sind wesentlich lockerer und mit deutlich sichtbaren Pinselspuren gemalt.

Das Bild ist zwar auf dem Bildträger unten rechts deutlich sichtbar signiert, jedoch kann der Signatur bisher kein Künstler eindeutig zugeordnet werden. Auch mit graphologischen Untersuchungsmethoden ist es noch nicht gelungen, die Signatur eindeutig zu entziffern. So liegen der zeitlichen Einordnung des Bildes gegen Ende des 19. Jahrhunderts ${ }^{2}$ allein stilkritische Anhaltspunkte zugrunde. Pinselführung und Farbgestaltung rücken das Bild dabei in stilistische Nähe zu den deutschen Impressionisten aus der Zeit um 1900.3

Die Provenienz des Bildes ist ungeklärt, auch wenn eine Notiz auf der Rückseite des Bildes, die in der Handschrift von Wolfgang Stechow abgefasst ist, nahelegt, dass sich das Bild bereits um 1930 in der Göttinger Universitätskunstsammlung befunden hat. ${ }^{4}$

In Verbindung mit dem ungewöhnlichen Bildträger - Pappe - erscheint die Vermutung plausibel, dass es sich bei dem Bild nicht um ein autonomes Porträt, sondern um eine Porträtstudie handelt. Solche Studienköpfe, wie sie sich beispielsweise auch im Nachlass Carl Oesterleys finden, waren im 19. Jahrhundert weit verbreitet. Insbesondere Historienmaler bedienten sich ihrer bei der Gestaltung der Personenstaffage ihrer Bilder. Auch die Verwendung des Bildes als Farb-

\footnotetext{
Für wichtige Hinweise danke ich Anika Kollarz M.A., Göttingen.

Unverfehrt 1987, S. 195, Kat. Nr. A 114.

Für diesen Hinweis anlässlich einer Arbeitstagung am 11.5.2012 danke ich Prof. Dr. Thomas Noll.

4 Vgl. den Aufsatz von Anne-Katrin Sors in diesem Band, S. 39 f.
} 
studie ist wegen des meisterhaft ausdifferenzierten Umganges mit Farbigkeit und Pinselführung durchaus denkbar. ${ }^{5}$

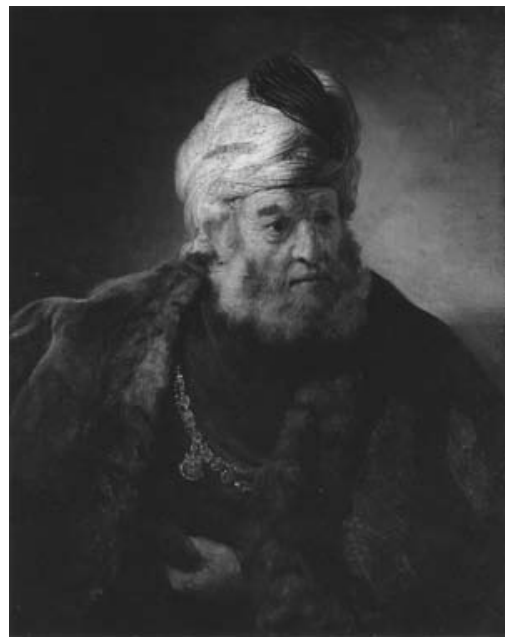

Abb. 42: Govert Flinck zugeschrieben: Morgenländischer Fürst, um 1642, Öl auf Leinwand, 85,1 x 67,3 $\mathrm{cm}$, Liverpool, National Museums and Galleries on Merseyside, Walker Art Gallery
Das Bild kann generell im Zusammenhang zu einer in der Frühen Neuzeit beginnenden und im 19. Jahrhundert wachsenden Orientfaszination gesehen werden. Darstellungen exotischer Themen und insbesondere Menschen außereuropäischer Herkunft waren seit jeher in den Bildenden Künsten vertreten. Bereits bei Künstlern wie Dürer, Rubens oder Rembrandt finden sich Porträtstudien von Afrikanern oder Orientalen. ${ }^{6}$ Ein prägnantes Beispiel, das einige formale Ähnlichkeiten zu dem Göttinger Bildnis aufweist, ist die Govert Flinck (1615-1660) zugeschriebene Darstellung eines morgenländischen Fürsten aus der Zeit um 1642 (Abb. 42). Wie bei dem aufblickenden Mann mit Turban ist der Hintergrund verunklärt. Die Farbpalette ist monochrom gehalten und es lässt sich eine deutliche innerbildliche Ausdifferenzierung der Malweise feststellen. So ist auch hier das Gesicht des Dargestellten weitaus feiner durchgebildet als die übrige Gestalt. Ähnlich wie der Dargestellte auf dem Göttinger Bild ist der morgenländische Fürst insbesondere durch Teint und Turban als Orientale ausgewiesen. Auch hier nimmt der Dargestellte keinen Blickkontakt zum Betrachter auf, es stellt sich beim Betrachter nicht der Eindruck ein, dass es sich um ein autonomes Porträt ${ }^{7}$ handelt.

Gereon Sievernich und Hendrik Budde verweisen in diesem Zusammenhang darauf, dass es sich bei Flincks Bild um eine Kopf- oder Charakterstudie handelt, die einerseits als vorbereitendes Werk für ein größeres Historiengemälde zu denken ist, der andererseits in der niederländischen Kunst des 17. Jahrhunderts aber auch als sogenanntes Tronie ein gewisser autonomer Eigenwert zugesprochen wurde. ${ }^{8}$ Diese Uneindeutigkeit der Tronies im Bezug auf ihre Gattungseinordnung ist ein Element, das auch das gut dreihundert Jahre später entstandene Göttinger Bild auszeichnet, ohne dass man für ein Werk des späten 19. Jahrhunderts noch

5 Für diesen Hinweis danke ich Prof. Dr. Michael Thimann.

6 Vgl. Daum 2009, S. 82.

7 Allerdings erfreuten sich gerade in Kreisen des europäischen Adels des 17. und 18. Jahrhunderts Porträts im sogenannten orientalischen oder türkischen Kostüm einiger Beliebtheit. Dass es sich bei dem Govert Flinck zugeschriebenen Werk sowie bei dem Göttinger Bild um eine solche Darstellung handelt, ist jedoch auszuschließen.

8 Ausst.-Kat. Berlin 1989a, S. 812; zum Tronie allgemein vgl. Hirschfelder 2008; Gottwald 2011. 
den Begriff Tronie verwenden würde. Solche formalen Bezüge stützen eine Einordnung des Aufblickenden Mannes mit Turban als Kopfstudie.

Im 19. Jahrhundert als Zeitalter des Imperialismus und der Kolonialisierung bildet sich zudem ein spezifischer Orientalismus als künstlerisches, politisches und soziokulturelles Phänomen heraus. ${ }^{9}$ Reisen in die bis dahin beinahe unerreichbaren Länder des Orients waren nun mit viel geringerem Aufwand möglich, so dass es viele Künstler auf der Suche nach neuen Motiven in diese Gebiete zog. ${ }^{10}$ Der Orientalismus hielt - von Frankreich und Großbritannien ausgehend - mit Künstlern wie Eugène Delacroix über Alexandre Gabriel Decamps sowie Ludwig Deutsch ${ }^{11}$ Einzug in das europäische Kunstschaffen.

Beliebt waren hierbei vor allem orientalisierende Genreszenen, die mit leuchtender Farbigkeit, sinnlicher Stofflichkeit und einer schier unglaublichen Detailfülle versuchten, orientalisches Flair in europäische Bürgerstuben zu zaubern. Aber auch in die Historienmalerei hielt der Orientalismus Einzug, indem insbesondere alttestamentarische Szenen nun vermehrt in ihr vermeintlich historisch korrektes „Setting“ - den alten Orient - eingeschrieben wurden. ${ }^{12}$

Stilistisch bedient sich das Göttinger Bild neuer, von akademischer Glattmalerei wegführender Entwicklungen. Gleichzeitig bleibt es im Sinne eines Naturalismus dem Abbild verpflichtet. Dem Bildnis eines Orientalen liegen orientalistische und kolonialzeitlich determinierte Ideen zugrunde. Dennoch wird der hier dargestellte Mann nicht stereotyp wiedergegeben oder als klischeehaftes Zerrbild des Orients vor Augen gebracht. Das bereits beschriebene Changieren der Darstellung zwischen autonomem Porträt und studienhafter, verallgemeinernder Idealisierung ist charakteristisch für einen von Denise Daum charakterisierten neuen Darstellungstypus: das sogenannte ethnographische Typenporträt. ${ }^{13}$ Mit der sich im 19. Jahrhundert verstärkt etablierenden Wissenschaft der Ethnographie erschloss sich Künstlern ein neues Aufgabenfeld. Ziel war es, europäischen Betrachtern das physiognomische Erscheinungsbild fremder Ethnien anschaulich vor Augen zu führen. Dem Bildtypus des ethnographischen Typenporträts liegt somit einerseits ein dokumentarisch-kulturbeschreibender und typisierender Ansatz zugrunde. Die porträthafte Darstellung eines gleichsam idealtypischen Vertreters einer außereuropäischen Ethnie steht also als pars pro toto für dessen gesamte Kultur. Aus dieser Ambivalenz der normativen Repräsentation einer Ethnie durch einen idealtypischen Vertreter derselben ergibt sich auch für das ethnographische Typenporträt ein irritierendes Changieren zwischen Individualisierung und Typisierung der Dargestellten, wie es sich beim Aufblickenden Mann mit Turban findet.

Somit erweisen sich für das Göttinger Orientalenbild zwei Funktionskontexte als plausibel. Es dürfte sich entweder um eine Porträtstudie für ein späteres Werk,

9 Günther 1990, S. 3.

10 Lemaire 2000, S. 8.

11 Für den Hinweis auf Ludwig Deutsch danke ich Prof. Dr. Michael Thimann.

12 Lemaire 2000, S. 178; vgl. auch Scholl 2012d, S. 62-64.

13 Daum 2009, S. 106-117. 
wahrscheinlich ein Historienbild, oder um eine ethnograpische, typisierende Darstellung handeln. Eine Verwendung des Bildes als autonomes Porträt erscheint in diesem Lichte trotz der scheinbaren Individualität der Darstellung wenig wahrscheinlich.

Das Bild Aufblickender Mann mit Turban ist demnach ein bemerkenswert facettenreiches Werk, das sich eng an den Bruchlinien und Diskursen der Kunst im ausgehenden 19. Jahrhundert bewegt. Auch wenn der Urheber des Werkes noch nicht ermittelt werden konnte, handelt es sich sicherlich um eines der maltechnisch brillantesten und ausdrucksstärksten Gemälde des 19. Jahrhunderts in der Göttinger Universitätskunstsammlung.

Verena Suchy 


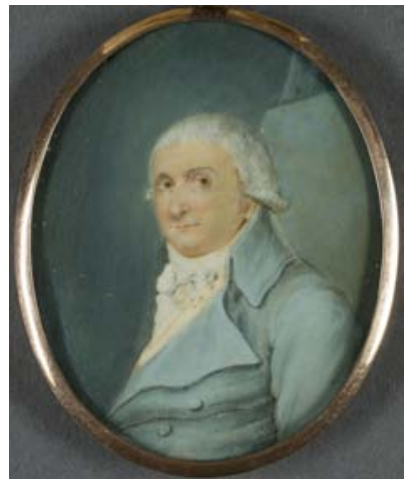

Kat. Nr. 34

Unbekannt, deutsch (evtl. Selbstporträt)

Bildnisminiatur des Johann

Dominicus Fiorillo (1748-1821)

Um 1800

Öl auf Pappe, 6,7 x 5,2 cm im Oval, nicht signiert und datiert, 1931 von Rektor und Senat der Universität überwiesen aus dem Besitz der Emilie Schreiter

Inv. Nr. GG 212

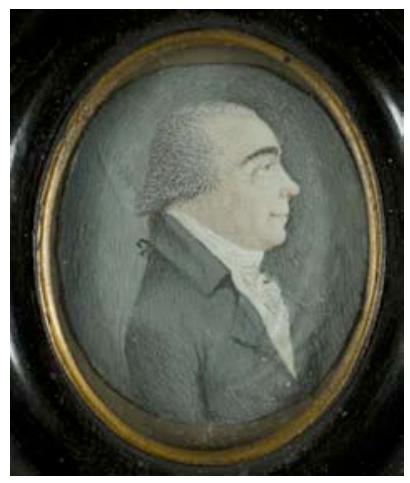

Kat. Nr. 35

Dr. Ernst

Johann Peter Waldeck (1751?1815?)

1800

Gouache auf Bein, 5,5 x 4,7 cm im Oval, rückseitig signiert und datiert, Provenienz unbekannt

Inv. Nr. GG 258

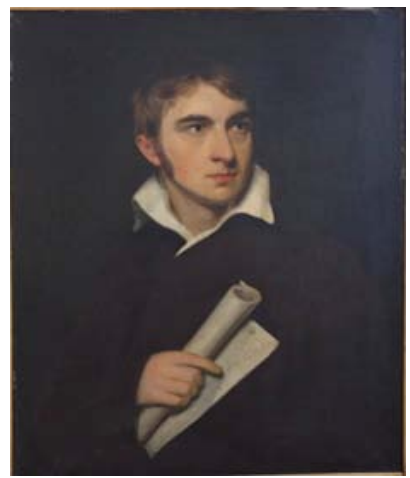

Kat. Nr. 36

M. Max Fellfoot

Bildnis des Afrikaforschers Georg Heinrich Roentgen (1787-1811)

frühes 19. Jahrhundert

Öl auf Leinwand, 78 × $63 \mathrm{~cm}$, nicht signiert und datiert, Provenienz unbekannt

Inv. Nr. GG 129 


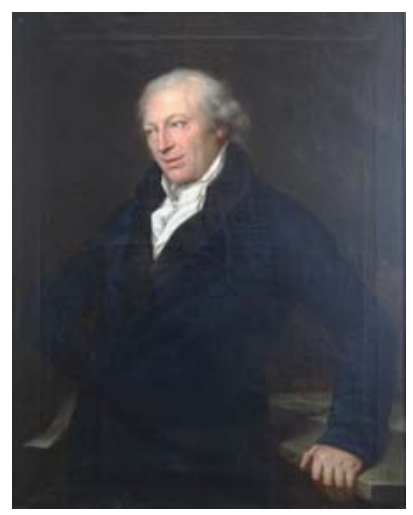

Kat. Nr. 37

Friedrich Georg Weitsch (1758-1828)

\section{Bildnis eines Herrn}

1804

Öl auf Leinwand, $99 \times 78 \mathrm{~cm}$, signiert und datiert, Provenienz unbekannt

Inv. Nr. GG 254

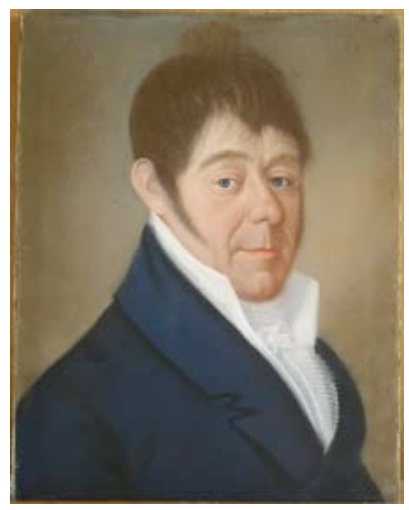

Kat. Nr. 38

Unbekannt, deutsch

Bildnis des Christoph Angebroth

frühes 19. Jahrhundert

Pastell auf Papier, 40 × $31 \mathrm{~cm}$, nicht signiert oder datiert, Schenkung E. Stahler 1962

Inv. Nr. GG 215

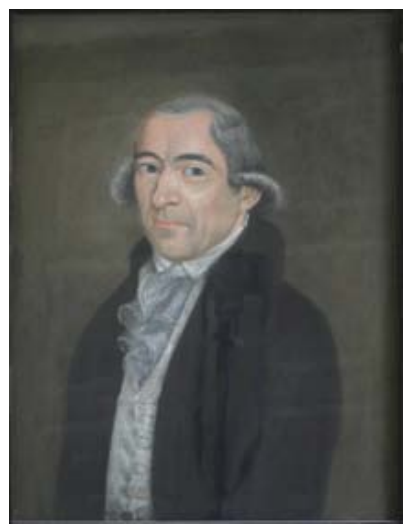

Kat. Nr. 39

Unbekannt, deutsch

Bildnis des Lorenz Friedrich von Crell (1744-1816)

frühes 19. Jahrhundert

Pastell auf Papier, 58 x $45 \mathrm{~cm}$, nicht signiert und datiert, erhalten vom Knapp-Archiv München, 1962

Inv. Nr. GG 208 


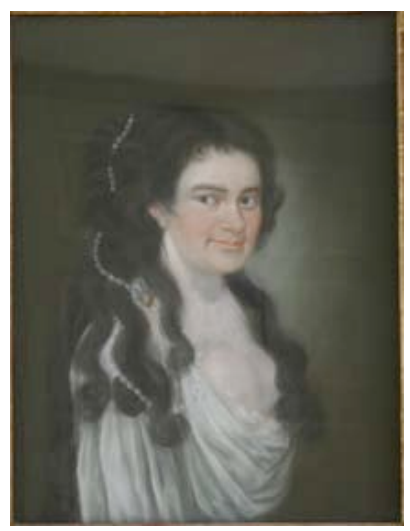

Kat. Nr. 40

Unbekannt, deutsch Bildnis der Auguste Pott

frühes 19. Jahrhundert

Pastell auf Papier, 58 x $45 \mathrm{~cm}$, nicht signiert und datiert, erhalten vom Knapp-Archiv München, 1962

Inv. Nr. GG 209

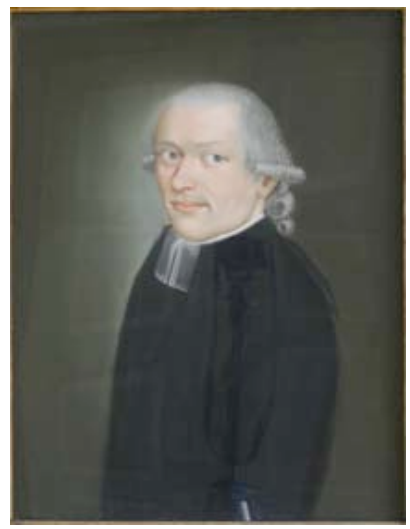

Kat. Nr. 41

Unbekannt, deutsch

Bildnis des David Julius Pott (1760-1838)

frühes 19. Jahrhundert

Pastell auf Papier, 58 x $45 \mathrm{~cm}$, nicht signiert und datiert, erhalten vom Knapp-Archiv München, 1962

Inv. Nr. GG 210

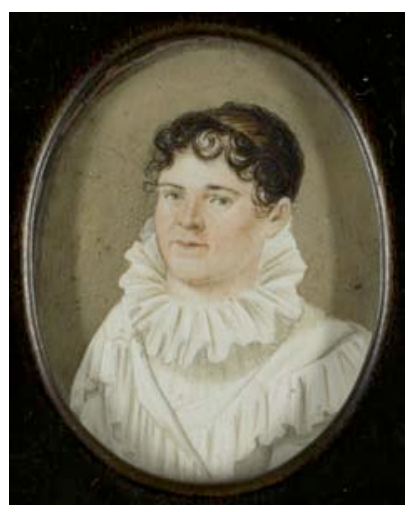

Kat. Nr. 42

Unbekannt, deutsch

Miniaturbildnis der Auguste Pott

vor 1816

Öl auf Bein, 4,8 x 3,7 cm im Oval, nicht signiert und datiert, erhalten vom Knapp-Archiv München, 1962

Inv. Nr. GG 277 


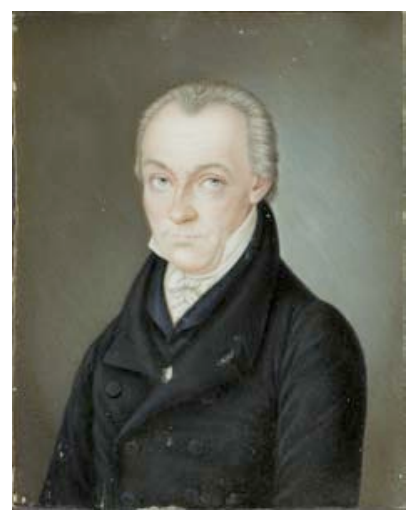

Kat. Nr. 43

Unbekannt, deutsch

Miniaturbildnis des David Julius Pott (1760-1838)

frühes 19. Jahrhundert

Öl auf Bein, 9,5 x 7,7 cm, nicht signiert und datiert, erhalten vom Knapp-Archiv München, 1962

Inv. Nr. GG 276

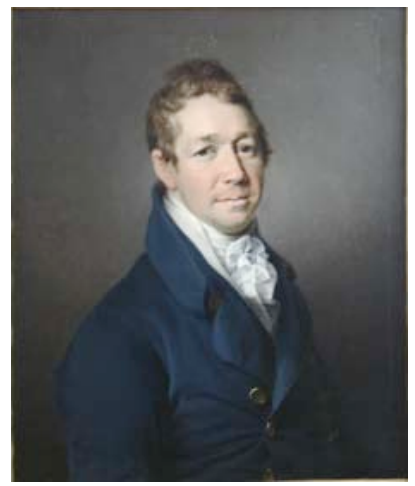

Kat. Nr. 44

Unbekannt, deutsch oder russisch?

Bildnis des Freiherrn Georg

Heinrich von Langsdorff

(1774-1852)

frühes 19. Jahrhundert

Öl auf Leinwand, $65 \times 53 \mathrm{~cm}$, nicht signiert und datiert,

Schenkung Baron von Asch?

Inv. Nr. GG 211

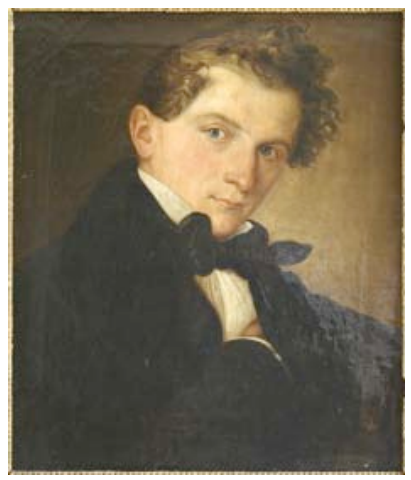

Kat. Nr. 45

Ernst Otto (1807-1847)

Selbstbildnis (?)

nach 1825

Öl auf Leinwand, 37 x 32 cm, signiert, nicht datiert, Leihgabe der Bundesrepublik Deutschland (Objektnr. 21078) 


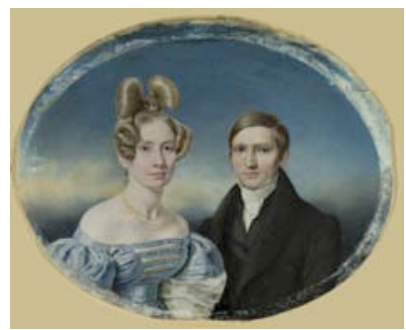

Kat. Nr. 46

Eduard Gärtner (1801-1877)

\section{Miniaturbildnis Pfarrer Kuntze} und seine Braut

1829

Öl auf Elfenbein, $12 \times 16 \mathrm{~cm}$ im Oval, signiert und datiert, aus Göttinger Privatbesitz

Inv. Nr. GG 271

Kat. Nr. 47

\section{A. Schmidt \\ Friedrich Gustav Jakob Henle}

1840

Öl auf Leinwand, $35 \times 27 \mathrm{~cm}$, signiert und datiert, Provenienz unbekannt

Inv. Nr. GG 278

Kat. Nr. 48

Unbekannt, deutsch

Miniaturbildnis des Benno Karl von Waechter (1813-1879)

vor 1842

Gouache auf Bein, $8 \times 7 \mathrm{~cm}$ im Oval, nicht signiert, rückseitig datiert, Schenkung Dr. G. Gruber 1969

Inv. Nr. GG 214 


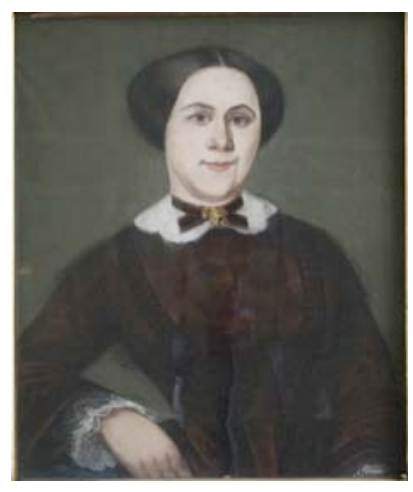

Kat. Nr. 49

Unbekannt, deutsch

Frauenbildnis (Frau Universitätsrath Ulrich geb. Junge?)

Mitte 19. Jahrhundert

Pastell auf Papier/Pappe, 36,5 x $30 \mathrm{~cm}$, rückseitig unleserlich bezeichnet, Herkunft unbekannt

Inv. Nr. GG 217

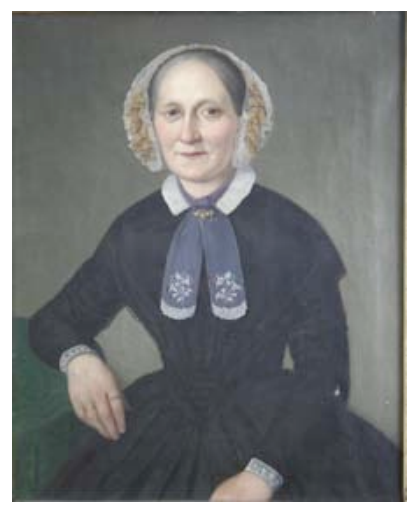

Kat. Nr. 50

Ferdinand Tellgmann (1811-1897)

Frauenporträt

1851

Öl auf Leinwand, 48,5 x 39,5 cm, rückseitig signiert und datiert, Schenkung E. Stadler, 1962

Inv. Nr. GG 182

Kat. Nr. 51

Unbekannt, deutsch

Herr mit Brille

1852

Öl auf Zinn, 32,5 x 33,3 cm; monogrammiert und datiert, Provenienz unbekannt

Inv. Nr. GG 213 


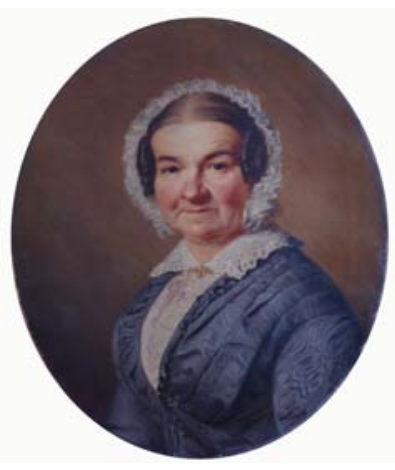

Kat. Nr. 52

\section{Heinrich Lichtenberger}

Christiane Künzel

\section{5}

Öl auf Leinwand, 64 x $54 \mathrm{~cm}$ im Oval, monogrammiert und datiert, 1973 aus Nachlass Prof. Dr. Kurt Müller, Göttingen, übernommen

Inv. Nr. GG 154

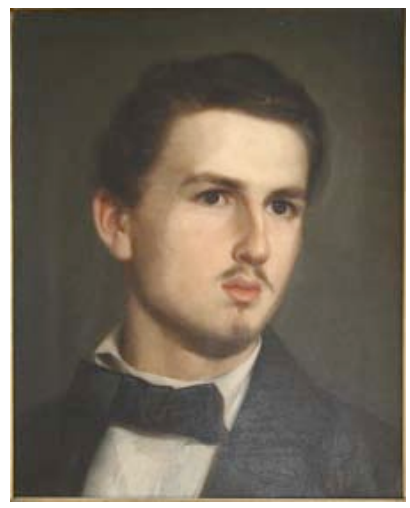

Kat. Nr. 53

Otto Peters (1835-1920)

\section{Ernst Ehlers als Student}

1859

Öl auf Leinwand, $35 \times 44 \mathrm{~cm}$, monogrammiert und datiert, Leihgabe des Museumsvereins für das Fürstentum Lüneburg

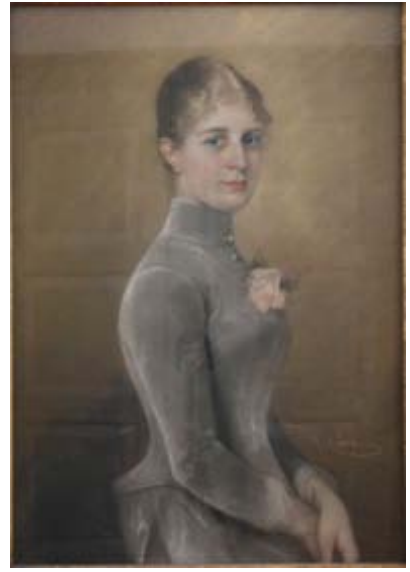

Kat. Nr. 54

Helene von Frauendorfer-Mühlthaler (1853-1933)

\section{Damenbildnis}

1887

Pastell auf Papier, 89,5 x $63 \mathrm{~cm}$, datiert, 1970 aus Göttinger

Privatbesitz gestiftet

Inv. Nr. GG 131 
Anhang 



\section{Archivgut}

Berlin, Nationalgalerie, Akte I/NG 1799

Archiv der Nationalgalerie Berlin, Akte I/NG 1799 Paul Meyerheim 1875-1915.

Göttingen, Kunstsammlung der Universität, Inventar 1884 ff.

Konrad Lange: Inventar der Gemäldesammlung (Inv. C.), in: Katalog der Gemälde (C) 1887 ff. Katalog der Gips-Abgüsse (I) 1884. Inventar der Möbel, Geräthe u. s. w. (A) 1886. Verzeichnis der Originalkupferplatten (D). Verzeichnis der seit 1927 neu erworbenen Aquarelle und Handzeichnungen (H), S. 1-75 und ff.

Paderborn, Diözesanarchiv, Sign. 466 Nr. 3

Acta Specialia zu den Kirchen- und Orgelbauten zu Langenstrasse des bischöflichen (heute erzbischöflichen) Generalvikariats in Paderborn verwahrt im Erzbistumsarchiv Paderborn, Sign. 466 Nr. 3.

Paderborn, Diözesanarchiv, Sign. 801 Nr. 3

Acta Specialia betreffend die Pfarrkirchengebäude zu Westönnen und die übrigen kirchlichen Bauten daselbst des bischöflichen Generalvikariats in Paderborn im Diözesanarchiv des Erzbistums Paderborn, Sign. 801 Nr. 3.

Paderborn, Diözesanarchiv, Sign. 801 Nr. 4

Acta Specialia betreffend die Pfarrkirchengebäude zu Westönnen und die übrigen kirchlichen Bauten daselbst des bischöflichen Generalvikariats in Paderborn im Diözesanarchiv des Erzbistums Paderborn, Sign. 801 Nr. 4.

München, Akademie der bildenden Künste, Matrikelbuch II

Matrikelbuch der Akademie der bildenden Künste München, Bd. II, 1841-1884. Url: http://matrikel.adbk.de/.

Weimar, Thüringisches Hauptstaatsarchiv [193] 
Akten der Großherzoglich Sächsischen Hochschule für bildende Kunst Weimar, Verzeichnis der in der Großherzoglichen Kunstschule vollendeten und zur Ausstellung gebrachten Werke. Die Bestände des ThHStA Weimar zur Kunstschule in Weimar finden sich detailliert aufgeschlüsselt bei Blaha/Boblenz/Wahl 2008.

\section{Literatur}

Abbazia Benedettina di S. Paolo 1994

Abbazia Benedettina di S. Paolo (Hg.): St. Paul vor den Mauern, Rom 1994.

Alberti 2002 [1436]

Leon Battista Alberti: Della Pittura. Über die Malkunst, hg. v. Oskar Bätschmann u. Sandra Gianfreda, Darmstadt 2002.

Allgemeine deutsche Biographie 1875-1912

Allgemeine deutsche Biographie. Auf Veranlassung und mit Unterstützung Seiner Majestät des Königs von Baiern Maximilian II. hg. durch die Historische Commission bei der Königlichen Academie der Wissenschaften, 56 Bde., Leipzig 1875-1912.

Anonym 1850

Wien, 15. Juli, in: Deutsches Kunstblatt 1, 1850, S. 215, 223 f.

Anonym 1852

Die diesjährige Berliner Kunstausstellung, in: Deutsches Kunstblatt 3, 1852, S. 330-332, 337-339, 346-348, 363-366, 373-377, 379 f., 388-391, 399 f., 406-409, 421-424, 431-433, 439-442.

Anonym 1867

Die triumphirende Union, in: Illustrierte Zeitung, Ausgabe 1274, Leipzig 30. November 1867.

Anonym 1939

Anonym: Theodor Valentiner 70 Jahre alt, in: Göttinger Tageblatt, 8. August 1939.

Arndt 1975

Karl Arndt: Denkmäler in Göttingen: Dichter und Gelehrte, in: Göttinger Jahrbuch 23, 1975, S. 107-143.

Arndt 1994

Karl Arndt (Hg.): Katalog der Bildnisse im Besitz der Georg-August-Universität Göttingen, Göttingen 1994 (= Göttinger Universitätsschriften Serie C: Kataloge, Band 4). 
Arndt 2000

Karl Arndt: Carl Wilhelm Friedrich Oesterley. Ein Göttinger Kunsthistoriker, Maler und

Zeichner, in: Göttinger Jahrbuch 48, 2000, S. 67-95.

Arnim/Selle 1930

Max Arnim, Götz von Selle (Bearb.): Corpus Academicum Gottingense (1737-1928), Göttingen 1930 .

Artinger 1995

Kai Artinger: Von der Tierbude zum Turm der blauen Pferde. Die künstlerische Wahrnehmung der wilden Tiere im Zeitalter der zoologischen Gärten, Berlin 1995.

Aubert 1894

Andreas Aubert: Den nordiske Naturfølelse og Johan Christian Dahl, Kristiania 1894.

Ausst.-Kat. Amsterdam 2000

Das Goldene Zeitalter der niederländischen Kunst. Gemälde, Skulpturen und Kunsthandwerk des 17. Jahrhunderts in Holland, Amsterdam, Rijksmuseum, 15. April - 17. September 2000, Stuttgart 2000 .

Ausst.-Kat. Antwerpen 2004

A house of art. Rubens as Collector, hg. v. Kristin Lohse Belkin u. Fiona Healy, Antwerpen, Rubenshuis, 6. März - 13. Juni 2004, Antwerpen 2004.

Ausst.-Kat. Apolda 2011

Die Weimarer Malerschule und das Weimarer Land, hg. v. Nadine Steinacker, Kunsthaus Apolda Avantgarde, 26. Juni - 21. August 2011, Kunststation Kleinsassen, 2. Oktober 4. Dezember 2011, Apolda 2011.

Ausst.-Kat. Basel 2006

Das frühe Porträt. Aus den Sammlungen des Fürsten von und zu Liechtenstein und dem Kunstmuseum Basel, bearb. von Stephan Kemperdick, Basel, Kunstmuseum, 25. Februar 2. Juli 2006, München, Berlin, London, New York 2006.

Ausst.-Kat. Berlin 1900

Gemälde und Zeichnungen von Paul Meyerheim. Akademische Kunstausstellung vom 1. April bis 13. Mai 1900, hg. v. der Akademie der Künste Berlin, Berlin 1900.

Ausst.-Kat. Berlin 1906a

Ausstellung deutscher Kunst aus der Zeit von 1775-1875 in der Königlichen Nationalgalerie Berlin 1906, hg. vom Vorstand der deutschen Jahrhundertausstellung. Auswahl der hervorragendsten Bilder mit einleitendem Text von Hugo von Tschudi, München 1906.

Ausst.-Kat. Berlin 1906b

Ausstellung deutscher Kunst aus der Zeit von 1775-1875 in der Königlichen Nationalgalerie Berlin 1906. Herausgegeben vom Vorstand der deutschen Jahrhundertausstellung. Katalog der Gemälde, München 1906 
Ausst.-Kat. Berlin 1989a

Europa und der Orient: 800-1900, hg. v. Gereon Sievernich u. Hendrik Budde, Berlin, Martin-Gropius-Bau, 28. Mai - 27. August 1989, Gütersloh 1989.

Ausst.-Kat. Berlin 1989b

Zeichnungen aus Dänemark von Abildgaard, Juel, Eckersberg, Købke, Lundbye und Marstrand. Kopenhagener Schule des 18. und 19. Jahrhunderts aus dem Besitz der Königlichen Kupferstichsammlung in Kopenhagen, hg. v. Marie Ursula Riemann, Berlin, Nationalgalerie, 5. April - 21. Mai 1989, Berlin 1989.

Ausst.-Kat. Berlin 2001a

Caravaggio in Preussen. Die Sammlung Giustiniani und die Berliner Gemäldegalerie, hg. v. Silvia Danesi Squaruona, Berlin, Altes Museum, 15. Juni - 9. September 2001, Rom, Palazzo Giustiniani, 26. Januar - 20. Mai 2001, Mailand 2001.

Ausst.-Kat Berlin 2001b

Preußen 1701. Eine europäische Geschichte, hg. v. Deutschen Historischen Museum imd der Stiftung Preußische Schlösser und Gärten Berlin-Brandenburg, Berlin, Schloss Charlottenburg, Große Orangerie, 6. Mai - 5. August 2001, 2 Bde., Berlin 2001.

Ausst.-Kat. Berlin 2001c

Eduard Gaertner 1801-1877, hg. v. Dominik Bartmann, Berlin, Museum Ephraim-Palais, 23. März - 4. Juni 2001, Berlin 2001.

Ausst.-Kat. Berlin 2011

Die Sammlung des Bankiers Wagener. Die Gründung der Nationalgalerie, hg. v. Udo Kittelmann, Birgit Verwiebe u. Angelika Wesenberg, Berlin, Nationalgalerie, 23. März 2011 8. Januar 2012, Leipzig 2011.

Ausst.-Kat. Braunschweig 2010

Stefanie K. Werner: Miniaturen - Große Malerei auf kleiner Fläche, Braunschweig, Burg Dankwarderode, 2. September - 5. Dezember 2010, Braunschweig 2010.

Ausst.-Kat. Bregenz/Schwarzenberg 2007

Angelika Kauffmann. Ein Weib von ungeheurem Talent, hg. v. Tobias G. Natter, Bregenz, Vorarlberger Landesmuseum, Schwarzenberg, Angelika Kauffmann Museum, 14. Juni -

5. November 2007, Ostfildern 2007.

Ausst.-Kat. Celle 2000

Miniaturen aus der Sammlung Tansey, hg. v. der Stiftung Miniaturensammlung Tansey im Bomann-Museum Celle, Celle, Bomann-Museum, 1. Juli 2000-?, München 2000.

Ausst.-Kat. Darmstadt 1977

Arnold Böcklin 1827-1901. Ausstellung zum 150. Geburtstag veranstaltet vom Magistrat der Stadt Darmstadt, Darmstadt, Institut Mathildenhöhe, 23. Oktober - 11. Dezember 1977, 2 Bde., Darmstadt 1977. 
Ausst.-Kat. Darmstadt 2001

Die Lebensreform. Entwürfe zur Neugestaltung von Leben und Kunst um 1900, hg. v. Kai Buchholz, Rita Latocha, Hilke Peckmann u. Klaus Wolbert, Darmstadt, Institut Mathildenhöhe, 21. Oktober 2001 - 24. Februar 2002, 2 Bde., Darmstadt 2001.

Ausst.-Kat. Dresden 1907

Gedächtnis-Ausstellung für Ferdinand von Rayski (1806-1890) und Karl Buchholz (18491889), Einleitung von Hans Rosenhagen, Dresden, Galerie Ernst Arnold, Mai - Juni 1907, Dresden 1907.

Ausst.-Kat. Düsseldorf 1979

Die Düsseldorfer Malerschule, hg. v. Wend von Kalnein, Düsseldorf, Kunstmuseum, 13. Mai - 8. Juli 1979, Darmstadt, Mathildenhöhe, 22. Juli - 9. September 1979, Mainz 1979.

Ausst.-Kat. Düsseldorf 1996

Angesichts des Alltäglichen. Genremotive in der Malerei zwischen 1830 und 1900, hg. v. Martina Sitt, Düsseldorf, Kunstmuseum, 6. Oktober 1996 - 30. März 1997, Köln 1996.

Ausst.-Kat. Düsseldorf 2000

Carl Friedrich Lessing. Romantiker und Rebell, hg. v. Martina Sitt, Düsseldorf, Kunstmuseum, 14. Mai - 30. Juli 2000, Oldenburg, Landesmuseum für Kunst und Kulturgeschichte, 24. August - 22. Oktober 2000, Bremen 2000.

Ausst.-Kat. Düsseldorf 2011

Die Düsseldorfer Malerschule und ihre internationale Ausstrahlung 1819-1918, hg. v. Bettina Baumgärtel, Düsseldorf, Museum Kunstpalast, 24. September 2011 - 22. Januar 2012, 2 Bde., Petersberg 2011.

Ausst.-Kat. Eisenach 2007

Elisabeth von Thüringen. Eine europäische Heilige, hg. v. Dieter Blume u. Werner Matthias, Wartburg bei Eisenach, 7. Juli - 19. November 2007, 2 Bde., Petersberg 2007.

Ausst.-Kat. Frankfurt a. M. 1977

Die Nazarener, hg. v. Klaus Gallwitz, Frankfurt a. M., Städelsches Kunstinstitut, 28. April 28. August 1977, Frankfurt a. M 1977.

Ausst.-Kat. Frankfurt a. M. 1994

Goethe und die Kunst, hg. v. Sabine Schulze, Frankfurt a. M., Schirn Kunsthalle, 21. Mai 7. August 1994, Weimar, Kunstsammlungen, 1. September - 30. Oktober 1994, OstfildernRuit 1994.

Ausst.-Kat. Frankfurt a. M. 2000

SeelenReich. Die Entwicklung des deutschen Symbolismus 1870-1920, hg. v. Ingrid Ehrhardt u. Simon Reynolds, Frankfurt a. M., Schirn Kunsthalle, 26. Februar - 30. April 2000, Birmingham, Museum and Art Gallery, 26. Mai - 30. Juli 2000, Stockholm, Prins Eugens Waldemarsudde, 25. August 2000 - 5. November 2000, München, London, New York 2000 . 
Ausst.-Kat. Frankfurt a. M. 2005

Religion Macht Kunst. Die Nazarener, hg. v. Max Hollein u. Christa Steinle, Frankfurt a. M., Schirn Kunsthalle, 15. April - 24. Juli 2005, Köln 2005.

Ausst.-Kat. Göttingen 2012

Vor den Gemälden. Eduard Bendemann zeichnet. Bestandskatalog der Zeichnungen und Skizzenbücher eines Hauptvertreters der Düsseldorfer Malerschule in der Göttinger Universitätskunstsammlung, hg. v. Christian Scholl u. Anne-Katrin Sors, Göttingen 2012.

Ausst.-Kat. Gotha 1999

Zwischen Ideal und Wirklichkeit. Künstlerinnen der Goethezeit zwischen 1750 und 1850, hg. v. Bärbel Kovalevski, Gotha, Schlossmuseum, 1. April - 18. Juli 1999, Konstanz, Rosgartenmuseum, 25. August - 24. Oktober 1999, Ostfildern 1999.

Ausst.-Kat. Graz 2007

Zur Natur des Menschen. Genremalerei des 19. und frühen 20. Jahrhunderts, hg. v. Christa Steinle, Graz, Neue Galerie, 17. November 2006 - 26. August 2007, Graz 2007.

Ausst.-Kat. Halberstadt 2010

Von Mensch zu Mensch. Porträtkunst und Porträtkultur der Aufklärung, hg. v. Reimar Lacher, Halberstadt, Gleimhaus, 29. August - 20. November 2010, Göttingen 2010.

Ausst.-Kat. Hamburg 1983

Luther und die Folgen für die Kunst, hg. v. Werner Hofmann, Hamburg, Kunsthalle, 10. November 1983 - 8. Januar 1984, München 1983.

Ausst.-Kat. Hamburg 1996

Mit klarem Blick. Hamburger Malerei im Biedermeier, hg. v. Helmut Leppien u. Dörte Zbikowski, Hamburg, Kunsthalle, 25. Oktober - 29. Dezember 1996, Hamburg 1996.

Ausst.-Kat. Hamburg 2000

Im Lichte Caspar David Friedrichs. Frühe Freilichtmalerei in Dänemark und Norddeutschland, hg. v. Helmut Leppien, Hamburg, Kunsthalle, 26. Januar - 26. März 2000, Hamburg 2000 .

Ausst. Kat. Heidelberg 1997

Landschaft als Geschichte. Carl Rottmann 1797-1850. Hofmaler König Ludwigs I., hg. v. Christoph Heilmann u. Erika Rödiger-Diruf, Heidelberg, Kurpfälzisches Museum der Stadt Heidelberg, 16. November 1997 - 18. Januar 1998, München, Kunsthalle der HypoKulturstiftung, 20. Januar - 13. April 1998, München 1997.

Ausst.-Kat. Heidelberg 2001

Ernst Fries. Heidelberg 1801 - 1833 Karlsruhe, hg. v. Frieder Hepp u. Annette Frese, Heidelberg, Kurpfälzisches Museum, 28. Oktober 2001 - 13. Januar 2002, Heidelberg 2001. 
Ausst.-Kat. Hildesheim 1993

Renaissance in der Romantik. Johann Dominicus Fiorillo, Italienische Kunst und die Georgia Augusta. Druckgraphik und Handzeichnungen aus der Kunstsammlung der Universität Göttingen, hg. v. Manfred Boetzkes, Gerd Unverfehrt u. Silvio Vietta, Hildesheim, Roemer- und Pelizaeus-Museum, 25. April - 16. Juni 1993, Jena, Romantikerhaus, 31. Mai 24. Juli 1994, Göttingen, Kunstsammlung der Universität, 6. November - 4. Dezember 1994, Hildesheim 1993.

Ausst.-Kat. Karlsruhe 1994

Edmund Kanoldt. Landschaft als Abbild der Sehnsucht, hg. v. Ursula Merkel u. Erika Rödiger-Diruf, Karlsruhe, Städtische Galerie im Prinz-Max-Palais, 10. Dezember 1994 19. Februar 1995, Karlsruhe 1994.

Ausst.-Kat. Karlsruhe 1998

Deutsche Künstlerkolonien 1890-1910. Worpswede, Dachau, Willingshausen, Grötzingen, Die „Brücke“, Murnau, hg. v. Erika Rödiger-Diruf u. Brigitte Baumstark, Karlsruhe, Städtische Galerie, 26. September 1998 - 17. Januar 1999, Karlsruhe 1998.

Ausst.-Kat. Kassel 2005

3 x Tischbein und die europäische Malerei um 1800. Kassel, Staatliche Museen, Neue Galerie, 1. Dezember 2005 - 26. Februar 2006, Leipzig, Museum der bildenden Künste, 18. März - 5. Juni 2006.

Ausst.-Kat. Kiel 2005

Die Kopenhagener Schule. Meisterwerke Dänischer und Deutscher Malerei von 17701850, hg. v. Dirk Luckow u. Dörte Zbikowski, Kiel, Kunsthalle, 28. Mai - 28. August 2005, Ostfildern-Ruit 2005.

Ausst.-Kat. Köln 1977

Bertel Thorvaldsen. Untersuchungen zu seinem Werk und zur Kunst seiner Zeit, hg. v. Gerhard Bott, Köln, Kunsthalle, 5. Februar - 3. April 1977, Köln 1977.

Ausst.-Kat. Kopenhagen 1981

Vor hundert Jahren: Dänemark und Deutschland 1864-1900. Gegner und Nachbarn, hg. v. Jens Christian Jensen, Kopenhagen, Statens Museum for Kunst, 31. Juli - 6. September 1981, Århus, Kunstmuseum, 19. September - 18. Oktober 1981, Kiel, Kunsthalle, 8. November - 27. Dezember 1981, Berlin, Orangerie Schloß Charlottenburg, 10. Januar 14. Februar 1982, Kopenhagen, Aarhus, Kiel, Berlin 1981/82.

Ausst.-Kat. Kronenburg/Eifel 2012

Lebensbilder. Genremalerei der Düsseldorfer Malerschule, hg. v. Ekkehard Mai, Kronenburg/Eifel, Kunstkabinett der Dr. Axe-Stiftung, 2012, Petersberg 2012.

Ausst.-Kat. Ludwigshafen 1990

Die Brüder Olivier. Gemälde, Zeichnungen und Druckgraphik aus der Staatlichen Galerie Dessau, hg. v. Richard Gassen u. Helge Heise, Ludwigshafen, Wilhelm-Hack-Museum, 16. Dezember 1990 - 3. Februar 1991, Ludwigshafen 1990. 
Ausst.-Kat. Lübeck 1989

Johann Friedrich Overbeck 1789-1869. Zur zweihundertsten Wiederkehr seines Geburtstages, hg. v. Andreas Blühm u. Gerhard Gerkens, Lübeck, Museum für Kunst und Kulturgeschichte - Behnhaus, 25. Juni - 3. September 1989, Lübeck 1989.

Ausst.-Kat. Lübeck 2000

Karl Buchholz 1849-1889. Ein Künstler der Weimarer Malerschule, hg. v. Eckart Kißling u. Hendrik Ziegler, Lübeck, Museum für Kunst- und Kulturgeschichte, 23. Januar - 5. März 2000, Erfurt, Angermuseum, 25. März - 6. Juni 2000, Leipzig 2000.

Ausst.-Kat. Lübeck 2009

„An den Wasserflüssen Banylons saßen wir“. Figurationen der Sehnsucht in der Malerei der Romantik. Ferdinand Olivier und Eduard Bendemann, hg. v. Alexander Bastek u. Michael Thimann, Lübeck, Museum Behnhaus Drägerhaus, 11. Oktober 2009 - 10. Januar 2010, Petersberg 2009.

Ausst.-Kat. Lüneburg 1974

Nikolaus und Otto Peters. Museumsverein für das Fürstentum Lüneburg, 6. April - 10. Mai 1974, Lüneburg 1974.

Ausst.-Kat. Mainz 2012

Die Nazarener - Vom Tiber an den Rhein. Drei Malerschulen des 19. Jahrhunderts, bearb. v. Norbert Suhr u. Nico Kirchberger, Mainz, Landesmuseum, 10. Juni - 25. November 2012, Regensburg 2012.

Ausst.-Kat. Mannheim 1995

William Turner in Deutschland, hg. v. Manfred Fath u. Cecilia Powell, Mannheim, Kunsthalle, 24. September 1995 - 14. Januar 1996, Hamburg, Kunsthalle, 26. Januar 1996 -

31. März 1996, München 1995.

Ausst.-Kat. Marburg 1983

Brigitte Rechberg: Die heilige Elisabeth in der Kunst - Abbild, Vorbild, Wunschbild, Marburg, Universitätsmuseum für bildende Kunst, Bd. 2, Marburg 1983.

Ausst.-Kat. München 1904

Münchener Jahresausstellung 1904. Glaspalast, München 1904.

Ausst.-Kat. München 1906

Münchener Jahresausstellung 1906. Glaspalast, München 1906.

Ausst.-Kat. München 1908

Münchener Jahres-Ausstellung. Verbunden mit einer Jubiläums-Ausstellung der allgem. deutschen Kunstgenossenschaft. Glaspalast 1908, München 1908. 
Ausst.-Kat. München 1911

Kgl. Glaspalast 1911. Jubiläums-Ausstellung der Münchener Künstler-Genossenschaft zu Ehren des 90. Geburtstages Sr. Kgl. Hoheit des Prinz Regenten Luitpold von Bayern, München 1911.

Ausst.-Kat. München 1992

Sammlung Graf Raczynski. Malerei der Spätromantik aus dem Nationalmuseum Poznan, hg. v. Konstanty Kalinowski u. Christoph Heilmann, München, Neue Pinakothek, 2. Oktober - 29. November 1992, Berlin, Alte Nationalgalerie, 18. Dezember 1992 - 14. Februar 1993, Kiel, Kunsthalle, 7. März - 18. April 1993, München 1992.

Ausst.-Kat. München 2003

Großer Auftritt. Piloty und die Historienmalerei, hg. v. Reinhold Baumstark u. Frank Büttner, München, Neue Pinakothek, 4. April - 27. Juli 2003, München, Köln 2003.

Ausst.-Kat. München 2007

Carl Rottmann. Die Landschaften Griechenlands, hg. v. Herbert W. Rott, Renate Poggendorf u. Elisabeth Stürmer, München, Neue Pinakothek, 25. Januar - 29. April 2007, Ostfildern 2007.

Ausst.-Kat. München 2010

Gabriel von Max. Malerstar, Darwinist, Spiritist, hg. v. Karin Althaus, München, Lenbachhaus und Kunstbau, 23. Oktober 2010 - 30. Januar 2011, München 2010.

Ausst.-Kat. Münster 1989

Christian Rohlfs: Gemälde, hg. v. Klaus Bußmann, Münster, Westfälisches Landesmuseum für Kunst und Kulturgeschichte, 10. Dezember 1989 - 11. Februar 1990, Weimar, Staatliche Kunstsammlung, 8. März - 6. Mai 1990, Stuttgart 1989.

Ausst.-Kat. Paderborn 2003

Das Stilleben in der deutschen Malerei des 19. Jahrhunderts, hg. v. Andrea Wandschneider, Paderborn, Städtische Galerie in der Reithalle Schloß Neuhaus, 6. September 2003 -

4. Januar 2004, Paderborn 2003.

Ausst.-Kat. Paris 2005

Melancholie. Genie und Wahnsinn in der Kunst, hg. v. Jean Clair, Paris, Galeries Nationales du Grand Palais, 10. Oktober 2005 - 16. Januar 2006, Berlin, Nationalgalerie, 17. Februar - 7. Mai 2006, Berlin 2005.

Ausst.-Kat. Rom 1981

Die Nazarener in Rom. Ein deutscher Künstlerbund der Romantik, hg. v. Klaus Gallwitz, Rom, Galleria Nazionale d'Arte Moderna, 22. Januar - 22. März 1981, München 1981. 
Ausst.-Kat. San Francisco 1962

Barbizon revisited, hg. v. Robert L. Herbert, San Francisco, California Palace of the Legion of Honor, 27. September - 4. November 1962, Toledo, Museum of Art, 20. November 27. Dezember 1962, Cleveland, Museum of Art, 15. Januar - 24. Februar 1963, Boston, Museum of Fine Arts, 14. März - 28. April 1963, New York 1962.

Ausst.-Kat. Schweinfurt 2004

Natur als Garten. Barbizons Folgen, hg. v. Sigrid Bertuleit u. Claudia Valter, Schweinfurt, Museum Georg Schäfer, 8. August 2004 - 9. Januar 2005, Schweinfurt 2004.

Ausst.-Kat. Schweinfurt 2010

Meisterwerke der Portraitkunst aus dem Gesamtbestand der bedeutenden Privatsammlung der Kunst des 19. Jahrhundert, hg. v. Siegrid Bertuleit, Schweinfurt, Museum Georg Schäfer, 9. Mai - 31. Oktober 2010, Dresden 2010.

Ausst.-Kat. Weimar 2010

Hinaus in die Natur! Barbizon, die Weimarer Malerschule und der Aufbruch zum Impressionismus, hg. v. Gerda Wendermann, Weimar, Neues Museum, 14. März - 30. Mai 2010, Bielefeld 2010.

Ausst.-Kat. Wien 2007

Porträts von Gainsborough bis Waldmüller 1750-1840, hg. v. Sabine Grabner u. Michael Krapf, Wien, Österreichischen Galerie Belvedere, 25. Oktober 2006 - 18. Februar 2007, München 2007.

Ausst.-Kat. Wien/München 2011

Dürer - Cranach - Holbein. Die Entdeckung des Menschen. Das deutsche Porträt um 1500, Wien, Kunsthistorisches Museum, 31. Mai - 4. September 2011, München, Kunsthalle der Hypo-Kulturstiftung, 16. September 2011 - 15. Januar 2012, München 2011.

Bahns 1997

Jörn Bahns: Jakob Daniel Georg Gottlieb Bernhard Fries, in: Paffrath 1997/98 (siehe dort), Bd. 1, S. 375-376.

Bamberg 2006

Ludwig Bamberg: Die Potsdamer Garnisonkirche. Baugeschichte - Ausstattung - Bedeutung, Berlin 2006.

Bartilla 1998

Stefan Bartilla: Carl Wilhelm Friedrich Oesterley d.Ä., in: Paffrath 1997/98 (siehe dort), Bd. 3, S. 64-65.

Baumgärtel, B. 2011a

Bettina Baumgärtel: Die Düsseldorfer Malerschule und ihre internationale Ausstrahlung, in: Ausst.-Kat. Düsseldorf 2011 (siehe dort), Bd. 1, S. 24-49. 
Baumgärtel, B. 2011b

Bettina Baumgärtel: National, regional und transnational. Die Monumentalmalerei der Düsseldorfer Malerschule - Apollinariskirche und Schloss Heltorf, in: Ausst.-Kat. Düsseldorf 2011 (siehe dort), Bd. 1, S. 115-139.

Baumgärtel, B. 2011c

Bettina Baumgärtel: Vom „Sonntagschristus“ zum „Alltagschristus“, in: Ausst.-Kat. Düsseldorf 2011 (siehe dort), Bd. 2, S. 128.

Baumgärtel, B. 2011d

Bettina Baumgärtel: Eduard von Gebhardt: Die Bergpredigt, in: Ausst.-Kat. Düsseldorf 2011 (siehe dort), Bd. 2, S. 158 f.

Baumgärtel, G. 2003

Gisela Baumgärtel: Die Stillebenmalerei der Düsseldorfer Malerschule, in: Ausst.-Kat.

Paderborn 2003 (siehe dort), S. 29-42.

Bayersdorfer 1902 [1874]

Adolph Bayersdorfer: Neue Kunstbestrebungen in München, in: Hans Mackowsky, August Pauly, Wilhelm Weigand (Hg.): Adolph Bayersdorfers Leben und Schriften, München 1902, S. 206-244.

Becker 2007

Ulrich Becker: Dumpfe Scheunen - aufgeräumte Stuben. Unbekannte Werke der Genremalerei aus der Alten Galerie, in: Ausst.-Kat. Graz 2007 (siehe dort), S. 10-27.

Becker-Göthel 2002

Dagmar Becker-Göthel: Defregger. Überarbeitete Neuausgabe, 2. Aufl., München 2002.

Belting 1979

Hans Belting: Zum Gedenken an Walter Paatz, in: Ruperto Carola 31, 1979, S. 116 f.

Beneke 1999

Sabine Beneke: Im Blick der Moderne. Die ,Jahrhundertausstellung deutscher Kunst (1775-1875)“ in der Berliner Nationalgalerie 1906, Berlin 1999.

Bernhard 1977

Klaus Bernhard: Idylle. Theorie, Geschichte, Darstellung in der Malerei 1750-1850. Zur Anthropologie deutscher Seligkeitsvorstellungen, Köln 1977 (= Dissertationen zur Kunstgeschichte, Bd. 4).

Bernt 1980

Walther Bernt: Die Niederländischen Maler und Zeichner des 17. Jahrhunderts, 4., überarbeitete Auflage, 5 Bde., München 1980. 
Bertsch 2007

Markus Bertsch: „Heiligenbildchenkram“? Zur Präsenz der Heiligen Elisabeth im Bilderkosmos der Nazarener, in: Ausst.-Kat. Eisenach 2007 (siehe dort), Bd. 2, Petersberg 2007, S. 521-538.

Bertsch/Wegner 2010

Markus Bertsch, Reinhard Wegner (Hg.): Landschaft am „Scheidepunkt“. Evolutionen einer Gattung in Kunsttheorie, Kunstschaffen und Literatur um 1800, Göttingen 2010 (= Ästhetik um 1800, Bd. 7).

Bertuleit 2004

Sigrid Bertuleit: Paris - München. Frankreich und Deutschland auf Tuchfühlung durch „Kunst und Kunstindustrie“, in: Ausst.-Kat. Schweinfurt 2004 (siehe dort), S. 9-16.

Beyer 2002

Andreas Beyer: Das Porträt in der Malerei, München 2002.

Beyrodt 1991

Wolfgang Beyrodt: Kunstgeschichte als Universitätsfach, in: Peter Ganz, Martin Gosebruch, Nikolaus Meier, Martin Warnke (Hg.): Kunst und Kunsttheorie 1400-1900, Wiesbaden 1991 (=Wolfenbütteler Forschungen, Bd. 48), S. 313-333.

Bickendorf 2007

Gabriele Bickendorf: Die ersten Überblickswerke zur „Kunstgeschichte': Jean-BaptisteLuis-Georges Séroux d'Agincourt (1730-1814), Luigi Lanzi (1732-1810), Johann Domenico Fiorillo (1748-1821) und Leopoldo Cicognara (1767-1834), in: Ulrich Pfisterer (Hg.): Klassiker der Kunstgeschichte, Bd. 1: Von Winckelmann bis Warburg, München, 2007, S. 2945 .

Bieber/Mai 1979

Dietrich Bieber, Ekkehard Mai: Gebhardt und Janssen - Religiöse und Monumentalmalerei im späten 19. Jahrhundert, in: Ausst. Kat. Düsseldorf 1979 (siehe dort), S. 165-185.

Biedermann/Herwig 1998

Goethes Gespräche. Eine Sammlung zeitgenössischer Berichte aus seinem Umgang. Auf Grund der Ausgabe und des Nachlasses von Flodoard Freiherrn von Biedermann. Ergänzt u. hg. v. Wolfgang Herwig, 5 Bde., Nachdruck der Ausgabe Düsseldorf/Zürich 1965-1987, München 1998.

Blaha/Boblenz/Wahl 2008

Dagmar Blaha, Frank Boblenz, Volker Wahl (Bearb.): Von der Kunstschule zum Bauhaus. Spezialrepertorium zu den Archivbeständen der Kunstlehranstalten in Weimar, Weimar 2008 (= Repertorien des Thüringischen Hauptstaatsarchivs Weimar, Bd. 4).

Börsch-Supan 1960

Helmut Börsch-Supan: Die Bildgestaltung bei Caspar David Friedrich. Phil. Diss. (Masch.) Freie Universität Berlin 1960. 
Börsch-Supan 1971

Helmut Börsch-Supan (Hg.): Die Kataloge der Berliner Akademie-Ausstellungen 17861850, 2 Bde., Berlin 1971.

Börsch-Supan 1980

Helmut Börsch-Supan: Die Kunst in Brandenburg-Preußen. Ihre Geschichte von der Renaissance bis zum Biedermeier dargestellt am Kunstbesitz der Berliner Schlösser, Berlin 1980.

Börsch-Supan 1988

Helmut Börsch-Supan: Die Deutsche Malerei von Anton Graff bis Hans von Marées 17601870, München 1988.

Börsch-Supan/Jähnig 1973

Helmut Börsch-Supan, Karl Wilhelm Jähnig: Caspar David Friedrich. Gemälde, Druckgraphik und bildmäßige Zeichnungen, München 1973.

Boetticher 1891-1901

Boetticher, Friedrich von: Malerwerke des neunzehnten Jahrhunderts, 2 Bde., Leipzig 1891-1901.

Brakensiek 2003

Stephan Brakensiek: Vom „Theatrum Mundi“ zum „Cabinet des Estampes“, Hildesheim 2003.

Brieger 1930

Peter Brieger: Die deutsche Geschichtsmalerei des 19. Jahrhunderts, Berlin 1930.

Brinkmann 2000

Jens-Uwe Brinkmann: ... in jeder Hinsicht vollkommen so schön als dergleichen Arbeiten irgendwo gemacht werden... Porzellanmalerei in Göttingen, Göttingen 2000.

Broer 1997

Werner Broer (Hg.): Vom Klassizismus zu den Wegbereitern der Moderne. Epochen der Kunst, Bd. 4, München 1997.

Brummer 2000

Hans Henrik Brummer: Noch einmal: Der Fall Böcklin, in: Ausst.-Kat. Frankfurt a. M. 2000 (siehe dort), S. 29-41.

Büttner 1979a

Frank Büttner: Peter Cornelius in Düsseldorf, in: Ausst.-Kat. Düsseldorf 1979 (siehe dort), S. 48-55.

Büttner 1979b

Frank Büttner: Die klugen und törichten Jungfrauen im 19. Jahrhundert. Zur religiösen Bildkunst der Nazarener, in: Städel-Jahrbuch, N. F., 7, 1979, S. 207-230. 
Büttner 1983

Frank Büttner: Der Streit um die „Neudeutsche religiös-patriotische Kunst“, in: Aurora 43, 1983, S. 55-76.

Büttner 1980/1999

Frank Büttner: Peter Cornelius: Fresken und Freskenprojekte, Bd. 1, Wiesbaden 1980, Bd. 2, Stuttgart 1999.

Büttner 1994

Büttner, Frank: Abwehr der Romantik, in: Ausst.-Kat. Frankfurt a. M. 1994 (siehe dort), S. 456-467.

Büttner 1990

Frank Büttner: Bildung des Volkes durch Geschichte. Zu den Anfängen öffentlicher Geschichtsmalerei in Deutschland, in: Mai 1990a (siehe dort), S. 77-94.

Büttner 2003

Frank Büttner: Gemalte Geschichte. Carl Theodor von Piloty und die europäische Historienmalerei des 19. Jahrhunderts, in: Ausst.-Kat. Münchern 2003 (siehe dort), S. 23-67.

Burckhardt 1843

Jakob Burckhardt: Bericht über die Kunstausstellung zu Berlin im Herbste 1842, in: Kunstblatt 24, 1843, S. 1 f., 5-7, 9-15, 81-83, 89-91, 93-95, 97-99.

Busch 1983

Werner Busch: Die autonome Ölskizze in der Landschaftsmalerei. Der wahr- und für wahr genommene Ausschnitt aus Zeit und Raum, in: Pantheon 41, 1983, S. 126-133.

Busch 1985

Werner Busch: Die notwendige Arabeske. Wirklichkeitsaneignung und Stilisierung in der deutschen Kunst des 19. Jahrhunderts, Berlin 1985.

Busch 1990

Werner Busch: Die fehlende Gegenwart, in: Reinhart Koselleck (Hg.): Bildungsbürgertum im 19. Jahrhundert, Teil II: Bildungsgüter und Bildungswissen, Stuttgart 1990 (= Industrielle Welt. Schriftenreihe des Arbeitskreises für moderne Sozialgeschichte, Bd. 41), S. 286316.

Busch 1991

Werner Busch: Adolph Menzels „Begegnung Friedrichs II. mit Kaiser Joseph II. in Neisse im Jahre 1769“ und Moritz von Schwinds „Kaiser Rudolfs Ritt zum Grabe“, in: Jahrbuch der Berliner Museen, Neue Folge, 33, 1991, S. 175-183.

Busch 1993

Werner Busch: Das sentimentalische Bild. Die Krise der Kunst im 18. Jahrhundert und die Geburt der Moderne, München 1993. 
Busch 1997a

Werner Busch (Hg.): Landschaftsmalerei, Berlin 1997 (= Geschichte der klassischen Bildgattungen in Quellentexten und Kommentaren, Bd. 3).

Busch 1997b

Werner Busch: Skizze, Atmosphäre und Bildgesetzlichkeit. Die unklassische Landschaft 1770-1850, in: Thorvaldsens Museum Bulletin 1997, S. 59-72.

Busch/Beyrodt 1982

Werner Busch, Wolfgang Beyrodt (Hg.): Kunsttheorie und Kunstgeschichte des 19. Jahrhunderts in Deutschland. Texte und Dokumente, Bd. 1: Kunsttheorie und Malerei. Kunstwissenschaft, Stuttgart 1982.

Bushart/Eberle/Jensen 2002

Bruno Bushart, Matthias Eberle, Jens Christian Jensen: Museum Georg Schäfer Schweinfurt. Erläuterungen zu den ausgestellten Werken, 2., vermehrte und durchgesehene Auflage, Schweinfurt 2002.

Castritius 2007

Helmut Castritius: Die Vandalen. Etappen einer Spurensuche, Stuttgart 2007.

Chronik der Georg-August-Universität 1898/99

Chronik der Georg-August-Universität zu Göttingen 1898/99, Göttingen 1999.

Clark, A. M. 1985

Anthony Morris Clark: Pompeo Batoni. A Complete Catalogue of his Works with an Introductory Text, Oxford 1985.

Clark, C. 2003

Christopher Clark: Der neue Katholizismus und der europäische Kulturkampf, in:

Clark/Kaiser 2003 (siehe dort), S. 14-37.

Clark/Kaiser 2003

Christopher Clark, Wolfram Kaiser (Hg.): Kulturkampf in Europa im 19. Jahrhundert, Leipzig 2003 (= Comparativ. Leipziger Beiträge zur Universalgeschichte und vergleichenden Gesellschaftsforschung 12, 2002, Heft 5/6, Leipzig 2003).

Conisbee 1979

Philip Conisbee: Pre-romantic plein-air painting, in: Art History. Journal of the Association of Art Historians, Bd. 4, Heft 2, 1979, S. 413-428.

Czymmek 2012

Götz Czymmek: Genre-Themen in der deutschen Malerei des 19. Jahrhunderts, in: Ausst.Kat. Kronenburg/Eifel 2012 (siehe dort), S. 9-23. 
Daege/Gruppe 1869

Eduard Daege, Otto Friedrich Gruppe: Kunst-Institute und -Vereine, Königliche Akademie der Künste zu Berlin, Bekanntmachung, in: Die Dioskuren. Deutsche Kunstzeitung, Hauptorgan der deutschen Kunstvereine, 14, 1869, S. 240.

Dahm 1953

Inge Dahm: Das „Schornsche“ Kunstblatt 1816-1849. Phil. Diss. (Masch.) München 1953.

Daum 2009

Denise Daum: Albert Eckhouts ,gemalte Kolonie‘. Bild- und Wissensproduktion über

Niederländisch-Brasilien um 1640, Marburg 2009.

Dehio Salzburg 1986

Bernd Euler-Rolle u.a.: Salzburg. Stadt und Land, Dehio-Handbuch, Die Kunstdenkmäler Österreichs, Wien 1986.

Deneke 2001

Otto Deneke: Göttinger Künstler, Dritter Teil, hg. u. kommentiert von Jens-Uwe Brinkmann, in: Göttinger Jahrbuch 49, 2001, S. 39-71.

Der Kunstverein in Bremen 1990

Der Kunstverein in Bremen, Jahresbericht, Kunsthalle Bremen, Bremen 1990.

Dibbern 1980

Margrit Dibbern: Die Hamburger Kunsthalle unter Alfred Lichtwark (1886-1914). Entwicklung der Sammlungen und Neubau, Phil. Diss., Hamburg 1980.

Dierkesmann 2006

Rainer Dierkesmann (Hg.): Seemanns Lexikon der Symbole, Leipzig 2006.

Dilly 1979

Heinrich Dilly: Kunstgeschichte als Institution. Studien zur Geschichte einer Disziplin, Frankfurt a. M., 1979.

Dinzelbacher 1998

Peter Dinzelbacher: Bernhard von Clairvaux. Leben und Werk des berühmten Zisterziensers, Darmstadt 1998.

Döhl 1997

Hartmut Döhl: Müller, Kurt Ferdinand, in: Neue Deutsche Biographie, Bd. 18, Berlin 1997, S. $449 \mathrm{f}$.

Droste 1980

Magdalena Droste: Das Fresko als Idee. Zur Geschichte öffentlicher Kunst im 19. Jahrhundert, Münster 1980 (= Kunstgeschichte: Form und Interesse, Bd. 2). 
Dudkowiak/Wendermann 2011

Carolin Dudkowiak, Gerda Wendermann: Albert Brendel und Barbizon, in: Ausst.-Kat. Weimar 2010 (siehe dort), S. 175-184.

Duverger 1984 ff.

Erik Duverger: Antwerpse kunstinventarissen uit de zeventiende eeuw, Brüssel 1984 ff.

E. K. 1942

E. K.: Berühmtes Erstlingswerk eines Göttingers, in: Südhannoversche Zeitung, Göttingen

d. 10. Februar 1942.

E. K. 1943

E. K.: Ein genialer Künstler unserer Heimatstadt, in: Südhannoversche Zeitung, Göttingen d. 4./5. Dezember 1943.

Ebel 1962

Wilhelm Ebel (Hg. u. Bearb.): Catalogus Professorum Gottingensium (1734-1962), Göttingen 1962 .

Ebert-Schifferer 1998

Sybille Ebert-Schifferer: Die Geschichte des Stillebens, München 1998.

Ebertshäuser 1979

Heidi C. Ebertshäuser: Malerei im 19. Jahrhundert. Münchner Schule, München 1979.

Ecker 1991

Jürgen Ecker: Anselm Feuerbach. Leben und Werk. Kritischer Katalog der Gemälde, Ölskizzen und Ölstudien, München 1991.

Eggers 1850

F[riedrich] E[ggers]: Die diesjährige Berliner Ausstellung, in: Deutsches Kunstblatt 1, 1850, S. 153-155, 161 f., 170-172, 177-180, 182-186, 210 f., 226 f., 235-237, 244-246.

Eimer 1999

Gerhard Eimer (Hg.): Caspar David Friedrich. Kritische Edition der Schriften des Künstlers und seiner Zeitzeugen I. „Äußerungen bei Betrachtung einer Sammlung von Gemählden von größtentheils noch lebenden und unlängst verstorbenen Künstlern“, Frankfurt a. M. 1999 (= Frankfurter Fundamente für Kunstgeschichte Bd. XVI).

Einem 1981

Herbert von Einem: Thorvaldsens „Christus“, in: Justus Müller-Hofstede, Werner Spies (Hg.): Festschrift für Eduard Trier zum 60. Geburtstag, Berlin 1981, S. 177-183.

Eismann 2007

Ingeborg Eismann: Franz Xaver Winterhalter (1805-1873). Der Fürstenmaler Europas, Petersberg 2007. 
Elsner 1921

Salesius Elsner O.F.M.: Die Heilige Elisabeth, Landgräfin von Thüringen in Kunst, Poesie und Legende, Mönchengladbach 1921.

Erler 1970

Heinrich Erler: Chronik der Künstlerfamilie Peters. Das Leben und Wirken von sechs Malern in vier Generationen von 1743 bis 1920, Limburg a. d. Lahn 1970.

Erler 1974

Heinrich Erler: Die Peters, in: Ausst.-Kat. Lüneburg 1974 (siehe dort), S. 5-11.

Ertz 1986

Klaus Ertz: Josse de Momper der Jüngere (1564-1635). Die Gemälde mit kritischem Euvrekatalog, Freren 1986.

Eschenburg 1998

Barbara Eschenburg: Die historische Landschaft. Überlegungen zu Form und Inhalt der Landschaftsmalerei im späten 18. und frühen 19. Jahrhundert, in: Ausst. Kat. Heidelberg 1997, S. 63-74.

Falke 1873

Jakob Falke: Zur Erinnerung an Heinrich Petri, in: Zeitschrift für bildende Kunst 8, 1873, S. 97-103.

Fastert 2000

Sabine Fastert: Die Entdeckung des Mittelalters. Geschichtsrezeption in der nazarenischen Malerei des frühen 19. Jahrhunderts, München, Berlin 2000.

Faulstich 2002

Werner Faulstich: Einführung in die Medienwissenschaft: Probleme, Methoden, Domänen, Stuttgart 2002.

Fernow 1806

Carl Ludwig Fernow: Über die Landschaftmalerei, in: Ders.: Römische Studien, Bd. 2, Zürich 1806, S. 11-130.

Fiedler 1971 [1913]

Conrad Fiedler: Über die Beurteilung von Werken der bildenden Kunst, in: Ders.: Schriften zur Kunst. Nachdruck der Ausgabe München 1913/14 mit weiteren Texten aus Zeitschriften und dem Nachlaß, einer einleitenden Abhandlung, einer Bibliographie und Registern, hg. v. Gottfried Boehm, 2 Bde., München 1971 (= Theorie und Geschichte der Literatur und der schönen Künste, Bd. 16), Bd. 1, S. 1-79.

Fiorillo 1805

Johann Dominicus Fiorillo: Beschreibung der Gemählde-Sammlung der Universität zu Göttingen, Göttingen 1805. 
Fiorillo 1820

Johann Dominicus Fiorillo: Blicke auf den gegenwärtigen Zustand der Mahlerey, besonders bey den Deutschen, in: Ders.: Geschichte der zeichnenden Künste in Deutschland und den vereinigten Niederlanden, Bd. 4, Hannover 1820, S. 79-116.

Förster 1842/43

Ernst Förster: Aus dem gegenwärtigen Kunstleben am Rhein und in den Niederlanden, in Briefen an einen Freund, in: Kunstblatt 23, 1842, S. 373-376, 393-395, 397-399; 1843, S. 30 f., 33-35, 109-113, $118 \mathrm{f}$.

Förster 1874

Ernst Förster: Peter von Cornelius. Ein Gedenkbuch aus seinem Leben und Wirken, mit Benutzung seines künstlerischen, wie handschriftlichen Nachlasses, nach mündlichen und schriftlichen Mittheilungen seiner Freunde und eigenen Erinnerungen und Aufzeichnungen, 2 Bde., Berlin 1874.

Frank 2002

Mitchell Benjamin Frank: ,Castrated Raphael': Friedrich Overbeck and allegory, in: Word \& Image 18, 2002, S. 87-89.

Franz-Duhme/Röper-Vogt 1991

Helga Nora Franz-Duhme, Ursula Röper-Vogt: Schinkels Vorstadtkirchen. Kirchenbau und Gemeindegründung unter Friedrich Wilhelm III. in Berlin, Berlin 1991.

Frauendorfer 1975

Sigmund von Frauendorfer: Helene Frauendorfer-Mühlthaler. Lebensbild und künstlerische Entwicklung, in: Oberbayerisches Archiv 100, 1975, S. 377-560.

Freigang 2002

Christian Freigang: Architektur und Städtebau von der Mitte des 17. Jahrhunderts bis 1866, in: Ernst Böhme, Rudolf Vierhaus (Hg.): Göttingen. Geschichte einer Universitätsstadt, Bd. 2: Vom Dreißigjährigen Krieg bis zum Anschluss an Preußen - Der Wiederaufstieg als Universitätsstadt (1648-1866), Göttingen 2002, S. 765-812.

Frese 2001

Annette Frese: „Ihm Gleichend bringt die Zeit uns keinen Wieder“. Zur Biographie von Ernst Fries, in: Ausst.-Kat. Heidelberg 2001 (siehe dort), S. 11-17.

Fuchs/Himmelheber 1999

Carl-Ludwig Fuchs, Susanne Himmelheber (Hg.): Biedermeier in Heidelberg 1812-1853, Heidelberg 1999.

Gaehtgens, B. 2002

Barbera Gaehtgens (Hg.): Genremalerei, Berlin 2002 (= Geschichte der klassischen Bildgattungen in Quellentexten und Kommentaren, Bd. 4). 
Gaehtgens, Th. 1996

Thomas W. Gaehtgens (Hg.): Historienmalerei. Zur Geschichte einer klassischen Bildgattung und ihrer Theorie, in: Gaehtgens/Fleckner 1996 (siehe dort), S. 15-76.

Gaehtgens/Fleckner 1996

Thomas W. Gaehtgens, Uwe Fleckner (Hg.): Historienmalerei, Berlin 1996 (= Geschichte der klassischen Bildgattungen in Quellentexten und Kommentaren, Bd. 1).

\section{Gagel 1979}

Hanna Gagel: Die Düsseldorfer Malerschule in der politischen Situation des Vormärz und 1848, in: Ausst.-Kat. Düsseldorf 1979 (siehe dort), S. 68-85.

Geismeier 1967

Willi Geismeier: Die Nazarener-Fresken der „Casa Bartholdy“, in: Staatliche Museen zu Berlin: Forschungen und Berichte. Kunsthistorische Beiträge 9, 1967, S. 45-53.

Geismeier 1984

Willi Geismeier: Die Malerei der deutschen Romantik, Stuttgart 1984.

Gerhardt 1908

Livia Gerhardt: Carl Ludwig Fernow, Leipzig 1908.

Gerson 1976

Horst Gerson: Wolfgang Stechow. Kiel, 1896 - Princeton, 1974, in: Walter L. Strauss (Hg): Tribute to Wolfgang Stechow. New York 1976.

Gethmann-Siefert 1984

Annemarie Gethmann-Siefert: Die Kritik an der Düsseldorfer Malerschule bei Hegel und den Hegelianern, in: Gerhard Kurz (Hg.): Düsseldorf in der deutschen Geistesgeschichte (1750-1850), Düsseldorf 1984, S. 263-288.

Gibbon 1790-92

Edward Gibbon: Geschichte der Abnahme und des Falls des Römischen Reichs aus dem Englischen des Eduard Gibbon Esqu. Übersetzt von C[hristoph] W[ilhelm] v[on] R[iemberg], 14 Bde., Wien 1790-92.

Girgensohn 1976

Georg Girgensohn: Göttingen. Neueröffnung der Gemäldegalerie der Universitätskunstsammlung, in: Pantheon 4, 1976, S. 340.

Gockel 1999

Bettina Gockel: Kunst und Politik der Farbe. Gainsboroughs Portraitmalerei, Berlin 1999.

Gönna/Simon 2002

Gerd von der Gönna, Erika Simon (Hg.): Homerische Hymnen. Übertragung, Einführung und Erläuterungen von Karl Arno Pfeiff, Tübingen 2002 (= Ad Fontes. Quellen europäischer Kultur, Bd. 8). 


\section{Görres 1874}

Joseph von Görres: Gesammelte Briefe, Bd. 2: Freundesbriefe, hg. v. Franz Binder, München 1874.

Goethe 1985-1999

Johann Wolfgang Goethe: Sämtliche Werke. Briefe, Tagebücher und Gespräche, hg. v. Friedmar Apel, Hendrik Birus u. a., Frankfurt a. M. 1985 ff.

Goethe 2006 [1798]

Johann Wolfgang von Goethe: Einleitung (in die ,Propyläen`), in: Ders.: Sämtliche Werke nach Epochen seines Schaffens. Münchner Ausgabe, hg. v. Karl Richter in Zusammenarbeit mit Herbert G. Göpfert, Norbert Miller u. Gerhard Sauder, Bd. 6.2: Weimarer Klassik 1798-1806, 2, München 2006, S. 9-26.

Goethe/Meyer 1970 [1817]

Johann Wolfgang von Goethe, Heinrich Meyer: Neu-deutsch religios-patriotische Kunst, in: Ueber Kunst und Alterthum in den Rhein Mayn Gegenden. Von Goethe. Zweites Heft, Stuttgart 1817. Nachdruck Bern 1970.

Gohr 1977

Siegried Gohr: Die Christusstatue von Bertel Thorvaldsen in der Frauenkirch zu Kopenhagen, in: Ausst.-Kat. Köln 1977 (siehe dort), S. 343-353.

Gottwald 2011

Franziska Gottwald: Das Tronie. Muster - Studie - Meisterwerk. Die Genese einer Gattung der Malerei vom 15. Jahrhundert bis hin zu Rembrandt, Berlin 2011 (= Kunstwissenschaftliche Studien, Bd. 164).

Grabner 2011

Sabine Grabner: Der Maler Josef Danhauser. Biedermeierzeit im Bild. Monografie und Werkverzeichnis, Wien, Köln, Weimar 2011.

Grewe 2009

Cordula Grewe: Painting the Sacred in the Age of Romanticism, Ashgate 2009.

Grewe 2011

Cordula Grewe: Nazarenisch oder nicht? Überlegungen zum Religiösen in der Düsseldorfer Malerschule, in: Ausst.-Kat. Düsseldorf 2011 (siehe dort), Bd. 1, S. 77-87.

Grewe 2012

Cordula Grewe: Raffaels Gemeinde: Nachahmung als religiöse Identitätsfindung, in: Heß/Agazzi/Décultot 2012 (siehe dort), S. 255-282.

Gries 1995

Carola Bettina Gries (Hg.): Eduard von Gebhardt. Ein protestantischer Historienmaler im 19. Jahrhundert, Aachen 1995. 
Gries 1997

Carola Bettina Gries: Gebhardt, Karl Franz Eduard von, in: Paffrath 1997/98 (siehe dort), Bd. 1, S. 390-393.

Gries 2006

Carola Bettina Gries: Gebhardt, Eduard (Eduard Karl Franz) von, in: Saur Allgemeines Künstlerlexikon 1992 ff. (siehe dort), Bd. 50, 2006, S. 478 f.

Groblewski 2001

Michael Groblewski: Thron und Altar. Der Wiederaufbau der Basilika St. Paul vor den Mauern (1823-1854), Freiburg i. Br. 2001.

Grossmann 1994

Joachim Grossmann: Künstler, Hof und Bürgertum. Leben und Arbeit von Malern in Preußen 1786-1850, Berlin 1994.

Grote 1932

Ludwig Grote: Johann Heinrich Ferdinand Olivier, in: Thieme/Becker 1907-1950 (siehe dort), Bd. 26, 1932, S. 1-3.

Grote 1938

Ludwig Grote: Die Brüder Olivier und die deutsche Romantik, Berlin 1938.

Günther 1990

Erika Günther: Die Faszination des Fremden. Der malerische Orientalismus in Deutschland, Münster 1990.

Gurlitt, C. 1890

Cornelius Gurlitt: Die Akademische Kunstausstellung in Berlin, in: Die Gegenwart.

Wochenschrift für Literatur, Kunst und öffentliches Leben 38, 1890, S. 29-31, 46 f., 61-63, 77 f., 94 f.

Gurlitt, C. 1899

Cornelius Gurlitt: Die deutsche Kunst des Neunzehnten Jahrhunderts. Ihre Ziele und Thaten, Berlin 1899.

Gurlitt, Ludwig 1912

Ludwig Gurlitt: Louis Gurlitt. Ein Künstlerleben des 19. Jahrhunderts, Berlin 1912.

Gurlitt, Louis 1940

Louis Gurlitt: Jugenderinnerungen, Sonderdruck des Hamburger Anzeigers, Hamburg 1940.

Häder 1999

Ulf Häder: Der Jungbrunnen für die Malerei. Holland und die deutsche Kunst am Vorabend der Moderne 1850-1900, Jena 1999. 
Härtl-Kasulke 1991

Claudia Härtl-Kasulke: Karl Theodor Piloty (1826-1886). Karl Theodor Pilotys Weg zur Historienmalerei 1826-1855 (mit einem kommentierten Katalog seiner Historienbilder), München 1991.

Hahn/Werner 1975

Karin Hahn, Friederike Werner: Elisabeth von Thüringen, in: Lexikon der christlichen Ikonographie 1968-1976 (siehe dort), Bd. 6, 1974, Sp. 133-140.

Hansky 1994

Sabine Hansky: Die Internationale Kunstausstellung von 1869 in München. Die französische Malerei in der zeitgenössischen Pressekritik, München 1994.

Haskell/Penny 1981

Francis Haskell, Nicholas Penny: Taste and the Antique. The Lure of Classical Sculpture, 1500-1900, New Haven 1981.

Haupt/Weysser 1890

Richard Haupt, Friedrich Weysser: Die Bau-und Kunstdenkmäler im Kreise Herzogtum Lauenburg, Ratzeburg 1890.

Haussherr 1984

Reiner Haussherr: Convenevolezza. Historische Angemessenheit in der Darstellung von Kostüm und Schauplatz seit der Spätantike bis ins 16. Jahrhundert, Wiesbaden 1984 (= Akademie der Wissenschaften und der Literatur Mainz. Abhandlungen der Geistes- und sozialwissenschaftlichen Klasse, Jahrgang 1984, Nr. 4).

Hederich 1996 [1770]

Benjamin Hederich: Gründliches mythologisches Lexikon, Reprint der Ausgabe Leipzig 1770, Darmstadt 1996.

Hegel 1986 [1835-38], Georg Wilhelm Friedrich Hegel: Vorlesungen über die Ästhetik I-III, Frankfurt a. M. 1986 (= Georg Wilhelm Friedrich Hegel, Werke, Bd. 13-15).

Held 2001

Jutta Held: Französische Kunsttheorie des 17. Jahrhunderts und der absolutistische Staat. Le Brun und die ersten acht Vorlesungen an der königlichen Akademie, Berlin 2001.

Hermanssen/Roussell/Steenberg 1945-1959

Victor Hermanssen, Aage Roussell, Jan Steenberg: Danmarks Kirker. Udgivet af Nationalmuseet: København, Bd. 1, Kopenhagen 1945-1959.

Heß/Agazzi/Décultot 2012

Gilbert Heß, Elena Agazzi, Elisabeth Décultot (Hg.): Raffael als Paradigma. Rezeption, Imagination und Kult im 19. Jahrhundert, Berlin, Boston 2012 (= Klassizistisch- 
romantische Kunst(t)räume. Imaginationen im Europa des 19. Jahrhunderts und ihr Beitrag zur kulturellen Identitätstiftung, Bd. 2).

Hess/Hirschfelder 2010

Daniel Hess, Dagmar Hirschfelder (Hg.): Renaissance, Barock, Aufklärung. Kunst und Kultur vom 16. bis zum 18. Jahrhundert, Nürnberg 2010.

Hirschfelder 2008

Dagmar Hirschfelder: Tronie und Porträt in der niederländischen Malerei des 17. Jahrhunderts, Berlin 2008.

Hirschfelder 2010a

Dagmar Hirschfelder: Repräsentation und Memoria: Bildnisse des 16. und 17. Jahrhunderts, in: Hess/Hirschfelder 2010 (siehe dort), S. 304-219.

Hirschfelder 2010b

Dagmar Hirschfelder: Bildnis und Individuum im Zeitalter der Aufklärung, in:

Hess/Hirschfelder 2010 (siehe dort), S. 362-373.

Hölderlin 1922 [1798-1800]

Friedrich Hölderlin. Sämtliche Werke. Historisch-kritische Ausgabe besorgt durch Ludwig von Pigenot, Bd. 3: Gedichte. Empedokles. Philosophische Fragmente. Briefe 1798-1800, Berlin 1922.

Hölter 1993

Achim Hölter: Zwischen zwei Welten: Giovan Domenico Fiorillo. Mitbegründer der deutschen Kunstgeschichte in: Ausst.-Kat. Hildesheim 1993 (siehe dort), S. 18-31.

Hölter 2004

Achim Hölter: Fiorillo, Giovanni Domenico (Johann Dominicus Justinus Augustus), in:

Saur Allgemeines Künstlerlexikon 1992 ff. (siehe dort), Bd. 40, 2004, S. 233 f.

\section{Hoffmann 1980}

Helga Hoffmann: Die Fresken Moritz von Schwinds auf der Wartburg, Berlin 1980.

Hoffmann-Fallersleben 1908/09

Franz Hoffmann-Fallersleben: Karl Buchholz - Persönliche Erinnerungen von F. Hoffmann-Fallersleben, in: Der Türmer. Monatsschrift für Gemüt und Geist, 11, 1908/09, Bd. I., Oktober 1908-März 1909, S. 573-578.

Holland 1896

Hyacinth Holland: Voltz, Friedrich, in: Allgemeine deutsche Biographie 1875-1912 (siehe dort), Bd. 40, 1896, S. 276-280.

Honisch 1977

Dieter Honisch: Der „Fall Böcklin“, in: Ausst.-Kat. Darmstadt 1977 (siehe dort), S. 14-23. 
Horn 2003

Klaus-Peter Horn: Erziehungswissenschaft in Deutschland im 20. Jahrhundert, Rieden 2003.

Huber 1979

Judith Huber: Zwei Bozzetti des Francesco Podesti zu den Fresken in der Basilika San Paolo fuori le Mura in Rom, in: Niederdeutsche Beiträge zur Kunstgeschichte 18, 1979.

Hütt 1955

Wolfgang Hütt: Das Genrebild, Dresden 1955.

Igelsheimer 1844

Ludwig Igelsheimer: Die belgischen Bilder. Eine Parallele mit der Münchner Schule, in: Jahrbücher der Gegenwart 2, 1844, S. 24-44.

Immel 1967

Ute Immel: Die deutsche Genremalerei im 19. Jahrhundert, Phil. Diss. Universität Heidelberg 1967.

Jahn/Lieb 2008

Wörterbuch der Kunst. Begründet von Johannes Jahn, fortgeführt von Stefanie Lieb, 13. vollst. überarbeitete u. ergänzte Auflage mit 330 Abb., Stuttgart 2008.

Jedding 1998:

Hermann Jedding: Johann Heinrich Roos. Werke einer Pfälzer Tiermalerfamilie in den Galerien Europas, Mainz 1998.

Jenderko-Sichelschmidt 1973

Ingrid Jenderko-Sichelschmidt: Die Historienbilder Carl Friedrich Lessings. Phil. Diss. Köln 1973.

Jenderko-Sichelschmidt 1979

Ingrid Jenderko-Sichelschmidt: Die profane Historienmalerei 1826-1860, in: Ausst.-Kat. Düsseldorf 1979 (siehe dort), S. 98-111.

Jensen 1994

Robert Jensen: Marketing Modernism in Fin-de-Siècle Europe, Princeton 1994.

Jordan/Klee 1904

Max Jordan, Alexis Klee: Die Verbindung für historische Kunst 1854-1904, Denkschrift, Berlin 1904.

Justi 1797

Karl Wilhelm Justi: Elisabeth die Heilige, Landgräfin von Thüringen. Nach ihren Schicksalen und ihrem Charakter dargestellt, Zürich 1797 (Neu aufgelegt Marburg 1835). 
Kadrnoska 1983

Franz Kadrnoska: Pichler Karoline. in: Österreichisches Biographisches Lexikon 18151950, hg. v. der Österreichischen Akademie der Wissenschaften, Bd. 8, Wien 1983, S. 56 f.

Kallen 1984

Peter W. Kallen (Bearb.): Museum für Kunst und Kulturgeschichte der Hansestadt Lübeck: Niederländische Malerei des 17. Jahrhunderts (= Lübecker Museumskataloge, hg. v. Wulf Schadendorf, Bd. 2, Heft 2), Lübeck 1984.

Kammel 2008

Frank Matthias Kammel: Von Schlitten und vom Schlittenfahren. Beiträge zu einem kulturgeschichtlichen Forschungsfeld, in: Anzeiger des Germanischen Nationalmuseums 2008, S. 109-127.

Kanz 1993

Roland Kanz: Dichter und Denker im Porträt. Spurengänge zur deutschen Porträtkultur des 18. Jahrhunderts, München 1993.

Kanz 1998

Roland Kanz: Die Einheit des Charakters. Das Seelenhafte, Symbolische und Charakteristische in der Porträt-Ästhetik der Romantik, in: Zeitschrift für Ästhektik und Allgemeine Kunstwissenschaft 43/2, 1998, S. 223-268.

Kemperdick 2006

Stephan Kemperdick: Die Gestalt des Menschen nach ihrem Tod bewahren. Bildnismalerei des 15. und 16. Jahrhunderts in Deutschland, Frankreich und den Niederlanden, in: Ausst.Kat. Basel 2006 (siehe dort), S. 19-37.

Kepetzis 2009

Ekaterini Kepetzis: Vergegenwärtigte Antike. Studien zur Gattungsüberschreitung in der französischen und englischen Malerei (1840-1914), Frankfurt a. M., Berlin, Bern u. a. 2009.

Kestner 1850

August Kestner: Römische Studien, Berlin 1850.

Kißling 2000a

Eckart Kißling: Der Landschaftsmaler Karl Buchholz - sein Leben und sein Werk, in: Ausst.-Kat. Lübeck 2000, S. 9-23.

Kißling 2000b

Eckart Kißling: Gemälde, Ölstudien, in: Ausst.-Kat. Lübeck 2000, S. 114-128.

Klose/Martius 1975

Olaf Klose, Lilli Martius: Skandinavische Landschaftsbilder. Deutsche Künstlerreisen von 1780 bis 1864, Neumünster 1975 (= Studien zur schleswig-holsteinischen Kunstgeschichte Bd. 13). 
König/Schön 1996

Eberhard König, Christiane Schön (Hg.): Stilleben, Berlin 1996.

Koerner 1998

Joseph Leo Koerner: Caspar David Friedrich. Landschaft und Subjekt. Aus dem Englischen von Christiane Spelsberg, München 1998.

Körner 2011

Hans Körner: „Unsichtbare Malerei“. Reflexion und Sentimentalität in Bildern der Düsseldorfer Malerschule, Düsseldorf 2011 (= Kunst in Düsseldorf, hg. v. Kreis der Freunde des Instituts für Kunstgeschichte der Heinrich-Heine-Universität Düsseldorf, Bd. 1).

Kohle 2001

Hubertus Kohle: Adolph Menzels Friedrich-Bilder. Theorie und Praxis der Geschichtsmalerei im Berlin der 1850er Jahre, München, Berlin 2001.

Kopp 2005

Robert Kopp: Die unauslotbaren Höllenkreise der Trauer. Erscheinungsformen der romantischen Melancholie von Chateaubriand bis Sartre, in: Ausst.-Kat. Paris 2005 (siehe dort), S. 328-341.

Koschnick 1985

Leonore Koschnick: Franz Kugler (1808-1858) als Kunstkritiker und Kulturpolitiker, Phil. Diss. (Masch.), Berlin 1985.

Koselleck 1989

Reinhart Koselleck: Historia Magistra Vitae. Über die Auflösung des Topos im Horizont neuzeitlich bewegter Geschichte, in: Ders.: Vergangene Zukunft. Zur Semantik geschichtlicher Zeiten, Frankfurt a. M. 1989, S. 38-65.

Krüger 2007

Matthias Krüger: Das Relief der Farbe. Pastose Malerei in der französischen Kunstkritik 1850-1890, München, Berlin 2007.

Lacher 2005a

Reimar F. Lacher: Friedrich Georg Weitsch (Braunschweig 1758 - 1828 Berlin). Maler, Kenner, Akademiker, Berlin 2005.

Lacher 2005b

Reimar F. Lacher: Künstlerbiografien in Berliner Klassik. Eine Großstadtkultur um 1800/Online- Dokumente, Berlin-Brandenburgische Akademie der Wissenschaften 2005, http://www.berliner_klassik.de/berliner_klassik/projekte/forschung/werkvertraege/lache r_autobiografien/autobiografien.html (eingesehen am 15.10.2011).

Lammel 1995

Gisold Lammel: Preußens Künstlerrepublik von Blechen bis Liebermann. Berliner Realisten des 19. Jahrhunderts, Berlin 1995. 


\section{Leeuw 1997}

Ronald de Leeuw: Die Darstellung der Landschaft im 18. und 19. Jahrhundert, in: Wiepke Loos, Robert-Jan te Rijdt, Marjan van Heteren (Hg.): Niederländische Landschaftsmaler. Meisterwerke des 18. und 19. Jahrhunderts, Stuttgart, Zürich 1997, S. 11-36.

Lehr 1924

Fritz Herbert Lehr: Die Blütezeit romantischer Bildkunst. Franz Pforr der Meister des Lukasbundes. Mit einem Anhang bisher unveröffentlichter Manuskripte romantischer Maler u. Zeichner Pforr, Overbeck, Cornelius u.a., Marburg 1924.

Lemaire 2000

Gérard-Georges Lemaire: Orientalismus. Das Bild des Morgenlandes in der Malerei, Köln 2005.

Leonardo 1909 [um 1500]

Leonardo da Vinci: Traktat von der Malerei. Nach der Übersetzung von Heinrich Ludwig neu hg. u. eingeleitet von Marie Herzfeld, Jena 1909.

Leuschner 1979

Vera Leuschner: Der Landschafts- und Historienmaler Carl Friedrich Lessing (1808-80), in: Ausst.-Kat. Düsseldorf 1979 (siehe dort), S. 86-97.

Leuschner 1981

Vera Leuschner: Der Kanzelaltar von Carl Oesterley in der Pfarrkirche St. Johannis in Rosdorf 1843-1851, in: Niederdeutsche Beiträge zur Kunstgeschichte, Bd. 20, Berlin 1981, S. 177-212.

Leuschner 1982

Vera Leuschner: Carl Friedrich Lessing 1808-1880. Die Handzeichnungen, 2 Bde., Köln, Wien 1982.

Levin, J. 1887

Julius Levin: Ueber moderne Malerei, in: Die Gegenwart. Wochenschrift für Literatur, Kunst und öffentliches Leben, 32, 1887, S. 55-57.

Levin, M. 2011

Mai Levin: Düsseldorf - Estland. Die Modernisierungsbewegung in der religiösen Kunst um 1900 in: Ausst.-Kat. Düsseldorf 2011 (siehe dort), Bd. 1, S. 241-249.

Lexikon der christlichen Ikonographie 1968-1976

Lexikon der christlichen Ikonographie, hg. v. Engelbert Kirschbaum SJ (Bd. 1-4) u. Wolfgang Braunfels (Bd. 5-8), 8 Bde., Freiburg i. Br. 1968-1976.

Lexikon der Kunst 1987-1994

Lexikon der Kunst. Architektur, Bildende Kunst, Angewandte Kunst, Industrieformgestaltung, Kunsttheorie, 7 Bde., Leipzig 1987-1994. 
Liber 1834

F. Liber: Kunstvereine, in: Kunstblatt 15, 1834, S. 381-383.

Lichtenberg 1998 a

Cordula Lichtenberg: Friedrich August Kessler (Keßler), in: Paffrath 1997/98 (siehe dort), Bd. 2, S. 227 f.

Lichtenberg $1998 \mathrm{~b}$

Cordula Lichtenberg: Johann Wilhelm Schirmer, in: Paffrath 1997/98 (siehe dort), Bd. 3, S. 204-207.

Lichtwark 1883

Alfred Lichtwark: Kunstausstellungen. Frühjahrsausstellung bei Gurlitt; Janssens ,Erziehung des Bacchus‘. In: Die Gegenwart. Wochenschrift für Literatur, Kunst und öffentliches Leben, 23, 1883, S. 221 f.

Lichtwark 1893

Alfred Lichtwark: Herrmann Kauffmann und die Kunst in Hamburg von 1800-1850, München 1893 (= Der Kunstverein Hamburg seinen Mitgliedern für 1891-1892).

Linnebach 1991

Andrea Linnebach: Arnold Böcklin und die Antike. Mythos - Geschichte - Gegenwart, München 1991.

List 1993

Claudia List: Tiere. Gestalt und Bedeutung in der Kunst, Stuttgart, u. a. 1993.

Locher 2005

Hubert Locher: Deutsche Malerei im 19. Jahrhundert, Darmstadt 2005.

Ludwig 1981-1983

Horst Ludwig (Hg.): Münchner Maler im 19. Jahrhundert, 4 Bde., München 1981-1983

(= Bruckmanns Lexikon der Münchner Kunst).

Ludwig 1982b

Horst Ludwig: Karl Adam Heinisch, in: Ludwig 1981-1983 (siehe dort), Bd. 2, S. 136.

Ludwig 2006

Horst G. Ludwig: Amerikaner in Oberbayern. Junge Maler aus der Neuen Welt machen den Klosterort Polling zum „American Village“, in: Weltkunst 76, 2006, S. 22-24.

Luh 2001

Jürgen Luh: Die Religionspolitik Friedrichs III./I., in: Ausst.-Kat. Berlin 2001b (siehe dort), Bd. 2, S. 156-164.

M. 1867

M. Die Triumphierende Union, in: Illustrirte Zeitung 49, 1867, S. 372. 
M. R. 1869

M. R.: Ein glücklicher Künstler, in: Die Gartenlaube 23, 1869, S. 815.

Mai 1979

Ekkehard Mai: Die Düsseldorfer Malerschule und die Malerei des 19. Jahrhunderts, in: Ausst.-Kat. Düsseldorf 1979 (siehe dort), S. 19-40.

Mai 1990a

Ekkehard Mai (Hg.): Historienmalerei in Europa. Paradigmen in Form, Funktion und Ideologie, Mainz 1990.

Mai 1990b

Ekkehard Mai: Poussin, Félibien und Le Brun. Zur Formierung der französischen Historienmalerei an der Académie Royale de Peinture et de Sculpture in Paris, in: Mai 1990a (siehe dort), S. 9-25.

Mai 1994

Ekkehard Mai: Landschaft zwischen Natur, Mythos und Ideal. Zur deutschen Land-

schaftsmalerei im 19. Jahrhundert, in: Ausst.-Kat. Karlsruhe 1994 (siehe dort), S. 95-111.

Mai 2010

Ekkehard Mai: Die deutschen Kunstakademien im 19. Jahrhundert. Künstlerausbildung zwischen Tradition und Avantgarde, Köln, Weimar, Wien 2010.

Mai 2011

Ekkehard Mai: Schadows Erfolgsmodell. Die Düsseldorfer Kunstakademie im Vergleich, in: Ausst.-Kat. Düsseldorf 2011 (siehe dort), Bd. 1, S. 51-61.

Mai 2012

Ekkehard Mai: Düsseldorfer Genremalerei - Lebenswelten der „Kleinhistorie“, in: Ausst.Kat. Kronenburg/Eifel 2012 (siehe dort), S. 25-39.

Marggraff 1839

Rudolf Marggraff: Die Zerstörung Sodom's von Bonaventura Genelli, in: Münchner Jahrbuch für bildende Kunst 2, 1839, S. 192-198.

Marggraff 1840

Rudolf Marggraff: Über die neue enkaustische Malerei in München und deren Stellung zu anderen Ausübungsarten der Malerei in älterer und neuerer Zeit. Ein Beitrag zur Geschichte der Malertechnik unserer Tage, in: Münchner Jahrbuch für bildende Kunst, 3. Heft, 1840, S. 225-265.

Maurenbrecher 1828

Romeo Maurenbrecher: Gemäldeausstellung in Düsseldorf im August 1828, in: Kunstblatt 9, 1828, S. 321-324, 328, $331 \mathrm{f}$. 
Mauß 1969

Martina Mauß: Christian E. B. Morgenstern 1807-67. Ein Beitrag zur Landschaftsmalerei der ersten Hälfte des 19. Jh., Phil. Diss. Universität Marburg 1969.

Mayer 1998

Hubert Mayer: Die Künstlerfamilie Winterhalter. Ein Briefwechsel, Karlsruhe 1998.

Meier-Graefe 1904

Julius Meier-Graefe: Entwickelungsgeschichte der modernen Kunst. Vergleichende Betrachtung der bildenden Künste, als Beitrag zu einer neuen Ästhetik, 3 Bde., Stuttgart 1904.

Meier-Graefe 1905

Julius Meier-Graefe: Der Fall Böcklin und die Lehre von den Einheiten. Stuttgart 1905.

Menke-Schwinghammer 1994

Annemarie Menke-Schwinghammer: Weltgeschichte als ,Nationalepos‘. Wilhelm von Kaulbachs kulturhistorischer Zyklus im Treppenhaus des Neuen Museums in Berlin, Berlin 1994.

Mertens 1994

Veronika Mertens: Die drei Grazien. Studien zu einem Bildmotiv in der Kunst der Frühen Neuzeit, Wiesbaden 1994.

Metken 1977

Günter Metken: Rom, der Kirchenstaat, Italien - Nazarener und Puristen im Klima der Restauration in: Ausst.-Kat. Frankfurt a. M. 1977 (siehe dort), S. 327-335.

Meyer 1798

Johann Heinrich Meyer: Ueber die Gegenstände der bildenden Kunst. In: Propyläen. Eine periodische Schrifft, herausgegeben von Goethe, 1, 1798, Erstes Stück, S. 20-54, Zweites Stück, S. 45-81.

Middeldorf Kosegarten 1997

Antje Middeldorf Kosegarten (Hg.): Johann Dominicus Fiorillo. Kunstgeschichte und die romantische Bewegung um 1800. Akten des Kolloquiums ,Johann Dominicus Fiorillo und die Anfänge der Kunstgeschichte in Göttingen“ am Kunstgeschichtlichen Seminar und der Kunstsammlung der Universität Göttingen vom 11. - 13. November 1994, Göttingen 1997.

Mittlmeier 1977

Werner Mittlmeier: Die Neue Pinakothek in München 1843-1854. Planung, Baugeschichte und Fresken. Mit einem Beitrag über die Sammlung Ludwigs I. von Christoph H. Heilmann, München 1977 (= Studien zur Kunst des neunzehnten Jahrhunderts, Bd. 16).

Moffett 1973

Kenworth Moffett: Meier-Graefe as art critic, München 1973 (= Studien zur Kunst des neunzehnten Jahrhunderts, Bd. 19). 
Monrad 2000

Kasper Monrad: Blick durch drei Bögen. Deutsch-dänische Künstlerbegegnungen in

Dänemark, Deutschland und Italien, in: Ausst.-Kat. Hamburg 2000 (siehe dort), S. 2-11.

Monschau-Schmittmann 1993

Birgid Monschau-Schmittmann: Julius Hübner (1806-1882). Leben und Werk eines Malers der Spätromantik, Münster, Hamburg 1993 (= Bonner Studien zur Kunstgeschichte,

Bd. 7).

Montaiglon 1875

Anatole de Montaiglon: Procès-verbaux de l'académie royale de peinture et de sculpture 1648-1792, Paris 1875.

Montalembert 1836

Charles de Montalembert: Histoire de Sainte Elisabeth de Hongrie, Duchesse de Thuringe: (1207-1231), Paris 1836.

Müller von Königswinter 1854

Wolfgang Müller von Königswinter: Düsseldorfer Künstler aus den letzten fünfundzwanzig Jahren. Kunstgeschichtliche Briefe von Wolfgang Müller von Königswinter, Leipzig 1854.

Müllerschön/Maier 2010

Bernd Müllerschön, Thomas Maier: Zurück zur Natur. Die Maler von Barbizon und die neue „paysage intime“, in: Ausst.-Kat. Weimar 2010 (siehe dort), S. 29-35.

Muhr 2006

Stefanie Muhr: Der Effekt des Realen. Die historische Genremalerei des 19. Jahrhunderts, Köln 2006.

Muther 1893

Richard Muther: Geschichte der Malerei des XIX. Jahrhunderts, 2 Bde., München 1893.

Nachtsheim 1984

Stephan Nachtsheim: Kunstphilosophie und empirische Kunstforschung 1870-1920, Berlin 1984 (= Kunst, Kultur und Politik im Deutschen Kaiserreich. Schriften eines ProjektKreises der Fritz-Thyssen-Stiftung, Bd. 7).

Nagler 1835-1852

Georg Kaspar Nagler (Bearb.): Neues allgemeines Künstlerlexikon, 35 Bde., Leipzig 18351852.

Neidhardt 1991

Hans Joachim Neidhardt: Ludwig Richter, Leipzig 1991.

Neidhardt 2003

Hans Joachim Neidhardt: Deutsche Malerei des 19. Jahrhunderts, Wien 2003. 
Noll 2012

Thomas Noll: „Das fast allen Menschen beywohnende Wohlgefallen an schoenen Aussichten“. Zur Theorie der Landschaftsmalerei um 1800, in: Noll/Stobbe/Scholl 2012 (siehe dort), S. 27-59.

Noll/Stobbe/Scholl 2012

Thomas Noll, Urte Stobbe, Christian Scholl (Hg.): Landschaft um 1800. Aspekte der Wahrnehmung in Kunst, Literatur, Musik und Naturwissenschaft, Göttingen 2012.

Noll/Stobbe/Scholl 2012b

Thomas Noll, Urte Stobbe, Christian Scholl: Landschaftswahrnehmung um 1800. Imaginations- und mediengeschichtliche Kontinuitäten und Brüche, in: Noll/Stobbe/Scholl 2012 (siehe dort), S. 9-26.

Oberhuber 1997

Konrad Oberhuber (Hg.): Die deutschen und Schweizer Zeichnungen des späten 18. Jahrhunderts, Wien 1997 (= Katalog der Handzeichnungen in der graphischen Sammlung Albertina, Bd. 9).

Oberhuber 1999

Konrad Oberhuber: Raffael - Das malerische Werk, München 1999.

Obermeier 1993

Manuela Obermeier: Das industrielle Auftraggeberbild in seiner Funktion als Ideologieträger am Beispiel von Paul Meyerheims Zyklus „Lebensgeschichte einer Lokomotive“, Berlin 1993.

Oppenheim 1876

Alphons Oppenheim: Crell, Lorenz von, in: Allgemeine deutsche Biographie 1875-1912 (siehe dort), Bd. 4, Leipzig 1876, S. 587 f.

Overdick 2007

Michael Overdick: Zwischen Almosenwunder und Rosenwunder. Zur Darstellung der Heiligen Elisabeth in der populären Druckgraphik des 19. Jahrhunderts, in: Ausst.-Kat. Eisenach 2007 (siehe dort), Bd. 2, S. 539-545.

Ovid 1952

Publius Ovidius Naso: Metamorphosen. In deutsche Hexameter übertragen und mit dem Text herausgegeben von Erich Rösch, München 1952.

Paatz 1976

Elisabeth Paatz, geb. Valentiner (Hg.): Lebensbilder aus der Familie Valentiner. Zwischen 1830 und 1970, Heidelberg 1976.

Paffrath 1997/98

Hans Paffrath (Hg.): Lexikon der Düsseldorfer Malerschule 1819-1918, Bd. 1, München 1997, Bd. 2+3, München 1998. 
Pagel 1905

Julius Pagel: Henle, Friedrich Gustav Jacob H., in: Allgemeine deutsche Biographie 1875-

1912 (siehe dort), Bd. 50, Leipzig 1905, S. 190 f.

Panter 1996

Armin Panter: Studien zu Franz Xaver Winterhalter, Karlsruhe 1996.

Partsch 1999

Susanna Partsch: Correggio, Josef, in: Saur Allgemeines Künstlerlexikon 1992 ff. (siehe dort), Bd. 21, 1999, S. 315.

Pauli 1927

Gustav Pauli: Einleitung, in: Kunsthalle zu Hamburg: Katalog der neueren Meister, 2. Auflage, Hamburg 1927, S. III-X.

Pecht 1877

Friedrich Pecht: Ludwig Knaus, in: Ders.: Deutsche Künstler des neunzehnten Jahrhunderts. Studien und Erinnerungen, Erste Reihe, Nördlingen 1877, S. 124-148.

Pecht 1884

Friedrich Pecht: Die deutsche Historienmalerei der Zukunft, in: Die Gegenwart. Wochenschrift für Literatur, Kunst und öffentliches Leben 26, 1884, S. 361-364.

Pecht 1888

Friedrich Pecht: Geschichte der Münchner Kunst im 19. Jahrhundert, München 1888.

Peer 2007

Peter Peer: Zur Natur des Menschen. Gedanken zur Entwicklung der Genremalerei im 19. Jahrhundert, in: Ausst.-Kat. Graz 2007 (siehe dort), S. 30-45.

Pérard 1930

Rudolf Pérard: Bernhard Fries. Ein Maler des Uebergangs im neunzehnten Jahrhunderts, in seinem Leben und künstlerischen Werk, Darmstadt 1930.

Pichler 1822

Caroline Pichler: Sämtliche Werke, Bd. 16, Wien 1822.

Pickartz 2012

Christiane Pickartz: Henry (Heinrich) Ritter, in: Ausst.-Kat. Kronenburg/Eifel 2012 (siehe dort), S. 166-169.

Pietsch 1881

Ludwig Pietsch: Paul Meyerheim, in: Nord und Süd. Eine deutsche Monatsschrift, 16, 1881, S. 198-211.

Piles 1699

Roger de Piles: Abregé de la vie des peintres, Paris 1699. 
Plaul 2011

Constantin Plaul: Die Imagination vollkommener Bildung. Schleiermachers frühromantische Idee einer zukünftigen Kunstreligion in: Manfred Lang (Hg.): Worte und Bilder. Beiträge zur Theologie, Christlichen Archäologie und Kirchlichen Kunst, Leipzig 2011, S. 187207.

Plischke 1937

Hans Plischke: Johann Friedrich Blumenbachs Einfluß auf die Entdeckungsreisenden seiner Zeit, Göttingen 1937 (= Abhandlungen der Gesellschaft der Wissenschaften zu Göttingen, Philologisch-historische Klasse, 3. F., Nr. 20).

Poeschke 1972

Joachim Poeschke: Segen, in: Lexikon der christlichen Ikonographie 1968-1976 (siehe dort), Bd. 4, 1972, Sp. 145 f.

Pomarède 2005

Vincent Pomarède: Die Lust an der Melancholie. Die Landschaft als Zustand der Seele, in: Ausst.-Kat.Paris 2005 (siehe dort), S. 318-327.

Powell 1995

Cecilia Powell: Entlang der Donau nach Wien 1833, in: Ausst.-Kat. Mannheim 1995 (siehe dort), S. 45-56.

Preimesberger/Baader/Suthor 1999

Rudolf Preimesberger, Hannah Baader, Nicola Suthor (Hg.): Porträt, Berlin 1999

(= Geschichte der klassischen Bildgattungen in Quellentexten und Kommentaren, Bd. 2).

Prochazka 1981

Edith Prochazka: Correggio, Joseph, in: Ludwig 1981-1983 (siehe dort), Bd. 1, S. 191 f.

Raczynski 1836

Athanasius Graf Raczynski: Geschichte der neueren deutschen Kunst, Bd. 1: Düsseldorf und das Rheinland. Mit einem Anhange: Ausflug nach Paris, Berlin 1836.

Radziewski 1983

Elke von Radziewsky: Kunstkritik im Vormärz. Dargestellt am Beispiel der Düsseldorfer Malerschule, Bochum 1983 (= Bochumer Studien zur Publizistik und Kommunikationswissenschaft, Bd. 36).

Rahman 1999

Samina Rahman: Heidelbergansichten von Georg August Wallis und Ernst Fries, in: Fuchs/Himmelheber 1999 (siehe dort), S. 23-36.

Ratzel 1883a

Friedrich Ratzel: Langsdorff, Georg Heinrich Freiherr von, in: Allgemeine deutsche Biographie 1875-1912 (siehe dort), Bd. 17, 1883, S. 689 f. 


\section{Ratzel 1883b}

Friedrich Ratzel: Krusenstern, Adam Johann von, in: Allgemeine deutsche Biographie 1875-1912 (siehe dort), Bd. 17, 1883, S. 270-274.

Rave 1948

Paul Ortwin Rave: Bildnis, in: Reallexikon zur deutschen Kunstgeschichte, hg. v. Otto Schmitt, Bd. 2, Stuttgart 1948, Sp. 639-680.

\section{Reber 1876}

Franz Reber: Geschichte der neueren deutschen Kunst vom Ende des vorigen Jahrhunderts bis zur Wiener Ausstellung 1873 mit Berücksichtigung der gleichzeitigen Kunstentwicklung in Frankreich, Belgien, Holland, England, Italien und den Ostseeländern, Stuttgart 1876.

\section{Regnet 1873}

Carl Albert Regnet: Kaulbach und die moderne Kunst, in: Die Gegenwart. Wochenschrift für Literatur, Kunst und öffentliches Leben, 4, 1873, S. 13 f.

\section{Reid 1993}

James Davidson Reid: The Oxford Guide to Classical Mythology in the Arts, 1300-1990s, 2. Bde., Oxford 1993.

\section{Reinhold 1934}

H. Reinhold: Reinhold, Friedrich Philipp, in: Thieme/Becker 1907-1950 (siehe dort), Bd. 28, 1934, S. 130 f.

\section{Reitzel 1883}

Carl Reitzel: Fortegnelse over Danske Kunstneres Arbejdeer paa de ved det Kgl. Akademie i Aarene 1807-1882 afholdte Charlottenburg-Udstillinger, Kopenhagen 1883.

\section{Richter 1895}

Adrian Ludwig Richter: Lebenserinnerungen eines deutschen Malers. Selbstbiographie nebst Tagebuchniederschriften und Briefen, hg. v. Heinrich Richter, 8. Aufl., Frankfurt a. M. 1895.

Ricke-Immel 1996

Ute Ricke-Immel: Die Verklärung des Alltäglichen. Zum Genrebild im 19. Jahrhundert, in: Ausst.-Kat. Düsseldorf 1996 (siehe dort), S. 9-15.

Riedl 1980

Peter Anselm Riedl: Walter Paatz (gest. am 2. Nov. 1978), in: Zeitschrift für Kunstgeschichte 43, 1980, S. 115-117.

\section{Rödiger-Diruf 1998}

Erika Rödiger-Diruf: Sehnsucht nach Natur. Zur Entwicklungsgeschichte der Künstlerkolonien im 19. Jahrhundert, in: Ausst.-Kat. Karlsruhe 1998 (siehe dort), S. 39-70. 
Rosenberg 1889

Adolf von Rosenberg: Aus Berliner Kunstausstellungen, in: Kunstchronik 24, 1889, Sp. 421-425

Rosenberg 1899

Adolf von Rosenberg: Eduard von Gebhardt, Bielefeld 1899.

Rosenberg 1910

Adolf Rosenberg: Friedrich August von Kaulbach, Bielefeld, Leipzig 1910 (= Knackfuß

Künstler-Monographien, Bd. 48).

Rossner 2006

Christiane Rossner: Der Bürger und die Denkmalkultur, in: Monumente. Magazin für

Denkmalkultur in Deutschland, 16, 2006, Nr. 11/12 (Dezember 2006), S. 54-57.

Rott 2003

Herbert W. Rott (Hg.): Ludwig I. und die Neue Pinakothek, Köln 2003.

Rott 2009

Herbert W. Rott: Sammlung Schack. Katalog der ausgestellten Gemälde, hg. v. den Bayerischen Staatsgemäldesammlungen, München, Ostfidern 2009.

Rousseau 1997 [1750]

Jean Jacques Rousseau: Abhandlung, welche bey der Akademie zu Dijon im Jahr 1750 den Preis über folgende von der Akademie vorgelegte Frage davongetragen hat: Ob die Wiederherstellung der Wissenschaften und Künste etwas zur Läuterung der Sitten beygetragen hat?, hg. v. Ralf Konersmann u. Gesine Märtens, St. Ingbert 1997 (= Kleines Archiv des 18. Jahrhunderts Bd. 28).

Rudloff 1977

Martina Rudloff: Rumohr und die Folgen. Zu den Bremer Ölskizzen Friedrich Nerlys, in: Niederdeutsche Beiträge zur Kunstgeschichte 16, 1977, S. 93-109.

Ruge 1838

Arnold Ruge: Die diesjährige hallische Kunstausstellung, in: Hallische Jahrbücher für deutsche Wissenschaft und Kunst 1, 1838, Sp. 1385-1388, 1393-1398.

Ruh 2008

Ulrich Ruh: Bleibende Ambivalenz. Säkularisierung/Säkularisation als geistesgeschichtliche Interpretationskategorie in: Silvio Vietta. Herbert Uerlings (Hg.): Ästhetik - Religion Säkularisierung, Bd. 1: Von der Renaissance zur Romantik, München 2008, S. 25-36.

Ruhmer 1984

Eberhard Ruhmer: Der Leibl-Kreis und die Reine Malerei, Rosenheim 1984.

Rumohr 1821 
Carl Friedrich von Rumohr: Rezension zu: Johann Dominik Fiorillo. Blick auf den gegenwärtigen Zustand der Malerey, besonders bey den Deutschen in: Kunstblatt 2, 1821, S. 201-203, 205-207, 210-212.

Runge 1965 [1840-41]

Philipp Otto Runge: Hinterlassene Schriften, 2 Bde., Göttingen 1965.

S. 1862

S.: Biblische Landschaften, in: Christliches Kunstblatt 1862, S. 13-16.

Saur Allgemeines Künstlerlexikon 1992 ff.

Saur Allgemeines Künstlerlexikon: Die bildenden Künstler aller Zeiten und Völker, München 1992 ff.

Schadow 1987 [1849]

Johann Gottfried Schadow: Kunstwerke und Kunstansichten. Ein Quellenwerk zur Berliner Kunst- und Kulturgeschichte zwischen 1780 und 1845, Kommentierte Neuausgabe von 1849, hg. v. Götz Eckardt, 3 Bde., Berlin 1987.

Schäfer-Richter/Klein 1992

Uta Schäfer-Richter, Jörg Klein: Die jüdischen Bürger im Kreis Göttingen 1933-1945:

Göttingen - Hann. Münden - Duderstadt. Ein Gedenkbuch, Göttingen 1992.

Schasler 1875

Max Schasler: Bemerkungen über Thiermalerei und Thierplastik. In: Die Dioskuren. Deutsche Kunst-Zeitung. Hauptorgan der Deutschen Kunstvereine, 20, 1875, S. 45 f., 53 f., 61 63, 153-155, $161 \mathrm{f}$.

Scheidig 1971

Walther Scheidig: Die Geschichte der Weimarer Malerschule 1860-1900, Weimar 1971.

Scheidig 1991

Walther Scheidig: Die Weimarer Malerschule 1860-1900, Leipzig 1991.

Scheidig/Müller-Krumbach 1991

Walther Scheidig, Renate Müller-Krumbach (Hg.): Die Weimarer Malerschule. 1860-1900, Leipzig 1991.

Schieder, Th. 1959

Theodor Schieder: Droysen, Johann Gustav Bernhard, in: Neue Deutsche Biographie, Bd. 4, Berlin 1959, S. 135-137.

Schieder, W. 1997

Wolfgang Schieder: Konfessionelle Erneuerung in Deutschland in: Hartmut Lehmann (Hg.): Säkularisierung, Dechristianisierung, Rechristianisierung im neuzeitlichen Europa. Bilanz und Perspektiven der Forschung, Göttingen 1997, S. 223-228. 
Schiller 2000 [1795]

Friedrich Schiller: Über die ästhetische Erziehung des Menschen in einer Reihe von

Briefen. Mit den Augustenburger Briefen, Stuttgart 2000.

Schlegel 1959 [1803]a

Friedrich Schlegel: Vom Raphael, in: Ders.: Ansichten und Ideen von der christlichen Kunst, hg. u. eingeleitet von Hans Eichner. Kritische Friedrich-Schlegel-Ausgabe, Abt. 1, Bd. 4, München, Paderborn, Wien 1959, S. 48-60.

Schlegel 1959 [1803]b

Friedrich Schlegel: Nachtrag italiänischer Gemälde, in: Ders.: Ansichten und Ideen von der christlichen Kunst, hg. u. eingeleitet von Hans Eichner. Kritische Friedrich-Schlegel-

Ausgabe, Abt. 1, Bd. 4, München, Paderborn, Wien 1959, S. 61-78.

Schleiermacher 2002 [1899]

Friedrich Schleiermacher: Über die Religion. Reden an die Gebildeten unter ihren Verächtern, in der Ausgabe von Rudolf Otto, Göttingen 2002.

Schmelzle 2012

Christoph Schmelzle: Klassizismus zwischen Renaissance und Griechenkult: Raffael als Ideal in: Heß/Agazzi/Décultot 2012 (siehe dort), S. 97-122.

Schmidt, F. A. 1824-54

Friedrich August Schmidt (Hg.): Neuer Nekrolog der Deutschen, 30 Bde., Ilmenau 18241854.

Schmidt, H.-W. 1985

Hans-Werner Schmidt: Die Förderung des vaterländischen Geschichtsbildes durch die Verbindung für historische Kunst 1854-1933, Marburg 1985.

Schneider 1992

Norbert Schneider: Porträtmalerei. Hauptwerke europäischer Bildniskunst 1420-1670, Köln 1992.

Schneider 2004

Norbert Schneider: Geschichte der Genremalerei. Die Entdeckung des Alltags in der Kunst der Frühen Neuzeit, Berlin 2004.

Schnell 1999

Werner Schnell: Die Historie als Spiegel der Gegenwart im Spiegel der Historie oder: Vom Nutzen des Historienbildes in Josef Danhausers ,Atelier mit Mäusen I‘ und anderen Atelierbildern, in: Niederdeutsche Beiträge zur Kunstgeschichte 38, 1999, S. 283-302.

Schnorr von Carolsfeld 1887

F. Schnorr von Carolsfeld: Olivier, Johann Heinrich Ferdinand, in: Allgemeine deutsche Biographie 1875-1912 (siehe dort), Bd. 24, 1887, S. 308-310. 
Schoch 1979

Rainer Schoch: Die belgischen Bilder. Ein Beitrag zum deutschen Geschichtsbild des Vormärz, in: Städel-Jahrbuch, N. F., 7, 1979, S. 171-186.

Schoch 1997

Rainer Schoch: Die „belgischen Bilder“. Zu einem Prinzipienstreit der Historienmalerei des 19. Jahrhunderts, in: Karl Möseneder (Hg.): Streit um Bilder. Von Byzanz bis Duchamp, Berlin 1997, S. 161-179.

Schoenebeck 1997

Gudrun von Schoenebeck: Becker, Friedrich. In: Paffrath 1997/98 (siehe dort), Bd. 1, S. 92.

Schöny 1983

Heinz Schöny: Reinhold, in: Österreichisches Biographisches Lexikon 1815-1950, hg. v. der Österreichischen Akademie der Wissenschaften, Bd. 8, Wien 1983, S. 46.

Scholl 2001

Christian Scholl: Caspar David Friedrich als Dichter, in: Umeni 49, 2001, S. 426-436.

Scholl 2007

Christian Scholl: Romantische Malerei als neue Sinnbildkunst. Studien zur Bedeutungsgebung bei Philipp Otto Runge, Caspar David Friedrich und den Nazarenern, München, Berlin 2007.

Scholl 2009

Christian Scholl: Publikum und Kanon im 19. Jahrhundert. Von Peter Cornelius zu Caspar David Friedrich, in: Marburger Jahrbuch für Kunstwissenschaft 36, 2009, S. 327-353.

Scholl 2011

Christian Scholl: Historisierter Klassizismus. Die Odyssee-Landschaften Friedrich Prellers d. Ä. und ihre zeitgenössische Rezeption, in: Ernst Osterkamp, Thorsten Valk (Hg.): Imagination und Evidenz. Tranformationen der Antike im ästhetischen Historismus, Berlin, Boston 2011 (= Klassik und Moderne. Schriftenreihe der Klassik Stiftung Weimar, Bd. 3), S. 101-128.

Scholl 2012a

Christian Scholl: Raffael im Vormärz. Zur Aktualität der Kunstgeschichte in den politischen und kunstkritischen Auseinandersetzungen 1830-1848, in: Heß/Agazzi/Décultot 2012 (siehe dort), S. 315-336.

Scholl 2012b

Christian Scholl: Revisionen der Romantik. Zur Rezeption der „neudeutschen Malerei“ 1817-1906, Berlin 2012. 
Scholl 2012c

Christian Scholl: Bendemanns Lehrer zeichnet: Wilhelm Schadows Vorstudie zum Gemälde ,Caritas', in: Ausst.-Kat. Göttingen 2012 (siehe dort), S. 35-44.

Scholl 2012d

Christian Scholl: Später Orientalismus: Eduard Bendemanns Gemälde „Wegführung der Juden in die Babylonische Gefangenschaft", in: Ausst.-Kat. Göttingen 2012 (siehe dort), S. 57-65.

Scholl 2013

Christian Scholl: Wahre Erben? Autonomieästhetik und Kunstpublizistik nach Johann Heinrich Meyer, in: Johannes Rößler, Alexander Rosenbaum (Hg.): Johann Heinrich Meyer - Kunst und Wissen im klassischen Weimar, Berlin, Boston 2013 (im Druck).

Schorn 1825

Ludwig Schorn: Ueber Styl und Motive in der bildenden Kunst. An Herrn Baron C. F. v. Rumohr, in: Kunstblatt 6, 1825, S. 1-4.

Schrapel 2004

Claudia Schrapel: Johann Dominicus Fiorillo: Grundlagen zur wissenschaftsgeschichtlichen Beurteilung der „Geschichte der zeichnenden Künste in Deutschland und den vereinigten Niederlanden“, Hildesheim, Zürich, New York 2004 (= Studien zur Kunstgeschichte 155).

Schubert 2008

Anselm Schubert: Christliche Klassik. Friedrich Wilhelm III. und die Anfänge der Preußischen Kirchenagende von 1822, in: Zeitschrift für Kirchengeschichte 119, 2008, S. 178202.

Schubert 2010

Anselm Schubert: Wilhelm Wachs „Allegorie. Stiftung der christlichen Kirche“ (1827). Zur politischen Karriere eines religiösen Bildes in der Restauration, in: Jahrbuch der Berliner Museen, N. F., 52, 2010, S. 117-125.

Schulte-Wülwer 1997

Ulrich Schulte-Wülwer: Louis Gurlitt - Leben und Werk, in: Ulrich Schulte-Wüwer, Bärbel Hedinger (Hg.): Louis Gurlitt. Porträts europäischer Landschaften in Gemälden und Zeichnungen, München 1997, S. 27-144.

Schulz-Hoffmann 1974

Carla Schulz-Hoffmann: Studien zur Rezeption der deutschen romantischen Malerei in Kunstliteratur und Kunstgeschichte, Phil. Diss. LMU München 1974.

Schuster 2005

Peter-Klaus Schuster: Melencolia I. Dürer und seine Nachfolger, in: Ausst.-Kat. Paris 2005 (siehe dort), S. 90-103. 
Schwarz 2004

Birgit Schwarz: Hitlers Museum, Wien 2004.

Schweizer 2007

Stefan Schweizer: Der katholische Maler und sein protestantischer Auftraggeber. Moritz von Schwinds Elisabeth-Fresken auf der Wartburg, Ausst.-Kat. Eisenach 2007, Bd. 2, S. 547-564.

Seeliger 1998

Hartmut Seeliger: Paatz, Walter, in: Neue Deutsche Biographie, Bd. 19, Berlin 1998, S. 736.

Seibert 2002

Jutta Seibert: Herders Lexikon der christlichen Kunst - Themen, Gestalten, Symbole, Erftstadt 2002.

Seidel 1988

Alma Seidel: Kirche und Schule in Stemmen, Bd. 1: Kirche 1497-1928, Teil B 1795-1928, Hannover 1988.

\section{Senf 1957}

Renate Senf: Das künstlerische Werk von Carl Oesterley, Göttingen 1957 (= Göttinger Studien zur Kunstgeschichte, Bd. 2).

Serra 1933

L. Serra: Podesti, Francesco, in: Thieme/Becker 1907-1950, (siehe dort), Bd. 27, 1933, S. 173.

Settele/Feldmann/Reinhardt 1999

Josef Settele, Reinart Feldmann, Rolf Reinhardt (Hg.): Die Tagfalter Deutschlands, Stuttgart 1999.

Sickel 2006

Lothar Sickel: Die Sammlung des Tommaso de' Cavalieri und die Provenienz der Zeichnungen Michelangelos, in: Römisches Jahrbuch der Bibliotheca Hertziana 37, 2006 (2008), S.163-221.

Siebeneicker 2001

Arnulf Siebeneicker: „Ringe, Ränder und Käntchens“. Gaertner als Lehrling und Maler der Königlichen Porzellan-Manufaktur, in: Ausst.-Kat. Berlin 2001c (siehe dort), S. 55-64.

Siegfried 1888

Carl Gustav Adolf Siegfried: Pott, David Julius, in: Allgemeine deutsche Biographie 18751912 (siehe dort), Bd. 26, 1888, S. 485 f.

Sillevis 2010

John Sillevis: Den Haag - Weimar - Barbizon. Die Haager Schule im internationalen Kontext, in: Ausst.-Kat. Weimar 2010 (siehe dort), S. 61- 74. 
Sitt 2000a

Martina Sitt: Von einem der auszog, ... aber von der Geschichte eingeholt wurde - C. F. Lessing - eine Einführung, in: Ausst.-Kat. Düsseldorf 2000 (siehe dort), S. 9-20.

Sitt 2000b

Martina Sitt: Duell an der Wand. Carl Friedrich Lessing. Die Hussiten-Gemälde, Dortmund 2000 .

Smitmans 1980

Adolf Smitmans: Die christliche Malerei im Ausgang des 19. Jahrhunderts. Theorie und Kritik. Eine Untersuchung der deutschsprachigen Periodica für christliche Kunst, 18701914, St. Augustin 1980.

Smitmans 1990

Adolf Smitmans: Künste, bildende IV. 19. und 20. Jahrhundert, in: Theologische Realenzyklopädie, Bd. 20, Berlin, New York 1990, S. 163-176.

Söntgen 2000a

Beate Söntgen: Sehen ist alles. Wilhelm Leibl und die Wahrnehmung des Realismus, München 2000 .

Söntgen 2000b

Beate Söntgen: Kein Appell an das Gemüt. Wilhelm Leibls Realismus, in: Uwe Fleckner, Martin Schieder, Michael F. Zimmermann (Hg.): Jenseits der Grenzen. Französische und deutsche Kunst vom Ancien Régime bis zur Gegenwart. Thomas W. Gaehtgens zum 60. Geburtstag, Köln 2000, Bd. 2, S. 391-400.

Spiller 1994

Monika Spiller: Becker, Friedrich, in: Saur Allgemeines Künstlerlexikon 1992 ff. (siehe dort), Bd. 8, 1994, S. 161.

Springer 1858

Anton Springer: Geschichte der bildenden Künste im neunzehnten Jahrhundert, Leipzig 1858.

Stalla 2001

Robert Stalla: „,...wird die schöne Kupferstichsammlung zweckmäßig benutzt werden...“. Die Funktion der Druckgraphik im universitären Kunstunterricht des 19. Jahrhunderts, in: Ders. (Hg.): Druckgraphik. Funktion und Form. Vorträge beim Symposium zur Ausstellung „Es muß nicht immer Rembrandt sein ... - Die Druckgraphiksammlung des Kunsthistorischen Instituts München“ vom 2. bis 3. Juli 1999, München, Berlin 2001, S. 37-47.

Stechow 1926

Wolfgang Stechow: Katalog der Gemäldesammlung der Universität Göttingen, Göttingen 1926. 
Sulzer 1792-1799

Johann Georg Sulzer: Allgemeine Theorie der schönen Künste in einzelnen, nach alphabetischer Ordnung der Kunstwörter aufeinanderfolgenden, Artikeln abgehandelt. Nachdruck der 2., vermehrten Auflage Leipzig 1792-99, 5 Bde., Hildesheim 1967.

Teichlein 1876

Anton Teichlein: Zur Charakteristik Wilhelm von Kaulbach's, in: Zeitschrift für bildende Kunst 11, 1876, S. 257-265.

Theilmann 1979

Rudolf Theilmann: Schirmer und die Düsseldorfer Landschaftsmalerei, in: Ausst.-Kat. Düsseldorf 1979 (siehe dort), S. 19-40.

Thiel 2004

Erika Thiel: Geschichte des Kostüms, Berlin 2004.

Thiel/Bruyn Kops/Cleveringa/Kloek/Vels Heijn 1976

Pieter J. J. van Tiel, C. J. de Bruyn Kops, Jola Cleveringa, Wouter Kloek, Annemarie Vels Hejn (Hg.): All the Paintings of the Rijksmuseum in Amsterdam. A Complete Illustrated Catalogue, Amsterdam 1976.

Thieme/Becker 1907-1950

Ulrich Thieme, Felix Becker (Hg.): Allgemeines Lexikon der Bildenden Künstler von der Antike bis zur Gegenwart, 37 Bde., Leipzig 1907-1950.

Thimann 2005

Michael Thimann: Vitae parallelae: Friedrich Overbeck, Tommaso Minardi und die Reflexion über das religiöse Bild im Purismo, in: Martina Hansmann, Max Seidel (Hg.): Pittura italiana nell'Ottocento, Venedig 2005, S. 255-278.

Thimann 2006

Michael Thimann: Malerei. Kinder Apolls, Söhne Mariens. Positionen deutscher Malerei zwischen Klassik und Romantik, in: Andreas Beyer (Hg.): Geschichte der bildenden Kunst in Deutschland, Bd. 6: Klassik und Romantik, München, Berlin, London, New York 2006, S. 351-438.

\section{Thomson 1991}

Erik Thomson: Eduard von Gebhardt - Leben und Werk. Aus dem Nachlaß bearb. u. mit einem Nachwort versehen von Günter Krüger, Lüneburg 1991.

Manthey/Tollmien 1999

Matthias Manthey, Cordula Tollmien: Juden in Göttingen, in: Rudolf von Thadden, Günter J. Trittel (Hg.): Göttingen. Geschichte einer Universitätsstadt, Bd. 3: Von der preußischen Mittelstadt zur südniedersächsischen Großstadt 1866-1989, Göttingen 1999, S. 675-760. 
Tremper 2001

Jörg Trempler: Das Wandbildprogramm von Karl Friedrich Schinkel, Altes Museum Berlin, Berlin 2001.

Trübner 1898

Wilhelm Trübner: Die Verwirrung der Kunstbegriffe, Frankfurt a. M. 1898.

Unverfehrt 1987

Gerd Unverfehrt (Bearb.): Kunstsammlung der Universität Göttingen. Die niederländischen Gemälde. Mit einem Verzeichnis der Bilder anderer Schulen, Göttingen 1987.

Unverfehrt 2007

Gerd Unverfehrt: Die Kunstsammlung, in: Brigitta Hauser-Schäublin, Gundolf Krüger (Hg.): Siberia and Russian America. Culture and art from the 1700s. The Asch collection Göttingen, München 2007, S. 24-26.

van Binnebeke 2008

Emile van Binnebeke: Niederländische Schlitten. Tradition, Typologie und Gebrauch, in: Anzeiger des Germanischen Nationalmuseums 2008, S. 129-151.

Vanhoeven 2000

Antje Vanhoeven: Friedrich Philipp Reinhold (1779-1840): Arkadische Landschaft, Dorfschmiede, in: Ulrike Lorenz (Hg.): Streifzüge durch die Kunstsammlung Gera. Orangerie und Otto-Dix-Haus, Gera 2000, S. 34 f.

Vietta 2008

Silvio Vietta: Einleitung, in: Silvio Vietta, Herbert Uerlings (Hg.): Ästhetik - Religion Säkularisierung, Bd. 1: Von der Renaissance zur Romantik, München 2008.

Vischer 1841

Friedrich Theodor Vischer: Der Triumph der Religion in den Künsten, von Friedrich Overbeck, in: Deutsche Jahrbücher für Wissenschaft und Kunst 1, 1841, 109-111, 113 f., 117-128.

Vischer 1842

Friedrich Theodor Vischer: Die Aquarell-Copien von Ramboux in der Gallerie zu Düsseldorf, in: Deutsche Jahrbücher für Wissenschaft und Kunst 2, 1842, S. 550-559, 841-846, 849-851, 853-855, 857-864.

Vogtherr 2001

Christoph M. Vogtherr: Die Erwerbungen Friedrich Wilhelms III. für die Berliner Museen und die königlichen Sammlungen, in: Ausst.-Kat. Berlin 2001a (siehe dort), S. 139-144.

von der Brüggen 2004

Viktoria von der Brüggen: Zwischen Ölskizze und Bild. Untersuchungen zu den Werken von John Constable, Eugène Delacroix und Adolph Menzel, Frankfurt a. M. 2004. 
Wackenroder 1991 [1797]

Wilhelm Heinrich Wackenroder: Herzergießungen eines kunstliebenden Klosterbruders, in: Ders.: Sämtliche Werke und Briefe. Historisch-kritische Ausgabe, hg. v. Silvio Vietta u.

Richard Littlejohns, Heidelberg 1991, S. 51-145.

Wähner 1833

Friedrich Wähner: Kunstverein in München, in: Kunstblatt 14, 1833, S. 229 f.

Wagner 1989

Monika Wagner: Allegorie und Geschichte. Ausstattungsprogramme öffentlicher Gebäude des 19. Jahrhunderts in Deutschland. Von der Cornelius-Schule zur Malerei der Wilhelminischen Ära, Tübingen 1989 (= Tübinger Studien zur Archäologie und Kunstgeschichte, Bd. 9).

Waldmann 1905

Emil Waldmann: Provisorischer Führer durch die Gemälde-Sammlung der Universität Göttingen, Göttingen 1905.

Wegner 2010

Reinhard Wegner: Die unvollendete Landschaft, in: Bertsch/Wegner 2010 (siehe dort), S. 437-450.

Weimarische Kunstfreunde 1999 [1817]

Weimarische Kunst Freunde: Neu-deutsche religiös-patriotische Kunst, in: Goethe: Sämtliche Werke. Briefe, Tagebücher und Gespräche, hg. von Friedmar Apel, Hendrik Birus u. a., 1. Abt., Bd. 20, Frankfurt a. M. 1999, S. 105-129.

Weis 1974

Elisabeth Weis: Johannes der Täufer, in: Lexikon der christlichen Ikonographie 1968-1976 (siehe dort), Bd. 7, 1974, Sp. 164-190.

Weiß 1998

Siegfried Weiß: Ritter, Henry (Heinrich), in: Paffrath 1997/98 (siehe dort), Bd. 3, S. 144148.

Wendermann 2010

Gerda Wendermann: Die Weimarer Malerschule im europäischen Umfeld. Eine Einführung in die Ausstellung, in: Ausst.-Kat. Weimar 2010 (siehe dort), S. 11-20.

Wendermann 2011

Gerda Wendermann: Die Entdeckung der Nähe. Die Weimarer Malerschule und das Weimarer Umland, in: Ausst.-Kat. Apolda 2011 (siehe dort), S. 15-21.

Wenzel 2008

Kai Wenzel: Johann Eleazar Zeissig gen. Schenau, in: Institut für Sächsische Geschichte und Volkskunde e.V (Hg.): Sächsische Biografie. http://saebi.isgv.de/biografie/ Johann_Eleazar_Zeissig_\%281737-1806\%29 [08.05.2012]. 
Werche 2010

Bettina Werche: Die frühe Barbizon-Rezeption in Deutschland. München 1869 und die Folgen, in: Ausst.-Kat. Weimar 2010 (siehe dort), S. 89-104.

Wesseling 1994

Klaus-Gunther Wesseling: Pott, David Julius, in: Biographisch-Bibliographisches Kirchenlexikon (BBKL). Bd. 7, Bautz, Herzberg 1994, Sp. 867 f.

Wichmann 1996

Siegfried Wichmann: Münchener Landschaftsmaler im 19. Jahrhundert. Meister, Schüler, Themen, Weyarn 1996.

Wiechers 2007

Simone Wiechers: Paul Baum (1859-1932). Entwicklung und frühe Rezeption eines Neoimpressionisten, Weimar 2007.

Wiegand 1994

Thomas Wiegand: Ferdinand Tellgmann. Gewerbsmäßiges Portraitieren in Malerei und Fotografie um 1850, Kassel 1994.

Wiese 1997

Kerstin Wiese: Louis Gurlitts Jugend und frühe Künstlerausbildung in Hamburg und Altona 1812-1832, in: Ulrich Schulte-Wüwer, Bärbel Hedinger (Hg.): Louis Gurlitt. Porträts europäischer Landschaften in Gemälden und Zeichnungen, München 1997, S. 11-26.

Wiesing 1997

Lambert Wiesing: Die Sichtbarkeit des Bildes. Geschichte und Perspektiven der formalen Ästhetik, Reinbek 1997.

Wiesing 2001

Lambert Wiesing: Formale Ästhetik nach Herbart und Zimmermann, in: Andreas Hoeschen, Lothar Schneider (Hg.): Herbarts Kultursystem. Perspektiven der Transdisziplinarität im 19. Jahrhundert, Würzburg 2001, S. 283-296.

Wild 1996

Monika von Wild: Georg August Wallis 1761-1847. Englischer Landschaftsmaler, Frankfurt a. M. 1996 (= Monographien zur bildenden Kunst, Bd. 3).

Wille 1970

Hans Wille: Kunstsammlung der Universität Göttingen 1770 bis 1970. Katalog der Neuerwerbungen aus Anlaß des zweihundertjährigen Jubiläums der Kunstsammlung, Göttingen 1970.

Wille 1972

Hans Wille: Göttinger Kostbarkeiten. Kunstsammlung der Universität. Friedrich Philipp Reinhold „Der Hirt auf der Bergspitze im Abendschein“, in: Informationszeitschrift für die Universitäts- und Kongressstadt 10. Göttingen 1972, S. 41. 
Wilton 1987

Andrew Wilton: Turner und seine Zeit, München 1987.

Winterfeld 1993

Dethard von Winterfeld: Die Kaiserdome Speyer, Mainz, Worms und ihr romanisches Umland, Würzburg 1993.

Wirth 1979

Irmgard Wirth: Eduard Gaertner. Der Berliner Architekturmaler, Frankfurt a. M., Berlin, Wien 1979.

Wolbert 2001

Klaus Wolbert: Deutsche Innerlichkeit. Die Wiederentdeckung Caspar David Friedrichs um 1900 und die Verbildlichung des reformerischen Naturverhältnisses, in: Ausst-Kat. Darmstadt 2001 (siehe dort), Bd. 2, S. 189-197.

Wolf 1995

Gunther G. Wolf: Die Wiener Reichskrone, Wien 1995 (= Schriften des Kunsthistorischen Museums, Bd. 1).

Wolff 1899

Carl Wolff (Hg.): Die Kunstdenkmäler der Provinz Hannover, Bd. 1,1, Landkreise Hannover und Linden, Hannover 1899.

Wolter 1912

Franz Wolter: Fritz August von Kaulbach, in: Die Kunst für Alle 28, 1912/13, 1. Oktober 1912, S. 1-13.

Wurzbach, A. 1906-1911

Alfred von Wurzbach (Bearb.): Niederländisches Künstlerlexikon, 3 Bde., Wien, Leipzig 1906-1911.

Wurzbach, C. v. 1856-1923

Constant von Wurzbach: Biographisches Lexikon des Kaiserthums Oesterreich, enthaltend die Lebensskizzen der denkwürdigen Personen, welche 1750 bis 1850 im Kaiserstaate und in seinen Kronländern gelebt haben, 61 Bde., Wien 1856-1923.

Zbikowski 2005

Dörte Zbikowski: Von Kopenhagen in die Welt und wieder zurück. Zur Entfaltung und Wirkung eines Kunstzentrums, in: Ausst.-Kat. Kiel 2005 (siehe dort), S. 14-28.

Ziegler 2000

Hendrik Ziegler: „Dem anscheinend Reizarmen seine Reize abzulauschen ...“ - Karl Buchholz und die Kunst der Weimarer Malerschule, in: Ausst.-Kat Lübeck 2000 (siehe dort), S. 24-37. 


\section{Ziegler 2001}

Hendrik Ziegler: Die Kunst der Weimarer Malerschule. Von der Pleinairmalerei zum Impressionismus, Köln, u. a. 2001.

Ziegler 2010

Hendrik Ziegler: „,... ein Entwickler von Individualitäten“. Theodor Hagen als Lehrer, in: Ausst.-Kat. Weimar 2010 (siehe dort), S. 195-203.

Ziemke 1977a

Hans-Joachim Ziemke: Zum Begriff der Nazarener, in: Ausst.-Kat. Frankfurt a. M. 1977 (siehe dort), S. 17-25.

Ziemke 1977b

Hans-Joachim Ziemke: Die Anfänge in Wien und in Rom, in: Ausst.-Kat. Frankfurt a. M. 1977 (siehe dort), S. 41-59.

Zimmermann, M. 1999

Michael F. Zimmermann: Painting of Nature - Nature of Painting. An Essay on Landscape and the Historical position of „Barbizon”, in: Andreas Burmeister, Christoph Heilmann, Michael F. Zimmermann (Hg.): Barbizon. Malerei der Natur - Natur der Malerei, München 1999, S. 18-57.

Zimmermann, R. 1858

Robert Zimmermann: Aesthetik. Erster, Historisch-kritischer Theil. Geschichte der Aesthetik als philosophischer Wissenschaft, Wien 1858.

Zimmermanns 1980

Klaus Zimmermanns: Friedrich August von Kaulbach 1890-1920. Monographie und

Werkverzeichnis, München 1980 (= Materialien zur Kunst des 19. Jahrhunderts, Bd. 26).

Zola 1988 [1878]

Émile Zola: Schriften zur Kunst. Die Salons von 1866-1896, Frankfurt a. M. 1988. 


\section{Konkordanz der Bestandskataloge und Inventare}

\begin{tabular}{|c|c|c|c|c|c|}
\hline $\begin{array}{l}\text { Inventar } \\
1887 \mathrm{ff}^{1}\end{array}$ & $\begin{array}{l}\text { Wald- } \\
\text { mann } \\
1905\end{array}$ & $\begin{array}{l}\text { Stechow } \\
1926\end{array}$ & $\begin{array}{l}\text { Wille } \\
1970\end{array}$ & $\begin{array}{l}\text { Unver- } \\
\text { fehrt } \\
1987\end{array}$ & $\begin{array}{l}\text { In der Kunst- } \\
\text { sammlung seit }\end{array}$ \\
\hline
\end{tabular}

Kat. Nr. 1

Kat. Nr. 2

256

Kat. Nr. $3 \quad 272$

255

Kat. Nr. 4

Kat. Nr. 5

294

Kat. Nr. 6

192

Kat. Nr. 7

Kat. Nr. 8

Kat. Nr. 9

Kat. Nr. 10

Kat. Nr. 11

Kat. Nr. 12

Kat. Nr. 13

Kat. Nr. 14

Kat. Nr. 15

Kat. Nr. $16 \quad 255$

Kat. Nr. 17

Kat. Nr. $18 \quad 227$

Kat. Nr. 19232

Kat. Nr. $20 \quad 248$

Kat. Nr. 21

Kat. Nr. 22

Kat. Nr. 23238

Kat. Nr. 24

Kat. Nr. 25
168
Nr. 113

/

/

Nr. 106

/

/

/

/

/

/

/

Nr. 105

Nr. 109

/

Nr. 23

Nr. 7

/

Nr. $17 \quad 70$

Nr. 18

/

/

/

Nr. 6

Nr. 114

/

/

/

/

/
A 111

A 74

A 73

A 34

A 71

A 18

A 60

A 54 nach 1970

A 12

A 64

A 1121966

A 22

1966

2008

1966

A 62

1968

A $28 \quad 1977$

A 26

1977

A 27

1977

A $20 \quad 1970$

/
A 87

A 36
1966, BRD

vor 1936

1 Die Nummern des Inventars 1884 ff. verstehen sich nicht als Inventarnummern. Solche wurden für Gemälde erst 2010 vergeben und sind mit GG gekennzeichnet (siehe S. 37). 


\begin{tabular}{|c|c|c|c|c|c|c|}
\hline Kat. Nr. 26 & 223 & / & / & Nr. 3 & A 6 & 1966 \\
\hline Kat. Nr. 27 & / & / & / & / & / & 2010 \\
\hline Kat. Nr. 28 & 226 & / & / & Nr. 9 & A 31 & 1966 \\
\hline Kat. Nr. 29 & / & / & / & Nr. 14 & A 51 & $1956 / 57$ \\
\hline Kat. Nr. 30 & 228 & / & / & Nr. 19 & $?$ & 1966 \\
\hline Kat. Nr. 31 & / & / & / & / & / & 2008 \\
\hline Kat. Nr. 32 & 235 & / & / & Nr. 22 & A 102 & 1969 \\
\hline Kat. Nr. 33 & $?$ & / & / & / & A 114 & vor 1936 \\
\hline Kat. Nr. 34 & 204 & / & / & l & A 107 & 1931 \\
\hline Kat. Nr. 35 & / & / & l & / & / & vor 1994 \\
\hline Kat. Nr. 36 & / & 162 & / & / & A 16 & vor 1905 \\
\hline Kat. Nr. 37 & / & / & / & / & / & vor 2008 \\
\hline Kat. Nr. 38 & $\begin{array}{l}\text { S. } 93 \text { (o. } \\
\text { Nr.) }\end{array}$ & / & / & / & A 110 & 1962 \\
\hline Kat. Nr. 39 & / & / & / & / & A 103 & 1962 \\
\hline Kat. Nr. 40 & / & / & / & / & A 104 & 1962 \\
\hline Kat. Nr. 41 & / & / & / & / & A 105 & 1962 \\
\hline Kat. Nr. 42 & / & / & / & / & / & 1962 \\
\hline Kat. Nr. 43 & / & / & / & / & / & 1962 \\
\hline Kat. Nr. 44 & / & / & 47 & / & A 106 & vor 1926 \\
\hline Kat. Nr. 45 & / & / & / & Nr. 108 & A 55 & $1966, B R D$ \\
\hline Kat. Nr. 46 & 242 & / & / & / & / & um 1970 \\
\hline Kat. Nr. 47 & / & / & / & / & / & vor 2009 \\
\hline Kat. Nr. 48 & / & / & / & / & A 109 & 1969 \\
\hline Kat. Nr. 49 & 245 & / & / & l & / & vor 1975 \\
\hline Kat. Nr. 50 & $\begin{array}{l}\text { S. } 93 \text { (o. } \\
\text { Nr.) }\end{array}$ & / & / & / & 75 & 1962 \\
\hline Kat. Nr. 51 & 244 & / & / & / & A 108 & vor 1987 \\
\hline Kat. Nr. 52 & / & / & / & / & A 43 & 1973 \\
\hline Kat. Nr. 53 & / & / & / & / & A 58 & \\
\hline Kat. Nr. 54 & / & / & / & Nr. 5 & A 107 & 1970 \\
\hline
\end{tabular}




\section{Namensregister}

Achenbach, Andreas 44

Adam, Albrecht 220

Aesop 241

Alberti, Leon Battista 54

Alexandra Feodorowna, Zarin von Russland 281

Almas-Dietrich, Maria 87

Angebroth, Christoph 273 f., 290

Arminius $81 \mathrm{f}$.

Arnolfo di Cambio 119

Aubert, Andreas 33

Bager, Johann Daniel 145

Banks, Joseph 267

Barbari, Jacopo de' 251 f.

Batoni, Pompeo Girolamo 111-113

Baum, Paul 184

Bayersdorfer, Adolph 29

Becker, Friedrich 19, 26, 40, 55, 65-68

Begas, Carl 67

Bendemann, Eduard 7, 11 (Anm.), 235, 277 (Anm.)

Bendixen, Siegfried 201, 203

Bernhard von Clairvaux 72-74

Bièfve, Edouard de 60

Bigari, Vittorio 111

Blechen, Carl 41 (Anm.)

Blumenbach, Johann Friedrich 267

Böcklin, Arnold 17 (Anm.), 63

Böhnisch, G. A. 270
Bonington, Richard Parkes 183

Borsig, Albert 248

Bottani, Giuseppe 111, 113

Brendel, Albert 184, 230 f.

Brueghel d. Ä., Pieter 41 (Anm.)

Buchholz, Edmund 226

Buchholz, Karl 6, 10 (Anm.), 16, 30, 33, 43, 184, 225-231

Bürger, Gottfried August 112

Bundsen, Jes 203

Burckhardt, Jacob 60

Caesar, Gaius Julius 268

Calame, Alexandre 218

Canova, Antonio 67

Caravaggio 98 f., 104, 253

Carl, Adolf $201 \mathrm{f}$.

Carl Alexander, Großherzog von Sachsen-Weimar $184 \mathrm{f}$.

Cavallini, Pietro 119

Caylus, Anne-Claude-Philippe de, Comte 61

Cézanne, Paul 67

Chodowiecki, Daniel 19, 104, 178

Christian, Kronprinz, später König

Christian VIII. von Dänemark 206

Christian, Prinz von Waldeck 269

Claesz, Pieter 252

Claude Lorrain 179, 188, 194, 215 f.

Codde, Pieter 171 
Conräder, Georg 71

Constable, John 183

Cornelius, Peter 5 f., 22, 28, 31, 58-61, 63, 65 f., 91, 139 f., 168, 181 f., 217

Corot, Camille 230

Correggio, Antonio da 40, 111 (Anm.)

Correggio, Joseph 21, 46, 254, 259-262

Correggio, Ludwig 260

Courbet, Gustave 29, 240, 247-249, 253

Couwenbergh, Christian van 41 (Anm.)

Crell, Lorenz Friedrich von 273, 290

Dahl, Johan Christian 33, 201 (Anm.), 204

Danhauser, Josef 24 f., 32, 41, 147, 149 153

Danhauser, Josef Ulrich 150

Darwin, Charles 241

Daubigny, Charles-François 184, 231

David, Jacques-Louis 90, 201

Decamps, Alexandre Gabriel 286

Defregger, Franz von 28, 31, 44, 146, 176

Deger, Ernst 122

Delacroix, Eugène 242, 286

Deutsch, Ludwig 286

Diderot, Denis 55

Dietrich, Christian Wilhelm 43 (Anm.), 258

Diez, Wilhelm von 239

Dillis, Johann Georg 41 (Anm.)

Droysen, Felix 45, 102

Droysen, Gustav 45

Droysen, Hans 45

Droysen, Johann Gustav Bernhard 45

Dümer, Minna 48

Dürer, Albrecht 91, 200, 285

Dujardin, Karel 165 f.

Dumont, Eugen 30, 40, 43 f., 163, 256, 258

Dumont, Irene 44

Duveneck, Frank 239

Dyck, Antonis van 67, 84

Eckersberg, Christoffer Wilhelm 201

Eggers, Friedrich 27 (Anm.)

Ehlers, Ernst Heinrich 270, 274, 295
Elisabeth von Österreich-Ungarn, Kaiserin 281

Elisabeth von Thüringen 128, $130 \mathrm{f}$.

Erhard, Johann Christoph 192

Ernst, Dr. j., 275, 289

Eudoxia: siehe Licinia Eudoxia

Eugénie, Kaiserin 281

Eyck, Jan van 168, 264

Falke, Jakob $121 \mathrm{f}$.

Félibien, André 177, 252

Fellfoot, M. Max 267, 269, 289

Fénelon, François 44

Fernow, Carl Ludwig 20 f., 30, 179 f.

Feuerbach, Anselm 7, 17 (Anm.), 63

Fiedler, Conrad 29

Fiorillo, Ignazio 111

Fiorillo, Johann Dominicus 6, 19, 22 f., 36 f., 44, 48, 90, 95, 107, 109-116, $135,276,289$

Flinck, Govert 285

Fobbe, Marie 48

Fobbe, Wilhelmine 48

Förster, Friedrich Christoph 157

Frauendorfer-Mühlthaler, Helene von 274, 295

Friedrich, Caspar David 19-21, 24, 33, 181 f., 195-197, 204

Friedrich Wilhelm III./I., Kurfürst von Brandenburg/König in Preußen 104

Friedrich Wilhelm III. von Preußen, König 100, 102, 104-106

Fries, Bernhard 21, 42, 180, 183, 213-218

Fries, Christian Adam 215-217

Fries, Ernst 216

Frisch, Johann Christoph 101

Frommel, Karl 210

Führich, Joseph von 139

Gaertner, Eduard 276-278, 293

Gaertner, Reinhold 277

Gainsborough, Thomas 269, 280

Gallait, Louis 60

Gebhardt, Eduard von 24, 43, 93 f., 144, 167-172, 188, 258

Geiserich, Vandalenanführer 78-80

Genelli, Bonaventura 61 
Georg von Preußen, Prinz 41

Géricault, Théodore 242

Germanicus 82

Gerson, Walter 46

Gibbon, Edward 78

Giorgione 84

Giotto 170

Görres, Joseph 22 (Anm.)

Goethe, Johann Wolfgang von 19 f., 22 f., 92, 114 f., 159 f., 216, 241

Goyen, Jan van 183

Gozzoli, Benozzo 61, 119

Grant, Ulysses S. 71

Greuze, Jean-Baptiste 19, 55

Grünewald, Justus Christoph 273

Grützner, Eduard 274

Gurlitt, Cornelius 29 f., 62

Gurlitt, Louis 6, 10 (Anm.), 17, 21, 30, 33, 43, 180, 199-212

Gurlitt, Ludwig 200 f., 203

Gysis, Nikolaus 174

Hagen, Theodor 184, $230 \mathrm{f}$.

Hasenclever, Johann Peter 146, 277 (Anm.)

Heem, Jan Davidsz. de 257

Hegel, Georg Wilhelm Friedrich 20

Heine, Wilhelm 146

Heinisch, Karl Ludwig Adam 30, 43, 182, 237-240

Henle, Gustav Jakob 235, 270, 293

Herbart, Johann Friedrich 27

Herterich, Johann Caspar 174

Hildebrandt, Theodor 234

Hiltensperger, Johann Georg 259 f.

Hitler, Adolf 41, 87, $151 \mathrm{f}$.

Hobbema, Meindert 183

Hoffmann-Fallersleben, Franz 226

Horemans I., Jan Joseph 171

Hotho, Heinrich Gustav 20 f.

Hübner, Carl Wilhelm 146, 156

Hummel, Johann Erdmann 146

Hus, Jan 60

Igelsheimer, Ludwig 60

Ittenbach, Franz 132
Jordan, Max 76

Jordan, Rudolf 156

Justi, Karl Wilhelm 131

Kalckreuth, Stanislaus von 71

Kalf, Willem 252

Kandinsky, Wassily 40 (Anm.)

Kauffmann, Angelika 269

Kaufmann, Friedrich von 134

Kaulbach, Frida von 87

Kaulbach, Friedrich 83, 134

Kaulbach, Friedrich August von 26, 32, 41, 63, 83-87, 134, 274

Kaulbach, Wilhelm von 31, 59, 63, 70, $83 \mathrm{f}$.

Keßler, August 21, 38 f., $223 \mathrm{f}$.

Kestner, August 138, 183

Klein, Johann Adam 192

Kobell, Wilhelm von 145

Koch, Joseph Anton 179, 183

Købke, Christen 202 f.

Konrad III., König 72-74

Koopmann, Johann Carl Heinrich 217

Koppay, Josef Arpád 274

Koselleck, Reinhart 56

Knaus, Ludwig 28, 31, 156

Krafft, Johann Peter 150

Kraus, Georg Melchior 145

Kreling, August von 83

Krusenstern, Adam Johann von 269

Kügelgen, Gerhard von 19

Künzel, Christiane 271 f., 295

Kuntze, Eduard, und Gattin 276 f., 293

Landauer, Moses J. 272

Landseer, Edwin 242

Lange, Konrad 37

Langsdorff, Georg Heinrich von 268 f., 274, 292

Laudage, Franz Xaver 24, 47, 91, 94 f., 127-132

Lavater, Johann Caspar 265

Lee, Robert Edward 71

Lehnen, Jacob 261 f.

Leibl, Wilhelm 29, 240

Leinweber, Johanna Auguste 274

Lelli, Ercole 111 
Lenbach, Franz von 44, 84, 274

Leonardo da Vinci 54

Lessing, Carl Friedrich 20, 44, 60, 62, 159 f., 168

Levin, Julius 31

Lichtenberger, Heinrich 271, 295

Lichtwark, Alfred 17 (Anm.), 32

Licinia Eudoxia 78-80

Lier, Adolf Heinrich 30, 182

Lippi, Filippino 170

Ludwig, Großherzog von Baden 280

Ludwig I., König von Bayern 182

Ludwig II., König von Bayern 221

Ludy, Friedrich 131

Luise, Prinzessin von Preußen 106

Makart, Hans 84

Manet, Édouard 253

Mantegna, Andrea 115

Marées, Hans von 17 (Anm.)

Marggraff, Rudolf 61

Martens, Johann Heinrich 209

Maurenbrecher, Romeo 23

Max, Gabriel von 84, 241 (Anm.)

Maximilian II., König von Bayern 218

Maximilian Leopold, Herzog von Braunschweig-Wolfenbüttel 112

Meier-Graefe, Julius 63

Menzel, Adolph 6, 61 f., 247-249

Meyer, Johann Heinrich 20, 22 f., 114116

Meyerheim, Eduard 247

Meyerheim, Paul 6, 10 (Anm.), 17 f., 26 f., 46, 184, 243, 247-249

Michelangelo Buonarroti 31, 115

Michelis, Alexander 230

Millet, Jean-François 184

Mohr, Johann 209

Momper d. J., Joos de 188 f.

Montalembert, Charles de 131

Morgenstern, Christian 203 f., 209

Müller, Kurt Ferdinand 271

Müller von Königswinter, Wolfgang $252 \mathrm{f}$.

Muther, Richard $31 \mathrm{f}$.

Nadorp, Franz 217
Napoleon III., Kaiser 281

Nerly, Friedrich 206 (Anm.), 207

Neureuther, Eugen Napoleon 41 (Anm.)

Nietzsche, Friedrich 63 (Anm.)

Oesterley, Carl Wilhelm Friedrich 6, 16 (Anm.), 18, 22-24, 32 f., 41, 70, 91, 93, 95, 122, 133-141, 284

Olivier, Ferdinand 192, $210 \mathrm{f}$.

Olivier, Friedrich 192, 210

Ommegancks, Balthasar-Paul 188

Onkel Theodor $168 \mathrm{f}$.

Otto, Ernst 268, 292

Overbeck, Friedrich 6, 23, 26 (Anm.), 91, 93 (Anm.), 123, 129 f., 131 f., 168, $170,172,192$

Paatz, Elisabeth 40

Paatz, Walter 40

Pauli, Gustav 17 (Anm.)

Pauwels, Ferdinand $71 \mathrm{f}$.

Pecht, Friedrich 28

Peters, Hermann Titian 234

Peters, Otto 46, 233-236, 270, 274, 295

Peters, Raphael 234

Petri, Anna 48

Petri, Emma 48

Petri, Heinrich 6, 24, 47 f., 95, 121-125

Petri, Philipp 48, 121

Petri, Wilhelmine 48

Petronius Maximus $78 \mathrm{f}$.

Pflug, Johann Baptist 145

Pforr, Franz 26 (Anm.), 57 f., 91, 129 f.

Pichler, Caroline 190, 196 f.

Piglheim, Bruno 274

Piles, Roger de 55

Piloty, Carl Theodor von 6, 26, 31, 61, 63, 70 f., 73 f., 79 (Anm.), 81, 84, 146, $174,176,185,235$

Pinturicchio 170

Podesti, Francesco 22, 32, 42 f., 95, $117-$ 120

Pott, Auguste Johanna 273, 275, 291

Pott, David Julius 273, 275, $291 \mathrm{f}$.

Poussin, Nicolas 54, 179, 188, 194, 215 f.

Preyer, Johann Wilhelm $261 \mathrm{f}$.

Pseudo-Bonaventura $97 \mathrm{f}$. 
Pyrker, Ladislaus 150

Raczynski, Athanasius Graf 181

Raffael 23, 91-93, 98 f., 104, 113, 190, 253

Ramberg, Arthur von 71

Raupp, Karl 83

Reber, Franz 28-30

Regemorter, Ignatius Josephus van 21, 43, 187-190

Regemorter, Petrus Johannes van 188

Regnet, Carl Albert 23

Reinhart, Johann Christian 177

Reinhold, Friedrich Philipp 6, 10 (Anm.), 21, 30, 42, 181, 191-197

Reinhold, Heinrich 192

Reinhold, Johann Friedrich Leberecht 192

Rembrandt 285

Retzsch, Moritz 268

Richter, Adrian Ludwig $180 \mathrm{f}$.

Riepenhausen, Franz und Johannes 132

Rist, Johann Christoph 210

Ritmüller, Eduard 139-141

Ritter, Henry 42, 155-157

Robert, Leopold 146

Roentgen, David 267

Roentgen, Georg Heinrich 267, 269, 289

Rohden, Johann Martin von 180

Rohlfs, Christian 184, 229, 231

Rohns, Christian Friedrich Andreas 236

Romano, Antoniazzo 119

Romney, George 280

Roos, Johann Heinrich 242 (Anm.)

Rosenberg, Adolf 274

Rottmann, Carl 180, 216, 218

Rousseau, Jean-Jacques 145, 178

Rousseau, Théodore 183

Rubens, Peter Paul 67, 75, 84, 285

Rudolf von Habsburg, Kaiser 58

Ruge, Arnold 25, 60

Rugendas, Moritz 269

Ruisdael, Jacob van 183

Runge, Philipp Otto 19, 24, 32 f., 192

Ruszow, Astronom 269

Schadow, Johann Gottfried 104
Schadow, Wilhelm von 6, 23, 48, 60, 65 f., 91, 93, 139, 155 f., 168, $181 \mathrm{f}$.

Schasler, Max 243 f.

Scheuren, Caspar 44

Schiller, Friedrich 178

Schinkel, Karl Friedrich 58, 181

Schirmer, Johann Wilhelm 166, 183, 217, 224, 230

Schlegel, August Wilhelm 6, 114

Schlegel, Friedrich 19, 22, 91

Schleich d. Ä., Eduard 30, 221

Schleiermacher, Friedrich Daniel Ernst 92 (Anm.)

Schlözer, Dorothea 112

Schlotterbeck, Friedrich Wilhelm 211

Schmidt, A. 235, 270, 293

Schneider, J. L. 201

Schnorr von Carolsfeld, F. 211

Schnorr von Carolsfeld, Julius 59, 112, 116, 210

Schreiter, Emilie 276

Schroedter, Adolph 156

Schuler, Karl 280

Schumann, Karl 101

Schumann, Karl Franz Jacob Heinrich 10 (Anm.), 24, 32, 45 f., 92, 95, 97 -

107, 116

Schwind, Moritz von 61, 132, 185 (Anm.)

Segestes 82

Seitz, Otto 174

Selvino, Giovanni Battista 101

Slevogt, Max 239

Sohn, Carl Ferdinand 156

Sohn, Wilhelm 168

Son, Joris van 21, 40, 43, 252, 255-258

Sophie, Königin der Niederlande 281

Sophie Wilhelmine (Sophie Guillemette), Großherzogin von Baden $280 \mathrm{f}$.

Spangenberg, Friedrich 6, 25 f., 32 f., 44 f., 61, 69-82

Spangenberg, Johann Friedrich 70, 74 f., 122

Spitzweg, Carl 221

Springer, Anton 28

Stahler, E. 274

Stechow, Wolfgang 39, 45, 284 
Steen, Jan 190

Stieler, Josef von 280

Sulzer, Johann Georg 265

Tellgmann, Cäcilie 272

Tellgmann, Ferdinand 272, 294

Thelott, Ernst 156

Thorvaldsen, Bertel $138 \mathrm{f}$.

Thusnelda $81 \mathrm{f}$.

Tieck, Ludwig 6, 91 f., 114

Tischbein, Johann Friedrich August 269

Tizian 84

Troyon, Constant 231

Trübner, Wilhelm 253

Tschudi, Hugo von 33

Turner, William 216

Uffenbach, Johann Friedrich Armand von 36 f., 48, 110 (Anm.)

Uhde, Fritz von 170

Ulrich, Christ. Friedr. Wilhelm, und Gattin 273, 294

Unverfehrt, Gerd 15, 40, 188, 256, 270

Valentiner, Justus Theodor $40 \mathrm{f}$.

Valentinian III., Kaiser 78

Vasari, Giorgio 92

Vautier, Benjamin 28, 43 f.

Veit, Philipp 210

Veronese, Paolo 84

Victoria, Königin von England 281

Victorijns, Anthoni 171

Victors, Jan $165 \mathrm{f}$.

Vischer, Friedrich Theodor 20, 23, 60
Vischer, Robert 48

Voltz, Johann Friedrich 30, 42, 145, 182, 219-221, 243

Voltz, Johann Michael 219

Voltz, Ludwig 145

Wach, Wilhelm 106 f.

Wachsmuth, Maximilian 28, 32, 46, 146, 173-175

Wackenroder, Wilhelm Heinrich 6, 91 f., 114

Waechter, Benno Karl von 276, 293

Wagenbauer, Max Joseph 219

Waldeck, Johann Peter 275, 289

Waldeck, Christian, Prinz von: siehe Christian, Prinz von Waldeck

Waldmann, Emil 45, 267

Wallis, Georg August 216 f.

Walter, Ilse 46

Weitsch, Friedrich Georg 266 f., 269, 290

Welker, Ernst 192

Weyden, Rogier van der 168, 264

Wiese, Robert 45, 102

Wille, Hans 16, 40

Winckelmann, Johann Joachim 91 f., 265

Winterhalter, Franz Xaver 42, 279-282

Zeissig gen. Schenau, Johann Eleazar 145, 192

Zimmermann, Robert 27

Zola, Émile 184

Zschorn, Johann Wilhelm 36, 48, 110

(Anm.) 


\section{Bildnachweis}

Georg-August-Universität Göttingen, Kunstsammlung, Foto: Katharina Anna Haase:

Farbabbildungen Kat. Nr. 1-12, 14-17, 19-26, 28, 32+33, Abb. 16, 21, 24, 25, 35, 41

Georg-August-Universität Göttingen, Kunstsammlung, Foto: Tobias Heine: Farbabbildungen Kat. Nr. 29, 36-41, 44+45, 47, 49-51, 53+54

Georg-August-Universität Göttingen, Kunstsammlung, Foto: Christine Hübner: Farbabbildungen Kat. Nr. 13, 18, 27, 30, 34+35, 42+43, 46, 48, 52, Abb. 38, 40

Marco Gronwald Abb. S. 12

Georg-August-Universität Göttingen, Kunstsammlung, Foto: Anne-Katrin Sors: Abb. 1

Georg-August-Universität Göttingen, Archäologisches Institut, Foto: Stephan Eckardt: Abb. 2-5

Kunsthalle zu Kiel: Abb. 6

Zimmermanns 1980, S. 171, Kat. 656: Abb. 7

Oberhuber 1999, S. 215, Abb. 193: Abb. 8

Ausst. Kat. Berlin 2001, S. 29, Abb. 33: Abb. 9

Harald Just, Diemarden: Abb. 10

Clark, A. M. 1985, Kat. Nr. 53, Abb. 49: Abb. 11

Börsch-Supan 1988, S. 222, Abb. 43: Abb. 12

Huber 1979, S. 200 f., Abb. 4+5: Abb. 13+14

Städtisches Museum Göttingen: Abb. 15

Ausst.-Kat. Eisenach 2007, Bd. 2, S. 541, Abb. 1: Abb. 17

Georg-August-Universität Göttingen, Kunstsammlung, Archiv: Abb. 18, 23, 39

Hermanssen/Roussell/Steenberg 1945-1959, S. 199, Fig. 122, Ausschnitt: Abb. 19

Wolff 1899, Fig. 42, Ausschnitt: Abb. 20

Grabner 2011, S. 212, Kat. 94: Abb. 22

Ausst.-Kat. Lübeck 1989, S. 105, Kat. 6: Abb. 26

Ausst.-Kat. Düsseldorf 2011, S. 135, Kat. Nr. 95: Abb. 27

Becker-Göthel 2002: Abb. 28

Ertz 1986, S. 272, Abb. 307: Abb. 29.

Börsch-Supan/Jähnig 1973, S. 81, Tafel 17, S. 149, Tafel 56: Abb. 30+31

Ausst.-Kat. Berlin 1989b, S. 9, Abb. 2: Abb. 32

Grote 1938, S. 197, Abb. 111: Abb. 33

Rott 2009, S. 99: Abb. 34

Klassik Stiftung Weimar: Abb. 36+37

Ausst.-Kat. Berlin 1989a, Abb. 12,1: Abb. 42 
D ie Kunstsammlung der Universität Göttingen ist vor allem für ihren Bestand an Niederländischer Kunst des 17 . Jahrhunderts bekannt. Dass sie darüber hinaus auch eine Kollektion von Gemälden des 19. Jahrhunderts umfasst, die einige wirkliche Schätze enthält, gleicht einer Neuentdeckung. Diese Kollektion wird hier erstmals in einem eigenen Bestandskatalog vorgestellt. Obwohl es sich um eine eher kleine Sammlung handelt, erweist sich diese doch als erstaunlich repräsentativ, um das Kunstverständnis des 19. Jahrhunderts mit seinen wechselnden Prämissen sowie kunsttheoretischen und künstlerischen Auseinandersetzungen an konkreten Kunstwerken aufzuzeigen. Eine zentrale Rolle spielt dabei die Gattungstheorie: Die seit der Frühen Neuzeit vertretene Ausdifferenzierung der Malerei in profane und religiöse Historie, Genre, Landschaft, Stillleben, Tierstück und Porträt wurde über das gesamte 19. Jahrhundert hinweg kontrovers diskutiert, blieb aber als wertsetzendes System lange präsent. Der vorliegende, von Dozenten und Studierenden des Kunstgeschichtlichen Seminars der Universität Göttingen gemeinsam erarbeitete Bestandskatalog nutzt die Gattungstheorie als „roten Faden“, um eine historische Perspektive auf den Bestand der Gemälde des 19. Jahrhunderts in der Göttinger Universitätskunstsammlung anzubieten.

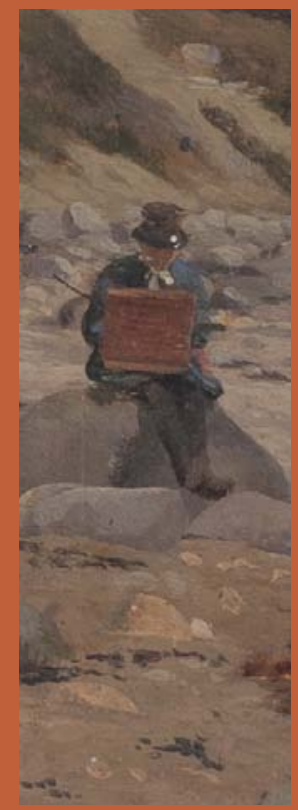

ISBN: $978-3-86395-102-3$

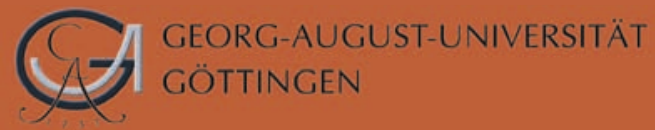

Universitätsverlag Göttingen 